COLUMBIA LIBRARIES OFFSITE

HEALTH SCIENCES STANDARD

QM601 .M36 1914 The development of

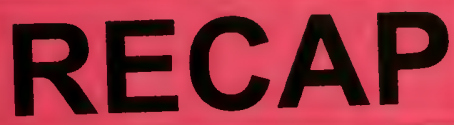




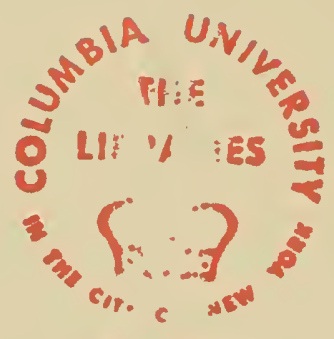

HEAITH

SCIEHCES

IIBRARY 
THE

\section{DEVELOPMENT OF THE HUMAN BODY \\ MCMURRICH}




\section{MORRIS'S ANATOMY}

FOURTH EDITION

UNDER AMERICAN EDITORSHIP

Rewritten, Revised, Improved, with Many New Illustrations

EDITED BY

HENRY MORRIS, F.R.C.S.

Consulting Surgeon to, and formerly Lecturer on Surgery and Anatomy at Middlesex Hospital, London, and Examiner in Anatomy, University of Durham, etc.

AND

\section{J. PLAYFAIR MCMURRICH, A. M., PH. D.}

Professor of Anatomy in the University of Toronto; formerly Professor of Anatomy, University of Michigan

Among the American contributors will be noted: J. Playfair McMurrich, R.

J. Terry, Irving Hardesty, G. Carl Huber, Abram T. Kerr, Charles R.

Bardeen and Florence R. Sabin. Henry Morris, R. Marcus Gunn and

W. H. A. Jacobson head the English contributors.

"The ever-growing popularity of the book with teachers and students is an index of its value, and it may safely be recommended to all interested."-From The Medical Record, New York.

The text has been completely revised. Very especial attention, in this new edition, has been paid to the illustrations, with the result that the teaching value of the book has been very materially increased.

It contains many features of special advantage to students. It is modern, up to date in every respect. It has been carefully revised, and in many parts rewritten, and includes many new illustrations.

Containing about I024 Illustrations, of which many are in Colors. One Handsome Octavo Volume. Thumb Index. Cloth, \$6.00. Sheep or Half Morocco, $\$ 7.00$, net. Or in Five Parts, as follows, each part sold separately:

PAR'T I.-Morphogenesis. Osteology. Articulation. Index. \$I.50.

PART II.-Muscles. Organs of Circulation. Lymphatics. Index. \$2.00.

PART III.-Nervous System. Organs of Special Sense. Index. \$r.50.

PART IV.--Organs of Digestion; of Voice and Respiration. Urinary and Reproductive Organs. Ductless Glands. Skin and Mammary Glands. Index. \$1.50.

PART V.-Surgical and Topograghical Anatomy. Index. \$r.oo.

Illustrated Circular upon request. 


\title{
THE
}

\section{DEVELOPMENT OF THE HUMAN BODY $=$}

\section{A MANUAL"OF HUMAN EMBRYOLOGY}

BY

J. Playfair McMURRICH, A. M., Ph. D., LL. D. PROFESSOR OF ANATOMY IN THE UNIVERSITY OF TORONTO FORMERLY PROFESSOR OF ANATOMY IN THE UNIVERSITY OF MICHIGAN

FOURTH EDITION, REVISED AND ENLARGED

With Two Hundred and Eighty-five lliustrations Several of which are Printed in Colors

\author{
PHILADELPHIA \\ P. BLAKISTON'S SON \& CO. \\ 1012 WALNUT STREET


601

M3 is

1914

Copyright, I9I3, by P. Blakiston's Son \& Co.

THE, MA P LE P PES B Y R K PA 


\section{PREFACE TO THE FOURTH EDITION.}

The increasing interest in human and mammalian embryology which has characterized the last few years has resulted in many additions to our knowledge of these branches of science, and has necessitated not a few corrections of ideas formerly held. In this fourth edition of this book the attempt has been made to incorporate the results of all important recent contributions upon the topics discussed, and, at the same time, to avoid any considerable increase in the bulk of the volume. Several chapters have, therefore, been almost entirely recast, and the subject matter has been thoroughly revised throughout, so that it is hoped that the book forms an accurate statement of our present knowledge of the development of the human body.

To several colleagues the author is indebted for valuable suggestions, and in this connection he desires especially to thank Dr. J. C. Watt for much generous assistance in the revision of the manuscript and for undertaking the correction of the proof-sheets.

In addition to the works mentioned in the preface to the first edition as of special value to the student of Embryology, mention should be made of the Handbuch der vergleichenden und experimentellen Entwicklungslehre der Wirbeltiere edited by Professor Oscar Hertwig and especially of the Manual of Human Embryology edited by Professors F. Keibel and F. P. Mall.

UnIVERSITY OF TORONTO. 
Digitized by the Internet Archive in 2010 with funding from Columbia University Libraries 


\section{PREFACE TO THE FIRST EDITION.}

The assimilation of the enormous mass of facts which constitute what is usually known as descriptive anatomy has always been a difficult task for the student. Part of the difficulty has been due to a lack of information regarding the causes which have determined the structure and relations of the parts of the body, for without some knowledge of the why things are so, the facts of anatomy stand as so many isolated items, while with such knowledge they become bound together to a continuous whole and their study assumes the dignity of a science.

The great key to the significance of the structure and relations of organs is their development, recognizing by that term the historical as well as the individual development, and the following pages constitute an attempt to present a concise statement of the development of the human body and a foundation for the proper understanding of the facts of anatomy. Naturally, the individual development claims the major share of attention, since its processes are the more immediate forces at work in determining the conditions in the adult, but where the embryological record fails to afford the required data, whether from its actual imperfection or from the incompleteness of our knowledge concerning it, recourse has been had to the facts of comparative anatomy as affording indications of the historical development or evolution of the parts under consideration.

It has not seemed feasible to include in the book a complete list of the authorities consulted in its preparation. The short bibliographies appended to each chapter make no pretensions to completeness, but are merely indications of some of the more important works, especially those of recent date, which consider the questions discussed. For a very full bibliography of all works treating of 
human embryology up to 1893 reference may be made to Minot's Bibliography of Vertebrate Embryology, published in the "Memoirs of the Boston Society of Natural History," volume iv, I893. It is fitting, however, to acknowledge an especial indebtedness, shared by all writers on human embryology, to the classic papers of His, chief among which is his Anatomie menschlicher Embryonen, and grateful acknowledgments are also due to the admirable text-books of Minot, O. Hertwig, and Kollmann.

ANatomical Laboratory,

UNIVERSITY OF MichigAN. 


\section{CONTENTS}

INTRODUCTION I

\section{PART I.-GENERAL DEVELOPMENT.}

CHAPTER I.

The Spermatozoön and Spermatogenesis; the Ovum and Its Maturation and Fertilization . . . . . . . . . . . . . II

CHAPTER II.

The Segmentation of the Ovum and the Formation of the Germ Layers . . . . . . . . . . . . . . . 38

CHAPTER III.

The Medullary Groove, Notochord, and Mesodermic Somites . . . 64 CHAPTER IV.

The Development of the External Form of the Human Embryo. . . 86 CHAPTER V.

The Yolk-stalk, Belly-stalk, and Fetal Membranes 107

\section{PART II.-ORGANOGENY.}

CHAPTER VI.

The Development of the Integumentary System . . . . . . . I4I CHAPTER VII.

The Development of the Connective Tissues and Skeleton . . . . I53 CHAPTER VIII.

The Development of the Muscular System 193 


\section{CHAPTER IX.}

The Development of the Circulatory and Lymphatic Systems . . . 22 I CHAPTER X.

The Development of the Digestive Tract and Glands . . . . . . 280 CHAPTER XI.

The Development of the Pericardium, the Pleuro-peritoneum, and the Diaphragm . . . . . . . . . . . . . . 3I6

\section{CHAPTER XII.}

The Development of the Organs of Respiration . . . . . . . . 33I CHAPTER XIII.

The Development of the Urinogenital System . . . . . . . . 338 CHAPTER XIV.

The Suprarenal System of Organs . . . . . . . . . . 370 CHAPTER XV.

The Development of the Nervous System . . . . . . . . . 377 CHAPTER XVI.

The Development of the Organs of Special Sense . . . . . . . 427 CHAPTER XVII.

Post-natal Development . . . . . . . . . . . . . . 470 INDEX . . . . . . . . . . . . . . . . . . . 487 


\section{THE DEVELOPMENT \\ OF THE

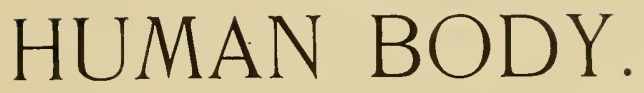

\section{INTRODUCTION.}

Somewhat more than seventy years ago (I839) one of the fundamental principles of biology was established by Schleiden and Schwann as the cell theory. According to this, all organisms are composed of one or more structural units termed cells, each of which, in multicellular organisms, maintains an individual existence and yet contributes with its fellows to the general existence of the individual. Viewed in the light of this theory, the human body is a community, an aggregate of many individual units, each of which leads to a certain extent an independent existence and yet both contributes to and shares in the general welfare of the community.

To the founders of the theory the structural units were vesicles with definite walls, and little attention was paid to their contents. Hence the use of the term "cell" in connection with them. Long before the establishment of the cell theory, however, the existence of organisms composed of a gelatinous substance showing no indications of a definite limiting membrane had been noted, and in 1835 a French naturalist, Dujardin, had described the gelatinous material of which certain marine organisms (Rhizopoda) were composed, terming it sarcode and maintaining it to be the material substratum which conditioned the various vital phenomena exhibited by the organisms. Later, in I846, a botanist, von Mohl, observed that living plant cells contained a similar substance, upon which he 
believed the existence of the cell as a vital structure was dependent, and he bestowed upon this substance the name protoplasm, by which it is now universally known.

By these discoveries the importance originally attributed to the cell-wall was greatly lessened, and in I864 Max Schultze reformulated the cell theory, defining the cell as a mass of protoplasm, the presence or absence of a limiting membrane or cell-wall being immaterial. At the same time the spontaneous origination of cells from an undifferentiated matrix, believed to occur by the older authors, was shown to have no existence, every cell originating by the division of a preëxisting cell, a fact concisely expressed in the aphorism of Virchow-omnis cellula a cellulâ.

Interpreted in the light of these results, the human body is an aggregate of myriads of cells, $*$-i.e., of masses of protoplasm, each of which owes its origin to the division of a preëxistent cell and all of which may be traced back to a single parent cell-a fertilized ovum. All these cells are not alike, however, but just as in a social community one group of individuals devotes itself to the performance of one of the duties requisite to the well-being of the community and another group devotes itself to the performance of another duty, so too, in the body, one group of cells takes upon itself one special function and another another. There is, in other words, in the cell-community a physiological division of labor. Indeed, the comparison of the cell-community to the social community may be carried still further, for just as gradations of individuality may be recognized in the individual, the municipality, and the state, so too in the cell-community there are cells; tissues, each of which is an aggregate of similar cells; organs, which are aggregates of tissues, one, however, predominating and determining the character of the organ; and systems, which are aggregates of organs having correlated functions.

It is the province of embryology to study the mode of division of

* It has been estimated that the number of cells entering into the composition of the body of an adult human being is about twenty-six million five hundred thousand millions! 
the fertilized ovum and the progressive differentiation of the resulting cells to form the tissues, organs, and systems. But before considering these phenomena as seen in the human body it will be well to get some general idea of the structure of an animal cell.

This (Fig. I), as has been already stated, is a mass of protoplasm, a substance which in the living condition is a viscous fluid resembling in many of its peculiarities egg-albumen, and like this being coagulated when heated or when exposed to the action of various chemical reagents. As to the structure of living protoplasm little is yet known, since the application of the reagents necessary for its accurate study and analysis results in its disintegration or coagulation. But even in the living cell it can be seen that the protoplasm is not a simple homogeneous substance. What is termed a mucleus is

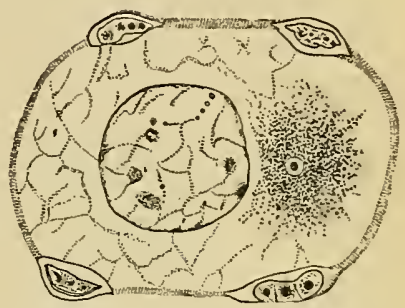

FIG. I.-OVUM OF NEW-BORN CHild with Foldicle-Celis.(Mertens.) usually clearly discernible as a more or less spherical body of a greater refractive index than the surrounding protoplasm, and since this is a permanent organ of the cell it is convenient to distinguish the surrounding protoplasm as the cytoplasm from the nuclear protoplasm or karyoplasm.

The study of protoplasm coagulated by reagents seems to indicate that it is a mixture of substances rather than a simple chemical compound. Both the cytoplasm and the karyoplasm consist of a more solid substance, the reticulum, which forms a network or feltwork, in the interstices of which is a more fluid material, the enchylema.* The karyoplasm, in addition, has scattered along the fibers of its reticulum a peculiar material termed chromatin and usually contains embedded in its substance one or more spherical bodies

* It has been observed that certain coagulable substances and gelatin, when subjected to the reagents usually employed for "fixing" protoplasm, present a structure similar to that of protoplasm, and it has been held that protoplasm in the uncoagulated condition is, like these substances, a more or less homogeneous material. On the other hand, Bütschli maintains that living protoplasm has a foam-structure and is, in other words, an emulsion. 
termed mucleoli, which may be simply larger masses of chromatin or bodies of special chemical composition. And, finally, in all actively growing cells there is differentiated in the cytoplasm a peculiar body known as the archoplasm sphere, in the center of which there is usually a minute spherical body known as the centrosome.

It has been already stated that new cells arise by the division of preëxisting ones, and this process is associated with a series of complicated phenomena which have great significance in connection with some of the problems of embryology. When such a cell as has been described above is about to-divide, the fibers of the reticulum in the neighborhood of the archoplasm sphere arrange themselves so as to form fibrils radiating in all directions from the sphere as a center, and the archoplasm with its contained centrosome gradually elongates and finally divides, each portion retaining its share of the radiating fibrils, so that two asters, as the aggregate of centrosome, sphere and fibrils is termed, are now to be found in the cytoplasm (Fig. 2, A). Gradually the two asters separate from one another and eventually come to rest at opposite sides of the nucleus (Fig. 2, C). In this structure important changes have been taking place in the meantime. The chromatin, originally scattered irregularly along the reticulum, has gradually aggregated to form a continuous thread (Fig. 2, A), and later this thread breaks up into a definite number of pieces termed chromosomes (Fig. $2 ; \mathrm{B}$ ), the number of these being practically constant for each species of animal. In man the number has been placed at twenty-four (Flemming, Duesberg), but the recent observations of Guyer indicate that it is probably twenty-four in the female and twenty-two in the male. The significance of this difference in the two sexes will be considered in connection with the fertilization of the ovum (p. 32).

As soon as the asters have taken up their position on opposite sides of the nucleus, the nuclear reticulum begins to be converted into a spindle-shaped bundle of fibrils which associate themselves with the astral rays and have lying scattered among them the chromosomes (Fig. 2, C). To the figure so formed the term amphiaster is applied, and soon after its formation the chromosomes arrange 
themselves in a circle or plane at the equator of the spindle (Fig. 2, D) and the stages preparatory to the actual division, the prophases, are completed.

The next stage, the metaphase (Fig. 3, A), consists of the division, usually longitudinally, of each chromosome, so that the cell now
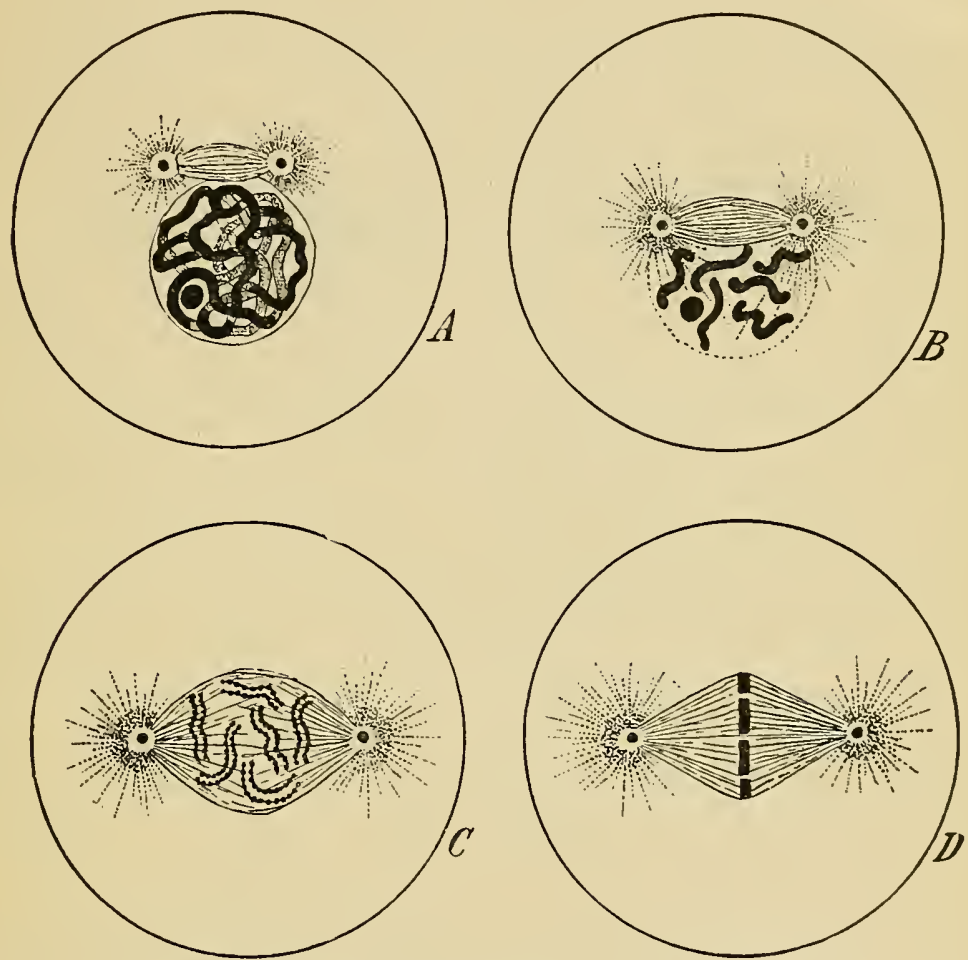

Fig. 2.-Diagrams Illustrating the Prophases of Mitosis.-(Adapied from E. B. Wilson.)

contains twice as many chromosomes as it did previously. As soon as this division is completed the anaphases are inaugurated by the halves of each chromosome separating from one another and approaching one of the asters (Fig. 3, B), and a group of chromosomes, containing half the total number formed in the metaphase, comes to 
lie in close proximity to each archoplasm sphere (Fig. 3, C). The spindle and astral fibers gradually resolve themselves again into the reticulum and the chromosomes of each group become irregular in shape and gradually spread out upon the nuclear reticulum so that .two nuclei, each similar to the one from which the process started,
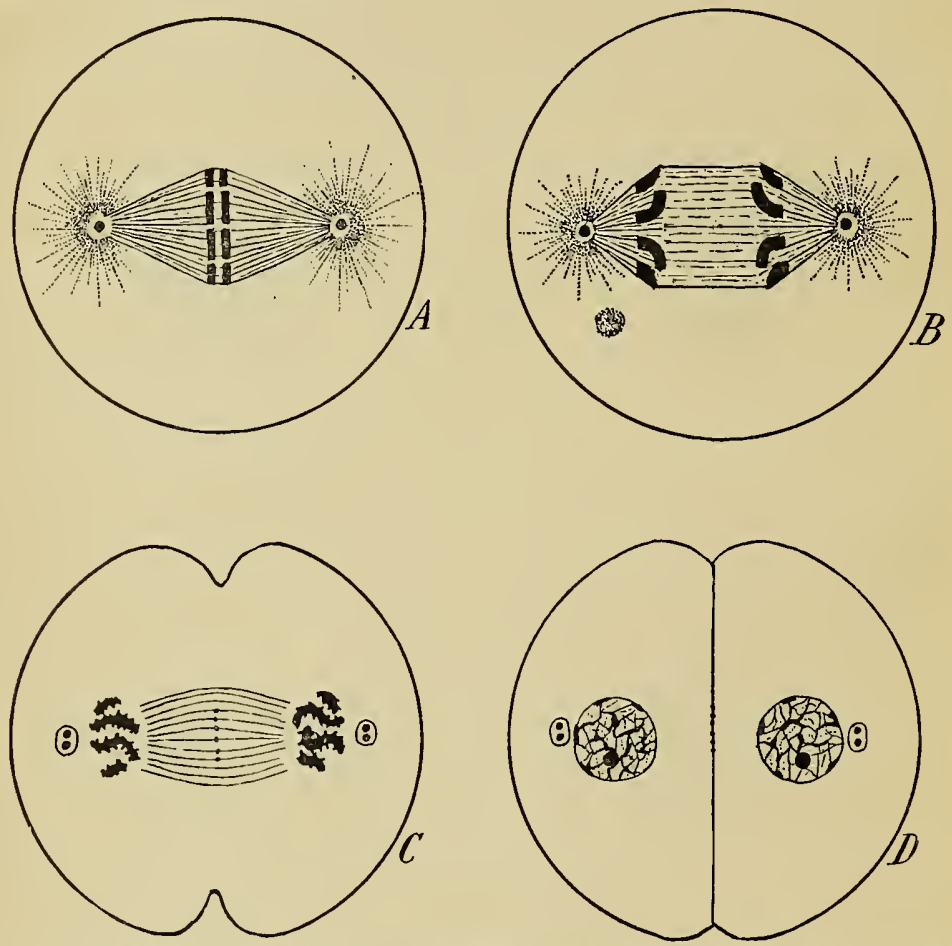

Fig. 3.-Diagrams Illustrating the Metaphase and Anaphases of Mitosis.(Adapted from E. B. Wilson.)

are formed (Fig. 3, D). Before all these changes are accomplished, however, a constriction makes its appearance at the surface of the cytoplasm (Fig. 3, C) and, gradually deepening, divides the cytoplasm in a plane passing through the equator of the amphiaster and gives rise to two separate cells (Fig. 3, D). 
This complicated process, which is known as karyokinesis or mitosis, is the one usually observed in dividing cells, but occasionally a cell divides by the nuclcus becoming constricted and dividing into two parts without any development of chromosomes, spindle, etc., the division of the cell following that of the nucleus. This amitotic method of division is, however, rare, and in many cases, though not always, its occurrence seems to be associated with an impairment of the reproductive activities of the cells. In actively reproducing cells the mitotic method of division may be regarded as the rule.

Since the process of development consists of the multiplication of a single original cell and the differentiation of the cell aggregate so formed, it follows that the starting-point of each line of individual development is to be found in a cell which forms part of an individual of the preceding generation. In other words, each individual represents one generation in esse and the succeeding generation in posse. This idea may perhaps be made clear by the following considerations. As a result of the division of a fertilized ovum there is produced an aggregate of cells, which, by the physiological division of labor, specialize themselves for various functions. Some assume the duty of perpetuating the species and are known as the sexual or germ cells, while the remaining ones divide among themselves the various functions necessary for the maintenance of the individual, and may be termed the somatic cells. The germ cells represent potentially the next generation, while the somatic cells constitute the present one. The idea may be represented schematicallythus:

\section{First generation}

$\overbrace{\text { Somatic cells }+ \text { germ cells }}^{\text {Second generation }}$
Third generation

Somatic cells + germ cells, etc.

It is evident, then, while the somatic cells of each generation die at their appointed time and are differentiated anew for each genera- 
tion from the germ cells, the latter, which may be termed collectively the germ-plasm, are handed on from generation to generation without interruption, and it may be supposed that this has been the case $a b$ initio. This is the doctrine of the continuity of the germ-plasm, a doctrine of fundamental importance on account of its bearings on the phenomena of heredity.

It is necessary, however, to fix upon some link in the continuous chain of the germ-plasm as the starting-point of the development of each individual, and this link is the fertilized ovum. By this is meant a germ cell produced by the fusion of two units of the germplasm. In many of the lower forms of life (e.g., Hydra and certain turbellarian worms) reproduction may be accomplished by a division of the entire organism into two parts or by the separation of a portion of the body from the parent individual. Such a method of reproduction is termed non-sexual. Furthermore in a number of forms (e.g., bees, Phylloxera, water-fleas) the germ cells are able to undergo development without previously being fertilized, this constituting a method of reproduction known as parthenogenesis. But in all these cases sexual reproduction also occurs, and in all the more highly organized animals it is the only method that normally occurs; in it a germ cell develops only after complete fusion with another germ cell. In the simpler forms of this process little difference exists between the two combining cells, but since it is, as a rule, of advantage that a certain amount of nutrition should be stored up in the germ cells for the support of the developing embryo until it is able to secure food for itself, while at the same time it is also advantageous that the cells which unite shall come from different individuals (cross-fertilization), and hence that the cells should retain their motility, a division of labor has resulted. Certain germ cells store up more or less food yolk, their motility becoming thereby impaired, and form what are termed the female cells or ova, while otners discard all pretensions of storing up nutrition, are especially motile and can seek and penetrate the inert ova; these latter cells constitute the male cells or spermatozoa. In many animals both kinds of cells are produced by the same individual, but in all the vertebrates (with rare exceptions 
in some of the lower orders) each individual produces only ova or spermatozoa, or, as it is generally stated, the sexes are distinct.

It is of importance, then, that the peculiarities of the two forms of germ cells, as they occur in the human species, should be considered.

\section{LITERATURE.}

E. B. WiLson: "The Cell in Development and Inheritance." Third edition. New York, 1900.

O. Hertwig: "Die Zelle und die Gewebe." Jena, I893. 



\section{PART I. GENERAL DEVELOPMENT.}

CHAPTER I.

\section{THE SPERMATOZOÖN AND SPERMATOGENESIS; THE OVUM AND ITS MATURATION AND FERTILIZATION.}

The Spermatozoön. - The human spermatozoön (Figs. 4 and 5) is a minute and greatly elongated cell, measuring about $0.05 \mathrm{~mm}$. in length. It consists of an anterior broader portion or head (Fig. $5, \mathrm{H}$ ), which measures about $0.005 \mathrm{~mm}$. in length and, when viewed from one surface (Fig. 4, I), has an oval outline, though since it is somewhat flattened or concave toward the tip, it has a pyriform shape when seen in profile (Fig. 4, 2). Covering the flattened portion of the head and fitting closely to it is a delicate cap-like membrane, the head-cap (Fig. 5, Hc), whose apex is a sharp edge, this structure corresponding to a pointed prolongation of the cap found in the spermatozoön of many of the lower vertebrates and known as the perforatorium. Immediately behind the head is a short portion known as the neck (Fig. 5, N), which consists of an upper more refractive body, the anterior nodule, and a lower clearer portion. To this succeeds the connecting or middle-piece (Figs. 4 and $5, m$ ) which begins with a posterior nodule, from the center of which there passes back through the axis of the piece an axial filament, enclosed within a sheath, this latter having wrapped around it a spiral filament. At the lower end of the middle-piece this spiral filament terminates in the annulus, through which the axial filament and its sheath passes into the flagellum or tail (Fig. 4, $f$ ). This portion, 
which constitutes about four-fifths of the total length of the spermatozoön is composed simply of the axial filament and its sheath, this latter gradually thinning out as it passes backward and ceasing altogether a short distance above the end of the axial filament.

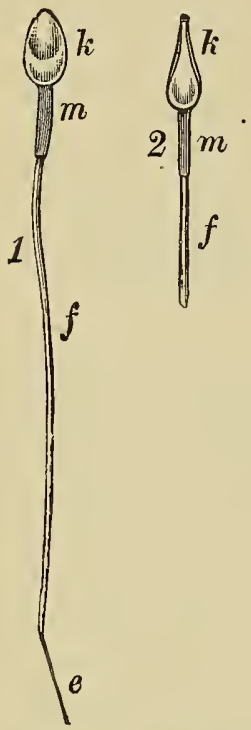

Fig. 4.-Human Spermatozoön.

I, Front view; 2, side view of the head; $e$, terminal filament; $k$, head; $f$, tail; $m$, middle-piece.-(After Retzius.)

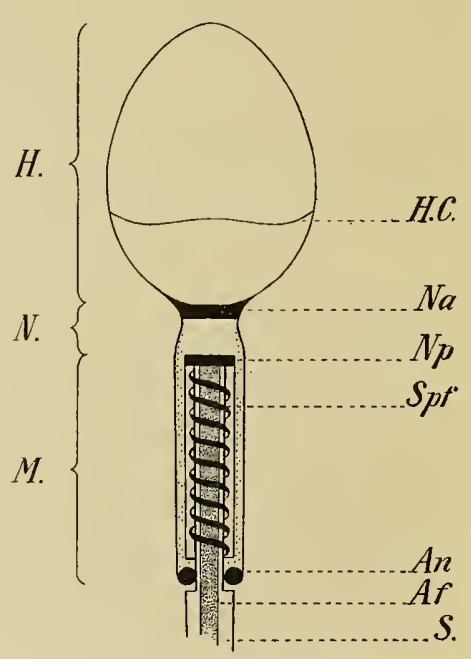

Fig. 5.-Diagram Showing the Structure OF a Human SPERMatozoön.

$A f$, Axial filament; $A n n$, annulus; $H$, head; $H c$, lower border of head-cap; $m$, middle-piece; $N$, neck; $N a$ and $N p$, anterior and posterior nodule; $S$, sheath of axial filament; $S p f$, spiral filament.-(Bonnet, after Meves.)

The filament thus projects somewhat beyond the actual end of the tail, forming what is known as the terminal filament or end-piece (Fig. 4, e).

To understand the significance of the various parts entering into the composition of the spermatozoön a study of their development is necessary, and since the various processes of spermatogenesis have been much more accurately observed in such mammalia as the rat 
and guinea-pig than in man, the description which follows will be based on what has been described as occurring in these forms. From what is known of the spermatogenesis in man it seems certain that it closely resembles that of these mammals so far as its essential features are concerned.

Spermatogenesis.-The spermatozoa are developed from the cells which line the interior of the seminiferous tubules of the testis. The various stages of development cannot all be seen at any one part of a tubule, but the formation of the spermatozoa seems to pass

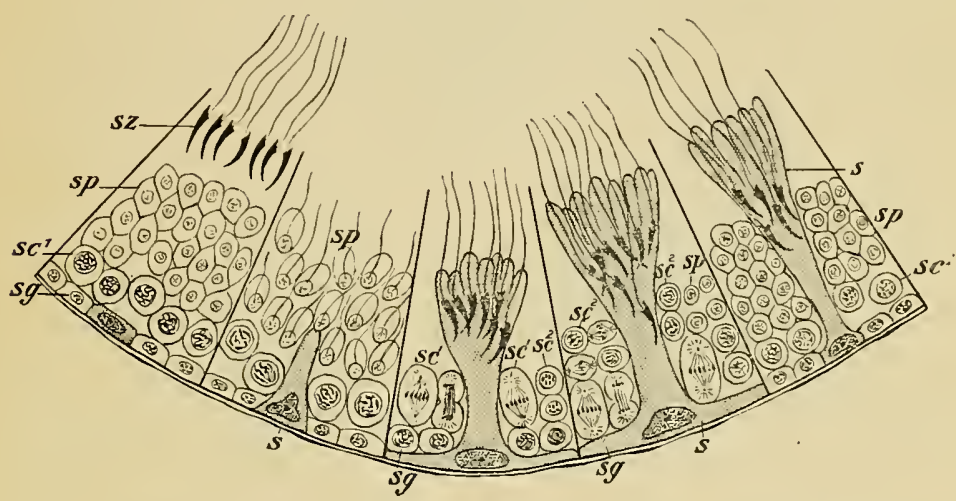

Fig. 6.-Diagram Showing Stages of Spermatogenesis as Seen in Different Sectors of a Seminiferous Tubule of a Rat.

$s$, Sertoli cell; $s c^{1}$, spermatocyte of the first order; $s c^{2}$, spermatocyte of the second order; sg, spermatogone; $s p$, spermatid; $s z$, spermatozoön.-(Modified from von Lenhossek.)

along each tubule in a wave-like manner and the appearances presented at different points of the wave may be represented diagrammatically as in Fig. 6.

In the first section of this figure four different generations of cells are represented; above are mature spermatozoa lying in the lumen of the tubule, while next the basement membrane is a series of cells from which a new generation of spermatozoa is about to develop. The cells of this series are of two kinds; the larger one $(s)$ 
will develop into a structure known as a Sertoli cell, while the others are parent cells of spermatozoa and are termed spermatogonia $(\mathrm{sg})$. In the next section the Sertoli cell is seen to have become considerably enlarged, its cytoplasm projecting toward the lumen of the tubule, and in the third section the enlargement has increased to such an extent that the spermatogonia are forced away from the basement membrane, with which the Sertoli cell alone is in contact. In the fourth section the spermatogonia are seen in process of division; one of the cells so formed will persist as a spermatogone, while the other forms what is termed a primary spermatocyte $\left(s c^{1}\right)$. The results of the division are seen in the last section, whece four spermatogonia are seen again in contact with the basement membrane and above them are four primary spermatocytes. Returning now to the first and second sections, the layer of primary spermatocytes may still be seen, indications of an approaching division being furnished by the arrangement of the chromatin in those of the second section, and in the third section the division is seen in progress, the two cells which result from it being termed secondary spermatocytes $\left(s c^{2}\right)$. These cells almost immediately undergo division, as shown in the fourth section, each giving rise to two spermatids $(s p)$, each of which becomes later on directly transformed into a spermatozoön (sz). From each primary spermatocyte there have been formed, therefore, as the result of two mitoses, four cells, each of which represents a spermatozoön.

During these divisions important departures from the typical method of mitosis occur, these departures leading to a reduction of the chromosomes in each spermatid to one-half the number occurring in the somatic cells. The general plan by which this is accomplished may be described as follows: In the division of the spermatogonia the number of chromosomes that appears is identical with that found in the somatic cells, so that in a form whose somatic number is eight, eight chromosomes appear in each spermatogonium, and divide so that eight pass to each of the resulting primary spermatocytes. When these cells divide, however, the number of chromosomes that appears is only one-half the somatic number, namely, four in the 
supposed case that is being described (Fig. 7, $s c^{1}$ ). The further history of these chromosomes indicates that each is composed of four elements more or less closely united to form a tetrad, and during mitosis each tetrad divides into two dyads, four of which will therefore pass into each secondary spermatocyte. These cells (Fig. $7, s c^{2}$ )

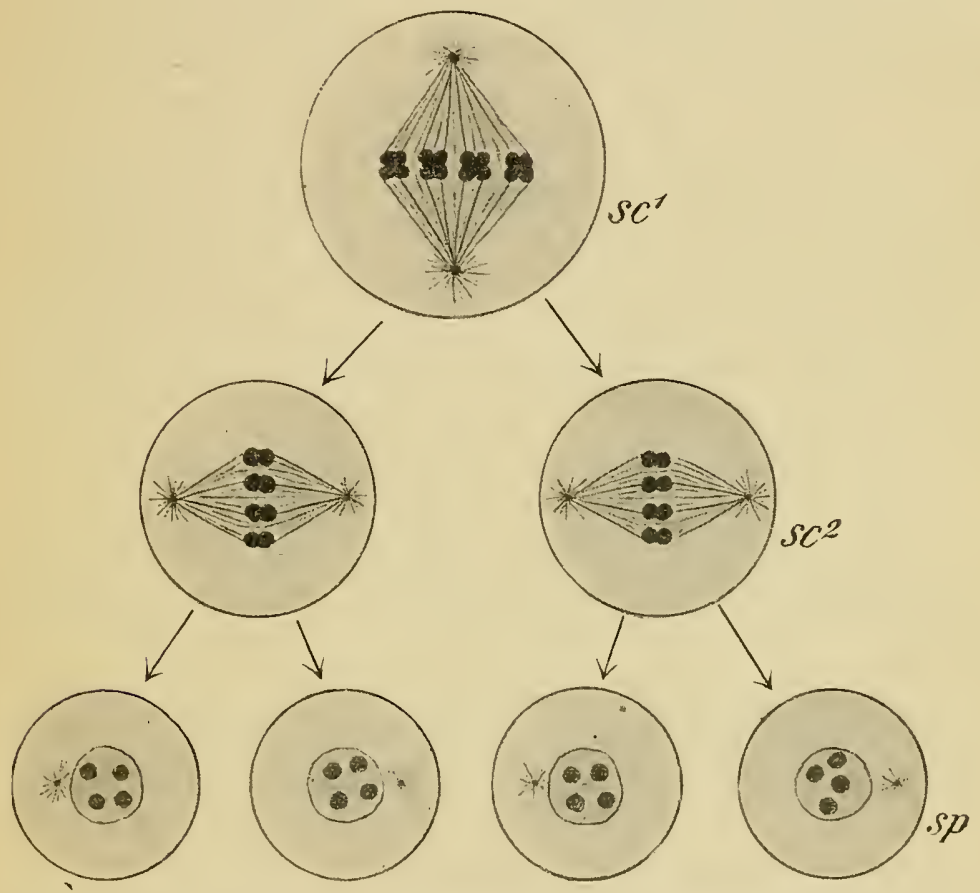

Fig. 7.-Diagram Illustrating the Reduction of the Chromosomes During SPERMATOGENESIS.

$s c^{1}$, Spermatocyte of the first order; $s c^{2}$, spermatocyte of the second order; $s p$, spermatid.

undergo division without the usual reconstruction of the nucleus and each of the dyads which they contain is halved, so that each spermatid receives a number of single chromosomes equal to half the number characteristic for the species (Fig. 7, sp).

This account of the behavior of the chromosomes during sper- 
matogenesis assumes that all the chromosomes of the primary spermatocytes are of equal value and behave similarly during mitosis. It has been found, however, that in a number of forms (insects, spiders, birds, etc.,) this is not the case and recent observations by Guyer indicate that in man certain of the spermatocytic chromosomes differ decidedly from their fellows. At the division of the primary spermatocytes twelve chromosomes make their appearance, but two of these differ from the rest in that they do not divide, but pass directly to one of the poles of the mitotic spindle (Fig. 8). When the division is completed, accordingly, one of the two daughter secondary spermatocytes will have received two undivided or accessory chromosomes plus ten ordinary chromosomes, resulting from the division of ten of the primary spermatocytic chromosomes; the other daughter cell, on the other hand, will have received only ten ordinary chromosomes in all, so that two classes of secondary spermatocytes are formed, in one of which the cells possess twelve chromosomes and in the other only ten.

In this respect, then, the spermatogenesis in man differs from the general plan described above and the division of the secondary spermatocytes reveals a second difference. For in these mitoses instead of twelve and ten chromosomes, seven and five, respectively, make their appearance. This may be explained on the supposition that the ten ordinary chromosomes, present in each class of secondary spermatocytes, have united to form five bivalent chromosomes, while the two accessory chromosomes, present in one of the classes have remained distinct. During the mitosis the accessory chromosomes divide just as do the ordinary ones, so that from each spermatocyte of one class two spermatids are formed, each containing seven chromosomes, while from each spermatocyte of the other class two spermatids, each containing five chromosomes, result (Fig. 8). Since the spermatids are directly transformed into spermatozoa, half of these latter will have received seven chromosomes, and the remaining half will have received five, or, since the five ordinary chromosomes are bivalent and the two accessories are univalent, the spermatozoa of one class will each have received the equivalent of 
ten plus two, i. e., twelve univalent chromosomes, while those of the other class will have received the equivalent of only ten.*

The transformation of the spermatids into spermatozoa takes place while they are in intimate association with the Sertoli cells, a number of them fusing with the cytoplasm of an enlarged Sertoli cell, as shown in Fig. 6, $s$, and probably receiving nutrition from it. In each spermatid there is present in addition to the nucleus, an

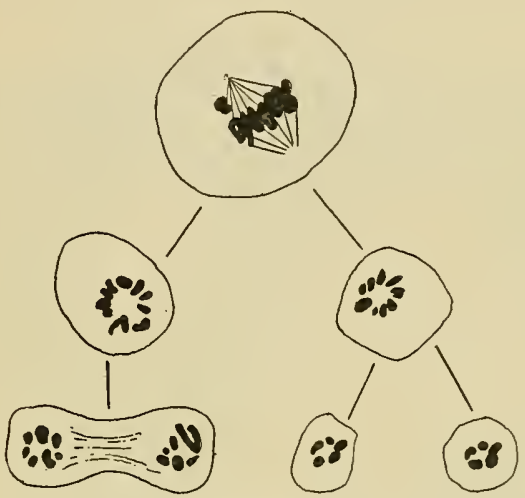

Fig. 8.-Diagram Illustrating the Behavior of the Chromosomes in Human SPERMATOGENESIS.

The upper figure shows the mitotic spindle of a primary spermatocyte with the two accessory chromosomes passing to one pole. The two figures in the second row represent the chromosomes of such a spindle in an anaphase, seen from either pole, and the figures of the last row represent spermatids derived from the two classes of secondary spermatocytes.-(Based on Guyer.)

archoplasm sphere and two centrosomes that have migrated from the archoplasm and lie free in the cytoplasm. The centrosomes and the archoplasm sphere take up their position at opposite poles of the nucleus, the archoplasm eventually forming the head-cap of the spermatozoön, and from one of the centrosomes a slender axial

* Doubt has been thrown upon the accuracy of these observations by Gutherz, who, while he finds a structure in the human spermatocyte which he identifies as an accessory chromosome, claims that it divides similarly to the other chromosomes. He does not find, therefore, any numerical difference in the chromosomes of the spermatids dividing them into two classes, although there may be qualitative differences indistinguishable by our present technique. 
filament grows out and soon projects beyond the limits of the cytoplasm (Fig. 9, $A$ ). The other centrosome becomes a rod-shaped structure which applies itself closely to the posterior pole of the nucleus, becoming the anterior nodule, while the lower one, from which the filament arises, becomes at first pyramidal in shape (Fig. 9, B) and later separates into a rod-like portion to which the filament is attached and a ring, through which the filament passes (Fig. 9, C). The rod-like portion becomes the posterior nodule,

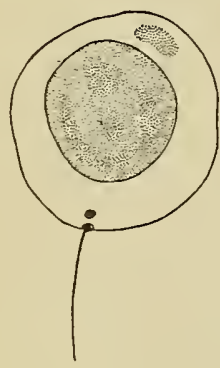

$A$

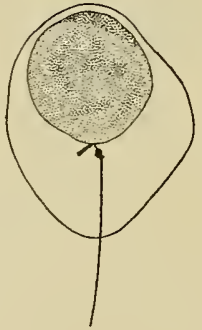

$B$

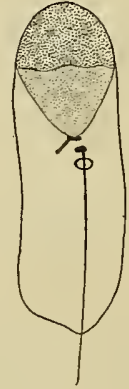

c

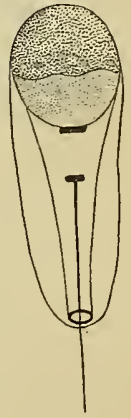

$D$

Fig. 9.-Stages in the Transformation of a Spermatid into a Spermatozoon.-(After Meves.)

and the ring separates from it to form the annulus (Fig. 9, D). The nucleus becomes the head of the spermatozoön, the cytoplasm surrounding it becoming reduced to an exceedingly delicate layer, so that the head is composed almost entirely of nuclear substance, if the head-cap be left out of consideration. The spiral filament of the middle-piece is, however, a derivative of the cytoplasm and according to some authors this portion of the spermatid also furnishes the material for the sheath of the axial filament, though this has been denied (Meves), the sheath being regarded as a differentiation of the axial filament. Each spermatozoön is, then, one of four equivalent cells, produced by two successive divisions of a primary spermatocyte and containing one-half the number of chromosomes characteristic for the species. 
The number of spermatozoa produced during the lifetime of a single individual is very large. It has been found that I cu. $\mathrm{mm}$. of human ejaculate contains 60,876 spermatozoa, a single ejaculate, therefore, containing over $200,000,000$. This would indicate that during his lifetime a man may produce 340 billion spermatozoa (Lode).

The Ovum.-The human ovum is a spherical cell measuring about $0.2 \mathrm{~mm}$. in diameter and is contained within a cavity situated

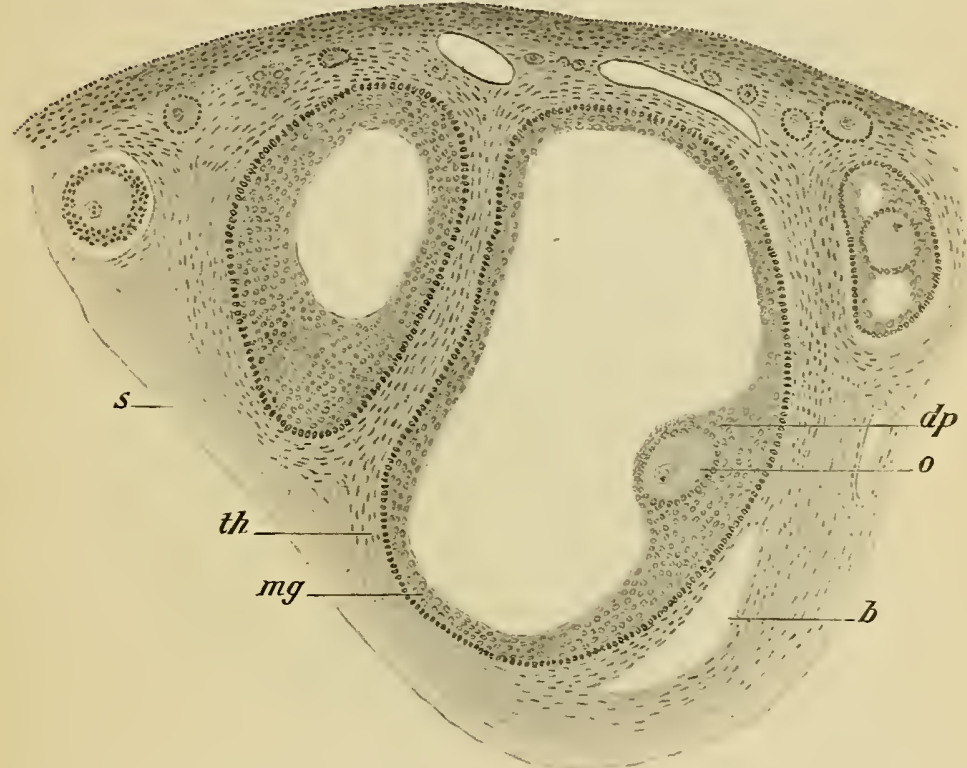

Fig. Io.-Section through PORTION OF an OVARy OF AN Opossum (Didephy's virginiana) Showing Ova and Follicles in Various Stages of Developien't.

$b$, Blood-vessel; $d p$, discus proligerus; $m g$, stratum granulosum; 0 , ovum; $s$, stroma; th, theca folliculi.

near or at the surface of the ovary and termed a Graafian follicle. This follicle is surrounded by a capsule composed of two layers, an outer one, the theca externa, consisting of fibrous tissue resembling that found in the ovarian stroma, and an inner one, the theca interna, composed of numerous spherical and fusiform cells. Both the 
thecæ are richly supplied with blood-vessels, the theca interna especially being the seat of a very rich capillary network. Internal to the theca interna there is a transparent, thin, and structureless hyaline membrane, within which is the follicle proper, whose wall is formed by a layer of cells termed the stratum gramulosum (Fig. Io, $\mathrm{mg}$ ) and inclosing a cavity filled with an albuminous fluid, the liquor

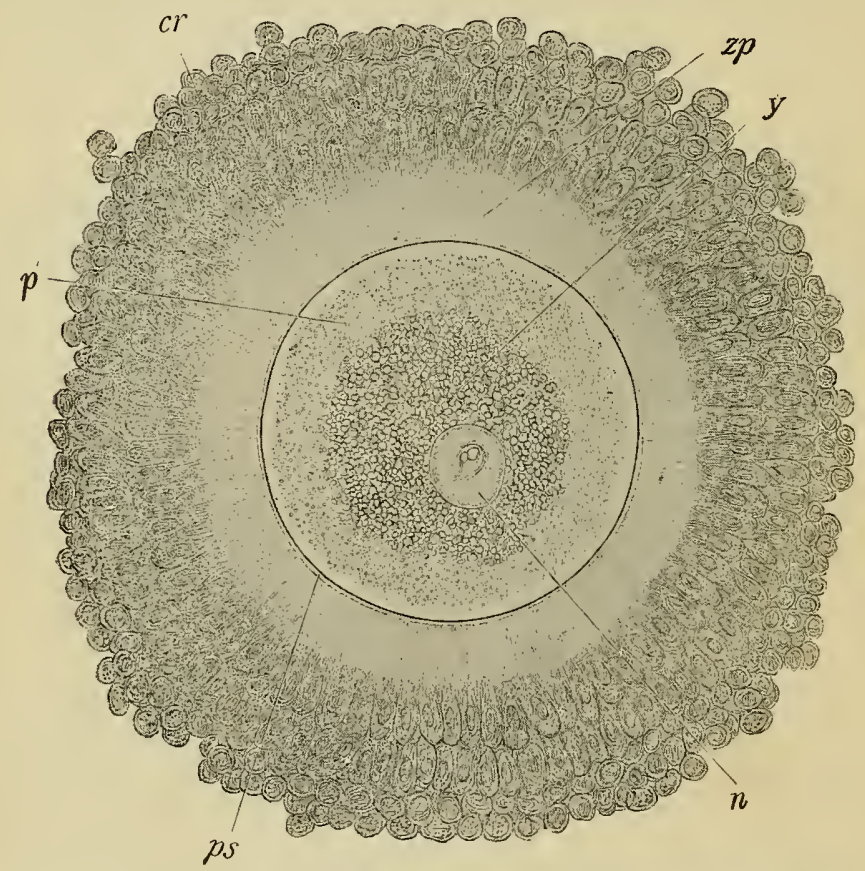

Fig. ix.-Ovum from Ovary of a Woman Thirty Years of Age.

$c r$, Corona radiata; $n$, nucleus; $p$, protoplasmic zone of ovum; $p s$, perivitelline space; $y$, yolk; $z p$, zona pellucida.-(Nagel.)

folliculi. At one point, usually on the surface nearest the center of the ovary, the stratum granulosum is greatly thickened to form a mass of cells, the discus proligerus $(d p)$, which projects into the cavity of the follicle and encloses the ovum $(o)$. Usually but a single ovum is contained in any discus, though occasionally two or even three may occur. 
The cells of the discus proligerus are for the most part more or less spherical or ovoid in shape and are arranged irregularly. In the immediate vicinity of the ovum, however, they are more columnar in form and are arranged in about two concentric rows, thus giving a somewhat radiated appearance to this portion of the discus, which is termed the corona radiata (Fig. II, $c r$ ). Immediately within the corona is a transparent membrane, the zona pellucida (Fig. II, $z p$ ), about as thick as one of the cell rows of the corona ( 0.02 to $0.024 \mathrm{~mm}$.), and presenting a very fine radial striation which has been held to be due to minute pores traversing the membrane and containing delicate prolongations of the cells of the corona radiata. Within the zona pellucida is the ovum proper, whose cytoplasm is more or less clearly differentiated into an outer more purely protoplasmic portion (Fig. II, $p$ ) and an inner mass $(y)$ which contains numerous fine granules of fatty and albuminous natures. These granules represent the food yolk or deutoplasm, which is usually much more abundant in the ova of other mammals and forms a mass of relatively enormous size in the ova of birds and reptiles. The nucleus $(n)$ is situated somewhat excentrically in the deutoplasmic portion of the ovum and contains a single, well-defined nucleolus.

A follicle with the structure described above and containing a fully grown ovum may measure anywhere from five to twelve millimeters in diameter, and is said to be "mature," having reached its full development and being ready to burst and set free the ovum. This, however, is not yet mature; it is not ready for fertilization, but must first undergo certain changes similar to those through which the spermatocyte passes, the so-called ovum at this stage being more properly a primary oöcyte. But before describing the phenomena of maturation of the ovum it will be well to consider the extrusion of the ovum and the changes which the follicle subsequently undergoes.

Ovulation and the Corpus Luteum.-As a rule, but a single follicle near maturity is found in either the one or the other ovary at any given time. In the early stages of its development a follicle is situated somewhat deeply in the stroma of the ovary, but during its growth it approaches the surface and eventually forms a marked 
prominence, only an exceedingly thin membrane separating the cavity of the follicle from the abdominal cavity. This thin membrane finally ruptures, and the liquor folliculi, which is apparently under some pressure while contained within the follicle, rushes out through the rupture, carrying with it the ovum surrounded by some of the cells of the discus proligerus.

The immediate cause of the bursting of the follicle is not yet clearly understood. It has been suggested that a gradual increase of the liquor folliculi under pressure must in itself finally lead to a rupture, and it has also been pointed out that just before the maturation of the follicle the theca interna undergoes an exceedingly rapid development and vascularization which may play an important part in the phenomenon.

Normally the ovum when expelled from its follicle is received at once into the Fallopian tube, and so makes its way to the uterus, in

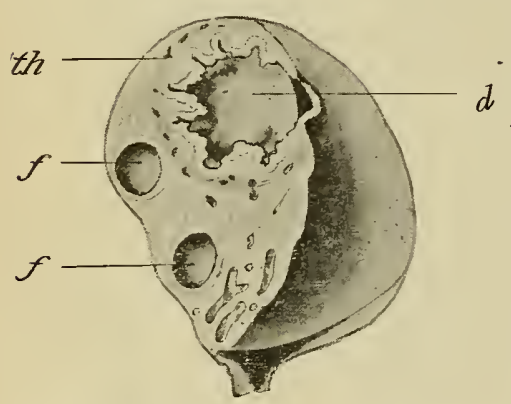

Fig. I2.--Ovary of a Woman NineTEEN YeARS of Age, Eight Days AfTer Menstruation.

$d$, Blood-clot; $f$, Graaffian follicle; th, theca.-(Kollmann.) whose cavity it undergoes its development. Occasionally, however, this normal course may be interfered with, the ovum coming to rest in the tube and there undergoing its development and producing a tubal pregnancy; or, again, the ovum may not find its way into the Fallopian tube, but may fall from the follicle into the abdominal cavity, where, if it has been fertilized, it will undergo development, producing an abdominal pregnancy; and, finally, and still more rarely, the ovum may not be expelled when the Graafian follicle ruptures and yet may be fertilized and undergo its development within the follicle, bringing about what is termed an ovarian pregnancy. All these varieties of extra-uterine pregnancy are, of course, exceedingly serious, since in none of them is the fetus viable. 
With the setting free of the ovum the usefulness of the Graafian follicle is at an end, and it begins at once to undergo retrogressive changes which result primarily in the formation of a structure known as the corpus luteum (Fig. I2). On the rupture of the follicle

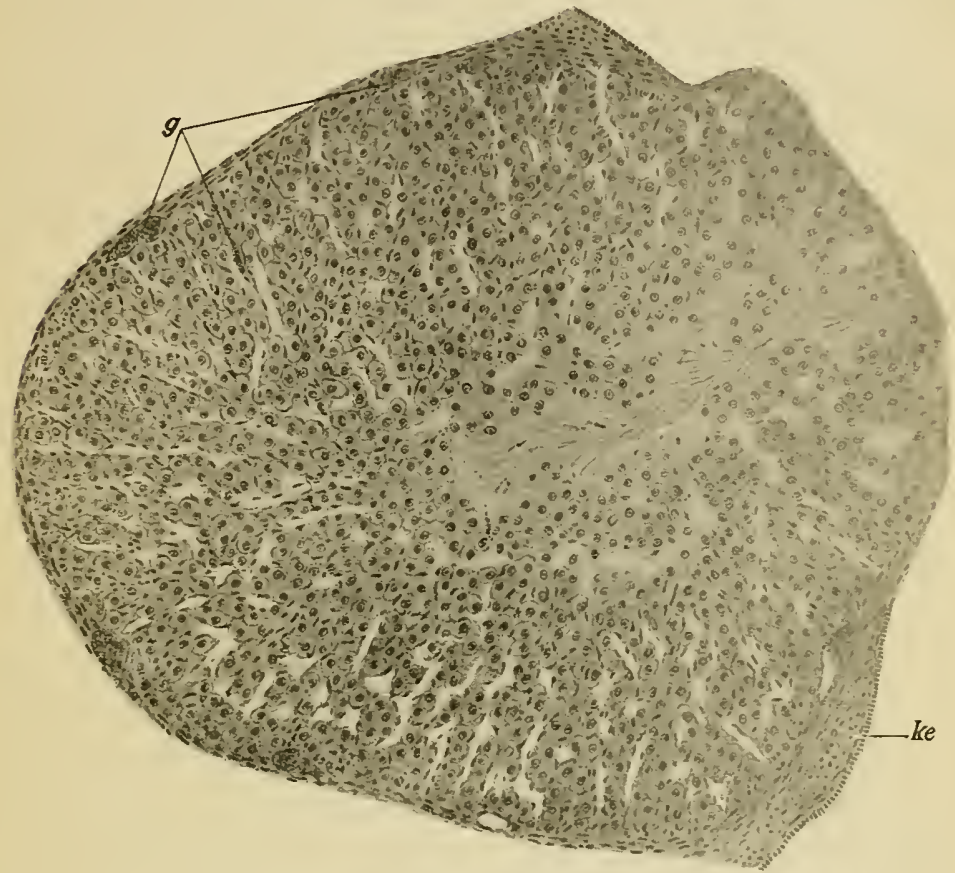

Fig. 13.-Section through the Corpus Luteum of a Rabiit, Seventy Hours post coitum.

The cavity of the follicle is almost completely filled with lutein cells among which is a certain amount of connective tissue. $g$, Blood-vessels; ke, ovarial epithelium.(Sobotta.)

a considerable portion of the stratum granulosum remains in place, and usually there is an effusion of a greater or less amount of blood from the vessels of the theca interna into the follicular cavity. The split in the wall of the follicle through which the orum escaped soon closes over and the cavity becomes filled with cells separated into groups by trabeculæ of connective tissue containing blood-ressels (Fig. I3). These cells contain a considerable amount of a peculiar 
yellow pigment known as lutein, the color imparted to the follicle by this substance having suggested the name corpus luteum which is now applied to it.

In later stages there is a gradual increase in the amount of connective tissue present and a corresponding diminution of the lutein cells, the corpus luteum gradually losing its yellow color and becoming converted into a whitish, fibrous, scar-like body, the corpus albicans, which may eventually almost completely disappear. These various changes occur in every ruptured follicle, whether or not the ovum which was contained in it be fertilized. But the rapidity with which the various stages of retrogression ensue differs greatly according to whether pregnancy occurs or not, and it is customary to distinguish the corpora lutea which are associated with pregnancy as corpora lutea vera from those whose ova fail to be fertilized and which form corpora lutea spuria. In the latter the retrogression of the follicle is completed usually in about five or six weeks, while the corpora vera persist throughout the entire duration of the pregnancy and complete their retrogression after the birth of the child.

Two very different views are held as to the origin of the lutein cells. According to one, which may be termed von Baer's view, the cells of the stratum granulosum remaining in the follicle rapidly undergo degeneration and completely disappear, and the lutein cells and connective-tissue trabecula are formed entirely from the cells of the theca interna, which increase rapidly both in size and number. The other view was first advanced by Bischoff and may be known by his name. It is to the effect that the granulosa cells do not disintegrate, but, on the contrary, increase rapidly in number and become converted into the lutein cells, only the connective tissue and the blood-vessels being derived from the theca interna.

Which of these two views is correct is at present uncertain. The majority of those who have within recent years studied the formation of the human corpus luteum have expressed themselves in favor of von Baer's theory. Sobotta has, however, made a thorough study of the phenomena in a perfect series of mice ovaries and has demonstrated that in that form the lutein cells are derived 
from the granulosa cells. It would be strange if the lutein cells had a different origin in two different mammals, and the observations on mice are so thorough that one is tempted to regard different results as being due to imperfections in the series of ovaries studied, important steps in the development of the corpora lutea being thus overlooked. This temptation is, moreover, greatly increased by the fact that Sobotta's observations have been confirmed in the cases of several other animals, such, for instance, as the rabbit (Sobotta, Honoré, Cohn), certain bats (van der Stricht), the sheep (Marshall), the marsupial dasyurus (Sandes), the spermophile (Völker), and the guinea-pig (Sobotta). The weight of evidence is at the present time strongly in favor of Bischoff's view, but until the adverse results obtained by Clarke and others from the study of the human corpus luteum and those obtained by Jankowski from the pig have been shown to be incorrect, the question as to the invariable derivation of the lutein cells from the stratum granulosum must be left open. Since it is held that both the granulosa and theca cells are derivatives of the embryonic ovarial epithelium the essential differences between the two origins that have been ascribed to the lutein cells may not be so great as has been supposed. Indeed, it is possible that both the follicular and thecal cells may in some cases contribute to the formation of the corpus luteum.

The persistence of the corpus luteum throughout the entire period of pregnancy and its disappearance within a few weeks if pregnancy does not supervene, have suggested the probability of its being related to the changes that take place in the uterus in connection with the implantation of the ovum in its wall. Experimental removal of the corpus luteum in rabbits either before or shortly after the implantation of the ovum produces a failure of pregnancy (Fraenkel), and similar results have been obtained in mice and bitches (Marshall and Jolly). It has accordingly been held that the corpus luteum is an organ of internal secretion directly concerned in the production and maintenance of the modifications of the uterus necessary for the implantation and further development of the ovum. 
The Relation of Ovulation to Menstruation.-It was long believed that ovulation was coincident with certain periodic changes of the uterus which constitute what is termed menstruation. This phenomenon makes its appearance at the time of puberty, the exact age at which it appears being determined by individual and racial peculiarities and by climate and other factors, and after it has once appeared it normally recurs at definite intervals more or less closely corresponding with lunar months (i.e., at intervals of about twentyeight days) until somewhere in the neighborhood of the fortieth or forty-fifth year, when it ceases.

In each menstrual cycle four stages may be recognized, one of which, the intermenstrual, greatly exceeds the others in its duration, occupying about one-half the entire period. During this stage the mucous membrane of the uterus is practically at rest, but toward its close the membrane gradually begins to thicken and the second stage, the premenstrual stage, then supervenes. This lasts for six or seven days and is characterized by a marked proliferation and swelling of the uterine mucosa, the subjacent tissue becoming at the same time highly vascular and eventually congested. The walls of the blood-vessels situated beneath the mucosa then degenerate and permit the escape of blood here and there beneath the mucous membrane, this leading to the third, or menstrual, stage in which the mucous membrane diminishes in thickness, those portions of it that overlie the effused blood undergoing fatty degeneration and desquamation, so that the stage is characterized by more or less extensive hæmorrhage. The duration of this stage is from three to five days and then ensues the postmenstrual stage, lasting from four to six days, during which the mucous membrane is regenerated and again returns to the intermenstrual condition.

It seems but natural to regard these changes as the expression of a periodic attempt to prepare the uterus for the reception of the fertilized ovum, this preparation being completed during the premenstrual stage, the succeeding menstrual and postmenstrual being merely the return of the uterine mucosa to the resting intermenstrual stage, pregnancy not having occurred. If this be the 
real significance of the menstrual cycle, one would expect to find ovulation occurring at a more or less definite portion of the cycle, at such a time that the ovum, if fertilized would be able to make use of the premenstrual preparation for its reception.

Attempts to determine the relation of ovulation to menstruation have been made by estimating the age of the corpora lutea occurring in ovaries removed in the course of operation from patients, the date of whose last menstruation was known. The results obtained by this method have, however, proved somewhat discordant. Thus, Fraenkel records out of eighty-five cases ten in which the operation was performed immediately before or after menstruation, and in none of these was any corpus luteum present; further, in twenty cases a newly formed corpus luteum was found and in these cases the last menstruation had occurred on the average nineteen $\left(\mathrm{r}_{3}-27\right)$ days previously. Villemin, too, reached a similar result, concluding that ovulation took place about fifteen days after menstruation. On the other hand, Leopold and Ravano found that in ninety-five cases ovulation coincided with menstruation in fifty-nine, while in the remaining thirty-six it occurred during other stages of the cycle.

If any conclusion may be drawn from these contradictory results it would seem to be that in the human species ovulation may take place at any stage of the menstrual cycle. Indeed, it may also be said that ovulation may take place independently of the menstrual cycle, since cases are on record of pregnancy having occurred in girls who had not yet menstruated. In other words, it seems probable that ovulation does not depend upon the condition of the uterine mucous membrane, but upon some other factor as yet undetermined.

The conditions in lower animals seem also to point in this direction. In these ovulation is, as a rule, associated with a certain condition known as astrus or "heat," this being preceded by certain phenomena constituting what is termed the proastrum and corresponding essentially to menstruation. In several forms, such as the dog and the pig, ovulation appears to occur regularly in association with "heat," but in others, such as the cat, the mouse and probably the rabbit, it occurs at this time only if copulation also occurs. Furthermore, it has been observed that 
although female monkeys menstruate regularly throughout the year, nevertheless there is but one annual œstral period when ovulation takes place (Heape).

The Maturation of the Ovum.-Returning now to the ovum, it has been shown that at the time of its extrusion from the Graafian follicle it is not equivalent to a spermatozoön but to a primary spermatocyte, and it may be remembered that such a spermatocyte

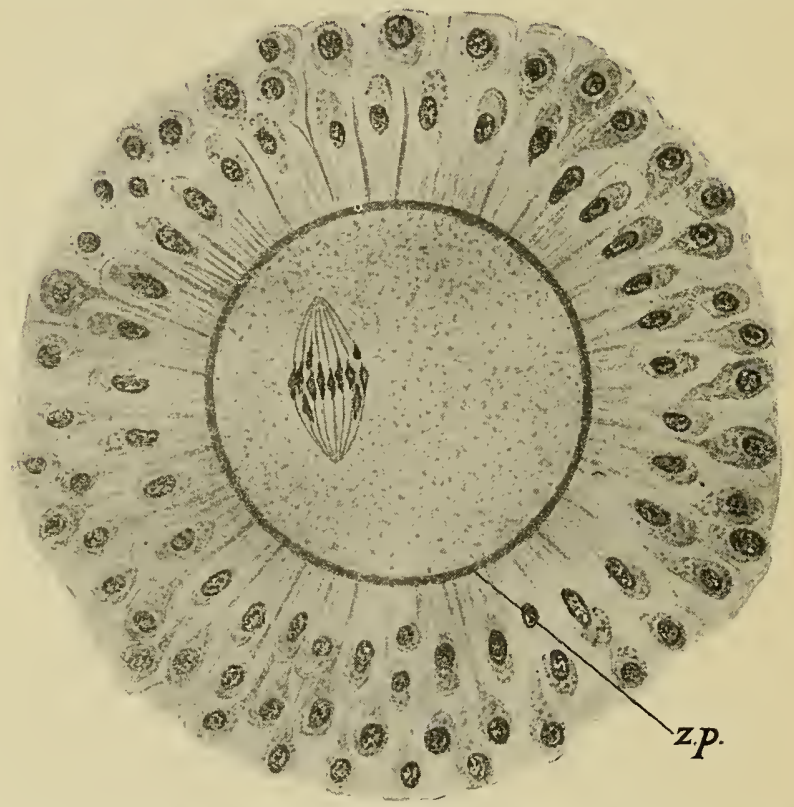

Fig. i4.-Ovum of a Mouse Showing the Maturation Spindle.

The ovum is enclosed by the zona pellucida $(z \cdot p)$, to which the cells of the corona radiata are still attached.-(Sobotta.)

becomes converted into a spermatozoön only after it has undergone two divisions, during which there is a reduction of the number of the chromosomes to practically one-half the number characteristic for the species.

Similar divisions and a similar reduction of the chromosomes occur in the case of the ovum, constituting what is termed its maturation. The phenomena have not as yet been observed in 
human ova, and, indeed, among mammals only with any approach to completeness in comparatively few forms (rat, mouse, guincapig, bat and cat); but they have been obscrved in so many other forms, both vertebrate and invertebrate, and present in all cases so

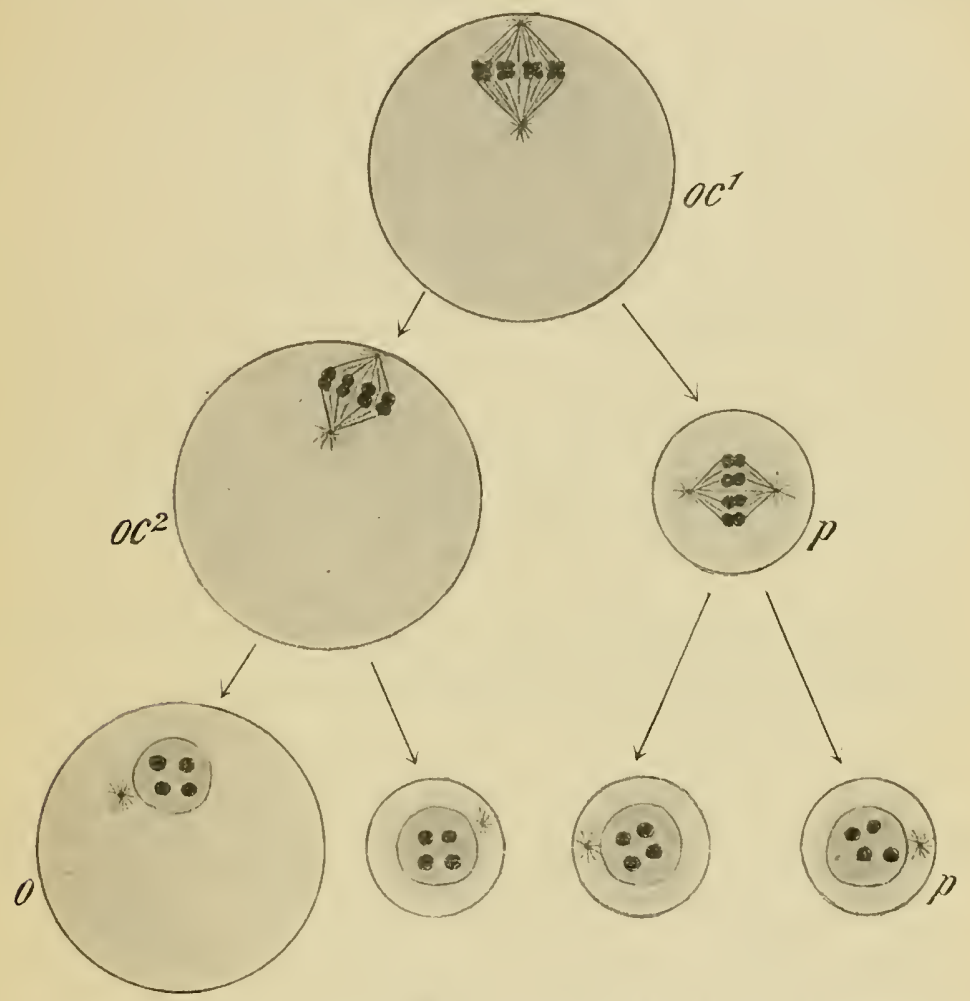

Fig. I5.-Diagram Illustrating the Reduction of The Chromosomes during the Maturation of the OvUM.

$o$, Ovum; $o c^{1}$, oöcyte of the first generation; $o c^{2}$, oöcyte of the second generation; $p$, polar globule.

much uniformity in their general features, that there can be little question as to their occurrence in the human ovum.

In typical cases the ovum (the primary oöcyte) undergoes a division in the prophases of which the chromatin aggregates to form half as many tetrads as there are chromosomes in the somatic cells 
(Fig. $\mathrm{I}_{5}, o c^{1}$ ) and at the metaphase a dyad from each tetrad passes into each of the two cells that are formed. These two cells (secondary oöcytes) are not, however, of the same size; one of them is almost as large as the original primary oöcyte and continues to be called an ovum $\left(o c^{2}\right)$, while the other is very small and is termed a polar globule $(p)$. A second division of the ovum quickly succeeds the first (Fig. I $5, o c^{2}$ ), and each dyad gives a single chromosome to each of the two cells which result, so that each of these cells possesses half the number of chromosomes characteristic for the species. The second division, like the first, is unequal, one of the cells being relatively very large and constituting the mature ovum, while the other is small and is the second polar globule. Frequently the first polar globule divides during the formation of the second one, a reduction of its dyads to single chromosomes taking place, so that

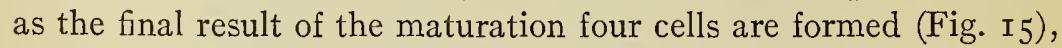
the mature ovum $(o)$, and three polar globules $(p)$, each of which contains half the number of chromosomes characteristic for the species.

The similarity of the maturation phenomena to those of spermatogenesis may be perceived trom the following diagram:

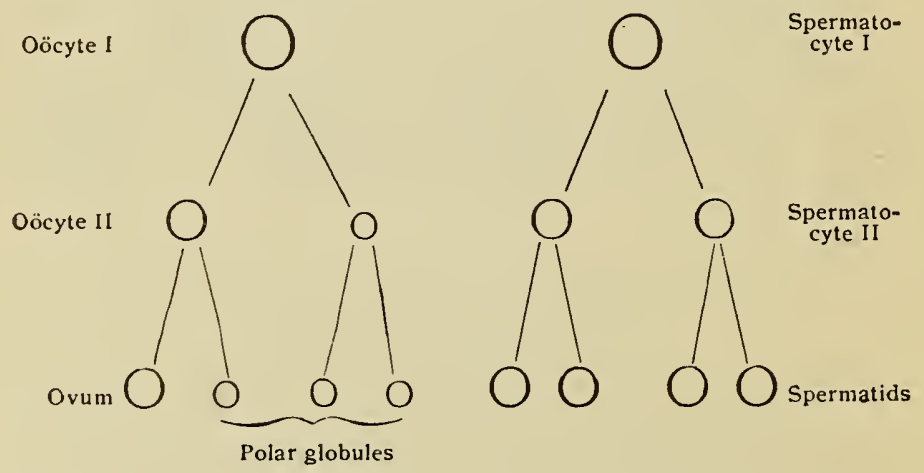

In both processes the number of cells produced is the same and in both there is a similar reduction of the chromosomes. But while each of the four spermatids is functional, the three polar globules are non-functional, and are to be regarded as abortive ova, formed 
during the process of reduction of the chromosomes only to undergo degeneration. In other words, three out of every four potential ova sacrifice themselves in order that the fourth may have the bulk, that is to say, the amount of nutritive material and cytoplasm necessary for efficient development.

The Fertilization of the Ovum.- - It is perfectly clear that the reduction of the chromosomes in the germ cells cannot very long be repeated in successive generations unless a restoration of the original number takes place occasionally, and, as a matter of fact, such a restoration occurs at the very beginning of the development of each individual, being brought about by the union of a spermatozoön with an ovum. This union constitutes what is known as the fertilization of the ovum.

The fertilization of the human ovum has not yet been observed, but the phenomenon has been repeatedly studied in lower forms, and a thorough study of the process has been made on the mouse by Sobotta, whose observations are taken as a basis for the following account.

The maturation of the ovum is quite independent of fertilization, but in many forms the penetration of the spermatozoön into the ovum takes place before the maturation phenomena are completed. 'This is the case with the mouse. A spermatozoön makes its way through the zona pellucida and becomes embedded in the cytoplasm of the ovum and its tail is quickly absorbed by the cytoplasm while its nucleus and probably the middle-piece persist as distinct structures. As soon as the maturation divisions are completed the nucleus of the ovum, now termed the female pronucleus (Fig. I6, ek), migrates toward the center of the ovum, and is now destitute of an archoplasm sphere and centrosome, these structures having disappeared after the completion of the maturation divisions. The spermatozoön nucleus, which, after it has penetrated the ovum, is termed the male promucleus $(s p k)$, may lie at first at almost any point in the peripheral part of the cytoplasm, and it now begins to approach the female pronucleus, preceded by the middle-piece, which becomes an archoplasm sphere with its contained centrosome and is surrounded by 
astral rays. The two pronuclei finally come into contact near the center of the ovum, forming what is termed the segmentation mucleus (Fig. I6), and the archoplasm sphere and centrosome which have been introduced with the spermatozoön undergo division and the two archoplasm spheres so formed migrate to opposite poles of the segmentation nucleus, an amphiaster forms and the compound nucleus passes through the various prophases of mitosis. Since, in the mouse, the male and female pronuclei have each contributed twelve chromosomes, the equatorial plate of the mitosis is composed of twenty-four chromosomes, the number characteristic for the species being thus restored.

In describing the spermatogenesis it was shown (p. I6) that two classes of spermatozoa were formed, those of one class containing the equivalent of twelve chromosomes, while those of the other class contained only ten. A similar separation of the ovum into two classes probably does not occur, the accessory chromosomes in the oöcytes dividing just as do the ordinary ones, so that each ovum possesses twelve chromosomes. When, therefore, the union of the male and female pronuclei takes place in fertilization, those ova that are fertilized by a spermatozoön with twelve chromosomes will possess twenty-four of these bodies, while in those in which the fertilization is accomplished by a spermatozoön with ten chromosomes, only twenty-two will occur. The number of chromosomes in the fertilized ovum determines the number in the somatic cells of the embryo that develops from it and hence there will be two classes of embryos, one in which the somatic cells possess twentyfour chromosomes and another in which there are twenty-two.

That this condition occurs in the human species is at present merely a conjecture based partly on what occurs during spermatogenesis and partly on what has been shown to occur in a number of invertebrates (insects). In these, two classes of spermatozoa have been found to occur as in man, and two classes of individuals, differing in the number of chromosomes in their somatic cells, develop from the fertilized ova; and it has been further found that in these forms those with the greater number of chromosomes 

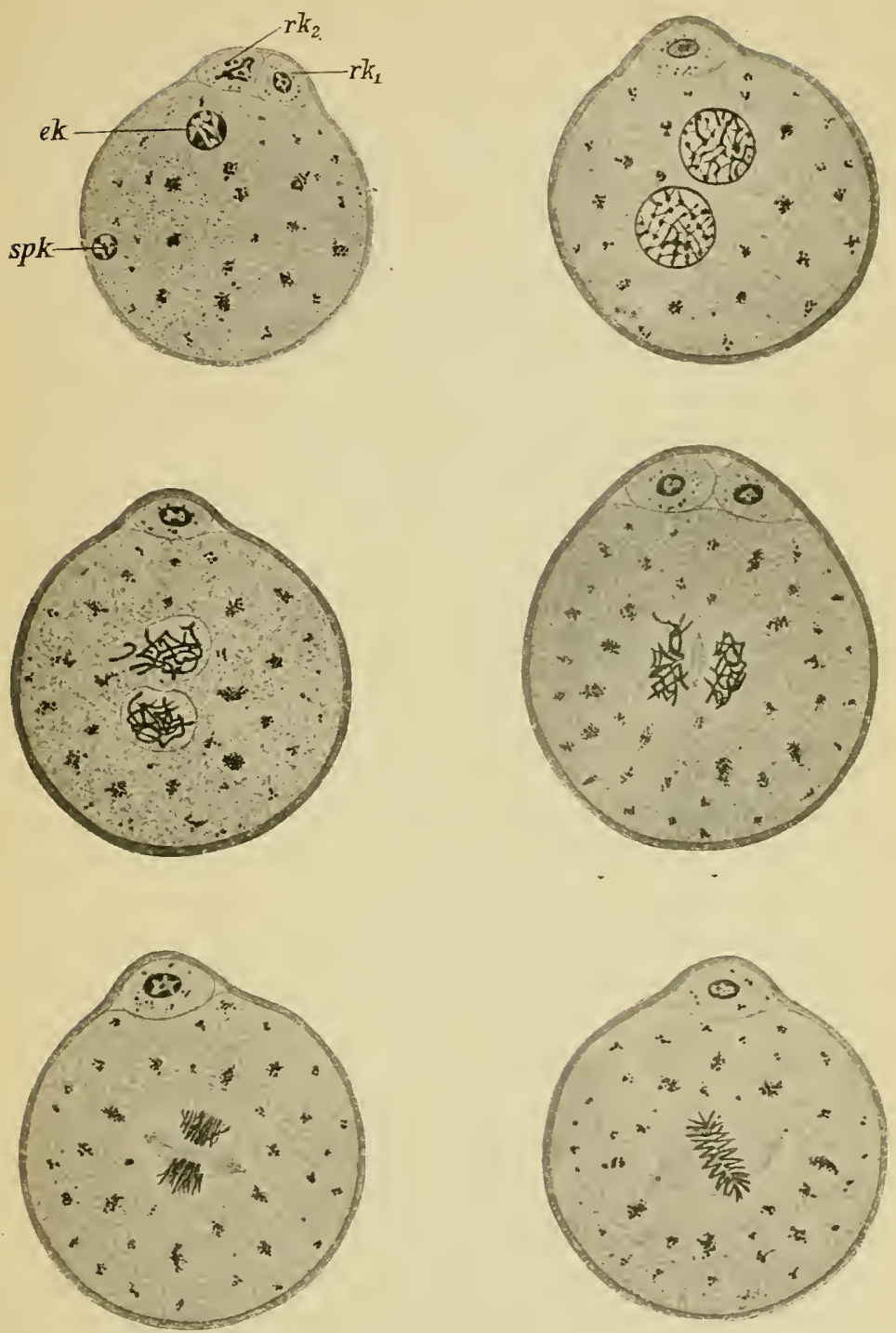

Fig. I6.-Six Stages in the Process of Fertilization of the Ovum of a Mouse.

After the first stage figured it is impossible to determine which of the two nuclei represents the male or female pronucleus. $e k$, Female pronucleus; $r k_{1}$ and $r k_{2}$, polar globules; $s p k$, male pronucleus.-(Sobotta.) 
become females and those with the smaller number males. If, as seems probable, this condition also obtains in the human species, it is evident that the sex of the future individual is determined at the ferlilization of the ovum and is correlated with the number of chromosomes present in the ovum at that stage.

It seems to be a rule that but one spermatozoön penetrates the ovum. Many, of course, come into contact with it and endeavor to penetrate it, but so soon as one has been successful in its endeavor no further penetration of others occurs. The reasons for this are in most cases obscure; experiments on the ova of invertebrates have shown that the subjection of the ova to abnormal conditions which impair their vitality favors the penetration of more than a single spermatozoön (polsypermy), and, indeed, it appears that in some forms, such as the common newt (Diemyctylus), polyspermy is the rule, only one of the spermatozoa, however, which have penetrated uniting with the female pronucleus, the rest being absorbed by the cytoplasm of the ovum.

Fertilization marks the beginning of development, and it is therefore important that something should be known as to where and when it occurs. It seems probable that in the human species the spermatozoa usually come into contact with the ovum and fertilize it in the upper part of the Fallopian tubes, and the occurrence of extra-uterine pregnancy (see p. 22) seems to indicate that occasionally the ovum may be fertilized even before it has been received into the tube.

It is evident, then, that when fertilization is accomplished the spermatozoön must have traveled a distance of about twenty-four centimeters, the length of the upper part of the vagina being taken to be about $5 \mathrm{~cm}$., that of the uterus as $7 \mathrm{~cm}$., and that of the tube as $12 \mathrm{~cm}$. A considerable interval of time is required for the com. pletion of this journey, even though the movement of the spermatozoön be tolerably rapid. The observations of Henle and Hensen indicate that a spermatozoön may progress in a straight line at about the rate of from I.2 to $2.7 \mathrm{~mm}$. per minute, while Lott finds the rate to be as high as $3.6 \mathrm{~mm}$. Assuming the rate of progress to be about 
$2.5 \mathrm{~mm}$. per minute, the time required by the spermatozoön to travel from the upper part of the vagina to the upper part of a Fallopian tube will be about one and a half hours (Strassmann). This, however, assumes that there are no obstacles in the way of the rapid progress of the spermatozoön, which is not the case, since, in the first place, the irregularities and folds of the lining membrane of the tube render the path of the spermatozoön a labyrinthine one, and, secondly, the action of the cilia of the epithelium of the tube and uterus being from the ostium of the tube toward the os uteri, it will greatly retard the progress; furthermore, it is presumable that the rapidity of movement of the spermatozoön diminishes after a certain interval of time. It seems probable, therefore, that fertilization does not occur for some hours after coition, eren providing an ovum is in the tube awaiting the approach of the spermatozoön.

But this condition is not necessarily present, and consequently the question of the duration of the vitality of the sperm cell becomes of importance. Ahlfeld has found that, when kept at a proper temperature, a spermatozoön will retain its vitality outside the body for eight days, and Dührssen reports a case in which living spermatozoa were found in a Fallopian tube removed from a patient who had last been in coitu about three and a half weeks previously. As regards the duration of the vitality of the ovum less accurate data are available. Hyrtl found an apparently normal ovum in the uterine portion of the left tube of a female who died three days after the occurrence of her second menstruation, and Issmer estimates the duration of the capacity for fertilization of an ovum to be about sixteen days.

It is evident, then, that even when the exact date of the coitus which led to the fertilization is known, the actual moment of the latter process can only be approximated, and in the immense majority of cases it is necessary to rely upon the date of the last menstruation for an estimation of the probable date of parturition. And by this method the possibilities for error are much greater, since, as been pointed out, ovulation is not necessarily associated with menstruation. The duration of pregnancy is normally ten 
lunar or about nine calendar months and it is customary to estimate the probable date of parturition as nine months and seven days from the last menstruation. From what has been said, it is clear that any such estimation can be depended upon only as an approximation, the possible variation from it being considerable.

Superfetation.-The occasional occurrence of twin fetuses in different stages of development has suggested the possibility of the fertilization of a second ovum as the result of a coition at an appreciable interval of time after the first ovum has started upon its development. There seems to be good reason for believing that many of the cases of supposed superfetation, as this phenomenon is termed, are instances of the simultaneous fertilization of two ova, one of which, for some cause concerned with the supply of nutrition, has later failed to develop as rapidly as the other. At the same time, however, even although the phenomenon may be of rare occurrence, it is by no means impossible, for occasionally a second Graafian follicle, either in the same or the other ovary, may be so near maturity that its ovum is extruded soon after the first one, and if the development of the latter and the incidental changes in the uterine mucous membrane have not proceeded so far as to prevent the access of the spermatozoön to the ovum, its fertilization and development may ensue. The changes, however, which prevent the passage of the spermatozoön are completed early in development and the difference between the normally developed embryo and that due to superfetation will be comparatively small, and will become less and less evident as development proceeds, provided that the supply of nutrition to both embryos is equal.

\section{LITERATURE.}

E. Ballowitz: "Untersuchungen über dic Struktur der Spermatozoen," No. 4. Zeitschr. für wissensch. Zool., LII, I89I.

K. VON BARDELEBEN: "Beiträge zur Histologie des Hodens und zur Spermatogenese beim Menschen," Archiv fur Anat. und Physiol., Anat. Abth., Supplement, I897.

TH. BOverI: "Befruchtung," Ergebnisse der Anat. und Entwicklungsgesch., I, I892.

J. G. ClaRK: "Ursprung, Wachsthum und Ende des Corpus luteum nach Beobachtungen am Ovarium des Schweines und des Menschen," Archiv für Anat. und Physiol., Anat. Abth., I898.

L. Fraenkel: "Neue Experimente zur Function des Corpus luteum," Arch. für Gynaek., xcr, I9ro.

L. GERLACH: "Ueber die Bildung der Richtungskörper bei Mus musculus," Wiesbaden, I906.

S. GutHeRz: "Ueber ein bemerkenswertes Strukturelement (Heterochromosome) in der Spermiogenese des Menschen," Arch.f. Mikr. Anat., Lxxıx, Igr2.

M. F. Guyer: "Accessory Chromosomes in Man," Biol. Bull., xıx, roro.

W. Heape: "The Sexual Season of Mammals and the Relation of the Procestrum to 
Menstruation," Quart. Journ. Micros.Sci., N.S., xLIV, Igor (contains very full bibliography).

O. Hertwig: "Vergleich der Ei- und Samenbildung bei Nematoden," Archiv für mikrosk. Anat., Xxxvx, I8go.

F. Hitschiann and L. AdLeR: "Der Bau der Uterusschleimhaut des geschlechtsreifen Weibes, mit besonderer Berücksichtigung der Menstruation," Monaisschr. fïr Geburtsh. und Gynaek., xxxrr, I908.

J. JANkowski: "Beitrag zur Entstehung des Corpus luteum der Säugetiere," Arch.f. mikr. Anat., LxIV, I904.

W. B. KIRKHAM: "The Maturation of the Mouse Egg," Biol. Bulletin, XII, I907.

H. LAMS and J. DOORME: "Nouvelles recherches sur la maturation et la fécondation de l'oeuf de mammiferes," Arch. de Biol., xxin, I907.

M. vON LENHOSSEK: "Untersuchungen über Spermatogenese," Archiv für mikrosk. Anat., LI, I8g8.

G. Leopold and A. Rovano: "Neuer Beitrag zur Lehre von der Menstruation und Ovulation," Arch. für Gynaek., LxxxIII, I907.

W. H. Longley: "The Maturation of the Egg and Ovulation in the Domeatic Cat," Amër. Journ. Anat., xII, I9II.

F. H. A. Marseali: "The CEstrus Cycle and the Formation of the Corpus luteum in the Sheep," Philos. Trans., Ser. B, cxcvi, I904.

F. H. A. Marshall: "The Development of the Corpus luteum: a Review," Quart. Journ. Micros.Sci., N.S., xLIx, Igo6.

F. Meves: "Ueber Struktur und Histogenese der Samenfäden des Meerschweinchens," Archiv für mikrosk. Anat., LIV, I899.

T. H. Montgomery: "Differentiation of the human Cells of Sertoli," Biolog. Bull., XXI, I9II.

W. NAGEL: "Das menschliche Ei," Archiv fïr mikrosk. Anat., xxxI, I888.

G. Niessing: "Die Betheiligung der Centralkörper und Sphäre am Aufbau des Samenfadens bei Säugethieren," Archiv für mikrosk. Anat., XIVIII, I8g6.

G. Retzius: "Die Spermien des Menschen," Biolog. Untersuch., xIV, I909.

W. RuBASCHKIN: "Ueber die Reifungs- und Befruchtungs-processe des Meerschweincheneies," Anat. Hefte, xxIx, I905.

J. Совотта: "Die Befruchtung und Furchung des Eies der Maus," Archiv für mikrosk. Anat., XLV, I895.

J. Sовотта: "Ueber die Bildung des Corpus luteum bei der Maus," Archiv für mikrosk. Anat., XIVII, I897.

J. Sовотта: "Ueber die Bildung des Corpus luteum beim Meerschweinchen," Anat. Hefte, Xxxir, Igo6.

J. SobottA and G. BurckHARD: "Reifung und Befruchtung der Eier des weissen Ratte," Anat. Hefle, xLII, I9Io.

P. Strassuranv: "Beiträge zur Lehre von der Ovulation, Menstruation und Conception," Archiv fïr Gynaekol., LII, I896.

F. Villesin: "Le corps jaune considéré comme glande à sécrétion interne," Paris, Igos.

W. WALdeyer: "Eierstock und Ei," Leipzig, I870. 


\section{CHAPTER II.}

\section{THE SEGMENTATION OF THE OVUM AND THE FORMATION OF THE GERM LAYERS.}

Segmentation.-The union of the male and female pronuclei has already been described as being accompanied by the formation of a mitotic spindle which produces a division of the ovum into two cells. This first division is succeeded at more or less regular intervals by others, until a mass of cells is produced in which a differentiation eventually appears. These divisions of the ovum constitute what is termed its segmentation.

The mammalian ovum has behind it a long line of evolution, and even at early stages in its development it exhibits peculiarities which can only be reasonably explained as an inheritance of past conditions. One of the most potent factors in modifying the character of the segmentation of the ovum is the amount of food yolk which it contains, and it seems to be certain that the immediate ancestors of the mammalia were forms whose ova contained a considerable amount of yolk, many of the peculiarities resulting from its presence being still clearly indicated in the early development of the almost yolkless mammalian ovum. To give some idea of the peculiarities which result from the presence of considerable amounts of yolk it will be well to compare the processes of segmentation and differentiation seen in ova with different amounts of it.

A little below the scale of the vertebrates proper is a form, Amphioxus, which possesses an almost yolkless ovum, presenting a simple process of development. The fertilized ovum of Amphioxus in its first division separates into two similar and equal cells, and these are made four (Fig. I7, A) by a second plane of division which cuts the previous one at right angles. A third plane at 
right angles to both the preceding ones brings about an eight-celled stage (Fig. I7, B), and further divisions result in the formation of a large number of cells which arrange themselves in the form of a hollow sphere which is known as a blastula (Fig. I7, E).

The minute amount of yolk which is present in the ovum of Amphioxus collects at an early stage of the segmentation at one pole of the ovum, the cells containing it being somewhat larger than those of the other pole (Fig. I7, B), and in the blastula the cells of one pole are larger and more richly laden with yolk than those of the other pole (Fig. I7, F). If, now, the segmenting ovum of an Amphibian be examined, it will be found that a very much greater amount of
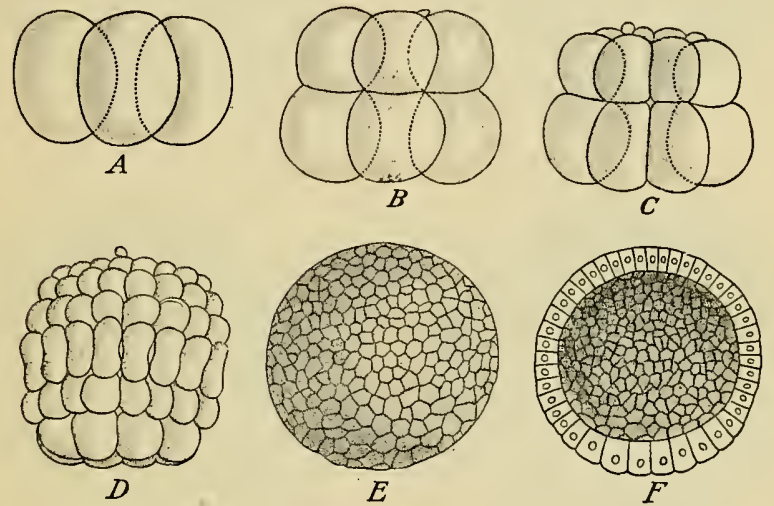

Fig. 17.-Stages in the Segmentation of Amphioxus.

$A$, Four-celled stage; $B$, eight-celled stage; $C$, sixteen-celled stage; $D$, early blastula; $E$, blastula; $F$, section of blastula.-(Hatschek.)

yolk is present and, as in Amphioxus, it is located especially at one pole of the ovum. The first three planes of segmentation have the same relative positions as in Amphioxus (Fig. I7), but one of the tiers of cells of the eight-celled stage is very much smaller than the other (Fig. I8, B). In the subsequent stages of segmentation the small cells of the upper pole divide more rapidly than the larger ones of the lower pole, the activity of the latter seeming to be retarded by the accumulation of the yolk, and the resulting blastula (Fig. I8, 
D) shows a very decided difference in the size of the cells of the two poles.

In the ova of reptiles and birds the amount of yolk stored up in the ovum is very much greater even than in the amphibia, and it is aggregated at one pole of the ovum, of which it forms the principal mass, the yolkless protoplasm appearing as a small disk upon the

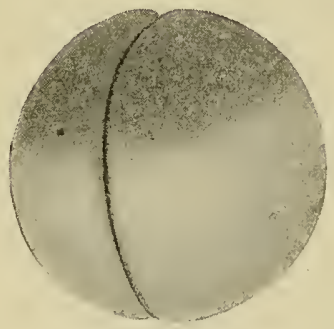

$A$

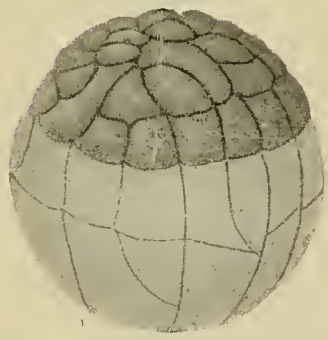

C

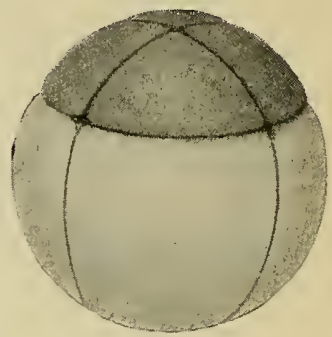

$B$

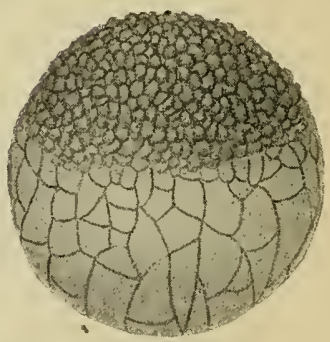

$D$

Fig. I8.-Stages in the Segmentation of A mblystoma.-(Eycleshymer.)

surface of a relatively huge mass of yolk. The inertia of this mass of nutritive material is so great that the segmentation is confined to the small yolkless disk of protoplasm and affects consequently only a portion of the entire ovum. To distinguish this form of segmentation from that which affects the entire ovum it is termed meroblastic segmentation, the other form being known as holoblastic.

In the ovum of a turtle or a bird the first plane of segmentation crosses the protoplasmic disk, dividing it into two practically equal 
halves, and the second plane forms at approximately right angles to the first one, dividing the disk into four quadrants (Fig. 19, A). The third division, like the two which precede it, is radial in position, while the fourth is circular and cuts off the inner ends of the six cells previously formed (Fig. I9, C). The disk now consists of six central smaller cells surrounded by six larger peripheral ones.
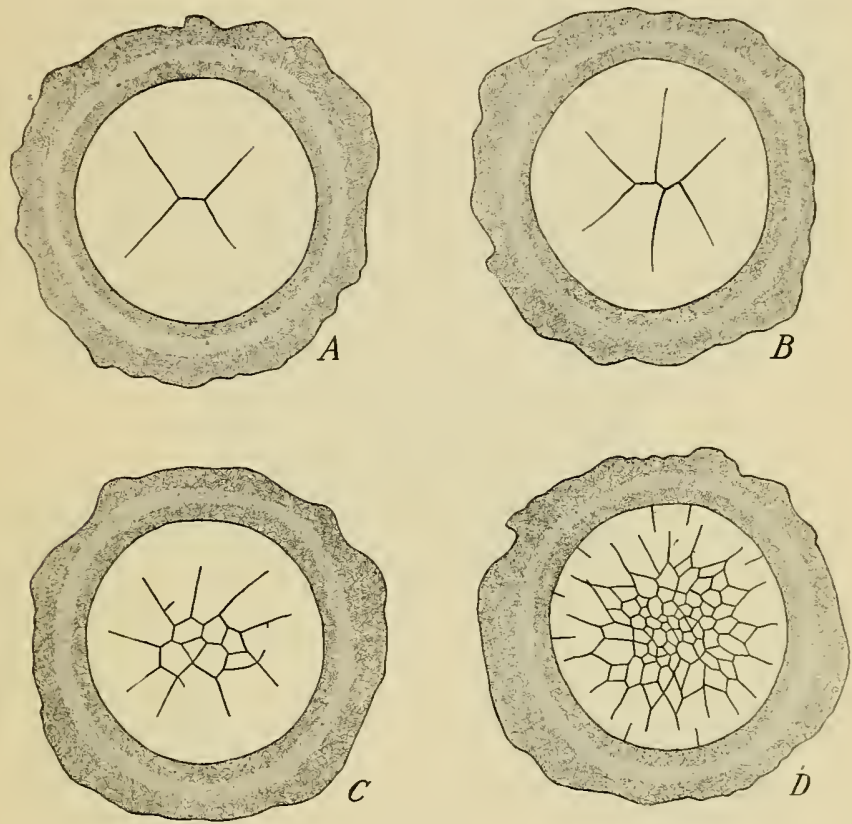

Fig. 19.-Four Stages in the Segmentation of the Blastodera of the Снтск.-(Coste.)

Beyond this period no regularity can be discerned in the appearance of the segmentation planes; but radial and circular divisions continuing to form, the disk becomes divided into a large number of cells, those at the center being much smaller than those at the periphery. In the meantime, however, the smaller central cells have begun to divide in planes parallel to the surface of the disk, which, from being a simple plate of cells, thus becomes a discoidal cellmass. 
During the segmentation of the disk it has increased materially in size, extending further and further over the surface of the yolk, into the substance of which some of the lower cells of the discoidal cell-mass have penetrated. A comparison of the diagram (Fig. 20) of the ovum of a reptile at about this stage of development with the figure of the amphibian blastula (Fig. I8, D) will indicate the similarity between the two, the lárge yolk-mass $(Y)$ of the reptile with the scattered cells which it contains corresponding to the lower pole

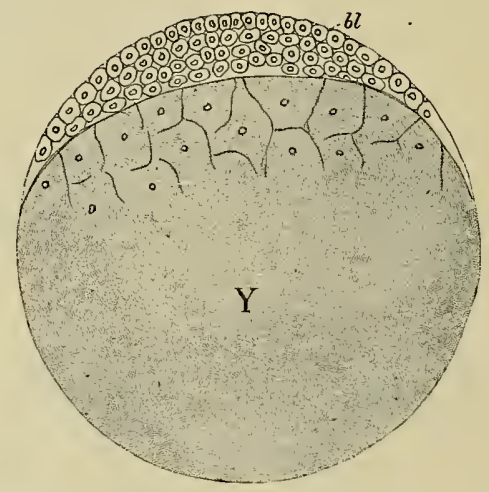

Fig. 20.-Diagram Illustrating a Section of the Ovum of a Reptile at a Stage Corresponding to the Blastula of an AmpHibian.

$b l$, Blastoderm; $Y$, yolk-mass.

cells of the amphibian blastula, the central cavity of which is practically suppressed in the reptile. Beyond this stage, however, the similarity becomes more obscured. The peripheral cells of the disk continue to extend over the surface of the yolk and finally completely enclose it, forming an enveloping layer which is completed at the upper pole of the egg by the discoidal cell-mass, or, as it is usually termed, the blastoderm.

Turning now to the mammalia, $*$ it will be found that the ovum in the great majority is almost or quite as destitute of food yolk as is

* The segmentation of the human ovum has not yet been observed; what follows is based on what occurs in the ovum of the rabbit, mole, and especially of a bat (Van Beneden). 
the ovum of Amphioxus, with the result that the segmentation is of the total or holoblastic type. It does not, however, proceed with that regularity which marks the segmentation of Amphioxus or an amphibian, but while at first it divides into two slightly unequal cells (Fig. 2I), thereafter the divisions become irregular, three-celled,
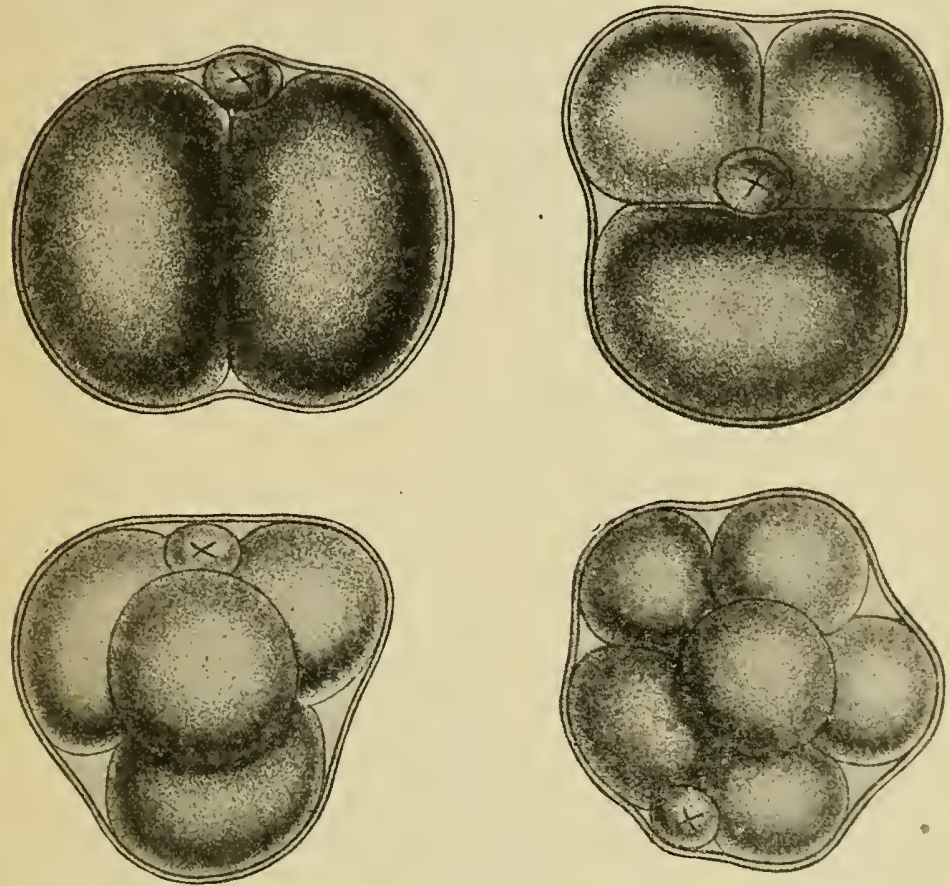

Fig. 2 I.-Four Stages in the Segmentation of the Ovum of a Mouse. $\times$, Polar globule.-(Sobotta.)

four-celled, five-celled, and six-celled stages having been observed in various instances. Nor is the result of the final segmentation a hollow vesicle or blastula, but a solid mass of cells, termed a morula, is formed. This structure is not, however, comparable to the blastula of the lower forms, but corresponds to a stage of reptilian development a little later than that shown in Fig. 20, since, as will be shown directly, the cells corresponding to the blastoderm and the 
enveloping layer are already present. There is, then, no blastula stage in the mammalian development.

Differentiation now begins by the peripheral cells of the morula becoming less spherical in shape and later forming a layer of flattened cells, the enveloping layer, surrounding the more spherical central cells (Fig. 22, A). In the latter vacuoles now make their appearance, especially in those cells which are nearest what may be regarded as the lower pole of the ovum (Fig. 22, C), and these vacuoles, gradually increasing in size, eventually become confluent, the condition represented in Fig. 22, D, being produced. At this stage the ovum consists of an enveloping layer, enclosing a cavity which is equivalent to the yolk-mass of the reptilian ovum, the vacuolization of the inner cells of the morula representing a belated formation of yolk. On the inner surface of the enveloping layer, at what may be termed the upper pole of the ovum, is a mass of cells projecting into the yolk-cavity and forming what is known as the inner cell-mass, a structure comparable to the blastoderm of the reptile. In one respect, however, a difference obtains, the inner cell-mass being completely enclosed within the enveloping cells, which is not the case with the blastoderm of the reptile. That portion of the enveloping layer which covers the cell-mass has been termed Rauber's covering layer, and probably owes its existence to the precocity of the formation of the enveloping layer.

It is clear, then, that an explanation of the early stages of development of the mammalian ovum is to be obtained by a comparison, not with a yolkless ovum such as that of Amphioxus, but with an ovum richly laden with yolk, such as the meroblastic ovum of a reptile or bird. In these forms the nutrition necessary for the growth of the embryo and for the complicated processes of development is provided for by the storing up of a quantity of yolk in the ovum, the embryo being thus independent of external sources for food. The same is true also of the lowest mammalia, the Monotremes, which are egg-laying forms, producing ova resembling greatly those of a reptile. When, however, in the higher mammals the nutrition of the embryo became provided 

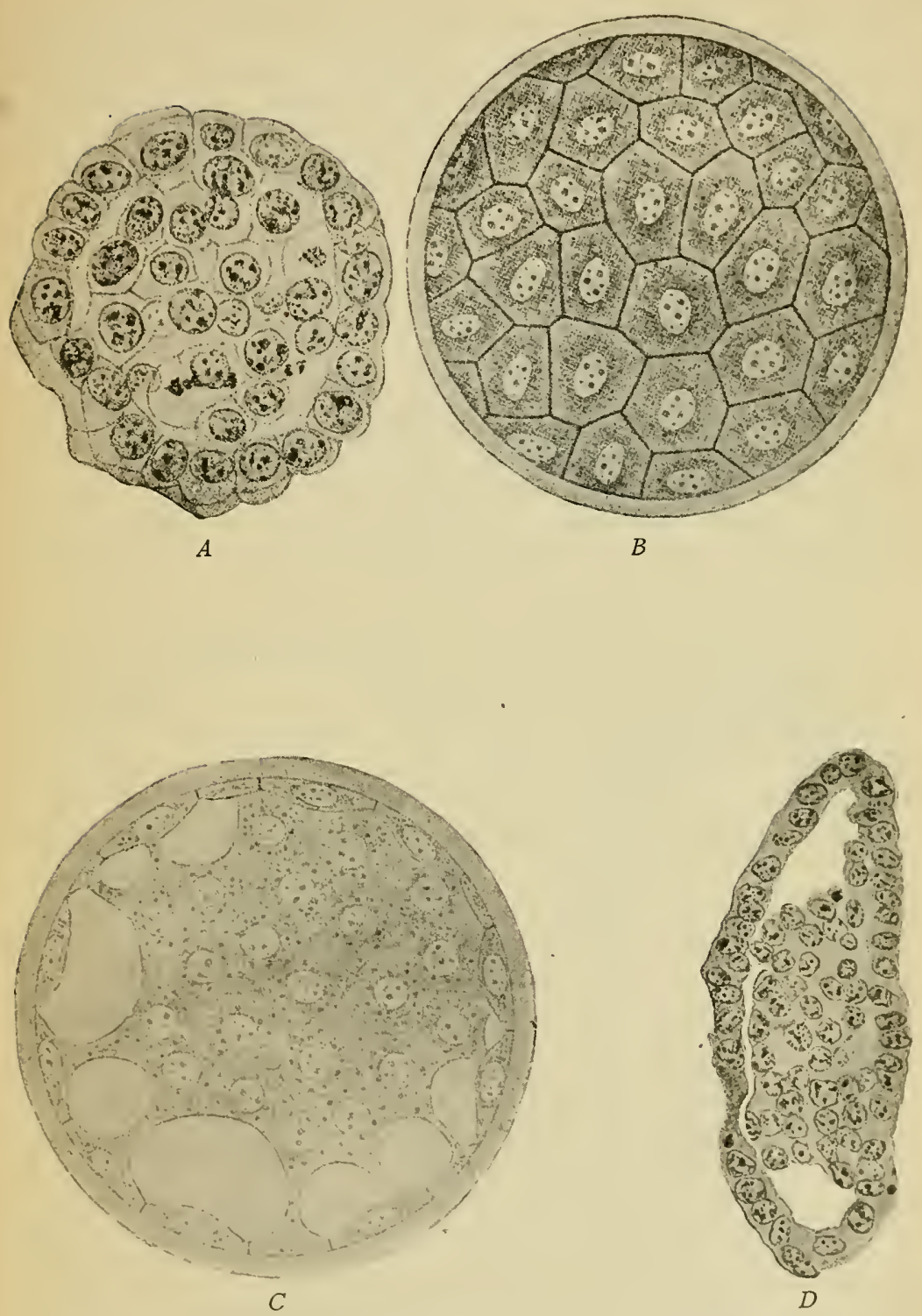

Fig. 22.-Later Stages in the Segmentation of the Ovum of a Bat. $A, C$, and $D$ are sections, $B$ a surface view.-(Van Beneden.) 
for by the attachment of the embryo to the walls of the uterus of the parent so that it could be nourished directly by the parent, the storing up of yolk in the ovum was unnecessary and it became a holoblastic ovum, although many peculiarities dependent on the original meroblastic condition persisted in its development.

Twin Development.-As a rule, in the human species but one embryo develops at a time, but the occurrence of twins is by no means infrequent, and triplets and even quadruplets occasionally are developed. The occurrence of twins may be due to two causes, either to the simultaneous ripening and fertilization of two ova, either from one or from both ovaries, or to the separation of a single fertilized ovum into two independent parts during the early stages of development. That twins may be produced by this latter process has been abundantly shown by experimentation upon developing ova of lower forms, each of the two cells of an Amphioxus ovum in that stage of development, if mechanically separated, completing its development and producing an embryo of about half the normal size.

Double Monsters and the Duplication of Parts.-The occasional occurrence of double monsters is explained by an imperfect separation into two parts of an originally single embryo, the extent of the separation, and probably also the stage of development at which it occurs, determining the amount of fusion of the two individuals constituting the monster. All gradations of separation occur, from almost complete separation, as seen in such cases as the Siamese twins, to forms in which the two individuals are united throughout the entire length of their bodies. The separation may also affect only a portion of the embryo, producing, for instance, double-faced or double-headed monsters or various forms of so-called parasitic monsters; and, finally, it may affect only a group of cells destined to form a special organ, producing an excess of parts, such as supernumerary digits or accessory spleens.

It has been observed in the case of double monsters that one of the two fused individuals always has the position of its various organs reversed, it being, as it were, the looking-glass image of its fellow. Cases of a similar situs inversus viscerum, as it is called, have not infrequently been observed in single individuals, and a plausible explanation of such cases regards them as one of a pair of twins formed by the division of a single embryo, the other individual having ceased to develop and either having undergone degeneration or, if the separation was an incomplete one, being included within the body of the apparently single individual. Another explanation of situs inversus has been advanced (Conklin) on the basis of what has been observed in certain invertebrates. In some species of snails situs inversus is a normal condition and it has been found that the inversion may be traced back in the development even to the 
earliest segmentation stages. The conclusion is thereby indicated that its primary cause may reside in an inversion of the polarity of the ovum, evidence being forthcoming in favor of the view that even in the ovum of these and other forms there is probably a distinct polar differentiation. How far this view may be applicable to the mammalian ovum is uncertain, but if it be applicable it explains the phenomenon of inversion without complicating it with the question of twin-formation.

The Formation of the Germ Layers.-During the stages which have been described as belonging to the segmentation period of development there has been but little differentiation of the cells. In Amphioxus and the amphibians the cells at one pole of the blastula are larger and more yolk-laden than those at the other pole, and in the mammals an inner cell-mass can be distinguished from the enveloping cells, this latter differentiation having been anticipated in the reptiles and being a differentiation of a portion of the ovum from which alone the embryo will develop from a portion which will give

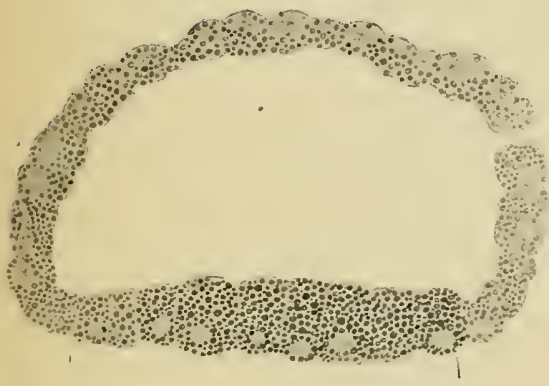

$A$

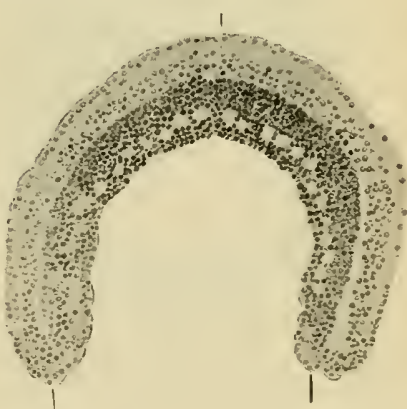

$B$

Fig. 23.-Two Stages in the Gastrulation of Amphioxus.-(Morgan and Hazen.)

rise to accessory structures. In later stages a differentiation of the inner cell-mass occurs, resulting first of all in the formation of a twolayered or diploblastic and later of a three-layered or triploblastic stage.

Just as the segmentation has been shown to be profoundly modified by the amount of yolk present in the ovum and by its secondary reduction, so, too, the formation of the three primitive layers 
is much modified by the same cause, and to get a clear understanding of the formation of the triploblastic condition of the mammal it will be necessary to describe briefly its development in lower forms.

In Amphioxus the diploblastic condition results from the flattening of the large-celled pole of the blastula (Fig. 23, A), and finally from the invagination of this portion of the vesicle within the other portion (Fig. 23, B). The original single-walled blastula in this way becomes converted into a double-walled sac termed a gastrula, the outer layer of which is known as the ectoderm or epiblast and the inner layer as the endoderm or hypoblast. The cavity bounded by the endoderm is the primitive gut or archenteron, and the opening by which this communicates with the exterior is the blastopore. This last structure is at first a very wide opening, but as development proceeds it

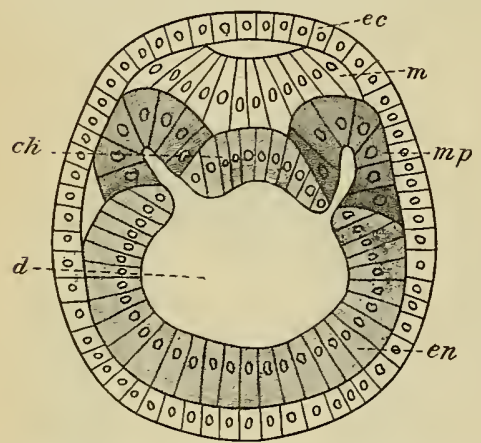

Fig. 24.-Transverse Section of Amphioxus EMBRYo with Five MesoDERMIC POUCHES.

$C h$, Notochord; $d$, digestive cavity; ec, ectoderm; en, endoderm; $m$, medullary plate; $m p$, mesodermic pouch.(Hatschek.) becomes smaller, and finally is a relatively small opening situated at the posterior extremity of what will be the dorsal surface of the embryo.

As the oval embryo continues to elongate in its later development the third layer or mesoderm makes its appearance. It arises as a lateral fold $(m p)$ of the dorsal surface of the endoderm (en) on each side of the middle line as indicated in the transverse section shown in Fig. 24. This fold eventually becomes completely constricted off from the endoderm and forms a hollow plate occupying the space between the ectoderm and endoderm, the cavity which it contains being the body-cavity or ccolom.

In the amphibia, where the amount of yolk is very much greater than in Amphioxus, the gastrulation becomes considerably modified. On the line where the large- and small-celled portions of the blastula become continuous a crescentic groove appears and, deepening, 
forms an invagination (Fig. 25, gc), the roof of which is composed of relatively small yolk-containing cells while its floor is formed by the large cells of the lower pole of the blastula. The cavity of the blastula is not sufficiently large to allow of the typical invagination of all these large cells, so that they become enclosed by the rapid growth of the ectoderm cells of the upper pole of the ovum over

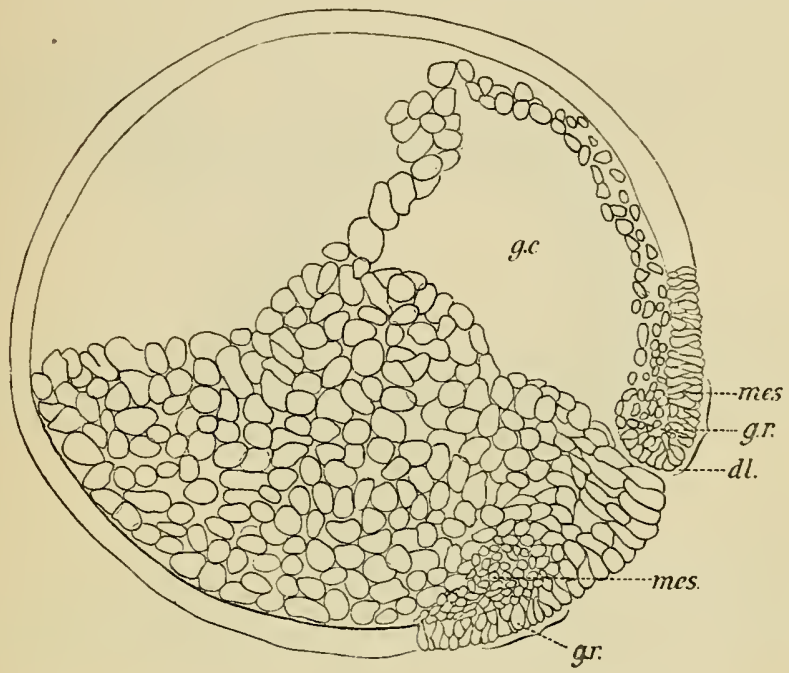

Fig. 25.-Section throvgh a Gastrula of A mblystoma.

$d l$, Dorsal lip of blastopore; $g c$, digestive cavity; $g r$, area of mesoderm formation; mes, mesoderm.-(Eycleshymer.)

them. Before this growth takes place the blastopore corresponds to the entire area occupied by the large yolk cells, but later, as the growth of the smaller cells gradually encloses the larger ones, it becomes smaller and is finally represented by a small opening situated at what will be the hind end of the embryo.

Soon after the archenteron has been formed a solid plate of cells, eventually splitting into two layers, arises from its roof on each side of the median line and grows out into the space between the ectoderm and endoderm (Fig. $26, m k^{1}$ and $m k^{2}$ ), evidently corresponding to the hollow plates formed in the same situations in Amphioxus. 
This is not, however, the only source of the mesoderm in the amphibia, for while the blastopore is still quite large there may be found surrounding it, between the endoderm and ectoderm, a ring of mesodermal tissue (Fig. 25, mes). As the blastopore diminishes in size and its lips come together and unite, the ring of mesoderm forms first an oval and then a band lying beneath the line of closure of the blastopore and united with both the superjacent ectoderm and the subjacent endoderm. This line of fusion of the three germ

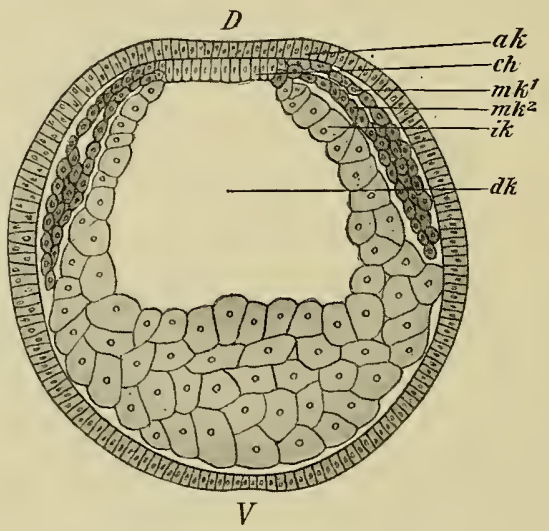

Fig. 26.-Section through an Embryo Amphibian (Triton) of $2 \frac{1}{2}$ Days, SHowing the Formation of the Gastral Mesoderm.

$a k$, Ectoderm; $c h$, chorda endoderm; $d k$, digestive cavity; $i k$, endoderm; $m k^{1}$ and $m k^{2}$, somatic and splanchnic layers of the mesoderm. $D$, dorsal and $V$, ventral.(Hertwig.)

layers is known as the primitive streak. It is convenient to distinguish the mesoderm of the primitive streak from that formed from the dorsal wall of the archenteron by speaking of the former as the prostomial and the latter as the gastral mesoderm, though it must be understood that the two are continuous immediately in front of the definitive blastopore.

In the reptilia still greater modifications are found in the method of formation of the germ layers. Before the enveloping cells have completely surrounded the yolk-mass, a crescentic groove, resembling that occurring in amphibia, appears near the posterior edge of the 
blastoderm, the cells of which, in front of the groove, arrange themselves in a superficial layer one cell thick, which may be regarded as the ectoderm (Fig. 27, ec), and a subjacent mass of somewhat scattered cells. Later the lowermost cells of this subjacent mass arrange themselves in a continuous layer, constituting what is termed the primary endoderm $\left(e n^{1}\right)$, while the remaining cells, aggregated
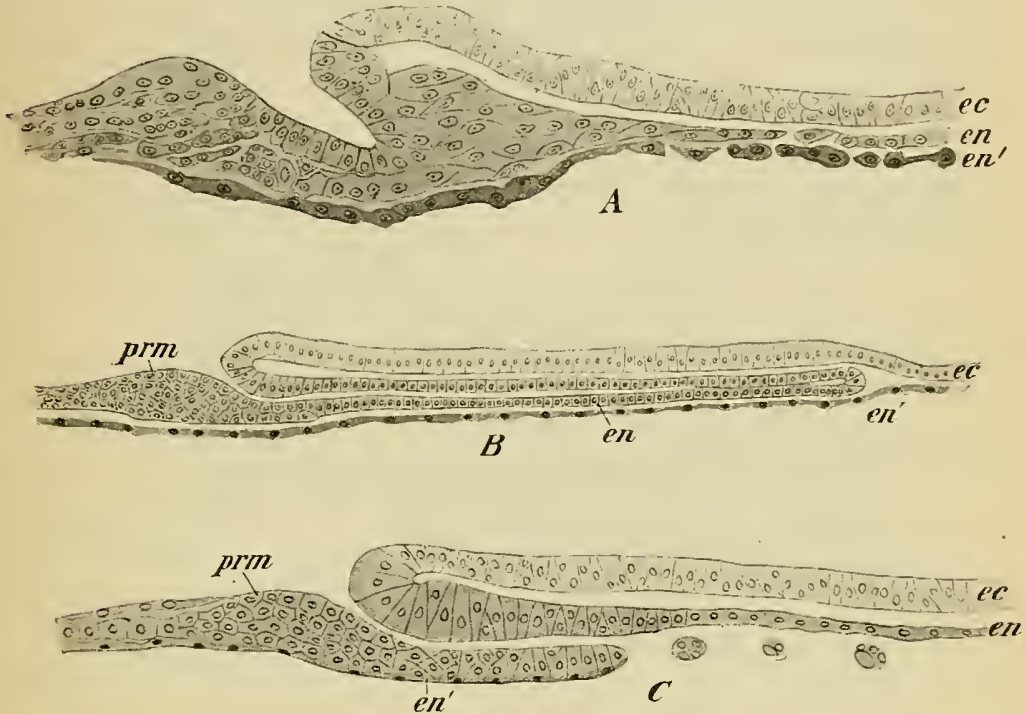

Fig. 27.-Longitudinal Sections through Blastoderms of the Gecko, showing - Gastrulation.

ec, Ectoderm; en, secondary endoderm; $e n^{\prime}$, primary endoderm; prm, prostomial mesoderm.-(Will.)

especially in the region of the crescentic groove, form the prostomial mesoderm $($ prm $)$. In the region enclosed by the groove a distinct delimitation of the various layers does not occur, and this region forms the primitive streak. The groove now begins to deepen, forming an invagination of secondary endoderm, the extent of this invagination being, however, very different in different species. In the gecko (Will) it pushes forward between the ectoderm and primary endoderm almost to the anterior edge of the blastoderm (Fig. 27, B), but later the cells forming its floor, together with those 
of the primary endoderm immediately below, undergo a degeneration, the roof cells at the tip and lateral margins of the invagination becoming continuous with the persisting portions of the primary endoderm (Figs. 27, C and 28, B). This layer, following the enveloping cells in their growth over the yolk-mass, gradually surrounds that structure so that it comes to lie within the archenteron. In some turtles, on the other hand, the disappearance of the floor of the invagination takes place at a very early stage of the infolding, the

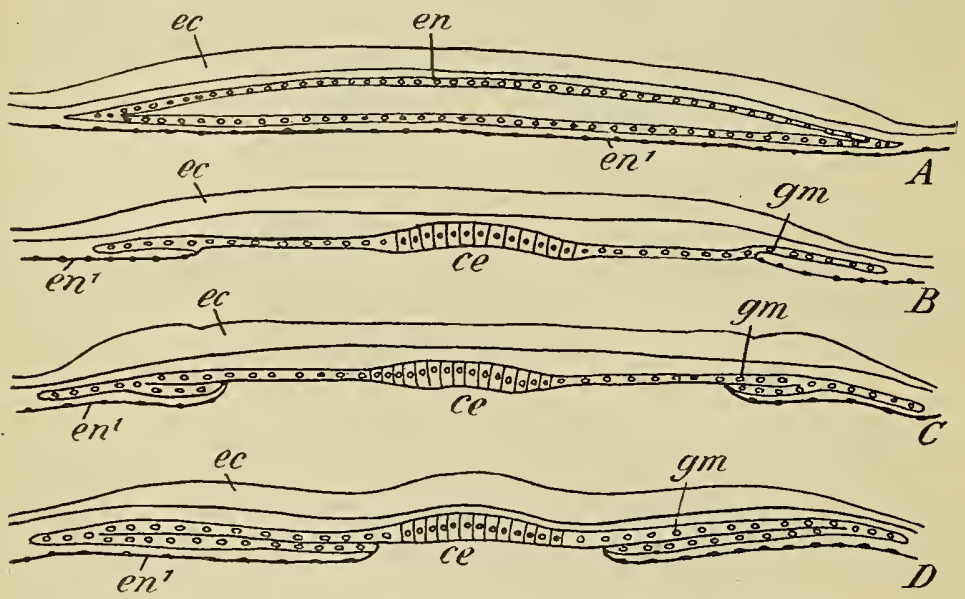

Fig. 28.-Diagrams Illustrating the Formation of the Gastral Mesoderm in THE GECKO.

$c e$, Chorda endoderm; ec, ectoderm; en, secondary endoderm; $e n^{1}$, primary endoderm; $\mathrm{gm}$, gastral mesoderm.-(Will.)

roof cells only persisting to grow forward to form the dorsal wall of the archenteron. This interesting abbreviation of the process occurring in the gecko indicates the mode of development which is found in the mammalia.

The existence of a prostomial mesoderm in connection with the primitive streak has already been noted, and when the invagination takes place it is carried forward as a narrow band of cells on each side of the sac of secondary endoderm. After the absorption of the ventral wall of the invagination a folding or turning in of the margins 
of the secondary endoderm occurs (Fig. 28), whereby its lumen becomes reduced in size and it passes off on each side into a double plate of cells which constitute the gastral mesoderm. Later these

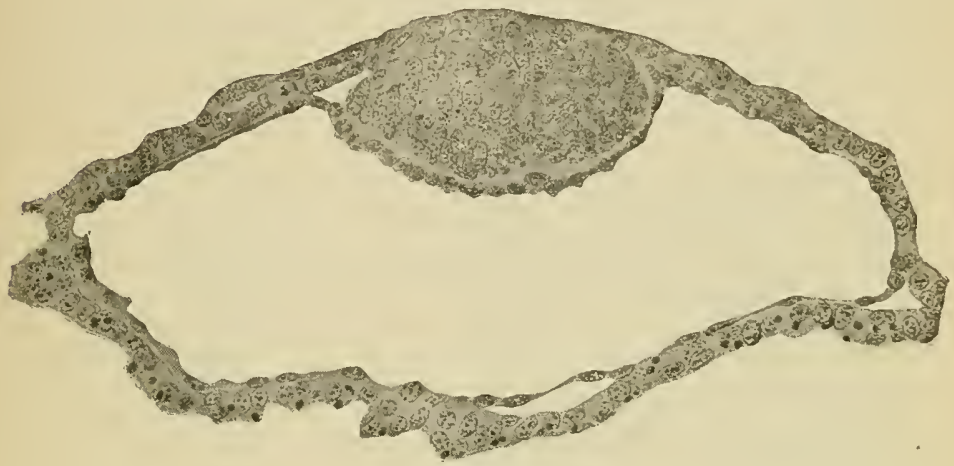

A

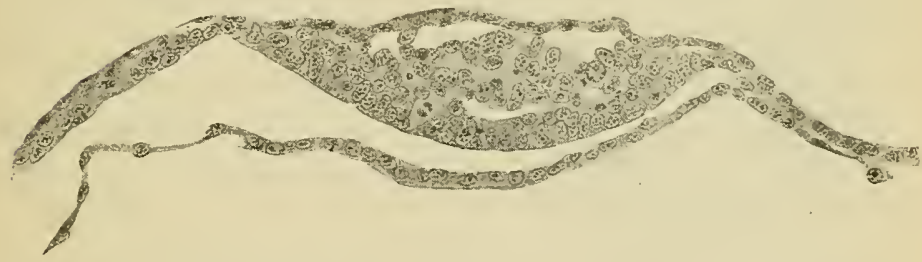

$B$

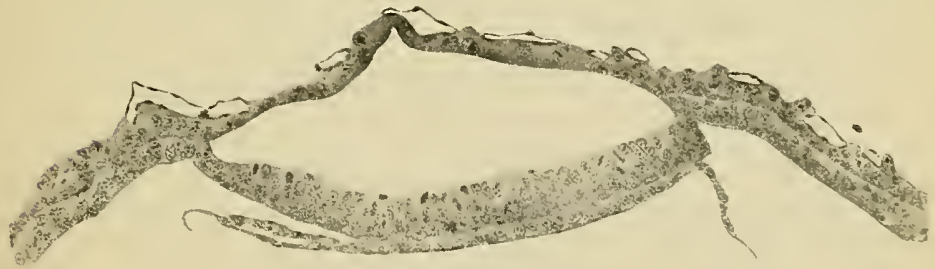

$C$

Fig. 29.-Sections of Ova of a Bat showing ( $A$ ) the Formation of the EndoDERM AND ( $B$ AND $C$ ) OF THE AMniotic Cavity.-(Van Beneden.)

plates separate from the archenteron as in the lower forms. All the prostomial mesoderm does not, however, arise from the primitive 
streak region, but a considerable amount also has its origin from the ectoderm covering the yolk outside the limits of the blastoderm proper, a mode of origin which serves to explain the phenomena later to be described for the mammalia.

In comparison with the amphibians and Amphioxus, the reptilia present a subordination of the process of invagination in the formation of the endoderm, a primary endoderm making its appearance independently of an invagination, and, in association with this subordination, there is an early appearance of the primitive streak, which, from analogy with what occurs in the amphibia, may be assumed to represent a portion of the blastopore which is closed from the very beginning.

Turning now to the mammalia, it will be found that these peculiarities become still more emphasized. The inner cell-mass of these forms corresponds to the blastoderm of the reptilian ovum, and the first differentiation which appears in it concerns the cells situated next the cavity of the vesicle, these cells differentiating to form a distinct layer which gradually extends so as to form a complete lining to the inner surface of the enveloping cells (Fig. 29, A). The layer so formed is endodermal and corresponds to the primary endoderm of the reptiles.

Before the extension of the endoderm is completed, however, cavities begin to appear in the cells constituting the remainder of the inner mass, especially in those immediately beneath Rauber's cells (Fig. 29, B), and these cavities in time coalesce to form a single large cavity bounded above by cells of the enveloping layer and below by a thick plate of cells, the embryonic disk (Fig. 29, C). The cavity so formed is the amniotic cavity, whose further history will be considered in a subsequent chapter.

It may be stated that this cavity varies greatly in its development in different mammals, being entirely absent in the rabbit at this stage of development and reaching an excessive development in such forms as the rat, mouse, and guinea-pig. The condition here described is that which occurs in the bat and the mole, and it seems probable, from what occurs in the youngest human embryos hitherto observed, that the processes in man are closely similar. 
While these changes have been taking place a splitting of the enveloping layer has occurred, so that the wall of the ovum is now formed of three layers, an outer one which may be termed the trophoblast, a middle one which probably is transformed into the extra-embryonic mesoderm of later stages, though its significance is at present somewhat obscure, and an inner one which is the
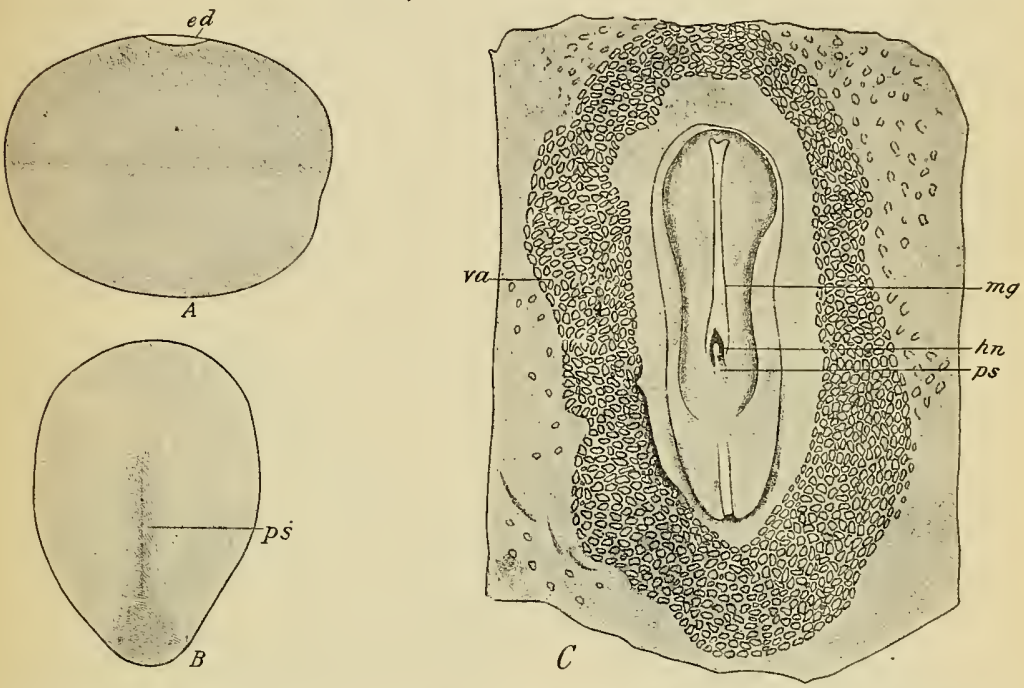

Fig. 30.- $A$, Side View of Ovum of Rabbit Seven Days Old (Kölliker); $B$, EMbryonic Disk of a Mole (Heape); $C$, Embryonic Disk of a Dog's Ovum of ABOUt Fifteen DAys (Bonnet).

$e d$, Embryonic disk; $h n$, Hensen's node; $m g$, medullary groove; $p s$, primitive streak; $v a$, vascular area.

primary endoderm. In the bat, of whose ovum Fig. 29, C, represents a section, that portion of the middle layer which forms the roof of the amniotic cavity disappears, only the trophoblast persisting in this region, but in another form this is not the case, the roof of the cavity being composed of both the trophoblast and the middle layer.

A rabbit's ovum in which there is yet no amniotic cavity and no splitting of the enveloping layer shows, when viewed from above, 
a relatively small dark area on the surface, which is the embryonic disk. But if it be looked at from the side (Fig. 30, A), it will be seen that the upper half of the ovum, that half in which the embryonic disk occurs, is somewhat darker than the lower half, the line of separation of the two shades corresponding with the edge of the primary endoderm which has extended so far in its growth around the inner surface of the enveloping layer. A little later a dark area appears at one end of the embryonic disk, produced by a proliferation of cells in this region and having a somewhat crescentic form. As the embryonic disk increases in size a longitudinal band makes its appearance, extending forward in the median line nearly to the center of the disk, and represents the primitive streak (Fig. 30, B), a slight groove along its median line forming what is termed the primitive groove. In slightly later stages an especially dark spot may be seen at the front end of the primitive streak and is termed Hensen's node (Fig. 30, C, $h n$ ), while still later a dark streak may be observed extending forward from this in the median line and is termed the head-process of the primitive streak.

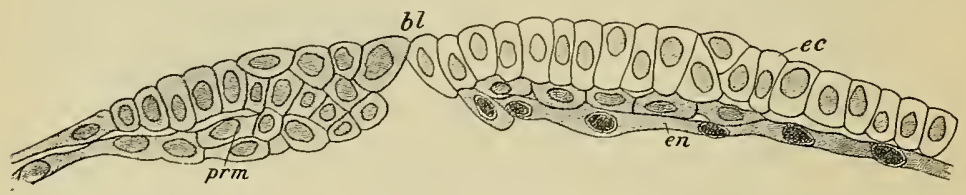

Fig. 3I.-Posterior Portion of a Longitudinal Section through the Embryonic DISK OF A MOLE.

$b l$, Blastopore, $e c$, ectoderm; en, endoderm; prm, prostomial mesoderm.-(After Heape.)

To understand the meaning of these various dark areas recourse must be had to the study of sections. A longitudinal section through the embryonic disk of a mole ovum at the time when the crescentic area makes its appearance is shown in Fig. 3I. Here there is to be seen near the hinder edge of the disk what is potentially an opening $(b l)$, in front of which the ectoderm (ec) and primary endoderm (en) can be clearly distinguished, while behind it no such distinction of 
the two layers is visible. This stage may be regarded as comparable to a stage immediately preceding the invagination stage of the reptilian ovum, and the region behind the blastopore will correspond to the reptilian primitive streak. The later forward extension of the primitive streak is due to the mode of growth of the embryonic disk. Between the stages represented in Figs. $3^{\mathrm{r}}$ and $30, \mathrm{~B}$, the disk has enlarged considerably and the primitive streak has shared in its elongation. Since the blastopore of the earlier stage is situated immediately in front of the anterior extremity of the primitive streak, the point corresponding to it in the older disk is occupied by Hensen's node, this structure, therefore, representing a proliferation of cells from the region formerly occupied by the blastopore.

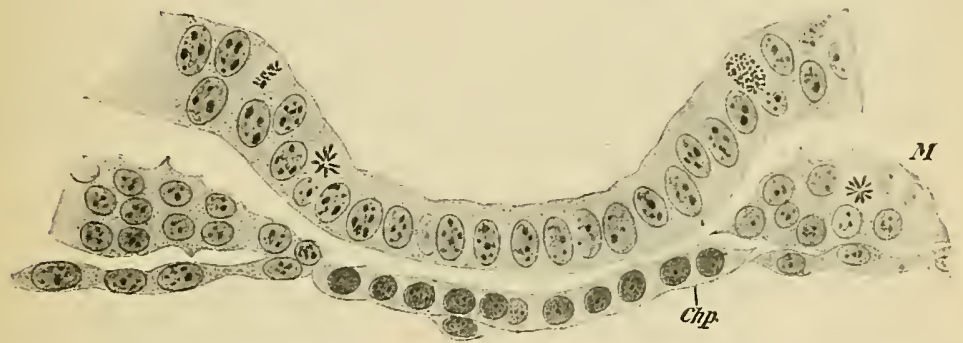

Fig. 32.-Transverse Section of the Embryonic Area of a Dog's Ovum at about the Stage of Developient shown in Fig. 29, C.

The section passes through the head process $(C h p) ; M$, mesoderm.-(Bonnet.)

As regards the head process, it is at first a solid cord of cells which grows forward in the median line from Hensen's node, lying between the ectoderm and the primary endoderm. Later a lumen appears in the center of the cord, forming what has been termed the chorda canal, and, in some forms, including man, the canal opens to the surface at the center of Hensen's node. The cord then fuses with the subjacent primary endoderm and then opens out along the line of fusion, becoming thus transformed into a flat plate of cells continuous at either side with the primary endoderm (Fig. 32, Chp). 'The portion of the chorda canal which traverses Hensen's node now 
opens below into what will be the primitive digestive tract and is termed the neurenteric canal (Fig. 33, nc); it eventually closes completely, being merely a transitory structure. The similarity of the head process to the invagination which in the reptilia forms the secondary endoderm seems clear, the only essential difference being that in the mammalia the head process arises as a solid cord which subsequently becomes hollow, instead of as an actual invagination. The difference accounts for the occurrence of Hensen's node and also for the mode of formation of the neurenteric canal, and cannot be considered as of great moment since the development of what are eventually tubular structures (e. $g$., glands) as solid cords of cells which subsequently hollow out is of common occurrence in the mammalia. It should be stated that in some mammals apparently the most anterior portion of the roof of the archenteron is formed directly from the cells of the primary endoderm, which in this region are not replaced by the head process, but aggregate to form a compact plate of cells with which the anterior extremity of the head process

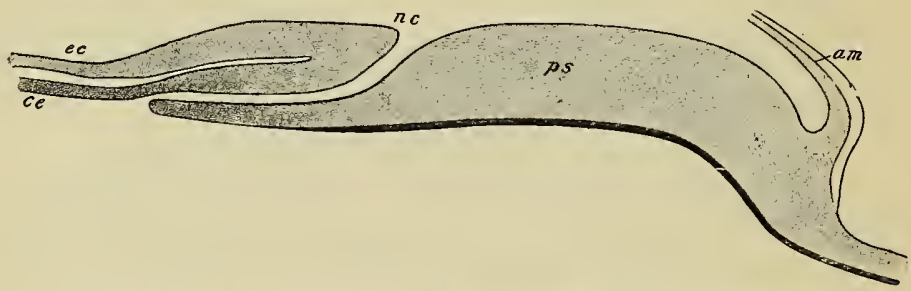

Fig. 33.-Diagram of a Longitudinal Section through the Embryonic Disk of A MOLE.

$a m$, Amnion; $c e$ chorda endoderm; $e c$, ectoderm; $n c$, neurenteric canal; $p s$, primitive streak.-(Heape.)

unites. Such a condition would represent a further modification of the original condition.

As regards the formation of the mesoderm it is possible to recognize both the prostomial and gastral mesoderm in the mammalian ovum, though the two parts are not so clearly distinguishable as in lower forms. A mass of prostomial mesoderm is formed from the primitive streak, and when the head process grows forward it carries 
with it some of this tissue. But, in addition to this, a contribution to the mesoderm is also apparently furnished by the cells of the head process, in the form of lateral plates situated on each side of the middle line. These plates are at first solid (Fig. 34, gm), but their

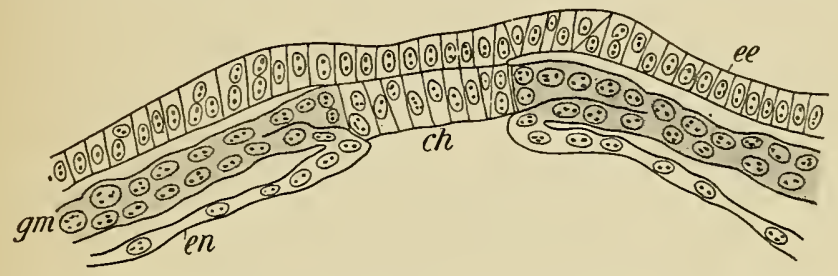

Fig. 34.-Transverse Section through the Embryonic Disk of a Rabbit. ch, Chorda endoderm; $e$, ectoderm; $e n$, endoderm; $g m$, gastral mesoderm.-(After van Beneden.)
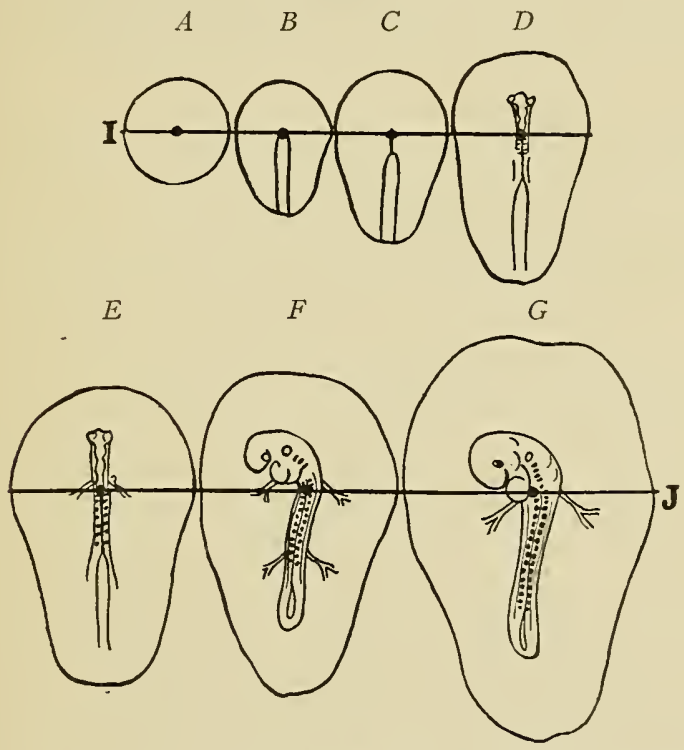

Fig. 35.-Diagrams Illustrating the Relations of the 'Chick Embryo to the Primitive Streak at Different Stages of Developament.-(Peebles.)

cells quickly arrange themselves in two layers, between which a cœlomic space later appears.

Furthermore, as has already been pointed out, the layer of 
enveloping cells splits into two concentric layers, the inner of which seems to be mesodermal in its nature and forms a layer lining the interior of the trophoblast and lying between this and the primary endoderm. This layer is by no means so evident in the lower forms, but is perhaps represented in the reptilian ovum by the cells which underlie the ectoderm in the regions peripheral to the blastoderm proper (see p. 54).

It has been experimentally determined (Assheton, Peebles) that in the chick, whose embryonic disk presents many features similar to those of the mammalian ovum, the central point of the unincubated disk corresponds to the anterior end of the primitive streak and to the point situated immediately behind the heart of the later embryo and immediately in front of the first mesodermic somite (see p. 77), as shown in Fig. 35. If these results be regarded as applicable to the human embryo, then it may be supposed that in this the head region is developed from the portion of the embryonic disk situated in front of Hensen's node, while the entire trunk is a product of the region occupied by the node.

\section{The Significance of the Germ Layers.-The formation of} the three germ layers is a process of fundamental importance, since it is a differentiation of the cell units of the ovum into tissues which have definite tasks to fulfil. As has been seen, the first stage in the development of the layers is the formation of the ectoderm and endoderm, or, if the physiological nature of the layers be considered, it is the differentiation of a layer, the endoderm, which has principally nutritive functions. In certain of the lower invertebrates, the class Cœlentera, the differentiation does not proceed beyond this diploblastic stage, but in all higher forms the intermediate layer is also developed, and with its appearance a further division of the functions of the organism supervenes, the ectoderm, situated upon the outside of the body, assuming the relational functions, the endoderm becoming still more exclusively nutritive, while the remaining functions, supportive, excretory, locomotor, reproductive, etc., are assumed by the mesoderm.

The manifold adaptations of development obscure in certain cases the fundamental relations of the three layers, certain portions of the mesoderm, for instance, failing to differentiate simultaneously 
with the rest of the layer and appearing therefore to be a portion of cither the ectoderm or endoderm. But, as a rulc, the layers are structural units of a higher order than the cells, and since each assumes definite physiological functions, definite structures have their origin from each.

Thus from the ectoderm there develop:

I. The epidermis and its appendages, hairs, nails, epidermal glands, and the enamel of the teeth.

2. The epithelium lining the mouth and the nasal cavities, as well as that lining the lower part of the rectum.

3. The nervous system and the nervous elements of the senseorgans, together with the lens of the eye.

From the endoderm develop:

I. The epithelium lining the digestive tract in general, together with that of the various glands associated with it, such as the liver and pancreas.

2. The lining epithelium of the larynx, trachea, and lungs.

3. The epithelium of the bladder and urethra (in part).

From the mesoderm there are formed:

I. The various connective tissues, including bone and the teeth (except the enamel).

2. The muscles, both striated and non-striated.

3. The circulatory system, including the blood itself and the lymphatic system.

4. The lining membrane of the serous cavities of the body.

5. The kidneys and ureters.

6. The internal organs of reproduction.

From this list it will be seen that the products of the mesoderm are more varied than those of either of the other layers. Among its products are organs in which in either the embryonic or adult condition the cells are arranged in a definite layer, while in other structures its cells are scattered in a matrix of non-cellular material, as, for example, in the connective tissue, bone, cartilage, and the blood and lymph. It has been proposed to distinguish these two forms of mesoderm as mesothelium and mesenchyme respectively, 
a distinction which is undoubtedly convenient, though probably devoid of the fundamental importance which has been attributed to it by some embryologists.

\section{LITERATURE.}

R. Assheton: "The Reinvestigation into the Early Stages of the Development of the Rabbit," Quarterly Journ. of Microsc. Science, xxxvir, I894.

R. Assheton: "The Development of the Pig During the First Ten Days," Quarterly Journ. of Microsc. Science, XLI, I898.

R. Assheton: "The Segmentation of the Ovum of the. Sheep, with Observations on the Hypothesis of a Hypoblastic Origin for the Trophoblast," Quarterly Journ. of Microsc. Science, xLI, I 898 .

E. VAN BENEDEN: "Recherches sur les premiers stades du développement du Murin (Vespertilio murinus)," Anatom. Anzeiger, xvı, r899.

R. BonNET: "Beiträge zur Embryologie der Wiederkäuer gewonnen am Schafei," Archiv für Anat. und Physiol., Anat. Abth., I884 and I889.

R. Bonnet: "Beiträge zur Embryologie des Hundes," Anat. Hefte, Ix, I897.

G. BORN: "Erste Entwickelungsvorgänge," Ergebnisse der Anat. und Entwicklungsgesch., I, I892.

E. G. Conklin: "The Cause of Inverse Symmetry," Anatom. Anzeiger, xxiII, I903.

A. C. Excleshymer: "The Early Development of Amblystoma with Observations on Some Other Vertebrates," Journ. of Morphol., x, I895.

B. Hatscheк: "Studien über Entwicklung des Amphioxus," Arbeiten aus dem zoolog. Instit. zu Wien, IV, I88ז.

W. Heape: "The Development of the Mole (Talpa europæa)," Quarterly Journ. of Microsc. Science, $\mathrm{xx} I \mathrm{II}, \mathrm{I} 883$.

A. A. W. Hubrecht: "Studies on Mammalian Embryology II: The Development of the Germinal Layers of Sorex vulgaris," Quarterly Journ. of Microsc. Science, XXXI, I89o.

F. KEIBEL: "Studien zur Entwicklungsgeschichte des Schweines," Morpholog. Arbeiten, III, I893.

F. KEIBEL: "Die Gastrulation und die Keimblattbildung der Wirbeltiere," Ergebnisse der Anat. und Entwicklungsgesch., x, г9ог.

M. KunSEMüLLER: "Die Eifurchung des Igels (Erinaceus europæus L.)," Zeitschr. für wissensch. Zool., LXXXv, I906.

K. Mitsukuri and C. Ishikawa: "On the Formation of the Germinal Layers in Chelonia," Quarterly Journ. of Microsc. Science, XxVII, I887.

F. Peebles: "The Location of the Chick embryo upon the Blastoderm," Journ. of Exper. Zool., I, I904.

E. SelenKa: "Studien über Entwickelungsgeschichte der Thiere," 4tes Heft, I886-87; 5 tes Heft, I89I-92.

J. Ковотта: "Die Befruchtung und Furchung des Eies der Maus," Archiv für mikrosk. Anat., xLV, I895. 
J. Sовотта: "Die Furchung des Wirbelthiereies," Ergebnisse der Anat. und Entwickelungsgeschichle, $\mathrm{vI}, \mathrm{I} 897$.

J. Совотта: "Neuere Auschauungen über die Entstehung der Doppel (miss) bildungen, mit besonderer Berücksichtigung der menschlichen $Z$ willingsgeburten," Wïrzburger Abhandl., I, І 90 I.

H. H. Wilder: "Duplicate Twins and Double Monsters," Amer. Jour. of Anal., III, 1904.

L. Will: "Beiträge zur Entwicklungsgeschichte der Reptilien," Zoolog. Jahrbücher Abth. fïr Anat., vI, 1893 . 


\section{THE MEDULLARY GROOVE, NOTOCHORD, AND MESO- DERMIC SOMITES.}

In the preceding chapter the development of the mammalian ovum has been described up to and including the formation of the three germinal layers. The earlier stages of development there described are practically unknown in the human ovum, but for the stages subsequent to the establishment of the germinal layers human material is available, and it will, therefore, now be convenient to consider the structure of the younger human ova at present known and to trace in them the appearance and development of such structures as the primitive streak, the head process and the gastral mesoderm.

The youngest human ovum at present known is that described by Bryce and Teacher, but, unfortunately, it presents certain features that are evidently abnormal, so that it becomes doubtful how far it may be accepted as representing the typical condition. The trophoblast, which was very thick and clearly differentiated into two layers, enclosed a space whose diameter was about 0.63 $\mathrm{mm}$. and which was largely occupied by a loose syncytial tissue, presumably mesoderm. Toward the center of this was an irregular cavity in which were two vesicles, quite separate from one another and probably together representing the embryo, the smaller one being the amniotic cavity and the larger one the yolk-sac (Fig. 36). The separation of these two structures is apparently an abnormality and it is possible that the cavity in which they lie is, as Bryce and Teacher suggest, an artefact produced by contraction of the syncytial mesoderm during the preservation of the ovum.

If comparison of this ovum with those of other mammals is warranted, it may be likened to that of the bat as shown in Fig. 29, 
$C$, with the difference that the mesoderm that lines the trophoblast in that ovum has become much more voluminous and forms the syncytial mass in which the ovum is supposed to have been imbedded, a condition that may be represented diagrammatically as in Fig. $38, A$.

Somewhat older are the ova described by Peters, Fetzer, Jung and Herzog. The Peters ovum was taken from the uterus of a

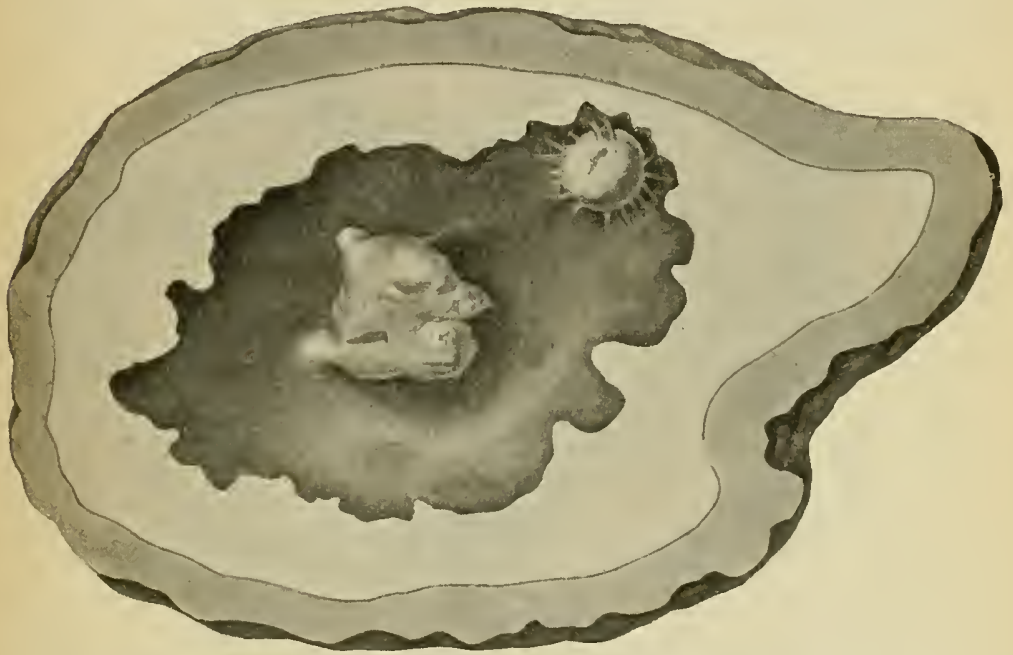

Fig. 36.-From a Reconstruction of the Bryce-Teacher Ovum.(Bryce-Teacher.)

woman who had committed suicide one calendar month after the last menstruation, and it measured about $\mathrm{I} \mathrm{mm}$. in diameter. The entire inner surface of the trophoblast (Fig. 37, ce) was lined by a layer of mesoderm $(\mathrm{cm})$, which, on the surface furthest away from the uterine cavity, was considerably thicker than elsewhere, forming an area of attachment of the embryo to the wall of the ovum. In the substance of this thickening was the amniotic cavity $(\mathrm{am})$, whose roof was formed by flattened cells, which, at the sides, became continuous with a layer of columnar cells forming the floor of the cavity and constituting the embryonic ectoderm $(e c)$. Immediately 
below this was a layer of mesoderm $(m)$ which split at the edge of the embryonic disk into two layers, one of which became continuous with the mesodermic thickening and so with the layer of mesoderm lining the interior of the trophoblast, while the other enclosed a sac lined by a layer of endodermal cells and forming the yolk-sac $(y s)$. The total length of the embryo was o.I9 mm., and so far as its ectoderm and mesoderm are concerned it might be described as a

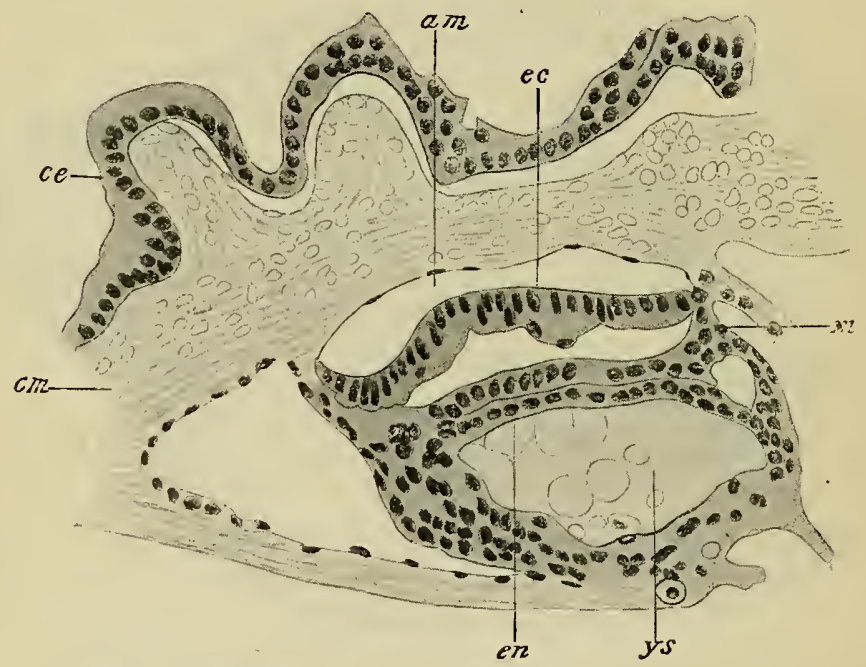

Fig. 37.-Section of Embryo and Adjacent Portion of an Ovum of i mm. $a m$, Amniotic cavity; $c e$, chorionic ectoderm; $c m$, chorionic mesoderm; $e c$, embryonic ectoderm; $e n$, endoderm; $m$, embryonic mesoderm; $y s$, yolk-sack.-(Peters.)

flat disk resting on the surface of the yolk-sac, though it must be understood that the yolk-sac also to a certain extent forms part of the embryo.

This embryo seems to be in an early stage of the primitive streak formation, before the development of the head process. On comparing it with the stage of development represented in Fig. 38, A, it will be seen to present some important advances. The cavity (Fig. 38, B, C) into which the yolk-sac projects is unrepresented in 
Fig. 38 , A. How this cavity is formed can only be conjectured, but it seems probable that it arises by the splitting of the layer of cells which lines the interior of the trophoblast in the earlier stage (or perhaps by the vacuolization of the central cells of this layer) and the subsequent accumulation of fluid between the two mesodermal layers so formed. However that may be, it seems clear that the size of the human ovum is due mainly to the rapid growth of this cavity, which, as future stages show, is the extra-embryonic portion of the body-cavity, the splitting or vacuolization of the
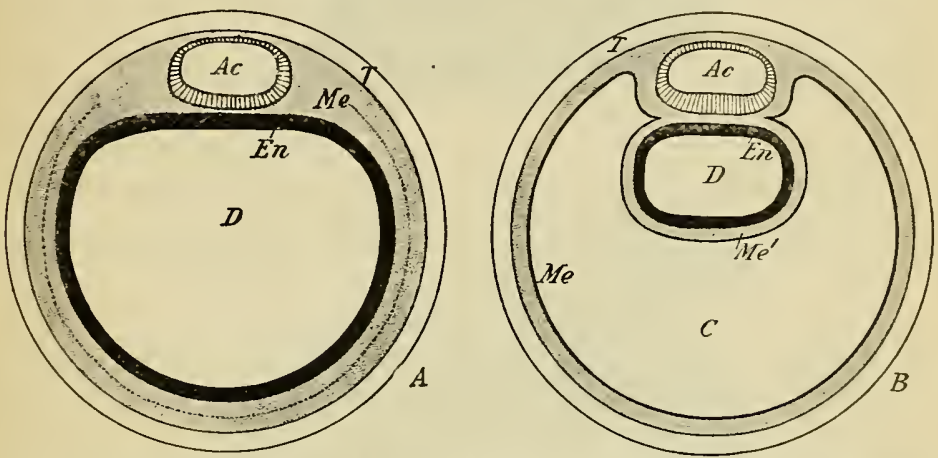

Fig. 38.-Diagrams to show the Probable Relationships of the Parts in the EMBryos RePresented IN Figs. 29, C, AND 37.

$A c$, Amniotic cavity; $C$, extra-embryonic body-cavity; $M e$, (in figure to the left) mesoderm, (in figure to the right) somatic mesoderm; $M \hat{e}$, splanchnic mesoderm; $D$, digestive tract; $E n$, endoderm; $T$, trophoblast. The broken line in the mesoderm of the figure to the left indicates the line along which the splitting of the mesoderm occurs.

mesoderm by which it is probably formed being the precocious appearance of the typical splitting of the mesoderm to form the embryonic body-cavity which, as will be seen in a subsequent chapter, takes place only at a later stage of development. From now on the trophoblast and the layer of mesoderm lining it may together be spoken of as the chorion, the mesoderm layer being termed the chorionic mesoderm.

A little older again than the Peters and Herzog ova are those described by Strahl and Beneke and by von Spee (Embryo v. H.), the chorionic cavity of the former two having an average diameter 
of about $2.4 \mathrm{~mm}$., while the corresponding size of the latter two was somewhat less than $4.0 \mathrm{~mm}$. Notwithstanding the considerable increase in the size of these older ova, due to the continued increase in the size of the extra-embryonic cœlom, the embryos are but

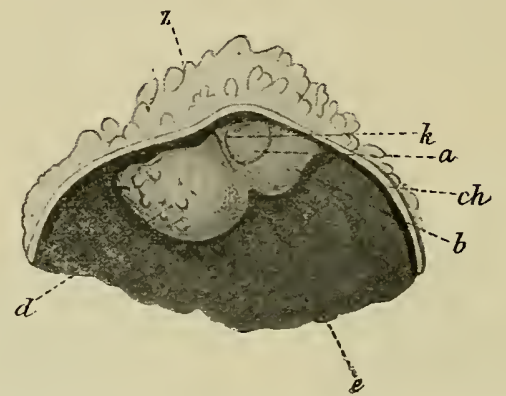

Fig. 39.-The Embryo v. H. of von Spee. The Left Half of the_Chorion has BEEN REMOVED TO SHOW THE EMBRYO.

$a$, Amniotic cavity; $b$, belly-stalk; $c h$, chorion; $d$, yolk-sac; $e$, extra-embryonic cœlom; $k$, embryonic disk; $z$, chorionic villus.-(von Spee.)

little advanced beyond the stage shown by the Peters embryo. The thickening of the chorionic mesoderm that encloses the amniotic cavity has increased in size and now forms a pedicle, known as the belly-stalk (Fig. 39, b), at the extremity of which is the yolk-sac

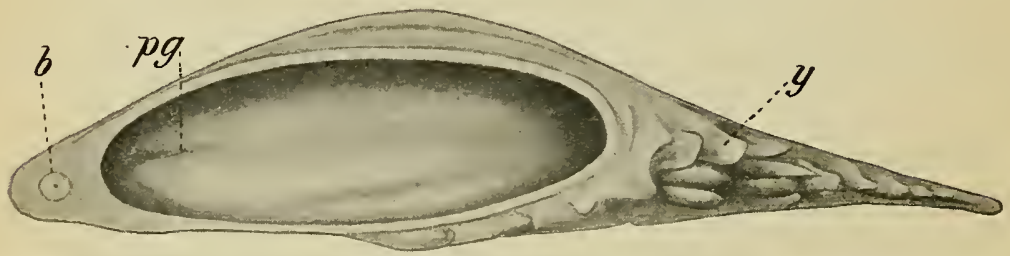

Fig. 40.--Embryo from the Beneke Ovum, the Roof of the Auniotic Cavity HAVING BEEN REMOVED.

From a model. $\quad b$, Belly-stalk; $p . g .$, primitive groove; $y$, yolk-sac-(Strahl and Beneke.)

$(d)$. Furthermore, the amniotic cavity ( $a$ ) now lies somewhat excentrically in this pedicle, being near what may be termed its anterior surface, and the entire embryo projects like a papilla from the inner surface of the chorion into the extra-embryonic cœlom. Fig. 40 is 
from a model of the Beneke embryo, detached from the chorion by cutting through the belly-stalk, and with the roof of the amniotic cavity removed. The dorsal surface of the embryo, thus exposed, is an oval disk, resting, as it were, on the yolk-sac, and quite smooth except for a slight longitudinal groove upon its posterior portion. This is the primitive groove and sections passing through it show the primitive streak, consisting of a sheet of mesoderm interposed between the ectoderm and endoderm, as in the Peters embryo, and but poorly defined from the other two layers. From its anterior edge a median process extends forward for a short distance and is the head process (see p. 56). In front and to the sides of this there is as yet no mesoderm intervening between the ectoderm and endoderm.

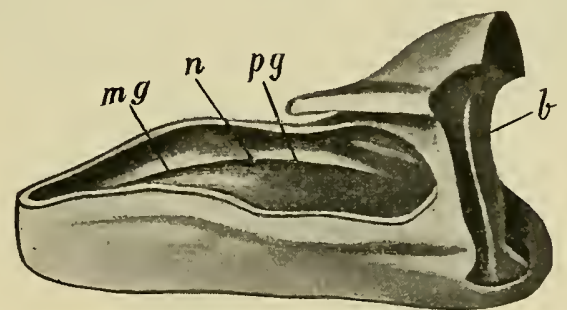

Fig. 41.-Embryo from the Frassi Ovum, the Roof of the Amniotic Cavity HAVING BEEN REMOVED.

From a model. $\quad b$, belly-stalk; $p$.g., primitive groove; $m g$, medullary groove; $n$, neurenteric canal.-(Frassi.)

The embryonic disk of the Beneke embryo measured $0.75 \mathrm{~mm}$. in length. That of an embryo described by Frassi (Fig. 4I) was I.I7 $\mathrm{mm}$. in length, and in correspondence with its greater size, it presents some advances in structure that are of interest. As in the younger embryo one sees a distinct primitive groove on the posterior portion of the embryonic disk, but the groove terminates anteriorly at a distinct pore $(n)$, which perforates the disk and opens ventrally into the yolk-sac. This is the neurenteric canal (see p. 58) and in front of it a groove extends forward in the median line almost to the anterior edge of the embryonic disk and is evidently the first 
indication of the medullary groove, whose walls are destined to give rise to the central nervous system. Sections passing through the region of the medullary groove show, lying beneath it, the head process (Fig. 42, $h p$ ), already fused with the endoderm (compare p. 57), and on each side of the process is a plate of mesoderm $(\mathrm{gm})$, representing the gastral mesoderm of lower forms (see Figs. 28 and 34), but not as yet showing any indications of splitting into the two layers that bound the embryonic cœlom (see p. 59).

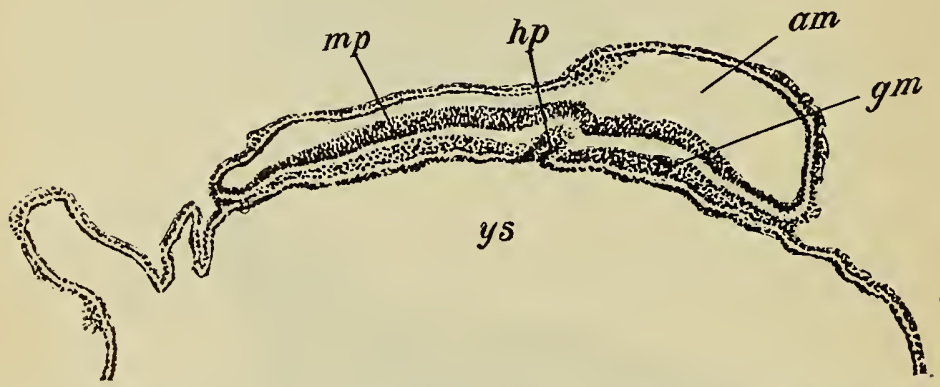

Fig. 42.-Section through the Frassi Embryo just in Front of the NeurenTERIC CANAL.

$a m$, Amniotic cavity; $g m$, gastral mesoderm; $h p$, head process; $m p$, medullary plate; $y s$, yolk-sac.-(Frassi.)

This is just beginning to appear in an embryo, also described by von Spee and known as embryo Gle. It measured $\mathrm{x} .54 \mathrm{~mm}$. in length and is closely similar, in general appearance, to an embryo described by Eternod and measuring $\mathrm{r} .34 \mathrm{~mm}$. in length (Fig. 43). It differs from the Frassi embryo most markedly in that the posterior portion of the embryonic disk, that is to say the primitive streak region, is bent ventrally so.as to lie almost at a right angle with the anterior portion. As a result the belly-stalk arises from the ventral surface of the embryo instead of from its posterior extremity, near which the opening of the neurenteric canal (Fig. $43, n c$ ) is now situated, almost the whole length of the surface seen in dorsal view being occupied by the medullary groove $(m)$, which, in the embryo $G l e$, is bounded laterally by distinct ridges, the medullary folds. 


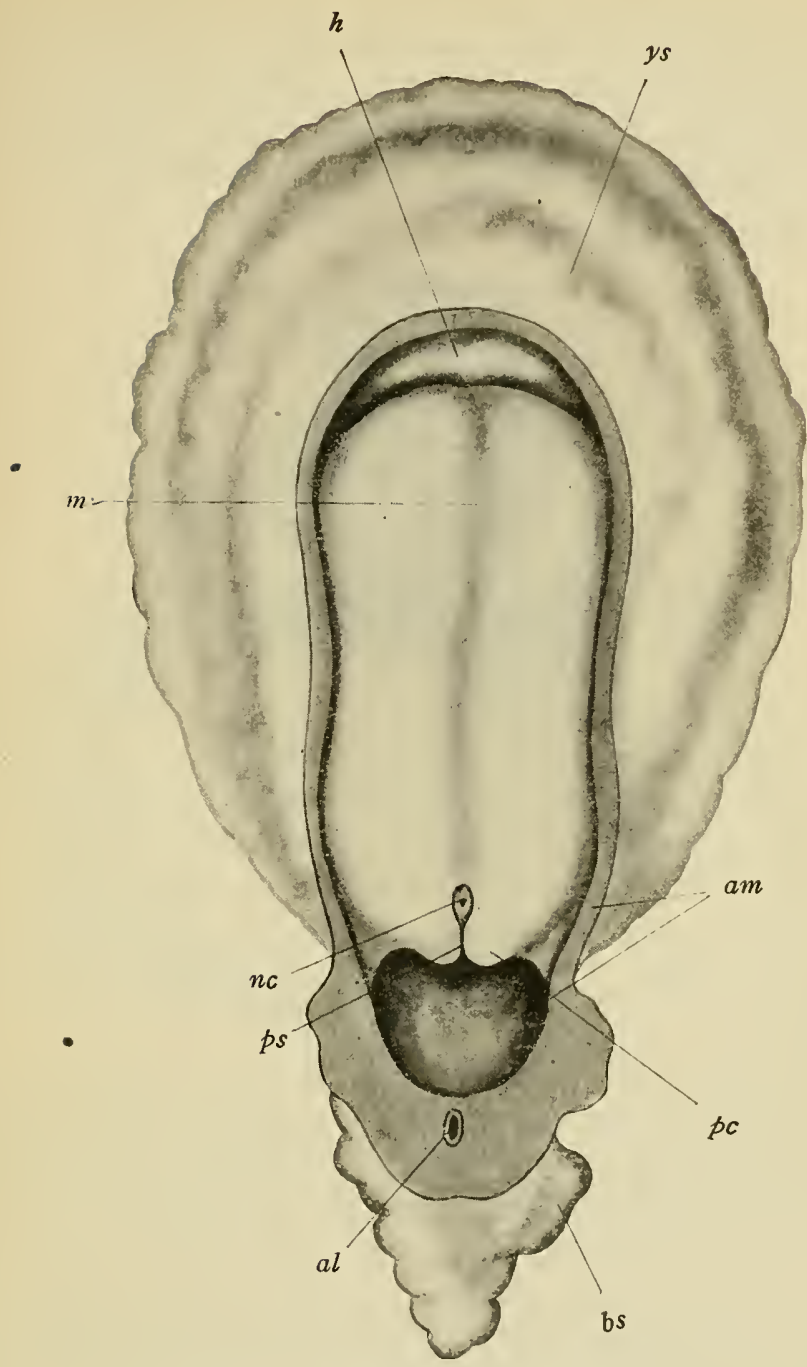

Fig. 43.-EMBryo I.34 MM. LONG.

al, Allantois; $a m$, amnion; $b s$, belly-stalk; $h$, heart; $m$, medullary groove; $n c$, neuren . teric canal; $p c$, caudal protuberance; $p s$, primitive streak; $y s$, yolk-stalk.-(Eternod.) 
In the Krömer embryo Klb (Fig. 44), measuring i. $8 \mathrm{~mm}$. in length, a new feature has made its appearance. The medullary folds have become quite high, and lateral to them there is on each side a series of five or six oblong elevations, which represent what are termed mesodermic somites and are due to divisions of the underlying mesoderm.

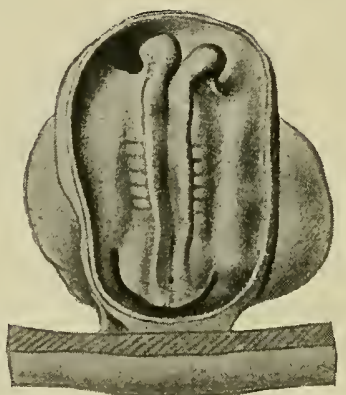

Fig. 44.-Model of the Krömer Embryo $K l b$ Seen from the Dorsal Surface, the Roof of the AmNiotic CAVITy Having BeEn Removed.-(Keibel and Elze.)

Instead of proceeding with a description of the external form of still older embryos it will be convenient to consider the further development of certain structures whose appearance has already been noted, namely, the head process, the medullary folds and the mesodermic somites, and first of all the medullary folds may be considered.

The Medullary Folds.-The two folds are continuous anteriorly, but behind they are at first separate, the anterior portion of the primitive streak lying between them. In forms, such as the Reptilia, which possess a distinct blastopore, this opening lies in the interval between the two, and consequently is in the floor of the medullary groove, and in the mammalia, even though no well-defined blastopore is formed, yet at the time of the formation of the medullary fold an opening breaks through at the anterior end of the primitive streak in the region of Hensen's node, and places the cavity lying below the endoderm in communication with the space bounded by the medullary folds. The canal so formed is termed the neurenteric 
canal (Figs. 43 and $45, n c$ ) and is so called because it unites what will later become the central canal of the nervous system with the intestine (enteron). The significance of this canal has already been discussed (p. $5^{8}$ ) ; it is of very brief persistence, closing at an early stage of development so as to leave no trace of its existence.

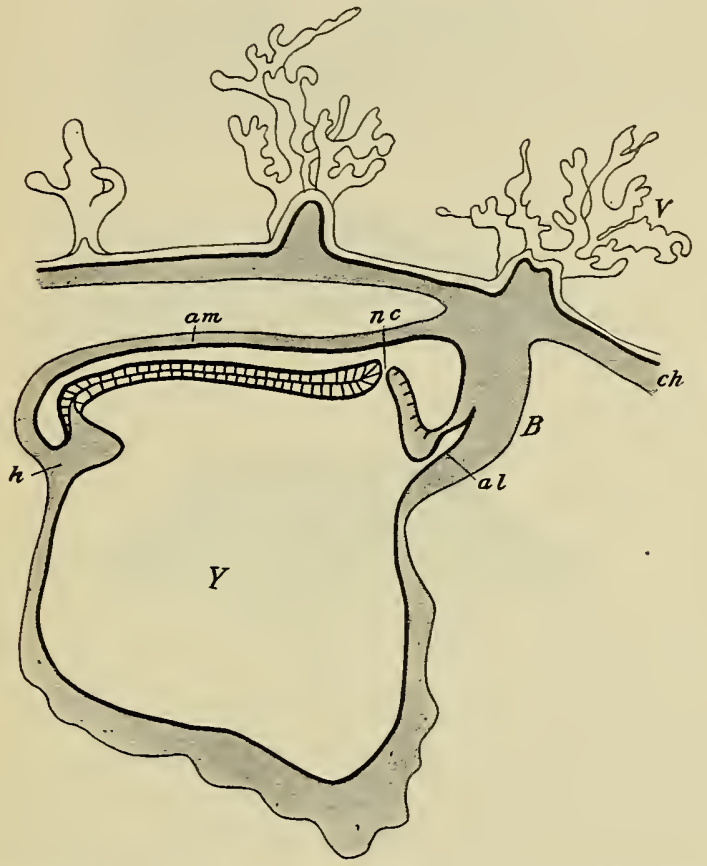

Fig. 45.-Diagram of a Longitudinal Section througe the Embryo Gle, MeasURING I.54 MMr. IN LENGTH.

$a l$, Allantois; $a m$, amnion; $B$, belly-stalk; $c h$, chorion; $h$, heart; $n c$, neurenteric canal; $V$, chorionic villi; $Y$, yolk-sac.-(von Spee.)

As development proceeds the medullary folds increase in height and at the same time incline toward one another (Fig. 44), so that their edges finally come into contact and later fuse, the two ectodermal layers forming the one uniting with the corresponding layers of the other (Fig. 46). By this process the medullary groove becomes converted into a medullary canal which later becomes the 
central canal of the spinal cord and the ventricles of the brain, the ectodermal walls of the canal thickening to give rise to the central nervous system. The closure of the groove does not, however, take place simultaneously along its entire length, but begins in what corresponds to the neck region of the adult and thence proceeds both
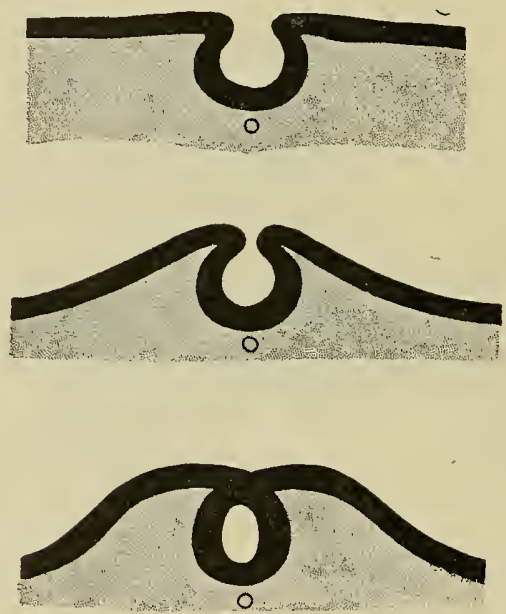

Fig. 46.-Diagrams showing the Manner of the Closure of the Medullary Groove.

anteriorly and posteriorly, the extension of the fusion taking place rather slowly, however, especially anteriorly, so that an anterior opening into the otherwise closed canal can be distinguished for a considerable period (Fig. 53).

The Notochord.-While these changes have been taking place in the ectoderm of the median line of the embryonic disk, modifications of the subjacent endoderm have also occurred. This endoderm, it will be remembered, was formed by the head process of the primitive streak, and was a plate of cells continuous at the sides with the primary endoderm and extending forward as far as what will eventually be the anterior part of the pharynx. Along the line of its junction with the primary endoderm it gives rise to the plates of gastral mesoderm (Fig. 28), while the remainder of it produces an 
important embryonic organ known as the notochord or chorda dorsalis and on this account is sometimes termed the chorda endoderm.

After the separation of the plates of gastral mesoderm the chorda endoderm, which is at first a flat band, becomes somewhat curved (Fig. 47, A), so that it is concave on its under surface, and, the curvature increasing, the edges of the plate come into contact and finally fuse together (Fig. 47, B), the edges of the primary endoderm at the same time uniting beneath the chordal tube so formed, so that this layer becomes a continuous sheet, as it was at its first appearance.

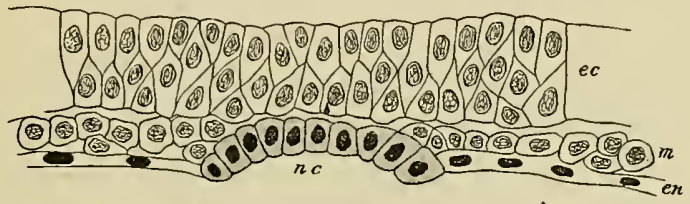

A

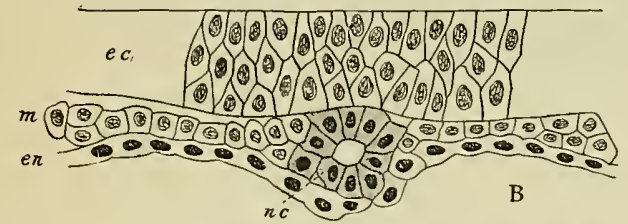

Fig. 47.-Transverse Sections through Mole Embryos, SHowing the Formation OF THE NOTOCHORD.

$e c$, Ectoderm; en, endoderm; $m$, mesoderm; $n c$, notochord.-(Heape.)

The lumen which is at first present in the chordal tube is soon obliterated by the enlargement of the cells which bound it, and these cells later undergo a peculiar transformation whereby the chordal tube is converted into a solid elastic rod surrounded by a cuticular sheath secreted by the cells. The notochord lies at first immediately beneath the median line of the medullary groove, between the ectoderm and the endoderm, and has on either side of it the mesodermal plates. It is a temporary structure of which only rudiments persist in the adult condition in man, but it is a structure characteristic of all vertebrate embryos and persists to a more or less perfect extent in many of the fishes, being indeed the only axial 
skeleton possessed by Amphioxus. In the higher vertebrates it is almost completely replaced by the vertebral column, which develops around it in a manner to be described later.

The Mesodermic Somites.-Turning now to the middle germinal layer, it will be found that in it also important changes take place during the early stages of development. The probable mode of development of the extra-embryonic mesoderm and body-cavity has already been described (p. 67) and attention may now be directed toward what occurs in the embryonic mesoderm. In both the Peters embryo and the embryo v.H described by von Spee this portion of the mesoderm is represented by a plate of cells lying between the ectoderm and endoderm and becoming continuous at the edges of the embryonic area with both the layer which surrounds the yolk-sac and, through the mesoderm of the belly-stalk, with the chorionic mesoderm (Fig. 37). It seems probable, since there is in these embryos no indication as yet of the formation of the chorda endoderm, that this plate of mesoderm corresponds to the prostomial mesoderm of lower forms. In older embryos, such as the embryo Gle of Graf Spee and the younger embryo described by Eternod (Fig. 43), the mesoderm no longer forms a continuous sheet extending completely across the embryonic disk, but is divided into two lateral plates, in the interval between which the ectoderm of the floor of the medullary groove and the chorda endoderm are in close contact (Fig. 48). These lateral plates represent the gastral mesoderm, whose origin has already been described (p. 59), and which apparently supplants the original prostomial mesoderm, whose fate in the human embryo is at present unknown. The changes which now occur have not as yet been observed in the human embryo, though they probably resemble those described in other mammalian embryos, and the phenomena which occur in the sheep may serve to illustrate their probable nature.

It has been seen that in the stage represented by the Frassi embryo a plate of mesoderm has formed on either side of the chorda endoderm, and that in a later stage, represented by the Krömer embryo $K l b$, a differentiation occurs in these plates leading to the 
formation of mesodermic somites. 'These make their appearance in what will later be the cervical region of the embryo and their formation proceeds backward as the body of the embryo increases in length. A longitudinal groove appears on the dorsal surface of each lateral plate of mesoderm, marking off the more median thicker portion from the lateral parts (Fig. 48), which from this stage onward may be termed the ventral mesoderm. 'The median or dorsal portions then become divided transversely into a number of more or less cubical masses which are termed the protovertebrce or, better,

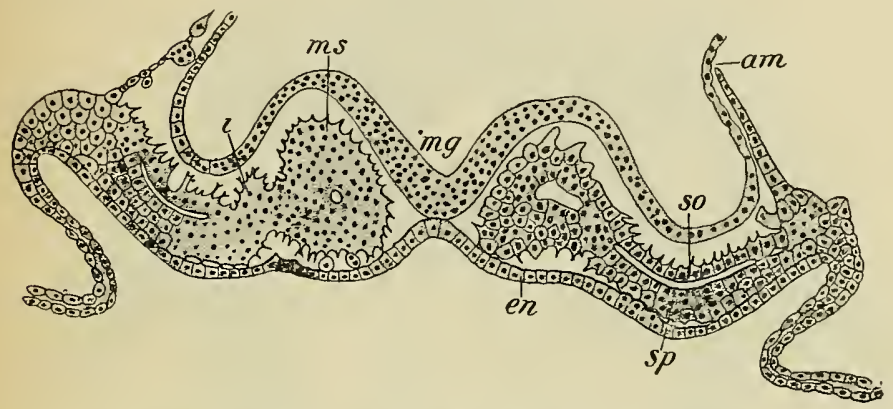

Fig. 48.-Transverse Section through the Second Mesodermic Somite of a SHEEP EMbryo 3 MM. LoNG.

$a m$, Amnion; $e n$, endoderm; $l$, intermediate cell-mass; $m g$, medullary groove; $m s$, mesodermic somite; so, somatic and $s p$, splanchnic layers of the ventral mesoderm.(Bonnet.)

mesodermic somites (Fig. 48, ms). The cells of the somites and of the ventral mesoderm, are at first stellate in form, but later become more spindle-shaped, and those near the center of each somite and those of the ventral mesoderm arrange themselves in regular layers so as to enclose cavities which appear in these regions (Fig. 48). Each original lateral plate of gastral mesoderm thus becomes divided longitudinally into three areas, a more median area composed of mesodermic somites, lateral to this a narrow area underlying the original longitudinal groove which separated the somite area from the ventral mesoderm and which from its position is termed the intermediate cell-mass (Fig. $48, l$ ), and, finally, the ventral mesoderm. This last portion is now divided into two layers, the 
dorsal of which is termed the somatic mesoderm, while the ventral one is known as the splanchnic mesoderm (Fig. 48, so and sp; and Fig. 49), the cavity which separates these two layers being the embryonic body-cavity or pleuroperitoneal cavity (cclom), which will eventually give rise to the pleural, pericardial and peritoneal cavities of the adult as well as the cavity of each tunica vaginalis testis.

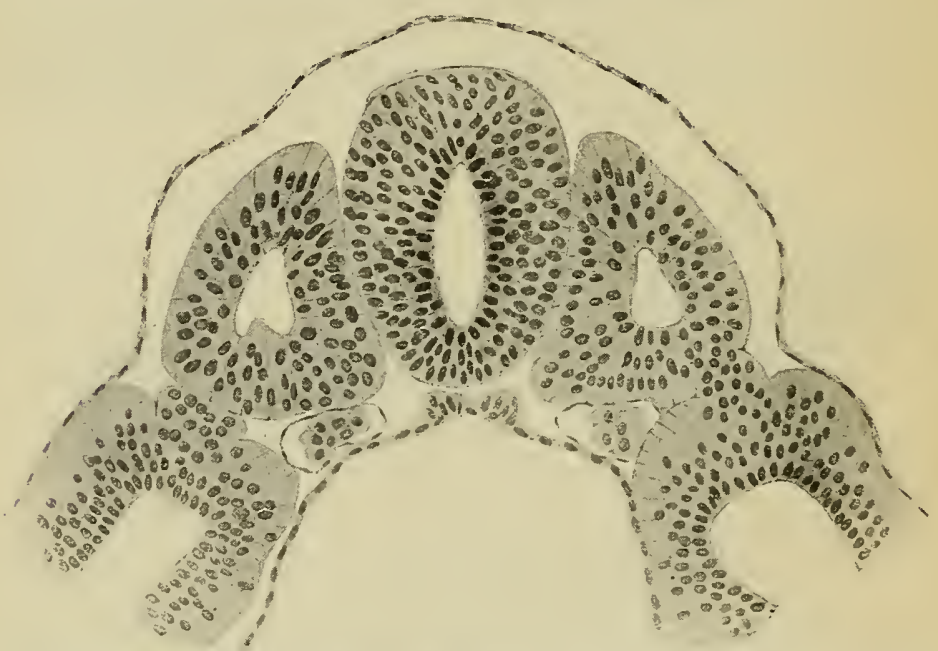

Fig. 49.-Transverse Section of an Embryo of 2.5 Mm. (See Fig. 53) Showing on either side of the Medullary Canal a Mesodermic Somite, the InterMediate CelL-MASS, AND THE Ventral MesoderM.-(von Lenhossek.)

Beginning in the neck region, the formation of the mesodermic somites proceeds posteriorly until finally there are present in the human embryo thirty-eight pairs in the neck and trunk regions of the body, and, in addition, a certain number are developed in what is later the occipital region of the head. Exactly how many of these occipital somites are developed is not known, but in the cow four have been observed, and there are reasons for believing that the same number occurs in the human embryo.

In the lower vertebrates a number of cavities arranged in pairs occur in the more anterior portions of the head and have been homologized with mesodermic somities. Whether this homology be perfectly correct or not, 
these head-cavities, as they are termed, indicate the existence of a division of the head mesoderm into somites, and although practically nothing is known as to their existence in the human embryo, yet, from the relations in which they stand to the cranial nerves and musculature in the lower forms, there is reason to suppose that they are not entirely unrepresented

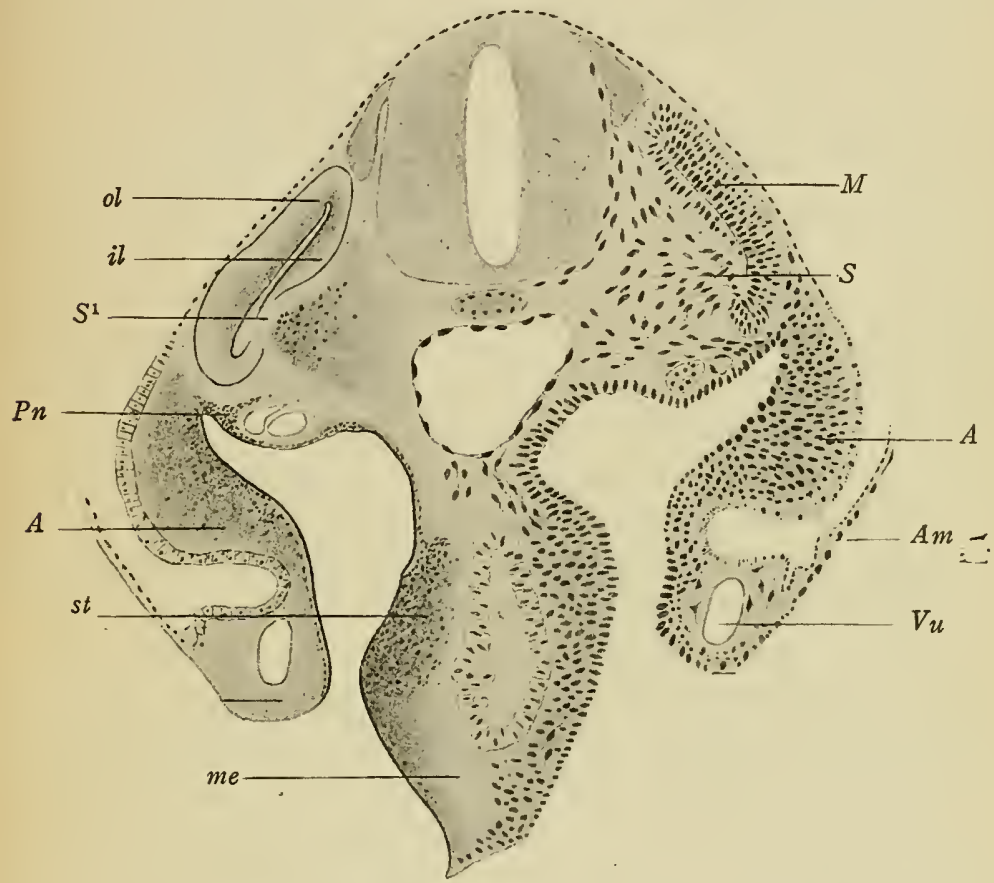

Fig. 50.-Transverse Section of an Embryo of 4.25 mM. AT the Level of the Arm RUDIMENT.

$A$, Axial mesoderm of arm; $A m$, amnion; $i l$, inner lamella of myotome; $M$, myotome; $m e$, splanchnic mesoderm; ol: outer lamella of myotome; $P_{n}$, place of origin of pronephros; $S$, sclerotome; $S^{1}$, defect in wall of myotome due to separation of the sclerotome; st, stomach; $V u$, umbilical vein.-(Kollmann.)

The mesodermic somites in the earliest human embryos in which they have been observed contain a completely closed cavity, and this is true of the majority of the somites in such a form as the sheep. In the four first-formed somites in this species, however, the somite cavity is at first continuous with the pleuroperitoneal 
cavity and only later becomes separated from it, and in lower vertebrates this continuity of the somite cavities with the general bodycavity is the rule. The somite cavities are consequently to be regarded as portions of the general pleuroperitoneal cavity which have secondarily been separated off. They are, however, of but short duration and early become filled up by spindle-shaped cells derived from the walls of the somites, which themselves undergo a differentiation into distinct portions. The cells of that portion of the wall of each somite which is opposite the notochord become spindleshaped and grow inward toward the median line to surround the notochord and central nervous system, and give rise eventually to the lateral half of the body of a vertebra and the corresponding portion of a vertebral arch. This portion of the somite is termed a sclerotome (Fig. 50, S), and the remainder forms a muscle plate or myotome $(M)$ which is destined to give rise to a portion of the voluntary musculature of the body. The outer wall of the somite has been generally believed to take part in the formation of the cutis layer of the integument and hence has been termed the cutis plate or dermatome, but it seems probable that it becomes entirely transformed into muscular tissue.

The intermediate cell-mass in the human embryo, as in lower forms, partakes of the transverse divisions which separate the individual mesodermic somites. From one portion of the tissue in most of the somites (Fig. 50, $P n$ ) the provisional kidneys or Wolffian bodies develop, this portion of each mass being termed a nephrotome, while the remaining portion gives rise to a mass of cells showing no tendency to arrange themselves in definite layers and constituting that form of mesoderm which has been termed mesenchyme (see p. 6I). These mesenchymatous masses become converted into connective tissues and blood-vessels.

The ventral mesoderm in the neck and trunk regions never becomes divided transversely into segments corresponding to the mesodermic somites, differing in this respect from the other portions of the gastral mesoderm. In the head, however, that portion of the middle layer which corresponds to the ventral mesoderm of 
the trunk does undergo a division into segments in connection with the development of the branchial arches and clefts (see p. 90). A consideration of these segments, which are known as the branchiomeres, may conveniently be postponed until the chapters dealing with the development of the cranial muscles and nerves, and in what follows here attention will be confined to what occurs in the ventral mesoderm of the neck and trunk.

Its splanchnic layer (Fig. $5 \mathrm{I}, \mathrm{vm}$ ), applies itself closely to the endodermal digestive tract, which is constricted off from the dorsal portion of the yolk-sac, and becomes converted into mesenchyme out of which the muscular coats of the digestive tract develop. The cells which line the pleuroperitoneal cavity, however, retain their arrangement in a layer and form a part of the serous lining of the peritoneal and other serous cavities, the remainder of the lining being formed by the corresponding cells of the somatic layer; and in the abdominal region the superficial cells, situated near the line where the splanchnic layer passes into the somatic, and in close proximity to the nephrotome of the intermediate cell-mass, become columnar in shape and are converted into reproductive cells.

The somatic layer, if traced peripherally, becomes continuous at the sides with the layer of mesoderm which lines the outer surface of the amnion (Fig. 50) and posteriorly with the mesoderm of the belly-stalk. That portion of it which lies within the body of the embryo, in addition to giving rise to the serous lining of the parietal layer of the pleuroperitoneum, becomes converted into mesenchyme, which for a considerable length of time is clearly differentiated into two zones, a more compact dorsal one which may be termed the somatic layer proper, and a thinner, more ventral vascular zone which is termed the membrana reuniens (Fig. 5I). In the earlier stages the somatic layer proper does not extend ventrally beyond the line which passes through the limb buds and it grows out into these buds to form an axial core for them, in which later the skeleton of the limb forms. The remainder of the mesoderm lining the sides and ventral portions of the body-wall is at first formed from the membrana reuniens, but as development proceeds the somatic 
layer gradually extends more ventrally and displaces, or, more properly speaking, assimilates into itself, the membrana reuniens until finally the latter has completely disappeared.

It is to be noted that no part of the voluntary musculature of the lateral and ventral walls of the neck and trunk is derived from the somatic layer; it is formed entirely from the myotomes which gradually extend ventrally (Fig. 5I) and finally come into contact with their fellows of the opposite side in the mid-ventral line.
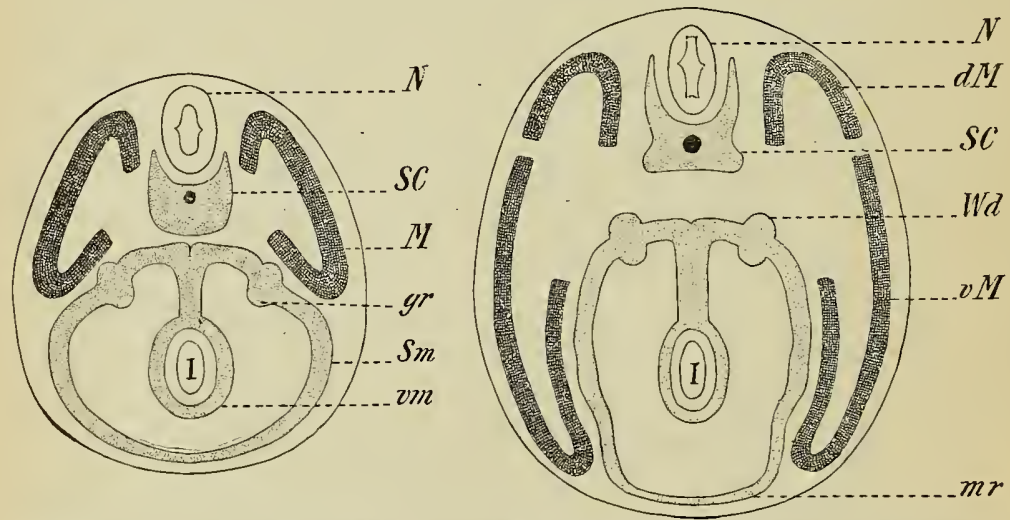

Fig. 5i.-Diagrams Illustrating the History of the Gastral Mesoderm.

$d M$, dorsal portion of myotome; $g r$, genital ridge; $I$, intestine; $M$, myotome, $m r$, membrana reuniens; $N$, nervous system; $S C$, sclerotome; $S m$, somatic mesoderm; $v m$, splanchnic mesoderm; $v M$, ventral portion of myotome; $W d$, Wolffian duct.

Whether the voluntary musculature of the limbs is also derived from the myotomes is at present doubtful. It has been very generally believed that the myotomes in their growth ventrally sent prolongations into the limb buds which invested the axial core of mesenchyme and eventually gave rise to the voluntary muscles. The actual existence of the prolongations of the myotomes and their conversion into the limb musculature has, however, not yet been observed and it is quite possible that the limb musculature may be derived from the axial core of somatic mesoderm from which the limb skeleton develops.

The appearance of the mesodermic somites is an important 
phenomenon in the development of the embryo, since it influences fundamentally the future structure of the organism. If each pair of mesodermic somites be regarded as a structural unit and termed a metamere or segment, then it may be said that the body is composed of a series of metameres, each more or less closely resembling its fellows, and succeeding one another at regular intervals. Each somite differentiates, as has been stated, into a sclerotome and a myotome, and, accordingly, there will primarily be as many vertebræ and muscle segments as there are mesodermic somites, or, in other words, the axial skeleton and the voluntary muscles of the trunk are primarily metameric. Nor is this all. Since each metamere is a distinct unit, it must possess its own supply of nutrition, and hence the primary arrangement of the blood-vessels is also metameric, a branch passing off on either side from the main longitudinal arteries and veins to each metamere. And, further, each pair of muscle segments receives its own nerves, so that the arrangement of the nerves, again, is distinctly metameric.

It is to be noted that this metamerism is essentially resident in the dorsal mesoderm, the segmentation shown by structures derived from other embryonic tissues being secondary and associated with the relations of these structures to the mesodermic somites. The metamerism is most distinct in the neck and trunk regions, and at first only in the dorsal portions of these regions, the ventral portions showing metamerism only after the extension into them of the myotomes. But there is clear evidence that the arrangement extends also into the head, and that a portion of its mesoderm is to beregarded as composed of metameres. It has been seen that in the notochordal region of the head of lower vertebrates mesodermic somites are present, while anteriorly in the præchordal region there are headcavities which resemble closely the mesodermic somites, and are probably directly comparable to the somites of the trunk. There is reason, therefore, for believing that the fundamental arrangement of the dorsal mesoderm in all parts of the body is metameric, but though this arrangement is clearly defined in early embryos, it loses distinctness in later periods of development. But eren in the 
adult the original metamerism is clearly indicated in the arrangement of the nerves and of parts of the axial skeleton, and careful study frequently reveals indications of it in highly modified muscles and blood-vessels.

In the head the development of the branchial arches and clefts produces a series of parts presenting many of the peculiarities of metameres, and, indeed, it has been a very general custom to regard them as expressions of the general metamerism which prevails throughout the body. It is to be noted, however, that they are produced by the segmentation of the ventral mesoderm, a structure which in the neck and trunk regions does not share in the general metamerism, and, furthermore, recent observations on the cranial nerves seem to indicate that these branchiomeres cannot be regarded as portions of the head metameres or even as structures comparable to these. They represent, more probably, a second metamerism superposed upon the more general one, or, indeed, possibly more primitive than it, but whose relations can only be properly understood in connection with a study of the cranial nerves.

\section{LITERATURE.}

In addition to many of the papers cited in the list at the close of Chapter II, the following may be mentioned:

C. R. BardeEn: "The Development of the Musculature of the Body Wall in the Pig, etc.," Johns Hopkins Hosp. Rep., Ix, rgoo.

T. H. Bryce and J. H. Teacher: "Contributions to the Study of the Early Development and Imbedding of the Human Ovum," Glasgow, I908.

A. C. F. Eternod: "Communication sur un ouf humain avec embryon excessivement jeune," Arch. Ital. de Biologie, xxII, I895.

A. C. F. Eternod: "Il y a un canal notochordal dans l'embryon humain," Anat. Anzeiger, XVI, I899.

FetZer: "Ueber ein durch Operation gewonnenes menschliches Ei das in seiner Entwickelung etwa dem Peterssehen Ei entspricht," Verh. Anat. Gesellschaft, XXIV, IgIo.

L. Frassi: "Weitere Ergebnisse des Studiums eines jungen menschlichen Eies in situ," Arch.f. mikr. Anat., Lxxi, xgo8.

W. HEAPE: "The Development of the Mole (Talpa Europæa)," Quarterly Journ. Microsc. Science, xxvII, $x 887$.

M. Herzog: "A Contribution to our Knowledge of the Earliest Known Stages of Placentation and Embryonic Development in Man," Amer. Journ. Anat., Ix, xgog. 
F. KeIbEL: "Zur Entwickelungsgeschichte der Chorda bei Säugern (Meerschweinchen und Kaninchen)," Archiv für Anat. und Physiol., Anat. Abth., I889.

S. KAESTNER: "Ueber die Bildung von animalen Muskelfasern aus dem Urwirbel," Arch. für Anat. und Phys., Anat. Abth., Suppl., I8go.

J. Kollmann: "Die Rumpfsegmente menschlicher Embryonen von I3 bis 35 Urwirbeln," Archiv für Anat. und Physiol., Anat. Abth., I89I.

H. Peters: "Ueber die Einbettung des menschlichen Eies und das früheste bisher bekannte menschliche Placentarstadium," Leipzig und Wien, I899.

F. Graf von SpEe: "Beobachtungen an einer menschlichen Keimscheibe mit offener Medullarrinne und Canalis neurentericus," Arch.f. Anat.u. Phys., Anat. Abth., 1889.

F. GRAF VON SPEE: "Ueber frühe Entwicklungsstufen des menschlichen Eies," Arch.f. Anat.u. Phys., Anat. Abth., I896.

H. Straht and R. Beneke: "Ein junger menschlicher Embryo," Wiesbaden, IgIo.

J. W. VAN WiJHE: "Ueber die Mesodermsegmente des Rumpfes und die Entwicklung des Excretionsystems bei Selachiern," Archiv fïr mikrosk. Anat., xxxIII, r889.

K. W. Zimmermann: "Ueber Köpfhöhlenrudimente beim Menschen," Archiv für mikrosk. Anat., LIII, I8g8. 


\section{CHAPTER IV.}

\section{THE DEVELOPMENT OF THE EXTERNAL FORM OF THE HUMAN EMBRYO.}

In the preceding chapter descriptions have been given of human embryos representing the earlier known stages and the development of the general form of the human embryo has been traced up to the time when the mesodermic somites have made their appearance. It will now be convenient to continue the history of the general development up to the stage when the embryo becomes a fetus.

In the earlier stages, that is to say up to that represented by the Eternod embryo (Fig. 43), the embryonic disk may be described as floating upon the surface of the yolk-sac, and while this description still holds good for the Eternod embryo a distinct groove may be seen in that embryo between the peripheral portions of the embryonic disk and the upper part of the sac. This groove marks the beginning of the separation or constriction of the embryo from the yolk-sac, the result of which is the transformation of the discoidal embryonic portion of the embryonic disk into a cylindrical structure. Primarily this depends upon the deepening of the furrow which surrounds the embryonic area, the edges of this area being thus bent in on all sides toward the yolk-sac. 'This bending in proceeds most rapidly at the anterior end of the body, as shown in the diagrams (Fig. 52), and less rapidly at the posterior end where the bellystalk is situated, and produces a constriction of the yolk-sac, the portion of this structure nearest the embryonic disk becoming enclosed within the body of the embryo to form the digestive tract, while the remainder is converted into a pedicle-like portion, the yolk-stalk, at the extremity of which is the yolk-vesicle. The further continuance of the folding in of the edges of the embryonic area leads to an almost complete closing in of the embryonic cœlom 
and reduces the opening through which the yolk-stalk and bellystalk communicate with the embryonic tissues to a small area known as the umbilicus.

In the Krömer embryo Klb (Fig. 44) this separation of the embryo proper from the yolk-sac has proceeded to such an extent that both extremities of the embryonic disk are free from the yolk-sac, and the anterior extremity is bent ventrálly almost at a right angle to
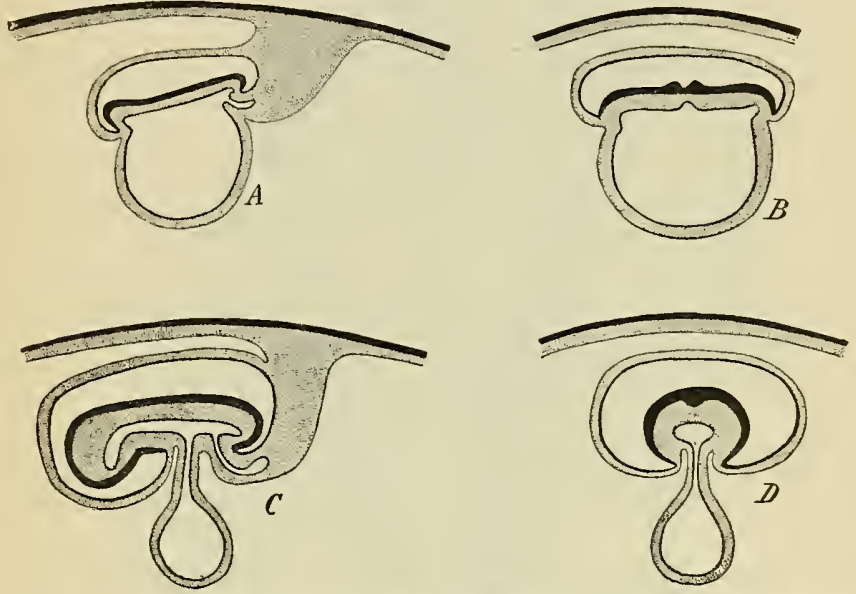

Fig. 52.-Diagrams Illustrating the Constriction of the Embryo from the YoLK-SAC.

$A$ and $C$ are longitudinal, and $B$ and $D$ transverse sections. $B$ is drawn to a larger scale than the other figures.

the rest of the disk, producing what is termed the vertex bend, a feature characteristic of all later embryos. The marked development in this embryo of the medullary folds and the occurrence of mesodermic somites have already been mentioned (p. 72).

Somewhat more advanced is the Bulle embryo described by Kollmann and shown from the side and dorsally in Fig. 53, the greater part of the yolk-sac having been removed as well as the most of the amnion. The embryo measured about $2.5 \mathrm{~mm}$. in length and showed a considerable increase in the number of mesodermic somites, there being about fourteen of them on either side. Pos- 
teriorly the medullary groove has become converted into a medullary canal by the medullary folds meeting over it and fusing, but anteriorly it is still open. The vertex bend is well marked and

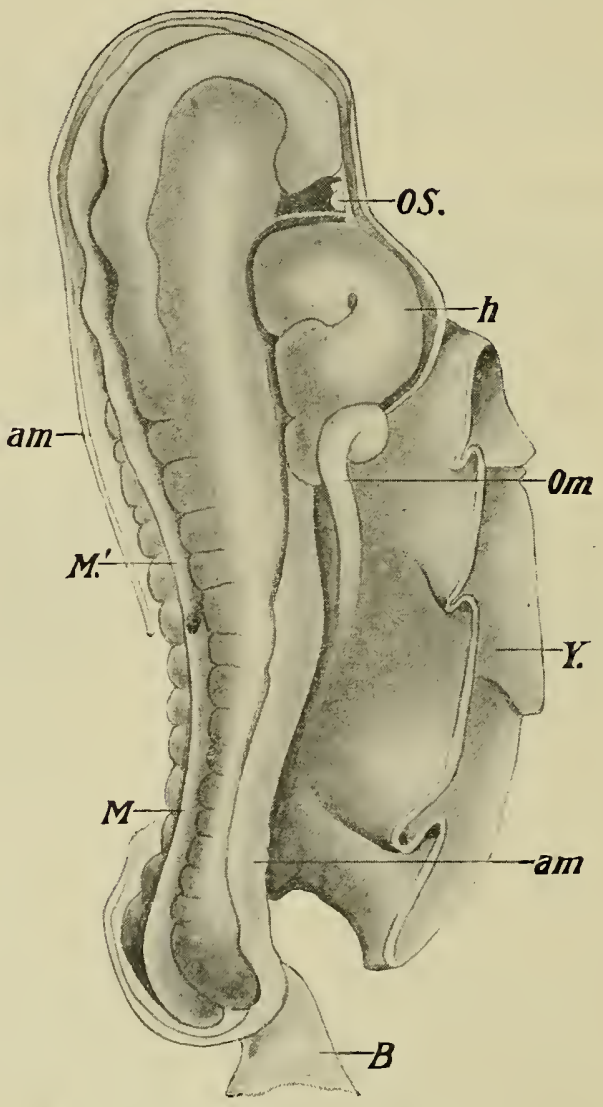

Fig. 53.-EMbRYo 2.5 MM. LONG.

$a m$, Amnion; $B$, belly-stalk; $h$, heart; $M$, closed, and $M^{\prime}$, still open portions of the medullary groove; $O m$, vitelline vein; $O S$, oral fossa; $Y$, yolk-sac.-(Kollmann.)

immediately behind the tip of the head, on the ventral surface of the body, there may be seen a well-marked depression, the oral fossa, between which and the anterior surface of the yolk-sac is a rounded 


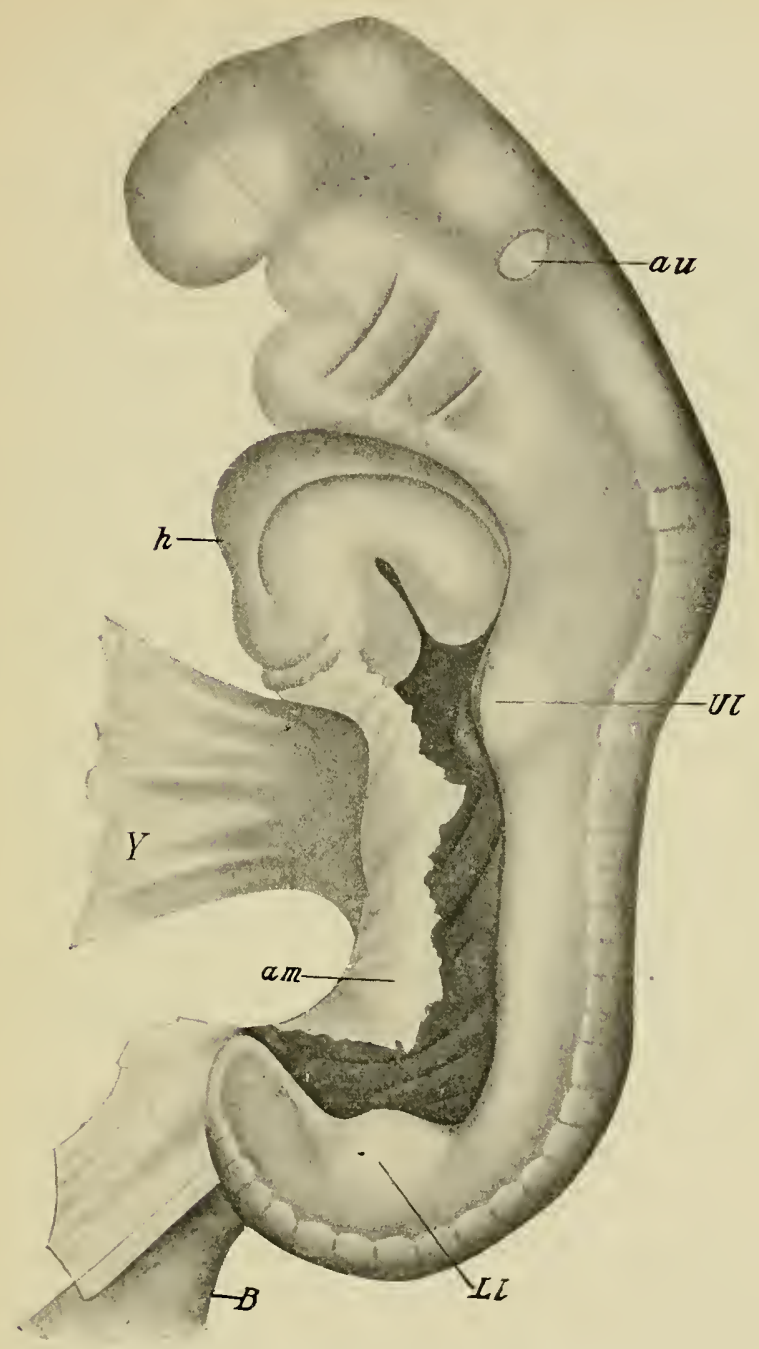

Fig. 54.-Firbryo Lr, 4.2 MM. Long.

$a m$, Amnion; $a u$, auditory capsule; $B$, belly-stalk; $h$, heart; $L l$, lower, and $U l$, upper limb; $Y$, yolk-sac.-(His.) 
elevation due to the formation of the heart. Attention may be called to the fact that the position of this organ is far forward of that which it will eventually occupy, so that it must undergo a marked retrogression during later development.

As an example of a later stage. of development the embryo $L r$ of His, measuring $4.2 \mathrm{~mm}$. in length, may be taken (Fig. 54). In this the constriction of the yolk-sac has progressed so far that its proximal portion may now be spoken of as the yolk-stalk. The mesodermic somites have undergone a further increase and have almost reached their final number, the vertex bend has become still more pronounced and the medullary groove, throughout its entire length, has been converted into the medullary canal, which, anteriorly, shows distinct enlargements and constrictions which foreshadow various portions of the future brain. The auditory organ, which made its appearance in earlier stages, has now become quite distinct, and a lateral bulging of the most anterior portion of the head indicates the position of the future eye.

In addition certain other important features have now appeared. Thus, about opposite the head a second bend, the nape bend, is becoming visible on the dorsal surface of the body and toward the posterior end a distinct sacral bend is evident. Secondly, a little posterior to the level of the nape bend a slight elevation is to be seen on the side of the body; this is the limb bud for the upper limb and a corresponding, though smaller, elevation in the region of the sacral bend represents the lower limb.

Thirdly, three grooves having a dorso-ventral direction have appeared on the sides of what will be the future pharyngeal region. These are representatives of a series of branchial clefts, structures that are of great morphological importance in the further development inasmuch as they determine to a large extent the arrangement of various organs of the head region. They represent the clefts which exist in the walls of the pharynx in fishes, through which water, taken in at the mouth, passes to the exterior, bathing on its way the gill filaments attached to the bars or arches, as they are termed, which separate successive clefts. Hence the name "bran- 
chial" which is applied to them, though in the mammals they never have respiratory functions to perform, but, appearing, persist for a time and then either disappear or are applied to some entirely different purpose. Indeed, in man they are never really clefts but merely grooves, and corresponding to each groove in the ectoderm there is also one in the subjacent endoderm of what will eventually be the pharyngeal region of the digestive tract, so that in the region of each cleft the ectoderm and endoderm are in close relation, being separated only by a very thin layer of mesoderm. In the intervals between successive clefts a more considerable amount of mesoderm is present (Fig. 55).

In the human embryo four clefts and five branchial arches develop

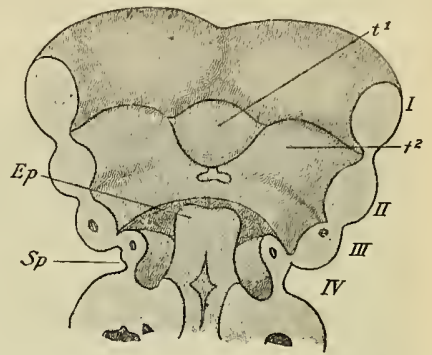

Fig. 55.-Floor of the Pharynx OF EMBryo B, 7 MM. LONG.

$E p$, Epiglottis; $S p$, sinus præcervicalis; $t^{1}$, tuberculum impar; $t^{2}$, posterior portions of the tongue; $I, I I, I I I$, and $I V$, branchial arches. -(His.) on each side of the body, the last arch lying posteriorly to the fourth cleft and not being very sharply defined along its posterior margin.

As just stated, the clefts are normally merely grooves, and in later development either disappear or are converted into special structures. Occasionally, however, a cleft may persist and the thin membrane which forms its floor may become perforated so that an opening from the exterior into the pharynx occurs at the side of the neck, forming what is termed a branchial fistula. Such an abnormality is most frequently developed from the lower (ventral) part of the first cleft; normally this disappears, the upper portion of the cleft persisting, however, to form the external auditory meatus and tympanic cavity.

A further stage in the differentiation of these clefts and arches is shown by the embryo represented in Fig. 56. The nape bend has now increased to such an extent that the whole anterior part of the body is bent at a right angle to the middle part and the entire embryo is coiled in a spiral manner. The limb buds are much more distinct than in the previous stage and four branchial arches are now present; the second and third have become more defined and 
a strong process has developed from the dorsal part of the anterior border of the first one, which has thus become somewhat $\ll$-shaped. The anterior limb of each $\mathrm{V}$ is destined to give rise to the upper jaw, and hence is known as the maxillary process, while the posterior limb represents the future lower jaw and is termed the mandibular process.

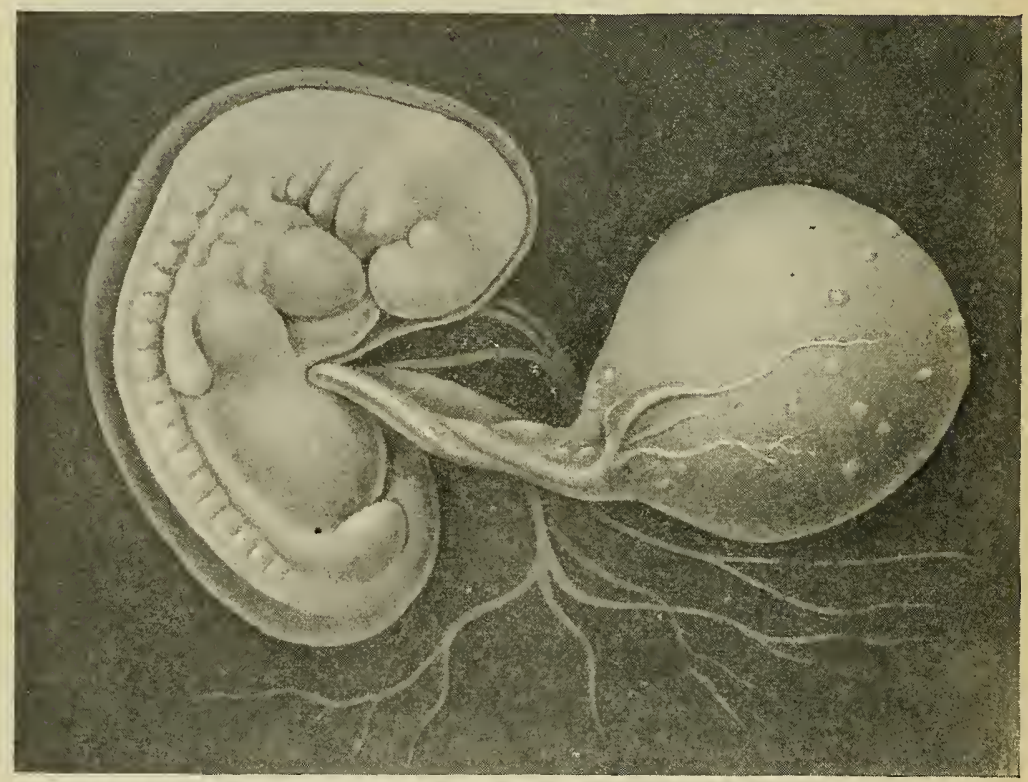

Fig. 56.--Embryo Bä́cker, 7.3 MM. IN Length. $\times 5 .-($ Keibel and Elze. $)$

In the stage represented by this embryo the closing in of the embryonic cœlom has progressed to such a degree that only a small opening is left in the ventral body-wall of the embryo through which the yolk-stalk and its accompanying vessels and the belly-stalk pass. Indeed the margins of the umbilicus may have begun to be prolonged outward over these structures, enclosing them in a cylindrical investment, the first stage of what will later be the umbilical cord being thus established. 
Leaving aside for the present all consideration of the further development of the limbs and branchial arches, the further evolution of the general form of the body may be rapidly sketched. In an embryo (Fig. 57) from Ruge's collection, described and figured by His and measuring 9.I $\mathrm{mm}$. in length,* the prolongation of the

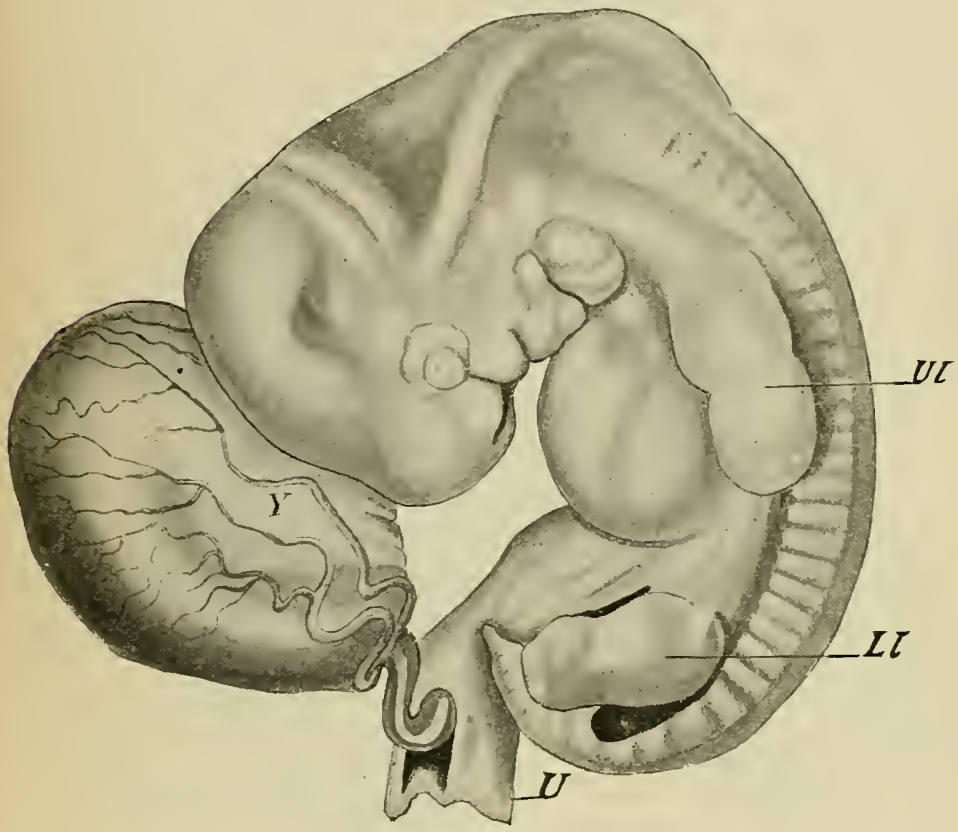

Fig. 57.-EMrbryo 9.I MMr. Long.

$L l$, Lower limb; $U$, umbilical cord; $U l$, upper limb; $Y$, yolk-sac.-(His.)

margins of the umbilicus has increased until more than half the yolk-stalk has become enclosed within the umbilical cord. The nape and sacral bends are still very pronounced, although the embryo is beginning to straighten out and is not quite so much coiled as in the preceding stage. At the posterior end of the body there has

* This measurement is taken in a straight line from the most anterior portion of the nape bend to the middle point of the sacral bend and does not follow the curvature of the embryo. It may be spoken of as the nape-rump length and is convenient for use during the stages when the embryo is coiled upon itself. 
developed a rather abruptly conical tail filament, in the place of the blunt and gradually tapering termination seen in earlier stages, and a well-marked rotundity of the abdomen, due to the rapidly increasing size of the liver, begins to become evident.

In later stages the enclosure of the yolk- and belly-stalks within the umbilical cord proceeds until finally the cord is complete through the entire interval between the embryo and the wall of the ovum. At the same time the straightening out of the embryo continues, as may be seen in Fig. $5^{8}$ representing the embryo $\mathrm{xLV}\left(\mathrm{Br}_{2}\right)$ of His, which shows also, both in front of and behind the neck bend, a

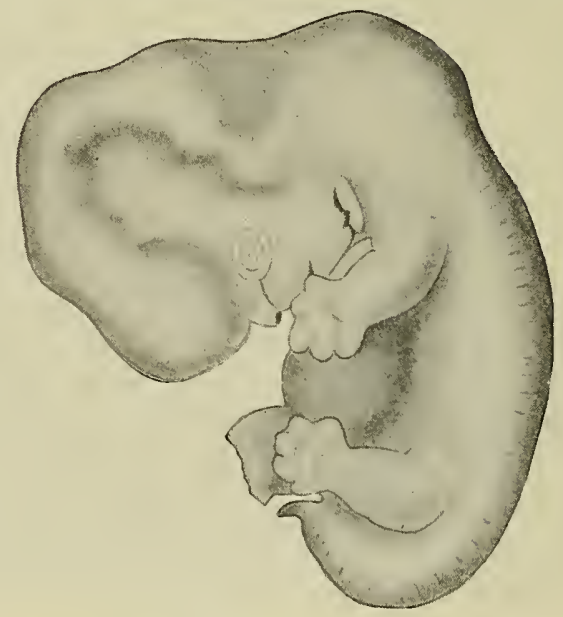

Fig. 58.-Еmbryo B R R $_{2}$, 3.6 mM. Long.-(His.)

distinct depression, the more anterior being the occipital and the more posterior the nape depression; both these depressions are the indications of changes taking place in the central nervous system. The tail filament has become more marked, and in the head region a slight ridge surrounding the eyeball and marking out the conjunctival area has appeared; a depression anterior to the nasal fossæ marks off the nose from the forehead; and the external ear, whose development will be considered later on, has become quite distinct. This embryo had a nape-rump length of $13.6 \mathrm{~mm}$. 
In the embryos $\operatorname{xxxv}\left(\mathrm{S}_{2}\right)$ and $\operatorname{xcIx}\left(\mathrm{L}_{3}\right)$ (Fig. 59, $\mathrm{A}$ and $\mathrm{B}$ ) of His' collection the straightening out of the nape bend is proceeding, and indeed is almost completed in embryo $\mathrm{xcIx}$, which begins to resemble closely the fully formed fetus. The tail filament, somewhat reduced in size, still persists and the rotundity of the abdomen continues to be well marked. The neck region is beginning to be distinguishable in embryo $\mathrm{S}_{2}$ and in embryo $\mathrm{L}_{3}$ the eyelids have. appeared as slight folds surrounding the conjunctival area. The
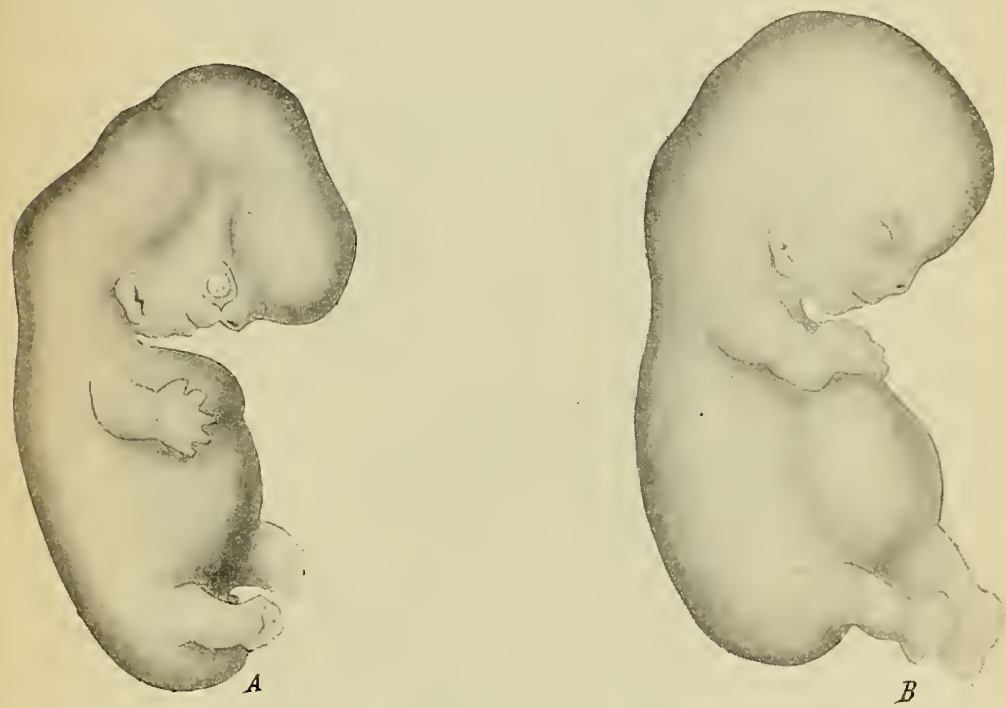

Fig. 59.- $A$, Embryo $\mathrm{S}_{2}$, I 5 MM. Long (Showing Ectopia of the Heart); $B$, Embryo $\mathrm{L}_{3}, \mathbf{I} 7.5$ MM. LONG.-(His.)

nose and forehead are clearly defined by the greater development of the nasal groove and the nose has also become raised above the general surface of the face, while the external ear has almost acquired its final fetal form. These embryos measure respectively about I 5 and $\mathrm{I} 7.5 \mathrm{~mm}$. in length.*

Finally, an embryo-again one of those described by His,

* The embryo $\mathrm{S}_{2}$ presents a slight abnormality in the great projection of the heart, but otherwise it appears to be normal. 
namely, his LxxvII (Wt), having a length of $23 \mathrm{~mm}$.-may be figured (Fig. 60) as representing the practical acquisition of the fetal form. This embryo dates from about the end of the second month of pregnancy, and from this period onward it is proper to use the term fetus rather than that of embryo. The changes which

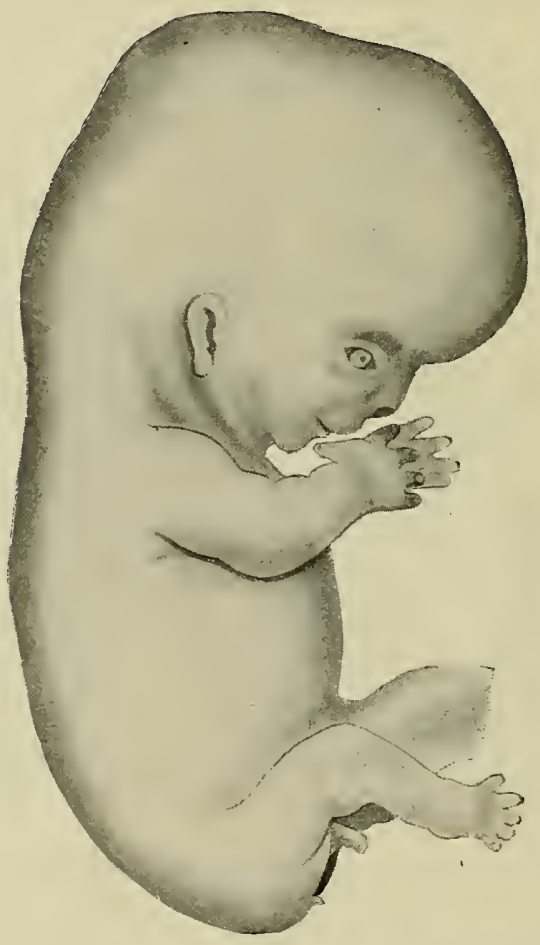

Fig. 6o.-ЕMвRYo Wt, 23 мM. Long.-(His.)

have been described in preceding stages are now complete and it remains only to be mentioned that the caudal filament, which is still prominent, gradually disappears in later stages, becoming, as it were, submerged and concealed beneath adjacent parts by the development of the buttocks. The incompleteness of the development of these regions in embryo Wt is manifest, not only from the 
projection of the tail filament, but also from the external genitalia being still largely visible in a side view of the embryo, a condition which will disappear in later stages.

The Later Development of the Branchial Arches, and the Development of the Face.-In the embryo shown in Fig. 56 , the four branchial clefts and five arches which develop in the numan embryo are visible in surface views, but in the Ruge embryo (Fig. 57) it will be noticed that only the first two arches, the first with a welldeveloped maxillary process, and the cleft separating them can be

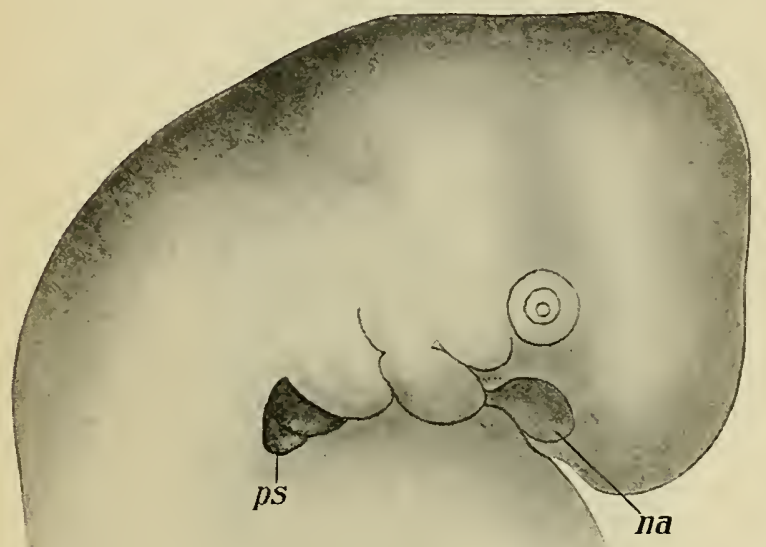

Fig. 6i.-Head of Fabryo of 6.9 Mar. $n a$, Nasal pit; $p s$, precervical sinus.-(His.)

distinguished. This is due to a sinking inward of the region occupied by the three posterior arches so that a triangular depression, the simus pracervicalis, is formed on each side of what will later become the anterior part of the neck region. This is well shown in an embryo $\left(\mathrm{Br}_{3}\right)$ described by His which measured $6.9 \mathrm{~mm}$. in length and of which the anterior portion is shown in Fig. 6r. The anterior boundary of the sinus $(p s)$ is formed by the posterior edge 
of the second arch and its posterior boundary by the thoracic wall, and in later stages these two boundaries gradually approach one another so as first of all to diminish the opening into the sinus and later to completely obliterate it by fusing together, the sinus thus becoming converted into a completely closed cavity whose floor is formed by the ectoderm covering the three posterior arches and the clefts separating these. This cavity eventually undergoes degeneration, no traces of it occurring normally in the adult, although

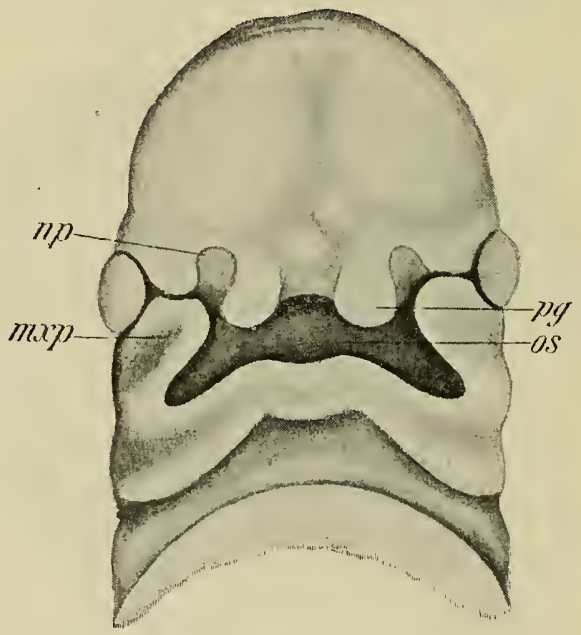

Fig. 62.-Face of Embryo of 8 mu.

$m x p$, Maxillary process; $n p$, nasal pit; os, oral fossa; $p g$, processus globularis.-(His.)

certain cysts occasionally observed in the sides of the neck may represent persisting portions of it.

A somewhat similar process results in the closure of the ventral portion of the first cleft,* a fold growing backward from the posterior edge of the first arch and fusing with the ventral part of the anterior border of the second arch. The upper part of the cleft persists, however, and, as already stated, forms the external auditory meatus, the pinna of the ear being developed from the adjacent parts of the first and second arches (Figs. $5^{8}$ and 59).

* See page $9 \mathbf{r}$, small type. 
The region immediately in front of the first arch is occupied by a rather deep depression, the oral fossa, whose early development has already been noticed. In an embryo measuring $8 \mathrm{~mm}$. in length (Fig. 62) the fossa (os) has assumed a somewhat irregular quadrilateral form. Its posterior boundary is formed by the mandibular processes of the first arch, while laterally it is bounded by the maxillary processes $(m x p)$ and anteriorly by the free edge of a median plate, termed the nasal process, which on either side of the

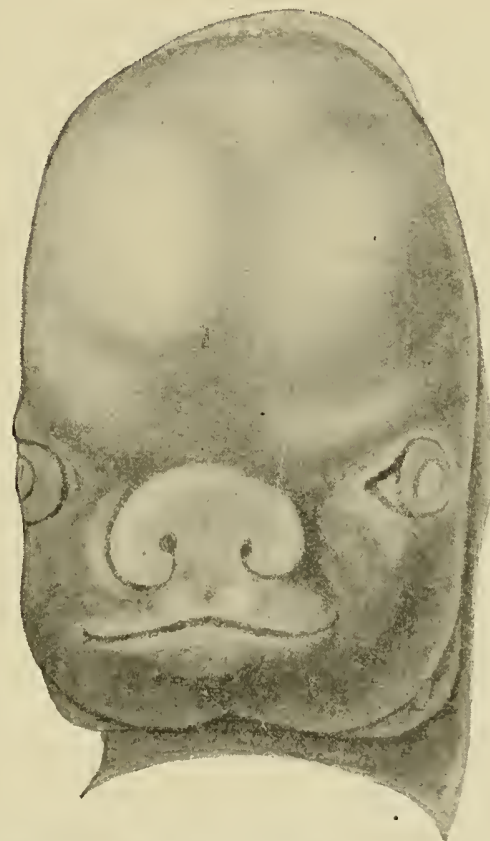

Fig. 63.-Face of Embryo after the Completion of the Upper Jaw.-(His.)

median line is elevated to form a marked protuberance, the processus globularis $(p g)$. The ventral ends of the maxillary processes are widely separated, the nasal process and the processus globulares intervening between them, and they are also separated from the globular processes by a deep and rather wide groove which anteriorly opens into a circular depression, the nasal pit (np). 
Later on the maxillary and globular processes unite, obliterating the groove and cutting off the nasal pits-which have by this time deepened to form the nasal fossæ-from direct communication with the mouth, with which, however, they later make new communications behind the maxillary processes, an indication of the anterior and posterior nares being thus produced.

Occasionally the maxillary and globular processes fail to unite on one or both sides, producing a condition popularly known as "harelip."

At the time when this fusion occurs the nasal fossæ are widely separated by the broad nasal process (Fig. 63), but during later development this process narrows to form the nasal septum and is gradually elevated above the general surface of the face as shown in Figs. 58-6o. By the narrowing of the nasal process the globular processes are brought nearer together and form the portions of the upper jaw immediately on each side of the median line, the rest of the jaw being formed by the maxillary processes. In the meantime a furrow has appeared upon the mandibular process, running parallel with its borders (Fig. 59); the portion of the process in front of this furrow gives rise to the lower lip and is known as the lip ridge, while the portion behind the furrow becomes the lower jaw proper and is termed the chin ridge.

The Development of the Limbs.-As has been already pointed out, the limbs make their appearance in an embryo measuring about $4 \mathrm{~mm}$. in length (Fig. 54) and are at first bud-like in form. As they increase in length they at first have their long axes directed parallel to the longitudinal axis of the body and become somewhat flattened at their free ends, remaining cylindrical in their proximal portions. A furrow or constriction appears at the junction of the flattened and cylindrical portions (Fig. 57), and later a second constriction divides the cylindrical portion into a proximal and distal moiety, the three segments of each limb - the arm, forearm, and hand in the upper limb, and the thigh, leg, and foot in the lower-being thus marked out. The digits are first indicated by the development of four radiating shallow grooves upon the hand and foot regions (Fig. 58), 
and a transverse furrow uniting the proximal ends of the digital furrows indicates the junction of the digital and palmar regions of the hand or of the toes and body of the foot. After this stage is reached the development of the upper limb proceeds more rapidly than that of the lower, although the processes are essentially the same in both limbs. The digits begin to project slightly, but are at first to a very considerable extent united together by a web, whose further growth, however, does not keep pace with that of the digits, these thus coming to project more and more in later stages. Even in comparatively early stages the thumb, and to a somewhat slighter extent the great toe, is widely separated from the second digit (Figs. 59 and 60).

While these changes have been taking place the entire limbs have altered their position with reference to the axis of the body, being in stages later than that shown in Fig. 57 directed ventrally so that their longitudinal axes are at right angles to that of the body. From the figures of later stages it may be seen that it is the thumb (radial) side of the arm and the great toe (tibial) side of the leg which are directed forward; the plantar and palmar surfaces of the feet and hands are turned toward the body and the elbow is directed outward and slightly backward, while the knee looks outward and slightly forward. It seems proper to conclude that the radial side of the arm is homologous with the tibial side of the leg, the palmar surface of the hand with the plantar surface of the foot, and the elbow with the knee.

The limbs are, however, still in the quadrupedal condition, and they must later undergo a second alteration in position so that their long axes again become parallel with that of the body. This is accomplished by a rotation of the limbs around axes passing through the shoulders and hip-joints, together with a rotation about their longitudinal axes through an angle of 90 degrees. This axial rotation of the upper limb is, however, in exactly the opposite direction to that of the lower limb of the corresponding side, so that the homologous surfaces of the two limbs have entirely different relations, the radial side of the arm, for instance, being the outer side while the tibial side 
of the leg is the inner side, and whereas the palmar surface of the hand looks ventrally, the plantar surface of the foot looks dorsally.

In making these statements no account is taken of the secondary position which the hand may assume as the result of its pronation; the positions given are those assumed by the limbs when both the bones of their middle segment are parallel to one another.

It may be pointed out that the prevalent use of the physiological terms flexor and extensor to describe the surfaces of the limbs has a tendency to obscure their true morphological relationships. Thus if, as is usual, the dorsal surface of the arm be termed its extensor surface, then the same term should be applied to the entire ventral surface of the leg, and all movements of the lower limb ventrally should be spoken of as movements of extension and any movement dorsally as movements of flexion. And yet a ventral movement of the thigh is generally spoken of as a flexion of the hip-joint, while a straightening out of the foot upon the leg-that is to say, a movement of it dorsally -is termed its extension.

The Age of the Embryo at Different Stages.-The age of an embryo must be dated from the moment of fertilization and from what has been said in preceding pages (pp. 27,34) it is evident that it must be difficult to determine the exact date of this event from that of the cessation of the menses, or even when the date of the coition that resulted in pregnancy is known. And, furthermore, not only is the actual date of the beginning of development uncertain, but in the majority of known early human embryos the time of the cessation of development is also more or less uncertain, since so many of these embryos are abortions and their expulsion need not necessarily have immediately succeeded their death.

These various sources of uncertainty are of especial importance in the cases of embryos in the early stages of development, when a day more or less means much, and it seems probable that many of the estimated ages given for young embryos, based on the date of the last menstruation, are too low. This certainly is the case with the ages assigned to such embryos by His, who estimated embryos of 2.2 to $3.0 \mathrm{~mm}$. to be two to two and one-half weeks old, those of 5.0 to $6.0 \mathrm{~mm}$. to be about three and one-half weeks and those of ro.o to II.O $\mathrm{mm}$. to be about four and one-half weeks. 
There are on record, however, a few cases in which the date of the fruitful coition is definitely known, and from these, few though they be, somewhat more definite information may be obtained. Thus it is fairly certain that the Bryce-Teacher ovum, with an embryo measuring about $0.15 \mathrm{~mm}$. in length, was the result of a coition which took place sixteen days before the ovum was aborted, and one cannot be far astray in assuming the embryo to be about two weeks old. Similarly, an embryo described by Eternod and measuring I. $3 \mathrm{~mm}$. in length was the result of a single coition occurring twentyone days previously and its age may be set at approximately three weeks or better at eighteen or nineteen days. A later embryo in which the nape bend and the coiling of the body had appeared and which measured $8.8 \mathrm{~mm}$. in vertex-breech length, resulted from a single coitus that took place thirty-eight days before the abortion, so that the embryo may be regarded as having been somewhat more than five weeks old. These and two other similar cases may be combined into a table thus:

\begin{tabular}{|c|c|c|c|}
\hline $\begin{array}{l}\text { Length of embryo } \\
\text { in } \mathrm{mm} \text {. }\end{array}$ & $\begin{array}{c}\text { Days intervening } \\
\text { between coition } \\
\text { and abortion }\end{array}$ & $\begin{array}{c}\text { Probable age in } \\
\text { days }\end{array}$ & Authority \\
\hline 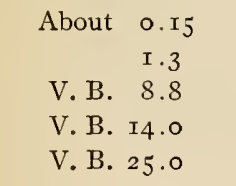 & $\begin{array}{l}I 6 \frac{1}{2} \\
2 \mathrm{I} \\
38 \\
47 \\
56\end{array}$ & $\begin{array}{l}\text { I3-I4 } \\
\text { I } 8-\mathrm{I9} \\
37 \\
44-45 \\
53-54\end{array}$ & $\begin{array}{l}\text { Bryce-Teacher. } \\
\text { Eternod } \\
\text { Tandler. } \\
\text { Rabl. } \\
\text { Mall. }\end{array}$ \\
\hline
\end{tabular}

If, on the basis of these figures, one may venture to estimate the age of embryos of other lengths those of 2.0 to $3.0 \mathrm{~mm}$. may be supposed to belong to the fourth week of development, those of 5.0 to 6.0 vertex-breech length to the latter part of the fifth week, those of ro.0 mm. to the end of the sixth week and those of 25.0 to 28.0 $\mathrm{mm}$. which are just passing into the fetus stage, to the end of the eighth week. As regards the later periods of development, the 
limits of error for any date become of less importance. Schröder gives the following measurements as the average:

$3 \mathrm{~d}$ lunar month.................... $70-90 \mathrm{~mm}$.

4 th lunar month.................... 100-170 mm.

$5^{\text {th }}$ lunar month..................... I80-270 mm.

6 th lunar month..................... $280-340 \mathrm{~mm}$.

7 th lunar month............................ $350-380 \mathrm{~mm}$.

8 th lunar month................... $\quad 425 \mathrm{~mm}$.

9 th lunar month.................... $467 \mathrm{~mm}$.

roth lunar month................... 490-500 mm.

The data concerning the weight of embryos of different ages are as yet very insufficient, and it is well known that the weights of newborn children may vary greatly, the authenticated extremes being, according to Vierordt, 7 77 grams and 6123 grams. It is probable that considerable variations in weight occur also during fetal life. So far as embryos of the first two months are concerned, the data are too imperfect for tabulation; for later periods Fehling gives the following as average weights:

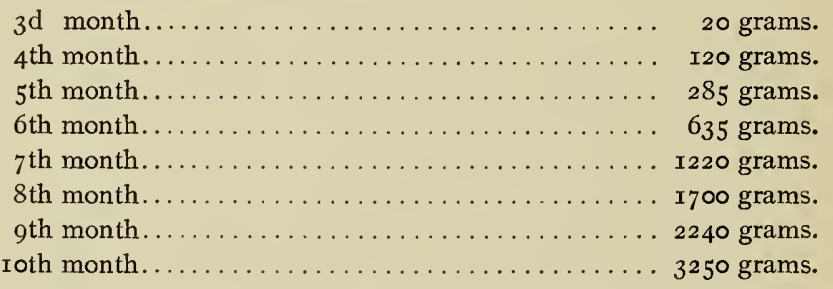

and the results obtained by Jackson are essentially similar.

\section{LITERATURE.}

In addition to the papers of Bryce and Teacher, Eternod, Fetzer, Frassi, Herzog, Peters, Von Spee and Strahl and Beneke cited in the preceding chapter, the following may be mentioned:

Bremer: "Description of a 4 mm. Human Embryo," Amer. Journ. Anat., v, 1906. J. Broman: "Beobachtung eines menschlichen Embryos von beinahe $3 \mathrm{~mm}$. Länge mit specieller Bemerkung über die bei demselben befindlichen Hirnfalten," Morpholog. Arbeiten, v, I895.

A. J. P. van den Broek: "Zur Kasuistik junger menschlicher Embryonen," Anat. Hefte, XLIV, IgII. 
J. M. Coste: "Histoire générale et particulière du développement des corps organisés," Paris, $\mathrm{rS} 47-\mathrm{I} 859$.

W. E. Dandy: "A Human Embryo with Seven Pairs of Somites, Measuring about $2 \mathrm{~mm}$. in Length," Amer. Journ. Anat., x, rgio.

A. ECKER: "Beiträge zur Kenntniss der äusserer Formen jüngster menschlichen Embryonen," Archiv für Anat. und Physiol., Anat. Abth., r88o.

C. ELzE: "Beschreibung eines menschlichen Embryos von zirka $7 \mathrm{~mm}$. grösster Lange," Anat. Hefte, xxxv, I907.

C. Giacomins: "Un œuf humain de ir jours," Archives Ital. de Biologie, xxix, r8g8.

V. Hensen: "Beitrag zur Morphologie der Körperform und des Gehirns des menschlichen Embryos," Archiv fiir Anat. und Physiol., Anat. Abth., I877.

W. His: "Anatomie menschlicher Embryonen," Leipzig, ISSo.

F. HochstetTER: "Bilder der äusseren Körperform einiger menschlicher Embryonen aus den beiden Ersten Monaten der Entwicklung," Munich, 1907.

N. W. Ingalls: "Beschreibung eines menschlichen Embryos von $4.9 \mathrm{~mm}$.," Arch. fïr mikr. Anat., Lxx, 1907.

C. M. JACKson: "On the Prenatal Growth of the Human Body and the Relative Growth of the Various Organs and Parts," Amer. Journ. Anat., IX, rgog.

J. JaNosıK: "Zwei junge menschliche Embryonen," Archiv für mikrosk. Anat., xxx, r887.

H. E JoRdan: "Description of a 5 mm. Human Embryo," Anat. Record, III, rgog.

P. JUNG: "Beiträge zur frühesten Ei-einbettung beim menschlichen Weibe," Berlin, rgo8.

F. KeIBel: "Ein sehr junges menschliches Ei," Archiv für Anat. und Physiol., Anat. Abth., I89o.

F. Keibel: "Ueber einen menschlichen Embryo von $6.8 \mathrm{~mm}$. grösster Länge," Verhandl. Anatom. Gesellsch., xIII, r899.

F. Keibel and C. Elze: "Normentafeln zur Entwicklungsgeschichte der Wirbeltiere," Heft viII, rgos.

J. Kollmann: "Die Körperform menschlicher normaler und pathologischer Embryonen," Archiv für Anat. und Physiol., Anat Abth., Supplement, I889.

A. Low: "Description of a Human Embryo of $\mathrm{r}_{3}-\mathrm{r}_{4}$ Mesodermic Somites," Journ. Anat. and Phys., xLIr, 1908.

F. P. Mall: "A Human Embryo Twenty-six Days Old," Journ. of Morphology, v, I8gr.

F. P. MALl: "A Human Embryo of the Second Week," Anat. Anzeiger, viII, I893.

F. P. MALL: "Early Human Embryos and the Mode of their Preservation," Bulletin of the Johns Hopkins Hospital, IV, IS94.

C. S. Minot: "Human Embryology," New York, 1892.

J. MüLlLer: "Zergliederungen menschlicher Embryonen aus früherer Zeit," Archiv für Anat. und Physiol., I830.

C. Phisalix: "Etude d'un Embryon humain de Ir millimeters," Archives de zoolog. experimentale et gênérale, Sér. 2, vi, I888.

H. PIPER: "Ein menschlicher Embryo von $6.8 \mathrm{~mm}$. Nackenlinie," Archiv fïr Anat. und Physiol., Anat. Abth., I8g8. 
C. RaBl: "Die Entwicklung des Gesichtes, Heft I, Das Gesicht der Säugetiere, Leipzig, r9o2.

G. REtzios: "Zur Kenntniss der Entwicklung der Körperformen des Menschen während der fötalen Lebensstufen," Biolog. Untersuch., XI, I904.

J. TANdLer: "Ueber einen menschlichen Embryo von 38 Tage," Anat. Anzeiger, $\mathrm{XXXI}, 1907$.

Alden THOMPSON: "Contributions to the History of the Structure of the Human Ovum and Embryo before the Third Week after Conception, with a Description of Some Early Ova," Edinburgh Med. and Surg. Journal, III, I839. (See also Froriep's Neue Notizen, xIII, I840.)

P. Thompson: "Description of a human embryo of twenty-three paired somites," Journ. Anat. and Phys., XLI, I907. 


\section{CHAPTER V.}

\section{THE YOLK-STALK, BELLY-STALK, AND FETAL MEMBRANES.}

The conditions to which the embryos and larvæ of the majority of animals must adapt themselves are so different from those under which the adult organisms exist that in the early stages of development special organs are very frequently developed which are of use only during the embryonic or larval period and are discarded when more advanced stages of development have been reached. This remark applies with especial force to the human embryo which leads for a period of nine months what may be termed a parasitic existence, drawing its nutrition from and yielding up its waste products to the blood of the parent. In-order that this may be accomplished certain special organs are developed by the embryo, by means of which it forms an intimate connection with the walls of the uterus, which, on its part, becomes greatly modified, the combination of embryonic and maternal structures producing what are termed the deciduce, owing to their being discarded at birth when the parasitic mode of life is given up.

Furthermore, it has already been seen that many peculiar modifications of development in the human embryo result from the inheritance of structures from more or less remote ancestors, and among the embryonic adnexes are found structures which represent in a more or less modified condition organs of considerable functional importance in lower forms. Such structures are the yolk-stalk and vesicle, the amnion, and the allantois, and for their proper understanding it will be well to consider briefly their development in some lower form, such as the chick.

At the time when the embryo of the chick begins to be constricted off from the surface of the large yolk-mass, a fold, consisting 
of ectoderm and somatic mesoderm, arises just outside the embryonic area, which it completely surrounds. As development proceeds the fold becomes higher and its edges gradually draw nearer together over the dorsal surface of the embryo (Fig. 64, A, Af), and finally meet and fuse (Fig. 64, B and C), so that the embryo becomes enclosed within a sac, which is termed the amnion and is formed by the fusion of the layers which constituted the inner wall of the fold. The layers of the outer wall of the fold after fusion form part of the
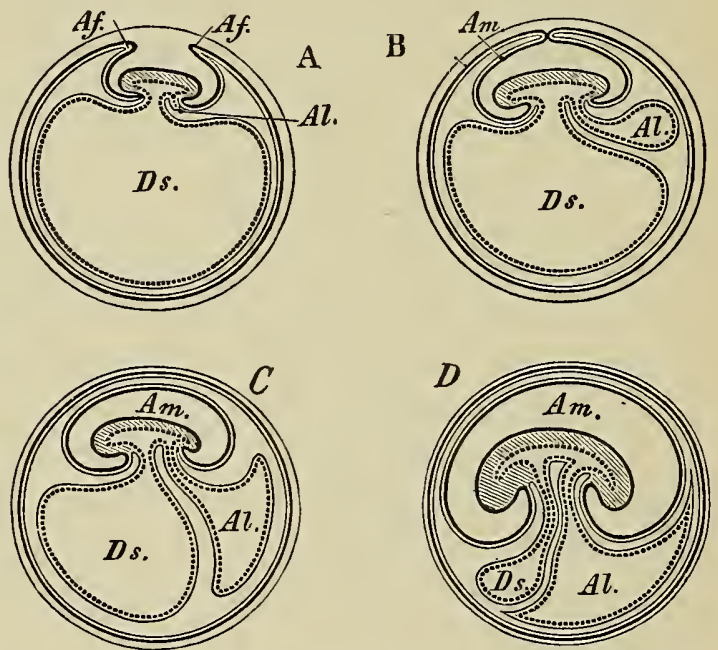

Fig. 64.-Diagrams Illustrating the Formation of the Amnion and Allantois IN THE CHICK.

$A f$, Amnion folds; $A l$, allantois; $A m$, amniotic cavity; $D s$, yolk-sac.-(Gegenbaur.)

general ectoderm and somatic mesoderm which make up the outer wall of the ovum and together are known as the serosa, corresponding to the chorion of the mammalian embryo. The space which occurs between the amnion and the serosa is a portion of the extraembryonic cœlom and is continuous with the embryonic pleuroperitoneal cavity.

In the ovum of the chick, as in that of the reptile, the protoplasmic material is limited to one pole and rests upon the large yolk- 
mass. As development proceeds the germ layers gradually extend around the yolk-mass and eventually completely enclose it, the yolkmass coming to lie within the endodermal layer, which, together with the splanchnic mesoderm which lines it, forms what is termed the yolk-sac. As the embryo separates from the yolk-mass the yolksac is constricted in its proximal portion and so differentiated into a yolk-stalk and a yolk-sac, the contents of the latter being gradually absorbed by the embryo during its growth, its walls and those of the stalk being converted into a portion of the embryonic digestive tract.

In the meantime, however, from the posterior portion of the digestive tract, behind the point of attachment of the yolk-sac, a diverticulum has begun to form (Fig. 64, A, Al). This increases in size, projecting into the extra-embryonic portion of the pleuroperitoneal cavity and pushing before it the splanchnic mesoderm which lines the endoderm (Fig. 64, B and C). This is the allantois, which, reaching a very considerable size in the chick and applying itself closely to the inside of the serosa, serves as a respiratory and excretory organ for the embryo, for which purpose its walls are richly supplied with blood-vessels, the allantoic arteries and veins.

Toward the end of the incubation period both the amnion and allantois begin to undergo retrogressive changes, and just before the hatching of the young chick they become completely dried up and closely adberent to the egg-shell, at the same time separating from their point of attachment to the body of the young chick, so that when the chick leaves the egg-shell it bursts through the driedup membranes and leaves them behind as useless structures.

The Amnion.--Turning now to the human embryo, it will be found that the same organs are present, though somewhat modified either in the mode or the extent of their development. A welldeveloped amnion occurs, arising, however, in a very different manner from what it does in the chick; a large yolk-sac occurs even though it contains no yolk; and an allantois which has no respiratory or excretory functions is present, though in a somewhat degenerated condition. It has been seen from the description of the earliest stages of development that the processes which occur in the lowe 
forms are greatly abbreviated in the human embryo. The enveloping layer, instead of gradually extending from one pole to enclose the entire ovum, develops in situ during the stages immediately succeeding segmentation, and the extra-embryonic mesoderm, instead of growing out from the embryo to enclose the yolk-sac, splits off directly from the enveloping layer. The earliest stages in the development of the amnion are not yet known for the human embryo, but from the condition in which it is found in the Peters embryo (Fig. 37) and in the embryo v.H. of von Spee (Fig. 39) it is probable that it arises, not by the fusion of the edges of a fold, as in the chick, but by a vacuolization of a portion of the inner cellmass, as has been described as occurring in the bat (p. 54). It is, then, a closed cavity from the very beginning, the floor of the cavity being formed by the embryonic disk, its posterior wall by the anterior surface of the belly-stalk, while its roof and sides are thin and composed of a single layer of flattened ectodermal cells lined on the outside by a layer of mesoderm continuous with the somatic mesoderm of the embryo and the mesoderm of the belly-stalk (Fig. 65, A).

When the bending downward of the peripheral portions of the embryonic disk to close in the ventral surface of the embryo occurs, the line of attachment of the amnion to the disk is also carried ventrally (Fig. 65, B), so that when the constriction off of the embryo is practically completed, the amnion is attached anteriorly to the margin of the umbilicus and posteriorly to the extremity of the band of ectoderm lining what may now be considered the posterior surface of the belly-stalk, while at the sides it is attached along an oblique line joining these two points (Fig. $65, \mathrm{~B}$ and $\mathrm{C}$, in which the attachment of the amnion is indicated by the broken line).

Leaving aside for the present the changes which occur in the attachment of the amnion to the embryo (see p. II6), it may be said that during the later growth of the embryo the amniotic cavity increases in size until finally its wall comes into contact with the chorion, the extra-embryonic body-cavity being thus practically obliterated (Fig. 65, D), though no actual fusion of amnion and 
chorion occurs. Suspended by the umbilical cord, which has by this time developed, the embryo floats freely in the amniotic cavity, which is filled by a fluid, the liquor amnii, whose origin is involved in doubt, some authors maintaining that it infiltrates into the cavity from the maternal tissues, while others hold that a certain amount
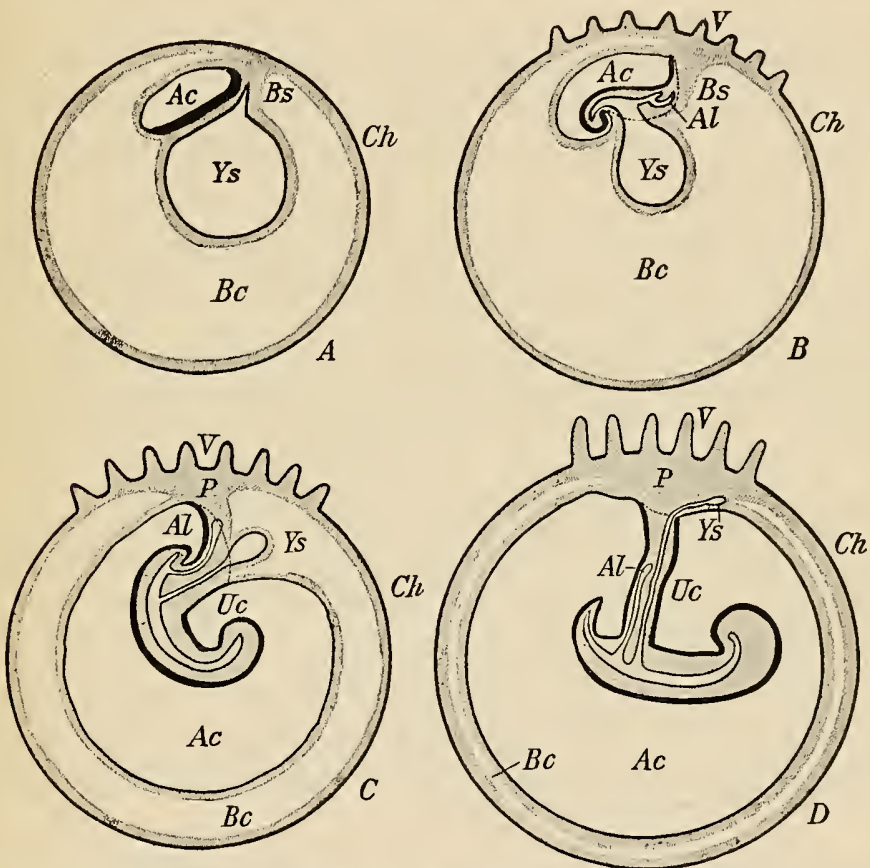

Fig. 65.-Diagrams Illustrating the Formation of the Umbilical Cord.

The heavy black line represents the embryonic ectoderm; the dotted line represents the line of reflexion of the body ectoderm into that of the amnion. Ac, Amniotic cavity; $A l$, allantois; $B c$, extra-embryonic coelom; $B s$, belly-stalk; $C h$, chorion; $P$, placenta; $U c$, umbilical cord; $V$, chorionic villi; $Y s$, yolk-sac.

of it at least is derived from the embryo. It is a fluid with a specific gravity of about $\mathrm{I} .003$ and contains about I per cent. of solids, principally albumin, grape-sugar, and urea, the last constituent probably coming from the embryo. When present in greatest quantity - that is to say, at about the beginning of the last month 
of pregnancy-it varies in amount between one-half and threefourths of a liter, but during the last month it diminishes to about half that quantity. To protect the epidermis of the fetus from maceration during its prolonged immersion in the liquor amnii, the sebaceous glands of the skin at about the sixth month of development pour out upon the surface of the body a white fatty secretion known as the vernix caseosa.

During parturition the amnion, as a rule, ruptures as the result of the contraction of the uterine walls and the liquor amnii escapes as the "waters," a phenomenon which normally precedes the delivery of the child. As a rule, the rupture is sufficiently extensive to allow the passage of the child, the amnion remaining behind in the uterus, to be subsequently expelled along with the deciduæ.

Occasionally it happens, however, that the amnion is sufficiently strong to withstand the pressure exerted upon it by the uterine contractions and the child is born still enveloped in the amnion, which, in such cases, is popularly known as the "caul," the possession of which, according to an old superstition, marks the child as a favorite of fortune.

As stated above, the liquor amnii varies considerably in amount in different cases, and occasionally it may be present in excessive quantities, producing a condition known as hydramnios. On the other hand, the amount may fall considerably below the normal, in which case the amnion may form abnormal unions with the embryo, sometimes producing malformations. Occasionally also bands of a fibrous character traverse the amniotic cavity and, tightening upon the embryo during its growth, may produce various malformations, such as scars, splitting of the eyelids or lips, or even amputation of a limb.

The Yolk-sac.-The probable mode of development of the yolk-sac in the human embryo, and its differentiation into yolk-stalk and yolk-vesicle have already been described (p. 86). When these changes have been completed, the vesicle is a small pyriform structure lying between the amnion and the chorionic mesoderm, some distance away from the extremity of the umbilical cord (Fig. 65, D), and the stalk is a long slender column of cells extending from the vesicle through the umbilical cord to unite with the intestinal tract of the embryo. The vesicle persists until birth and may be found among the decidual tissues as a small sac measuring from 3 to 
Io $\mathrm{mm}$. in its longest diameter. The stalk, however, early undergoes degeneration, the lumen which it at first contains becoming obliterated and its endoderm also disappearing as early as the end of the second month of development. The portion of the stalk which extends from the umbilicus to the intestine usually shares in the degeneration and disappears, but in about 3 per cent. of cases it persists, forming a more or less extensive diverticulum of the lower part of the small intestine, sometimes only half an inch or so in length and sometimes much larger. It may or may not retain connection with the abdominal wall at the umbilicus, and is known as Meckel's diverticulum.

This embryonic rudiment is of no little importance, since, when present, it is apt to undergo invagination into the lumen of the small intestine and so occlude it. How frequently this happens relatively to the occurrence of the diverticulum may be judged from the fact that out of one hundred cases of occlusion of the small intestine six were due to an invagination of the diverticulum.

In the reptiles and birds the yolk-sac is abundantly supplied with blood-vessels by means of which the absorption of the yolk is carried on, and even although the functional importance of the yolk-sac as an organ of nutrition is almost nil in the human embryo, yet it still retains a well-developed blood-supply, the walls of the vesicle, especially possessing a rich network of vessels. The future history of these vessels, which are known as the vitelline vessels, will be described later on.

The Allantois and Belly-stalk.-It has been seen that in reptilian and avian embryos the allantois reaches a high degree of development and functions as a respiratory and excretory organ by coming into contact with what is comparable to the chorion of the mammalian embryo. In man it is very much modified both in its mode of development and in its relations to other parts, so that its resemblance to the avian organ is somewhat obscured. The differences depend partly upon the remarkable abbreviation manifested in the early development of the human embryo and partly upon the fact that the allantois serves to place the embryo in relation with the 
maternal blood, instead of with the external atmosphere, as is the case in the egg-laying forms. Thus, the endodermal portion of the allantois, instead of arising from the intestine and pushing before it a layer of splanchnic mesoderm to form a large sac lying freely in the extra-embryonic portion of the body-cavity, appears in the human embryo before the intestine has differentiated from the yolk-sac and pushes its way into the solid mass of mesoderm which forms the belly-stalk (Fig. 65, A). To understand the significance of this process it is necessary to recall the abbreviation in the human embryo of the development of the extra-embryonic mesoderm and body-cavity. Instead of growing out from the embryonic area, as it does in the lower forms, this mesoderm develops in situ by splitting off from the layer of enveloping cells and, furthermore, the extra-embryonic

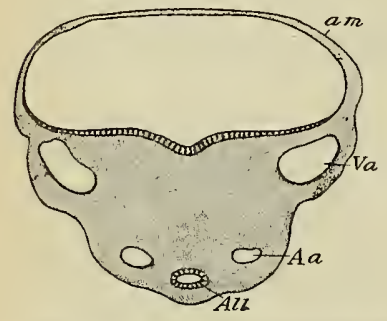

Fig. 66.-Transverse SecTION THROUGH THE BELLY-STALK OF AN EMBRRYO OF 2.I5 MM.

$A a$, Umbilical (allantoic) artery; All, allantois; am, amnion; $V a$, umbilical (allantoic) vein.-(His.) body-cavity arises by a splitting of the mesoderm so formed before there is any trace of a splitting of the embryonic mesoderm (Fig. 38). The belly-stalk, whose development from a portion of the inner cell-mass has already been traced (p. 68), is to be regarded as a portion of the body of the embryo, since the ectoderm which covers one surface of it resembles exactly that of the embryonic disk and shows an extension backward of the medullary groove upon its surface (Fig. 66). The mesoderm, therefore, of the belly-stalk is to be regarded as a portion of the embryonic mesoderm which has not yet undergone a splitting into somatic and splanchnic layers, and, indeed, it never does undergo such a splitting, so that there is no body-cavity into which the endodermal allantoic diverticulum can grow.

But this does not account for all the peculiarities of the human allantois. In the birds, and indeed in the lower oviparous mammals, the endodermal portion of the allantois is equally developed with 
the mesodermal portion, the allantois being an extensive sac whose cavity is filled with fluid, and this is also true of such mammals as the marsupials, the rabbit, and the ruminants. In man, however, the endodermal diverticulum never becomes a sac-like structure, but is a slender tube extending from the intestine to the chorion and lying in the substance of the mesoderm of the belly-stalk (Fig. 65, D), the greater portion of which is to be regarded as homologous with the relatively thin layer of splanchnic mesoderm covering the endodermal diverticulum of the chick. An explanation of this disparity in the development of the mesodermal and endodermal portions of the human allantois is perhaps to be found in the altered conditions under which the respiration and secretion take place. In all forms, the lower as well as the higher, it is the mesoderm which is the more important constituent of the allantois, since in it the blood-vessels, upon whose presence the physiological functions depend, arise and are embedded. In the birds and oviparous mammals there are no means by which excreted material can be passed to the exterior of the ovum, and it is, therefore, stored up within the cavity of the allantois, the allantoic fluid containing considerable quantities of nitrogen, indicating the presence of urea. In the higher mammals the intimate relations which develop between the chorion and the uterine walls allow of the passage of excreted fluids into the maternal blood; and the more intimate these relations, the less necessity there is for an allantoic cavity in which excreted fluid may be stored up. The difference in the development of the cavity in the ruminants, for example, and man depends probably upon the greater intimacy of the union between ovum and uterus in the latter, the arrangement for the passage of the excreted material into the maternal blood being so perfect that there is practically no need for the development of an allantoic cavity.

The portion of the endodermal diverticulum which is enclosed within the umbilical cord persists until birth in a more or less rudimentary condition, but the intra-embryonic portion extending from the apex of the bladder to the umbilicus becomes converted into a solid cord of fibrous tissue termed the urachus. 
Occasionally a lumen persists in the urachal portion of the allantois and may open to the exterior at the umbilicus, in which case urine from the bladder may escape at the umbilicus.

Since the allantois in the human embryo, as well as in the lower forms, is responsible for respiration and excretion, its blood-vessels are well developed. They are represented in the belly-stalk by two veins and two arteries (Fig. 66), known in human embryology as the umbilical veins and arteries. These extend from the body of the embryo out to the chorion, there branching repeatedly to enter the numerous chorionic villi by which the embryonic tissues are placed in relation with the maternal.

The Umbilical Cord.-During the process of closing in of the ventral surface of the embryo a stage is reached in which the embryonic and extra-embryonic portions of the body-cavity are completely separated except for a small area, the umbilicus, through which the yolk-stalk passes out (Fig. 65, B). At the edges of this area in front and at the sides the embryonic ectoderm and somatic mesoderm become continuous with the corresponding layers of the amnion, but posteriorly the line of attachment of the amnion passes up upon the sides of the belly-stalk (Fig. ${ }_{5}, \mathrm{~B}$ ), so that the whole of the ventral surface of the stalk is entirely uncovered by ectoderm, this layer being limited to its dorsal surface (Fig. 66). In subsequent stages the embryonic ectoderm and somatic mesoderm at the edges of the umbilicus grow out ventrally, carrying with them the line of attachment of the amnion and forming a tube which encloses the proximal part of the yolk-stalk. The ectoderm of the belly-stalk at the same time extending more laterally, the condition represented in Fig. $6_{5}, \mathrm{C}$, is produced, and, these processes continuing, the entire belly-stalk, together with the yolk-stalk, becomes enclosed within a cylindrical cord extending from the ventral surface of the body to the chorion and forming the umbilical cord (Fig. 65, D).

From this mode of development it is evident that the cord is, strictly speaking, a portion of the embryo, its surfaces being completely covered by embryonic ectoderm, the amnion being carried 

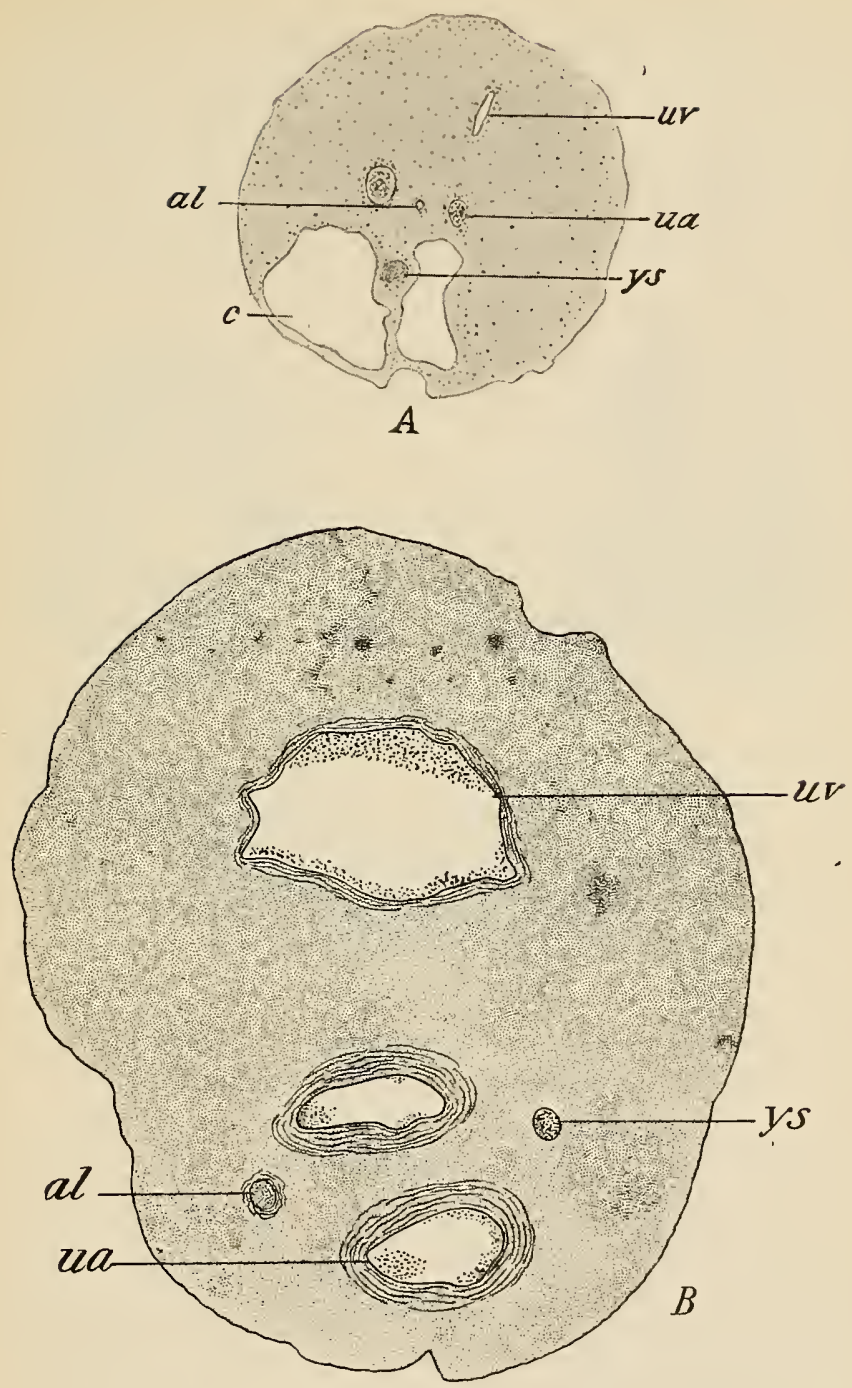

Fig. 67.-Transverse Sections of the Umbilical Cord of Embryos of $(A)$ i. 8 car. AND $(B) 25$ CM.

$a l$, Allantois; $c$, cœlom; $u a$, umbilical artery; $u v$, umbilical vein; $y s$, yolk-stalk. 
during its formation further and further from the umbilicus until finally it is attached around the distal extremity of the cord.

In enclosing the yolk-stalk the umbilical cord encloses also a small portion of what was originally the extra-embryonic bodycavity surrounding the yolk-stalk. A section of the cord in an early stage of its development (Fig. 67, A) will show a thick mass of mesoderm occupying its dorsal region; this represents the mesoderm of the belly-stalk and contains the allantois and the umbilical arteries and vein (the two veins originally present in the belly-stalk having fused), while toward the ventral surface there will be seen a distinct cavity in which lies the yolk-stalk with its accompanying blood-vessels. The portion of this cœlom nearest the body of the embryo becomes much enlarged, and during the second month of development contains some coils of the small intestine, but later the entire cavity becomes more and more encroached upon by the growth of the mesoderm, and at about the fourth month is entirely obliterated. A section of the cord subsequent to that period of development will show a solid mass of mesoderm in which are embedded the umbilical arteries and vein, the allantois, and the rudiments of the yolk-stalk (Fig. $67, \mathrm{~B}$ ).

When fully formed, the umbilical cord measures on the average $55 \mathrm{~cm}$. in length, though it varies considerably in different cases, and has a diameter of about $1.5 \mathrm{~cm}$. It presents the appearance of being spirally twisted, an appearance largely due, however, to the spiral course pursued by the umbilical arteries, though the entire cord may undergo a certain amount of torsion from the movements of the embryo in the later stages of development and may even be knotted. The greater part of its substance is formed by the mesoderm, the cells of which become stellate and form a recticulum, the meshes of which are occupied by connective-tissue fibrils and a mucous fluid which gives to the tissue a jelly-like consistence, whence it has received the name of Wharton's jelly.

The Chorion.-To understand the developmental changes which the chorion undergoes it will be of advantage to obtain some insight into the manner in which the ovum becomes implanted in 
the wall of the uterus. Nothing is known as to how this implantation is effected in the case of the human ovum; it has already been accomplished in the youngest ovum at present known. But the process has been observed in other mammals, and what takes place in Spermophilus, for example, may be supposed to give a clue to what occurs in the human ovum. In the spermophile the ovum lies free in the uterine cavity up to a stage at which the vacuolization
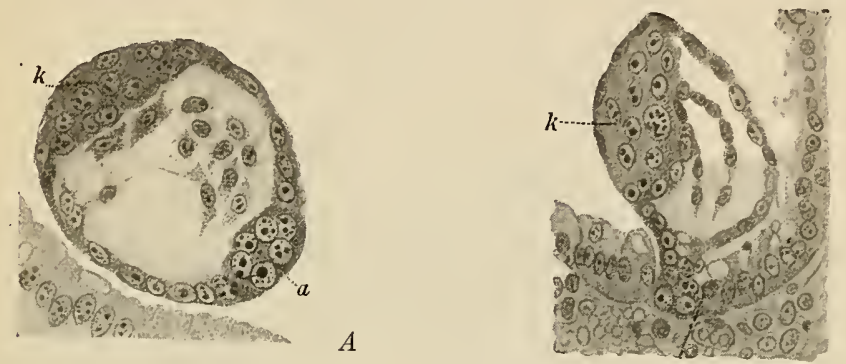

$B$

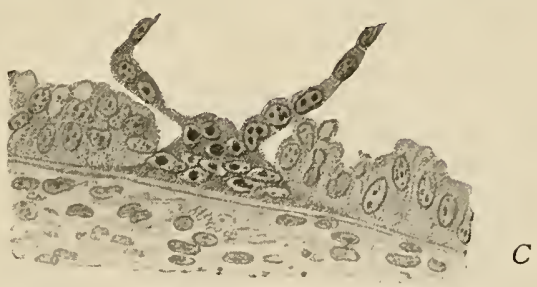

Fig. 68.-Successive Stages in the Implantation of the Ovum of the Spermophile. $a$, syncytial knob; $k$, inner cell-mass.-(Rejsek.)

of the central cells is almost completed (Fig. 68, A). At one region of the covering layer the cells become thicker and later form a syncytial projection or knob which comes into contact with the uterine mucosa (Fig. 68, B), and at the point of contact the mucosa cells undergo degeneration, allowing the knob to come into relation with the deeper tissues of the uterus (Fig. 68, C), the process apparently being one in which the mucosa cells are eroded by the syncytial knob.

It seems probable that in the human ovum the process is at first of a similar nature and that as the covering layer cells come into 

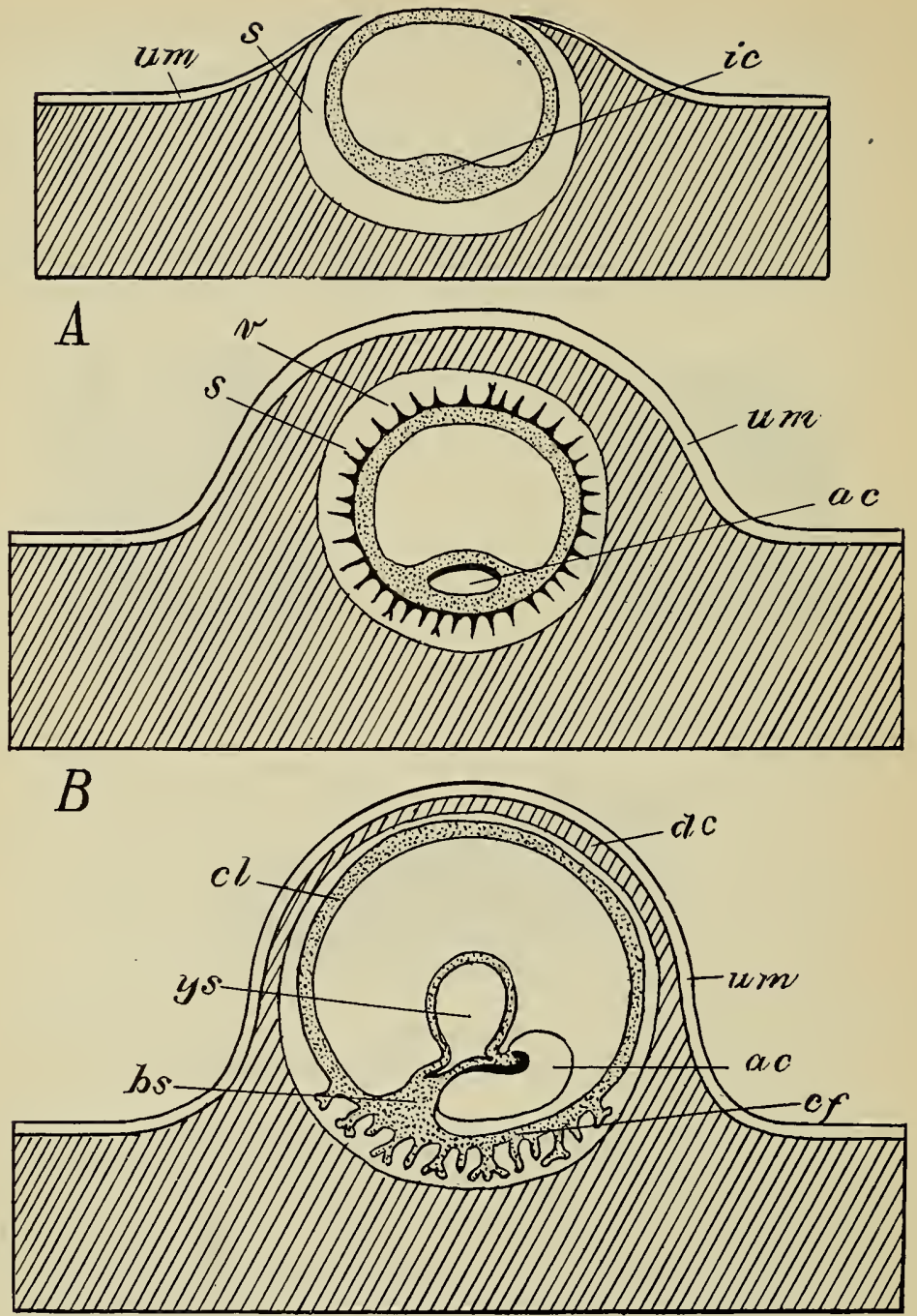

C

Fig. 69.-Diagrams Illustrating the Implantation of the Ovum.

$a c$, amniotic cavity; $b s$, belly-stalk; $c f$, chorion frondosum; $c l$, chorion læve; $d c$, decidua capsularis; $i c$, inner cell-mass; $s$, space surrounding ovum which becomes the intervillous space; $u m$, uterine mucosa; $v$, chorionic villus; $y s$, yolk-sac. 
contact with the deeper layers of the uterus, these too are eroded, and, the uterine blood-vessels being included in the erosion process, an extravasation of blood plasma and corpuscles occurs in the vicinity of the burrowing ovum. In the meantime the ovum has increased considerably in size, its growth in these early stages being especially rapid, and the area of contact consequently increases in size, entailing continued erosion of the uterine mucosa. At the same time, too, the uterine tissues surrounding the ovum grow up around it, forming at first as it were a circular wall (Fig. 69, A), and eventually com-

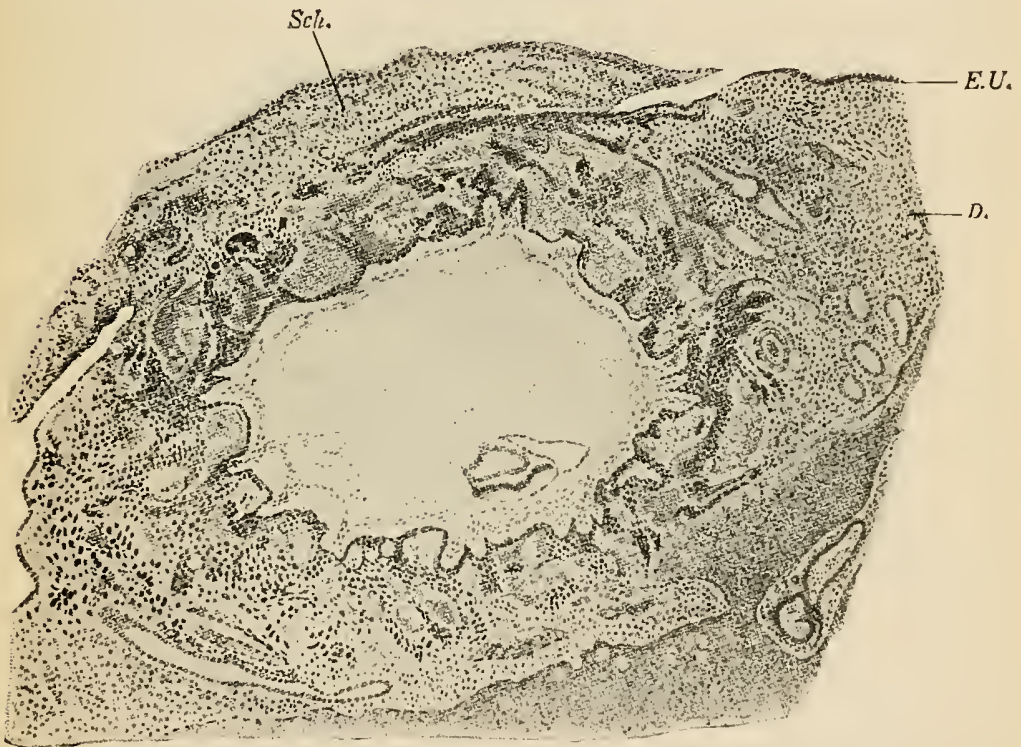

Fig. 70.-Section of an Ovum of i mm. A Section of the Embryo Lies in the Lower Part of the Cavity of The Ovum.

$D$, Decidua; E.U., uterine epithelium; Sch, blood-clot closing the aperture left by the sinking of the ovum into the uterine mucosa.-(From Strahl, after Peters.)

pletely enclose it, forming an envelope known as the decidua capsularis or reflexa. The blood extravasation is now contained within a closed space bounded on the one hand by the uterine tissues and on the other by the wall of the ovum (Fig. 69, B).

The youngest known human ova have already reached approxi- 
mately this stage. Thus, the Peters ovum (Fig. 70) had already sunk deeply into the uterine mucosa, the point of entrance being indicated by a gap in the decidua capsularis, closed in this case by a patch of coagulated blood $(S c h)$. The uterine tissues in the immediate vicinity of the ovum were much swollen and apparently somewhat necrotic and their blood-vessels could be seen to communicate with the space between the wall of the ovum and the maternal tissues. This space, however, was converted into an irregular network of blood lacunæ by anastomosing cords of cells, which arose from the wall of the ovum and extended through the space to the maternal tissues; these cords of cells are represented in Fig. 70 by the darker masses projecting from the wall of the ovum and scattered among the paler blood lacunæ. This stage of implantation of the ovum is shown diagrammatically in Fig. 69, B, where, for simplicity's sake, the cell cords are represented merely as processes radiating from the ovum without reaching the maternal tissues.

The cell cords are derivatives of the trophoblast and are, therefore, of embryonic origin. If examined under a higher magnification than that shown in Fig. 7o they will be seen to be composed of an axial core of cells with distinct outlines, enclosed within a layer of protoplasm which lacks all traces of cell boundaries, although it contains numerous nuclei, being what is termed a syncytium or plasmodium. The original trophoblast has thus become differentiated into two distinct tissues, a cellular one, which has been termed the cyto-trophoblast, and a plasmodial one, which, similarly, is known as the plasmodi-trophoblast and is the tissue that comes into contact with the maternal blood contained in the lacunar spaces and with the maternal tissues, in connection with these latter sometimes developing into masses of considerable extent. To this plasmoditrophoblast may be ascribed the active part in the destruction of the maternal tissues and probably also the absorption of the products of the destruction for the nutrition of the growing ovum. For up to this stage the ovum has been playing the rôle of a parasite thriving upon the tissues of its host.

The food material that the ovum thus obtains may conveniently 
be termed the embryotroph and the type of placentation which obtains up to this stage and for some time longer may be termed the embryotrophic type. But even in the Peters ovum the preparation for another type has begun. In earlier stages the cell cords were entirely trophoblastic, but in this ovum (Fig. 70) processes from the chorionic mesoderm may be seen projecting into the bases of the cell cords, and in later stages these processes extend farther and farther into the axis of each cord, the anastomoses of the cords disappear and the cords themselves become converted into branching processes, the

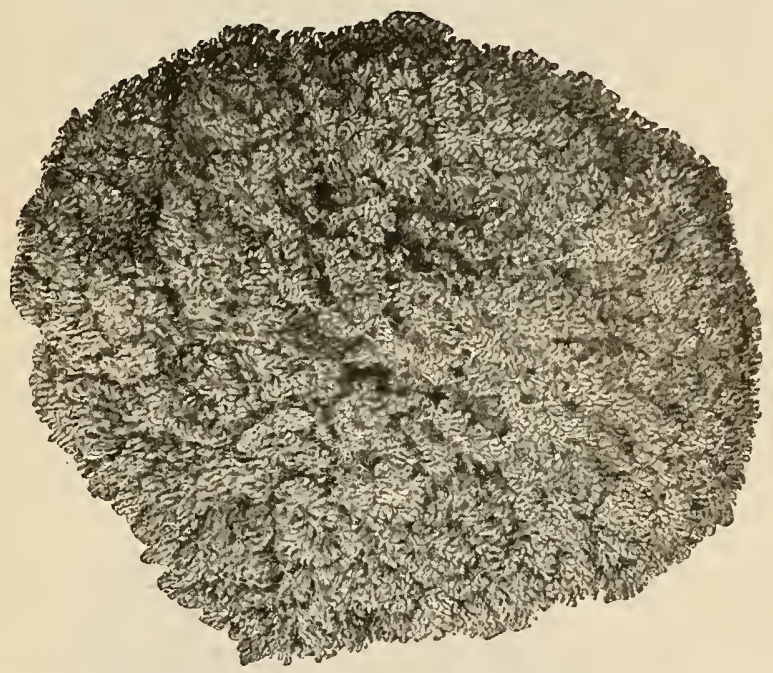

Fig. 71.-Entire Ovum Aborted at about the Beginning of the Second MoNTH. XI I/2.-(Grosser.)

chorionic villi, which project from the entire surface of the ovum (Fig. 7I) into the surrounding space, which may now be termed the intervillous space, and are bathed by the maternal blood which it contains. Toward the maternal surface of the space some masses of the trophoblast still persist, uniting the extremities of certain of the villi to the enclosing uterine wall, such villi being termed fixation villi to distinguish them from the majority, which project freely into the intervillous space. Later, when the embryonic blood-vessels 
develop, those associated with the allantois extend outward into the chorionic mesoderm and thence send branches into each villus. The second type of placentation; the hamotrophic type, is thus established, the fetal blood contained in the vessels of the villi receiving nutrition through the walls of the villi from the maternal blood contained in the intervillous space, and, similarly, transferring waste products to it.

At first, as stated above, the villi usually cover the entire surface of the ovum, but later, as the ovum increases in size, those villi which are remote from the attachment of the belly-stalk to the chorion are placed at a disadvantage so far as their blood supply is concerned

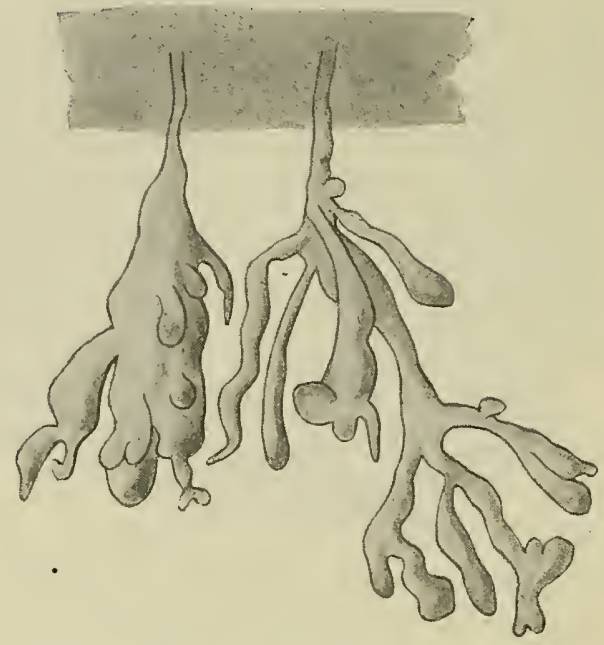

Fig. 72.-Two Villi from the Chorion of an Embryo of 7 MMr.

and gradually disappear, and this process continues until, finally, only those villi are retained which are in the immediate region of the belly-stalk (Fig. 69, C), these persisting to form the fetal portion of the placenta. By these changes the chorion becomes differentiated into two regions (Fig. 69, C), one of which is destitute of villi and is termed the chorion leve, while the other provided with them, is known as the chorion frondosum. 

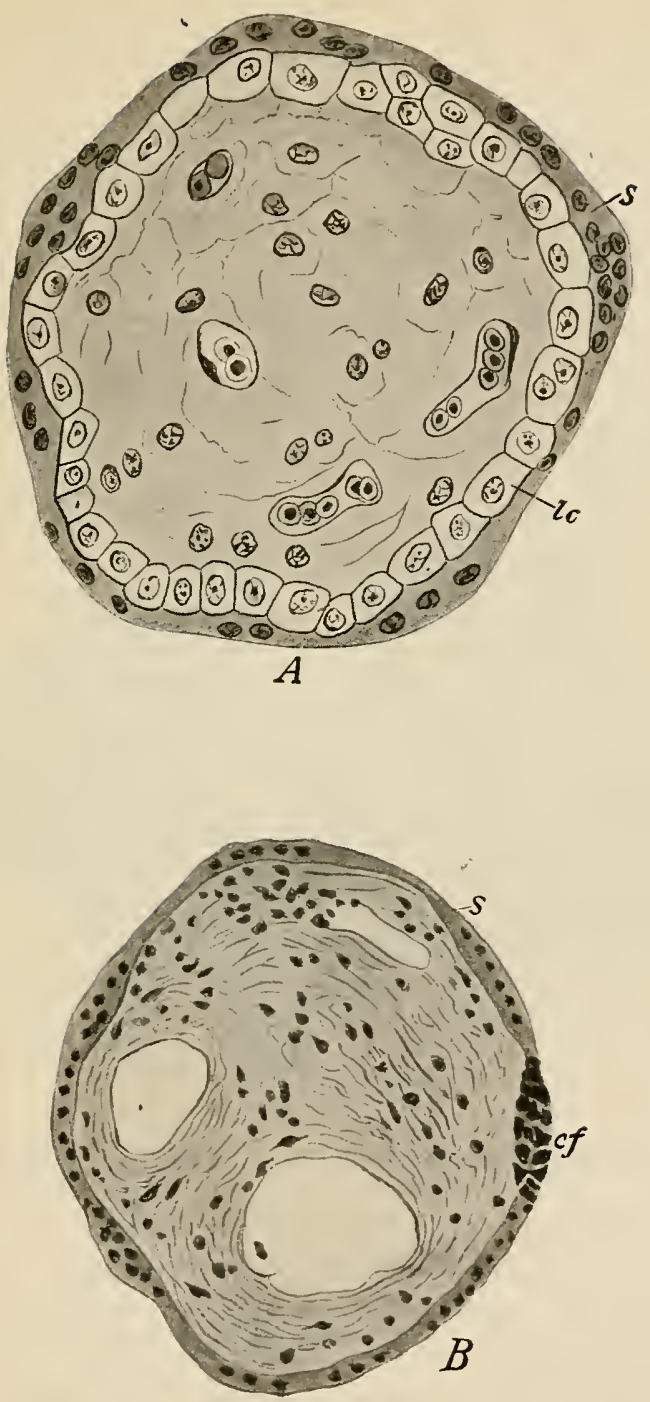

Fig. 73.-Transverse Sections through Chorionic Villi in $(A)$ the Fifth and (B) the Sevente Month of Developaent.

$c f$, Canalized fibrin; $l c$, Langhans cells; $s$, syncytium. - $(A$ which is more highly magnified than B, from Szymonowicz; B from Minot.) 
Occasionally one or more patches of villi may persist in the area that normally becomes the chorion læve and thus accessory placentce (placentce succenturiatce), varying in number and size, may be formed.

The villi when fully formed are processes of the chorion, branching profusely and irregularly (Fig. 72), and each consists of a core of mesoderm, containing blood-vessels, enclosed within a double layer of trophoblastic tissue (Fig. 73, A). The inner layer consists of a sheet of well defined cells arranged in a single series; it is derived from the cyto-trophoblast and forms what is known as the layer of Langhans cells. The outer layer is syncytial in structure and is formed from the plasmodi-trophoblast.

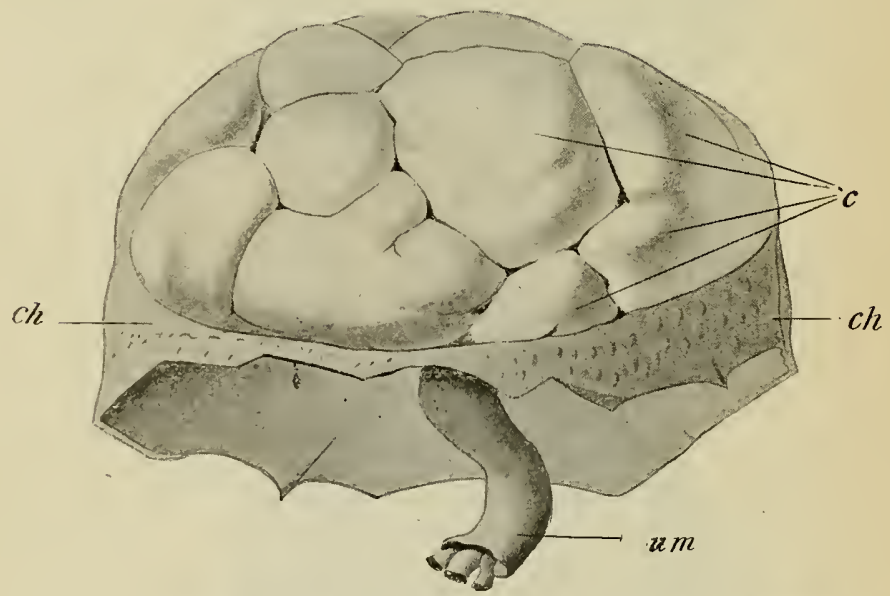

Fig. 74.-Mature Placenta after Separation from the Uterus. c, Cotyledons; ch, chorion, amnion, and decidua vera; um, umbilical cord.-(Kollmann.)

As development proceeds the villi, which are at first distributed evenly over the chorion frondosum, become separated into groups termed cotyledons (Fig. 74) by the growth into the intervillous space of trabeculæ from the walls of the uterus, the fixation villi becoming connected with these septa as well as with the general uterine wall. The ectoderm of the villi also undergoes certain changes with advancing growth, the layer of Langhans cells disappearing except in small areas scattered irregularly in the villi, and the syncytium, 
though persisting, undergoes local thickenings which become replaced, more or less extensively, by depositions of fibrin (Fig. $73, \mathrm{~B}, c f$ ).

The changes which occur during the later stages of development in the chorion are very similar to those described for the villi.

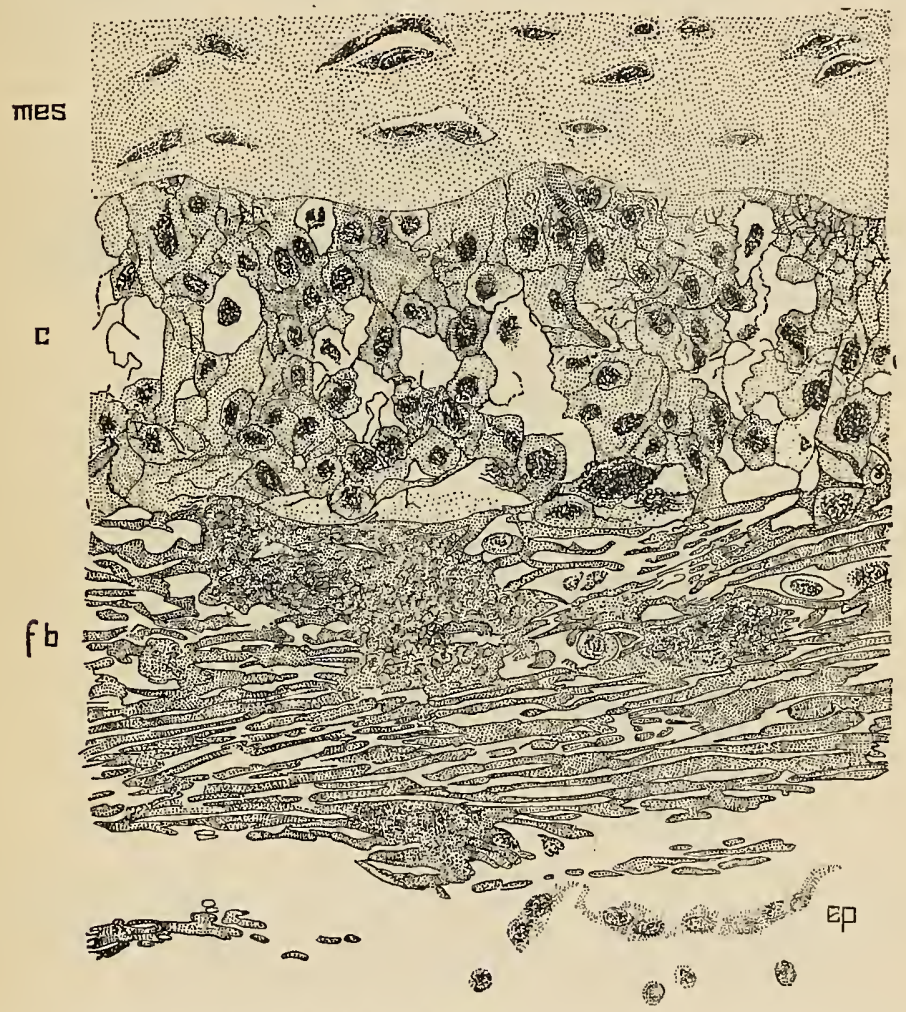

Fig. 75.-Section through the Placental Chorion of an Embryo of Seven MONTHS.

$c$, Cell layer; $e p$, remnants of epithelium; $f b$, fibrin layer; mes, mesoderm.-(Minot.)

Thus, the mesoderm thickens, its outermost layers becoming exceedingly fibrillar in structure, while the ectoderm differentiates into two layers, the outer of which is syncytial while the inner is cellular, and later still, as in the villi, the syncytial layer is replaced 
in irregular patches by a peculiar form of fibrin which is traversed by flattened anastomosing spaces and to which the name canalized fibrin or fibrinoid has been applied (Fig. 75).

The Deciduæ.-It has been pointed out (p. 26) that in connection with the phenomenon of menstruation periodic alterations occur in the mucous membrane of the uterus. If during one of these periods a fertilized ovum reaches the uterus, the desquamation

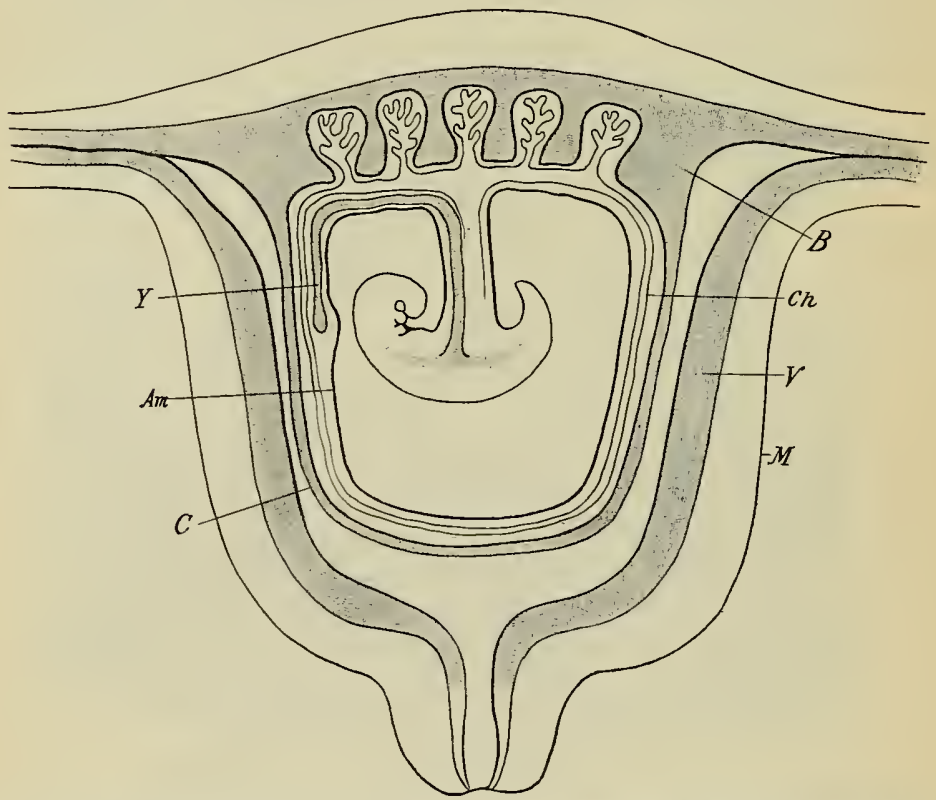

Fig. 76.-Diagram showing the Relations of the Fetal Membranes. $A m$, Amnion; $C h$, chorion; $M$, muscular wall of uterus; $C$, decidua capsularis; $B$, decidua basalis; $V$, decidua vera; $Y$, yolk-stalk.

of portions of the epithelium does not occur nor is there any appreciable hemorrhage into the cavity of the uterus; the uterine mucosa remains in what is practically the ante-menstrual condition until the conclusion of pregnancy, when, after the birth of the fetus, a considerable portion of its thickness is expelled from the uterus, forming what is termed the deciduce. In other words, the sloughing of the 
uterine tissue which concludes the process of menstruation is postponed until the close of pregnancy, and then takes place simultaneously over the whole extent of the uterus. Of course, the changes in the uterine tissues are somewhat more extensive during pregnancy than during menstruation, but there is an undoubted fundamental similarity in the changes during the two processes.

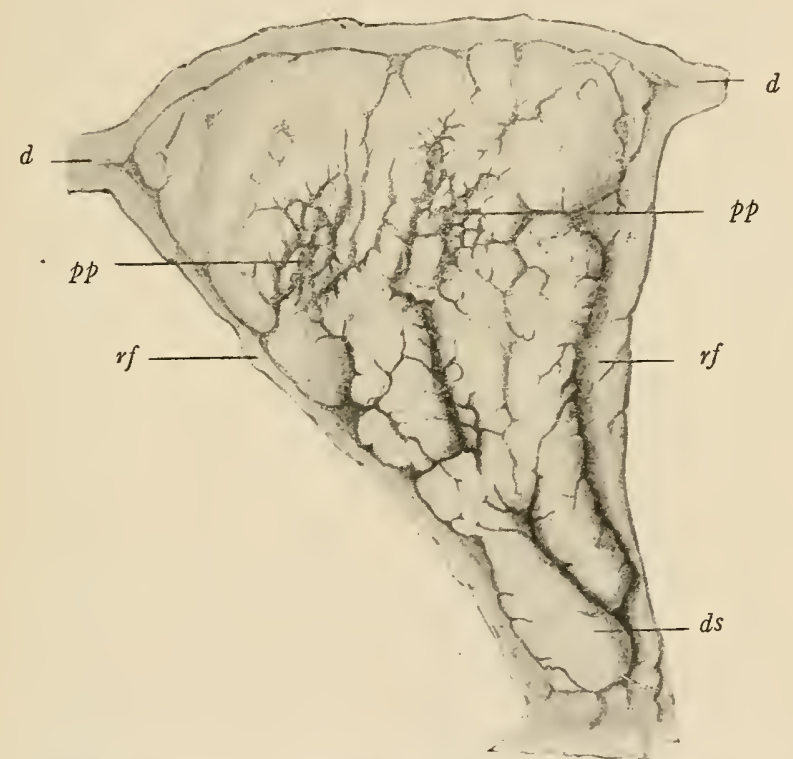

Fig. 77.-Surface View of Half of the Decidua Vera at the End of the Third WeEk of GESTATION.

$d$, Mucous membrane of the Fallopian tubes; $d s$, prolongation of the vera toward the cervix uteri; $p p$., papillæ; $r f$, marginal furrow. (Kollmann.)

The human ovum comes into direct apposition with only a small portion of the uterine wall, and the changes which this portion of the wall undergoes differ somewhat from those occurring elsewhere. Consequently it becomes possible to divide the deciduæ into (I) a portion which is not in direct contact with the ovum, the decidua vera (Fig. 76, V) and (2) a portion which is. The latter portion is again 
capable of division. The ovum becomes completely embedded in the mucosa, but, as has been pointed out, the chorionic villi reach their full development only over that portion of the chorion to which the belly-stalk is attached. The decidua which is in relation to this chorion frondosum undergoes much more extensive modifications than that in relation to the chorion læve, and to it the name of decidua basalis (decidua serotina) (Fig. $76, B$ ) is applied, while the rest of the decidua which encloses the ovum is termed the decidua capsularis (decidua reflexa) $(C)$.

The changes which give rise to the decidua vera may first be described and those occurring in the others considered in succession.

(a) Decidua vera.-On opening a uterus during the fourth or fifth month of pregnancy, when the decidua vera is at the height of its development, the surface of the mucosa presents a corrugated appearance and is traversed
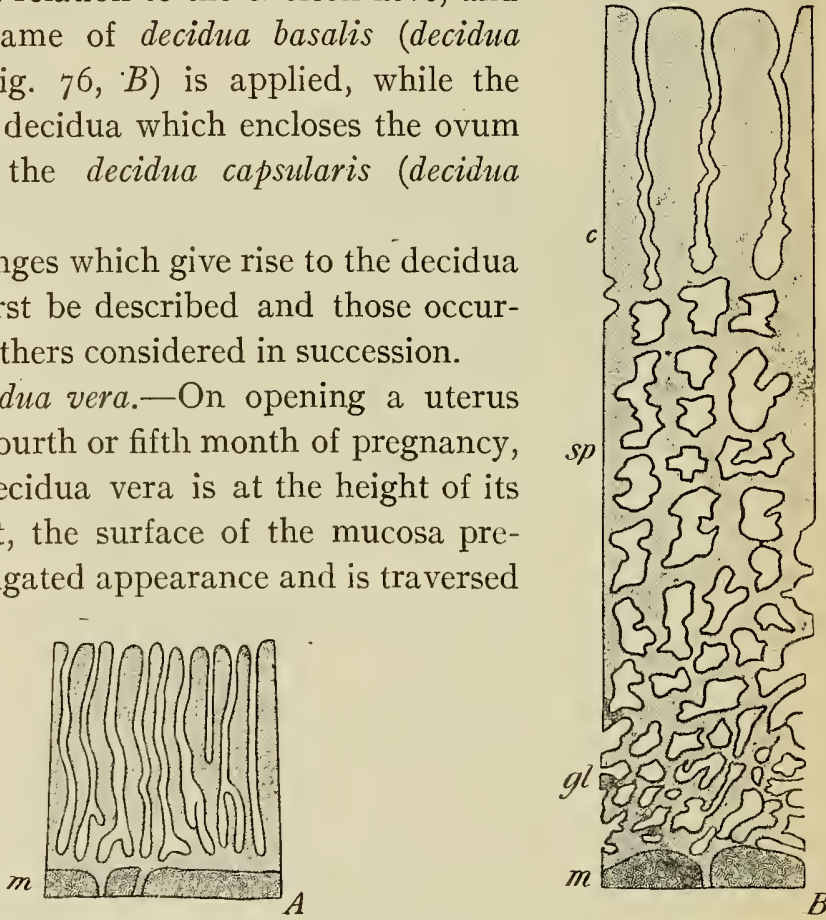

Fig. 78.-Diagrammatic Sections of the Uterine Mucosa, A, in the NonPREgnant Uterus, and $B$, at the Beginning of Pregnancy.

$c$, Stratum compactum; $g l$, the deepest portions of the glands; $m$, muscular layer; $s p$, stratum spongiosum.- (Kundrat and Engelmann.)

by irregular and rather deep grooves (Fig. 77). This appearance ceases at the internal orifice, the mucous membrane of the cervix uteri not forming a decidua, and the deciduæ of the two surfaces of the uterus are separated by a distinct furrow known as the marginal groove. 
In sections the mucosa is found to have become greatly thickened, frequently measuring $\mathrm{I} \mathrm{cm}$. in thickness, and its glands have undergone very considerable modification. Normally almost straight (Fig. 78, A), they increase in length, not only keeping pace with the thickening of the mucosa, but surpassing its growth, so that they become very much contorted and are, in addition, considerably dilated (Fig. 78, B). Near their mouths they are dilated, but not very much contorted, while lower down the reverse is the case, and it is possible to recognize three layers in the decidua, (I) a stratum compactum nearest the lumen of the uterus, containing the straight but dilated portions of the glands; (2) a stratum spongiosum, so called from the appearance which it presents in sections owing to the dilated and contorted portions of the glands being cut in various planes; and (3) next the muscular coat of the uterus a layer containing the contorted but not dilated extremities of the glands is found. Only in the last layer does the epithelium of the glands retain its normal columnar form; elsewhere the cells, separated from the walls of the glands, become enlarged and irregular in shape and eventually degenerate.

In addition to these changes, the epithelium of the mucosa disappears completely during the first month of pregnancy, and the tissue between the glands in the stratum compactum becomes packed with large, often multinucleated cells, which are termed the decidual cells and are probably derived from the connective tissue cells of the mucosa.

After the end of the fifth month the increasing size of the embryo and its membranes exerts a certain amount of pressure on the decidua, and it begins to diminish in thickness. The portions of the glands which lie in the stratum compactum become more and more compressed and finally disappear, while in the spongiosum the spaces become much flattened and the vascularity of the whole decidua, at first so pronounced, diminishes greatly.

(b) Decidua capsularis.-The decidua capsularis has also been termed the decidua reflexa, on the supposition that it was formed as a fold of the uterine mucosa reflected over the ovum after this had 
attached itself to the uterine wall. Since, however, the attachment of the ovum is to be regarded as a process of burrowing into the uterine tissues (see p. II9), the necessity for an upgrowth of a fold is limited to an elevation of the uterine tissues in the neighborhood of the ovum to keep pace with its increasing size. Since it is part of the area of contact with the ovum it possesses no epithelium upon the surface turned toward the ovum, although in the earlier stages its surface is covered by an epithelium continuous with that of the decidua vera, and between it and the chorion there is a portion of the blood extravasation in which the villi formed from the chorion læve float. Glands and blood-vessels also occur in its walls in the earlier stages of development.

As the ovum continues to increase in size the capsularis begins to show signs of degeneration, these appearing first over the pole of the ovum opposite the point of fixation. Here, even in the case of the ovum described by Rossi Doria, the cavity of which measured $6 \times 5 \mathrm{~mm}$. in diameter, it has become reduced to a thin membrane destitute of either blood-vessels or glands, and the degeneration gradually extends throughout the entire capsule, the portion of the blood space which it encloses also disappearing. At about the fifth month the growth of the ovum has brought the capsularis in contact throughout its whole extent with the vera, and it then appears as a whitish transparent membrane with no trace of either glands or blood-vessels, and it eventually disappears by fusing with the vera.

(c) Decidua basalis. - The structure of the decidua basalis, also known as the decidua serotina, is practically the same as that of the vera up to about the fifth month. It differs only in that, being part of the area of contact of the ovum, it loses its epithelium much earlier and is also the seat of extensive blood extravasations, due to the erosion of its vessels by the chorionic trophoblast. Its glands, however, undergo the same changes as those of the vera, so that in it also a compactum and a spongiosum may be recognized. Beyond the fifth month, however, there is a great difference between it and the vera, in that, being concerned with the nutrition of the embryo, it does not partake of the degeneration noticeable in the other deciduæ, 
but persists until birth, forming a part of the structure termed the placenta.

The Placenta.-This organ, which forms the connection between the embryo and the maternal tissues, is composed of two parts, separated by the intervillous space. One of these parts is of embryonic origin, being the chorion frondosum, while the other belongs to the maternal tissues and is the decidua basalis. Hence the terms placenta fetalis and placenta uterina frequently applied to the two parts. The fully formed placenta is a more or less discoidal structure, convex on the surface next the uterine muscularis and concave on that turned toward the embryo, the umbilical cord being continuous with it near the center of the latter surface. It averages about $3.5 \mathrm{~cm}$. in thickness, thinning out somewhat toward the edges, and has a diameter of 15 to $20 \mathrm{~cm}$., and a weight varying between 500 and I250 grams. It is situated on one of the surfaces of the uterus, the posterior more frequently than the anterior, and usually much nearer the fundus than the internal orifice. It develops, in fact, wherever the ovum happens to become attached to the uterine walls, and occasionally this attachment is not accomplished until the ovum has descended nearly to the internal orifice, in which case the placenta may completely close this opening and form what is termed a placenta pravia.

If a section of a placenta in a somewhat advanced stage of development be made, the following structures may be distinguished: On the inner surface there will be a delicate layer representing the amnion (Fig. 79, $A m$ ), and next to this a.somewhat thicker one which is the chorion $(C h o)$, in which the degenerative changes already mentioned may be observed. Succeeding this comes a much broader area composed of the large intervillous blood space in which lie sections of the villi (vi) cut in various directions. Then follows the stratum compactum of the basalis, next the stratum spongiosum $\left(D^{\prime}\right)$, next the outermost layer of the mucosa $\left(D^{\prime \prime}\right)$, in which the uterine glands retain their epithelium, and, finally, the muscularis uteri $(M c)$

These various structures have, for the most part, been already 


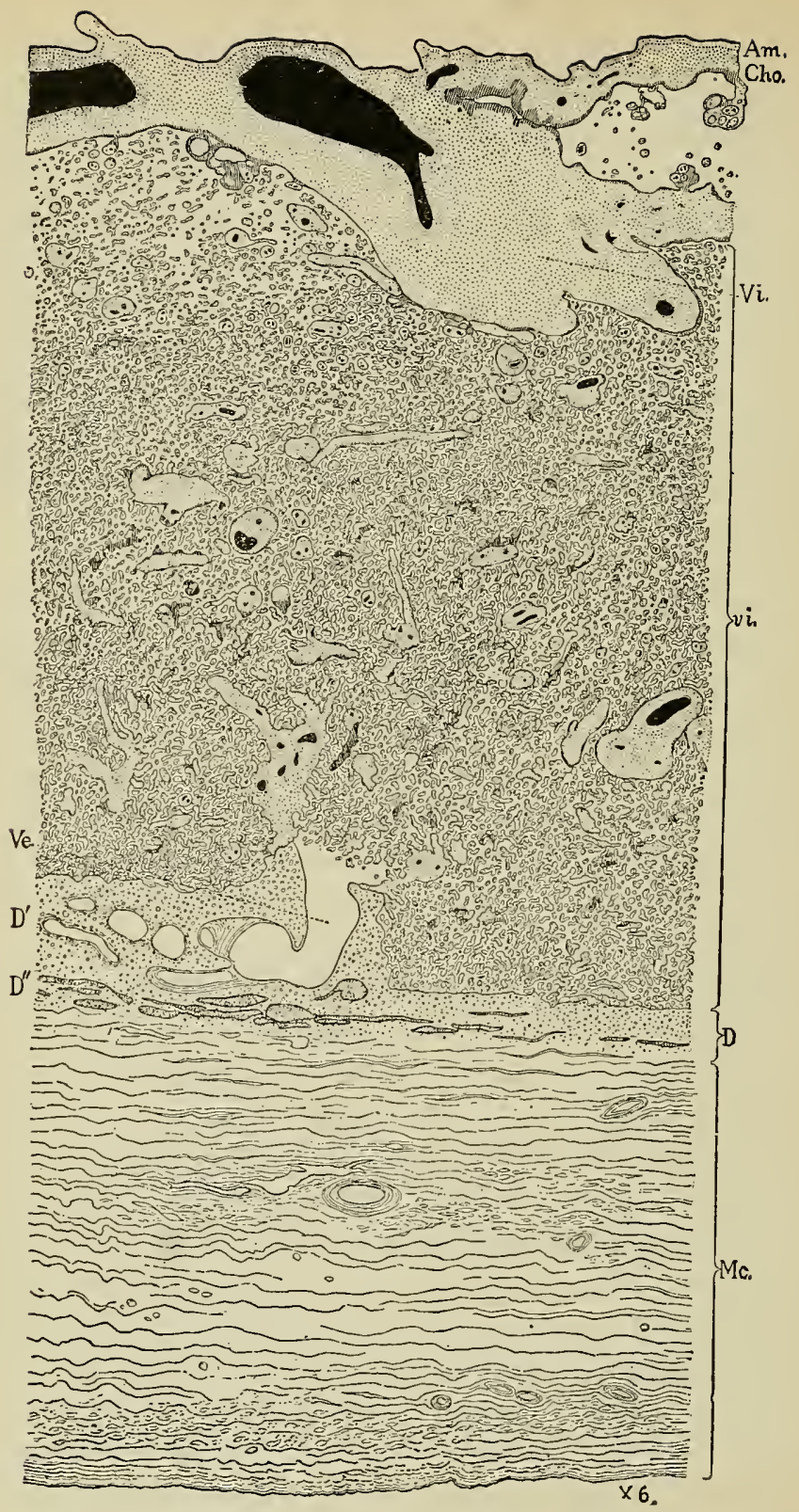

Fig. 79.-Section through a Placenta of Seven Months' Development.

$A m$, Amnion; cho, chorion; $D$, layer of decidua containing the uterine glands; $\$ M c$, muscular coat of the uterus; $V e$, maternal blood-vessel; $V i$, stalk of a villus; $v i$, villi in section.-(Minot.) 
described and it remains here only to say a few words concerning the special structure of the basal compactum and concerning certain changes that take place in the intervillous space.

The stratum compactum of the basal decidua forms what is termed the basal plate of the placenta, closing the intervillous space on the uterine side and being traversed by the maternal blood-vessels that open into the space. The formation of canalized fibrin, already mentioned in connection with the decidua vera and the syncytium of the villi, also occurs in the basal portion of the decidua, a definite layer of it, known as Nitabuch's fibrin stria, being a characteristic constituent of the basal plate and patches of greater or less extent also occur upon the surface of the plate. Leucocytes also occur in considerable abundance in the plate and their presence has been taken to indicate an attempt on the part of the maternal tissues to resist the erosive action of the parasitic ovum. From the surface of the basal plate processes, termed placental septa, project into the intervillous space, grouping the villi into cotyledons and giving attachment to some of the fixation villi (Fig. 80). Throughout the greater extent of the placenta the septa do not reach the surface of the chorion, but at the periphery, throughout a narrow zone, they do come into contact with the chorion and unite beneath it to form a membrane which has been termed the closing plate. Beneath this lies the peripheral portion of the intervillous space, which, owing to the arrangement of the septa in this region, appears to be imperfectly separated from the rest of the space and forms what is termed the marginal sinus (Fig. 80).

Attention has already been called to the formation of canalized fibrin or fibrinoid in connection with the syncytium of the villi. In the later stages of pregnancy there may be produced by this process masses of fibrinoid of considerable size, lying in the intervillous space; these, on account of their color, are termed white infarcts and may frequently be observed as whitish or grayish patches through the walls of the placenta after its expulsion. Red infarcts produced by the clotting of the blood, also occurs, but with much less regularity and frequency. 


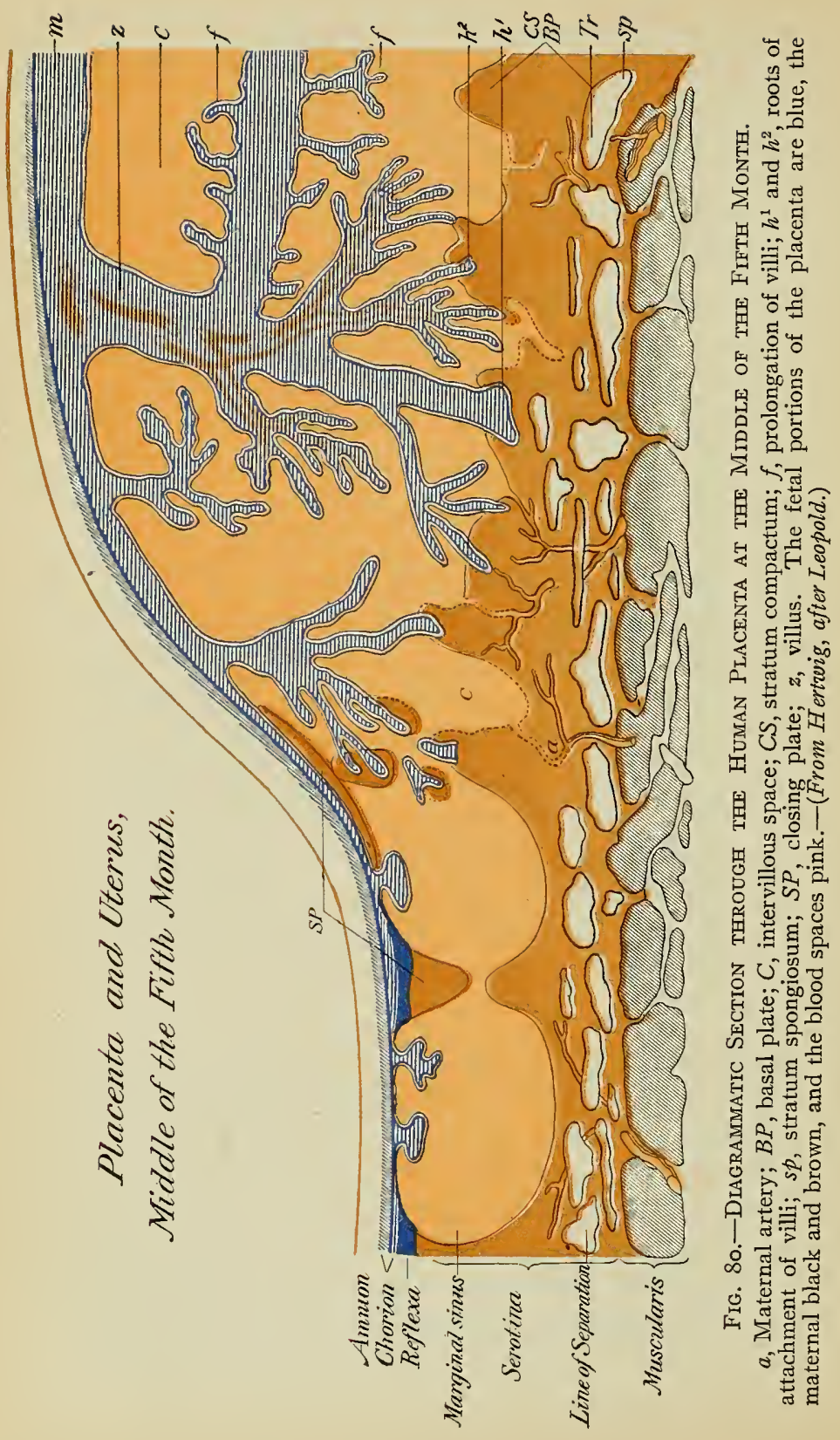


The Separation of the Deciduæ at Birth.-At parturition, after the rupture of the amnion and the expulsion of the fetus, there still remain in the uterine cavity the decidur and the amnion, which is in contact but not fused with the decidur. A continuance of the uterine contractions, producing what are termed the "after-pains," results in the separation of the placenta from the uterine walls, the separation taking place in the deep layers of the spongiosum, so that the portion of the mucosum which contains the undegenerated glands remains behind. As soon as the placenta has separated, the separation of the decidua vera takes place gradually though rapidly, the line of separation again being in the deeper layers of the stratum spongiosum, and the whole of the deciduæ, together with the amnion, is expelled from the uterus, forming what is known as the "after-birth."

Hemorrhage from the uterine vessels during and after the separation of the deciduæ is prevented by the contractions of the uterine walls, assisted, according to some authors, by a preliminary blocking of the mouths of the uterine vessels by certain large polynuclear decidual cells found during the later months of pregnancy in the outer layers of the decidua basalis. The regeneration of the uterine mucosa after parturition has its starting-point from the epithelium of the undegenerated glands which persist, this epithelium rapidly evolving a complete mucosa over the entire surface of the uterus.

The complicated arrangement of the human placenta is, of course, the culmination of a long series of specializations, the path along which these have proceeded being probably indicated by the conditions obtaining in some of the lower mammals. The Monotremes resemble the reptiles in being oviparous and in this group of forms there is no relation of the ovum to the maternal tissues such as occurs in the formation of a placenta. In the other mammals viviparity is the rule and this condition does demand some sort of connection between the fetal and maternal tissues. One of the simplest of such connections is that seen in the pig, where the chorionic villi of the ovum fit into corresponding depressions in the uterine mucosa, this tissue, however, undergoing no destruction, and at birth the villi simply withdraw from the depressions of the mucosa, leaving it intact. This type of placentation is an embryotrophic one, and since there is no separation of deciduæ from the uterine wall after pregnancy it is also of the indeciduate type. In the sheep the placentation is 
also embryotrophic and indeciduate, but destruction of the maternal mucosa does take place, the villi penetrating deeply into it and coming into relation with the connective tissue surrounding the maternal blood-vessels. Another step in advance is shown by the dog, in which even the connective tissue around the maternal vessels in the placental area undergoes almost complete destruction so that the chorionic villi are separated from the maternal blood practically only by the endothelial lining of the maternal vessels. In this case the mucosa undergoes so much alteration that the undestroyed portions if it are sloughed off after birth as a decidua, so that the placentation, like that in man, is of the deciduate type. It still represents, however, an embryotrophic type, although closely approximating to the hæmotrophic one found in man, in which, as described above, the destruction of the maternal tissues proceeds so far as to open into the maternal blood-vessels, so that the fetal villi are in direct contact with the maternal blood.

If these various stages may be taken to represent steps by which the conditions obtaining in the human placenta have been evolved, the entire process may be regarded as the result of a progressive activity of a parasitic ovum. In the simplest stage the pabulum supplied by the uterus was sufficient for the nutrition of the parasite, but gradually the ovum, by means of its plasmodi-trophoblast, began to attack the tissues of its host, thus obtaining increased nutrition, until finally, breaking through into the maternal blood-vessels, it achieved for itself still more favorable nutrition, by coming into direct contact with the maternal blood.

\section{LITERATURE.}

In addition to the papers by Beneke and Strahl, Bryce and Teacher, Frassi, Jung, and Herzog, cited in Chapter III, the following may be mentioned:

E. Cova: "Ueber ein menschliches Ei der zweiten Woche," Arch. für Gynaek., Lxxxin, I907.

L. FraSSI: "Ueber ein junges menschliches Ei in situ," Arch. fïr mikr. Anat., Lxx, I907.

O. Grosser: "Vergleichende Anatomie und Entwicklungsgeschichte der Eihäute und der Placenta mit besonderer Berücksichtigung des Menschen," Wien, I909.

H. HAPPE: "Beobachtungen an Eihäuten junger menschlicher Eier," Anat. Hefte, XXXII, 1906.

W. HIs: "Die Umschliessung der menschlichen Frucht während der frühesten Zeit. des Schwangerschafts," Archiv für Anat. und Physiol., Anat. Abth., 1897.

M. HofmeIer: "Die menschliche Placenta," Wiesbaden, I89o.

F. KeIbel: "Zur Entwickelungsgeschichte der Placenta," Anat. Anzeiger, Iv, I88g.

J. Kollmann: "Die menschlichen Eier von $6 \mathrm{~mm}$. Grösse," Archiv für Anat. und Physiol., Anat. Abth., I879.

G. LEOPOLD: "Ueber ein sehr junges menschliches Ei in situ," Arb. aus der königl Frauenklinik in Dresden, Iv, $\mathbf{1 9 0 6 .}$ 
F. MarChand: "Beobachtungen an jungen menschlichen Eiern," Anat.Hefte, xxi, I903.

J. MertTEns: "Beiträge zur normalen und pathologischen Anatomie der menschlichen Placenta," Zcitschrift für Geburlshiilfe und Gynaekol., xxx and xxxi, I89.4.

C. S. Minot: "Uterus and Embryo," Joumal of Morphol., II, I889.

G. Paladino: "Sur la genèse des espaces intervilleux du placenta humain et de leur premier contenu, comparativement à la même partie chez quelques mammifères," Archives Ital. de Biolog., XXXI and XxxII, ISg9.

H. Peters: "Ueber die Einbettung des menschlichen Eies und das früheste bisher bekannte menschliche Placentationsstadium," Leipzig und Wien, I899.

J. REJSEK: "Anheftung (Implantation) des Sangetiereies an die Uteruswand, insbesondere des Eies von Spermophilus citellus," Arch. für mikrosk. Anat., LXIII, I904.

T. Rossi DoRIA: "Ueber die Einbettung des menschlichen Eies, studirt an einem kleinen Eie der zweiten Woche," Arch. fïr Gynaek., LxxvI. I905.

C. Ruge: "Ueber die menschliche Placentation," Zeitschrift für Geburtshiulfe und Gynaekol., Xxxix, $\mathrm{I} 898$.

Siegenbeek van Heukelom: "Ueber die menschliche Placentation," Arch. $f$. Anat. und Phys., Anat. Abth., I8g8.

F. Graf SPEE: "Ueber die menschliche Eikammer und Decidua reflexa," Verhandl. des Anat. Gesellsch., XII, I 898 .

H. Strahl: "Die menschliche Placenta," Ergebn der Anat. und Entwickl., II, I893. "Neues über den Bau der Placenta," ibid, v1, I897.

"Placentaranatomie," ibid., vIII, 1899.

R. Todyo: "Ein junges menschliches Ei," Arch. für Gynaek, xCv, IgI2.

VAN CAUwenberghe: "Recherches sur la rôle du Syncytium dans la nutrition embryonnaire de la femme," Arch. de Biol., xxill, I907.

J. C. Webster: "Human Placentation," Chicago, Igor.

E. WormSer: "Die Regeneration der Uterusschleimhaut nach der Geburt," Arch. für Gynaek., LXIX, 1903 . 



\section{PART II. \\ ORGANOGENY.}

CHAPTER VI.

\section{THE DEVELOPMENT OF THE INTEGUMENTARY SYSTEM.}

The Development of the Skin.-The skin is composed of two embryologically distinct portions, the outer epidermal layer being developed from the ectoderm, while the dermal layer is mesenchymatous in its origin.

The ectoderm covering the general surface of the body is, in the earliest stages of development, a single layer of cells, but at the end of the first month it is composed of two layers, an outer one, the epitrichium, consisting of slightly flattened cel's, and a lower one whose cells are larger and which will give rise to the epidermis (Fig. $8 \mathrm{I}, \mathrm{A}$ ). During the second month the differences between the two layers become more pronounced, the epitrichial cells assuming a characteristic domed form and becoming vesicular in structure (Fig. 8I, B). These cells persist until about the sixth month of development, but after that they are cast off, and, becoming mixed with the secretion of sebaceous glands which have appeared by this time, form a constituent of the vernix caseosa.

In the meantime changes have been taking place in the epidermal layer which result in its becoming several layers thick (Fig. 8I, B), the innermost layer being composed of cells rich in protoplasm, while those of the outer layers are irregular in shape and have clearer contents. As development proceeds the number of layers increases and the superficial ones, undergoing a horny degeneration, give rise to the stratum corneum, while the deeper ones become the stratum 
Malpighii. At about the fourth month ridges develop on the under surface of the epidermis, projecting downward into the dermis, and later secondary ridges appear in the intervals between the primary ones, while on the palms and soles ridges appear upon the outer surface of the epidermis, corresponding in position to the primary ridges of the under surface.

The mesenchyme which gives rise to the dermis grows in from all sides between the epidermis and the outer layer of the myotomes,
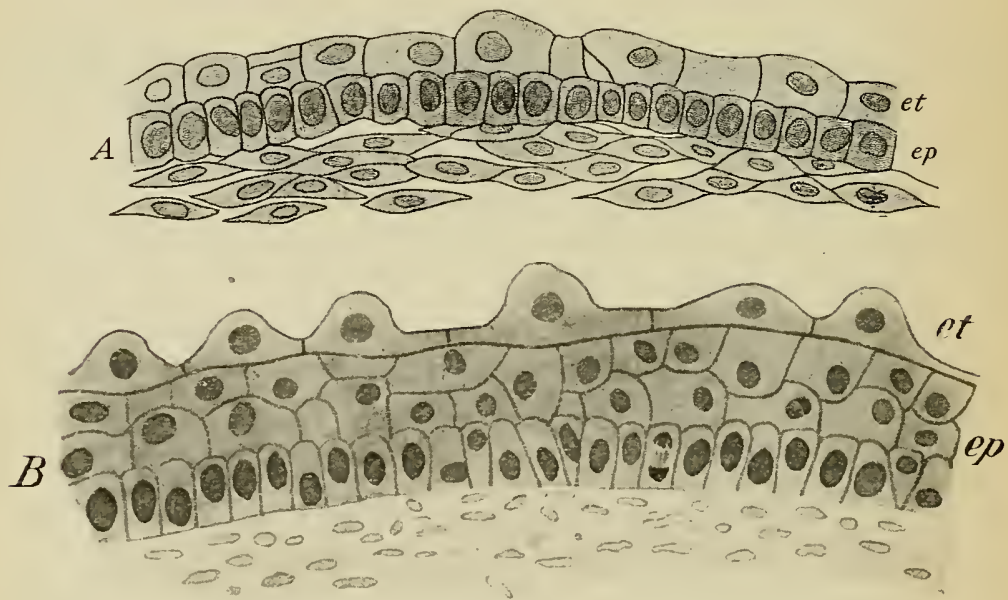

Fig. 8i.-A, Section of Skin from the Dorsum of Finger of an Embryo of 4.5 CM.; $B$, from the Plantar Surface of the Foot of an Embryo of 10.2 C.M et, Epitrichium; ep, epidermis.

which are at first in contact, and forms a continuous layer underlying the epidermis and showing no indications of a segmental arrangement. It becomes converted principally into fibrous connective tissue, the outer layers of which are relatively compact, while the deeper ones are looser, forming the subcutaneous areolar tissue. Some of the mesenchymal cells, however, become converted into non-striated muscle-fibers, which for the most part are few in number and associated with the hair follicles, though in certain regions, such as the skin of the scrotum, they are very numerous and 
form a distinct layer known as the dartos. Some cells also arrange themselves in groups and undergo a fatty degeneration, well-defined masses of adipose tissue embedded in the lower layers of the dermis being thus formed at about the sixth month.

Although the dermal mesenchyme is unsegmental in character, yet the nerves which send branches to it are segmental, and it might be expected that indications of this condition would be retained by the cutaneous nerves even in the adult. A study of the cutaneous nerve-supply in the adult realizes to a very considerable extent this expectation, the areas supplied by the various nerves forming more or less distinct zones, and being therefore segmental (Fig. 82). But a considerable commingling of adjacent areas has also occurred. Thus, while the distribution of the cutaneous branches of the fourth thoracic nerve, as determined experimentally in the monkey (Macacus), is distinctly zonal or segmental, the nipple lying practically in the middle line of the zone, the upper half of its area is also supplied or overlapped by fibers of the third nerve and the lower half by fibers of the fifth (Fig. 83), so that any area of skin in the zone is innervated by fibers coming from at least two segmental nerves (Sherrington). And, furthermore, the distribution of each nerve crosses the mid-ventral line of the body, forming a more or less extensive crossed overlap.

And not only is there a confusion of adjacent areas but an area may shift its position relatively to the deeper structures supplied by the same nerve, so that the skin over a certain muscle is not necessarily supplied by fibers from the nerve which supplies the muscle. Thus, in the lower half of the abdomen, the skin at any point will be supplied by fibers from higher nerves than those supplying the underlying muscles (Sherrington), and the skin of the limbs may receive twigs from nerves which are not represented at all in the muscle-supply (second and third thoracic and third sacral).

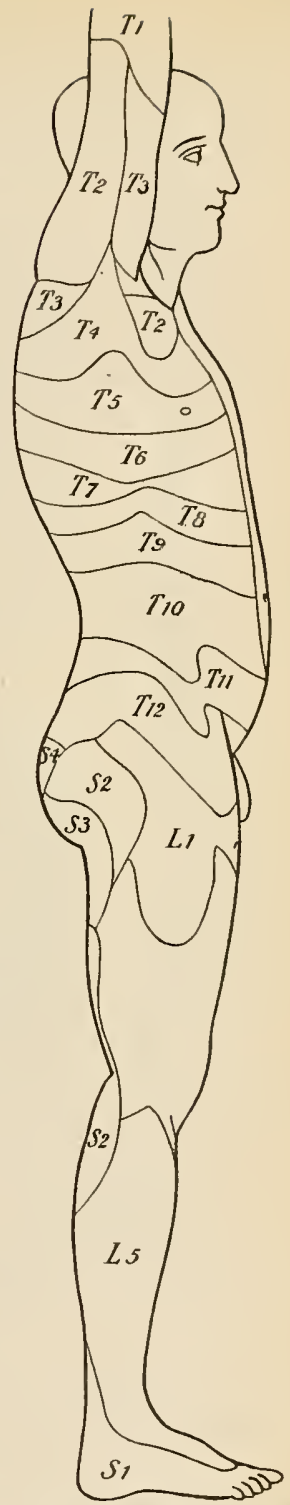

FIG. S2.-DIAGRA M SHOWING THE CUTANEOUS DISTRIBUTION OF THE Spinal Nerves.-(Head.) 
The Development of the Nails. - The earliest indications of the development of the nails have been described by Zander in embryos of about nine weeks as slight thickenings of the epidermis

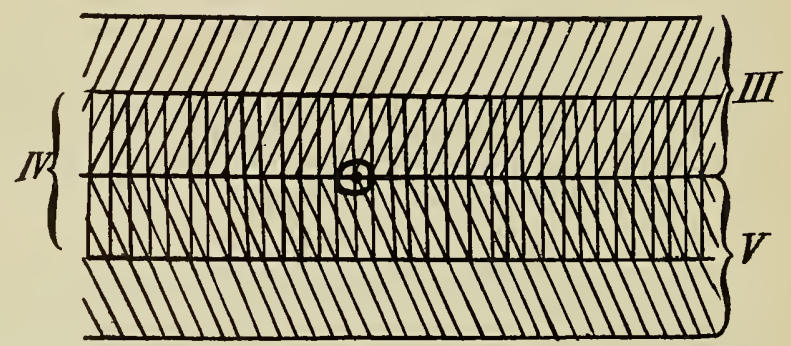

Fig. 83.-Diagram Showing the Overlap of the $I I I, I V$, and $V$ Intercostai, NERVES OF A MONKEY.-(Sherrington.)

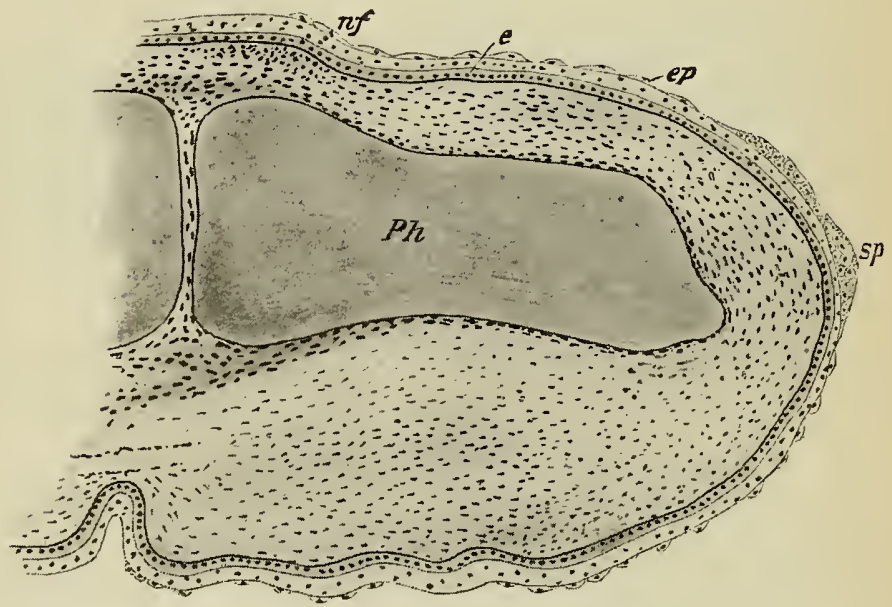

Fig. 84.-Longitudinal Section through the Terminal Joint of the IndexFINGER OF AN EMBRYO OF 4.5 CM.

$e$, Epidermis; $e p$, epitrichium; $n f$, nail fold; $P h$, terminal phalanx; $s p$, sole plate.

of the tips of the digits, these thickenings being separated from the neighboring tissue by a faint groove. Later the nail areas migrate to the dorsal surfaces of the terminal phalanges (Fig. 84) and the 
grooves surrounding the areas deepen, especially at their proximal edges, where they form the nail-folds $(n f)$, while distally thickenings of the epidermis occur to form what have been termed sole-plates $(s p)$, structures quite rudimentary in man, but largely developed in the lower animals, in which they form a considerable portion of the claws.

The actual nail substance does not form, however, until the embryo has reached a length of about $17 \mathrm{~cm}$. By this time the epidermis has become several layers thick and its outer layers, over the nail areas as well as elsewhere, have become transformed into the stratum corneum (Fig. 85, sc), and it is in the deep layers of this (the stratum lucidum) that keratin granules develop in cells which degenerate to give rise to the nail substance ( $n$ ). At its first formation, accordingly, the nail is covered by the outer layers of the stratum corneum as well as by the epitrichium, the two together forming what has been termed the eponychium (Fig. 85, ep). The epitrichium soon disappears, however, leaving only the outer layers of the stratum corneum as a covering, and this also later disappears with the exception of a narrow band surrounding the base of the nail which persists as the perionyx.

The formation of the nail begins in the more proximal portion of the nail area and its further growth is by the addition of new keratinized cells to its proximal edge and lower surface, these cells being formed only in the proximal part of the nail bed in a region marked by its whitish color and termed the lunula.

The first appearance of the nail-areas at the tips of the digits as described by Zander has not yet been

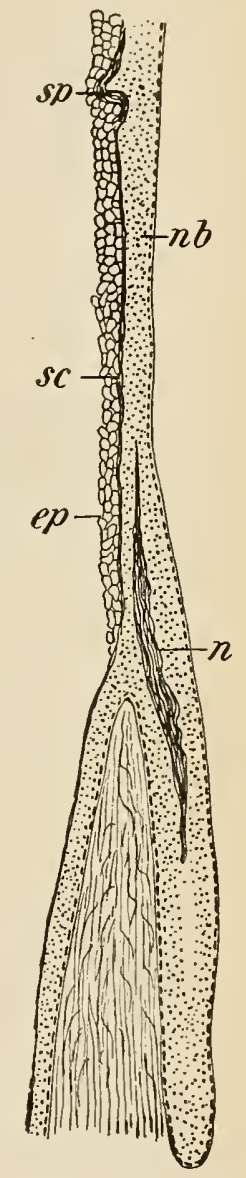

FIG. 85.-LONGITUdinAL SECTION THROUGH THE NAIL Area IN AN Embryo OF I7 CM.

$e p$, Eponychium; $n$, nail substance; $n b$, nail bed; $s c$, stratum corneum; sp, sole plate.-(Okamura.) 
confirmed by later observers, but the migration of the areas to the dorsal surface necessitated by such a location of the primary differentiation affords an explanation of the otherwise anomalous cutaneous nerve-supply of the nail-areas in the adult, this being from the palmar (plantar) nerves.

The Development of the Hairs.-The hairs begin to develop at about the third month and continue to be formed during the remaining portions of fetal life. They arise as solid cylindrical downgrowths, projecting obliquely into the subjacent dermis from

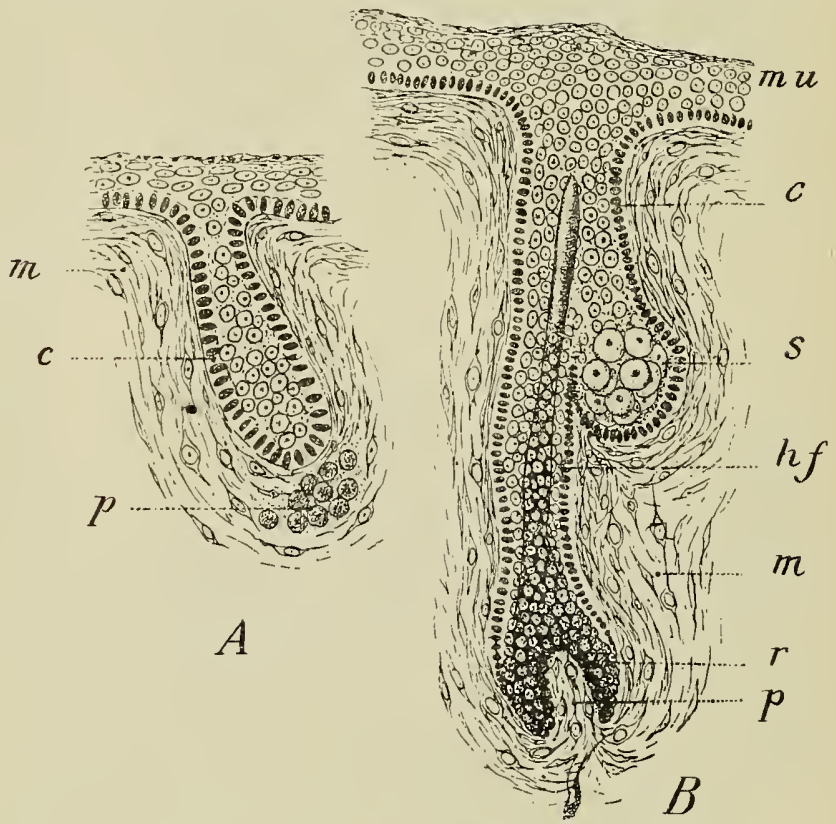

Fig. 86.-The Development of a Hair.

$c$, Cylindrical cells of stratum mucosum; $h f$, wall of hair follicle; $m$, mesoderm; $m u$, stratum mucosum of epidermis; $p$, hair papilla; $r$, root of hair; $s$, sebaceous gland. $-($ Kollmann.)

the lower surface of the epidermis. As these downgrowths continue to elongate, they assume a somewhat club-shaped form (Fig. 86, $A$ ), and later the extremity of each club moulds itself over the summit of a small papilla which develops from the dermis (Fig. 86, B). Even before the dermal papilla has made its appearance, however, a 
differentiation of the cells of the downgrowth becomes evident, the central cells becoming at first spindle-shaped and then undergoing a keratinization to form the hair shaft, while the more peripheral ones assume a cuboidal form and constitute the lining of the hair follicle. The further growth of the hair takes place by the addition to its basal portion of new keratinized cells, probably produced by the multiplication of the epidermal cells which envelop the papilla.

From the cells which form the lining of each follicle an outgrowth takes place into the surrounding dermis to form a sebaceous gland, which is at first solid and club-shaped, though later it becomes lobed. The central cells of the outgrowth separate from the peripheral and from one another, and, their protoplasm undergoing a fatty degeneration, they finally pass out into the space between the follicle walls and the hair and so reach the surface, the peripheral cells later giving rise by division to new generations of central cells. During fetal life the fatty material thus poured out upon the surface of the body becomes mingled with the cast-off epitrichial cells and constitutes the white oleaginous substance, the vernix caseosa, which covers the surface of the new-born child. The muscles, arrectores pilorum, connected with the hair follicles arise from the mesenchyme cells of the surrounding dermis.

The first growth of hairs forms a dense covering over the entire surface of the fetus, the hairs which compose it being exceedingly fine and silky and constituting what is termed the lamugo. This growth is cast off soon after birth, except over the face, where it is hardly noticeable on account of its extreme fineness and lack of coloration. The coarser hairs which replace it in certain regions of the body probably arise from new follicles, since the formation of follicles takes place throughout the later periods of fetal life and possibly after birth. But even these later formed hairs do not individually persist for any great length of time, but are continually being shed, new or secondary hairs normally developing in their places. The shedding of a hair is preceded by a cessation of the proliferation of the cells covering the dermal papilla and by a shrinkage of the papilla, 
whereby it becomes detached from the hair, and the replacing hair arises from a papilla which is probably budded off from the older one before its degeneration and carries with it a cap of epidermal cells.

It is uncertain whether the cases of excessive development of hair over the face and upper part of the body which occasionally occur are due to an excessive development of the later hair follicles (hypertrichosis) or to a persistence and continued growth of the lanugo.

The Development of the Sudoriparous Glands.-The sudoriparous glands arise during the fifth month as solid cylindrical out-

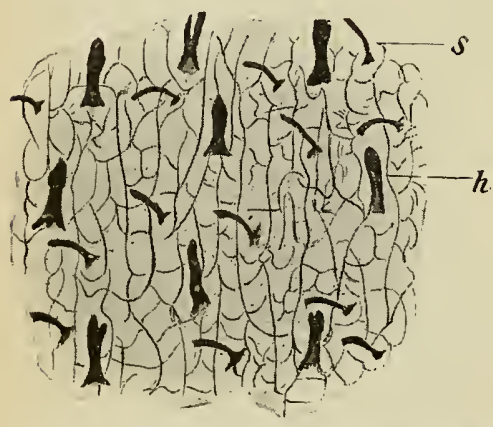

Fig. 87.-Lower Surface OF A DETACHED PORTION OF EPIDERMIS FROM THE DoRsum OF THE HAND.

$h$, Hair follicle; $s$, sudoriparous gland.(Blaschko.) growths from the primary ridges of the epidermis (Fig. 87), and at first project vertically downward into the subjacent dermis. Later, however, the lower end of each downgrowth is thrown into coils, and at the same time a lumen appears in the center. Since, however, the cylinders are formed from the deeper layers of the epidermis, their lumina do not at first open upon the surface, but gradually approach it as the cells of the deeper layers of the epidermis replace those which are continually being cast off from the surface of the stratum corneum. The final opening to the surface occurs during the seventh month of development.

The Development of the Mammary Glands.-In the majority of the lower mammals a number of mammary glands occur, arranged in two longitudinal rows, and it has been observed that in the pig the first indication of their development is seen in a thickening of the epidermis along a line situated at the junction of the abdominal walls with the membrana reuniens (Schulze). This thickening subsequently becomes a pronounced ridge, the milk ridge, from which, at certain points, the mammary glands develop, the ridge 
disappearing in the intervals. In a human embryo $4 \mathrm{~mm}$. in length an epidermal thickening has been observed which extended from just below the axilla to the inguinal region (Fig. 88) and was apparently equivalent to the milk line of the pig, and in embryos of 14 or I $5 \mathrm{~mm}$. the upper end of the line had become a pronounced ridge, while more posteriorly the thickening had disappeared.

The further history of the ridge has not, however, been yet traced in human embryos, and the next stage of the development of the glands which has been observed is one in which they are represented by a circular thickening of the epidermis which projects downward into the dermis (Fig. 89, A). Later the thickening becomes lobed (Fig. 89, B), and its superficial and central cells become cornified and are cast off, so that the gland area appears as a depression of the surface of the skin. During the fifth and sixth months the lobes elongate into solid cylindrical columns of cells

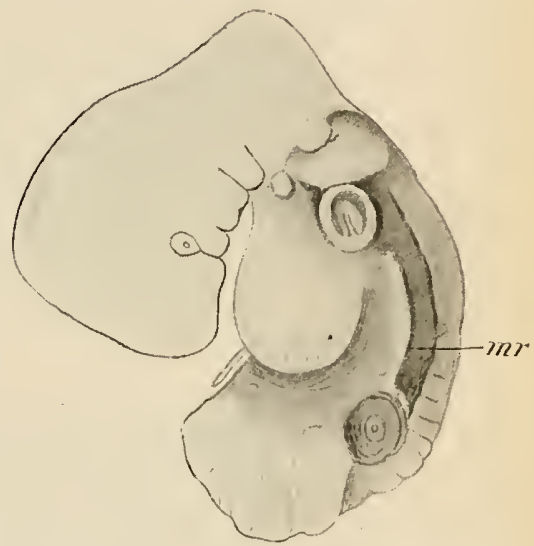

Fig. 88.-Milk Ridge ( $m r$ ) IN A HuMaN EMBRYO.-(Kallius.)

(Fig. 90) resembling not a little the cylinders which become converted into sudoriparous glands, and each column becomes slightly enlarged at its lower end, from which outgrowths begin to develop to form the acini. A lumen first appears in the lower ends of the columns and is formed by the separation and breaking down of the central cells, the peripheral cells persisting as the lining of the acini and ducts.

The elevation of the gland area above the surface to form the nipple appears to occur at different periods in different embryos and frequently does not take place until after birth. In the region around the nipple sudoriparous and sebaceous glands develop, the latter also occurring within the nipple area and frequently opening into 
the extremities of the lacteal ducts. In the areola, as the area surrounding the nipple is termed, other glands known as Montgomery's glands, also appear, their development resembling that of the mammary gland so closely as to render it probable that they are really rudimentary mammary glands.
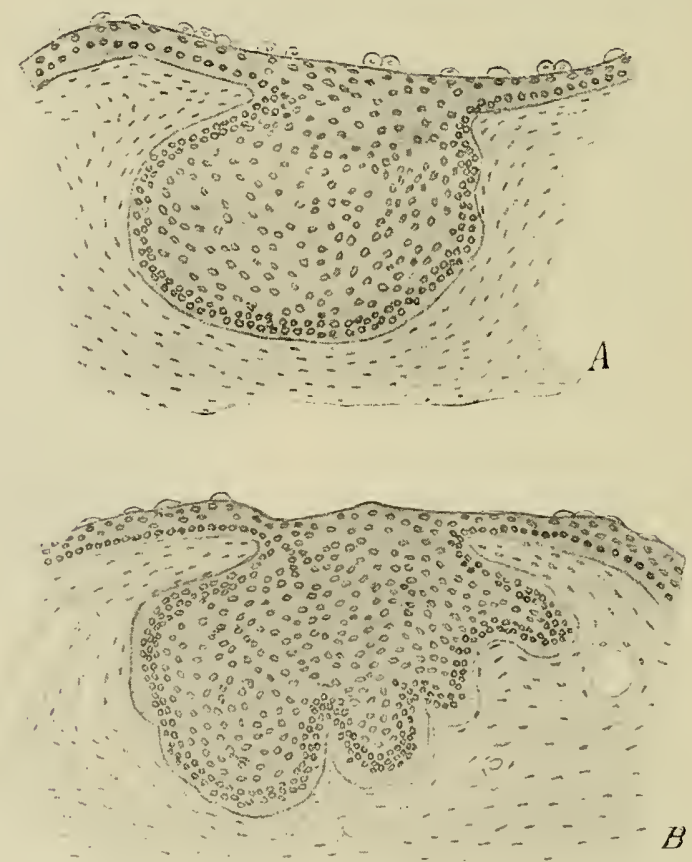

Fig. 89.-Sections through the Epidermal Thickenings which Represent the Mammary Gland in Embryos (A) of $6 \mathrm{~cm}$. ANd $(B)$ of $10.2 \mathrm{CM}$.

The further development of the glands, consisting of an increase in the length of the ducts and the development from them of additional acini, continues slowly up to the time of puberty in both sexes, but at that period further growth ceases in the male, while in females it continues for a time and the subjacent dermal tissues, especially the adipose tissue, undergo a rapid development. 
The occurrence of a milk ridge has not yet been observed in a sufficient number of embryos to determine whether it is a normal development or is associated with the formation of supernumerary glands (polymastia). This is by no means an infrequent anomaly; it has been observed in 19 per cent. of over 100,000 soldiers of the German army who were examined, and occurs in 47 per cent. of individuals in certain regions of Germany The extent to which the anomaly is developed varies from the occurrence of well-developed accessory glands to that of rudimentary accessory nipples (hyperthelia), these latter sometimes occurring in the areolar area of a normal gland and being possibly due in such cases to an hypertrophy of one or more of Montgomery's glands.

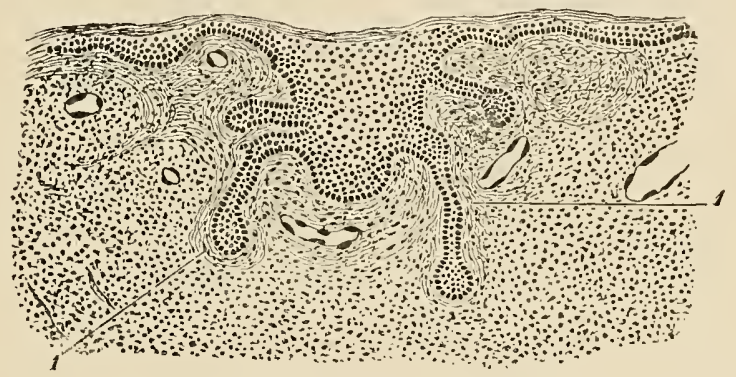

Fig. 90.-Section through the Mammary Gland of an Embryo of 25 CM. I, Stroma of the gland.--(From Nagel, after Basch.)

Although the mammary glands are typically functional only in females in the period immediately succeeding pregnancy, cases are not unknown in which the glands have been well developed and functional in males (gynacomastia). Furthermore, a functional activity of the glands normally occurs immediately after birth, infants of both sexes yielding a few drops of a milky fluid, the so-called witch-milk (Hexenmilch), when the glands are subjected to pressure.

\section{LITERATURE.}

J. T. Bowen: "The Epitrichial Layer of the Human Epidermis," Anat. Anzeiger, IV I889.

Brounta: "Recherches sur les diverses phases du développement et de l'activité cie la mammelle," Arch. de Biol., xxI, I905.

G. BURCKHARD: "Ueber embryonale Hypermastie und Hyperthelie," Anat. Hefle VIII, 1897 .

H. HEad: "On Disturbances of Sensation with Special Reference to the Pain of Visceral Disease," Brain, XVI, I892; xVII, I894; and xIx, 1896 .

E. Kallius: "Ein Fall von Milchleiste bei einem menschlichen Embryo," Anat. Hefte, vIII, I897. 
T. OKamura: "Ueber die Entwicklung des Nagels beim Menschen," Archiv für Dermatol. und Syphilol., xxv, I9oo.

H. Sснмпдт: "Ueber normale Hyperthelie menschlicher Embryonen und über die erste Anlage der menschlichen Milchdrüsen überhaupt," Morphol. Arbeiten, xvir, I897.

C. S. Sherrington: "Experiments in Examination of the Peripheral Distribution of the Fibres of the Posterior Roots of some Spinal Nerves," Philos. Trans. Royal Soc., CLXXxiv, I893, and Cxc, I898.

P. SтоHR: "Entwickelungsgeschichte des menschlichen Wollhaares," Anat. Hefte, XXIII, I903.

H. StraHL: "Die erste Entwicklung der Mammarorgane beim Menschen," Verhandl. Anat. Gesellsch., xIr, I8g8. 


\section{CHAPTER VII.}

\section{THE DEVELOPMENT OF THE CONNECTIVE TISSUES AND SKELETON.}

It has been seen that the cells of a very considerable portion of the somatic and splanchnic mesoderm, as well as of parts of the mesodermic somites, become converted into mesenchyme. A very considerable portion of this becomes converted into what are termed connective or supporting tissues, characterized by consisting of a non-cellular matrix in which more or less scattered cells are embedded. These tissues enter to a greater or less extent into the formation of all the organs of the body, with the exception of those forming the central nervous system, and constitute a network which holds together and supports the elements of which the organs are composed; in addition, they take the form of definite membranes (serous membranes, fasciæ), cords (tendons, ligaments), or solid masses (cartilage), or form looser masses or layers of a somewhat spongy texture (areolar tissue). The intermediate substance is somewhat varied in character, being composed sometimes of white, non-branching, non-elastic fibers, sometimes of yellow, branching, elastic fibers, of white, branching, but inelastic fibers which form a reticulum, or of a soft gelatinous substance containing considerable quantities of mucin, as in the tissue which constitutes the Whartonian jelly of the umbilical cord. Again, in cartilage the matrix is compact and homogeneous, or, in other cases, more or less fibrous, passing over into ordinary fibrous tissue, and, finally, in bone the organic matrix is largely impregnated with salts of lime.

Two views exist as to the mode of formation of the matrix, some authors maintaining that in the fibrous tissues it is produced by the actual transformation of the mesenchyme cells into fibers, while others claim that it is manufactured by the cells but does not directly 
represent the cells themselves. Fibrils and material out of which fibrils could be formed have undoubtedly been observed in connective-tissue cells, but whether or not these are later passed to the exterior of the cell to form a connective-tissue fiber is not yet certain, and on this hangs mainly the difference between the theories. Recently it has been held (Mall) that the mesenchyme of the embryo is really a syncytium in and from the protoplasm of which the matrix

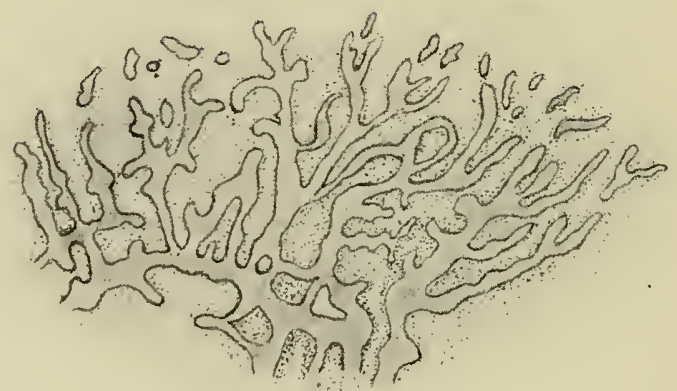

Fig. 9r.-Portion of the Center of Ossification of the Parietal Bone of a Human EMbryo.

forms; if this be correct, the distinction which the older views make between the intercellular and intracellular origin of the matrix becomes of little importance.

Bone differs from the other varieties of connective tissue in that it is never a primary formation, but is always developed either in fibrous tissue or cartilage; and according as it is associated with the one or the other, it is spoken of as membrane bone or cartilage bone. In the development of membrane bone some of the connective-tissue cells, which in consequence become known as osteoblasts, deposit lime salts in the matrix in the form of bony spicules which increase in size and soon unite to form a network (Fig. 9I). The trabeculæ of the network continue to thicken, while, at the same time, the formation of spicules extends further out into the connective-tissue membrane, radiating in all directions from the region in which it first 
developed. Later the connective tissue which lies upon either surface of the reticular plate of bone thus produced condenses to form a stout membrane, the periosteum, between which and the osseous plate osteoblasts arrange themselves in a more or less definite layer and deposit upon the surface of the plate a lamella of compact bone. A membrane bone, such as one of the flat bones of the skull, thus comes to be composed of two plates of compact bone, the inner and outer tables, enclosing and united to a middle plate of spongy bone which constitutes the diploe.

With bones formed from cartilage the process is somewhat different. In the center of the cartilage the intercellular matrix becomes increased so that the cells appear to be more scattered and a calcareous deposit forms in it. All around this region of calcification the cells arrange themselves in rows (Fig. 92) and the process of calcification extends into the trabeculæ of matrix which separate these rows. While these processes have been taking place the mesenchyme surrounding the cartilage has become converted into a

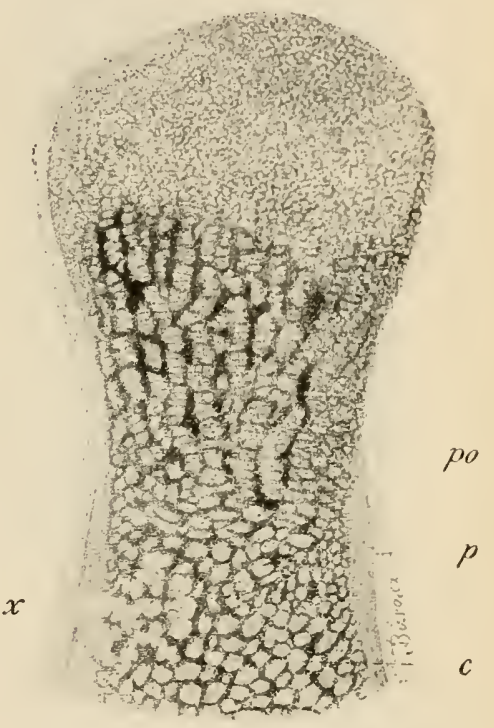

Fig 92.-Longitudinal SECtion of Phalanx of a Finger of an Embryo OF $3 \mathrm{I} / 2$ MONTHS.

$c$, Cartilage trabeculæ; $p$, periosteal bone; po, periosteum; $x$, ossification center.-(Szymonowicz.) periosteum ( $p o)$, similar to that of membrane bone, and its osteoblasts deposit a layer of bone $(p)$ upon the surface of the cartilage. The cartilage cells now disappear from the intervals between the trabeculæ of calcified matrix, which form a fine network into which masses of mesenchyme (Fig. 93, pi), containing blood-vessels and osteoblasts, here and there penetrate from the periosteum, after having broken through the layer of periosteal bone. These masses absorb a portion of the fine calcified network and so transform it 
into a coarse network, the meshes of which they occupy to form the bone makzow $(m)$, and the osteoblasts which they contain arrange themselves on the surface of the persisting trabeculæ and deposit layers of bone upon their surfaces. In the meantime the calcification of the cartilage matrix has been extending, and as fast as the

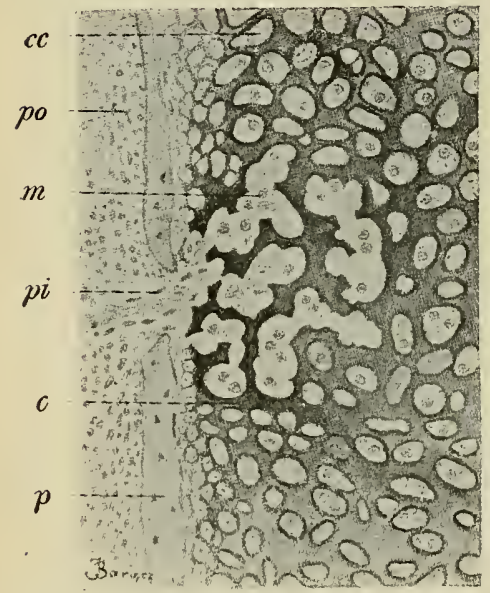

Fig. 93.-The Ossification Center OF Fig. 92 More Highly Magnified.

$c$, Ossifying trabeculæ; $c c$, cavity of cartilage network; $m$, marrow cells; $p$, periosteal bone; $p i$, irruption of periosteal tissue; po, periosteum.-(Szymonowicz.) network of calcified trabeculæ is formed it is invaded by the mesenchyme, until finally the cartilage becomes entirely converted into a mass of spongy bone enclosed within a layer of more compact periosteal bone.

As a rule, each cartilage bone is developed from a single center of ossification, and when it is found that a bone of the skull, for instance, develops by several centers, it is to be regarded as formed by the fusion of several primarily distinct bones, a conclusion which may generally be confirmed by a comparison of the bone in question with its homologues in the lower vertebrates. Exceptions to this rule occur in bones situated in the median line of the body, these occasionally developing from two centers lying one on either side of the median line, but such centers are usually to be regarded as a double center rather than as two distinct centers, and are merely an expression of the fundamental bilaterality which exists even in median structures.

More striking exceptions are to be found in the long bones in which one or both extremities develop from special centers which give rise to the epiphyses (Fig. 94, $e p, e p^{\prime}$ ), the shaft or diaphysis (d) being formed from the primary center. Similar secondary centers appear in marked prominences on bones to which powerful muscles 
are attached (Fig. 94, $a$ and $b$ ), but these, as well as the epiphysial centers, can readily be recognized as secondary from the fact that they do not appear until much later than the primary centers of the bones to which they belong. These secondary centers give the necessary firmness required for articular surfaces and for the attachment of muscles and, at the same time, make provision for the growth in length of the bone, since a plate of cartilage always intervenes between the epiphyses and the diaphysis. This cartilage continues to be transformed into bone on both its surfaces by the extension of both the epiphysial and diaphysial ossification into it, and, at the same time, it grows in thickness with equal rapidity until the bone reaches its required length, whereupon the rapidity of the growth of the cartilage diminishes and it gradually becomes completely ossified, uniting together the epiphysis and diaphysis.

The growth in thickness of the long bones is, however, an entirely different process, and is due to the formation of new layers of periosteal bone on the outside of those already present. But in connection with this process an absorption of bone also takes place. A section through the middle of the shaft of a humerus, for example, at an early stage of development would show a peripheral zone of

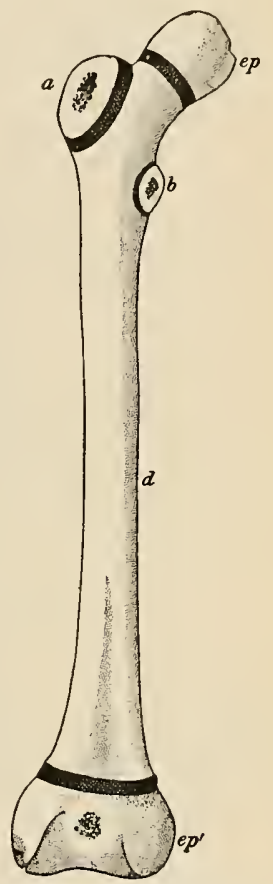

FIG. 94.-THE OssiFICATION CENTERS OF THE FEMUR.

$a$, and $b$, Secondary centers for the great and lesser trochanters; $d$, diaphysis; $e p$, upper and $e p^{\prime}$, lower epiphysis. (Testut.) compact bone surrounding a core of spongy bone, the meshes of the latter being occupied by the marrow tissue. A similar section of an adult bone, on the other hand, would show only the peripheral compact bone, much thicker than before and enclosing a large marrow cavity in which no trace of spongy bone might remain. The difference depends on the fact that as the periosteal bone 
increases in thickness, there is a gradual absorption of the spongy bone and also of the earlier layers of periosteal bone, this absorption being carried on by large multinucleated cells, termed osteoclasts, derived from the marrow mesenchyme. By their action the bone is enabled to reach its requisite diameter and strength, without becoming an almost solid and unwieldy mass of compact bone.

During the ossification of the cartilaginous trabeculæ osteoblasts become enclosed by the bony substance, the cavities in which they lie forming the lacune and processes radiating out from them, the
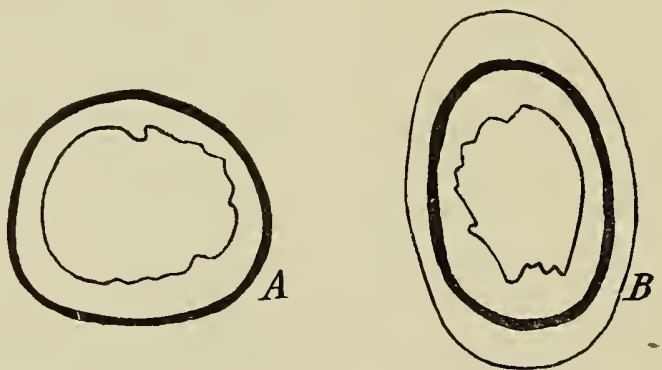

Fig. 95.- $A$, Transverse`Section of the Femur of a Pig Kililed after Having Been fed with Madder for Four Weeks; $B$, the Same of a Pig Killed Two Months after the Cessation of the Madder Feeding.

The heavy black line represents the portion of bone stained by the madder.-(After Flourens.)

canaliculi, so characteristic of bone tissue. In the growth of periosteal bone not only do osteoblasts become enclosed, but bloodvessels also, the Haversian canals being formed in this way, and around these lamellæ of bone are deposited by the enclosed osteoblasts to form Haversian systems.

That the absorption of periosteal bone takes place during growth can be demonstrated by taking advantage of the fact that the coloring substance madder, when consumed with food, tinges the bone being formed at the time a distinct red. In pigs fed with madder for a time and then killed a section of the femur shows a superficial band of red bone (Fig. 95, A), but if the animals be allowed to live for one or two months after the cessation of the madder feeding, the red band will be found to be covered by a layer of white bone varying in thickness according to the interval elapsed since the cessation of feeding (Fig. 95, B); and if this 
interval amount to four months, it will be found that the thickness of the uncolored bone between the red bone and the marrow cavity will have greatly diminished (Flourens).

The Development of the Skeleton.-Embryologically considered, the skeleton is composed of two portions, the axial skeleton, consisting of the skull, the vertebræ, ribs, and sternum, developing

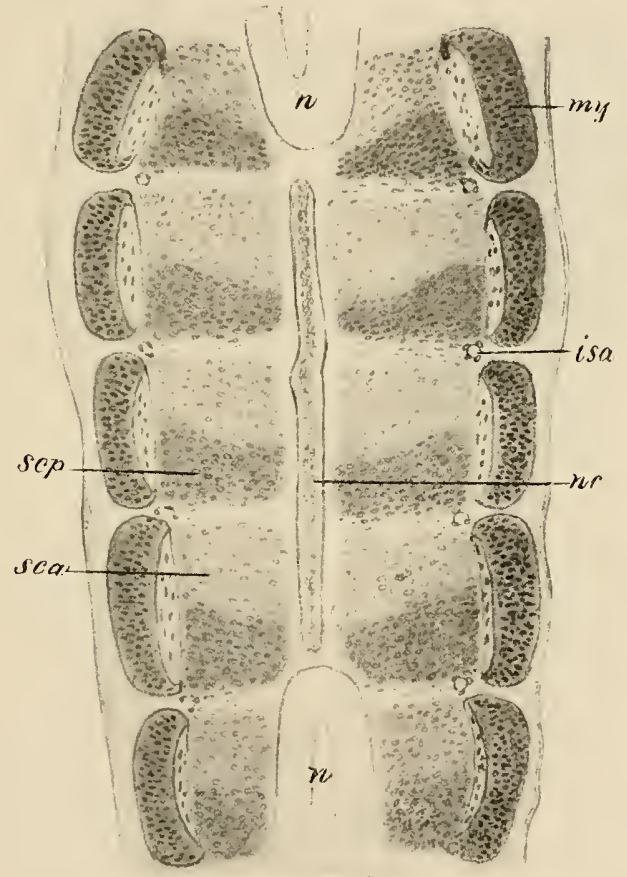

Fig. 96.-Frontal Section through Mesodermic Somites of a Calf Embryo. isa, Intersegmental artery; $m y$, myotome; $n$, central nervous system; $n c$, notochord; $s c a$ and $s c p$, anterior and posterior portions of sclerotomes.

from the sclerotomes of the mesodermal somites, and the appendicular skeleton, which includes the pectoral and pelvic girdles and the bones of the limbs, and which arises from the mesenchyme of the somatic mesoderm. It will be convenient to consider first the development of the axial skeleton, and of this the differentiation of the vertebral column and ribs may first be discussed. 
The Development of the Vertebræ and Ribs.-The mesenchyme formed from the sclerotome of each mesodermic somite grows inward toward the median line and forms a mass lying between the notochord and the myotome, separated from the similar mass in front and behind by some loose tissue in which lies an intersegmental artery. Toward the end of the third week of

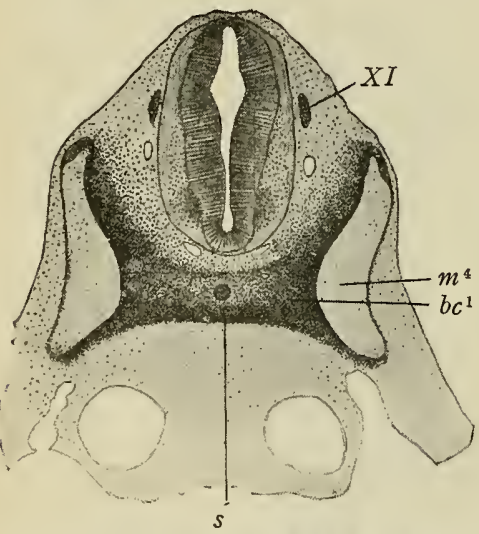

Fig. 97.-Transverse Section THROUGH THE INTERVERTEBRAL Plate of the First Cervical Vertebra of a CAlf Embryo of 8.8 mir.

$b c^{1}$, Intervertebral plate; $m^{4}$, fourth myotome; $s$, hypochordal bar; $X I$, spinal accessory nerve.-(Froriep.) development the cells of the posterior portion of each sclerotome condense to a tissue more compact than that of the anterior portion (Fig. 96), and a little later the two portions become separated by a cleft. At about the same time the posterior portion sends a process medially, to enclose the notochord by uniting with a corresponding process from the sclerotome of the other side, and it also sends a prolongation dorsally between the myotome and the spinal cord to form the vertebral arch, and a third process laterally and ventrally along the distal border of the myotome to form a costal process (Fig. 97). The looser tissue of the anterior half of the sclerotome also grows medially to surround the notochord, filling up the intervals between successive denser portions, and it forms too a membrane extending between successive vertebral arches. Later the tissue surrounding the notochord, which is derived from the anterior half of the sclerotome, associates itself with the posterior portion of the preceding sclerotome to form what will later be a vertebra, the tissue occupying and adjacent to the line of division between the anterior and posterior portions of the sclerotomes condensing to form intervertebral fibrocartilages. Consequently each vertebra is formed by parts 
from two sclerotomes, the original intersegmental artery passes over the body of a vertebra, and the vertebræ themselves alternate with the myotomes. With this differentiation the first or blastemic stage of the development of the vertebræ closes.

In the second or cartilaginous stage, portions of the sclerotomic mesenchyme become transformed into cartilage. In the posterior portion of each vertebral body, that is to say in the portion formed from the anterior halves of the more posterior of the two pairs of sclerotomes entering into its formation, two centers of chondrification appear, one on each side of the median line, and these eventually unite to form a single cartilaginous body, the chondrification probably also extending to some extent into the denser anterior portion of the body. A center also appears in each half of the vertebral arch and in each costal process, the cartilages formed in the costal processes of the anterior cervical region uniting across the median line below the notochord, to form what has been termed a hypochordal bar (Figs. 97 and 98). These bars are for the most part but transitory, recalling structures occurring in the lower vertebrates; in the mammalia they degenerate before the close of the cartilaginous stage of development, except in the case of the atlas, whose development will be described later. As development proceeds the cartilages of the vertebral arches and costal processes increase in length and come into contact with the cartilaginous bodies, with which they eventually fuse, and from the vertebral arches processes grow out which represent the future transverse and articular processes.

The fusion of the cartilage of the costal process with the body of the vertebra does not, however, persist. Later a solution of the junction occurs and the process becomes a rib cartilage, the mesenchyme surrounding the area of solution forming the costo-vertebral ligaments. At first the rib cartilage is separated by a distinct interval from the transverse process of the vertebral arch, but later it develops a process, the tubercle, which bridges the gap and forms an articulation with the transverse process.

The mesenchyme which extends between successive vertebral arches does not chondrify, but later becomes transformed into the 
interspinous ligaments and the ligamenta flava, while the anterior and posterior longitudinal ligaments are formed from unchondrified portions of the tissue surrounding the vertebral bodies.

As was pointed out, the mesenchyme in the region of the cleft separating the anterior and posterior portions of a sclerotome becomes an intervertebral fibrocartilage, and, as the cartilaginous bodies develop, the portions of the notochord enclosed by them become constricted, while at the same time the portions in the intervertebral regions increase in size. Finally the notochord disappears from the vertebral regions, although a canal, representing its former position, traverses each body for a considerable time, but in the intervertebral regions it persists as relatively large flat disks forming the pulpy nuclei of the fibrocartilages.

The mode of development described above applies to the great majority of the vertebræ, but some departures from it occur, and these may be conveniently considered before passing on to an account of the ossification of the cartilages. The variations affect principally the extremes of the series. Thus the posterior vertebræ present a reduction of the vertebral arches, those of the last sacral vertebræ being but feebly developed, while in the coccygeal vertebræ they are indicated only in the first. In the first cervical vertebra, the atlas, the reverse is the case, for the entire adult vertebra is formed from the posterior portion of a sclerotome, its lateral masses and posterior arch being the vertebral arches, while its anterior arch is the hypochordal bar, which persists in this vertebra only. A welldeveloped centrum is also formed, however (Fig. 98), but it does not unite with the parts derived from the preceding sclerotome, but during its ossification unites with the centrum of the epistropheus (axis), forming the odontoid process of that vertebra. The epistropheus consequently is formed by one and a half sclerotomes, while but half a one constitutes the atlas.

The extent to which the ribs are developed in connection with the various vertebræ also varies considerably. Throughout the cervical region they are short, the upper five or six being no longer than the transverse processes, with the tips of which their extremities 
unite at an early stage. In the upper five or six vertebræ a relatively large interval persists between the rib and the transverse process, forming the costo-transverse foramen, through which the vertebral vessels pass, but in the seventh vertebra the fusion is more extensive and the foramen is very small and hardly noticeable. In the thoracic region the ribs reach their greatest development, the upper eight or

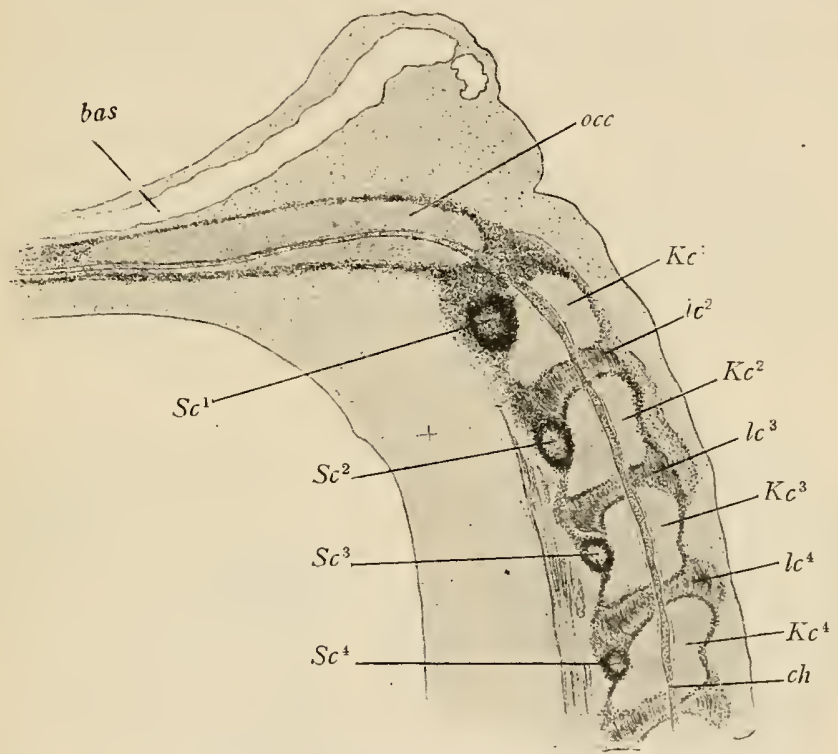

Fig. 98.-Longitudinal Section through the Occipital Region and Upper Cervical Vertebre of a Calf EMbryo of $19.5 \mathrm{~mm}$.

bas, Basilar artery; ch, notochord; $K c^{1-4}$, vertebral centra; $l c^{2-4}$, intervertebral disks; occ, basioccipital; $S c^{1-4}$, hypochordal bars.-(Froriep.)

nine extending almost to the mid-ventral line, where their extremities unite to form a longitudinal cartilaginous bar from which the sternum develops (see p. I66). The lower three or four thoracic ribs are successively shorter, however, and lead to the condition found in the lumbar vertebræ, where they are again greatly reduced and firmly united with the transverse processes, the union being so close that only the tips of the latter can be distinguished, forming what are known as the accessory tubercles. In the sacral region the ribs 
are reduced to short flat plates, which unite together to form the lateral masses of the sacrum, and, finally, in the coccygeal region the blastemic costal processes of the first vertebra unite with the transverse processes to form the transverse processes of the adult vertebra, but no indications of them are to be found in the other vertebræ beyond the blastemic stage.

The third stage in the development of the axial skeleton begins with the ossification of the cartilages, and in each vertebra there are typically as many primary centers of ossification as there were originally cartilages, except that but a single center appears in the body. Thus, to take a thoracic vertebra as a type, a center appears in each half of each vertebral arch at the base of the transverse process and gradually extends to form the bony lamina, pedicle, and the greater portion of the transverse and spinous processes; a single center gives rise to the body of the vertebra; and each rib ossifies
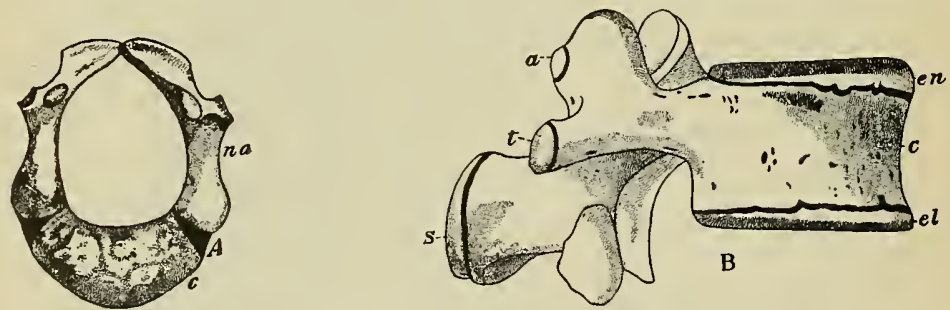

Fig. 99.- $A$, A Vertebra at Birth; $B$, Lumbar Vertebra showing Secondary Centers of Ossification.

$a$, Center for the articular process; $c$, body; $e l$, lower epiphysial plate; en, upper epiphysial plate; $n a$, vertebral arch; $s$, center for spinous process; $t$, center for transverse process.-(Sappey.)

from a single center. These various centers appear early in embryonic life, but the complete transformation of the cartilages into bone does not occur until some time after birth, each vertebra at that period consisting of three parts, a body and two halves of an arch, separated by unossified cartilage (Fig. 99, A). At about puberty secondary centers make their appearance; one appears in the cartilage which still covers the anterior and posterior surfaces of the vertebral body, producing disks of bone in these situations (Fig. 99, 
$\mathrm{B}, e n$ and $e l)$, another appears at the tip of each spinous and transverse process (Fig. 99, B), and in the lumbar vertebræ others appear at the tips of the articulating processes. The epiphyses so formed remain separate until growth is completed and between the sixteenth and twenty-fifth years unite with the bones formed from the primary centers, which have fused by this time, to form a single vertebra.

Each rib ossifies from a single primary center situated near the angle, secondary centers appearing for the capitulum and tuberosity.

In some of the vertebræ modifications of this typical mode of ossification occur. Thus, in the upper five cervical vertebræ the centers for the rudimentary ribs are suppressed, ossification extending into them from the vertebral arch centers, and a similar suppression of the costal centers occurs in the lower lumbar vertebræ, the first only developing a separate rib center. Furthermore, in the
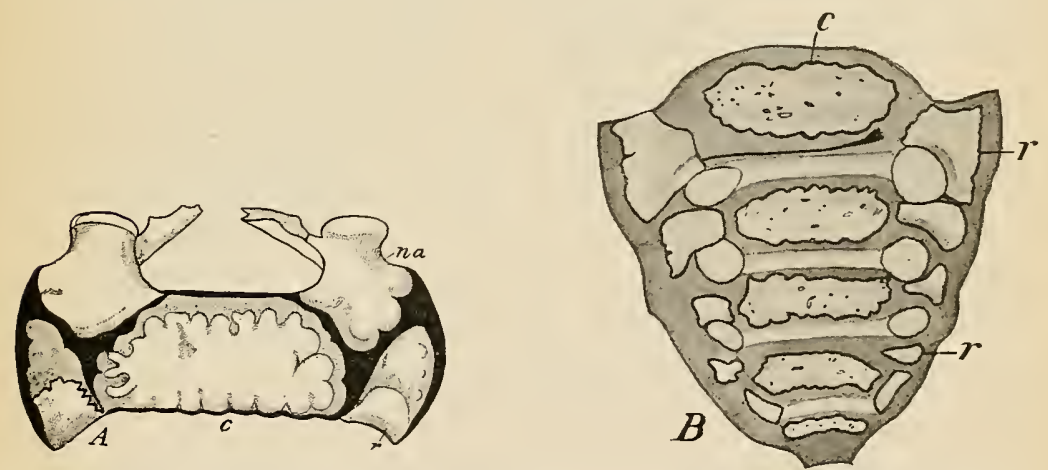

Fig. ioo.- $A$, Upper Surface of the Frrst Sacral Vertebra, and $B$, Ventral View of the Sacrum showing Primary Centers of Ossification. $c$, Body; $n a$, vertebral arch; $r$, rib center.-(Sappey.)

atlas a double center appears in the persisting hypochordal bar, and the body which corresponds to the atlas, after developing the terminal epiphysial disks, fuses with the body of the epistropheus (axis) to form its odontoid process, this vertebra consequently possessing, in addition to the typical centers, one (double) other primary and two secondary centers. In the sacral region the typical centers appear 
in all five vertebræ, with the exception of rib centers for the last one or two (Fig. Ioo) and two additional secondary centers give rise to plate-like epiphyses on each side, the upper plates forming the articular surface for the ilium. At about the twenty-fifth year all the sacral vertebræ unite to form a single bone, and a similar fusion occurs also in the rudimentary vertebræ of the coccyx.

The majority of the anomalies seen in the vertebral column are due to the imperfect development of one or more cartilages or of the centers of ossification. Thus, a failure of an arch to unite with the body or even the complete absence of an arch or half an arch may occur, and in cases of spina bifida the two halves of the arches fail to unite dorsally. Occasionally the two parts of the double cartilaginous center for the body fail to unite, a double body resulting; or one of the two parts may entirely fail, the result being the formation of only one-half of the body of the vertebra. Other anomalies result from the excessive development of parts. Thus, the rib of the seventh cervical vertebra may sometimes remain distinct and be long enough to reach the sternum, and the first lumbar rib may also fail to unite with its vertebra. On the other hand, the first thoracic rib is occasionally found to be imperfect.

The Development of the Sternum.-Longitudinal bars, which are formed by the fusion of the ventral ends of the anterior eight or nine cartilaginous thoracic ribs, represent the future sternum. At an early period the two bars come into contact anteriorly and fuse together (Fig. IOI), and at this anterior end two usually indistinctly separated masses of cartilage are to be observed at the vicinity of the points where the ventral ends of the cartilaginous clavicles articulate. These are the episternal cariilages $(\mathrm{em})$, which later normally unite with the longitudinal bars and form part of the manubrium sterni, though occasionally they persist and ossify to form the ossa suprasternalia. The fusion of the longitudinal bars gradually extends backward until a single elongated plate of cartilage results, with which the seven anterior ribs are united, one or two of the more posterior ribs which originally took part in the formation of each bar having separated. The portions of the bars formed by these posterior ribs constitute the xiphoid process.

The ossification of the sternum (Fig. IO2) partakes to a certain extent of the original bilateral segmental origin of the cartilage, 
but there is a marked condensation of the centers of ossification and considerable variation in their number also occurs. In the portion of the cartilage which lies below the junction of the third costal cartilages a series of pairs of centers appears just about birth, each center

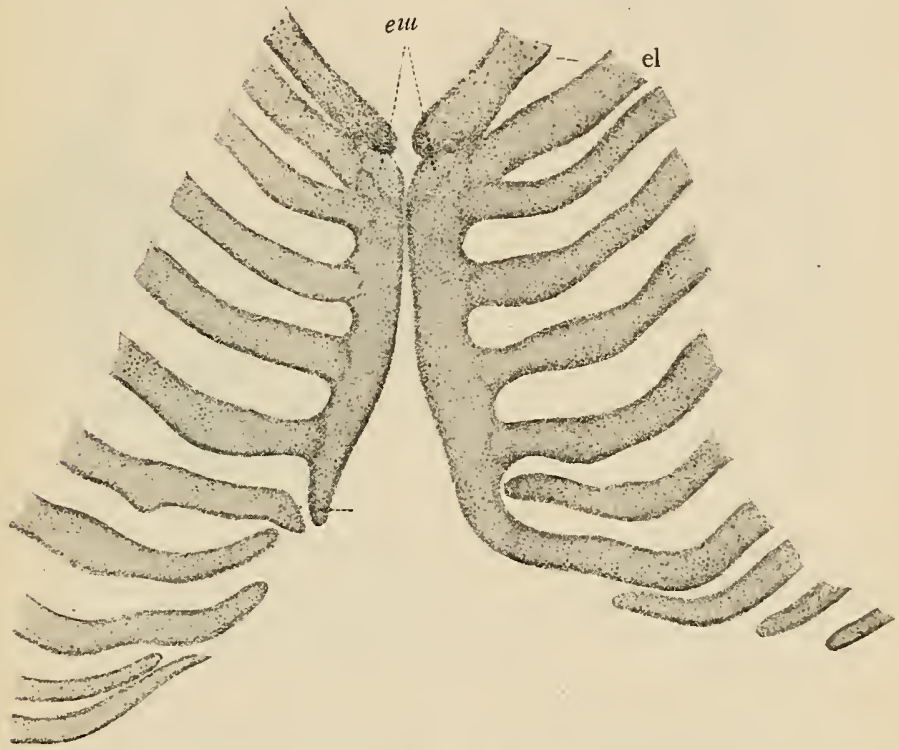

Fig. ior.-Formation of the Sternum in an Embryo of About 3 ch. $e l$, Clavicle; $e m$, episternal cartilage.-(Ruge.)

probably representing an epiphysial center of a corresponding rib. Later the centers of each pair fuse and the single centers so formed, extending through the cartilage, eventually unite to form the greater part of the body of the bone. In each of the two uppermost segments, however, but a single center appears, that of the second segment uniting with the more posterior centers and forming the upper part of the body, while the uppermost center gives rise to the manubrium, which frequently persists as a distinct bone united to the body by a hinge-joint. 
A failure of the cartilaginous bars to fuse produces the condition known as cleft stermum, or if the failure to fuse affects only a portion of the bars there results a perforated sternum. A perforation or notching of the xiphoid cartilage is of frequent occurrence owing to this being the region where the fusion of the bars takes place last.

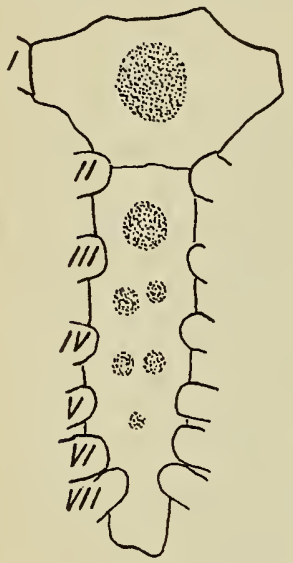

Fig. IO2.-STERNUM OF NEW-BORN CHILD, SHOWING Centers of Ossification. $I$ to $V I I$, Costal cartilages.(Gegenbaur.)

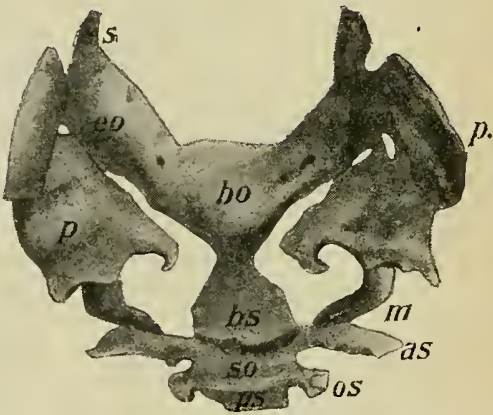

Fig. io3.-Reconstruction of the ChondroCRANIUM OF AN EMBRYO OF I4 MM.

$a s$, Alisphenoid; $b o$, basioccipital; $b s$, basisphenoid; eo, exoccipital; $m$, Meckel's cartilage; $o s$, orbitosphenoid; $p$, periotic; $p s$, presphenoid; so, sella turcica; s, supraoccipital.-(Levi.)

The suprasternal bones are the rudiments of a bone or cartilage, the omosternum, situated in front of the manubrium in many of the lower mammalia. It furnishes the articular surfaces for the clavicles and is possibly formed by a fusion of the ventral ends of the cartilages which represent those bones; hence its appearance as a pair of bones in the rudimentary condition.

The Development of the Skull.-In its earliest stages the human skull is represented by a continuous mass of mesenchyme which invests the anterior portion of the notochord and extends forward beyond its extremity into the nasal region, forming a core for the nasal process (see p. 99). From each side of this basal mass a wing projects dorsally to enclose the anterior portion of the medullary canal which will later become the cerebral part of the central nervous system. No indications of a segmental origin are to be 
found in this mesenchyme; as stated, it is a continuous mass, and this is likewise true of the cartilage which later develops in it.

The chondrification occurs first along the median line in what will be the occipital and sphenoidal regions of the skull (Fig. I03) and thence gradually extends forward into the ethmoidal region and to a certain extent dorsally at the sides and behind into the regions later occupied by the wings of the sphenoid (as and os) and the squamous portion of the occipital ( $s$ ). No cartilage develops, however, in the rest of the sides or in the roof of the skull, but the mesenchyme of these regions becomes converted into a dense membrane of connective tissue. While the chondrification is proceeding in the regions mentioned, the mesenchyme which encloses the internal ear becomes converted into cartilage, forming a mass, the periotic capsule (Fig. I03, p), wedged in on either side between the occipital and sphenoidal regions, with which it eventually unites to form a continuous chondrocranium, perforated by foramina for the passage of nerves and vessels.

The posterior part of the basilar portion of the occipital cartilage presents certain peculiarities of development. In calf embryos there are in this region, in very early stages, four separate condensations of mesoderm corresponding to as many mesodermic somites and to the three roots of the hypoglossal nerve together with the first cervical or suboccipital nerve (Froriep) (Fig. 104). These mesenchymal masses in their general characters and relations resemble vertebral bodies, and there are good reasons for believing that they represent four vertebræ which, in later stages, are taken up into the skull region and fuse with the primitive chondrocranium. In the human embryo they are less distinct than in lower mammals, but since a three-rooted hypoglossal and a suboccipital nerve also occur in man it is probable that the corresponding vertebræ are also represented. Indeed, confirmation of their existence may be found in the fact that during the cartilaginous stage of the skull the hypoglossal foramina are divided into three portions by two cartilaginous partitions which separate the three roots of the hypoglossal nerve. It seems certain from the evidence derived from embryology and comparative 
anatomy that the human skull is composed of a primitive unsegmental chondrocranium plus four vertebræ, the latter being added

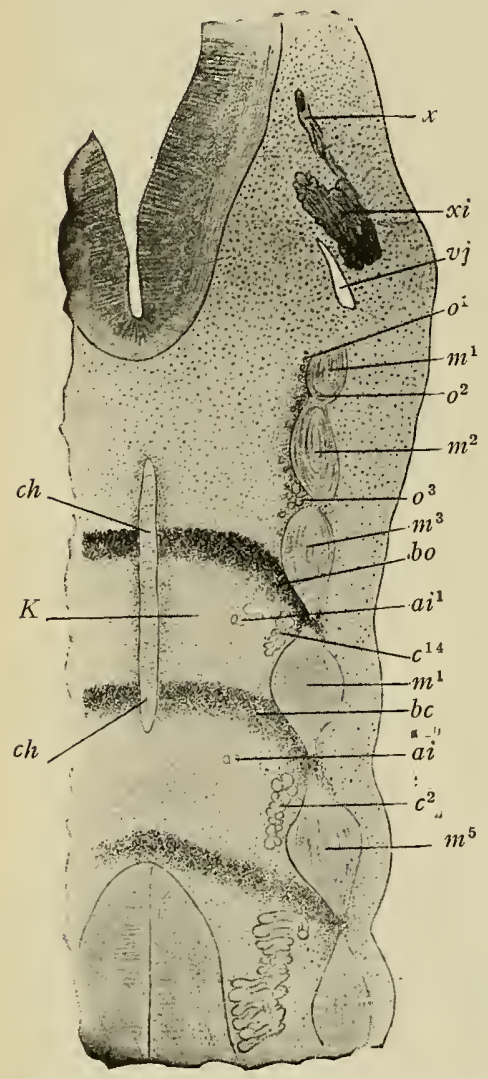

FIG. TO4.-FRONTAL SECTION THROUGH THE OCCIPITAL AND UPPER Cervical Regions of a CAlf Embryo OF $8.7 \mathrm{MM}$.

$a i$ and $a i^{1}$, Intervertebral arteries; $b c^{1}$, first cervical intervertebral plate; $b o$, suboccipital intervertebral plate; $c^{1-2}$, cervical nerves; $c h$, notochord; $K$, vertebral centrum; $\mathrm{m}^{1-3}$, occipital myotomes; $m^{4-5}$, cervical myotomes; $0^{1-3}$, roots of hypoglossal nerve; $v j$, jugular vein; $x$ and $x i$, vagus and spinal accessory nerves.-(Froriep.) to and incorporated with the occipital portion of the chondrocranium.

Emphasis must be laid upon the fact that the cartilaginous portion of the skull forms only the base and lower portions of the sides of the cranium, its entire roof, as well as the face region, showing no indication of cartilage, the mesenchyme in these regions being converted into fibrous connective tissue, which, especially in the cranial region, assumes the form of a dense membrane.

But in addition to the chondrocranium and the vertebræ incorporated with it, other cartilaginous elements enter into the composition of the skull. The mesenchyme which occupies the axis of each branchial arch undergoes more or less complete chondrification, cartilaginous bars being so formed, certain of which enter into very close relations with the skull. It has been seen (p. 92) that each half of the first arch gives rise to a maxillary process which grows forward and ventrally to form the anterior boundary of the mouth, while the remaining portion of the arch forms the mandibular process. The whole of the axis of the mandib- 
ular process becomes chondrified, forming a rod known as Meckel's cartilage, and this, at its dorsal end, comes into relation with the periotic capsule, as does also the dorsal end of the cartilage of the second arch. In the remaining three arches cartilage forms only in the ventral portions, so that their rods do not come into relation with the skull, though it will be convenient to consider their further history together with that of the other branchial arch cartilages. The arrangement of these cartilages is shown diagrammatically in Fig. 105.

By the ossification of these various parts three categories of bones are formed: (I) cartilage bones formed in the chondrocranium, (2) membrane bones, and (3) cartilage bones developing from the cartilages of the branchial arches. The bones belonging to each of these cate-

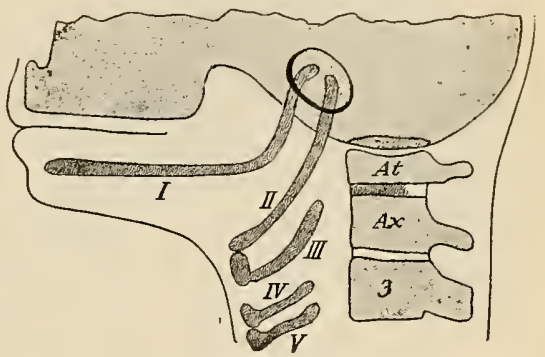

Fig. I05.-DiagraM SHOWING THE Five Branchial Cartilages, $I$ to $V$. $A t$, Atlas; $A x$, epistropheus; 3 , third cervical vertebra. gories are primarily quite distinct from one another and from those of the other groups, but in the human skull a very considerable amount of fusion of the primary bones takes place, and elements belonging to two or even to all three categories may unite to form a single bone of the adult skull. In a certain region of the chondrocranium also and in one of the branchial arches the original cartilage bone becomes ensheathed by membrane bone and eventually disappears completely, so that the adult bone, although represented by a cartilage, is really a membrane bone. And, indeed, this process has proceeded so far in certain portions of the branchial arch skeleton that the original cartilaginous representatives are no longer developed, but the bones are deposited directly in connective tissue. These various modifications interfere greatly with the precise application to the human skull of the classification of bones into the three categories given above, and indeed the true significance of certain of the skull bones can only be perceived by comparative 
studies. Nevertheless it seems advisable to retain the classification, indicating, where necessary, the confusion of bones of the various categories.

The Ossification of the Chondrocranium.-The ossification of the cartilage of the occipital region results in the formation of four distinct bones which even at birth are separated from one

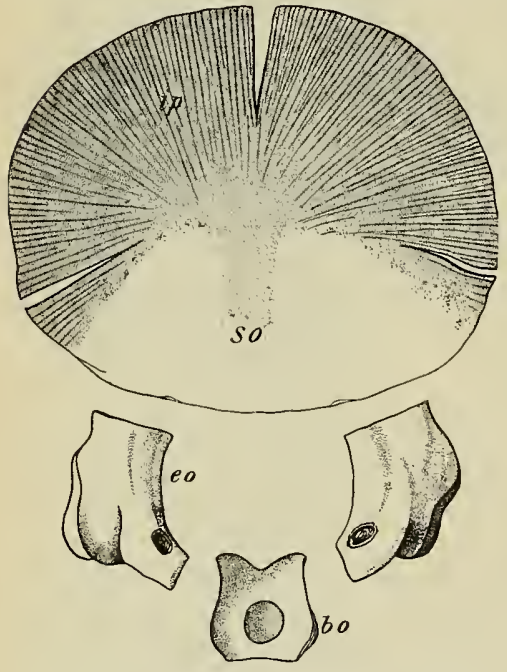

Fig. io6.-Occipttal Bone of a Fetus AT TERM.

$b o$, Basioccipital; eo, exoccipital; ip, interparietal; so, supraoccipital. another by bands of cartilage. The portion of cartilage lying in front of the foramen magnum ossifies to form a basioccipital bone (Fig. Io6, bo), the portions on either side of this give rise to the two exoccipitals (eo), which bear the condyles, and the portion above the foramen produces a supraoccipital (so), which represents the part of the squamous portion of the adult bone lying below the superior nuchal line. All that portion of the bone which lies above that line is composed of membrane bone which owes its origin to the fusion of two or sometimes four centers of ossification, appearing in the membranous roof of the embryonic skull. The bone so formed (ip) represents the interparietal of lower vertebrates and, at an early stage, unites with the supraoccipital, although even at birth an indication of the line of union of the two parts is to be seen in two deep incisions at the sides of the bone. The union of the exoccipitals and supraoccipital takes place in the course of the first or second year after birth, but the basioccipital does not fuse with the rest of the bone until the sixth or eighth year. It will be noticed that no special centers occur for the four occipital vertebræ, these structures having become completely incorporated in the chondro- 
cranium, and even the cartilaginous partitions which divide the hypoglossal foramina usually disappear during the process of ossification.

Two pairs of centers have been described for the interparietal bone and it has been claimed that the deep lateral incisions divide the lower pair, so that when the incisions meet and persist as the sutura mendosa, separating the so-called inca bone from the rest of the occipital, the division does not correspond to the line between the supraoccipital and the interparietal, but a portion of the latter bone remains in connection with the supraoccipital. Mall, however, in twenty preparations, found but a single pair of centers for the interparietal.

Occasionally an additional pair of small centers appear for the uppermost angle of the interparietal, and the bones formed from them may remain distinct as what have been termed fontanelle bones.

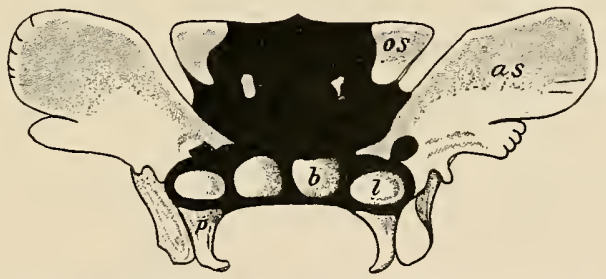

Fig. I07.-Sphenoid Bone From EMbryo of $3 \frac{1}{2}$ To 4 Months.

The parts which are still cartilaginous are represented in black. as, Alisphenoid; $b$, basisphenoid; $l$, lingula; os, orbitosphenoid; $p$, internal pterygoid plate.-(Sappey.)

In the sphenoidal region the number of distinct bones which develop is much greater than in the occipital region. At the beginning of the second month a center appears in each of the cartilages which represent the alisphenoids (great wings). These cartilages do not, however, represent the entire extent of the great wings and their ossification gives rise only to those portions of the bone in the neighborhood of the foramina ovale and rotundum and to the lateral pterygoid plates. The remaining portions of the wings, the orbital and temporal portions, develop as membrane bone (Fawcett) 
and early unite with the portions formed from the cartilage. At the end of the second month a center appears in each orbitosphenoid (lesser wing) cartilage (Fig. I07, os), and a little later a pair of centers $(b)$, placed side by side, are developed in the cartilage representing the posterior portion of the body; together these form what is known as the basisphenoid. Still later a center appears on either side of the basisphenoids to form the lingule $(l)$, and another pair appears in the anterior part of the cartilage, between the orbitosphenoids, and represent the presphenoid.

In addition to these ten centers in cartilage and the membrane portion of the alisphenoid, two other membrane bones are included in the adult sphenoid. Thus, a little before the appearance of the center for the alisphenoids an ossification is formed in the mesenchyme of each lateral wall of the posterior part of the nasal cavity and gives rise to the medial lamina of the pterygoid process, the mesenchyme at the tip of the ossification condensing to form a cartilaginous hook-like structure over which the tendon of the tensor veli palatini plays. This cartilage later ossifies to form the pterygoid hamulus, the medial pterygoid lamina being thus a combination of membrane and cartilage, the latter, however, being a secondary development and quite independent of the chondrocranium.

By the sixth month the lingulæ have fused with the basisphenoid and the orbitosphenoids with the presphenoid, and a little later the basisphenoid and presphenoid unite. The alisphenoids and medial pterygoid laminæ remain separate, however, until after birth, fusing with the remaining portions of the adult bone during the first year.

The cartilage of the ethmoidal region of the chondrocranium forms somewhat later than the other portions and consists at first of a stout median mass projecting downward and forward into the nasal process (Fig. I08, lp), and two lateral masses $(l m)$, situated one on either side in the mesenchyme on the outer side of each olfactory pit. Ossification of the lateral masses or ectethmoids begins relatively early, but it appears in the upper part of the median cartilage only after birth, producing the crista galli and the perpendicular plate, which together form what is termed the mesethmoid. When 
first formed, the three cartilages are quite separate from one another, the olfactory and nasal nerves passing down between them to the olfactory pit, but later trabeculæ begin to extend across from the mesethmoid to the upper part of the ectethmoids and eventually form a fenestrated horizontal lamella which ossifies to form the cribriform plate.

The lower part of the median cartilage does not ossify, but a center appears on each side of the median line in the mesenchyme behind and below its posterior or lower border. From these centers two vertical bony plates develop which unite by their median surfaces below, and above invest the lower border of the cartilage and form the vomer. The portion of the cartilage which is thus invested undergoes resorption, but the more anterior portions persist to form the cartilaginous septum of the nose. The vomer, consequently, is not really a portion of the chondrocranium, but is a membrane bone; its intimate relations with the median ethmoidal cartilage, however, make it convenient

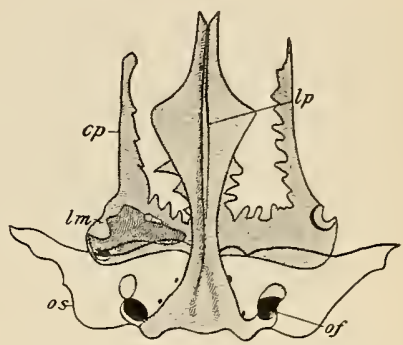

Fig. io8.-Anterior Portion of the Base of the Skull of a 6 to 7 Months' Embryo.

The shaded parts represent cartilage. $c p$, Cribriform plate; $l m$, lateral mass of the ethmoid; lp, perpendicular plate; of, optic foramen; os, orbitosphenoid.(After von Spee.) to consider it in this place.

When first formed, the ectethmoids are masses of spongy bone and show no indication of the honeycombed appearance which they present in the adult skull. This condition is produced by the absorption of the bone of each mass by evaginations into it of the mucous membrane lining the nasal cavity. This same process also brings about the formation of the curved plates of bone which project from the inner surfaces of the lateral masses and are known as the superior and middle conchæ (turbinated bones). The inferior and sphenoidal conchæ are developed from special centers, but belong to the same category as the others, being formed from portions of the lateral ethmoidal cartilages which become almost 
separated at an early stage before the ossification has made much progress. Absorption of the body of the sphenoid bone to form the sphenoidal cells, of the frontal to form the frontal sinuses, and of the maxillaries to form the maxillary antra is also produced by outgrowths of the nasal mucous membrane, all these cavities, as well as the ethmoidal cells, being continuous with the nasal cavities and lined with an epithelium which is continuous with the mucous membrane of the nose.

In the lower mammalia the erosion of the mesial surface of the ectethmoidal cartilages results, as a rule, in the formation of five conchr, while in man but three are usually recognized. Not infrequently, however, the human middle concha shows indications, more or less marked, of a division into an upper and a lower portion, which correspond to the third and fourth bones of the typical mammalian arrangement. Furthermore, at the upper portion of the nasal wall, in front of

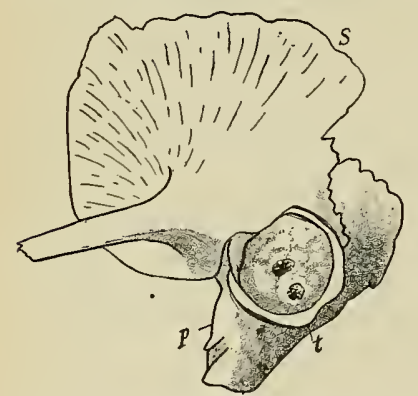

Fig. IO9.-THE TEMPORAL BONe AT BirTh. The STYLOID PROCESS AND AUdITORY OSSICLES ARE NOT REPRESENTED.

$p$, Petrous bone; s, squamosal;

$t$, tympanic.-(Poirier.) the superior concha, a slight elevation, termed the agger nasi, is always observable, its lower edge being prolonged downward to form what is termed the uncinate process of the ethmoid. This process and the agger together represent the uppermost concha of the typical arrangement, to which, therefore, the human arrangement may be reduced.

A number of centers of ossification-the exact number is yet uncertain-appear in the periotic capsule during the later portions of the fifth month, and during the sixth month these unite together to form a single center from which the complete ossification of the cartilage proceeds to form the petrous and mastoid portions of the temporal bone (Fig. Io9, $p$ ). The mastoid process does not really form until several years after birth, being produced by the hollowing and bulging out of a portion of the petrous bone by out-growths from the lining membrane of the middle ear. The cavities so formed are the mastoid cells, and their relations to the middle-ear cavity are in all respects similar to those of the ethmoidal 
and sphenoidal cells to the nasal cavities. The remaining portions of the temporal bone are partly formed by membrane bone and partly from the branchial arch skeleton. An ossification appears at the close of the eighth week in the membrane which forms the side of the skull in the temporal region and gives rise to a squamosal bone $(s)$, which later unites with the petrous to form the squamosal portion of the adult temporal, and another membrane bone, the tympanic $(t)$, develops from a center appearing in the mesenchyme surrounding the external auditory meatus, and later also fuses with the petrous to form the floor and sides of the external meatus, giving attachment at its inner edge to the tympanic membrane. Finally, the styloid process is developed from the upper part of the second branchial arch, whose history will be considered later.

The various ossifications which form in the chondrocranium and the portions of the adult skull which represent them are shown in the following table:

\section{REgION OF
CHONDROCRANIUM. OSSIFICATION.}

Occipital ..... $\left\{\begin{array}{l}\text { Basioccipital } \\ \text { Exoccipitals } \\ \text { Supraoccipital }\end{array}\right.$

Sphenoidal .... $\left\{\begin{array}{l}\text { Basisphenoid } \\ \text { Presphenoid } \\ \text { Lingulæ } \\ \text { Alisphenoids } \\ \text { Orbitosphenoids }\end{array}\right.$

Ethmoidal .... $\left\{\begin{array}{l}\text { Mesethmoid } \\ \text { Ectethmoids } \\ \begin{array}{l}\text { Inferior concha. } \\ \text { Sphenoidal concha. }\end{array}\end{array}\right.$

Periotic capsule

\section{Parts of Adult Skull;}

Basilar process.

Condyles.

Squamous portion below superior nuchal line.

Body.

Greater wings (in part).

Lesser wings.

Lamina perpendicularis.

Crista galli.

Nasal septum.

Lateral masses.

Superior concha.

Middle concha.

The Membrane Bones of the Skull.-In the membrane forming the sides and roof of the skull in the second stage of its develop- 
ment ossifications appear, which give rise, in addition to the interparietal and squamosal bones already mentioned in connection with the occipital and temporal, to the parietals and frontal. Each of the former bones develops from a single center which appears at the end of the eighth week, while the frontal is formed at about the same time from two centers situated symmetrically on each side of the median line and eventually fusing completely to form a single bone, although more or less distinct indications of a median suture, the metopic, are not infrequently present.

Furthermore, ossifications appear in the mesenchyme of the facial region to form the nasal, lachrymal, and zygomatic bones, all of which arise from single centers of ossification. In the case of each zygomatic bone, however, three osseous thickenings appear on the inner surface of the original ossification, which then disappears and the thickenings unite to form the adult bone, though occasionally one or more of their lines of union may persist, producing a bipartite or tripartite zygomatic.

The vomer, which has already been described, belongs also strictly to the category of membrane bones, as do also the maxillæ and the palatines; these latter, however, primarily belonging to the branchial arch skeleton, with which they will be considered.

The purely membrane bones in the skull, are, then, the following:

Interparietals............ Part of squamous portion of occipital.

Pterygoids................ Medial pterygoid plates.

Squamosals............... Squamous portions of temporals.

Tympanics............... Tympanic plates of temporals.

Parietals.

Frontal.

Nasals.

Lachrymals.

Zygomatics.

Vomer.

The Ossification of the Branchial Arch Skeleton.-It has been seen (p. I7I) that a cartilaginous bar develops only in the mandibular process of the first branchial arch. In the maxillary process no cartilaginous skeleton forms, but two membrane bones, 
the palatine and maxilla, are developed in it, their cartilaginous representatives, which are to be found in lower vertebrates, having been suppressed by a condensation of the development. The palatine bone develops from a single center of ossification, but for each maxilla no less than five centers have been described (Fig. Iro). One of these gives rise to so much of the alveolar border of the bone as contains the bicuspid and molar teeth; a second forms the nasal process and the part of the alveolar border which contains the canine tooth; a third the portion which contains the incisor teeth; while the fourth and fifth centers lie above the first and give rise to the inner and outer portions of the orbital plate and the body of the bone. The first, second, fourth, and fifth portions early unite together, but the third center, which really lies in the

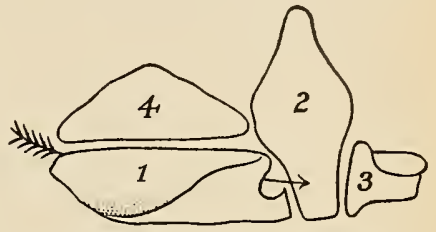

Fig. i io.-Diagram of the OssiFICATIONS OF WHICH THE MAXILLA IS COMPOSED, AS SEEN FROM THE OUter Surface. THE ARrow PASSES THROUGH THE INFRAORBITAL Canal.-(From von Spee, after Sappey.)

ventral part of the nasal process, remains separate for some time, forming what is termed the premaxilla, a bone which remains permanently distinct in the majority of the lower mammals.

The above is the generally accepted view as to the development of the maxilla. Mall, however, maintains that it has but two centers of ossification, one giving rise to the premaxilla and the other to the rest of the bone. The maxillary center makes its appearance about the middle of the sixth week.

Since the condition known as hare-lip results from a failure of the maxillary process to unite completely with the frontonasal process (see p. IOo), and since the premaxilla develops in the latter and the maxilla in the former, the cleft may pass between these two bones and prevent their union (see also p. 284 ).

The upper end of Meckel's cartilage passes between the tympanic bone and the outer surface of the periotic capsule and thus comes to lie apparently within the tympanic cavity of the ear; this portion of the cartilage divides into two parts which ossify to form two of the bones of the middle ear, the malleus and incus, a description of 
whose further development may be postponed until a later chapter. At about the middle of the sixth week of development a plate of membrane bone appears to the outer side of the lower portion of the cartilage and gradually extends to form the body and ramus of the mandible.

In the region of the body the bone develops so as to enclose the cartilage, together with the inferior alveolar (dental) nerve which lies to the outer side of the cartilage, but in the region of the ramus

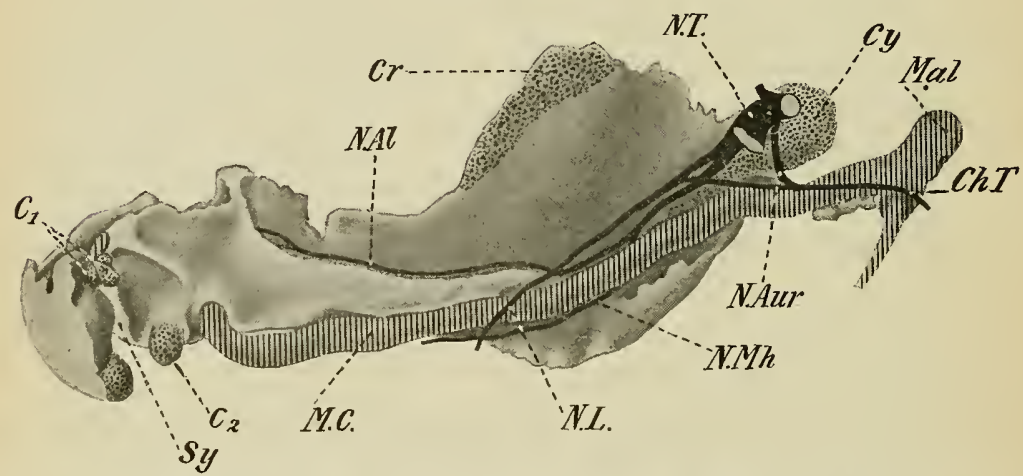

Fig. iil.-Model of Right Half of Mandible of a Fetus 95 My. in Length, SEEN FROM THE MESTAL SURFACE.

$C_{1}$ and $C_{2}$, Accessory cartilages; $C h . T$., chorda tympani; $C r$., cartilage for coronoid process; $C y$., cartilage for condyloid process; $M a l$., malleus; $M$.C., Meckel's cartilage; $N$. $A l$., inferior alveolar nerve; $N$. Aur., auriculo-temporal nerve; $N . L$., lingual nerve; N.Mh., mylo-hyoid nerve; N.T., trigeminal nerve; $S y$., symphysis.-(Low.)

the bone remains entirely to the outer side of the cartilage and nerve, whence the position of the mandibular foramen on the inner surface of the adult bone. The anterior portion of Meckel's cartilage becomes ossified by the extension of ossification from the membrane bone into it, the portion corresponding to the body of the bone behind the mental foramen disappears and the portion above the mandibular foramen is said to become transformed into fibrous connective tissue and to persist as the spheno-mandibular ligament. At the upper extremity of the ramus two nodules of cartilage develop, quite independently, however, of Meckel's cartilage (Fig. I I , $C r$ and $C y$ ), 
and ossification extends into these from the ramus to form the coronoid and condyloid processes. And, finally, two other independent cartilages appear toward the anterior extremity of each half

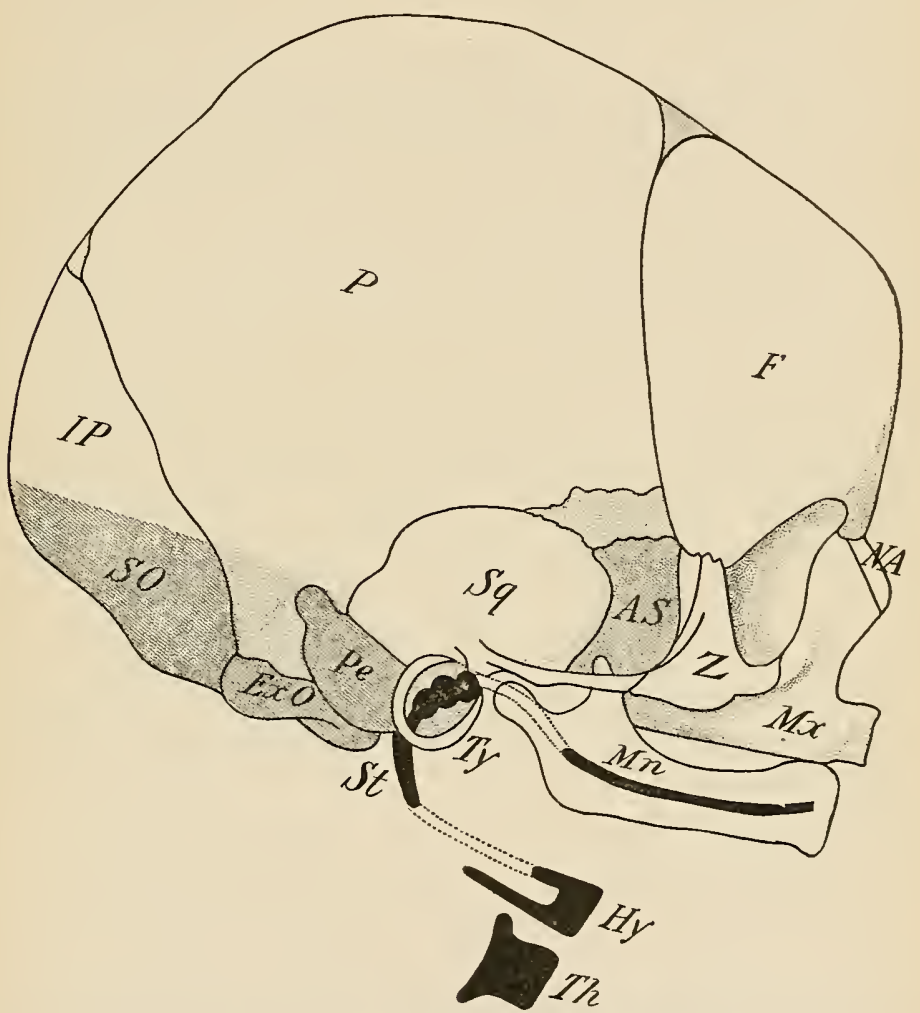

Fig. il2.-Diagram showing the Categories to which the Bones of the Skull BELONG.

The unshaded bones are membrane bones, the heavily shaded represent the chondrocranium, while the black represents the branchial arch elements. $A S$, Alisphenoid; $E x O$, exoccipital; $F$, frontal; $H y$, hyoid; $I P$, interparietal; $Z$, zygomatic; $M n$, mandible; $M x$, maxilla; $N A$, nasal; $P$, parietal; $P e$, periotic; $S O$, supraoccipital; $S g$, squamosal; $S t$, styloid process; $T h$, thyreoid cartilage; $T y$, tympanic.

of the bone, one at the alveolar $\left(C_{1}\right)$ and the other at the lower border $\left(\dot{C}_{2}\right)$, and these also are later incorporated into the bone without developing special centers of ossification. 
Each half of the mandible thus ossifies from a single center, and is essentially a membrane bone replacing a cartilaginous precursor. At birth the two halves are united at the symphysis by fibrous tissue, into which ossification extends later, union occurring in the first or second year.

The upper part of the cartilage of the second branchial arch also comes into relation with the tympanic cavity and ossifies to form the styloid process of the temporal bone. The succeeding moiety of the cartilage undergoes degeneration to form the stylo-hyoid ligament, while its most ventral portion ossifies as the lesser cormu of the hyoid bone. The great variability which may be observed in the length of the styloid processes and of the lesser cornua of the hyoid depends upon the extent to which the ossification of the original cartilage proceeds, the length of the stylo-hyoid ligaments being in inverse ratio to the length of the processes or cornua. The greater cormua of the hyoid are formed by the ossification of the cartilages of the third arch, and the body of the bone is formed from a cartilaginous plate, the copula, which unites the ventral ends of the two arches concerned.

Finally, the cartilages of the fourth and fifth branchial arches early fuse together to form a plate of cartilage, and the two plates of opposite sides unite by their ventral edges to form the thyreoid cartilage of the larynx.

The accompanying diagram (Fig. I I2) shows the various structures derived from the branchial arch skeleton, as well as some of the other elements of the skull, and a resume of the fate of the branchial arches may be stated in tabular form as follows, the parts represented by cartilage which becomes replaced by membrane bone being printed in italics, while membrane bones which have no cartilaginous representatives are enclosed in brackets:

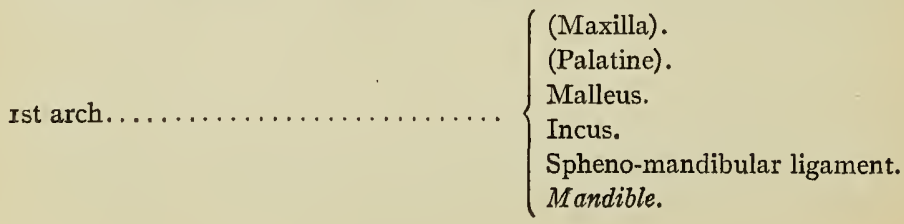




$2 d \operatorname{arch} \ldots \ldots \ldots \ldots \ldots \ldots \ldots \ldots\left\{\begin{array}{l}\text { Styloid process of the temporal. } \\ \text { Stylo-hyoid liganient. } \\ \text { Lesser cornu of hyoid. }\end{array}\right.$

$3 \mathrm{~d}$ arch.

$4^{\text {th }}$ and $5^{\text {th }}$ arches.
Greater cornu of hyoid.

Thyreoid cartilage of larynx.

The Development of the Appendicular Skeleton.-While the greater portion of the axial skeleton is formed from the sclerotomes of the mesodermic somites, the appendicular skeleton is derived from the somatic mesenchyme, which is not divided into metameres. This mesenchyme forms the core of the limb bud and becomes converted into cartilage, by the ossification of which all the bones of the limbs, with the possible exception of the clavicle, are formed.

Of the bones of the pectoral girdle the clavicle requires further study before it can be certain whether it is to be regarded as a purely cartilage bone or as a combination of cartilage and membrane ossification (Gegenbaur). It is the first bone of the skeleton to ossify, two centers appearing for each bone at about the sixth week of development. The tissue in which the ossifications form has certain peculiar characters, and it is difficult to say whether it is to be regarded as cartilage which, on account of the early differentiation of the center, has not yet become thoroughly differentiated histologically, or as some other form of connective tissue. However that may be, true cartilage develops on either side of the ossifying region, and into this the ossification gradually extends, so that at least a portion of the bone is preformed in cartilage.

The scapula is at first a single plate of cartilage in which two centers of ossification appear. One of these gives rise to the body and the spine, while the other produces the coracoid process (Fig. I I $3, c o$ ), the rudimentary representative of the coracoid bone which extends between the scapula and sternum in the lower vertebrates. The coracoid does not unite with the body until about the fifteenth year, and secondary centers which give rise to the vertebral edge (b) and inferior angle of the bone $(a)$ and to the acromion process $(c)$ unite with the rest of the bone at about the twentieth year. 
The humerus and the bones of the forearm are typical long bones, each of which develops from a primary center, which gives rise to the shaft, and has, in addition, two or more epiphysial centers. In the humerus an epiphysial center appears for the head, another for the greater tuberosity, and usually a third for the lesser tuberosity, while at the distal end there is a center for each condyle, one for the trochlea and one for the capitulum, the fusion of these various epiphyses with the shaft taking place between the seventeenth and

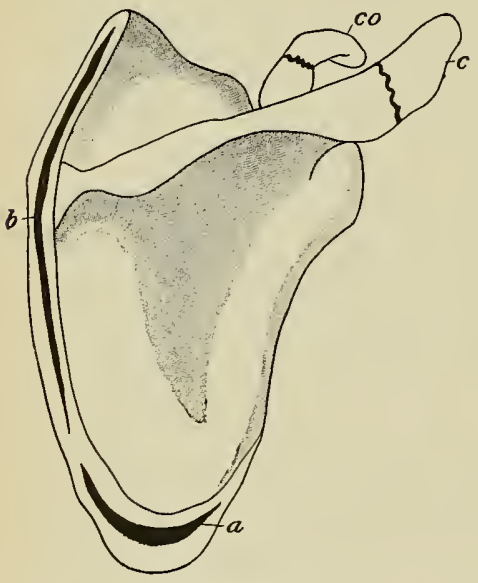

Fig. in3.-The Ossification CenTERS OF THE SCAPULA.

$a, b$, and $c$, Secondary centers for the angle, vertebral border, and acromion; co, center for the coracoid process.-(Testut.)

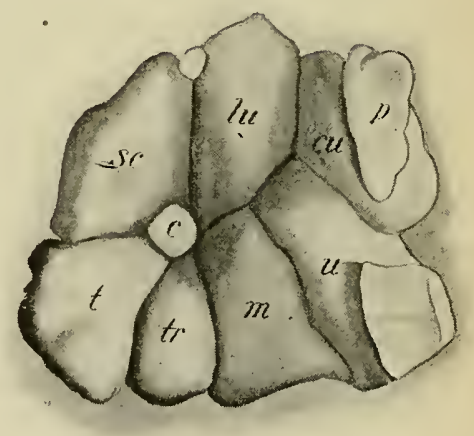

Fig. II4.-RECONSTRUCTION OF AN EMBRYONIC CARPUS.

$c$, Centrale; $c u$, triquetral; $l u$, lunate; $m$, capitate; $p$, pisiform; $s c$, navicular; $t$, greater multangular; $t r$, lesser multangular; $u$, hamate.

twentieth years. The radius and ulna each possesses a single epiphysial center for each extremity in addition to the primary center for the shaft, the proximal epiphysial center for the ulna giving rise to the tip of the olecranon process.

The embryological development of the carpus is somewhat complicated. A cartilage is found representing each of the bones normally occurring in the adult (Fig. II4), and these are arranged in two distinct.rows: a proximal one consisting of three elements, 
named from their relation to the bones of the forearm, radiale, intermedium, and ulnare; and a distal one composed of four elements, termed carpalia. In addition, a cartilage, termed the pisiform, is found on the ulnar side of the proximal row and is generally regarded as a sesamoid cartilage developed in the tendon of the fleter carpi ulnaris, and furthermore a number of inconstant cartilatges have been observed whose significance in the majority of cases is more or less obscure. These accessory cartilages either disappear in later stages of development or fuse with neighboring cartilages, or, in rare cases, ossify and form distinct elements of the carpus. One of them, however, occurs so frequently as almost to deserve classification as a constant element; it is known as the centrale (Fig. II4, c) and occupies a position between the cartilages of the proximal and distal rows and apparently corresponds to a cartilage typlically present in lower forms and orfying to form a distinct bone. In the human carpus its fate varies, $w_{6}$ it may either disappear or unite with other cartilages, that with which it most usually fuses being probably the radiale. There is evidence also to show that another of the accessory cartilages unites/with the ulnar element of the distadrow, representing the carpale $\mathrm{v}$ tydically present in lower forms.

Each of the elements corresponding to an adult bone ossifies from a single center with the exception of carpale IV- 5 which has two centers, a further indication of its composite character. The relation of the carthergs to the adult bones may be seen from the table given on page $18 x$.

With regard to the metacarpals and phalanges, it need merely be stated that each develops from a single primary center for the shaft and one secondary epiphysial center. The primary center appears at about the middle of the shaft except in the terminal phalanges, in which it appears at the distal end of the cartilage. The epiphyses for the metacarpals are at the distatends of the bones, except in the case of the metacarpal of the thumb, which resembles the phalanges in having its epiphysis at the proximal end.

Each innominate bone appears as a somewhat oral plate of cartilage whose long axis is directed almost at right angles to the 
vertebral column and which is in close relation with the fourth and fifth sacral vertebræ. As development proceeds a rotation of the cartilage, accompanied by a slight shifting of position, occurs, so that eventually the plate has its long axis almost parallel with the vertebral column and is in relation with the first three sacrals. Ossification appears at three points in each cartilage, one in the

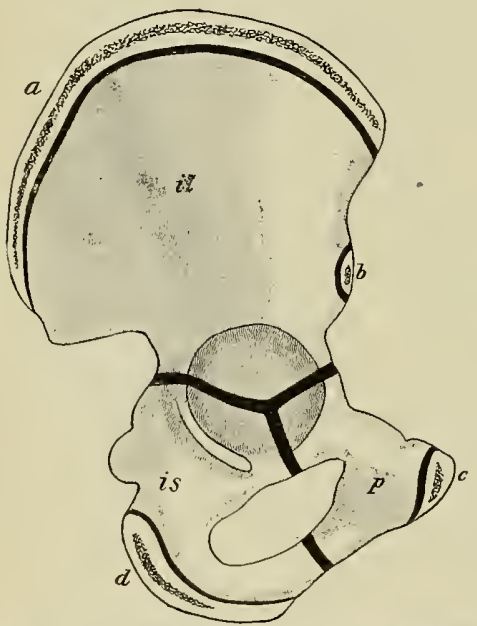

Fig. i I 5.-The Ossification Centers OF THE Os InNominatum.

$a, b, c$, and $d$, Secondary centers for the crest, anterior inferior spine, symphysis, and ischial tuberosity; il, ilium; is, ischium; $p$, pubis.-(Testut.)

upper part to form the ilium (Fig. I $5, i l)$ and two in the lower part, the anterior of these giving rise to the pubis $(p)$, while the posterior produces the ischium (is). At birth these three bones are still separated from one another by a $\mathrm{Y}$-shaped piece of cartilage whose three limbs meet at the bottom of the acetabulum, but later a secondary center appears in this cartilage and unites the three bones together. The central part of the lower half of each original cartilage plate does not undergo complete chondrification, but remains membranous, constituting the obturator membrane which closes the obturator foramen.

In addition to the $\mathrm{Y}$-shaped secondary center, other epiphysial centers appear in the prominent portions of the cartilage, such as the pubic crest (Fig. II 5, c), the ischial tuberosity $(d)$, the anterior inferior spine $(b)$ and the crest of the ilium $(a)$, and unite with the rest of the bone at about the twentieth year.

The femur, tibia, and fibula each develop from a single primary center for the shaft and an upper and a lower epiphysial center, the femur possessing, in addition, epiphysial centers for the greater and lesser trochanters (Fig. 94). The patella does not belong to the same category as the other bones, but resembles the pisiform 
bone of the carpus in being a sesamoid bone, developed in the tendon of the quadriceps extensor cruris. Its cartilage does not appear until the fourth month of intrauterine life, when most of the primary centers for other bones have already appeared, and its ossification does not begin until the third year after birth.

The tarsus, like the carpus, consists of a proximal row of three cartilages, termed the tibiale, the intermedium, and the fibulare, and of a distal row of four tarsalia. Between these two rows a single cartilage, the centrale, is interposed. Each of these cartilages ossifies from a single center, that of the intermedium early fusing with the tibiale, though it occasionally remains distinct as the os trigomum, and from a comparison with lower forms it seems probable that the fibular cartilage of the distal row really represents two separate elements, there being, properly speaking, five tarsalia instead ot four. The fibulare, in addition to its primary center, possesses also an epiphysial center, which develops at the point of insertion of the tendo Achillis.

A comparison of the carpal and tarsal cartilages and their relations to the adult bones may be seen from the following table:

\begin{tabular}{|c|c|c|c|}
\hline \multicolumn{2}{|c|}{ Carpus } & \multicolumn{2}{|c|}{ Tarsus } \\
\hline Cartilages & Bones & Bones & Cartilages \\
\hline $\left.\begin{array}{l}\text { Radiale } \\
\text { Intermedium } \\
\text { Ulnare } \\
\text { Sesamoid cartilage } \\
\text { Centrale } \\
\text { Carpale I } \\
\text { Carpale II } \\
\text { Carpale III } \\
\text { Carpale IV } \\
\text { Carpale V }\end{array}\right\}$ & $\begin{array}{l}\text { Navicular } \\
\text { Lunate } \\
\text { Triquetral } \\
\text { Pisiform } \\
\text { Fuses with navicular } \\
\text { Gr. multangular } \\
\text { Less. multangular } \\
\text { Capitate } \\
\text { Hamate }\end{array}$ & $\begin{array}{l}\text { Talus } \\
\text { Calçaneus } \\
\text { Navicular } \\
\text { rst Cuneiform } \\
\text { 2d Cuneiform } \\
\text { 3d Cuneiform } \\
\text { Cuboid }\end{array}$ & $\begin{array}{l}\left\{\begin{array}{l}\text { Tibiale } \\
\text { Intermedium }\end{array}\right. \\
\text { Fibulare } \\
\text { Centrale } \\
\text { Tarsale I } \\
\text { Tarsale II } \\
\text { Tarsale III } \\
\left\{\begin{array}{l}\text { Tarsale IV } \\
\text { Tarsale V }\end{array}\right.\end{array}$ \\
\hline
\end{tabular}


The development of the metatarsals and phalanges is exactly similar to that of the corresponding bones of the hand (see p. I85).

The Development of the Joints.-The mesenchyme which primarily represents each vertebra, or the skull, or the skeleton of a limb, is at first a continuous mass, and when it becomes converted into cartilage this also may be continuous, as in the skull, or may appear as a number of distinct parts united by unmodified portions of the mesenchyme. In the former case the various ossifications as they extend will come into contact with their neighbors and will either fuse with them or will articulate with them directly, forming a suture.

When, however, a portion of unmodified mesenchyme intervenes between two cartilages, the mode of articulation of the bones formed from these cartilages will vary. The intermediate mesenchyme may in time undergo chondrification and unite the bones in an almost immovable articulation known as a synchondrosis (e.g., the articulation of the first rib with the sternum); or a cavity may appear in the center of the intervening cartilage so that a slight amount of movement of the two bones is possible, forming an amphiarthrosis (e. g., the symphysis pubis); or, finally, the intermediate mesenchyme may not chondrify, but its peripheral portions may become converted into a dense sheath of connective tissue (Fig. II6, c) which surrounds the adjacent ends of the two bones like a sleeve, forming the articular capsule, while the central portions degenerate to form a cavity. The bones which enter into such an articulation are more or less freely movable upon one another and the joint is termed a diarthrosis (e. g., the knee- or shoulder-joint).

In a diarthrosis the connective-tissue cells near the inner surface of the capsule arrange themselves in a layer to form a synovial membrane for the joint, and portions of the capsule may thicken to form special bands, the reinforcing ligaments, while other strong fibrous bands, which may pass from one bone to the other, forming accessory ligaments, are shown by comparative studies to be in many cases degenerated portions of what were originally muscles.

In certain diarthroses, such as the temporo-mandibular and 
sterno-clavicular, the whole of the central portions of the intermediate mesenchyme does not degenerate, but it is converted into a fibro-cartilage, between each surface of which and the adjacent bone there is a cavity. These interarticular cartilages seem, in the sterno-clavicular joints, to represent the sternal ends of a bone existing in lower vertebrates and known as the precoracoid, but it seems doubtful. if those of the temporo-mandibular and knee-

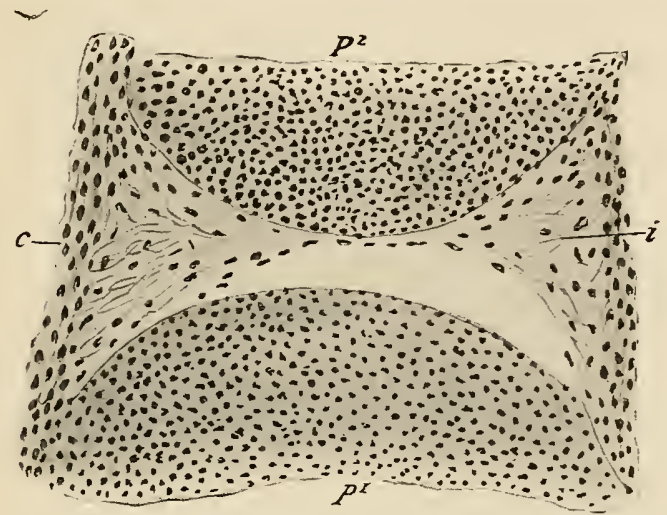

Fig. il6.-Longitudinal Section through the JoINT of the Great ToE IN aN EMBRYO OF $4.5 \mathrm{CM}$.

$c$, Articular capsule; $i$, intermediate mesenchyme which has almost disappeared in the center; $p^{1}$ and $p^{2}$, cartilages of the first and second phalanges.-(Nicholas.)

joints have a similar significance, the most recent observations on their development tending to derive them from the intermediate mesenchyme.

From their mode of development it is evident that the cavities of diarthrodial joints are completely closed and their walls, except where they are formed by cartilage, are lined by a continuous layer of synovial cells. Ligaments or tendons, which, at first sight, appear to traverse the cavities of certain joints, are in reality excluded from them, being lined by a sheath of synovial cells continuous with the layer lining the general cavity. Thus, the tendon of the long head of the biceps, which seems to traverse the shoulder-joint is, in the fetus, entirely outside the articular capsule, upon which it rests. Later it sinks in toward the joint cavity, pushing the articular capsule before it, so that it lies at first in a groove in the capsule, which later on becomes converted into a canal and, finally, separates from the rest of the capsule except at its two extremities, 
forming a cylindrical canal, open at either end, traversing the joint cavity and containing the tendon of the biceps.

The ligamentum teres of the hip-joint is similarly excluded from the joint cavity by a sheath of synovium, which extends outward around it from the bottom of the acetabular fossa to the depression in the head of the femur, and in the knee-joint the crucial ligaments are also excluded from the cavity by a reflection of the synovium. This joint, indeed, is in the fetus incompletely divided into two parts, one corresponding to each femoral condyle, by a partition which extends backward from the patellar ligament to the crucial ligaments, remains of this partition persisting in the adult as the so-called ligamentum mucosum.

\section{LITERATURE.}

C. R. BARdeEn: "The Development of the Thoracic Vertebrx in Man," Amer. Journ. Anat., IV, I905.

C. R. Bardeen: "Studies of the Development of the Human Skeleton," Amer Journ. Anat. IV, I905.

C. R. BARDEen: "Early Development of the Cervical Vertebræ and the Base of the Occipital Bone in Man," Amer. Journ. Anat., viII, I908.

C. R. BARDEen: "Vertebral Regional Determination in Young Human Embryos," Anat. Record, II, I908.

E. T. Bell: "On the Histogenesis of the Adipose Tissue of the Ox," Amer. Journ. Anat., IX, I909.

A. Bernays: "Die Entwicklungsgeschichte des Kniegelenks des Menschen mit Bemerkungen über die Gelenke im Allgemeinen," Morpholog. Jahrbuch, IV, I878.

E. Dursy: "Zur Entwicklungsgeschichte des Kopfes des Menschen und der höheren Wirbelthiere," Tübingen, r869.

E. Fawcetr: "On the Development, Ossification and Growth of the Palate Bone," Journ. Anat. and Phys., XL, I906.

E. Fawcett: "Notes on the Development of the Human Sphenoid," Journ. Anat. and Phys., Xurv, I9IO.

E. Fawcett: "The Development of the Human Maxilla, Vomer and Paraseptal Cartilages," Journ. Anat. and Phys., XLv, I9I r.

A. FrorieP: "Zur Entwicklungsgeschichte der Wirbelsäule, insbesondere des Atlas und Epistropheus und der Occipitalregion," Archiv für Anat. und Physiol., Anat. Abth., 1886.

E. GAupp: "Alte Probleme und neuere Arbeiten über den Wirbeltierschädel," Ergeb. der Anat. und Entwicklungsgesch., x, I90I.

C. GegenbauR: "Ein Fall von erblichem Mangel der Pars acromialis Claviculæ, mit Bemerkungen über die Entwicklung der Clavicula," Jenaische Zeitschr. für medic. Wissensch., I, I864.

J. Golowinski: "Zur Kenntnis der Histogenese der Bindegewebsfibrillen," Anat. Hefte, xxxIIr, I907. 
E. Gräfenberg: "Die Entwicklung der Knochen, Muskeln und Nerven der Hand und der für die Bewegungen der Hand bestimmten Muskeln des Unterarms," Anat. Hefte, xxx, 1906.

Henke ANd ReYHer: "Studien über die Entwickelung der Extremitaten des Menschen, insbesondere der Gelenkflächen," Sitzungsberichte der kais. Akad. Wien, LXx, I875.

M. ЈАкову: "Beitrag zur Kenntnis des menschlichen Primordialcraniums," Archiv für mikrosk. Anat., xLIV, I894.

K. KJellberg: "Beiträge zur Entwicklungsgeschichte des Kiefergelenks," Morph. Jahrbuch, XXxir, 1904.

H. LEBoucQ: "Recherches sur la morphologie du carpe chez les mammifères," Archives de Biolog., v, 1884 .

G. Levi: "Beitrag zum Studium der Entwickelung des knorpeligen Primordialcraniums des Menschen," Archiv für mikrosk. Anat., LV, r 900.

A. LinCK: "Beiträge zur Kenntnis der menschlichen Chorda dorsalis in Hals- und Kopfskelett, etc.," Anat. Hefte, xLII, IgrI.

A. Low: "Further Observations on the Ossification of the Human Lower Jaw," Journ. Anat. and Phys., xLIV, I9Io.

M. Lucien: "Développement de l'articulation du genou et formation du ligament adipeux," Bibliogr. Anat., xiII, 1904.

F. P. MALL: "The Development of the Connective Tissues from the Connective-tissue Syncytium," Amer. Jour. Anat., I, I902.

F. P. Mall: "On Ossification Centers in Human Embryos Less Than One Hundred Days Old," Amer. Journ. Anat., v 1906.

F. Merkel: "Betrachtungen über die Entwicklung des Bindegewebes," Anat. Hefte, xxxviII, I909.

W. vAN NOORDEN: "Beitrag zur Anatomie der knorpeligen Schädelbasis menschlicher Embryonen," Archiv für Anat. und Physiol., Anat. Abth., 1887.

A. M. Paterson: "The Human Sternum," Liverpool, I904.

K. Peter: "Anlage und Homologie der Muscheln des Menschen und der Säugetiere," Arch. für mikrosk. Anat., LX, I902.

J. IV. Pryor: "The Chronology and Order of Ossification of the Bones of the Human Carpus," Bulletin State Univ., Lexington, Ky., I908.

Rambaut et Renault: "Origine et développement des Os," Paris, i864.

E. Rosenberg: "Ueber die Entwickelung der Wirbelsäule und das Centrale carpi des Menschen," Morpholog. Jahrbuch, I, I876.

H. And H. Rouvière: "Sur le développement de l'antre mastoidien et les cellules mastoidiennes," Bibliogr. Anat., xx, Igro.

G. RUGE: "Untersuchungen über die Entwickelungsvorgänge am Brustbein des Menschen," Morpholog. Jahrbuch, vI, I880.

J. P. Schaffer: "The Lateral Wall of the Cavum Nasi in Man, with Especial Reference to the Various Developmental Stages," Journ. Morph., xxi, 1910.

J. P. Schaffer: "The Sinus Maxillaris and its Relations in the Embryo, Child and Adult Man," Amer Joum. Anat., x, Igio.

G. THILENius: "Untersuchungen über die morphologische Bedeutung accessorischer Elemente am menschlichen Carpus (und Tarsus)," Morpholog. Arbeiten, v, ISg6. 
K. Toldt JR.: "Entwicklung und Struktur des menschlichen Jochbeines," Sitzungsber. k. Acad. Wissensch. Wien, Math.-naturwiss Kl., cxI, I902.

A. VinogradofF: "Développement de l'articulation temporo-maxillaire chez l'homme dans la période intrauterine," Internat. Monatsschr. Anat. Phys., xxvir, I9IO.

R. H. Whitehead and J. A. Waddell: "The Early Development of the Mammalian Sternum," A mer. Journ. Anat., xil, Igr I.

L. W. Williams: "The Later Development of the Notochord," Amer. Journ. Anat., VIII, Ig08.

E. ZuCKerkandL: "Ueber den Jacobsonschen Knorpel und die Ossifikation des Pflugscharbeines," Sitzb. Akad. Wiss. Wien., cxVII, I908. 
CHAPTER VIII.

\section{THE DEVELOPMENT OF THE MUSCULAR SYSTEM.}

Two forms of muscular tissue exist in the human body, the striated tissue, which forms the skeletal muscles and is under the control of the central nervous system, and the non-striated, which is controlled by the sympathetic nervous system and is found in the skin, in the walls of the digestive tract, the blood-vessels and lymphatics, and in connection with the genito-urinary apparatus. In the walls of the heart a muscle tissue occurs which is frequently regarded as a third form, characterized by being under control of the sympathetic system and yet being striated; it is, however, in its origin much more nearly allied to the non-striated than to the striated form of tissue, and will be considered a variety of the former.

The Histogenesis of Non-striated Muscular Tissue.-With the exception of the sphincter and dilator of the pupil and the muscles of the sudoriparous glands, which are formed from the ectoderm, all the non-striated muscle tissue of the body is formed by the conversion of mesenchyme cells into muscle-fibers. The details of this process have been worked out by McGill for the musculature of the digestive and respiratory tracts of the pig and are as follows: The mesenchyme surrounding the mucosa in these tracts is at first a loose syncytium (Fig. II $7, m$ ) and in the regions where the muscle tissue is to form a condensation of the mesenchyme occurs followed by an elongation of the mesenchyme cells and their nuclei, so that the muscle layers become clearly distinguishable from the neighboring undifferentiated tissue (Fig. II7, $\mathrm{mm}$ ). Fibrils of two kinds then begin to appear in the cytoplasm of the muscle cells. Coarse fibrils $(f . c)$ make their appearance as rows of granules, which enlarge and increase in number until they finally fuse to form homogeneous 


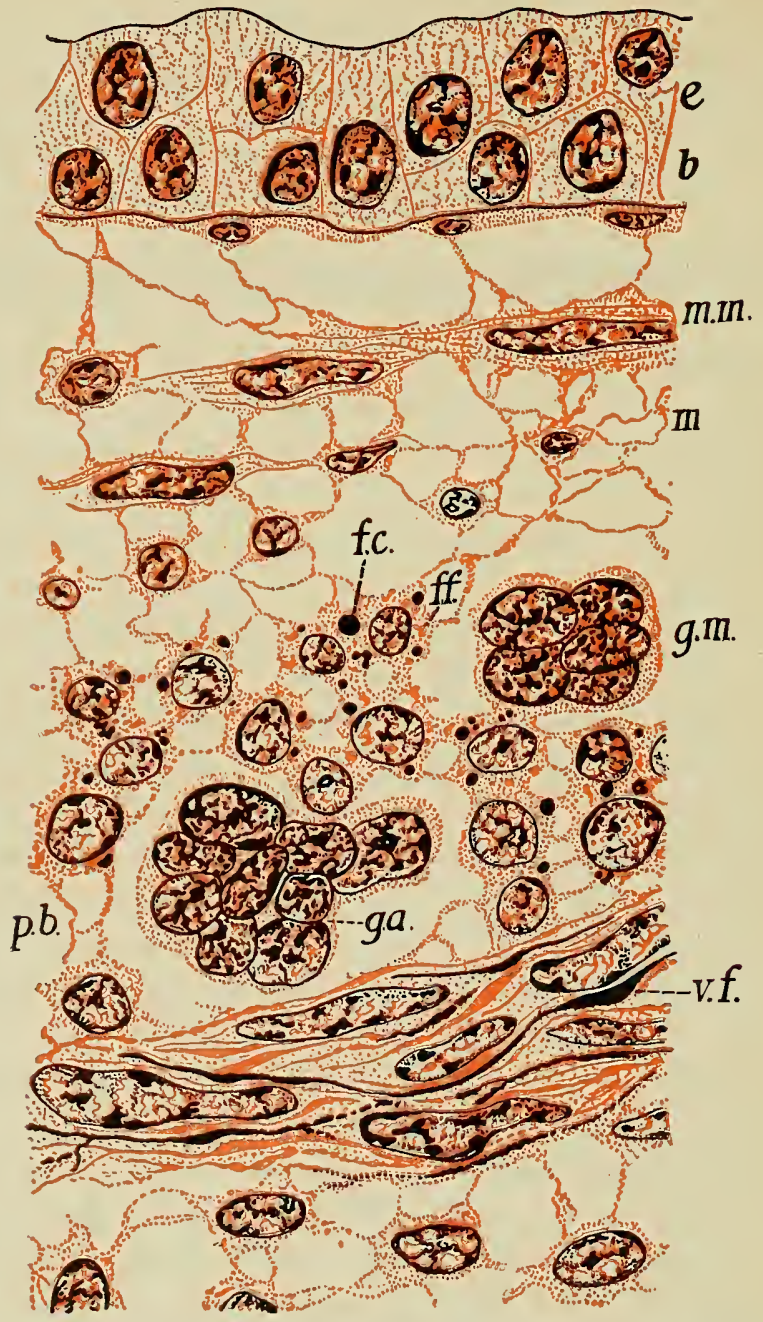

Fig. ir7.-Longitudinal Section of the Lower Part of the Oesophagus of a Pig EMbryo of I5 MM, Showing the Histogenesis of the Non-Striated MUSCULATURE.

$b$, Basement membrane; $e$, epithelium; f.c., coarse fibril; $f . f$., fine fibril; $g a$, ganglion of Auerbach's plexus; $g m$, ganglion of Meissner's plexus; $m$, mesenchyne; $m m$, muscularis mucosæ; $p b$, protoplasmic bridge; $v f$, varicose fibril.-(McGill.) 
fibrils that are at first varicose, but later become of uniform caliber. Fine fibrils $(f . f)$ which are homogeneous from the first, make their appearance after the coarse ones and in some cases seem to be formed by the splitting of the latter. They are scattered uniformly throughout the cytoplasm of the muscle cells and increase in number as development proceeds, while the coarse fibrils diminish and may be entirely wanting in the adult tissue.

Some of the mesenchyme cells in each muscle sheet fail to undergo the differentiation just described and multiply to form the interstitial connective tissue, which usually divides the muscle cells into more or less distinct bundles. Traces of the original syncytial nature of the tissue are to be seen in the intercellular bridges that occur between the non-striated muscle cells of many adult forms.

The cells from which the heart musculature develops are at first of the usual well defined embryonic type, but, as development proceeds, they become irregularly stellate in form, the processes of neighboring cells fuse and, eventually, there is formed a continuous

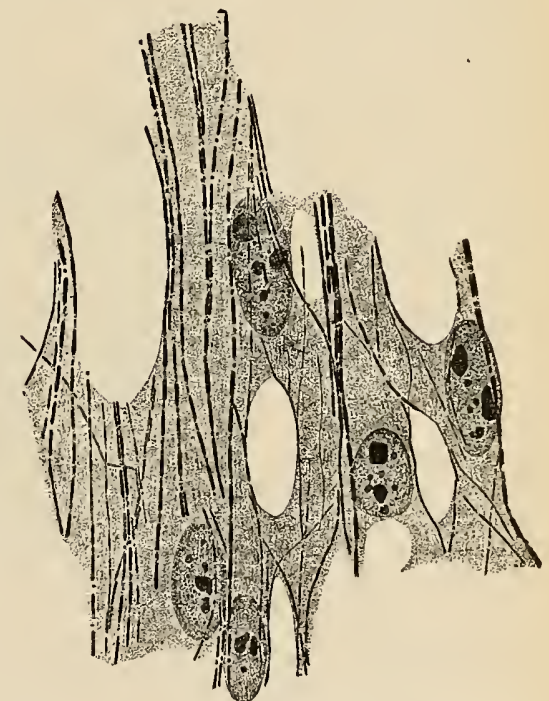

Fig. it8.-Section through the HeartWall of a Duck Embryo of Three Days. -(M. Heidenhain.)

mass of protoplasm or syncytium in which all traces of cell boundaries are lacking (Fig. II 8). While the individual cells, or myoblasts as they are termed, are still recognizable, granules appear in their cytoplasm, and these arrange themselves in rows and unite to form slender fibrils, which at first do not extend beyond the limits of the myoblasts in which they have appeared, but later, as the fusion of the cells proceeds, are continued from one cell territory into the other 
through considerable stretches of the syncytium, without regard to the original cell areas.

The fibrils multiply, apparently by longitudinal division, and arrange themselves in circles around areas of the syncytium (compare Fig. II9). As the multiplication of the fibrils continues those newly formed arrange themselves around the interior of each of the original circles and gradually occupy the entire cytoplasm, or sarcoplasm as it may now be termed, except immediately around the nuclei where, even in the adult, a certain amount of undifferentiated sarcoplasm persists. The fibrils when first formed are apparently homo-

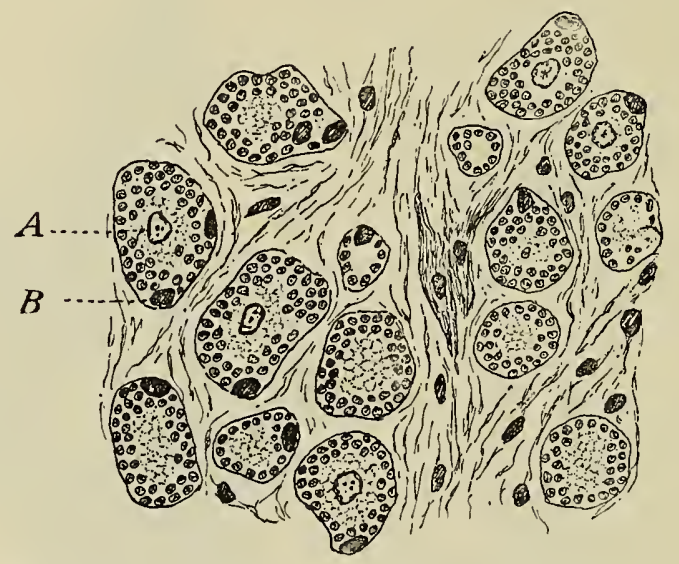

Fig. i ig.-Cross-section of a Muscle from the Thigh of a Pig Embryo 75 mm. LONG.

$A$, Central nucleus; $B$, new peripheral nucleus.-(Macallum.)

geneous, but later they become differentiated into two distinct substances which alternate with one another throughout the length of the fibril and produce the characteristic transverse striation of the tissue. Finally stronger interrupted transverse bands of so-called cement substance appear, dividing the tissue into areas which have usually been regarded as representing the original myoblasts, but are really devoid of significance as cells, the tissue remaining, strictly speaking, a syncytium. 
The Histogenesis of Striated Muscle Tissue.-The histogenesis of striated or voluntary muscle tissue resembles very closely that which has just been described for the heart muscle. There is a similar formation of a syncytium by the fusion of the cells of the myotomes, an appearance of granules which unite to form fibrils, an increase of the fibrils by longitudinal division and a primary arrangement of the fibrils around the periphery of areas of sarcoplasm (Fig. II9), each of which represents a muscle fiber. In addition there is an active proliferation of the nuclei of the original myoblasts, the new nuclei arranging themselves more or less regularly in rows and later migrating from their original central position to the periphery of the fibers, and, in the limb muscles, the development is further complicated by a process of degeneration which affects groups of muscle fibers, so that bundles of normal fibers are separated by strands of degenerated tissue in which the fibrils have disappeared, the nuclei have become pale and the sarcoplasm vacuolated and homogeneous. Later the degenerated tissue seems to disappear entirely and mesenchymatous connective tissue grows in between the persisting fibers, grouping them into bundles and the bundles into the individual muscles.

So long as the formation of new fibrils continues, the increase in the thickness of a muscle is probably due to a certain extent to an increase in the actual number of fibers, which results from the division of those already existing. Subsequently, however, this mode of growth ceases, the further increase of the muscle depending upon an increase in size of its constituent elements (Macallum).

The Development of the Skeletal Muscles.-It has already been pointed out that all the skeletal muscles of the body, with the exception of those connected with the branchial arches, are derived from the myotomes of the mesodermic somites, even the limb muscles possibly having such an origin, although the cells of the tissue from which the muscles of the limb buds form lack an epithelial arrangement and are indistinguishable from the somatic mesenchyme which forms the axial cores of the limbs.

The various fibers of each myotome are at first loosely arranged, 
but later they become more compact and are arranged parallel with one another, their long axes being directed antero-posteriorly. This stage is also transitory, however, the fibers of each myotome undergoing various modifications to produce the conditions existing in the adult, in which the original segmental arrangement of the fibers can be perceived in comparatively few muscles. The exact nature of these modifications is almost unknown from direct observation, but since the relation between a nerve and the myotome belonging to the same segment is established at a very early period of development and persists throughout life, no matter what changes of fusion, splitting, or migration the myotome may undergo, it is possible to trace out more or less completely the history of the various myotomes by determining their segmental innervation. It is known, for example, that the latissimus dorsi arises from the seventh and eighth* cervical myotomes, but later undergoes a migration, becoming attached to the lower thoracic and lumbar vertebræ and to the crest of the ilium, far away from its place of origin (Mall), and yet it retains its nerve-supply from the seventh and eighth cervical nerves with which it was originally associated, its nerve-supply consequently indicating the extent of its migration.

By following the indications thus afforded, it may be seen that the changes which occur in the myotomes may be referred to one or more of the following processes:

I. A longitudinal splitting into two or more portions, a process well illustrated by the trapezius and sternomastoid, which have differentiated by the longitudinal splitting of a single sheet and contain therefore portions of the same myotomes. The sternohyoid and omohyoid have also differentiated by the same process, and, indeed, it is of frequent occurrence.

2. A tangential splitting into two or more layers. Examples of this are also abundant and are afforded by the muscles of the fourth, fifth, and sixth layers of the back, as recognized in English text-books

* This enumeration is based on convenience in associating the myotomes with the nerves which supply them. The myotomes mentioned are those which correspond to the sixth and seventh cervical vertebræ. 
of anatomy, by the two oblique and the transverse layers of the abdominal walls, and by the intercostal muscles and the transversus of the thorax.

3. A fusion of portions of successive myotomes to form a single muscle, again a process of frequent occurrence, and well illustrated by the rectus abdominis (which is formed by the fusion of the ventral portions of the last six or seven thoracic myotomes) or by the superficial portions of the sacro-spinalis.

4. A migration of parts of one or more myotomes over others. An example of this process is to be found in the latissimus dorsi, whose history has already been referred to, and it is also beautifully shown by the serratus anterior and the trapezius, both of which have extended far beyond the limits of the segments from which they are derived.

5. A degeneration of portions or the whole of a myotome. This process has played a very considerable part in the evolution of the muscular system in the vertebrates. When a muscle normally degenerates, it becomes converted into connective tissue, and many of the strong aponeurotic sheets which occur in the body owe their origin to this process. Thus, for example, the aponeurosis connecting the occipital and frontal portions of the occipito-frontalis is formed in this process and is muscular in such forms as the lower monkeys, and a good example is also to be found in the aponeurosis which occupies the interval between the superior and inferior serrati postici, these two muscles being continuous in lower forms. The strong lumbar aponeurosis and the aponeuroses of the oblique and transverse muscles of the abdomen are also good examples.

Indeed, in comparing one of the mammals with a member of one of the lower classes of vertebrates, the greater amount of connective tissue compared with the amount of muscular tissue in the former is very striking, the inference being that these connectivetissue structures (fasciæ, aponeuroses, ligaments) represent portions of the muscular tissue of the lower form (Bardeleben). Many of the accessory ligaments occurring in connection with diarthrodial joints apparently owe their origin to a degeneration of muscle tissue, the 
fibular lateral ligament of the knee-joint, for instance, being probably a degenerated portion of the peroneus longus, while the sacrotuberous ligament appears to stand in a similar relation to the long head of the biceps femoris (Sutton).

6. Finally, there may be associated with any of the first four processes a change in the direction of the muscle-fibers. The original antero-posterior direction of the fibers is retained in comparatively few of the adult muscles and excellent examples of the process here referred to are to be found in the intercostal muscles and the muscles of the abdominal walls. In the musculature associated with the branchial arches the alteration in the direction of the fibers occurs even in the fishes, in which the original direction of the muscle-fibers is very perfectly retained in other myotomes, the branchial muscles, however, being arranged parallel with the branchial cartilages or even passing dorso-ventrally between the upper and lower portions of an arch, and so forming what may be regarded as a constrictor of the arch. This alteration of direction dates back so far that the constrictor arrangement may well be taken as the primary condition in studying the changes which the branchial musculature has undergone in the mammalia.

It would occupy too much space in a work of this kind to consider in detail the history of each one of the skeletal muscles of the human body, but a statement of the general plan of their development will not be out of place. For convenience the entire system may be divided into three portions-the cranial, trunk and limb musculature; and of these, the trunk musculature may first be considered.

The Trunk Musculature.-It has already been seen (p. 82) that the myotomes at first occupy a dorsal position, becoming prolonged ventrally as development proceeds so as to overlap the somatic mesoderm, until those of opposite sides come into contact in the mid-ventral line. Before this is accomplished, however, a longitudinal splitting of each myotome occurs, whereby there is separated off a dorsal portion which gives rise to a segment of the dorsal musculature of the trunk and is supplied by the ramus dorsalis 
of its corresponding spinal nerve. In the lower vertebrates this separation of each of the trunk myotomes into a dorsal and ventral portion is much more distinct in the adult than it is in man, the two portions being separated by a horizontal plate of connective tissue extending the entire length of the trunk and being attached by its inner edge to the transverse processes of the vertebræ, while peripherally it becomes continuous with the connective tissue of the

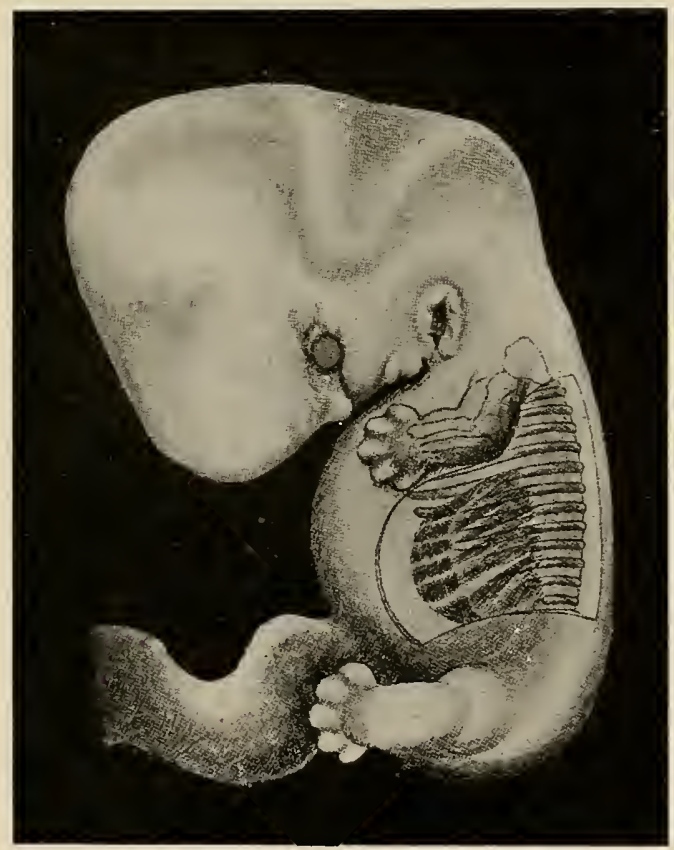

Fig. I20.-Embryo of I3 Mm. Showing the Formation of the Rectus Muscle.(Mall.)

dermis along a line known as the lateral line. In man the dorsal portion is also much smaller in proportion to the ventral portion than in the lower vertebrates. From this dorsal portion of the myotomes are derived the muscles belonging to the three deepest layers of the dorsal musculature, the more superficial layers being 
composed of muscles belonging to the limb system. Further longitudinal and tangential divisions and a fusion of successive myotomes bring about the conditions which obtain in the adult dorsal musculature.

While the myotomes are still some distance from the mid-ventral line another longitudinal division affects their ventral edges (Fig. I20), portions being thus separated which later fuse more or less perfectly to form longitudinal bands of muscle, those of opposite sides being brought into apposition along the mid-ventral line by the continued growth ventrally of the myotomes. In this way are formed the rectus and pyramidalis muscles of the abdomen and the depressors of the hyoid bone, the genio-hyoid and genio-glossus* in the neck region. In the thoracic region this rectus set of muscles, as it may be termed, is not represented except as an anomaly, its absence being probably correlated with the development of the sternum in this region.

The lateral portions of the myotomes which intervene between the dorsal and rectus muscles divide tangentially, producing from their dorsal portions in the cervical and lumbar regions muscles, such as the longus capitis and colli and the psoas, which lie beneath the vertebral column and hence have been termed hyposkeletal muscles (Huxley). More ventrally three sheets of muscles, lying one above the other, are formed, the fibers of each sheet being arranged in a definite direction differing from that found in the other sheets. In the abdomen there are thus formed the two oblique and the transverse muscles, in the thorax the intercostals and the transversus thoracis, while in the neck these portions of some of the myotomes disappear, those of the remainder giving rise to the scaleni muscles, portions of the trapezius and sternomastoid (Bolk), and possibly the hyoglossus and styloglossus. In the abdominal region, and to a considerable extent in the neck also, the various portions of myotomes fuse together, but in the thorax they retain in the intercostals their original distinctness, being separated by the ribs.

* This muscle is supplied by the hypoglossal nerve, but for the present purpose it is convenient to regard this as a spinal nerve, as indeed it primarily is. 


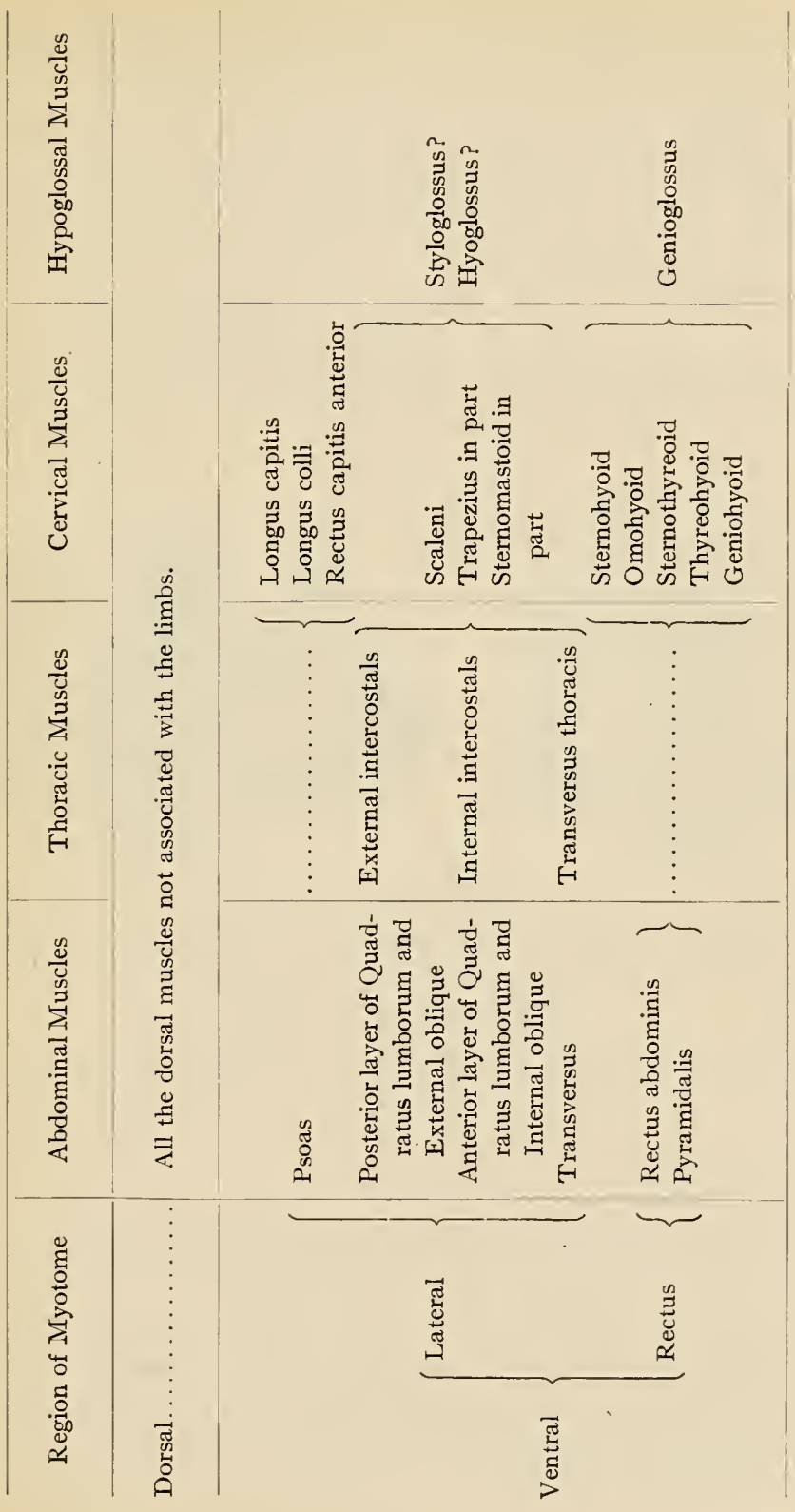


The table on page 203 will show the relation of the various trunk muscles to the portions of the myotomes.

The intimate association between the pelvic girdle and the axial skeleton brings about extensive modifications of the posterior trunk myotomes. So far as their dorsal portions are concerned probably all these myotomes as far back as the fifth sacral are represented in the sacro-spinalis, but the ventral portions from the first lumbar myotome onward are greatly modified. The last myotome taking part in the formation of the rectus abdominis is the twelfth thoracic and the last to be represented in the lateral musculature of the

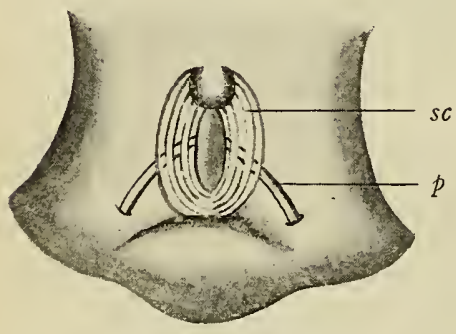

A

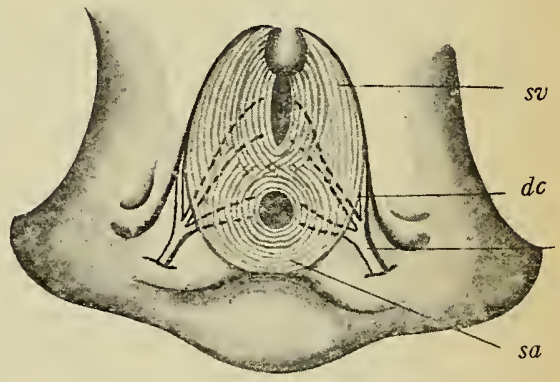

$B$

Fig. i2 I.-Perineal Region of Embryos of $(A)$ Two Months and $(B)$ Four to Five Months, showing the Development of the Perineal Muscles. $d c$, Nervus dorsalis clitoridis; $p$, pudendal nerve; $s a$, sphincter ani; $s c$ sphincter cloacæ; $s v$, sphincter vaginæ.-(Poporssky.)

abdomen is the first lumbar, the ventral portions of the remaining lumbar and of the first and second sacral myotomes either having disappeared or being devoted to the formation of the musculature of the lower limb.

The ventral portions of the third and fourth sacral myotomes are represented, however, by the levator ani and coccygeus, and are the last myotomes which persist as muscles in the human body, although traces of still more posterior myotomes are to be found in muscles such as the curvator coccygis sometimes developed in connection with the coccygeal vertebræ.

The perineal muscles and the external sphincter ani are also 
developments of the third and fourth (and second) sacral myotomes. At a time when the cloaca (see p. 280) is still present, a sheet of muscles lying close beneath the integument forms a sphincter around its opening (Fig. I2I). On the development of the partition which divides the cloaca into rectal and urinogenital portions, the sphincter is also divided, its more posterior portion persisting as the external sphincter ani, while the anterior part gradually differentiates into the various perineal muscles (Popowsky).

The Cranial Musculature.-As was pointed out in an earlier chapter, the existence of distinct mesodermic somites has not yet been completely demonstrated in the head of the human embryo, but in lower forms, such as the elasmobranch fishes, they are clearly distinguishable, and it may be supposed that their indistinctness in man is a secondary condition. Exactly how many of these somites are represented in the mammalian head it is impossible to say, but it seems probable, from comparison with lower forms, that there is a considerable number. The majority of them, however, early undergo degeneration, and in the adult condition only three are recognizable, two of which are præoral in position and one postoral. The myotomes of the anterior præoral segment give rise to the muscles of the eye supplied by the third cranial nerve, those of the posterior one furnish the superior oblique muscles innervated by the fourth nerve, while from the postoral myotomes the lateral recti, supplied by the sixth nerve, are developed. The muscles supplied by the hypoglossal nerve are also derived from myotomes, but they have already been considered in connection with the trunk musculature.

The remaining muscles of the head differ from all other voluntary muscles of the body in the fact that they are derived from the branchiomeres formed by the segmentation of the cephalic ventral mesoderm. These muscles, therefore, are not to be regarded as equivalent to the myotomic muscles if their embryological origin is to be taken as a criterion of equivalency, and in their case it would seem, from the fact that they are innervated by nerves fundamentally distinct from those which supply the nuyotomic muscles, that this 
criterion is a good one. They must be regarded, therefore, as belonging to a special category, and may be termed branchiomeric muscles to distinguish them from the myotomic set.

If their embryological origin be taken as a basis for homology, it is clear that they should be regarded as equivalent to the muscles derived from the ventral mesoderm of the trunk, and these, as has been seen, are the non-striated muscles associated with the viscera, among which may be included the striated heart muscle. At first sight this homology seems decidedly strained, chiefly because long-continued custom has regarded the histological and physiological peculiarities of striated and non-striated muscle tissue as fundamental. It may be pointed out, however, that the branchiomeric muscles are, strictly speaking, visceral muscles, and indeed give rise to muscle sheets (the constrictors of the pharynx) which surround the upper or pharyngeal portion of the digestive tract. It is possible, then, that the homology is not so strained as might appear, but further discussion of it may profitably be deferred until the cranial nerves are under consideration.

The skeleton of the first branchial arch becomes converted partly into the jaw apparatus and partly into auditory ossicles, and the muscles derived from the corresponding branchiomere become the muscles of mastication (the temporal, masseter, and pterygoids), the mylohyoid, anterior belly of the digastric, the tensor veli palatini and the tensor tympani. The nerve which corresponds to the first branchial arch is the trigeminus or fifth, and consequently these various muscles are supplied by it.

The second arch has corresponding to it the seventh nerve, and its musculature is partly represented by the stylohyoid and posterior belly of the digastric and by the stapedius muscle of the middle ear. From the more superficial portions of the branchiomere, however, a sheet of tissue arises which gradually extends upward and downward to form a thin covering for the entire head and neck, its lower portion giving rise to the platysma and the nuchal fascia which extends backward from the dorsal border of this muscle, while its upper parts become the occipito-frontalis and the superficial muscles of the face (the muscles of expression), together with the fasciæ which unite the various muscles of this group. The extension of the platysma sheet of muscles over the face is well shown by the 

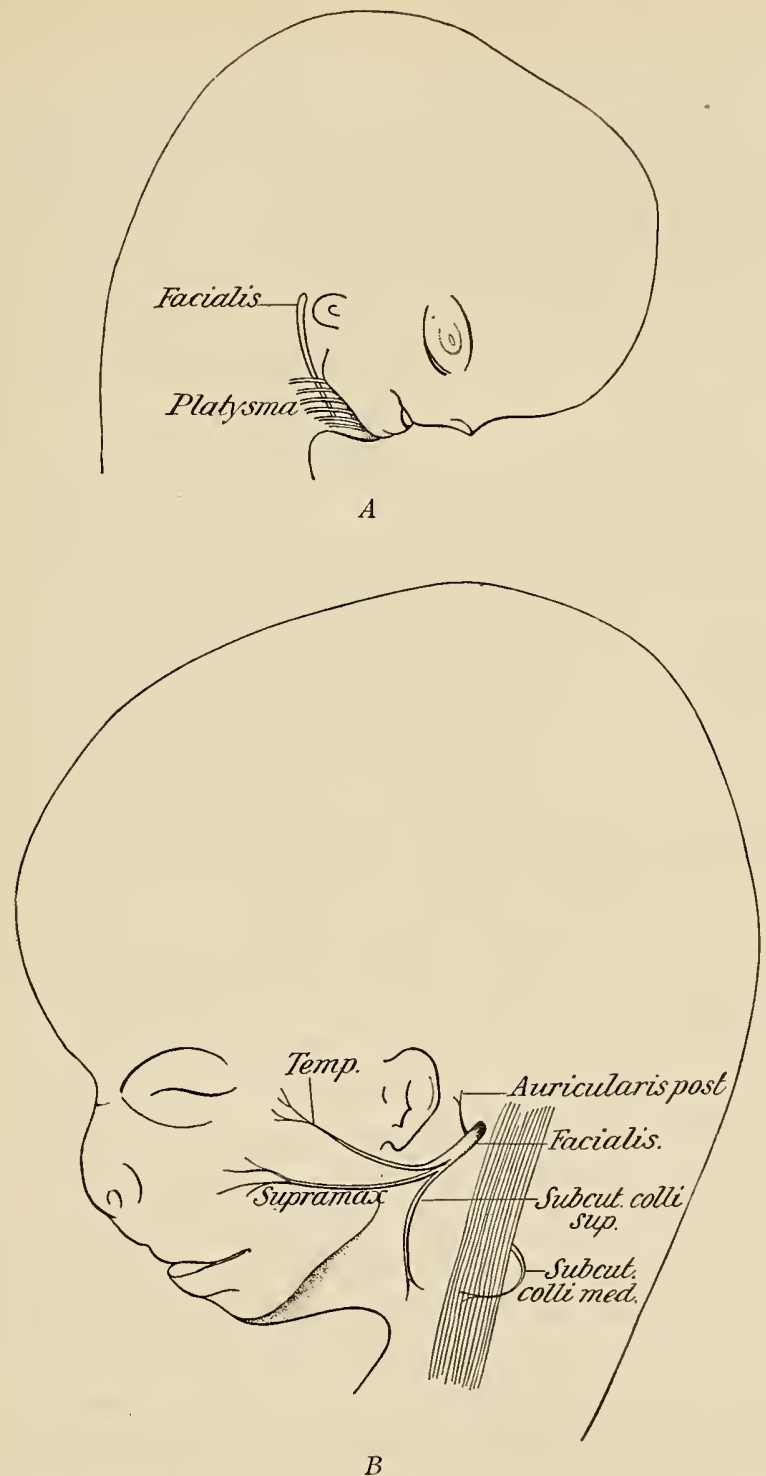

B

Fig. I22.-Head of Embryos (A) of Two Months and (B) of Three Months showing the Extension of the Seventh Nerve upon the Face.(Popowesky.) 
development of the branches of the facial nerve which supply it (Fig. I22).

The degeneration of the upper part of the third arch produces a shifting forward of one of the muscles derived from its branchiomere, the stylopharyngeus arising from the base of the styloid process. The innervation of this muscle by the ninth nerve indicates, however, its true significance, and since fibers of this nerve of the third arch also pass to the constrictor muscles of the pharynx, a portion of these must also be regarded as having arisen from the third branchiomere.

The cartilages of the fourth and fifth arches enter into the formation of the larynx and the muscles of the corresponding branchiomeres constitute the muscles of the larynx, together with the remaining portions of the constrictors of the pharynx and the muscles of the soft palate, with the exception of the tensor. Both these arches have branches of the tenth nerve associated with them and hence this nerve supplies the muscles named. In addition, two of the extrinsic muscles of the tongue, the glosso-palatinus and chondroglossus, belong to the fourth or fifth branchiomere, although the remaining muscles of this physiological set are myotomic in origin.

Finally, portions of two other muscles should probably be included in the list of branchiomeric muscles, these muscles being the trapezius and sternomastoid. It has already been seen that they are partly derived from the cervical myotomes, but they are also innervated in part by the spinal accessory, and since the motor fibers of this nerve are serially homologous with those of the vagus it would seem that the muscles which they supply are probably branchiomeric in origin. Observations on the development of these muscles, determining their relations to the branchiomeres, are necessary, however, before their morphological significance can be regarded as definitely settled.

The table on page 209 shows the relations of the various cranial muscles to the myotomes and branchiomeres, as well as to the motor cranial nerves. 


\begin{tabular}{|c|c|c|}
\hline 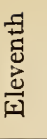 & . & 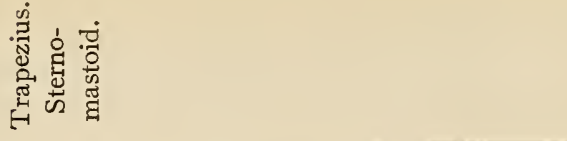 \\
\hline 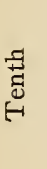 & $\begin{array}{l}\vdots \\
\vdots \\
\vdots\end{array}$ & 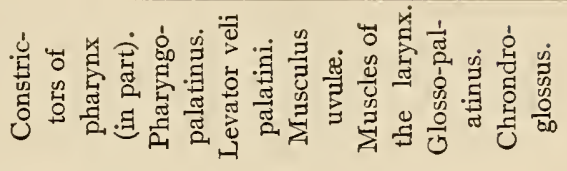 \\
\hline 点 & $\begin{array}{l}\vdots \\
\vdots \\
\vdots\end{array}$ & 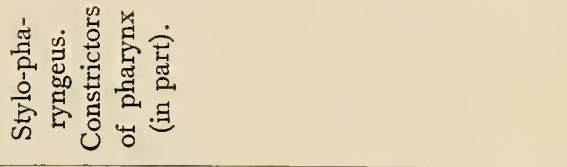 \\
\hline 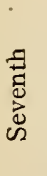 & 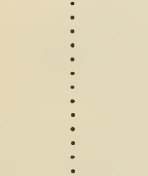 & 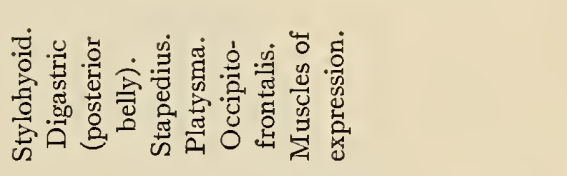 \\
\hline 营 & 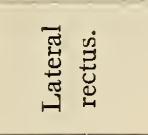 & $\begin{array}{l}\vdots \\
\vdots \\
\vdots\end{array}$ \\
\hline 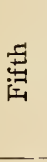 & $\begin{array}{l}\vdots \\
\vdots \\
\vdots\end{array}$ & 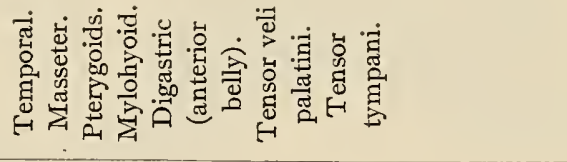 \\
\hline 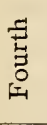 & 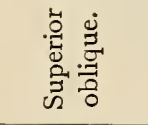 & $\vdots$ \\
\hline 胥 & 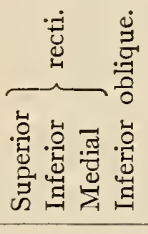 & $\begin{array}{l}\vdots \\
\vdots \\
\vdots \\
\vdots\end{array}$ \\
\hline 总 & 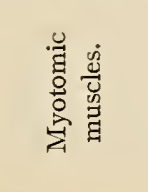 & 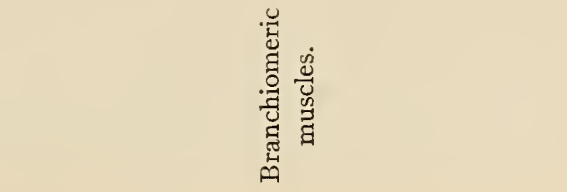 \\
\hline
\end{tabular}


The Limb Muscles.-It has been customary to regard the limb muscles as derivatives of certain of the myotomes, these structures in their growth ventrally in the trunk walls being supposed to pass out upon the postaxial surface of the limb buds and loop back again to the trunk along the præaxial surface, each myotome thus giving rise to a portion of both the dorsal and the ventral musculature of the limb. This view has not, however, been verified by direct observation of an actual looping of the myotomes over the axis of the limb buds; indeed, on the contrary, the limb muscles have been found to develop from the cores of mesenchyme which form the axes of the limb buds and from which the limb skeleton is also developed. This may be explained by supposing that the limb muscles are primarily derivatives of the myotomes and that an extensive concentration of their developmental history has taken place, so that the axial mesenchyme actually represents myotomic material even though no direct connection between it and the myotomes can be discovered. Condensations of the developmental history certainly occur and the fact that the muscles of the human limbs, as they differentiate from the axial cores, present essentially the same arrangement as in the adult seems to indicate that there is actually an extensive condensation of the phylogenetic history of the individual muscles, since comparative anatomy shows the arrangement of the muscles of the higher mammalian limbs to be the result of a long series of progressive modifications from a primitive condition. However, even though this be the case, there is yet the possibility that the limb musculature, like the limb skeleton, may take its origin from the ventral mesoderm and consequently belong to a different embryological category from the axial myotomic muscles.

The strongest evidence in favor of the myotomic origin of the limb muscles is that furnished by their nerve supply, this presenting a distinctly segmental arrangement. This does not necessarily imply, however, a corresponding primarily metameric arrangement of the muscles, any more than the pronouncedly segmental arrangement of the cutaneous nerves implies a primary metamerism of the 
dermis (see p. 143). It may mean only that the nerves, being segmental, retain their segmental relations to one another even in their distribution to non-metameric structures, and that, consequently, the limb musculature is supplied in succession from one border of the limb bud to the other from succeeding nerve roots.

But whether further observation may prove or disprove the myotomic origin of the limb musculature, the fact remains that it possesses a segmentally arranged innervation, and it is possible,

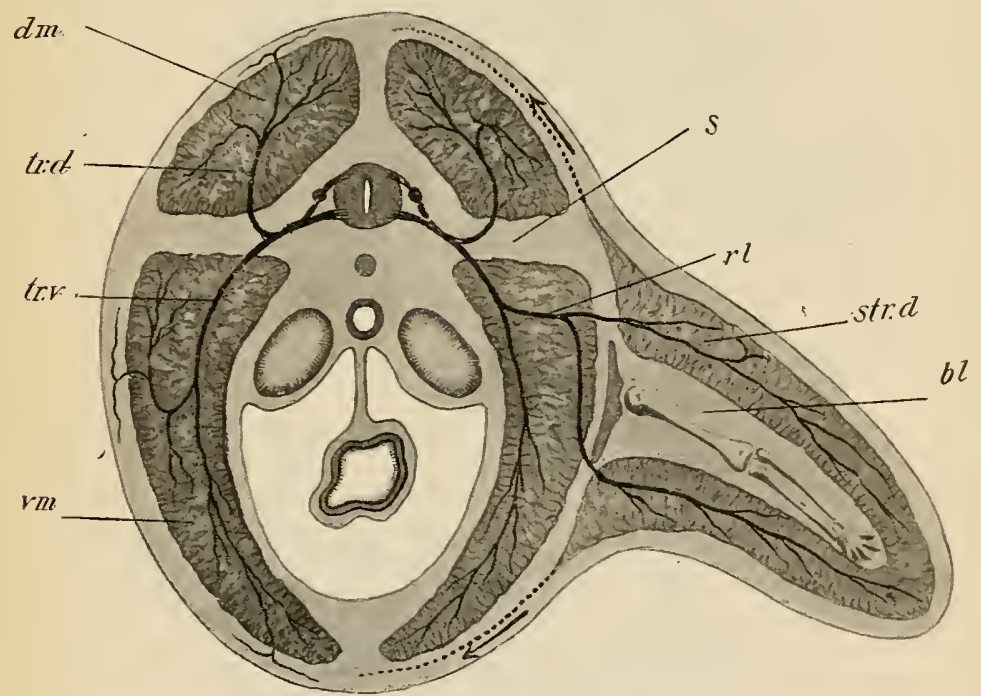

Fig. i23.-Diagram of a Segment of the Body and Limb.

$b l$, Axial blastema; $d m$, dorsal musculature of trunk; $r l$, nerve to limb; $s$, septum between dorsal and ventral trunk musculature; str.d, dorsal layer of limb musculature; tr.d and $t r . v$, dorsal and ventral divisions of a spinal nerve; $v m$, ventral musculature of the trunk.-(Kollmann.)

therefore, to recognize in the limb buds a series of parallel bands of muscle tissue, extending longitudinally along the bud and each supplied by a definite segmental nerve. And furthermore, corresponding to each band upon the ventral (præaxial) surface of the limb bud, there is a band similarly innervated upon the dorsal (postaxial) surface, since the fibers which pass to the limb from each nerve root sooner or later arrange themselves in præaxial and postaxial 
groups as is shown in the diagram Fig. I23. The first nerve which enters the limb bud lies along its anterior border, and consequently the muscle bands which are supplied by it will, in the adult, lie along

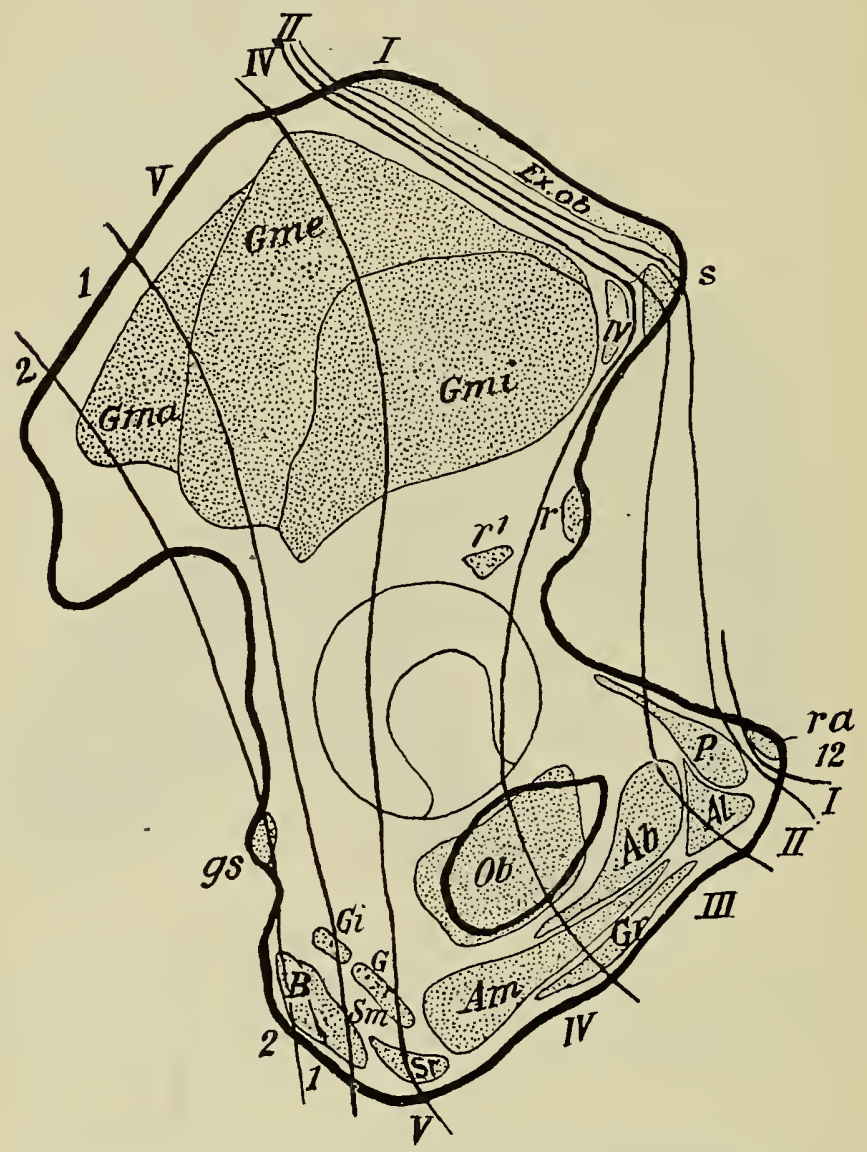

Fig. 124.-External. Surface of the Os Innominatum Showing the Attachment of Muscles aNd the ZoNes Supplied by the VARIOUS NeRves.

I2, Twelfth thoracic nerve; $I$ to $V$, lumbar nerves; $I$ and 2, sacral nerves.-(Bolk.)

the outer side of the arm and along the inner side of the leg, in consequence of the rotation in opposite directions which the limbs undergo during development (see p. Ior). 
The first nerve which supplies the muscles attached to the dorsum of the ilium is the second lumbar, and following that there come successively from before backward the remaining lumbar and the
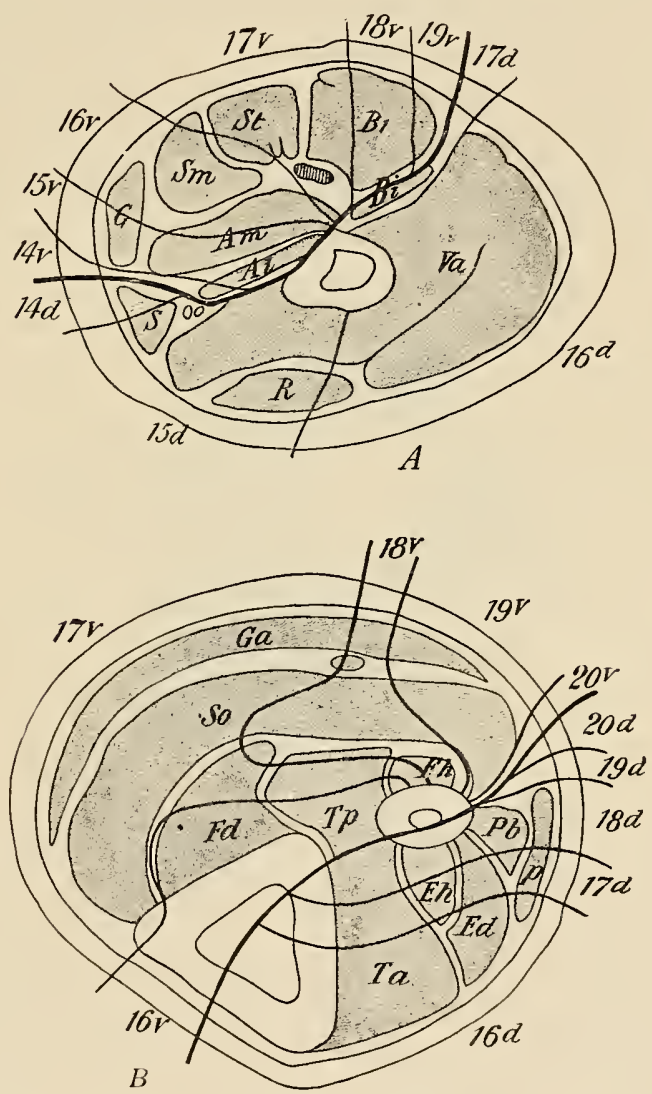

Fig. I25.--Sections through $(A)$ the Thigh and $(B)$ the Calf Showing the Zones Supplied by the Nerves. The Nerves are Numbered in Continuation With THE THORACIC SERIES.-(A, after Bolk.)

first and second sacral nerves. The arrangement of the muscle bands supplied by these nerves and the muscles of the adult to which they contribute may be seen from Fig. I24. What is shown there is only the upper portions of the postaxial bands, their lower portions 
extending downward on the anterior surface of the leg. Only the sacral bands, however, extend throughout the entire length of the limb into the foot, the second lumbar band passing down only to about the middle of the thigh, the third to about the knee, the fourth to about the middle of the crus and the fifth as far as the base of the fifth metatarsal bone, and the same is true of the corresponding præaxial bands, which descend from the ventral surface of the os coxæ (innominatum) along the inner and posterior surfaces of the leg to the same points. The first and second sacral bands can be traced into the foot, the first giving rise to the musculature of its

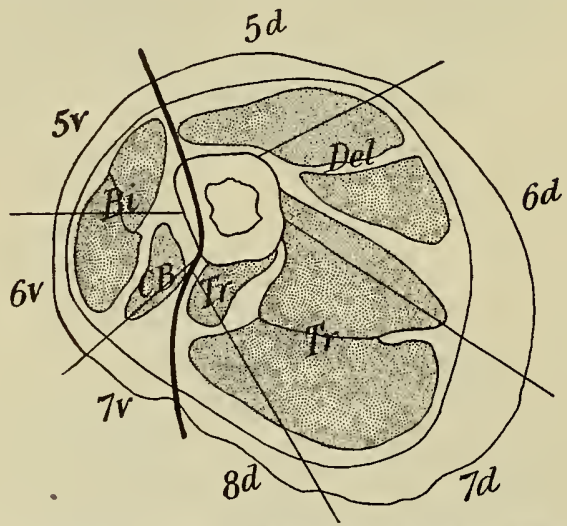

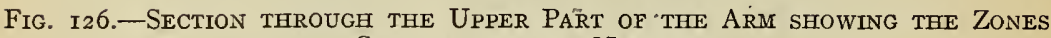
SUPPLIEd BY THE NeRVES.

$5^{v}$ to $7 v$, Ventral branches; $5 d$ to $8 d$, dorsal branches of the cervical nerves.-(Bolk.)

inner side and the second to that of its outer side, the præaxial bands forming the plantar musculature, while the postaxial ones are upon the dorsum of the foot as a result of the rotation which the limb has undergone.

In a transverse section through a limb at any level all the muscle bands, both præaxial and postaxial, which descend to that level will be cut and will lie in a definite succession from one border of the limb to the other, as is seen in Fig. I25. In the differentiation of the individual muscles which proceeds as the nerves extend from the trunk into the axial mesenchyme of the limb, the muscle bands 
undergo modifications similar to those already described as occurring in the trunk myotomes. Thus, each of the muscles represented in Fig. $125, B$, is formed by the fusion of elements derived from two or more bands; the soleus and gastrocnemius represent deep and superficial layers formed from the same bands by a horizontal (tangential) splitting, these same muscles contain a portion of the second sacral band which overlaps muscles composed only of higher myotomes, and the intermuscular septum between the peroneus brevis and the flexor hallucis longus represents a portion of the third sacral band which has degenerated into connective tissue.

A similar arrangement occurs in the bands which are to be recognized in the musculature of the upper limb. These are supplied by the fourth, fifth, sixth, seventh and eighth cervical and the first thoracic nerves, and only those supplied by the eighth cervical and the first thoracic nerves extend as far as the tips of the fingers. The arrangement of the bands in the upper part of the brachium may be seen from Fig. 126, in connection with which it must be noted that the fourth cervical band does not extend down to the level at which the section is taken and that the præaxial band of the eighth cervical nerve and both the præaxial and postaxial bands of the first thoracic are represented only by connective tissue in this region.

In another sense than the longitudinal one there is a division of the limb musculature into more or less definite areas, namely, in a transverse direction in accordance with the jointing of the skeleton. Thus, there may be recognized a group of muscles which pass from the axial skeleton to the pectoral girdle, another from the limb girdle to the brachium or thigh, another from the brachium or thigh to the antibrachium or crus, another from the antibrachium or crus to the carpus or tarsus, and another from the carpus or tarsus to the digits. This transverse segmentation, if it may be so termed, is not, however, perfectly definite, many muscles, even in the lower vertebrates, passing over more than one joint, and in the mammalia, especially, it is further obscured by secondary migrations, by the partial degeneration of muscles and by an end to end union of primarily distinct muscles. 
The latissimus dorsi, serratus anterior and pectoral muscles are all examples of a process of migration as is shown by their innervation from cervical nerves, as well as by the actual migration which has been traced in the developing embryo (Mall, Lewis). In the lower limb evidences of migration may be seen in the femoral head of the biceps, comparative anatomy showing this to be a derivative of the gluteal set of muscles which has secondarily become attached to the femur and has associated itself with a præaxial muscle to form a compound structure. An appearance of migration may also be produced by a muscle making a secondary attachment below its original origin or above the insertion and the upper or lower part, as the case may be, then degenerating into connective tissue. This has been the case with the peroneus longus, which, in the lower mammals, has a femoral origin, but has in man a new origin from the fibula, its upper portion being represented by the fibular lateral ligament of the knee-joint. So too the pectoralis minor is primarily inserted into the humerus, but it has made a secondary attachment to the coracoid process, its distal portion forming a coraco-humeral ligament.

The comparative study of the flexor muscles of the antibrachial and crural regions has yielded abundant evidence of extensive modifications in the differentiation of the limb muscles. In the tailed amphibia these muscles are represented by a series of superposed layers, the most superficial of which arises from the humerus or femur, while the remaining ones take their origin from the ulna or fibula and are directed distally and laterally to be inserted either into the palmar or plantar aponeurosis, or, in the case of the deeper layers, into the radius (tibia) or carpus (tarsus). In the arm of the lower mammalia the deepest layer becomes the pronator quadratus, the lateral portions of the superficial layer are the flexor carpi ulnaris and the flexor carpi radialis, while the intervening layers, together with the median portion of the superficial one, assuming a more directly longitudinal direction, fuse to form a common flexor mass which acts on the digits through the palmar aponeurosis. From this latter structure and from the carpal and metacarpal bones five 
layers of palmar muscles take origin. The radial and ulnar portions of the most superficial of these become the flexor pollicis brevis and abductor pollicis brevis and the abductor quinti digiti, while the rest of the layer degenerates into connective tissue, forming tendons
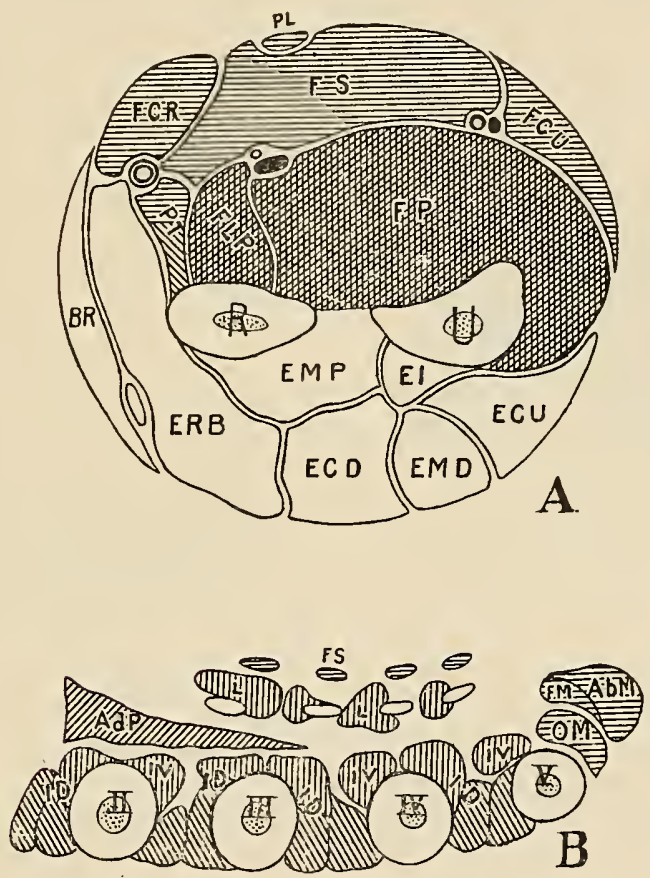

FIG. 127.- Transverse sections through (A) the forearm and (B) the hand showing the arrangement of the layers of the flexor muscles. The superficial layer is shaded horizontally, the second layer vertically, the third obliquely to the left, the fourth vertically, and the fifth obliquely to the right. $A b M$, abductor digiti quinti; $A d P$, adductor pollicis; $B R$, brachio-radialis; $E C D$, extensor digitorum communis; $E C U$, extensor carpi ulnaris; $E I$, extensor indicis; $E M D$, extensor digiti quinti; $E M P$, abductor pollicis longus; $E R B$, extensor carpi radialis brevis; $F C R$, flexor carpi radialis; $F C U$, flexor carpi ulnaris; FLP, flexor pollicis longus; FM, flexor digiti quinti brevis; $F P$, flexor digitorum profundus; $F S$, flexor digitorum sublimis; $I D$, interossei dorsales: $I V$, interossei volares; $L$, lumbricales; $O M$, opponens digiti quinti; $P L$, palmaris longus; $P T$, pronator teres; $R$, radius; $U$, ulna; II-V, second to fif th metacarpal.

which pass to the four ulnar digits. Gradually superficial portions of the antibrachial flexor mass separate off, carrying with them the layers of the palmar aponeurosis from which the tendons representing 
the superficial layer of the palmar muscles arise, and they form with these the flexor digitorum sublimis. The deeper layers of the antibrachial flexor mass become the flexor digitorum profundus and the flexor pollicis longus (Fig. I27, A), and retain their connection with the deeper layers of the palmar aponeurosis which form their tendons; and since the second layer of the palmar muscles takes origin from this portion of the aponeurosis it becomes the lumbrical muscles, arising from the profundus tendons (Fig. I27,
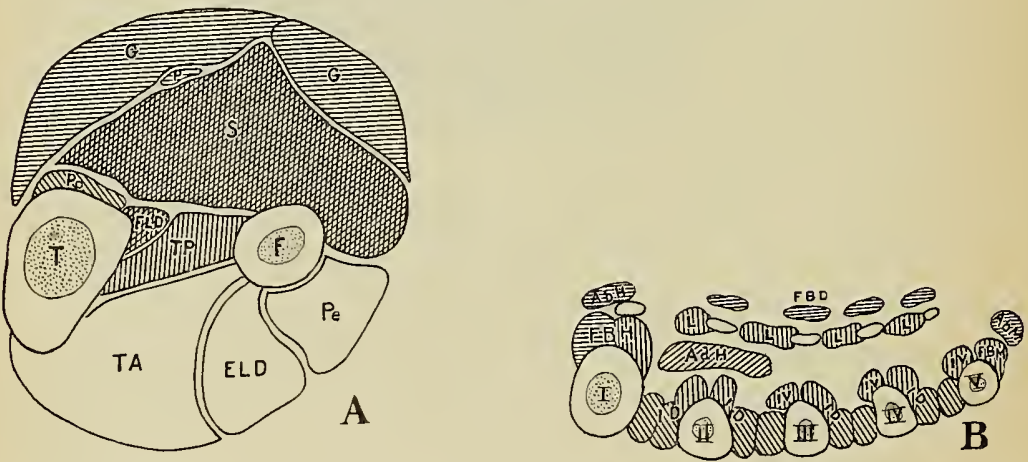

FIG. 128.- Transverse sections through (A) the crus and (B) the foot, showing the arrangement of the layers of the flexor muscles. The shading has the same significance as in the preceding figure. $A b H$, abductor hallucis; $A b M$, abductor minimi digiti; $A d H$, adductor hallucis; $E L D$, extensor longus digitorum; $F$, fibula; $F B D$, flexor brevis digitorium; $F B H$, flexor brevis hallucis; $F B M$, flexor brevis minimi digiti; $F L D$, flexor longus digitorum; $G$, gastrocnemius; $I D$, interossei dorsalis; $I V$, interossei ventrales; $L$, lumbricales; $P$, plantaris; $P e$, peroneus longus; $P o$, popliteus; $S$, soleus; $T$, tibia; $T A$, tibialis anticus; $T P$, tibialis posticus; $I-V$, first to fifth metatarsal.

B). The third layer of palmar muscles becomes the adductors of the digits, reduced in man to the adductor pollicis, while from the two deepest layers the interossei are developed. Of these the fourth layer consists primarily of a pair of slips corresponding to each digit, while the fifth is represented by a series of muscles which extend obliquely across between adjacent metacarpals. With these last muscles certain of the fourth layer slips unite to form the dorsal interossei, while the rest become the volar interossei. a The modifications of the almost identical primary arrangement in the crus and foot are somewhat different. The superficial layer 
of the crural flexors becomes the gastrocnemius and plantaris (Fig. I $28, \mathrm{~A})$ and the deepest layer becomes the popliteus and the interosseous membrane. The second and third layers unite to form a common mass which is inserted into the deeper layers of the plantar aponeurosis and later differentiates into the soleus and the long digital flexor, the former shifting its insertion from the plantar aponeurosis to the os calcis, while the flexor retains its connection with the deeper layers of the aponeurosis, these separating from the superficial layer to form the long flexor tendons. The fourth layer partly assumes a longitudinal direction and becomes the tibialis posterior and the flexor hallucis longus and partly retains its original cblique direction and its connection with the deep layers of the plantar aponeurosis, becoming the quadratus plantæ. In the foot (Fig. I28, B) the superficial layer persists as muscular tissue, forming the abductors, the flexor digitorum brevis and the medial head of the flexor hallucis brevis, the second layer becomes the lumbricales, and the third the lateral head of the flexor hallucis brevis and the adductor hallucis, while the fourth and fifth layers together form the interossei, as in the hand, the flexor quinti digiti brevis really belonging to that group of muscles.

\section{LITERATURE.}

C. R. Bardeen and W. H. Lewis: "Development of the Limbs, Body-wall, and Back in Man," The American Journal of Anat., I, I9or.

K. Bardeleben: "Muskel und Fascia," Jenaische Zeitschr. für Naturwissensch., $\mathrm{XV}, \mathrm{I} S 82$.

L. BolK: "Beziehungen zwischen Skelett, Muskulatur und Nerven der Extremitäten, dargelegt am Beckengürtel, an dessen Muskulatur sowie am Plexus lumbosacralis," Morphol. Jahrbuch, xxI, I894.

L. BoLK: "Rekonstruktion der Segmentirung der Gliedmassenmuskulatur dargelegt an den Muskeln des Oberschenkels und des Schultergürtels," Morphol. Jahrbuch, xxII, I895.

L. BoLK: "Die Sklerozonie des Humerus," Morphol. Jahrbuch, xxIII, ISg6.

L. Bolk: "Die Segmentaldifferenzierung des menschlichen Rumpfes und seiner Extremitäten," I, Morphol. Jahrbuch, xxv, IS9S.

R. Futamura: "Ueber die Entwickelung der Facialismuskulatur des Menschen," Anat. Hefte, xxx, 1906.

E. Godlewski: "Die Entwicklung des Skelet- und Herzmuskelgewebes der Säugethiere," Archiv für mikr. Anat., LX, I902. 
E. Grifenberg: "Die Entwicklung der menschlichen Beckenmuskulatur," Anat. Hefte, xxim, I904.

W. P. Herringham: "The Minute Anatomy of the Brachial Plexus," Proceedings of the Royal Soc.London, XLI, I886.

W. H. Lewis: "The Development of the Arm in Man," Amer. Jour. of Anat., I, I9o2

J. B. MacCallum: "On the Histology and Histogenesis of the Heart Muscle-cell," Anat. Anzeiger, xIII, I897.

J. B. MacCallum: "On the Histogenesis of the Striated Muscle-fiber and the Growth of the Human Sartorius Muscle," Johns Hopkins Hospital Bulletin, I898

F. P. MALL: "Development of the Ventral Abdominal Walls in Man," Journ. of Morphol., xIV, I898.

Caroline McGill: "The Histogenesis of Smooth Muscle in the Alimentary Canal and Respiratory Tract of the Pig," Internat. Monatschr. Anat. und Phys., xxIv, I907.

J. P. McMurrich: "The Phylogeny of the Forearm Flexors," Amer. Journ, of Anat., II, I903.

J. P. McMurrich: "The Phylogeny of the Palmar Musculature," Amer. Journ. of Anat., II, I903.

J. P. MCMurRich: "The Phylogeny of the Crural Flexors," Amer. Journ. of Anat., IV, I904.

J. P. MCMurRich: "The Phylogeny of the Plantar Musculature," Amer. Journ. of Anat., vI, I907.

A. Meek: "Preliminary Note on the Post-embryonal History of Striped Muscle-fibers in Mammalia," Anat. Anzeiger, xıv, r898. (See also Anat. Anzeiger, xv, I899.)

B. MoRPURGo: "Ueber die post-embryonale Entwickelung der quergestreiften Muskel von weissen Ratten," Anat. Anzeiger, xv, r899.

I. Popowsky: "Zur Entwicklungsgeschichte des N. facialis beim Menschen," Morphol. Jahrbuch, xxIII, I896.

I. Popowsky: "Zur Entwickelungsgeschichte der Dammmuskulatur beim Menschen," Anat. Hefte, xI, r899.

L. RETHI: "Der peripheren Verlauf der motorischen Rachen- und Gaumennerven," Sitzungsber. der kais. Akad. Wissensch. Wien. Math.-Naturwiss. Classe, CI, I893.

C. S. Sherrington: "Notes on the Arrangement of Some Motor Fibers in the Lumbosacral Plexus," Journal of Physiol., XIIr, 1892.

J. B. Sutton: "Ligaments, their Nature and Morphology," London, I897. 


\section{CHAPTER IX.}

\section{THE DEVELOPMENT OF THE CIRCULATORY AND LYM- PHATIC SYSTEMS.}

At present nothing is known as to the earliest stages of development of the circulatory system in the human embryo, but it may be supposed that they resemble in their fundamental features what has been observed in such forms as the rabbit and the chick. In both these the system originates in two separate parts, one of which, located in the embry onic mesoderm, gives rise to the heart, while the other, arising in the extra-embryonic mesoderm, forms the first blood-vessels. It will be convenient to consider these two parts separately, and the formation of the blood-vessels may be first described.

In the rabbit the extension of the mesoderm from the embryonic region, where it first appears, over the yolk-sac is a gradual process, and it is in the more peripheral portions of the layer that the bloodvessels first make their appearance. They can be distinguished before the splitting of the mesoderm has been completed, but are always developed in that portion of the layer which is most intimately associated with the yolk-sac, and consequently becomes the splanchnic layer. They belong, indeed, to the deeper portion of that layer, that nearest the endoderm of the yolk-sac, and so characteristic is their origin from this portion of the layer that it has been termed the angioblast and has been held to be derived from the endoderm independently of the mesoderm proper. The first indication of blood-vessels is the appearance in the peripheral portion of the mesoderm of cords or minute patches of spherical cells (Fig. I29, $A$ ). These increase in size by the division and separation of the cells from one another (Fig. I29, B), a clear fluid appearing in the intervals which separate them. Soon the cells surrounding each cord arrange 
themselves to form an enclosing wall, and the cords, increasing in size, unite together to form a network of vessels in which float the spherical cells which may be known as mesamaboids (Minot): Viewed from the surface at this stage a portion of the vascular area of the mesoderm would have the appearance shown in Fig. I30, revealing a dense network of canals in which, at intervals, are groups of mesamæboids adherent to the walls, constituting what have been termed the blood-islands, while in the meshes of the network unaltered mesoderm cells can be seen, forming the so-called substance-islands.
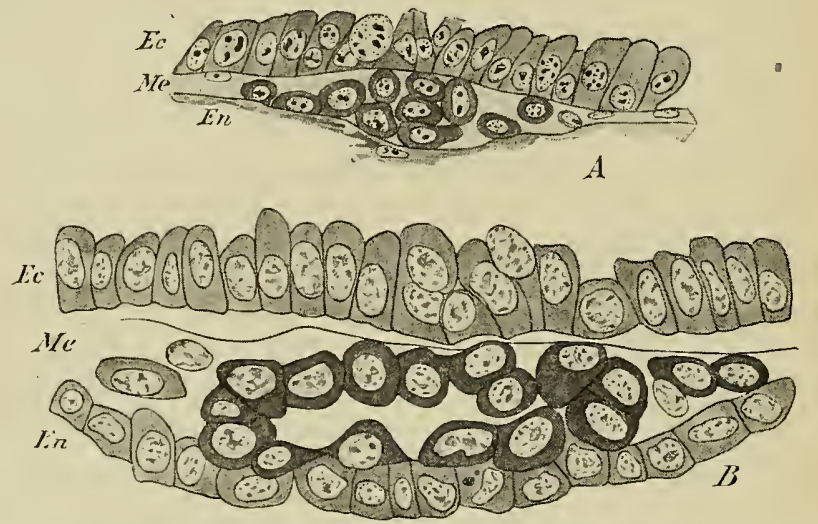

Fig. I29.--Transverse Section through the Area Vasculosa of Rabbit Embryos SHOWINg tHE TRANSFORMATION OF MESOdERM CELlS INTO THE VASCULAR CORDS.

$$
\text { Ec, Ectoderm; En, endoderm; Me, mesoderm.-(van der Stricht.) }
$$

At the periphery of the vascular area the vessels arrange themselves to form a sinus terminalis enclosing the entire area, and the vascularization of the splanchnic mesoderm gradually extends toward the embryo. Reaching it, the vessels penetrate the embryonic tissues and eventually come into connection with the heart, which has already differentiated and has begun to beat before the connection with the vessels is made, so that when it is made the circulation is at once established. Before, however, the vascularization reaches the embryo some of the canals begin to enlarge (Fig. 
I3I, $A$ ), producing arteries and veins, the rest of the network forming capillaries uniting these two sets of vessels, and, this process continuing, there are eventually differentiated a single vitelline artery and two vitelline veins (Fig. I3 I, B).

In the human embryo the small size of the yolk-sac permits of the extension of the vascular area over its entire surface at an early period, and this condition has already been reached in the earliest stages known and consequently no sinus terminalis such as occurs in the rabbit is visible. Otherwise the conditions are probably similar to what has been described above, the first circulation developed being associated with the yolk-sac.

It is to be noted that the capillary network of the area vasculosa consists of relatively wide anastomosing spaces whose endothelial lining rests directly upon the substance islands (Fig. I30). In certain of the embryonic organs, notably the liver, the metanephros and the heart, the network has a similar character, consisting of wide anastomosing spaces bounded by an endothelium which rests directly, or almost so, upon the parenchyma of the organ (the hepatic

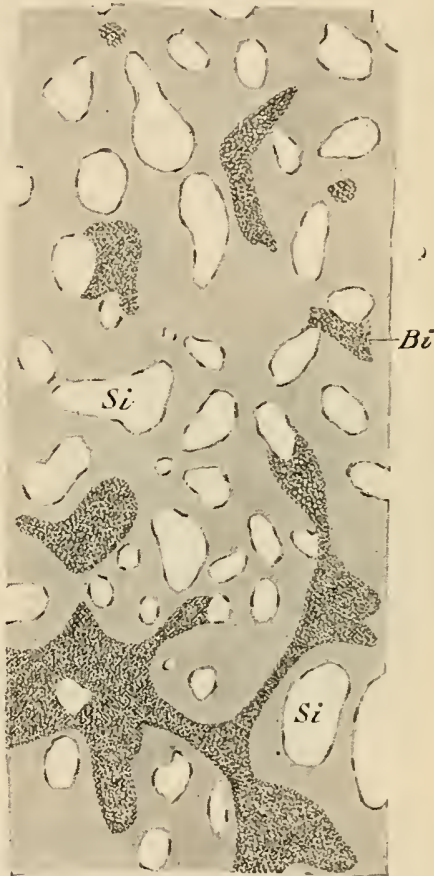

Fig. I30.-SuRface VIEW OF A Portion of the ARea Vasculosa of A CHICK.

The vascular network is represented by the shaded portion. Bi, Bloodisland; $S i$, substance-island.-(Disse.) cylinders, the mesonephric tubules, or the cardiac muscle trabeculæ) (Figs. I32 and I9o, B). To this form of capillary the term sinusoid has been applied (Minot), and it appears to be formed by the expansion of the wall of a previously existing blood-vessel, which thus moulds itself, as it were, over the parenchyma of the organ. The 
true capillaries, on the other hand, are more definitely tubular in form, are usually imbedded in mesenchymatous connective tissue and are developed in the same manner as the primary capillaries of the area vasculosa, by the aggregation of vasifactive cells to form cords, and the subsequent hollowing out of these. Whether these vasifactive cells are new differentiations of the embryonic mesenchyme or are budded off from the walls of existing capillaries which have grown in from extra-embryonic regions, is at present undecided.

The Formation of the Blood.-The mesamœboids, which are
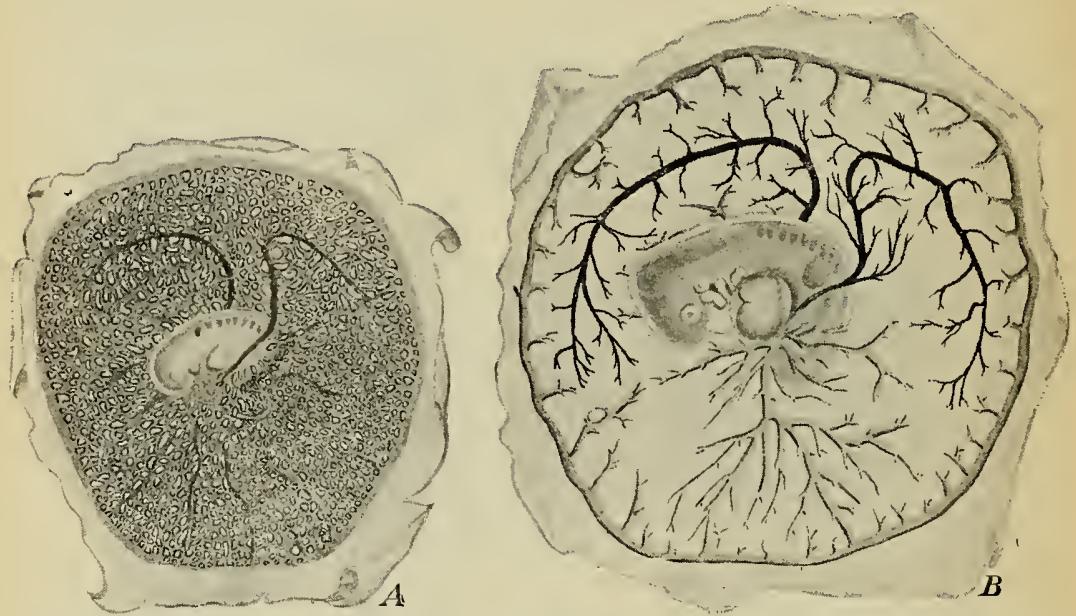

Fig. I3I.-The Vascular Areas of Rabbit Embryos. In $B$ the Veins are

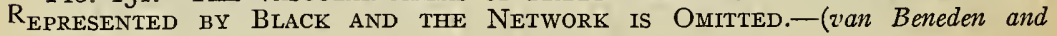
Julin.)

the first formed blood-corpuscles are all nucleated and destitute or nearly so of himoglobin. They have been held by some observers to be the only source of the various forms of corpuscles that are found in the adult vessels, while others maintain that they give rise only to the red corpuscles, the leukocytes arising in tissues external to the blood-vessels and only secondarily making their way into them. According to this latter view the red and white corpuscles have a different origin and remain distinct throughout life. 
So long as the formation of blood-vessels is taking place in the extra-embryonic mesoderm, so long are new mesamœboids being differentiated from the mesoderm. But whether the formation of blood-vessels within the embryo results from a differentiation of the embryonic mesoderm in situ, or from the actual ingrowth of vessels from the extra-embryonic regions (His), is as yet uncertain, and hence it is also uncertain whether mesamœboids are differentiated from the embryonic mesoderm or merely pass into the embryonic region from the more peripheral areas. However this may be, it is certain that they and the erythrocytes that are formed from them increase by division in the interior of the embryo, and that there are certain portions of the body in which these divisions take place most abundantly, partly, perhaps, on account of the more favorable conditions of nutrition which they present and partly because they are regions where the circulation is sluggish and permits the accumulation of erythrocytes. These regions constitute what have been termed the hamatopoietic organs, and are especially noticeable in the later stages of fetal life, diminishing in number and variety about the time of birth. It must be remembered, however, that the life of individual corpuscles is comparatively short, their death and disintegration taking place continually during the entire life of the individual, so that there is a necessity for the formation of new corpuscles and for the existence of hæmatopoietic organs at all stages of life.

In the fetus mesamœeboids in process of division may be found in the general circulation and even in the heart itself, but they are much more plentiful in places where the blood-pressure is diminished, as, for instance, in the larger capillaries of the lower limbs and in the capillaries of all the visceral organs and of the subcutaneous tissues. Certain organs, however, such as the liver, the spleen, and the bone-marrow, present especially favorable conditions for the multiplication of the blood-cells, and in these not only are the capillaries enlarged so as to afford resting-places for the corpuscles, but gaps appear in the walls of the vessels through which the blood-elements may pass and so come into intimate relations with the actual tissues 
of the organs (Fig. I32). After birth the hæmatopoietic function of the liver ceases and that of the spleen becomes limited to the formation of white corpuscles, though the complete function may be re-established in cases of extreme anæmia. The bone-marrow, however, retains the function completely, being throughout life the seat of formation of both red and white corpuscles, the lymphatic nodes and follicles, as well as the spleen, assisting in the formation of the latter elements.

The mesamoboids early become converted into nucleated red

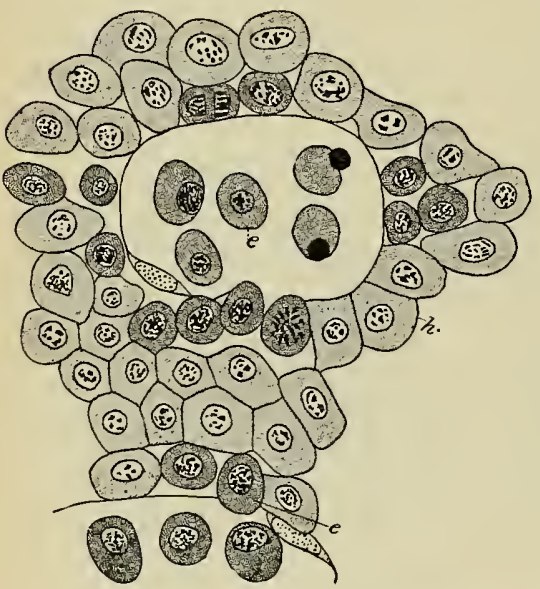

Fig. I32.-Section of a Portion of THE Liver of a RabBit EMbryo of 5 MM. $e$, Erythrocytes in the liver substance and in a capillary; $h$, hepatic cells.-(van der Stricht.) corpuscles or erythrocytes by the development of hæmoglobin in their cytoplasm, their nuclei at the same time becoming granular. Up to a stage at which the embryo has a length of about $\mathrm{I} 2 \mathrm{~mm}$. these are the only form of red corpuscle in the circulation, but at this time (Minot) a new form, characterized by its smaller size and more deeply staining nucleus, makes its appearance. These erythrocytes have been termed normoblasts (Ehrlich), although they are merely transition stages leading to the formation of erythroplastids by the extrusion of their nuclei (Fig. I33). The cast-off nuclei undergo degeneration and phagocytic absorption by the leukocytes, and the masses of cytoplasm pass into the circulation, becoming more and more numerous as development proceeds, until finallythey are the typical hæmoglobin-containing elements in the blood and form what are properly termed the red bloodcorpuscles.

It has already (p. 224) been pointed out that discrepant views 
prevail as to the origin of the white blood-corpuscles. Indeed, three distinct modes of origin have been assigned to them. According to one view they have a common origin with the erythrocytes from the mesamœboids (Weidenreich), according to another they are formed from mesenchyme cells outside the cavities of the blood-vessels (Maximow), while according to a third view the first formed leukocytes take their origin from the endodermal epithelial cells of the thymus gland (Prenant).

But whatever may be their origin in later stages the leukocytes multiply by mitosis and there is a tendency for the dividing cells to collect in the lymphoid tissues, such as the lymph nodes, tonsils, etc., to form more or less definite groups which have been termed germ-centers (Flemming). The new cells when they first pass into the circulation have a relatively large nucleus surrounded by a
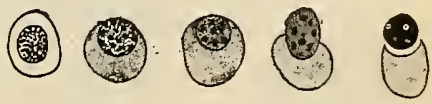

FIG. I33.-STAGES IN THE Transformation OF A N ERYTHROCYTE INTO AN ERYTHROPLASTID.-(van der Stricht.) small amount of cytoplasm without granules and, since they resemble the cells found in the lymphatic vessels, are termed lymphocytes (Fig. I34, a). In the circulation, however, other forms of leukocytes also occur, which are believed to have their origin from cells with much larger nuclei and more abundant cytoplasm, which occur throughout life in the bone-marrow and have been termed myelocytes. Cells of a similar type, free in the circulation, constitute what are termed the finely gramular leukocytes (neutrophile cells of Ehrlich) (Fig. I34, b), but whether these and the myelocytes are derived from lymphocytes or have an independent origin is as yet undetermined. Less abundant are the coarsely gramular leukocytes (eosinophile cells of Ehrlich) (Fig. I34, c), characterized by the coarseness and staining reactions of their cytoplasmic granules and by their reniform or constricted nucleus. They are probably derivatives of the finely granular type and it has been. maintained by Weidenreich that their granules have been acquired by the phagocytosis of degenerated erythrocytes. Finally, a third type is formed by the polymorphomuclear or polymuclear leukocytes (basophile cells 
of Ehrlich) (Fig. I34, d), which are to be regarded as leukocytes in the process of degeneration and are characterized by their irregularly lobed or fragmented nuclei; as well as by their staining peculiarities.

In the fetal hæmatopoietic organs and in the bone-marrow of the adult large, so-called giant-cells are found, which, although they do not enter into the general circulation, are yet associated with the development of the blood-corpuscles. These giant-cells as they

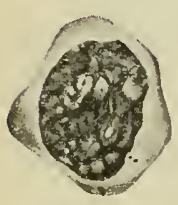

a

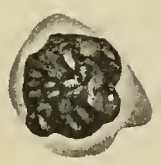

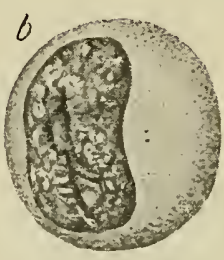

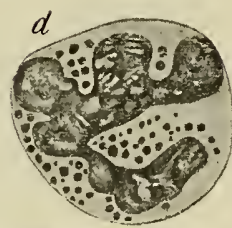

IN HuMan BloOd.

$a$, Lymphocytes; $b$, finely granular (neutrophile) leukocyte; $c$, coarsely granular (eosinophile) leukocyte; $d$, polymorphonuclear (basophile) leukocyte.-(Weidenreich.)

occur in the bone-marrow are of two kinds which seem to be quite distinct, although both are probably formed from leukocytes. In one kind the cytoplasm contains several nuclei, wherce they have been termed polycaryocytes, and they seem to be the cells which have already been mentioned as osteoclasts (p. 158). In the other kind (Fig. I35) the nucleus is single, but it is large and irregular in shape, frequently appearing as if it were producing buds. These megacaryocytes appear to be phagocytic cells, having as their function the destruction of degenerated corpuscles and of the nuclei of the erythrocytes. 
The blood-platelets have recently been shown by Wright to be formed from the cytoplasm of the megacaryocytes, by the constriction and separation of portions of the slender processes to which they give rise in their amœboid movements (Fig. I35).

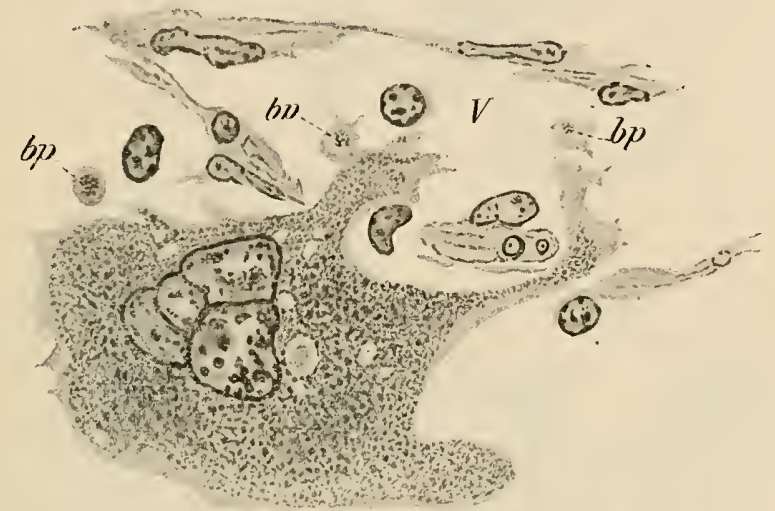

Fig. I35.-Megacaryocyte from a Kitten, which has Extended two PSEudopodial Processes through the Wall of BlOOd-Vessel and is Budding OFF BLOOD-PLATELETS.

$b p$, Blood-platelets; $V$, blood-vessel.- $(J . H$. Wright. $)$

The Formation of the Heart.-The heart makes its appearance while the embryo is still spread out upon the surface of the yolk-sac, and arises as two separate portions which only later come into contact in the median line. On each side of the body near the margins of the embryonic area a fold of the splanchnopleure appears, projecting into the cœlomic cavity, and within this fold a very thinwalled sac is formed, probably by a splitting off of its innermost cells (Fig. I $_{3} 6, A$ ). Each fold will produce a portion of the muscular walls (myocardium) of the heart, and each sac part of its endothelium (endocardium). As the constriction of the embryo from the yolk-sac proceeds, the two folds are gradually brought nearer together (Fig. I36, $B$ ), until they meet in the mid-ventral line, when the myocardial folds and endocardial sacs fuse together (Fig. ${ }_{3} 6, C$ ) to form a cylindrical heart lying in the mid-ventral line of the body, in front of the anterior surface of the yolk-sac and in what will later be the 
cervical region of the body. At an early stage the various veins which have already been formed, the vitellines, umbilicals, jugulars
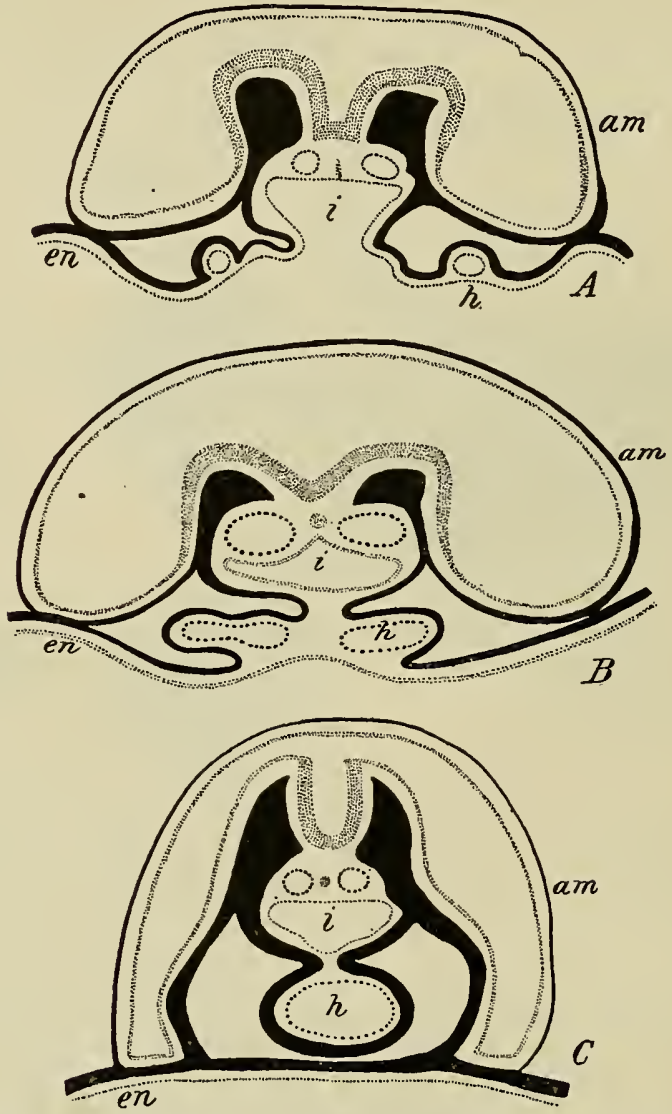

Fig. I36.-Diagrams Illustrating the Formation of the Heart in the GUINEA-PIG.

The mesoderm is represented in black and the endocardium by a broken line. am, Amnion; en, endoderm; $h$, heart; $i$, digestive tract.-(After Strahl and Carius.)

and cardinals, unite together to open into a sac-like structure, the sinus venosus, and this opens into the posterior end of the heart cylinder. The anterior end of the cylinder tapers off to form the 
aortic bulb, which is continued forward on the ventral surface of the pharyngeal region and carries the blood away from the heart. The blood accordingly opens into the posterior end of the heart tube and flows out from its anterior end.

The simple cylindrical form soon changes, however, the heart tube in embryos of $2.15 \mathrm{~mm}$. in length having become bent upon itself into a somewhat S-shaped curve (Fig. I37). Dorsally and to the left is the end into which the sinus venosus opens, and from this

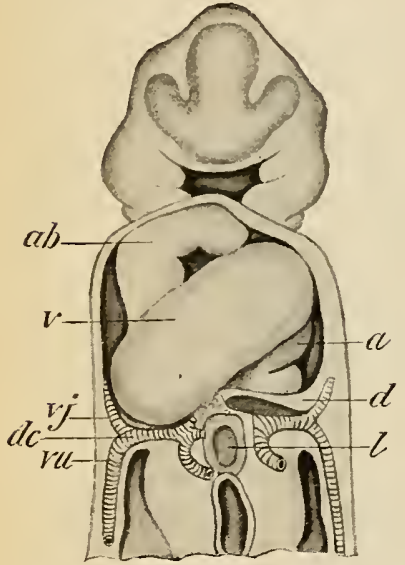

Fig. 137.-Heart of EMbryo"of 2 . 5 MM., FROM A RECONSTRUCTION. $a$, Atrium; $a b$, aortic bulb; $d$, diaphragm; $d c$, ductus Cuvieri; $l$, liver; $v$, ventricle; $v j$, jugular vein; $v u$, umbilical vein.-(His.)

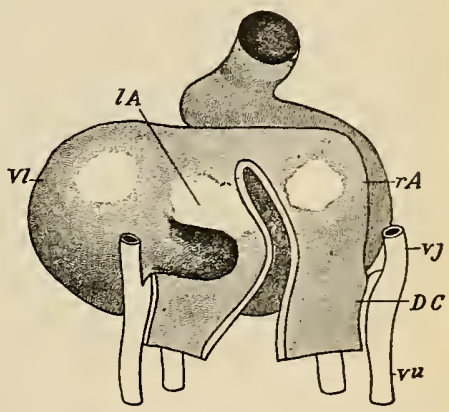

Fig. I38.-Heart of Embryo of 4.2 MM., SEEN FROM THE DORSAL SURFACE.

$D C$, Ductus Cuvieri; $l A$, left atrium $r A$, right atrium; $v j$, jugular vein; $V l$, left ventricle; $v u$, umbilical vein.(His.)

the heart tube ascends somewhat and then bends so as to pass at first ventrally and then caudally and to the right, where it again bends at first dorsally and then anteriorly to pass over into the aortic bulb. The portion of the curve which lies dorsally and to the left is destined to give rise to both atria, the portion which passes from right to left represents the future left ventricle, while the succeeding portion represents the right ventricle. In later stages (Fig. I38) the left ventricular portion drops downward in front of the atrial 
portion, assuming a more horizontal position, while the portion which represents the right ventricle is drawn forward so as to lie in the same plane as the left.

At the same time two small out-pouchings develop from the atrial part of the heart and form the first indications of the two atria. As development progresses, these increase in size to form large pouches opening into a common atrial canal (Fig. I39) which is directly continuous with the left ventricle, and as the enlargement of the pouches continues their openings into the canal enlarge,

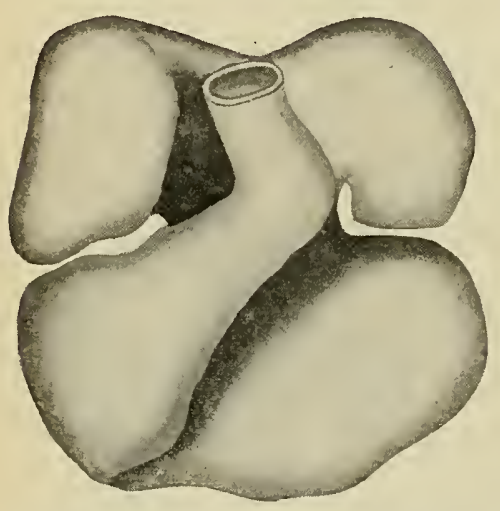

Fig. T39.-Heart of Embryo of 5 MM., SEEN FROM IN FroNT AND SLIGHTLY FROM ABOVE.-(His). until finally the pouches become continuous with one another, forming a single large sac, and the atrial canal becomes reduced to a short tube which is slightly invaginated into the ventricle (Fig. I40).

In the meantime the sinus venosus, which was originally an oval sac and opened into the atrial canal, has elongated transversely until it has assumed the form of a crescent whose convexity is in contact with the walls of the atria, and its opening into the heart has verged toward the right, until it is situated entirely within the area of the right atrium. As the enlargement of the atria continues, the right horn and median portion of the crescent are gradually taken up into their walls, so that the various veins which originally opened into the sinus now open directly into the right atrium by a single opening, guarded by a projecting fold which is continued upon the roof of the atrium as a muscular ridge known as the septum spurium (Fig. I40, sp). The left horn of the crescent is not taken up into the atrial wall, but remains upon its posterior surface as an elongated sac forming the coronary sinus.

The division of the now practically single atrial cavity into the 
permanent right and left atria begins with the formation of a falciform ridge running dorso-ventrally across the roof of the cavity. This is the atrial septum or septum primum (Fig. I40, ss), and it rapidly increases in size and thickens upon its free margin, which reaches almost to the upper border of the short atrial canal (Fig. 142). The continuity of the two atria is thus almost dissolved, but is soon re-cstablished by the formation in the dorsal part of the septum of an opening which soon reaches a considerable size and is known as

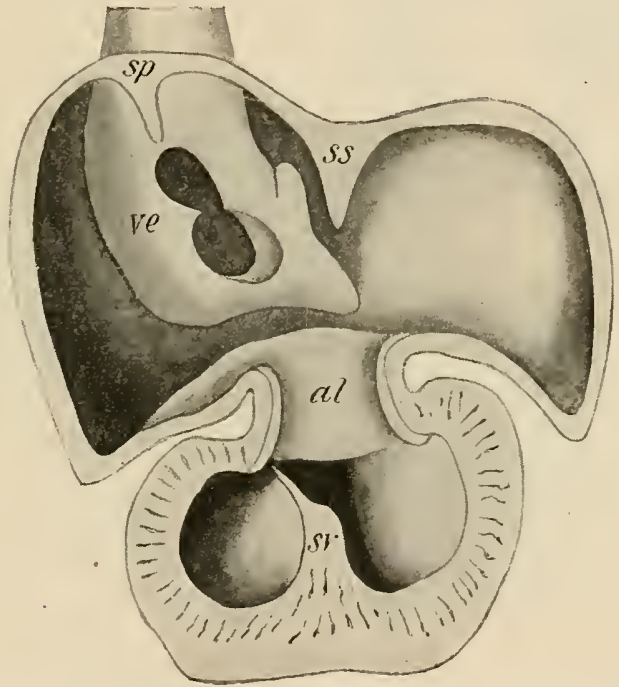

Fig. I40.-Inner Surface of the Heart of an Embryo of io mi. $a l$, Atrio-ventricular thickening; $s p$, septum spurium; $s s$, septum primum; $s v$, septum ventriculi; ve, Eustachian valve.-(His.)

the foramen ovale (Fig. I4I, fo). Close to the atrial septum, and parallel with it, a second ridge appears in the roof and ventral wall of the right atrium. This septum secundum (Fig. I4I, $S_{2}$ ) is of relatively slight development in the human embryo, and its free edge, arching around the ventral edge and floor of the foramen ovale, becomes continuous with the left lip of the fold which guards the opening of the sinus venosus and with this forms the anmulus of Vieussens of the adult heart. 
When the absorption of the sinus venosus into the wall of the right atrium has proceeded so far that the veins communicate directly with the atrium, the vena cava superior opens into it at the upper part of the dorsal wall, the vena cava inferior more laterally, and below this is the smaller opening of the coronary sinus. The

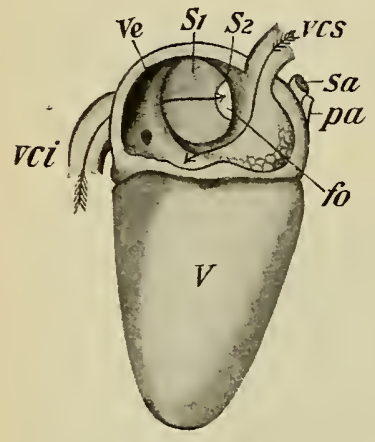

Fig. I4I.-Heart of Embryo OF IO.2 CM. FROM WHICH HALF OF THE RIGHT AURICLE HAS BEEN REMOVED.

fo, Foramen ovale; $p a$, pulmonary artery; $S_{1}$, septum primum; $S_{2}$, septum secundum; $S a$, systemic aorta; $V$, right ventricle; $v c i$ and $v c s$, inferior and superior venæ cavæ; $V e$, Eustachian valve. upper portion of the right lip of the fold which originally surrounded the opening of the sinus venosus, together with the septum spurium, gradually disappears; the lower portion persists, however, and forms (I) the Eustachian valve (Fig. I4I, $V e)$, guarding the opening of the inferior cava and directing the blood entering by it toward the foramen ovale, and (2) the Thebesian valve, which guards the opening of the coronary sinus. At first no veins communicate with the left atrium, but on the development of the lungs and the establishment of their vessels, the pulmonary veins make connection with it. Two veins arise from each lung, and as they pass toward the heart they unite in pairs, the two vessels so formed again uniting to form a single short trunk which opens into the upper part of the atrium (Fig. I42, Vep). As is the case with the right atrium and the sinus venosus, the expansion of the left atrium brings about the absorption of the short single trunk into its walls, and, the expansion continuing, the two vessels are also absorbed, so that eventually the four primary veins open independently into the atrium.

While the atrial septa have been developing there has appeared on the dorsal wall of the atrial canal a tubercle-like thickening of the endocardium, and a similar thickening also forms on the ventral wall. These endocardial cushions increase in size and finally unite together by their tips, forming a complete partition, dividing the 
atrial canal into a right and left half (Fig. I42). With the upper edge of this partition the thickened lower edge of the atrial septum unites, so that the separation of the atria would be complete were it not for the foramen ovale.

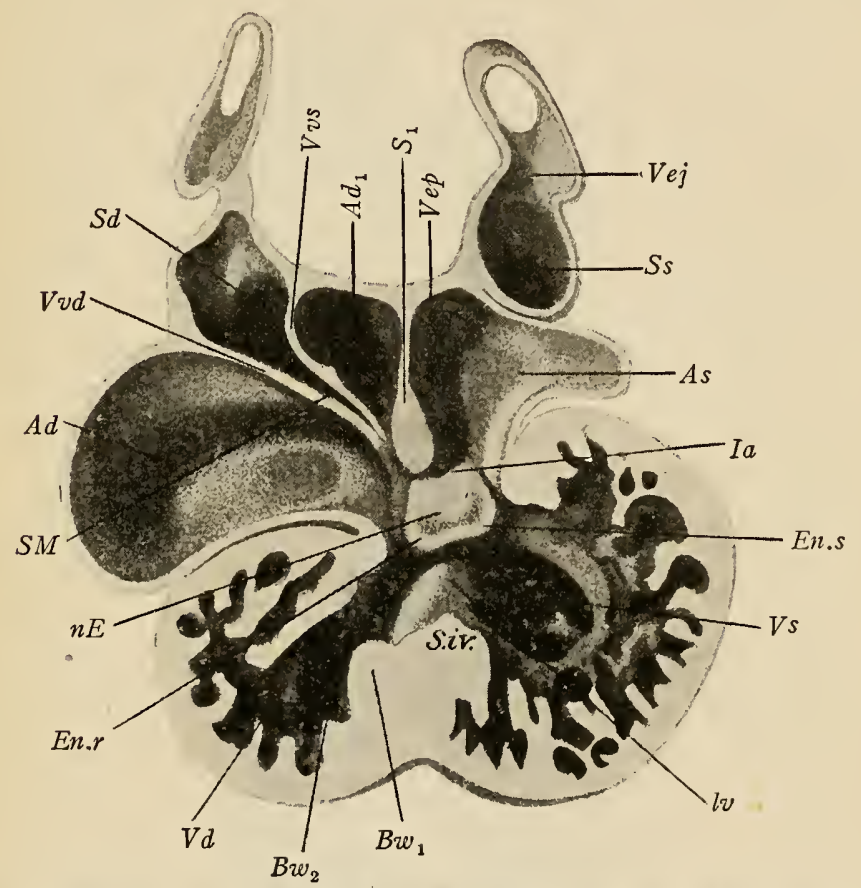

Fig. I42.-Section through a Reconstruction of the Heart of a Rabbit EMBRYO OF IO.I MM.

$A d$ and $A d_{1}$, Right and $A s$, left atrium; $B w_{1}$ and $B w_{2}$, lower ends of the ridges which divide the aortic bulb; En, endocardial cushion; En.r and En.s, thickenings of the cushion; $I a$, interatrial and $I v$, interventricular communication; $S_{1}$, septum primum; $S d$, right and $S s$, left horn of the sinus venosus; $S . i v$, ventricular septum; $S M$, opening of the sinus venosus into the atrium; $V d$, right and $V s$, left ventricle; $V e j$, jugular vein; $V e p$, pulmonary vein; $V v d$ and $V v s$, right and left limbs of the valve guarding the opening of the sinus venosus.-(Born.)

While these changes have been taking place in the atrial portion of the heart, the separation of the right and left ventricles has also been progressing, and in this two distinct septa take part. From the floor of the ventricular cavity along the line of junction of the 
right and left portions a ridge, composed largely of muscular tissue, arises (Figs. 140 and $\mathrm{I}_{4}$ ), and, growing more rapidly in its dorsal than its ventral portion, it comes into contact and fuses with the dorsal part of the partition of the atrial canal. Ventrally, however, the ridge, known as the ventricular septum, fails to reach the ventral part of the partition, so that an oval foramen, situated just below the point where the aortic bulb arises, still remains between the two ventricles. This opening is finally closed by what it termed the aortic septum. This makes its appearance in the aortic bulb just at the point where the first lateral branches which give origin to the pulmonary arteries (see p. 243) arise, and is formed by the fusion of the free edges of two endocardial ridges which develop on opposite sides of the bulb. From its point of origin it gradually extends down the bulb until it reaches the ventricle, where it fuses with the free edge of the ventricular septum and so completes the separation of the two ventricles (Fig. r43). The bulb now consists of two vessels lying side by side, and owing to the position of the partition at its anterior end, one of these vessels, that which opens into the right ventricle, is continuous with the pulmonary arteries, while the other, which opens into the left ventricle, is continuous with the rest of the vessels which arise from the forward continuation of the bulb. As soon as the development of the partition is completed, two grooves, corresponding in position to the lines of attachment of the partition on the inside of the bulb, make their appearance on the outside and gradually deepen until they finally meet and divide the bulb into two separate vessels, one of which is the pulmonary aorta and the other the systemic aorta.

In the early stages of the heart's development the muscle bundles which compose the wall of the ventricle are very loosely arranged, so that the ventricle is a somewhat spongy mass of muscular tissue with a relatively small cavity. As development proceeds the bundles nearest the outer surface come closer together and form a compact layer, those on the inner surface, however, retaining their loose arrangement for a longer time (Fig. 142). The lower edge of the atrial canal becomes prolonged on the left side into one, and on the 
right side into two, flaps which project downward into the ventricular cavity, and an additional flap arises on each side from the lower
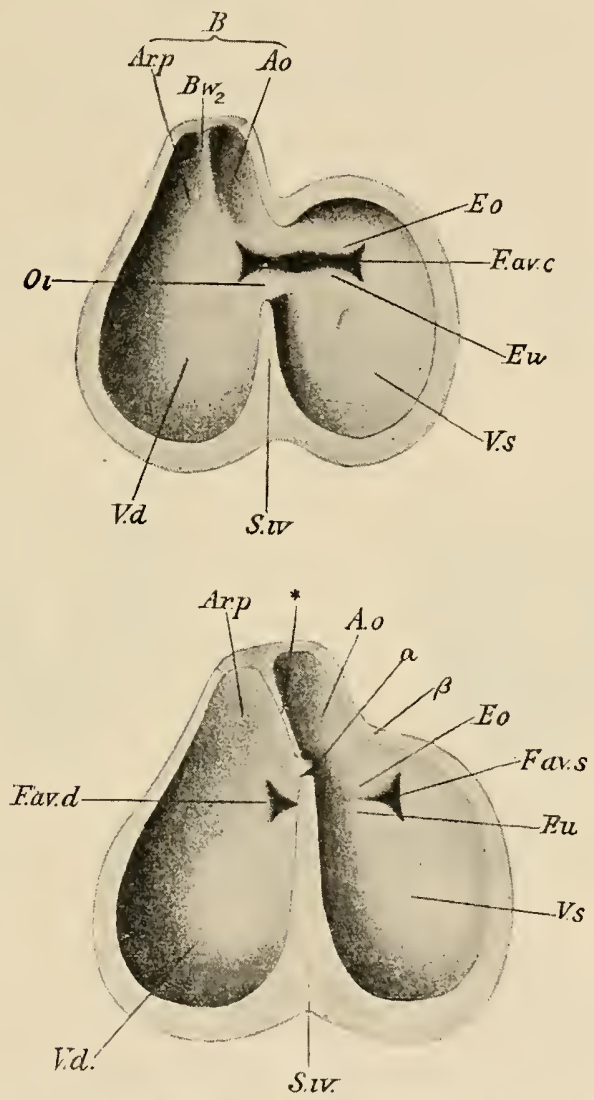

Fig. I43.-Diagrams of Sections through the Heart of Embryo Rabbits

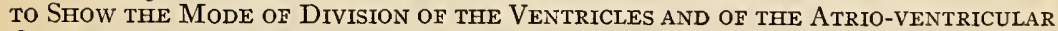
ORIFICE.

$A o$, Aorta; $A r . p$, pulmonary artery; $B$, aortic bulb; $B w_{2}$ and $*$, one of the ridges which divide the bulb; $E o$, and $E u$, upper and lower thickenings of the margins of the atrio-ventricular orifice; F.av.c, the original atrio-ventricular orifice; F.av.d and $F . a v . s$, right and left atrio-ventricular orifices; $O i$, interventricular communication; $S . i v$, ventricular septum; $V d$ and $V s$, right and left ventricles.-(Born.)

edge of the partition of the atrial canal, so that three flaps occur in the right atrio-ventricular opening and two in the left. To the 
under surfaces of these flaps the loosely arranged muscular trabeculæ of the ventricle are attached, and muscular tissue also occurs in the flaps. This condition is transitory, however; the muscular tissue of the flaps degenerates to form a dense layer of connective tissue, and at the same time the muscular trabeculæ undergo a condensation. Some of them separate from the flaps, which represent the atrio-ventricular valves, and form muscle bundles which may fuse throughout their entire length with the more compact portions of the ventricular walls, or else may be attached only by their ends, forming loops; these two varieties of muscle bundles constitute the trabeculce carnea of the adult heart. Other bundles
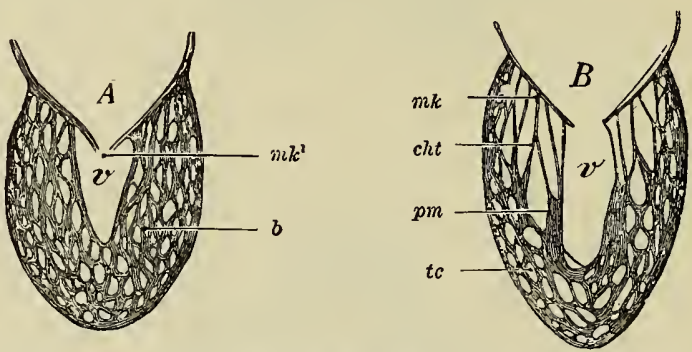

Fig. I44.-Diagrams Showing the DeVelopment of the Auriculo-Ventricular VALVES.

$b$, Muscular trabeculæ; cht, chordæ tendinæ; $m k$ and $m k^{1}$, valve; $p m$, musculus papillaris; tc, trabeculæ carnex; v, ventricle.-(From Hertwig, after Gegenbaur.)

may retain a transverse direction, passing across the ventricular cavity and forming the so-called moderator bands; while others, again, retaining their attachment to the valves, condense only at their lower ends to form the musculi papillares, their upper portions undergoing conversion into strong though slender fibrous cords, the chorda tendinea (Fig. I44).

The endocardial lining of the ventricles is at first a simple sac separated by a distinct interval from the myocardium, but when the condensation of the muscle trabeculæ occurs the endocardium applies itself closely to the irregular surface so formed, dipping into all the crevices between the trabeculæ carneæ and wrapping itself around 
the musculi papillares and chordæ tendineæ so as to form a complete lining of the inner surface of the myocardium.

The aortic and pulmonary semilunar valves make their appearance, before the aortic bulb undergoes its longitudinal splitting, as four tubercle-like thickenings of connective tissue situated on the inner wall of the bulb just where it arises from the ventricle. When the division of the bulb occurs, two of the thickenings, situated on opposite sides, are divided, so that both the pulmonary and systemic aortæ receive three thickenings (Fig. I45). Later the thickenings become hollowed out on the surfaces directed away from the ventricles and are so converted into the pouch-like valves of the adult.

Changes in the Heart after Birth.-The heart when first formed lies far forward in the neck region of the embryo, between the head and the anterior surface of the yolk-sac, and
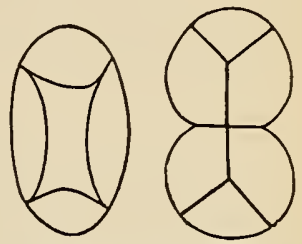

FIG. I45.-DLAGRAMS ILLUSTRATING THE FORMATION OF THE SEMILUNAR VALVES.-(Gegenbaur.) from this position it gradually recedes until it reaches its final position in the thorax. And not only does it thus change its relative position, but the direction of its axes also changes. For at an early stage the ventricles lie directly in front of (i.e., ventrad to) the atria and not below them as in the adult heart, and this primitive condition is retained until the diaphragm has reached its final position (see p. 322).

In addition to these changes in position, which are antenatal, important changes also occur in the atrial septum after birth. Throughout the entire period of fetal life the foramen ovale persists, permitting the blood returning from the placenta and entering the right atrium to pass directly across to the left atrium, thence to the left ventricle, and so out to the body through the systemic aorta (see p. 267). At birth the lungs begin to function and the placental circulation is cut off, so that the right atrium receives only venous blood and the left only arterial; a persistence of the foramen ovale beyond this period would be injurious, since it would permit of a mixture of the arterial and venous bloods, and, consequently, it 
closes completely soon after birth. The closure is made possible by the fact that during the growth of the heart in size the portion of the atrial septum which is between the edge of the foramen ovale and the dorsal wall of the atrium increases in width, so that the foramen is carried further and further away from the dorsal wall of the atrium and comes to be almost completely overlapped by the annulus of Vieussens (Fig. I4I). This process continuing, the dorsal portion of the atrial septum finally overlaps the free edge of the annulus, and after birth the fusion of the overlapping surfaces takes place and the foramen is completely closed.

In a large percentage ( 25 to 30 per cent.) of individuals the fusion of the surfaces of the septum and annulus is not complete, so that a slit-like opening persists between the two atria. This, however, does not allow of any mingling of the blood in the two cavities, since when the atria contract the pressure of the blood on both sides will force the overlapping folds together and so practically close the opening. Occasionally the growth of the dorsal portion of the septum is imperfect or is inhibited, in which case closure of the foramen ovale is impossible.

The Development of the Arterial System.-It has been seen (p. 22I) that the formation of the blood-vessels begins in the extraembryonic splanchnic mesoderm surrounding the yolk-sac and extends thence toward the embryo. Furthermore, it has been seen that the vessels appear as capillary networks from which definite stems are later elaborated. This seems also to be the method of formation of the vessels developed within the body of the embryo, the arterial and venous stems being first represented by a number of anastomosing capillaries, from which, by the enlargement of some and the disappearance of the others, the definite stems are formed.

The earliest known embryo that shows a blood circulation is that described by Eternod (Fig. 43). From the plexus of vessels on the yolk-sack two veins arise which unite with two other veins returning from the chorion by the belly-stalk and passing forward to the heart as the two umbilical veins (Fig. I46,Vu). There is as yet no vitelline vein, the chorionic circulation in the human embryo apparently taking precedence over the vitelline. From the heart a short arterial stem arises, which soon divides so as to form three 
branches* passing dorsally on either side of the pharynx. The branches of each side then unite to form a paired dorsal aorta $(d A r$, $d A s$ ) which extends caudally and is continued into the belly-stalk and so to the chorion as the umbilical arteries $(A u)$. There is as yet no sign of vitelline arteries passing to the yolk-sack, again an indication of the subservience of the vitelline to the chorionic circulation in the human embryo.

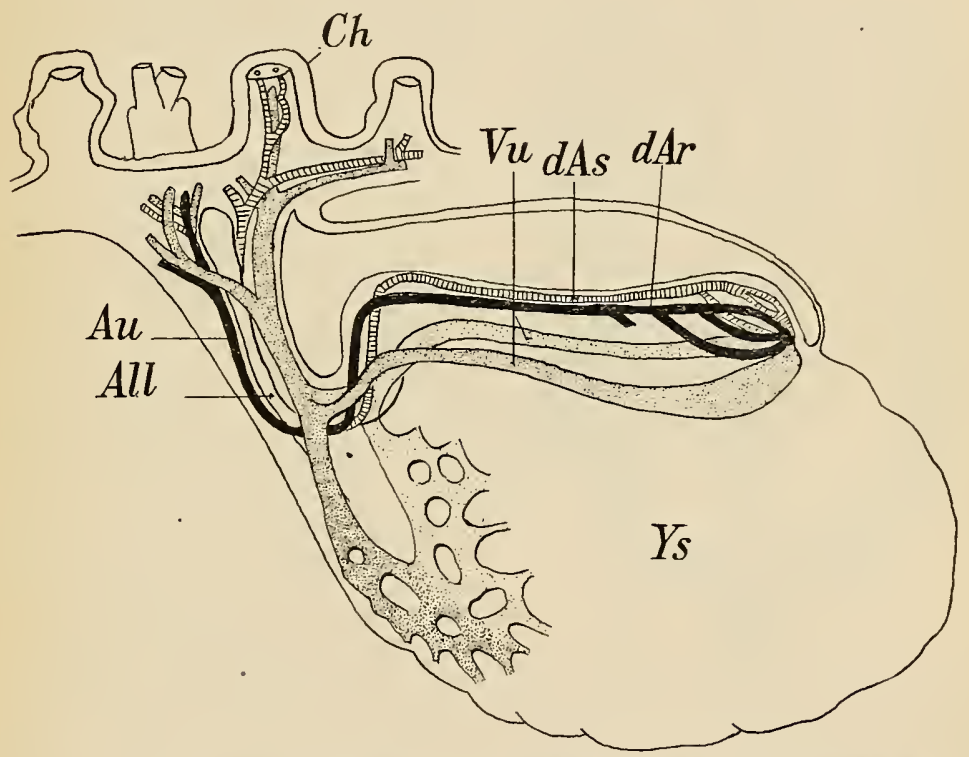

Fig. I46.-Diagram SHowing the ARrangement of the Blood-vessels in an EMBRYO I.3 MM. IN LENGTH.

$A u$, Umbilical artery; $A l l$, allantois; $C h$, chorionic villus; $d A r$ and $d A s$, right and left dorsal aortæ; $V u$, umbilical veins; $Y s$, yolk-sack.-(From Kollmann after Eternod.)

In later stages when the branchial arches have appeared the dorsally directed arteries are seen to lie in these, forming what are termed the branchial arch vessels, and later also the two dorsal

* Evans (Keibel-Mall, Human Embryology, Vol. II, I9I2) considers two of these branches to be probably plexus formations rather than definite stems, since there is evidence to indicate that only one such stem exists at such an early stage of development. 
aortæ fuse as far forward as the region of the eighth cervical segment to form a single trunk from which segmental branches arise.

It will be convenient to consider first the history of the vessels which pass dorsally in the branchial arches. Altogether, six of these vessels are developed, the fifth being rudimentary and transitory, and when fully formed they have an arrangement which may be under-

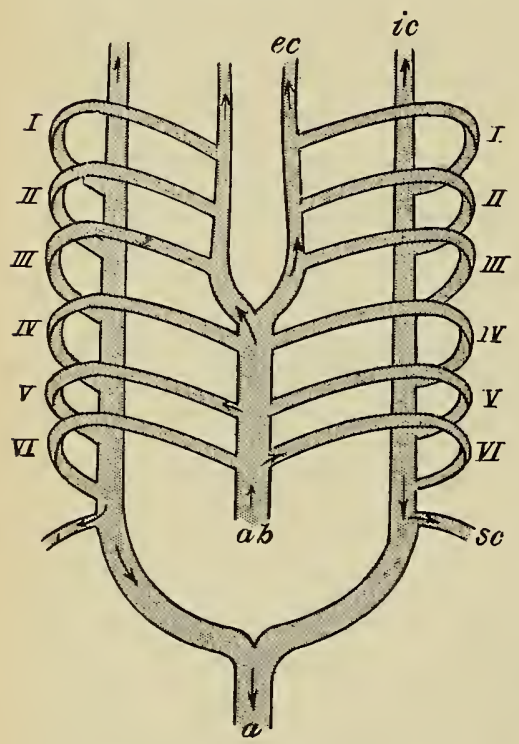

Fig. I47.-Diagram Ili.ustrating the PRIMARY ARRANGeMEent OF THE BRANCHIAL ARCH VESSELS.

$a$, aorta; $a b$, aortic bulb; $e c$, external carotid; $i c$, internal carotid; $s c$, subclavian; $I-V I$, branchial arch vessels. stood from the diagram (Fig. I47). This arrangement represents a condition which is permanent in the lower vertebrates. In the fishes the respiration is performed by means of gills developed upon the branchial arches, and the heart is an organ which receives venous blood from the body and pumps it to the gills, in which it becomes arterialized and is then collected into the dorsal aortæ, which distribute it to the body. - But in terrestrial animals, with the loss of the gills and the development of the lungs as respiratory organs, the capillaries of the gills disappear and the afferent and efferent branchial vessels become continuous, the condition represented in the diagram resulting.

But this condition is merely temporary in the mammalia and numerous changes occur in the arrangement of the vessels before the adult plan is realized. The first change is a disappearance of the vessel of the first arch, the ventral stem from which it arose being continued forward to form the temporal arteries, giving off near the point where the branchial vessel originally arose a branch which represents the internal maxillary artery in part, and possibly also a 
second branch which represents the external maxillary (His). A little later the second branchial vessel also degenerates (Fig. I48), a branch arising from the ventral trunk near its former origin, possibly representing the future lingual artery (His), and then the portion of the dorsal trunk which intervenes between the third and fourth branchial vessels vanishes, so that the dorsal trunk anterior to the third branchial arch is cut off from its connection with the dorsal aorta and forms, together with the vessel of the third arch, the internal carotid, while the ventral trunk, anterior to the point of

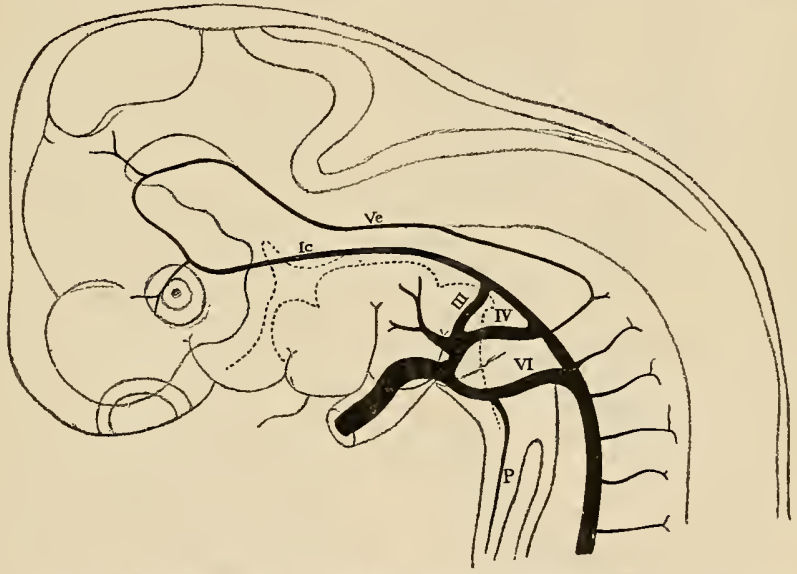

Fig. I48.-Arterial, System of aN Embryo of Io MM.

$I c$, Internal carotid; $P$, pulmonary artery; $V e$, vertebral artery; $I I I$ to $V I$, persistent branchial vessels.-(His.)

origin of the third vessel, becomes the external carotid, and the portion which intervenes between the third and fourth vessels becomes the common carotid (Fig. I49).

The rudimentary fifth vessel, like the first and second, disappears, but the fourth persists to form the aortic arch, there being at this stage of development two complete aortic arches. From the sixth vessel a branch arises which passes backward to the lungs, forming the pulmonary artery, and the portion of the vessel of the right side which intervenes between this and the aortic arch disappears, while the corresponding portion of the left side persists 
until after birth, forming the ductus arteriosus (ductus Botalli) (Fig. I49). When the longitudinal division of the aortic bulb occurs (p. 236), the septum is so arranged as to place the sixth arch in communication with the right ventricle and the remaining vessels in connection with the left ventricle, the only direct communication

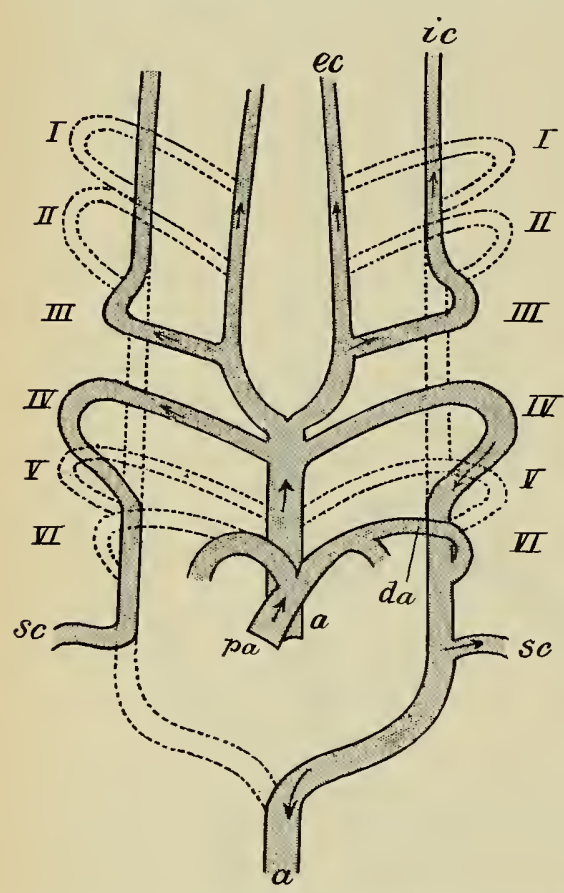

Fig. I49.-Diagram Illustrating the CHANges IN THE BRANCHIAL ARCH Vessels.

$a$, Aorta; $d a$, ductus arteriosus; $e c$, external carotid; $i c$, internal carotid; $p a$, pulmonary artery; sc, subclavian; $I-V I$, aortic arch vessels. between the systemic and pulmonary vessels being by way of the ductus arteriosus, whose significance will be explained later (p. 267).

One other change is still necessary before the vessels acquire the arrangement which they possess during fetal life, and this consists in the disappearance of the lower portion of the right aortic arch (Fig. I49), so that the left arch alone forms the connection between the heart and the dorsal aorta. The upper part of the right aortic arch persists to form the proximal part of the right subclavian artery, the portion of the ventral trunk which unites the arch with the aortic bulb becoming the innominate artery.

From the entire length of the thoracic aorta, and in the embryo from the aortic arches, lateral branches arise corresponding to each segment and accompanying the segmental nerves. The first of these branches arises just below the point of union of the vessel of the sixth arch with the dorsal trunk and accompanies the hypoglossal nerve (Fig. I5o, $h$ ), and that which accompanies the seventh 
cervical nerve arises just above the point of union of the two aortic arches (Fig. I5o, s), and extends out into the limb bud, forming the subclavian artery.*

Further down twelve pairs of lateral branches, arising from the thoracic portion of the aorta, represent the intercostal arteries, and still lower four pairs of lumbar arteries are formed, the fifth lumbars being represented by two large branches, the common iliacs, which seem from their size to be the continuations of the aorta rather than branches of it. The true continuation of the aorta is, however, the middle sacral artery, which represents in a degenerated form the caudal prolongation of the aorta of other mammals, and, like this, gives off lateral branches corresponding to the sacral segments.

In addition to the segmental lateral branches arising from the aorta, visceral branches, which have their origin rather from the ventral surface, also occur. In embryos of $5 \mathrm{~mm}$. these branches are arranged in

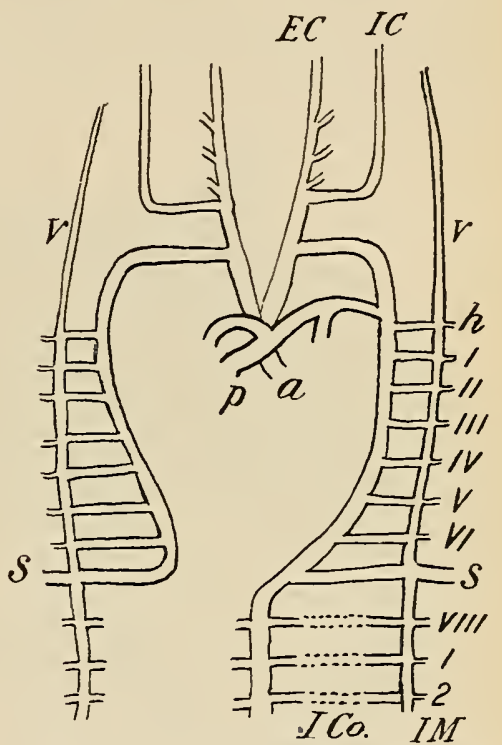

Fig. I50.-DIAGRAM SHOWING THE RELations OF THE LATERAL BRANCHES to THE AORTIC ARCHES.

$E C$, External carotid; $h$, lateral branch cacompanying the hypoglossal nerve; IC, internal carotid; $I C o$, intercostal; $I M$, internal mammary; $s$, subclavian; $v$, vertebral; I to VIII, lateral cervical branches; I, 2, lateral thoracic branches. a segmental manner in threes, a median unpaired vessel passing to the digestive tract and a pair of more lateral branches passing to the mesonephros (see p. 339) corresponding to each of the paired branches passing to the body wall (Fig. I5I). As

* It must be remembered that the right subclavian of the adult is more than equivalent to the left, since it represents the fourth branchial vessel + a portion of the dorsal longitudinal trunk + the lateral segmental branch (see Fig. 142). 
development proceeds the great majority of these visceral branches disappear, certain of the lateral ones persisting, however, to form the renal, internal spermatic, and hypogastric arteries of the adult, while the unpaired branches are represented only by the coliac artery and the superior and inferior mesenterics. The superior mesenteric artery is the adult representative of the vitelline artery of the embryo and arises from the aorta by two, three or more roots, which correspond to the fifth, fourth and higher thoracic

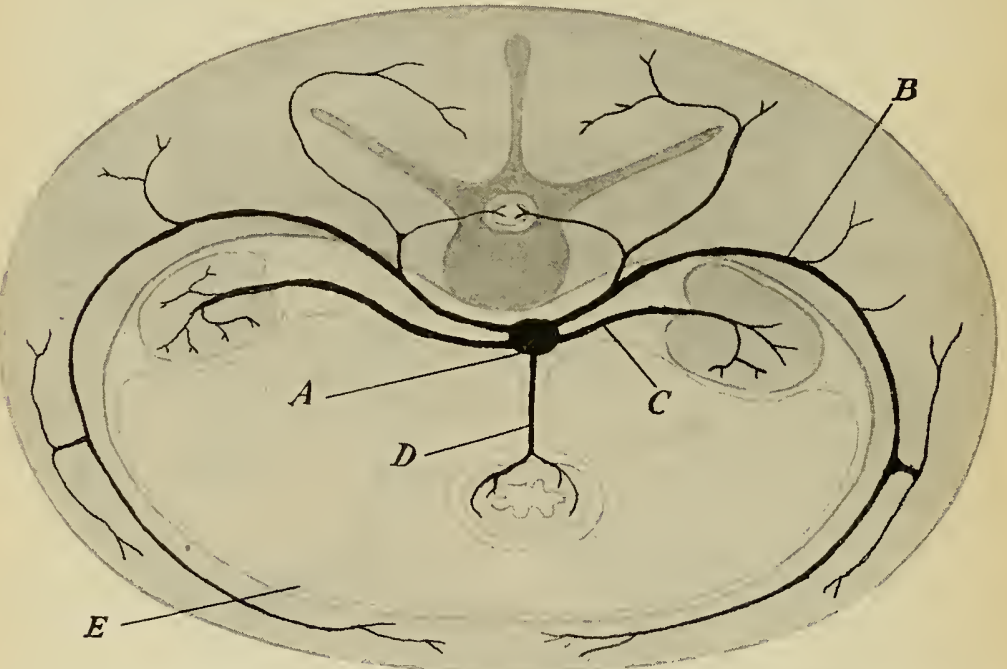

Fig. I5I.-Diagram showing the ArRangement of the Segmental Branches ARISING FROM THE AORTA.

$A$, Aorta; $B$, lateral somatic branch; $c$, lateral visceral branch; $D$, median visceral branch; $E$, peritoneum.

segments. Later, all but the lowest of the roots disappear and the persisting one undergoes a downward migration in accordance with the recession of the diaphragm and viscera (see p. 322), until in embryos of I7 mm. it lies opposite the first lumbar segment. Similarly the cœliac and inferior mesenteric arteries, which when first recognizable in embryos of $9 \mathrm{~mm}$. correspond with the fourth and twelfth thoracic segments respectively, also undergo a secondary downward migration, the cœliac artery in embryos of $\mathrm{I} 7 \mathrm{~mm}$. arising 
opposite the twelfth thoracic and the infcrior mesenteric opposite the third lumbar segment.

The umbilical arteries of the embryo seem at first to be the direct continuations of the dorsal aortæ (Fig. I46), but as development proceeds they come to arise from the aorta opposite the third lumbar segment, where they are in line with the lateral visceral segmental branches. They pass ventral to the Wolffian duct (see p. 339) and are continued out along with the allantois to the chorionic villi. Later this original stem is joined, not far from its origin, by what appears to be the lateral somatic branch of the fifth lumber segment, whereupon the proximal part of the original umbilical vessel degenerates and the umbilical comes to arise from the somatic branch, which is the common iliac artery of adult anatomy (Fig. I52). Hence it is that this vessel in the adult gives origin both to branches such as the external iliac, the gluteal, the sciatic and the internal pudendal, which are

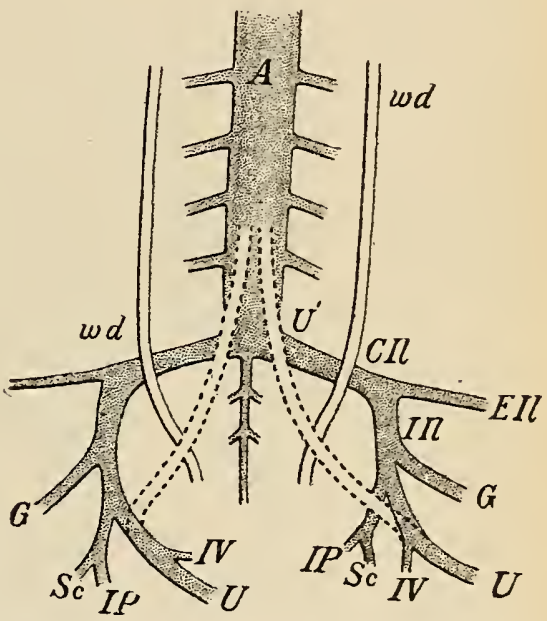

Fig, I52.-Diagram Illustrating the DEVELOPMENT OF THE UMBILICAL ARTERIES.

$A$, Aorta; $C I l$, common iliac; $E I l$, external iliac; $G$, gluteal; $I I l$, internal iliac; $I P$, internal pudic; $I V$, inferior vesical; $S c$, sciatic; $U$, umbilical; $U^{\prime}$, primary proximal portion of the umbilical; wd, Wolffian duct. distributed to the body walls or their derivatives, and to others, such as the vesical, inferior hæmorrhoidal and uterine, which are distributed to the pelvic viscera. At birth the portions of the umbilical arteries beyond the umbilicus are severed when the umbilical cord is cut, and their intra-embryonic portions, which have been called the hypogastric arteries, quickly undergo a reduction in size. Their proximal portions remain functional as the superior vesical arteries, carrying blood to the urinary bladder, but the portions which intervene between the 
bladder and the umbilicus become reduced to solid cords, forming the obliterated hypogastric arteries of adult anatomy.

+ In its general plan, accordingly, the arterial system may be regarded as consisting of a pair of longitudinal vessels which fuse together throughout the greater portion of their length to form the dorsal aorta, from which there arise segmentally arranged lateral somatic branches and ventral and lateral visceral branches. With the exception of the aortic trunks (together with their anterior continuations, the internal carotids) and the external carotids, no longitudinal arteries exist primarily. In the adult, however, several longitudinal vessels, such as the vertebrals, internal mammary, and epigastric arteries, exist. The formation of these secondary longitudinal trunks is the result of a development between adjacent vessels of anastomoses, which become larger and more important blood-channels than the original vessels.

At an early stage each of the lateral branches of the dorsal aorta gives off a twig which passes forward to anastomose with a backwardly directed twig from the next anterior lateral branch, so as to form a longitudinal chain of anastomoses along each side of the neck. In the earliest stage at present known the chain starts from the lateral branch corresponding to the first cervical (suboccipital) segment and extends forward into the skull through the foramen magnum, terminating by anastomosing with the internal carotid. To this original chain other links are added from each of the succeeding cervical lateral branches as far back as the seventh (Figs. I50 and I53). But in the meantime the recession of the heart toward the thorax has begun, with the result that the common carotid stems are elongated and the aortic arches are apparently shortened so that the subclavian arises on the left side almost opposite the point where the aorta was joined by the sixth branchial vessel. As this apparent shortening proceeds, the various lateral branches which give rise to the chain of anastomoses, with the exception of the seventh, disappear in their proximal portions and the chain becomes an independent stem, the vertebral artery, arising from the seventh lateral branch, which is the subclavian. 
The recession of the heart is continued until it lies below the level of the upper intercostal arteries, and the upper two of these, together with the last cervical branch on each side, lose their connection with the dorsal aorta, and, sending off anteriorly and posteriorly

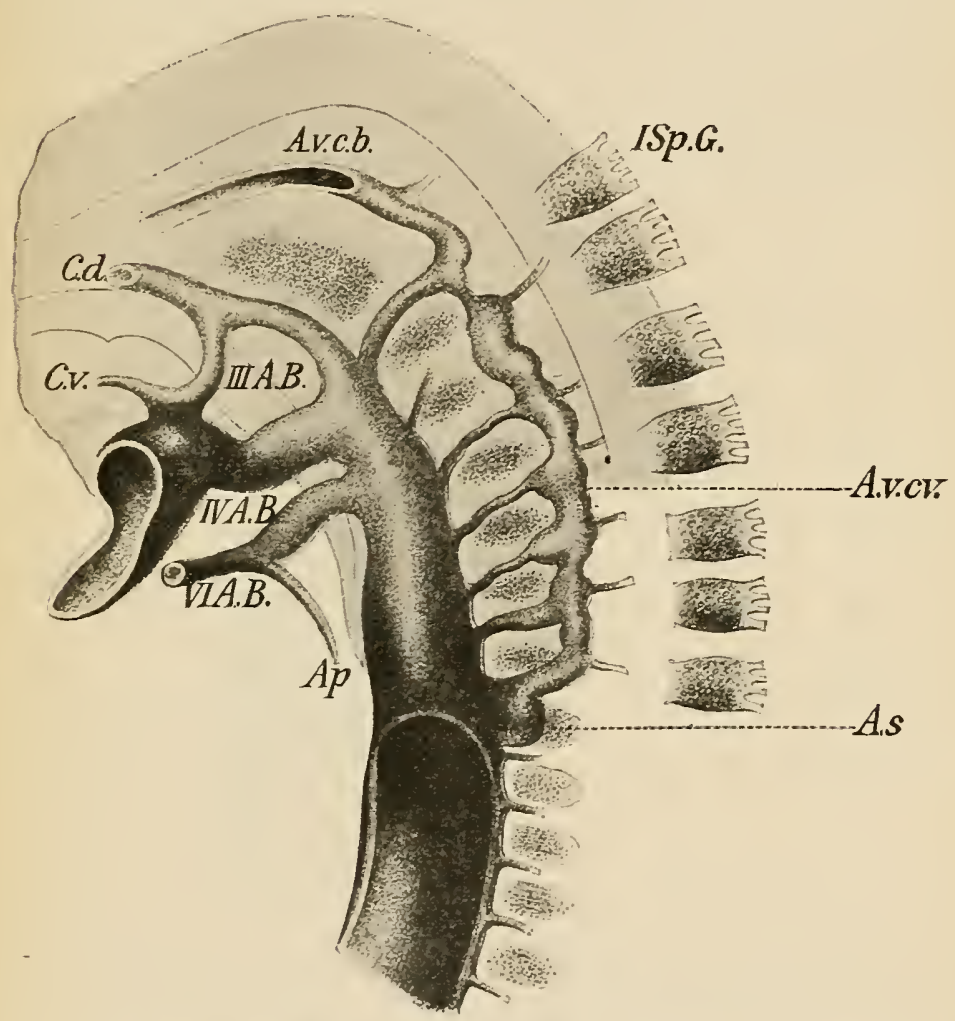

Fig. I53.-The Developaent of the Vertebral Artery in a Rabbit EMbryo of Twelve Days.

IIIA.B to VIA.B, Branchial arch vessels; $A p$, pulmonary artery. A.v.c.b and $A . v . c v$, cephalic and cervical portions of the vertebral artery; A.s, subclavian; $C . d$ and $C . \tau^{\prime}$ internal and external carotid; ISp.G, spinal ganglion.-(Hochstelter.)

anastomosing twigs, develop a short longitudinal stem, the superior intercostal, which opens into the subclavian.

The intercostals and their abdominal representatives, the 
lumbars and iliacs, also give rise to longitudinal anastomosing twigs near their ventral ends (Fig. I54), and these increasing in size give rise to the internal mammary and inferior epigastric arteries, which together form continuous stems extending from the subclavians to the external iliacs in the ventral abdominal walls. The superficial epigastrics and other secondary longitudinal vessels are formed in a similar manner.

The Development of the Arteries of the Limbs.-The earliest stages in the development of the limb arteries are unknown in man,

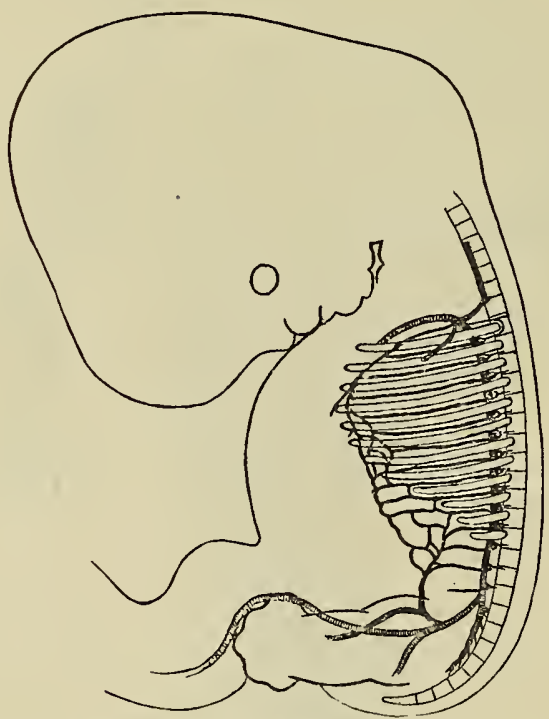

Fig. 154.-Embryo of I3 MM. Showing the Mode of Development of the Internal Mammary and Deep Epigastric Arteries.-(Mall.)

but it has been found that in the mouse the primary supply of the anterior limb bud is from five branches arising from the sides of the aorta. These anastomose to form a plexus from which later a single stem, the subclavian artery, is elaborated, occupying the position of the seventh cervical segmental vessel, the remaining branches of the plexus having disappeared. The common iliac artery similarly 
represents the fifth lumbar segmental artery, but whether or not it also is elaborated from a plexus is as yet unknown.

The later history of the limb arteries is also but imperfectly known and one must rely largely upon the facts of comparative anatomy and on the anomalies that occur in the adult for indications of what the development is likely to be. The comparative evidence indicates the existence of several stages in the development of the limb vessels, and so far as embryological observations go they confirm the conclusions drawn from this source, although the various stages show apparently a great amount of overlapping owing to a concentration of the developmental stages. In the simplest arrangement the subclavian is continued as a single trunk along the axis of the limb as far as the carpus, where it divides into digital branches for the fingers. In its course through the forearm it lies in the interval between the radius and ulna, resting on the interosseous membrane, and in this part of its course it may be termed the arteria interossea. In the second stage a new artery accompanying the median nerve appears, arising from the main stem or brachial artery a little below the elbow-joint. This may be termed the arteria mediana, and as it develops the arteria interossea gradually diminishes in size, becoming finally the small volar interosseous artery of the adult (Fig. I55), and the median, uniting with its lower end, takes from it the digital branches and becomes the principal stem of the forearm.

A third stage is then ushered in by the appearance of a branch from the brachial which forms the arteria ulnaris, and this, passing down the ulnar side of the forearm, unites at the wrist with the median to form a superficial palmar arch from which the digital branches arise. A fourth stage is marked by the diminution of the median artery until it finally appears to be a small branch of the interosseous, and at the same time there develops from the brachial, at about the middle of the upper arm, what is known as the arteria radialis superficialis (Fig. I55, rs). This extends down the radial side of the forearm, following the course of the radial nerve, and at the wrist passes upon the dorsal surface of the hand to form the 
dorsal digital arteries of the thumb and index finger. At first this artery takes no part in the formation of the palmar arches, but later it gives rise to the superficial volar branch, which usually unites with the superficial arch, while from its dorsal portion a perforating branch develops which passes between the first and second meta-
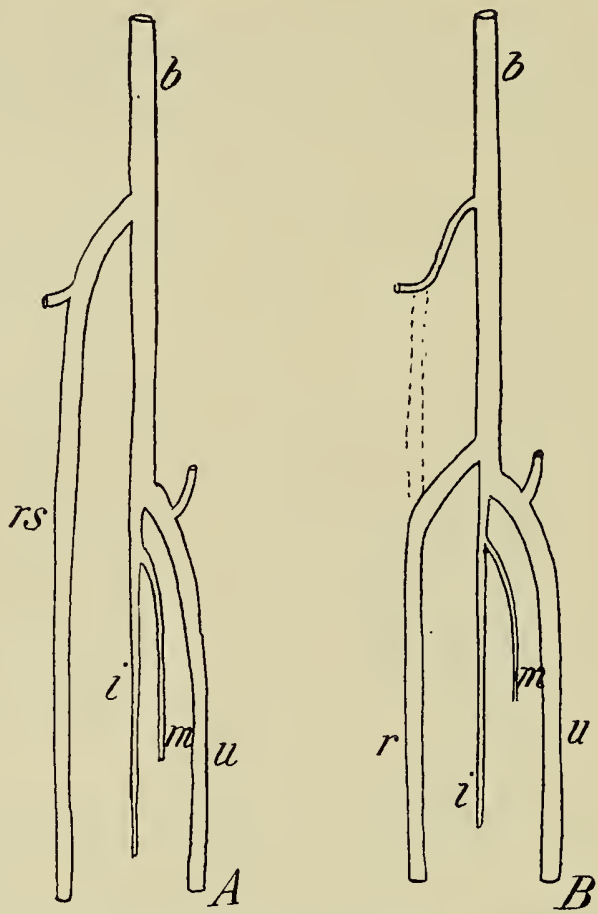

Fig. I55.-Diagrams showing an Eariy and a Late Stage in the Development of THE ARTERIES OF THE ARM.

$b$, Brachial; $i$, interosseous; $m$, median; $r$, radial; $r s$, superficial radial; $u$, ulnar.

carpal bones and unites with a deep branch of the ulnar to form the deep arch. The fifth or adult stage is reached by the development from the brachial below the elbow of a branch (Fig. I55, r) which passes downward and outward to unite with the superficial radial, whereupon the upper portion of that artery degenerates until it is 
represented only by a branch to the biceps muscle (Schwalbe), while the lower portion persists as the adult radial.

The various anomalies seen in the arteries of the forearm are, as a rule, due to the more or less complete persistence of one or other of the stages described above, what is described, for instance, as the high branching of the brachial being the persistence of the superficial radial.

In the leg there is a noticeable difference in the arrangement of the arteries from what occurs in the arm, in that the principal artery of the thigh, the femoral, does not accompany the principal nerve, the sciatic. This difference is apparently secondary, but, as in the case of the upper limb, it is necessary to rely largely on the facts of comparative anatomy and on anomalies which occur in the human body for an idea of the probable development of the arteries of the lower limb. It has already been seen that the common iliac artery is to be regarded as a lateral branch of the dorsal aorta, and in the simplest condition of the limb arteries its continuation, the anterior division of the hypogastric, passes down the leg as a well-developed sciatic artery as far as the ankle (Fig. I 56, s). At the knee it occupies the position of the popliteal of adult anatomy, and below the knee gives off a branch corresponding to the anterior tibial (at) which, passing forward to the extensor surface of the leg, quickly loses itself in the extensor muscles. The main artery continues downward on the interosseous membrane, and some distance above the ankle divides into a strong anterior and a weaker posterior branch; the former perforates the membrane and is continued down the extensor surface of the leg to form the lower part of the anterior tibial and the dorsalis pedis arteries, while the latter, passing upon the plantar surface of the foot, is lost in the plantar muscles. At this stage the external iliac is a secondary branch of the common iliac, being but poorly developed and not extending as far as the knee.

In the second stage the external iliac artery increases in size until it equals the sciatic, and it now penetrates the adductor magnus muscle and unites with the popliteal portion of the sciatic. Before doing this, however, it gives off a strong branch $(s a)$ which accompanies the long saphenous nerve down the inner side of the leg, and, 
passing behind the internal malleolus, extends upon the plantar surface of the foot, where it gives rise to the digital branches. From this arrangement the adult condition may be derived by the continued increase in size of the external iliac and its continuation, the femoral $(f)$, accompanied by a reduction of the upper portion of the sciatic and its separation from its popliteal portion $(p)$ to form the inferior gluteal artery of the adult. The continuation of the popli-
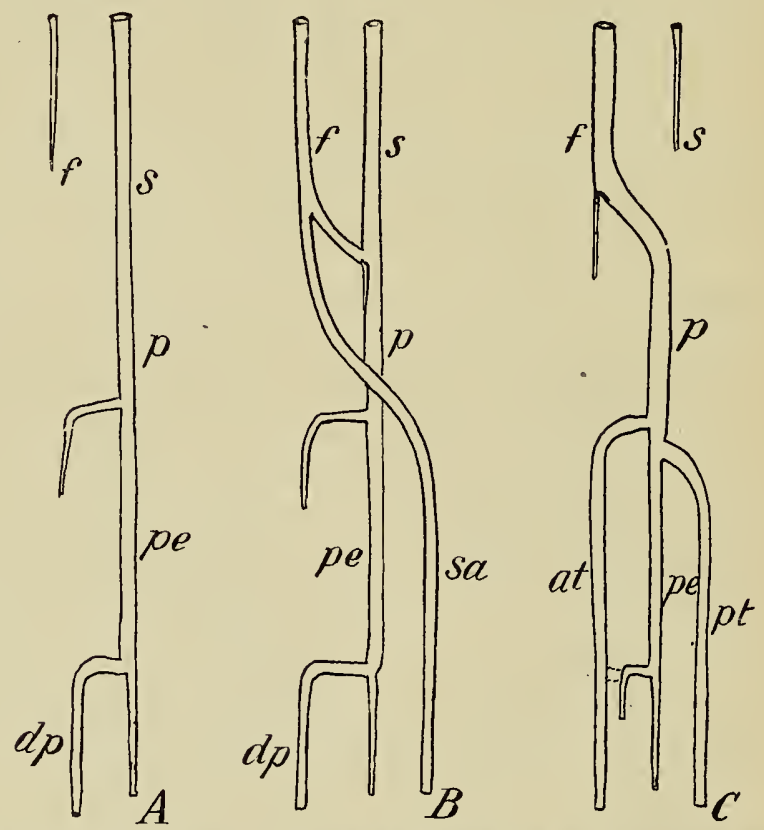

Fig. I56.-Diagrams Illustrating Stages in the Development of the Arteries OF THE LEG.

$a t$, Anterior tibial; $d p$, dorsalis pedis; $f$, femoral; $p$, popliteal; $p e$, peroneal $p t$, posterior tibial; $s$, sciatic (inferior gluteal); sa, saphenous.

teal down the leg is the peroneal artery (pe) and the upper perforating branch of this unites with the lower one to form a continuous anterior tibial, the lower connection of which with the peroneal persists in part as the anterior peroneal artery. A new branch arises from the upper part of the peroneal and passes down the back of the leg 
to unite with the lower part of the arteria saphena, forming the posterior tibial artery $(p t)$, and the upper part of thc saphenous becomes much reduced, persisting as the superficial branch of the art. genu suprema and a rudimentary chain of anastomoses which accompany the long saphenous nerve.

The Development of the Venous System.-The earliest veins to develop are those which accompany the first-formed arteries, the umbilicals, but it will be more convenient to consider first the veins which carry the blood from the body of the embryo back to the heart. These make their appearance, while the heart is still in the pharyngeal region, as two pairs of longitudinal trunks, the anterior and posterior cardinal veins, into which lateral branches, arranged more or less segmentally, open. The anterior cardinals appear somewhat earlier than the posterior and form the internal jugular veins of adult anatomy. Each vein extends forward from the heart at the side of the notochord and is continued on the under surface of the brain, lying medial to the roots of the cranial nerves. Later sprouts arising from the vein form loops around the nerve roots and the portion of the loops formed by the original vein then disappear, so that the vessel now lies lateral to the nerve roots, except in the case of the trigeminus, where the original vessel persists to form the cavernous simus. From the vena capitis lateralis so formed three veins, an anterior, a middle and a posterior cerebral, pass to the brain, the anterior cerebral together with the ophthalmic vein opening into the anterior end of the cavernous sinus, the middle cerebral into the posterior extremity of the same sinus and the posterior cerebral into the vena capitis lateralis behind the ear vesicle (Fig. I57). The branches of the anterior cerebral vein extending over the cerebral hemisphere unite with their fellows of the opposite side to form a longitudinal trunk, the superior sagittal simus, lying between the two cerebral hemispheres. At first this sinus drains by way of the anterior cerebral vein (Fig. I $58, A$ ), but as the cerebral hemispheres increase in size it is gradually carried backward and makes connections first with the middle cerebral and later with the posterior cerebral vein (Fig. I58, $B$ and $C$ ), each of these becoming in turn the principal 
drainage of the sinus. The connections which join the veins to the sinus become the proximal portion of the transverse simus, the posterior cerebral vein itself becoming the distal portion, the middle cerebral vein becomes the superior petrosal sinus, while the anterior cerebral vein persists as the middle cerebral vein of adult anatomy

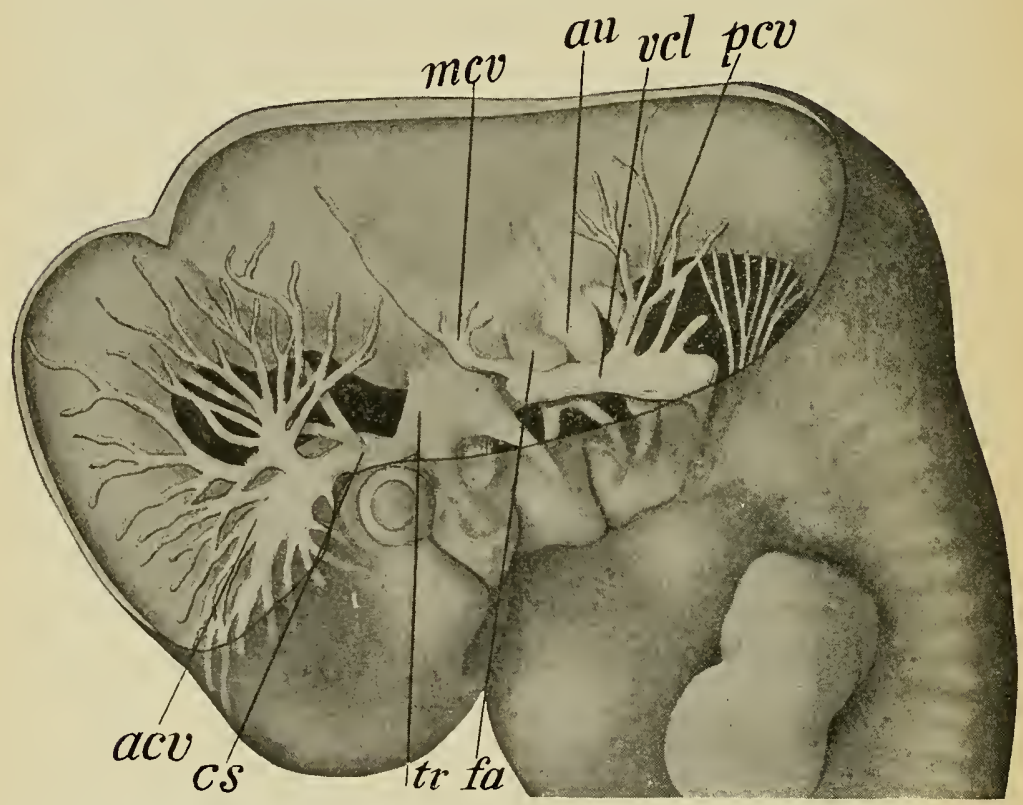

Fig. 157.-Reconstruction of the Head of a Human Embryo of 9 mm. SHowing the Cerebral Veins.

$a c v$, Anterior cerebral vein; au, auditory vesicle; $c s$, cavernous sinus; $f a$, facial nerve; mcv, middle cerebral vein; $p c v$, posterior cerebral vein; $t r$, trigeminal nerve; v'cl, lateral cerebral vein.-(Mall.)

(Fig. $158, C$ ). Additional sprouts from the terminal portion of the superior sagittal sinus give rise to the straight and inferior sagittal simuses, and, after the disappearacne of the vena capitis lateralis, a new stem develops between the cavernous and transverse sinuses, passing medial to the ear vesicle, and forms the inferior petrosal sinus (Fig. $158, C$ ). This joins the transverse sinus at the jugular 
foramen and from this junction onward the anterior cardinal vein may now be termed the internal jugular vein.

Passing backward from the jugular foramen the internal jugular veins unite with the posterior cardinals to form on each side a common trunk, the ductus Cuvieri, and then passing transversely toward the median line open into the sides of the sinus venosus. So long as the heart retains its original position in the pharyngeal region the jugular

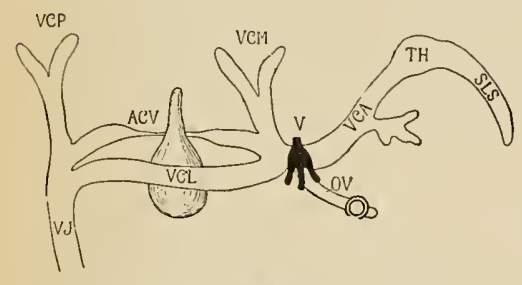

$A$

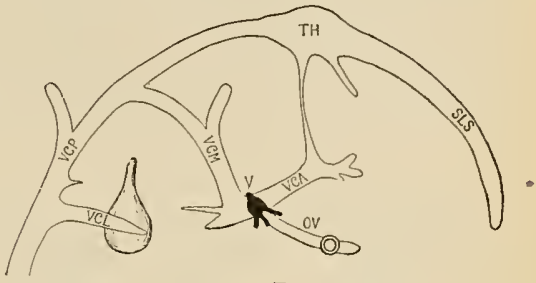

$B$

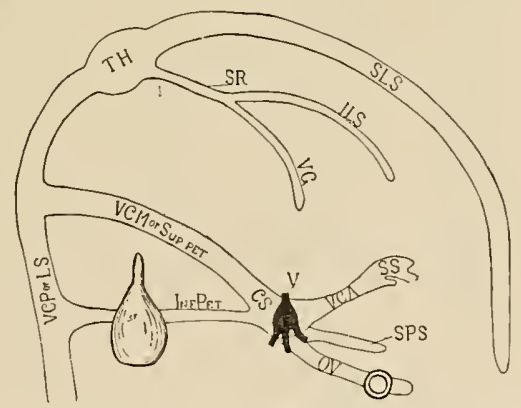

$C$

Fig. I 58.-Diagrams Showing the ARrangement of the Cerebral Veins in Embryos of (A) the Fifth WeEk, (B) the Beginning of the THird Month and IN (C) AN Older Fetus.

$a c v$, Anterior cerebral vein; $c s$, cavernous sinus; $i l s$, inferior sagittal sinus; Inf. Pet., inferior petrosal sinus; $l s$, transverse sinus; ov, ophthalmic vein; $s l s$, superior sagittal sinus; $s p s$, spheno-parietal sinus; sr, straight sinus; $s s$, middle cerebral vein (Sylvian); sup. pet, superior petrosal sinus; th, torcular Herophili; $v$, trigeminal nerve; $v c a$, anterior cerebral vein; $v c l$. lateral cerebral vein; $v c m$, middle cerebral vein; $v c p$, posterior cerebral vein; $v g$, vein of Galen; $v j$, internal jugular.-(Mall.)

is a short trunk receiving lateral veins only from the uppermost segments of the neck and from the occipital segments, the remaining segmental veins opening into the inferior cardinals. As the heart recedes, however, the jugulars become more and more elongated 
and the cervical lateral veins shift their communication from the cardinals to the jugulars, until, when the subclavians have thus shifted, the jugulars become much larger than the cardinals. When the sinus venosus is absorbed into the wall of the right auricle, the course of the left Cuvierian duct becomes a little longer than that of the right, and from the left jugular, at the point where it is joined by the left subclavian, a branch arises which extends obliquely a cross to join the right jugular, forming the left innominate vein. When this is established, the connection between the left jugular and Cuvierian duct is dissolved, the blood from the left side of the head and neck and from the left subclavian vein passing over to empty
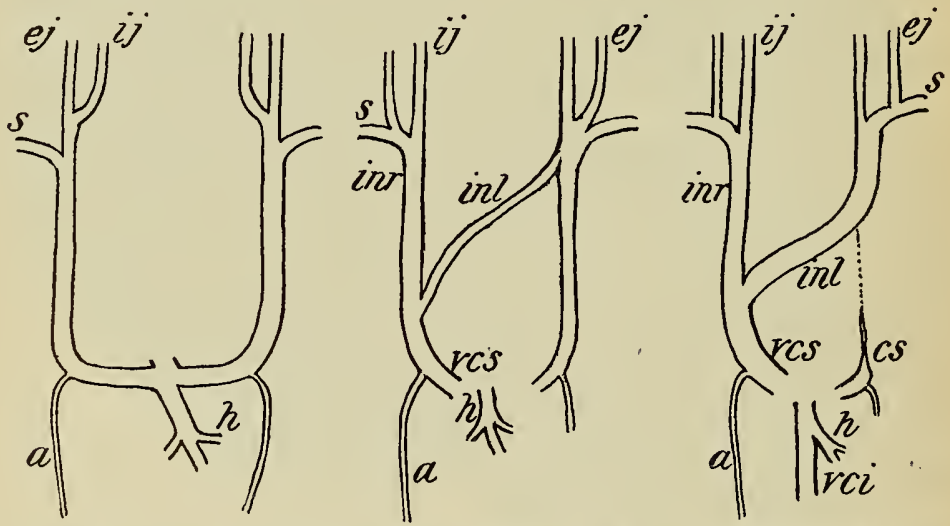

Fig. I59.-Diagrams Showing the Development of the Superior Vena Cava.

$a$, Azygos vein; $c s$, coronary sinus; $e j$, external jugular; $h$, hepatic vein; $i j$, internal jugular; inr and inl, right and left innominate veins; $s$, subclavian; vci and $v c s$, inferior and superior venæ cavæ.

into the right jugular, whose lower end, together with the right Cuvierian duct, thus becomes the superior vena cava. The left Cuvierian duct persists, forming with the left horn of the sinus venosus the coronary sinus (Fig. I59).

The external jugular vein develops somewhat later than the internal. The facial vein, which primarily forms the principal affluent of this stem, passes at first into the skull along with the fifth nerve and communicates with the internal jugular system, but later 
this original communication is broken and the facial vein, uniting with other superficial veins, passes over the jaw and extends down the neck as the external jugular. Later still the facial anastomoses with the ophthalmic at the inner angle of the eye and also makes connections with the internal jugular just after it has crossed the jaw, and so the adult condition is acquired.

It is interesting to note that in many of the lower mammals the external jugular becomes of much greater importance than the internal, the latter in some forms, indeed, eventually disappearing and the blood from the interior of the skull emptying by means of anastomoses which have developed into the external jugular system. In man the primitive condition is retained, but indications of a transference of the intracranial blood to the external jugular are seen in the emissary veins.

The posterior cardinal veins, or, as they may more simply be termed, the cardinals, extend backward from their union with the jugulars along the sides of the vertebral column, receiving veins from the mesentery and also from the various lateral segmental veins of the neck and trunk regions, with the exception of that of the first cervical segment which opens into the jugular. Later, however, as already described (p. 258), the cervical veins shift to the jugulars, as do also the first and second thoracic (intercostal) veins, but the remaining intercostals, together with the lumbars and sacrals, continue to open into the cardinals. In addition, the cardinals receive in early stages the veins from the primitive kidneys (mesonephros), which are exceptionally large in the human embryo, but when they are replaced later on by the permanent kidneys (metanephros) their afferent veins undergo a reduction in number and size, and this, together with the shifting of the upper lateral veins, produces a marked diminution in the size of the cardinals. The changes by which they acquire their final arrangement are, however, so intimately associated with the development of the inferior vena cava that their description may be conveniently postponed until the history of the vitelline and umbilical veins has been presented.

The vitelline veins are two in number, a right and a left, and pass in along the yolk-stalk until they reach the embryonic intestine, along the sides of which they pass forward to unite with the corre- 
sponding umbilical veins. These are represented in the bellystalk by a single venous trunk which, when it reaches the body of the embryo, divides into two stems which pass forward, one on each side of the umbilicus, and thence on each side of the median line of the ventral abdominal wall, to form with the corresponding vitelline veins common trunks which open into the ductus Cuvieri. As the liver develops it comes into intimate relation with the vitelline veins, which receive numerous branches from its substance and, indeed, seem to break up into a network (Fig. I60, A) traversing the liver
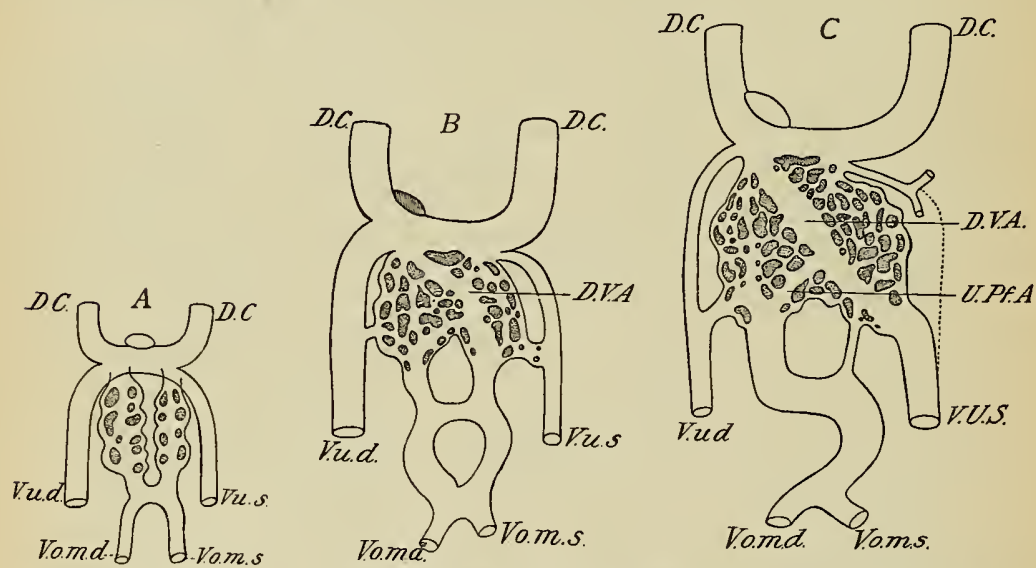

Fig. i6o.-Diagrams Illustrating the Transformations of the Viteline ani) UMbilical Veins.

D.C, Ductus Cuvieri; D.V.A, ductus venosus; V.o.m.d and V.o.m.s, right and left vitelline veins; V.u.d and V.u.s, right and left umbilical veins.-(Hochstetter.)

substance and uniting again to form two stems which represent the original continuations of the vitellines. From the point where the common trunk formed by the right vitelline and umbilical veins opens into the Cuvierian duct a new vein develops, passing downward and to the left to unite with the left vitelline; this is the ductus venosus (Fig. I60, $\mathrm{B}, D . V . A$ ). In the meantime three cross-connections have developed between the two vitelline veins, two of which pass ventral and the other dorsal to the intestine, so that the latter is 
surrounded by two venous loops (Fig. I6r, A), and a connection is developed between each umbilical vein and the corresponding vitelline (Fig. I6o, B), that of the left side being the larger and uniting with the vitelline just where it is joined by the ductus venosus so as to seem to be the continuation of this vessel (Fig. I6o, C). When these connections are complete, the upper portions of the umbilical veins degenerate (Fig. I6 $\mathrm{I}$ ), and now the right side of the lower of the two vitelline loops which surround the intestine disappears, as does also that portion of the left side of the upper loop which intervenes
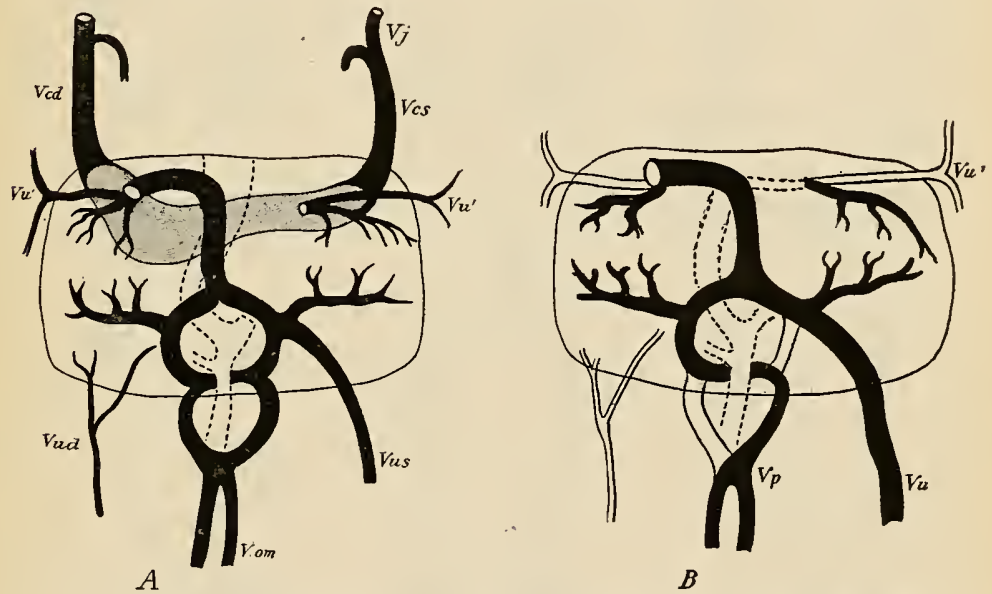

Fig. i6r.- $A$, The Venous Trunks of aN Embryo of 5 MM. SEen From the Ventral Surface; $B$, Diagram Illustrating the Transformation to the Adult Condition.

$V c d$ and $V c s$, Right and left superior venæ cavæ; $V j$, jugular vein; $V . o m$, vitelline vein; $V p$, vena porta; $V u$, umbilical vein (lower part); Vu', umbilical vein (upper part); Vud and Vus, right and left umbilical veins (lower parts).-(His.)

between the middle cross-connection and the ductus venosus, and so there is formed from the vitelline veins the vena porta.

While these changes have been progressing the right umbilical vein, originally the larger of the two (Fig. I60, A and B, V.u.d), has become very much reduced in size and, losing its connection with the left vein at the umbilicus, forms a vein of the ventral abdominal wall in which the blood now flows from above downward. The 
left umbilical now forms the only route for the return of blood from the placenta, and appears to be the direct continuation of the ductus venosus (Fig. I6r, C), into which open the hepatic veins, returning the blood distributed by the portal vein to the substance of the liver.

Returning now to the posterior cardinal veins, it has been found that in the rabbit the branches which come to them from the mesentery anastomose longitudinally to form a vessel lying parallel and slightly ventral to each cardinal. These may be termed the sub-

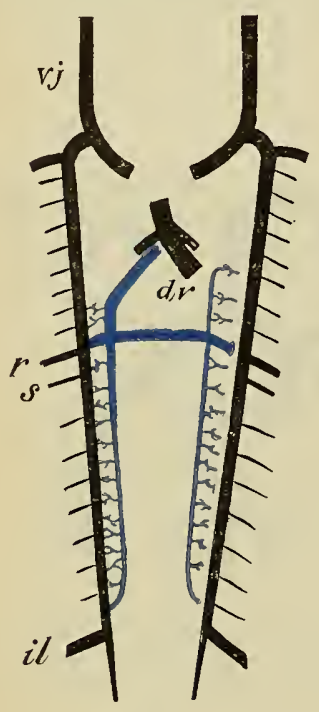

A

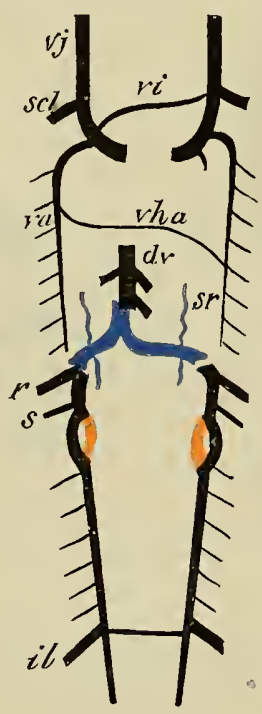

$B$

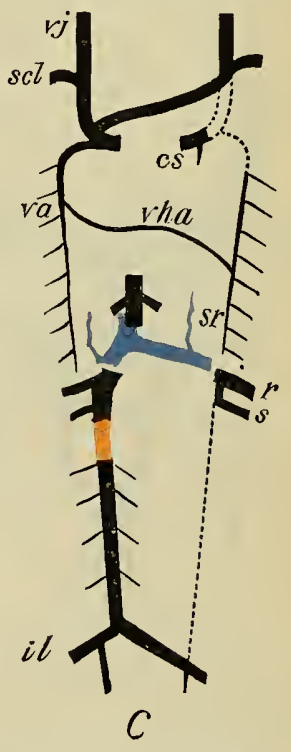

Fig. i62.-Diagrams Illustrating the Development of the INFerior Vena Cava.

The cardinal veins and ductus venosus are black, the subcardinal system blue, and the supracardinal yellow. $c s$, coronary sinus; $d v$, ductus venosus; $i l$, iliac vein; $r$, renal; $s$, internal spermatic; $s c l$, subclavian; $s r$, suprarenal; $v a$, azygos; $v h a$, hemiazygos; $v i$, innominate; $v j$, internal jugular.

cardinal veins (Lewis), and in their earliest condition they open at either end into the corresponding cardinal, with which they are also united by numerous cross-branches. Later, in rabbits of $8.8 \mathrm{~mm}$., these cross-branches begin to disappear and give place to a large cross-branch situated immediately below the origin of the superior 
mesenteric artery, and at the same point a cross-branch between the two subcardinals also develops. The portion of the right subcardinal which is anterior to the cross-connection now rapidly enlarges and unites with the ductus venosus about where the hepatic veins open into that vessel (Fig. I62, A), and the portion of each posterior cardinal immediately above the entrance of the renal veins degenerates, so that all the blood received by the posterior portions of the cardinals is returned to the heart by way of the right subcardinal, its cross-connections, and the upper part of the ductus venosus.

When this is accomplished the lower portions of the subcardinals disappear, while the portions above the large cross-connection persist, greatly diminished in size, as the suprarenal veins (Fig. I62, B).

In the early stages the veins which drain the posterior abdominal walls empty into the posterior cardinals, and later they form, in the region of the kidney on each side, a longitudinal anastomosis which opens at either extremity into the posterior cardinal. The ureter thus becomes surrounded by a venous ring, the dorsal limb of which is formed by the new longitudinal anastomosis, which has been termed the supracardinal vein (McClure and Huntington), while the ventral limb is formed by a portion of the posterior cardinal (Fig. I62, B). Still later the ventral limb of the loop disappears and the dorsal supracardinal limb replaces a portion of the more primitive posterior cardinal. An anastomosis now develops between the right and left cardinals at the point where the iliac veins open into them (Fig. I62, B), and the portion of the left cardinal which intervenes between this anastomosis and the entrance of the internal spermatic vein disappears, the remainder of it, as far forward as the renal vein, persisting as the upper part of the left internal spermatic vein, which thus comes to open into the renal vein instead of into the vena cava as does the corresponding vein of the right side of the body (Fig. I62, C, s). The renal veins originally open into the cardinals at the point where these are joined by the large crossconnection, and when the lower part of the left cardinal disappears, this cross-connection forms the proximal part of the left renal vein, which consequently receives the left suprarenal (Fig. I62, C). 
The observations upon which the above description is based have been made upon the rabbit, but it seems probable from the partial observations that have been made that similar changes occur also in the human embryo. It will be noted from what has been said that the inferior vena cava is a composite vessel, consisting of at least four elements: (I) the proximal part of the ductus venosus; (2) the anterior part of the right subcardinal; (3) the right supracardinal; and (4) the posterior part of the right cardinal.

The complicated development of the inferior vena cava naturally gives rise to numerous anomalies of the vein due to inhibitions of its development. These anomalies affect especially the post-renal portion, a persistence of both cardinals (interpreting the conditions in the terms of what occurs in the rabbit) giving rise to a double post-renal cava, or a persistence of the left cardinal and the disappearance of the right to a vena cava situated on the left side of the vertebral column and crossing to the right by way of the left renal vein. So, too, the occurrence of accessory renal veins passing dorsal to the ureter is explicable on the supposition that they represent portions of the supracardinal system of veins.

It has already been noted that the portions of the posterior cardinals immediately anterior to the entrance of the renal veins disappear. The upper part of the right vein persists, however, and becomes the vena azygos of the adult, while the upper portion of the left vein sends a cross-branch over to unite with the azygos and then separates from the coronary sinus to form the vena hemiazygos. At least this is what is described as occurring in the rabbit. In the cat, however, only the very uppermost portion of the right posterior cardinal persists and the greater portion of the azygos and perhaps the entire hemiazygos vein is formed from the prerenal portions of the supracardinal veins, the right one joining on to the small persisting upper portion of the right posterior cardinal, while the crossconnection between the hemiazygos and azygos represents one of the originally numerous cross-connections between the supracardinals.

The ascending lumbar veins, frequently described as the commencements of the azygos veins, are in reality secondary formations developed by the anastomoses of anteriorly and posteriorly directed branches of the lumbar veins. 
The Development of the veins of the Limbs.-The development of the limb veins of the human embryo requires further investigation, but from a comparison of what is known with what has been observed in rabbit embryos it may be presumed that the changes which take place are somewhat as follows: In the anterior extremity the blood brought to the limb is collected by a vein which passes distally along the radial border of the limb bud, around its distal border, and proximally along its ulnar border to open in to the anterior cardinal vein; this is the primary unnar vein. Later a second vein grows out from the external jugular along the radial border of the limb, representing the cephalic vein of the adult, and on its appearance the digital veins, which were formed from the primary ulnar vein, become connected with it, and the distal portion of the primary ulnar vein disappears. Its proximal portion persists, however, to form the basilic vein, from which the brachial vein and its continuation, the ulnar vein, are developed, while the radial vein develops as an outgrowth from the cephalic, which at an early stage secures an opening into the axillary vein, its original communication with the external jugular forming the jugullo-cephalic vein.

In the lower limb a primary fibular vein, exactly comparable to the primary ulnar of the arm, surrounds the distal border of the limbbud and passes up its fibular border to open with the posterior cardinal vein. The further development in the lower limb differs considerably, however, from that of the upper limb. From the primary fibular vein an anterior tibial vein grows out, which receives the digital branches from the toes, and from the posterior cardinal, anterior to the point where the primary fibular opens into it, a vein grows down the tibial side of the leg, forming the long saphenous vein. From this the femoral vein is formed and from it the posterior tibial vein is continued down the leg. An anastomosis is formed between the femoral and the primary fibular veins at the level of the knee and the proximal portion of the latter vein then becomes greatly reduced, while its distal portion possibly persists as the small saphenous vein (Hochstetter).

The Pulmonary Veins.-The development of the pulmonary veins 
has already been described in connection with the development of the heart (see p. 234).

The Fetal Circulation.-During fetal life while the placenta is the sole organ in which occur the changes in the blood on which the

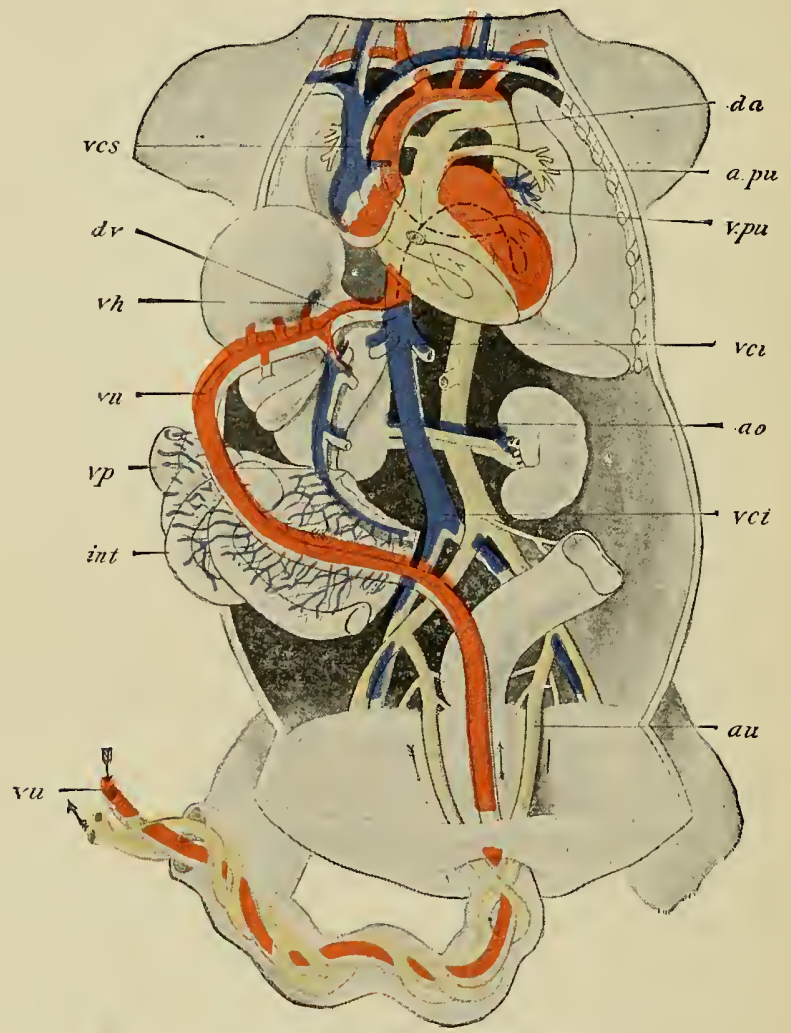

Fig. i63.-The Fetal Circulation.

ao, Aorta; a.pu., pulmonary artery; au, umbilical artery; da, ductus arteriosus; $d v$, ductus venosus; int, intestine; vci and $v c s$, inferior and superior vena cava; $v h$, hepatic vein; $v p$, vena portæ; v.pu, pulmonary vein; $v u$, umbilical vein.-(From Kollmann.)

nutrition of the embryo depends, the course of the blood is necessarily somewhat different from what obtains in the child after birth. Taking the placenta as the starting-point, the blood passes along the 
umbilical vein to enter the body of the fetus at the umbilicus, whence it passes forward in the free edge of the ventral mesentery (see p. $32 \mathrm{r}$ ) until it reaches the liver. Here, owing to the anastomoses between the umbilical and vitelline veins, a portion of the blood traverses the substance of the liver to open by the hepatic veins into the inferior vena cava, while the remainder passes on through the ductus venosus to the cava, the united streams opening into the right atrium. This blood, whose purity is only slightly reduced by mixture with the blood returning from the inferior vena cava, is prevented from passing into the right ventricle by the Eustachian valve, which directs it to the foramen ovale, and through this it passes into the left atrium, thence to the left ventricle, and so out by the systemic aorta.

The blood which has been sent to the head, neck, and upper extremities is returned by the superior vena cava also into the right atrium, but this descending stream opens into the atrium to the right of the annulus of Vieussens (see Fig. I4r) and passes directly to the right ventricle without mingling to any great extent with the blood returning by way of the inferior cava. From the right ventricle this blood passes out by the pulmonary artery; but the lungs at this period are collapsed and in no condition to receive any great amount of blood, and so the stream passes by way of the ductus arteriosus into the systemic aorta, meeting there the placental blood just below the point where the left subclavian artery is given off. From this point onward the aorta contains only mixed blood, and this is distributed to the walls of the thorax and abdomen and to the lungs and abdominal viscera, the greater part of it, however, passing off in the hypogastric arteries and so out again to the placenta.

This is the generally accepted account of the fetal circulation and it is based upon the idea that the foramen ovale is practically a connection between the inferior vena cava and the left atrium. If it be correct the right ventricle receives only the blood returning to the heart by the vena cava superior, while the left receives all that returns by the inferior vena cava together with what returns by the pulmonary veins. One would, therefore, expect that the capacity and pressure of the right ventricle would in the fetus be less than those of the left. Pohlman, who has recently investigated the question in embryo pigs, finds, on the contrary, that the capacities and pressures of the two ventricles are equal and 
maintains that the foramen ovale is actually a connection between the two atria. That is to say, he holds that there is an actual mingling of the blood from the two venæ cavæ in the right atrium, whence the mixed blood passes to the right ventricle, a certain amount of it, however, passing through the foramen ovale and so to the left ventricle to equalize the deficiency that would otherwise exist in that chamber owing to the small amount of blood returning by the pulmonary veins. According to this view there would be no difference in the quality of the blood distributed to different portions of the body, such as is provided for by the current theory; all the blood leaving the heart would be mixed blood and in favor of this view is the fact that starch granules injected into either the superior or the inferior vena cava in living pig embryos were in all cases recovered from both sides of the heart.

At birth the lungs at once assume their functions, and on the cutting of the umbilical cord all communication with the placenta ceases. Shortly after birth the foramen ovale closes more or less perfectly, and the ductus arteriosus diminishes in size as the pulmonary arteries increase and becomes eventually converted into a fibrous cord. The hypogastric arteries diminish greatly, and after they have passed the bladder are also reduced to fibrous cords, a fate likewise shared by the umbilical vein, which becomes converted into the round ligament of the liver.

The Development of the Lymphatic System.-Concerning the development of the lymphatic system two discordant views exist, one (Sabin, Lewis) regarding it in its entirety as a direct development from the venous system, while the other (Huntington, McClure) recognizes for it a dual origin, a portion being derived directly from the venous system and the rest from a series of mesenchýmal spaces developing in relation to veins but quite unconnected with them.

The portion of the system concerning which harmony prevails is that which forms the connection with the venous system in the adult and constitutes what in the embryo is termed the jugular lymph sac. In the early stages of development a capillary network extends along the line of the jugular veins, communicating with them at various points. In embryos of to $\mathrm{mm}$. a portion of this network, on either side of the body, becomes completely separated 
from the jugular and gives rise to a number of closed cavities lined with endothelium and situated in the neighborhood of the junction of the primary ulnar and cephalic veins with the jugular. In
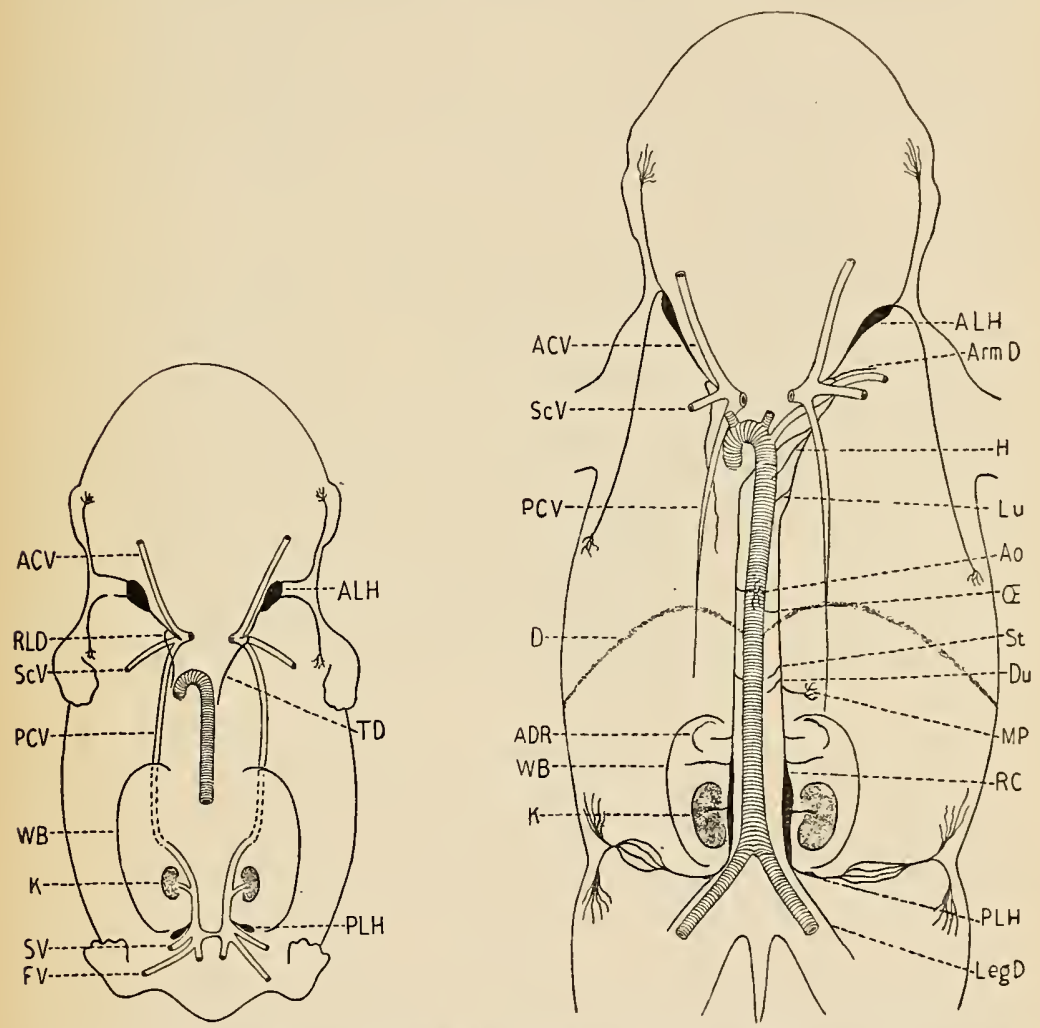

Fig. i64.-Dlagrams showing the Arrangement of the Lymphatic Vesseis in Pig Embryos of (A) 20 MM. AND $(B) 40$ MM.

$A C V$, Jugular vein; $A D R$, suprarenal body; $A L H$, jugular lymph sac; $A o$, aorta; Arm $D$, deep lymphatics to the arm; $D$, diaphragm; $D u$, branches to duodenum; $F V$, femoral vein; $H$, branches to heart; $K$, kidney; $\operatorname{Leg} D$, deep lymphatics to leg; $L u$, branches to lung; $M P$, branches to mesenteric plexus; $\mathscr{E}$, branch to œsophagus; $P C V$, cardinal vein; $P L H$, posterior lymph sac; $R C$, cisterna chyli; $R L D$, right lymphatic duct; $S c V$, subclavian vein; $S V$, sciatic vein; $S t$, branches to stomach; $T D$, thoracic duct; WB. Wolffian body.-(Sabin.)

later stages these cavities enlarge and unite to form a large sac, the jugular lymph sac (Fig. I64, $A L H$ ), and this, still later, makes a 
new connection with the jugular, the opening being guarded by a valve. This communication becomes the adult communication of the thoracic duct or right lymphatic duct with the venous system, but the sac itself, as development proceeds, becomes divided into smaller portions and gives rise to a number of lymph nodes.

A similar pair of lymph sacs also develop in relation to the sciatic vein, but their exact mode of origin is uncertain. In embryos of $20 \mathrm{~mm}$. venous plexuses, similar to the jugular plexuses of younger stages, are found accompanying the sciatic veins, and a little later there are found in the same region a pair of posterior or sciatic lymph sacs (Fig. I64, PLH), which, like the jugular sacs, later give rise to a series of lymph nodes. At about the same stage of development a retroperitoneal sac (Fig. ${ }^{6} 6_{5}, L s r$ ) is also formed in the root of the mesentery cranial to the origin of the superior mesenteric artery, and this, too, later gives rise to a plexus of lymphatic vessels in connection with which the mesenteric lymphatic nodes develop. This last sac is much more pronounced in the pig embryo than in man, and in that form it has been found to have its origin from a capillary network that separates from the renal veins (Baetjer).

There are thus formed five sacs, all of which are associated with the formation of groups of lymphatic nodes, and in the case of one pair at least it is agreed that they are directly developed from venous capillaries. It is in connection with the remaining sac and especially with the formation of the thoracic duct and the peripheral lymphatics that the want of harmony referred to above occurs. The first portion of the thoracic duct to appear is the cisterna chyli, which is found in embryos of $23 \mathrm{~mm}$. in the region of the third and fourth lumbar segments, in close proximity to the vena cava (Fig. I65, Cc). After its appearance the rest of the thoracic duct develops quickly, it being completely formed in embryos of $30 \mathrm{~mm}$., and it is interesting to note that at this stage the duct is paired in its caudal portion, two trunks passing forward from the cisterna chyli, the right one passing behind the aorta and uniting with the left after it has entered the thorax. 
The mode of origin of the duct has not yet been made out in human embryos. In the pig and rabbit isolated spaces lined with endothelium occur along the course of the duct, but without communicating with it, and the fact that some of these showed connection with the neighboring azygos veins gave basis for the view that they were the remains of a venous capillary plexus from which the duct had developed. It is possible, however, that the duct is formed

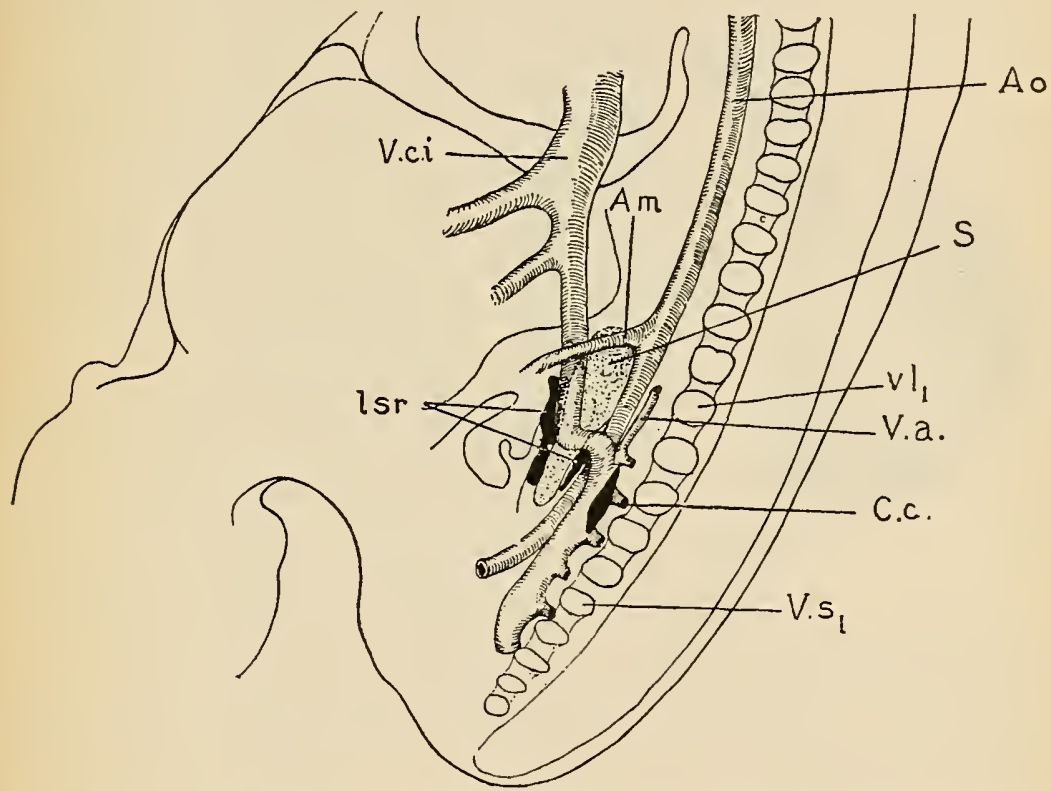

Fig. I65.-Diagram of the Posterior Portion of the Body of a Human EMBRYo OF 23 MM., SHOWING THE RELATIONS OF THE RETROPERITONEAL LyMPE SaC and the Cisterna Chyli to the Veins.

$A m$, Superior mesenteric artery; $A o$, aorta; $C c$, cisterna chyli; $l s r$, retroperitoneal lymph sac; $S$, suprarenal body; $V a$, vena azygos; $V c i$, vena cava inferior; $v l_{1}$, first lumbar vertebra; $v s_{1}$, first sacral vertebra.-(After Sabin.)

by the union of outgrowths from the cisterna chyli and jugular sac, in which case it would also be a derivative of the venous system, provided that the cisterna chyli is formed in the same way as the jugular sac. Huntington and McClure, however, maintain that it 
is formed by the fusion of spaces appearing in the mesenchyme immediately external to the intima of degenerating veins; hence the spaces are termed extraintimal spaces. These at first have no endothelial lining and they are never in connection with the lumina of the veins. They are perfectly independent structures and any connections they may make with the venous system are entirely secondary. This mode of origin from extraintimal spaces is not

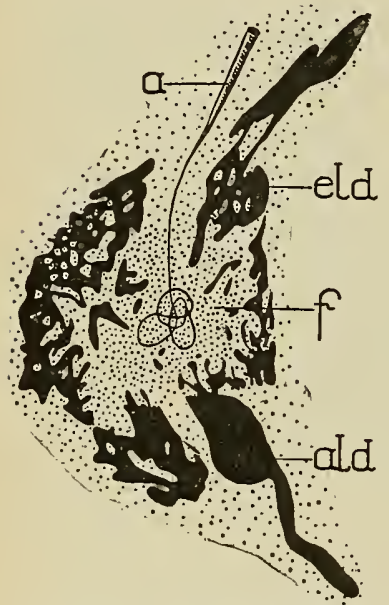

Fig. I66.-DIAGRAM OF A PRIMARY LYMPH NODE OF AN EMbryo Pig of 8 CM.

$a$, Artery; ald, afferent lymph duct; eld, efferent lymph duct; $f$, follicle.-(Sabin.) confined to the thoracic duct, according to the authors mentioned, but is the method of development of all parts of the lymphatic system, with the exception of the jugular sacs. According to the supporters of the direct venous origin the peripheral lymphatic stems develop, like blood-vessels, as outgrowths from the stems already present.

Lymph nodes have not been observed in human embryos until toward the end of the third month of development, but they appear in pig embryos of $3 \mathrm{~cm}$. Their unit of structure is a blood-vessel, breaking up at its termination into a leash of capillaries, around which a condensation of lymphocytes occurs in the mesenchyme. A structure of this kind forms what is termed a lymphoid follicle and may exist, even in this simple condition, in the adult. More frequently, however, there are associated with the follicle lymphatic vessels, or rather the follicle develops in a network of lymphatic vessels, which become an investment of the follicle and form with it a simple lymph node (Fig. I66). This condition is, however, in many cases but transitory, the artery branching and collections of lymphoid tissue forming around each of the branches, so that a series of follicles are formed, which, together with the surrounding lymphatic vessels, become enclosed by a connective-tissue capsule to 
form a compound lymph node. Later trabeculæ of connective tissue extend from the capsule toward the center of the node, between the follicles, the lymphatic network gives rise to peripheral and central lymph sinuses, and the follicles, each with its arterial branch, constitute the peripheral nodules and the medullary cords, the portions of these immediately surrounding the leash of capillaries into which

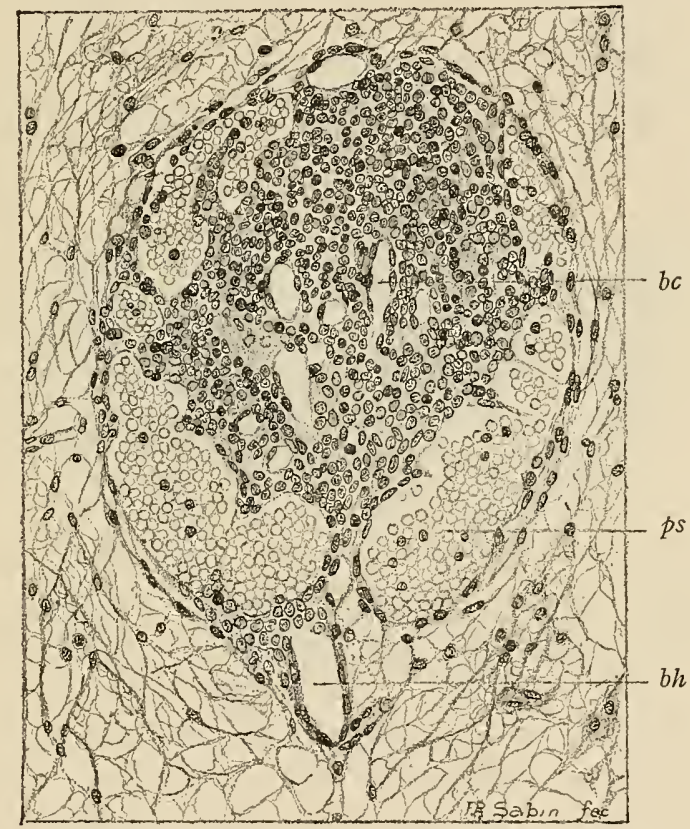

Frg. i67.-Developing HæmolympH Node.

$b c$, central blood-vessel; $b h$, blood-vessel at hilus; $p s$, peripheral blood sinus.-(Sabin from Morris' Human Anatomy.)

the artery dissolves, constituting the so-called germ centers in which multiplication of the lymphocytes occurs.

In various portions of the body, but especially along the root of the mesentery, what are termed hamolymph nodes occur. In these the lymph sinus is replaced by a blood sinus, but with this exception their structure resembles that of an ordinary lymph node, a simple 
one consisting of a follicle, composed of adenoid tissue with a central blood-vessel, and a peripheral blood sinus (Fig. I67).

The Development of the Spleen.-Recent studies (Mall) have shown that the spleen may well be regarded as possessing a structure comparable to that of the lymph nodes, the pulp being more or less distinctly divided by trabeculæ into areas termed pulp cords, the axis of each of which is occupied by a twig of the splenic artery. The spleen, therefore, seems to fall into the same category of organs as the lymph and hæmolymph nodes, differing from these chiefly in the absence of sinuses. It has generally been regarded as a development of the mesenchyme situated between the two layers of the mesogastrium. To this view, however, recent observers have taken exception, holding that the ultimate origin of the organ is in part or entirely from the cœelomic epithelium of the left layer of the mesogastrium. The first indication of the spleen has been observed in embryos of the fifth week as a slight elevation on the left (dorsal) surface of the mesogastrium, due to a local thickening and vascularization of the mesenchyme, accompanied by a thickening of the cœlomic epithelium which covers the elevation. The mesenchyme thickening presents no differences from the neighboring mesenchyme, but the epithelium is not distinctly separated from it over its entire surface, as it is elsewhere in the mesentery. In later stages, which have been observed in detail in pig and other amniote embryos, cells separate from the deeper layers of the epithelium (Fig. I68) and pass into the mesenchyme thickening, whose tissue soon assumes a different appearance from the surrounding mesenchyme by its cells being much crowded. This migration soon ceases, however, and in embryos of forty-two days the colomic epithelium covering the thickening is reduced to a simple layer of cells.

The later stages of development consist of an enlargement of the thickening and its gradual constriction from the surface of the mesogastrium, until it is finally united to it only by a narrow band through which the large splenic vessels gain access to the organ The cells differentiate themselves into trabeculæ and pulp cords 
special collections of lymphoid cells around the branches of the splenic artery forming the Malpighian corpuscles.

It has already been pointed out (p. 225) that during embryonic life the spleen is an important hæmatopoietic organ, both red and white corpuscles undergoing active formation within its substance. The Malpighian corpuscles are collections of lymphocytes in which multiplication takes place, and while nothing is as yet known as to the fate of the cells which are contributed to the spleen from the cœlomic epithelium, since they quickly come to resemble the mesenchyme cells with which they are associated, yet the growing number of observations indicating an epithelial origin for lymphocytes suggests the possibility that the cells in question may be responsible for the first leukocytes of the spleen.

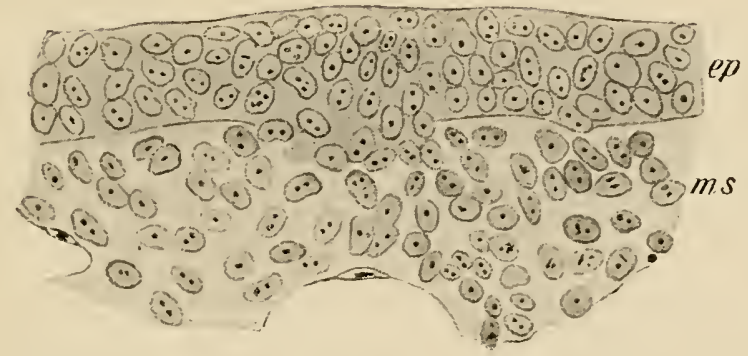

Fig. i68.-Section through the Left Layer of the Mesogastrium of a CHick Embryo of Ninety-three Hours, Showing the Origin of the Spleen. $e p$, Cœlomic epithelium; $m s$, mesenchyme.-(Tonkoff.)

The Coccygeal or Luschka's Ganglion.-In embryos of about $\mathrm{r} 5$ $\mathrm{cm}$. there is to be found on the ventral surface of the apex of the coccyx a small oval group of polygonal cells, clearly separated from the surrounding tissue by a mesenchymal capsule. Later, connective-tissue trabeculæ make their way into the mass, which thus becomes divided into lobules, and, at the same time, a rich vascular supply, derived principally from branches of the middle sacral artery, penetrates the body, which thus assumes the adult condition in which it presents a general resemblance to a group of lymph follicles.

It has generally been supposed that the coccygeal ganglion was in part derived from the sympathetic nervous system and belonged to the same group of organs as the suprarenal bodies. The most recent 
work on its development (Stoerk) tends, however, to disprove this view, and the ganglion seems accordingly to find its place among the lymphoid organs.

\section{LTTERATURE.}

W. A. Baetjer: "On the Origin of the Mesenteric Sac and the Thoracic Duct in the Embryo Pig," Amer. Journ. Anat., viII, I908.

E. vAN BENEDEN and C. JuLIN: "Recherches sur la formation des annexes fotales chez les mammifères," Archives de Biolog., v, I884.

A. C. Bernays: "Entwickelungsgeschichte der Atrioventricularklappen," Morphol. Jahrbuch, II, I876.

G. BORN: "Beiträge zur Entwicklungsgeschichte des Säugethierherzens," Archiv für mikrosk. Anat., xxxIII, I889.

J. L. BREMER: "On the Origin of the Pulmonary Arteries in Mammals," Anat. Record, III, I909.

I. Broman: "Ueber die Entwicklung, Wanderung und Variation der Bauchaortenzweige bei den Wirbeltiere," Ergeb. Anat. und Entwick., xvI, I906.

I. BRoman: "Ueber die Entwicklung und "Wanderung" der Zweige der aorta abdominalis beim Menschen," Anat. Hefte, xxxvi, rgo8.

E. E. Butterfield: "Ueber die ungranulierte Vorstufen der Myelocyten und ihre Bildung in Milz, Leber und Lymphdrüsen," Deutsch. Arch. f. klin. Med., xcII, I908.

E. R. Clark: "Observations on Living Growing Lymphatics in the Tail of the Frog Larva," Anat. Record, III, Igog.

C. B. Coulter: "The Early Development of the Aortic Arches of the Cat, with Especial Reference to the Presence of a Fifth Arch." Anat. Record, III, I909.

D. M. DAvis: "Studies on the Chief Veins in Early Pig Embryos and the Origin of the Vena Cava Inferior," Amer. Journ. Anat., x, igro.

J. DisSE: "Die Entstehung des Blutes und der ersten Gefässe im Huhnerei," Archiv für mikrosk. Anat., XVI, I879.

A. C. F. Eternod: "Premiers stades de la circulation sanguine dans l'œuf et l'embryon humain," Anat. Anzeiger, xv, I899.

H. M. Evans: "On the Development of the Aortæ, Cardinal and Umbilical Veins, and the other Blood-vessels of Vertebrate Embryos from Capillaries," Anat. Record, III, I909.

V. Federow: "Ueber die Entwicklung der Lungenvene," Anat. Hefte, xL, I9Io.

W. FELIX: "Zur Entwicklungsgeschichte der Rumpfarterien des menschlichen Embryo," Morphol. Jahrb., XLI, I9I0.

G. J. He UeR: "The Development of the Lymphatics in the Small Intestine of the Pig," Amer. Journ. Anat., Ix, Igog.

W. HIs: "Anatomie menschlicher Embryonen," Leipzig, 1880-r882.

F. HochstetTER: "Ueber die ursprungliche Hauptschlagader der hinteren Gliedmasse des Menschen und der Säugethiere, nebst Bemerkungen über die Entwicklung der Endäste der Aorta abdominalis," Morphol. Jahrbuch, xvI, 1890 . 
F. Hochstetter: "Ueber die Entwicklung der A. vertebralis beim Kaninchen, nebst Bemerkungen über die Entstehung der Ansa Vieusseni," Morphol. Jahrbuch, xvI, I8go.

F. Hochstetter: "Beiträge zur Entwicklungsgeschichte des Venensystems der Amnioten." Morphol. Jahrbuch, xx, I893.

W. H. Howell: "The Life-history of the Formed Elements of the Blood, Especially the Red Blood-corpuscles," Journ. of Morphol., IV, I89o.

W. H. Howell: "Observations on the Occurrence, Structure, and Function of the Giant-cells of the Marrow," Journ. of Morph., IV, I89o.

G. S. Huntington: "The Genetic Principles of the Development of the Systemic Lymphatic Vessels in the Mammalian Embryo," Anat. Record, IV, I910.

G. S. Huntington: "The Anatomy and Development of the Systemic Lymphatic Vessels of the Domestic Cat," Memoirs of Wistar Institute, I, I912.

G. S. Huntington and C. F. W. McClure: "Development of Post-cava and Tributaries in the Domestic Cat," Amer. Journ. Anat., vi, I907.

G. S. Huntington And C. F. W. McClure: "The Development of the Main Lymph Channels of the Cat in their Relations to the Venous System," Amer. Journ Anat., vi, I907.

G. S. Huntington and C. F. W. MeClure: "The Anatomy and Development of the Jugular Lymph Sacs in the Domestic Cat," Amer. Journ. Anat., x, I910.

H. E. JoRdAN: "A Microscopical Study of the Umbilical Vesical of a I3 mm. Human Embryo, with Special Reference to the Entodermal Tubules and the Blood Islands," Anat. Anzeiger, xxxvII, I9ro.

C. A. Kling: "Studien über die Entwicklung der Lymphdrüsen beim Menschen," Archiv. für mikrosk. Anat., LXIII, I904.

H. Lehmann: "On the Embryonic History of the Aortic Arches in Mammals," Anat. Anzeiger, xxvi, 1905 .

F. T. Lewis: "The Development of the Vena Cava Inferior," Amer. Journ. of Anat., I, I902.

F. T. Lewis: "The Development of the Veins in the Limbs of Rabbit Embryos." Amer. Journ. Anat., v, Igo6.

F. 'T. LEwis: "The Development of the Lymphatic System in Rabbits," Amer. Journ. Anat., v, Ig06.

F. 'T. Lewis: "On the Cervical Veins and Lymphatics in Four Human Embryos," Amer. Journ. Anat., Ix, I909.

F. T. Lewis: "The First Lymph Glands in Rabbit and Human Embryos," Anat. Record, III, I909.

W. A. Locy: "The Fifth and Sixth Aortic Arches in Chick Embryos, with Comments on the Condition of the same Vessels in other Vertebrates," Anat. Anzeiger xxix, I906.

F. P. MALL: "Development of the Internal Mammary and Deep Epigastric Arteries in Man," Johns Hopkins Hospital Bulletin, I89S.

F. P. MALL: "On the Developmennt of the Blood-vessels of the Brain in the Human Embryo," Amer. Journ. Anat., Iv, I905.

A. Maximow: "Untersuchungen über Blut und Bindegewebe," Arch. fïr mikr. Anat., LXxIII, I909; LXxIV, I909; LxxVI, I9I0. 
C. F. W. MCClure: "The Development of the Thoracic and Right Lymphatic Ducts in the Domestic Cat (Felis Domestica)," Anat. Anzeiger, xxxIr, 1908.

C. F. W. MCCluRE: "The Extra-intimal Theory of the Development of the Mesenteric

Lymphatics in the Domestic Cat," Verhandl. Anat. Gesellsch., xxIv, I9Io.

C. S. Minot: "On a Hitherto Unrecognized Form of Blood Circulation without

Capillaries in the Organs of Vertebrata," Proc. Boston Soc. Nat. Hist., xxix, I9oo.

S. MoltIER: "Die Blutbildung in der Embryonalen Leber des Menschen und der Säügetiere," Arch. für mikrosk. Anat., Lxxrv, Igog.

A. G. PoHlman: "The Course of the Blood through the Fetal Mammalian Heart," Anat. Record, II, I908.

F. ReAGAN: "The Fifth Aortic Arch of Mammalian Embryos." Amer. Journ. Anat., XII, I9I2.

E. RetTeRER: "Sur la part que prend l'epithélium à la formation de la bourse de Fabricius, des amygdales et des plaques de Peyer," Journ. de l'Anat. et de la Physiol., XXIx, I893.

R. RETZER: "Some Results of Recent Investigations on the Mammalian Heart," Anat. Record, II, I908.

C. RösE: "Zur Entwicklungsgeschichte des Säugethierherzens," Morphol. Jahrbuch, $\mathrm{XV}, \mathrm{I} 889$.

FLORENCE R. SABIN: "On the Origin of the Lymphatic System from the Veins and the Development of the Lymph Hearts and Thoracic Duct in the Pig," Amer. Journ. of Anat., I, Igo2.

Florence R. SABIN: "The Development of the Lymphatic Nodes in the Pig and their Relation to the Lymph Hearts," Amer. Journ. Anat., IV, I905.

Florence R. SABIN: "Further Evidence on the Origin of the Lymphatic Endothelium from the Endothelium of the Blood Vascular System," Anat. Record, II, Igo8.

Florence R. SABIN: On the Development of the Lymphatic System in Human . Embryos with a Consideration of the Morphology of the System as a Whole," Amer. Journ. Anat., IX, Igog.

Florence R. SAbIn: "A Critical Study of the Evidence Presented in Several Recent Articles on the Development of the Lymphatic System," Anat. Record, v, IgIr.

F. SAXER: "Ueber die Entwicklung und der Bau normaler Lymphdrüsen und die Entsehung der roten und weissen Blutkörperchen," Anat. Hefte, vi, I8g6.

H. SCHRIDDE: "Die Entstehung der ersten embryonalen Blutzellen des Menschen," Folia hamatol, Iv, I907.

P. STÖHR: "Ueber die Entwicklung der Darmlymphknötchen und über die Rückbildung von Darmdrüsen," Archiv für mikrosk. Anat., II, I 898 .

O. vAN DER STRICHT: "Nouvelles recherches sur la genèse des globules rouges et des globules blancs du sang," Archives de Biolog., XII, I892.

O. VAN DER STRICHT: "De la première origine du sang et des capillaires sanguins dans l'aire vasculaire du Lapin," Comptes Rendus de la Soc. de Biolog. Paris, Sér. Io, II, I895.

O. Stoerk: "Ueber die Chromreaktion der Glandula coccygea und die Beziehung, dieser Drüse zum Nervus sympathicus." Arch. für mikroskop. Anat., LXIX, Igo6.

J. TANDlen: "Zur Entwicklungsgeschichte der Kopfarterien bei den Mammalia." Morphol. Jahrbuch, xxx, 1902. 
J. TANDleR: "Zur Entwickelungsgeschichte der menschlichen Darmarterien," Anat. Hefte, xxiII, I903.

J. TANDLER: "Ueber die Varietäten der arteria cœliaca und deren Entwicklung," Anat. Hefte, xxv, I904.

J. Tandler: "Ueber die Entwicklung des fünften Aortenbogens und der fünften Schlundtasche beim Menschen," Anat. Hefte, xxxviII, I909.

W. Tonkoff: "Die Entwickelung der Milz bei den Amnioten," Arch. für mikrosk. Anat., LVI, Igoo.

BERTHA DE VRIESE: "Recherches sur l'évolution des vaissaux sanguins des membres chez l'homme," Archives de Biolog., xvIII, Igoz.

F. WeIDENREICH: "Die roten Blutkörperchen," Ergeb. Anat. und Entwick., XIII, Igo3 XIV, I904.

F. Weidenreich: "Die Leucocyten und verwandte zellformen," Ergeb. Anat. und; Entwick., XVI, I9II.

J. H. WRIGHT: "The Histogenesis of the Blood Platelets," Journ. of Morph., xxI, rgro. 


\section{CHAPTER X. \\ THE DEVELOPMENT OF THE DIGESTIVE TRACT AND GLANDS.}

The greatest portion of the digestive tract is formed by the constriction off of the dorsal portion of the yolk-sac, as shown in Fig. 52, the result being the formation of a cylinder, closed at either end, and composed of a layer of splanchnic mesoderm lined on its inner surface by endoderm. This cylinder is termed archenteron and has connected with it the yolk-stalk and the allantois, the latter communicating with its somewhat dilated terminal portion, which also receives the ducts of the primitive kidneys and is known as the cloaca (Fig. I70).

At a very early stage of development the anterior end of the embryo begins to project slightly in front of the yolk-sac, so that a shallow depression is formed between the two structures. As the constriction of the embryo from the sac proceeds, the anterior portion of the brain becomes bent ventrally and the heart makes its appearance immediately in front of the anterior surface of the yolk-sac, and so the depression mentioned above becomes deepened (Fig. I69) to form the oral sinus. The floor of this, lined by ectoderm, is immediately opposite the anterior end of the archenteron, and, since mesoderm does not develop in this region, the ectoderm of the sinus and the endoderm of the archenteron are directly in contact, forming a thin pharyngeal membrane separating the two cavities (Fig. I69, pm) In embryos of $2.15 \mathrm{~mm}$. this membrane is still existent, but soon after it becomes perforated and finally disappears, so that the archenteron and oral sinus become continuous.

Toward its posterior end th: archenteron comes into somewhat similar relations with the ectoderm, though a marked difference is noticeable in that the area over which the cloacal endoderm is in 
contact with the ectoderm to form the cloacal membrane (Fig. I $70, \mathrm{~cm}$ ) lies a little in front of the actual end of the archenteric cylinder, the portion of the latter which lies posterior to the membrane forming what has been termed the postanal gut (p.an). This diminishes in size during development and early disappears altogether, and the pouch-like fold seen in Fig. I 70 between the intestinal portion of the archenteron and the allantoic stalk (al) deepening until its floor comes into contact with the cloacal membrane, the cloaca becomes divided into a ventral portion, with which the allantois and the primitive excretory ducts (w) are connected, and a dorsal portion which becomes the lower end of the rectum. This latter abuts upon the dorsal portion of the cloacal membrane, and this eventually ruptures, so that the posterior communication of the archenteron with the exterior becomes established. This rupture, however, does not occur until a comparatively late period of development, until after the embryo has reached the fetal stage;

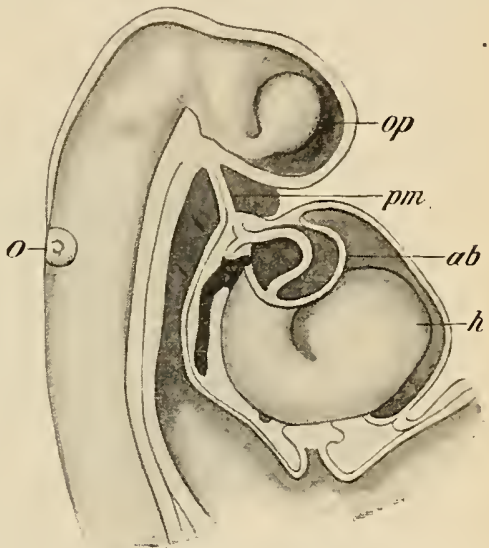

Fig. i69.-Reconstruction OF THE Anterior Portion of an Embryo of 2.I 5 MM.

$a b$, Aortic bulb; $h$, heart; $o$, auditory capsule; $o p$, optic evagination; $p m$, pharyngeal membrane.-(His.) nor does the position of the membrane correspond with the adult anus, since later there is a considerable development of mesoderm around the mouth of the cloaca, bulging out, as it were, the surrounding ectoderm, more especially anteriorly where it forms the large genital tubercle (see ChapterXIII), and posteriorly where it produces the anal mbercle. This appears as a rounded elevation on each side of the median line, immediately behind the cloacal membraneand separated from the root of the caudal projection by a depression, the precaudal recess. Later the two elevations unite across the median line to form a transverse ridge, the ends of which curve 
forward and eventually meet in front of the original anal orifice. From the mesoderm of the circular elevation thus produced the external sphincter ani muscle is formed, and it would seem that so much of the lower end of the rectum as corresponds to this muscle is formed by the inner surface of the elevation and is therefore ectodermal. The definitive anus being at the end of this terminal portion of the gut is therefore some distance away from the position of the original cloacal membrane.

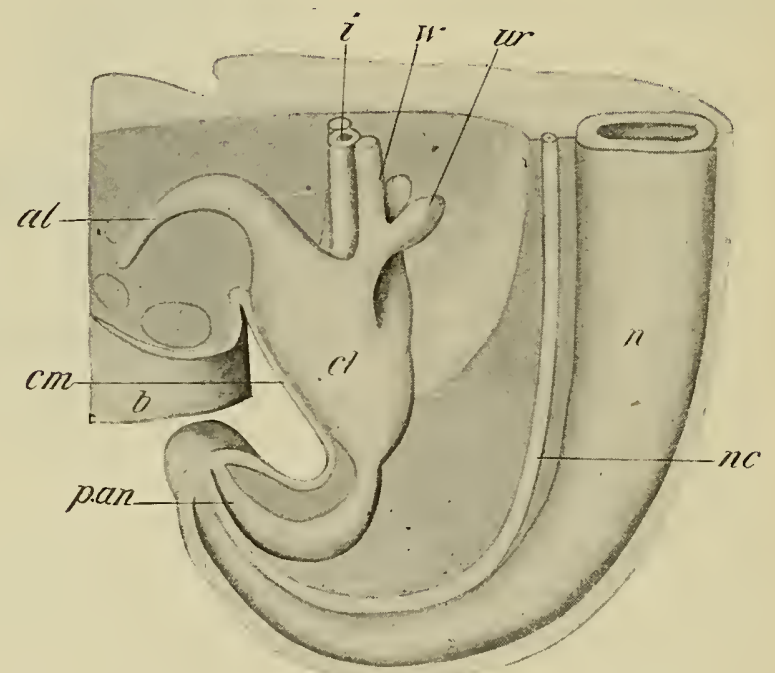

Fig. 170.-Reconstruction of the Hind End of An Embryo 6.5 MM. Long

$a l$, Allantois; $b$, belly-stalk; $c l$, cloaca; $c m$, cloacal membrane; $i$, intestine; $n$, spinal cord; $n c$, notochord; p.an, postanal gut; ur, outgrowth to form ureter and metanephros; $w$, Wolffian duct.-(Keibel.)

It will be noticed that the digestive tract thus formed consists of three distinct portions, an anterior, short, ectodermal portion, an endodermal portion representing the original archenteron, and a posterior short portion which is also ectodermal. The differentiation of the tract into its various regions and the formation of the various organs found in relation with these may now be considered. 
The Development of the Mouth Region.-The deepening of the oral sinus by the development of the first branchial arch and its separation into the oral and nasal cavities by the development of the palate have already been described (p. 99), but, for the sake of continuity in description, the latter process may be briefly recalled. At first the nasal pits communicate with the oral sinus by grooves lying one on each side of the fronto-nasal process, but by the union of the latter, through its processus globularis, with the maxillary processes these communications are interrupted and the floors of the nasal pits are separated from the oral cavity by thin bucco-nasal membranes, formed of the nasal epithelium in contact with that of the oral cavity. In embryos of about $\mathrm{I}_{5} \mathrm{~mm}$. these membranes break through and disappear, and the nasal and oral cavities are again in communication, but the communications are now behind the maxillary processes and constitute what are termed the primitive choance. The oral cavity at this stage does not, however, correspond with the adult mouth cavity, since there is as yet no palate, the roof of the oral cavity being the base of the skull. From the maxillopalatine portions of the upper jaw, shelf-like ridges begin to grow, being at first directed downward so that their surfaces are parallel with the sides of the tongue, which projects up between them. Later, however, they become bent upward to a horizontal position (Fig. I 7 I) and eventually meet in the median line to form the palate, separating the nasal cavities from the mouth cavity. All that portion of the original oral cavity which lies behind the posterior edge of the palatal shelf is now known as the pharynx, the boundary between this and the mouth cavity being emphasized by the prolongation backward and downward of the posterior angles of the palatal shelf as ridges, which form the pharyngo-palatine arches (posterior pillars of the fauces). The nasal cavities now communicate with the upper part of the pharynx (naso-pharynx) by the posterior choanæ. The palatal processes are entirely derived from the maxillary processes, the premaxillary portion of the upper jaw, which is a derivative of the fronto-nasal processes, not taking part in their formation." Consequently a gap exists between the palatal 
shelves and the premaxillæ for a time, by which the nasal and mouth cavities communicate; it places the organ of Jacobson (see p. 429) in communication with the mouth cavity and may persist until after birth. Later it becomes closed over by mucous membrane, but may be recognized in the dried skull as the foramen incisivum (anterior palatine canal).

Occasionally there is a failure of the union of the palatal plates, the condition known as cleft palate resulting. The inhibition of development which brings about this condition may take place at different stages, but frequently it occurs while the plates still have an almost vertical direction. Typically cleft palate is a deficiency in the median line of the roof of the

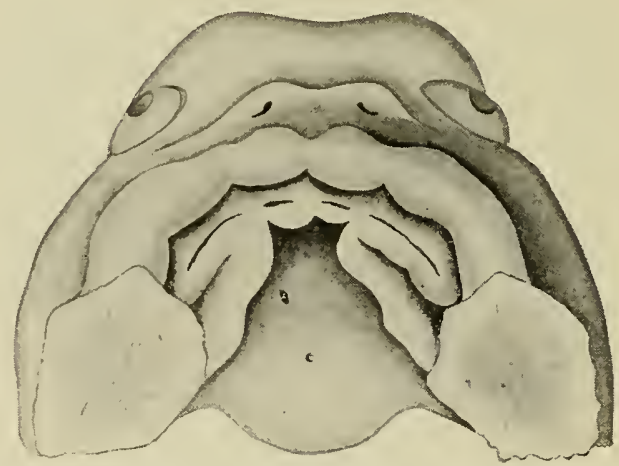

Fig. I7I.-View OF the RoOf OF the ORAL FosSa of EMbryo SHOWing the Lipgroove and the Formation of the Palate.-( $H$ is.)

mouth, not affecting the upper jaw, but very frequently it is combined with the defect which produces hare-lip (see p. IOO), in which case the cleft may be continued through the upper jaw between its maxillary and premaxillary portions on either or both sides, according to the extent of the defect.

At about the fifth week of development a downgrowth of epithelium into the substance of both the maxillary and fronto-nasal processes above and the mandibular process below takes place, and the surface of the downgrowth becomes marked by a deepening groove (Fig. I $7 \mathrm{I}$ ), which separates an anterior fold, the $l i p$, from the jaw proper (Fig. I72). Mention should also be made of the 
fact that at an early stage of development a pouch is formed in the median line of the roof of the oral sinus, just in front of the pharyngeal membrane, by an outgrowth of the epithelium. This pouch, known as Rathke's pouch, comes in contact above with a downgrowth from the floor of the brain and forms with it the pituitary body (see p. 399).

The Development of the Teeth.-When the epithelial downgrowth which gives rise to the lip groove is formed, a horizontal outgrowth develops from it which extends backward into the substance of the jaw, forming what is termed the dental shelf (Fig. I72, A). This at first is situated on the anterior surface of the jaw, but with the continued development of the lip fold it is gradually shifted until it comes to lie upon the free surface (Fig. I72, B), where its superficial edge is marked by a distinct groove, the dental groove (Fig. I7I). At first the dental shelf of each jaw is a continuous plate of cells, uniform in thickness throughout its entire width, but later ten thickenings develop upon its deep edge, and beneath each of these the mesoderm condenses to form a dental papilla, over the surface of which the thickening moulds itself to form a cap, termed the enamel organ (Fig. I72, B). These ten papillæ in each jaw, with their enamel caps, represent the teeth of the first dentition.

The papillæ do not, however, project into the very edge of the dental shelf, but obliquely into what, in the lower jaw, was originally its under surface (Fig. I 72, B), so that the edge of the shelf is free to grow still deeper into the surface of the jaw. This it does, and upon the extension so formed there is developed in each jaw a second set of thickenings, beneath each of which a dental papilla again appears. These tooth-germs represent the incisors, canines, and premolars of the permanent dentition. The lateral edges of the dental shelf being continued outward toward the articulations of the jaws as prolongations which are not connected with the surface epithelium, opportunity is afforded for the development of three additional thickenings on each side in each jaw, and, papillæ developing beneath these, twelve additional tooth-germs are formed. These represent the permanent molars; their formation is much 
later than that of the other teeth, the germ of the second molar not appearing until about the sixth week after birth, while that of the third is delayed until about the fifth year.

As the tooth-germs increase in size, they approach nearer and nearer to the surface of the jaw, and at the same time the enamel organs separate from the dental shelf until their connection with it is a mere neck of epithelial cells. In the meantime the dental shelf itself has been undergoing degeneration and is reduced to a reticulum

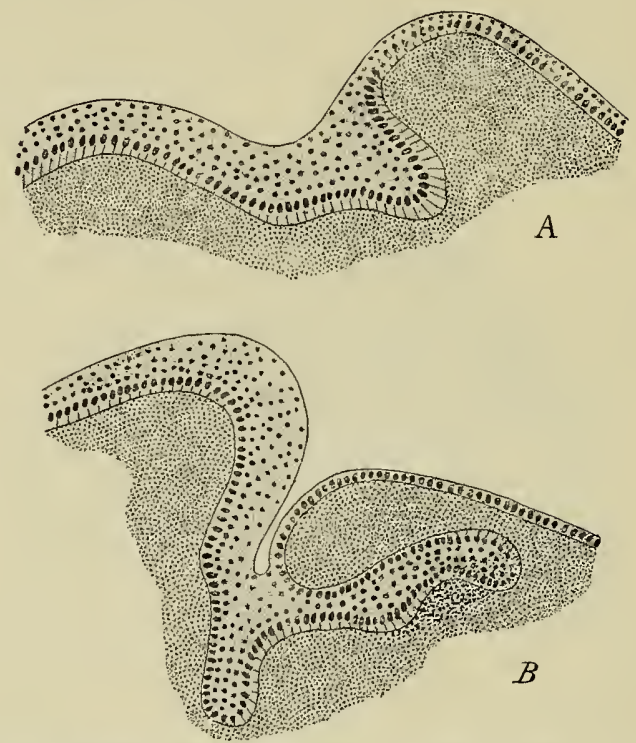

Fig. i72.-Transverse Sections through the Lower Jaw showing the Formation of the Dental Shelf in Embryos of $(A)$ I 7 MM. AND $(B) 40$ MM.(Röse.)

which eventually completely disappears, though fragments of it may occasionally persist and give rise to various malformations. With the disappearance of the last remains of the shelf, the various toothgerms naturally lose all connection with one another.

It will be seen, from what has been said, that each tooth-germ consists of two portions, one of which, the enamel organ, is derived from the ectoderm, while the other, the dental papilla, is mesen- 
chymatous. Each of these gives rise to a definite portion of the fully formed tooth, the enamel organ, as its name indicates, producing the enamel, while from the dental papilla the dentine and pulp are formed.

The cells of the enamel organ which are in contact with the surface of the papilla, at an early stage assume a cylindrical form and become arranged in a definite layer, the enamel membrane (Fig. I73, SEi), while the remaining cells $(S E a)$ apparently degenerate eventually, though they persist for a time to form what has been termed the enamel pulp. The formation of the enamel seems to be due to the direct transformation of the enamel cells, the process beginning at the basal portion of each cell, and as a result, the enamel consists of a series of prisms, each of which represents one of the cells of the enamel membrane. The transformation proceeds until the cells have become completely converted into enamel prisms, except at their very tips, which form a thin membrane, the enamel cuticle, which is shed soon after the eruption of the teeth.

The dental papillæ are at first composed of a closely packed mass of mesenchyme cells, which later become differentiated into connective tissue into which blood-vessels and nerves penetrate. The superficial cells form a more or less definite layer (Fig. I73, od), and are termed odontoblasts, having the function of manufacturing the dentine. This they accomplish in the same manner as that in which the periosteal osteoblasts produce bone, depositing the dentine between their surfaces and the adjacent surface of the enamel. The outer surface of each odontoblast is drawn out into a number of exceedingly fine processes which extend into the dentine to occupy the minute dentinal tubules, just as processes of the osteoblasts occupy the canaliculi of bone.

At an early stage the enamel membrane forms an almost complete investment for the dental papilla (Fig. I73), but as the ossification of the tooth proceeds, it recedes from the lower part, until finally it is confined entirely to the crown. The dentine forming the roots of the tooth then becomes enclosed in a layer of cement, which is true bone and serves to unite the tooth firmly to the walls of its 
socket. As the tooth increases in size, its extremity is brought nearer to the surface of the gum and eventually breaks through, the eruption of the first teeth usually taking place during the last half of the first year after birth. The growth of the permanent teeth

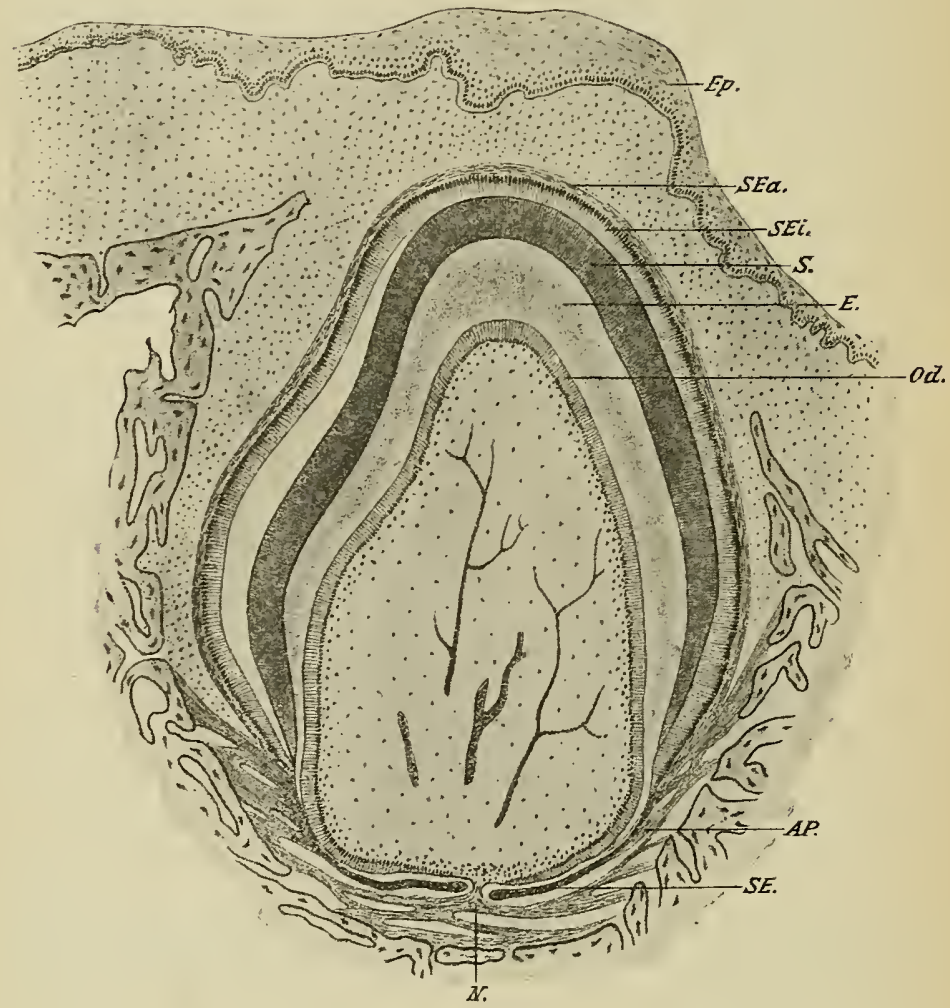

Fig. I73.-Section through the First Molar Tooth of a Rat, Twelve Days Old.

$A p$, Periosteum; $E$, dentine; Ep, epidermis; Od, odontoblasts; $S$, enamel; SEa and $S E i$, outer and inner layers of the enamel organ; $S E$, portion of the enamel organ which does not produce enamel.-(von Brunn.)

proceeds slowly at first, but later it becomes more rapid and produces pressure upon the roots of the primary teeth. These roots then undergo partial absorption, and the teeth are thus loosened 
in their sockets and are readily pushed out by the further growth of the permanent teeth.

The dates and order of the eruption of the teeth are subject to considerable variation, but the usual sequence is somewhat as follows:

Primary Dentition.

Median incisors................ 6 th to 8 th month.

Lateral incisors................ 8 th to I2 month.

First molars.................... Beginning of $2 \mathrm{~d}$ year.

Canines....................... $1_{\frac{1}{2}}^{\frac{1}{2}}$ years.

Second molars.................. 3 to $3 \frac{1}{2}$ years.

The teeth of the lower jaw generally precede those of the upper.

Permanent Dentition.

First molars..................... 7 th year.

Middle incisors.................... 8th year.

Lateral incisors....................

First premolars................... Ioth year.

Second premolars.................... II th year.

Canines

Second molars

I 3 th to 14 th years.

Third molars................... I 7 th to 4 oth years.

In a considerable percentage of individuals the third molars (wisdom teeth) never break through the gums, and frequently when they do so they fail to reach the level of the other teeth, and so are only partly functional. These and other peculiarities of a structural nature shown by these teeth indicate that they are undergoing a retrogressive evolution.

The Development of the Tongue.-Strictly speaking, the tongue is largely a development of the pharyngeal region of the digestive tract and only secondarily grows forward into the floor of the mouth. In embryos of about $3 \mathrm{~mm}$. there may be seen in the median line of the floor of the mouth, between the ventral ends of the first and second branchial arches, a small rounded elevation which has been termed the tuberculum impar (Fig. I74, Ti). It was at one time believed that this gave rise to the anterior portion of the tongue, but recent observations seem to show that it reaches its greatest development in embryos of about $8 \mathrm{~mm}$., after which it becomes less prominent and finally unrecognizable. But before 
this occurs a swelling appears in the anterior part of the mouth on each side of the median line (Fig. I74, $t$ ), and these gradually increase

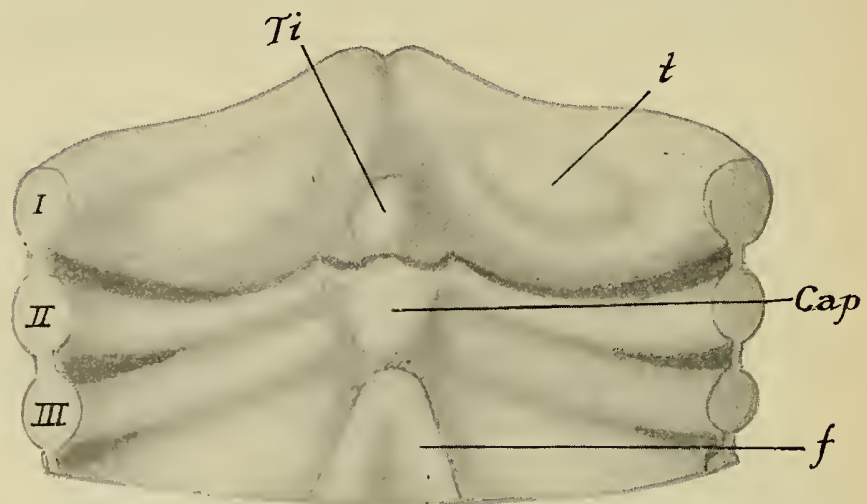

Fig. I74.-Floor of the Mouth and Pharynx of an Embryo of 7.5 MM., From A ReCONSTRUCTION.

Cop. Copula; $f$, furcula; $t$, swelling that gives rise to the body of the tongue; $T i$, tuberculum impar; $I-I I I$, branchial arches.

in size and eventually unite in the median line to form the main mass of the body of the tongue. They are separated from the

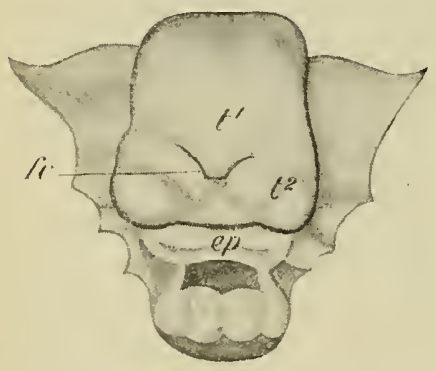

FIG. I75.-THE FLOOR OF THE Pharynx OF an EMbryo of about 20 MM.

$e p$, Epiglottis; $f c$, foramen cæcum; $t^{1}$ and $t^{2}$ median and lateral portions of the tongue. - (His.) second and third arches the posterior portion of the tongue develops.
The tongue then consists of two distinct portions, which evensecond and third arches the posterior portion of the tongue develops.
The tongue then consists of two distinct portions, which evenbranchial arch by a deep groove, the alveolo-lingual groove, and posteriorly are separated from the second arch by a groove which later becomes distinctly V-shaped (Fig. I75), a deep depression, which gives rise to the thyreoid body lying at the apex of the $V$. Behind the thyreoid pouch the ventral ends of the second and third branchial arches unite to form an elevation, the copula (Fig. I74, cop), and from this and the adjacent portions of the neighboring portions of the first 
tually fuse together, but the groove which originally separated them remains more or less clearly distinguishable (Fig. I75), the vallate papillæ (see p. 430) developing immediately anterior to it.

The tongue is essentially a muscular organ, being formed of a central mass of muscular tissue, enclosed at the sides and dorsally by mucous membrane derived from the floor of the mouth and pharynx. The muscular tissue consists partly of fibers limited to the substance of the tongue and forming the $m$. lingualis, and also of a number of extrinsic muscles, the hyoglossi, genioglossi, styloglossi, glossopalatini, and chondroglossi. The last two muscles are innervated by the vagus nerve, and the remaining extrinsic muscles receive fibers from the hypoglossal, while the lingualis is supplied partly by the hypoglossal and partly, apparently, by the facial through the chorda tympani. That the facial should take part in the supply is what might be expected from the mode of development of the tongue, but the hypoglossal has been seen to correspond to certain primarily postcranial metameres (p. I69), and its relation to structures taking part in the formation of an organ belonging to the anterior part of the pharynx seems somewhat anomalous. It may be supposed that in the evolution of the tongue the extrinsic muscles, together with a certain amount of the lingualis, have grown into the tongue thickenings from regions situated much further back, for the most part from behind the last branchial arch.

Such an invasion of the tongue by muscles from posterior segments would explain the distribution of its sensory nerves (Fig. I76). The anterior portion, from its position, would naturally be supplied by branches from the fifth and seventh nerves, while the posterior portion might be expected to be supplied by the seventh. There seems, however, to have been a dislocation forward, if it may be so expressed, of the mucous membrane, the sensory distribution of the ninth nerve extending forward upon the posterior part of the anterior portion of the tongue, while a considerable amount of the posterior portion is supplied by the tenth nerve. The distribution of the sensory fibers of the facial is probably confined entirely to the anterior portion, though further information is needed to determine the exact distribution of both the motor and sensory fibers of this nerve in the tongue.

The Development of the Salivary Glands.- In embryos of about $8 \mathrm{~mm}$. a slight furrow may be observed in the floor of the groove which connects the lip grooves of the upper and lower jaws at the angle of the mouth and may be known as the cheek groove. In later stages this furrow deepens and eventually becomes closed in to form a hollow tubular structure, which in embryos of $17 \mathrm{~mm}$. 
has separated from the epithelium of the floor of the cheek groove except at its anterior end and has become embedded in the connective tissue of the cheek. This tube is readily recognizable as the parotid gland and duct, and from the latter as it passes across the masseter muscle a pouch-like outgrowth is early formed which probably represents the socia parotidis.

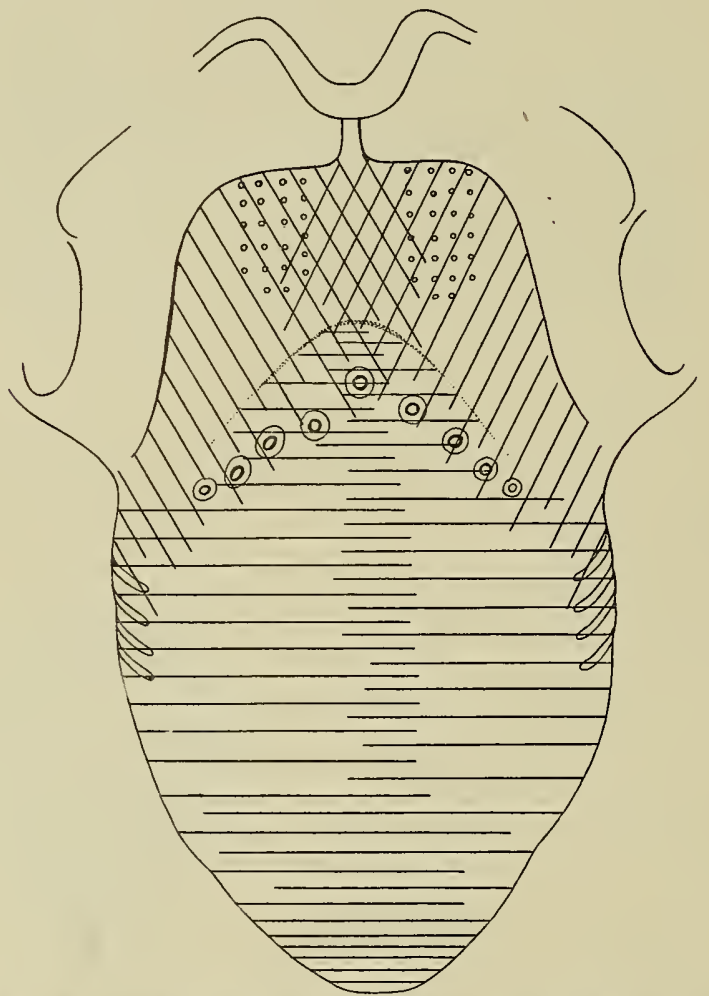

Fig. I76.-Diagram of the Distribution of the Sensory Nerves of the Tongue. The area supplied by the fifth (and seventh) nerve is indicated by the transverse lines; that of the ninth by the oblique lines; and that of the tenth by the small circles. -(Zander.)

The submaxillary gland and duct appear in embryos of about I3 $\mathrm{mm}$. as a longitudinal ridge-like thickening of the epithelium of the floor of the alveolo-lingual groove (see p. 290). This ridge 
gradually separates from behind forward from the floor of the groove and sinks into the subjacent connective tissue, retaining, however, its connection with the epithelium at its anterior end, which indicates the position of the opening of the duct. In the vicinity of this there appear in embryos of $24.4 \mathrm{~mm}$. five small bud-like downgrowths of the epithelium (Fig. I77,SL), which later increase considerably in number as well as in size, and constitute a group of glands which are generally spoken of as the sublingual gland.

As these representatives of the various glands increase in length,

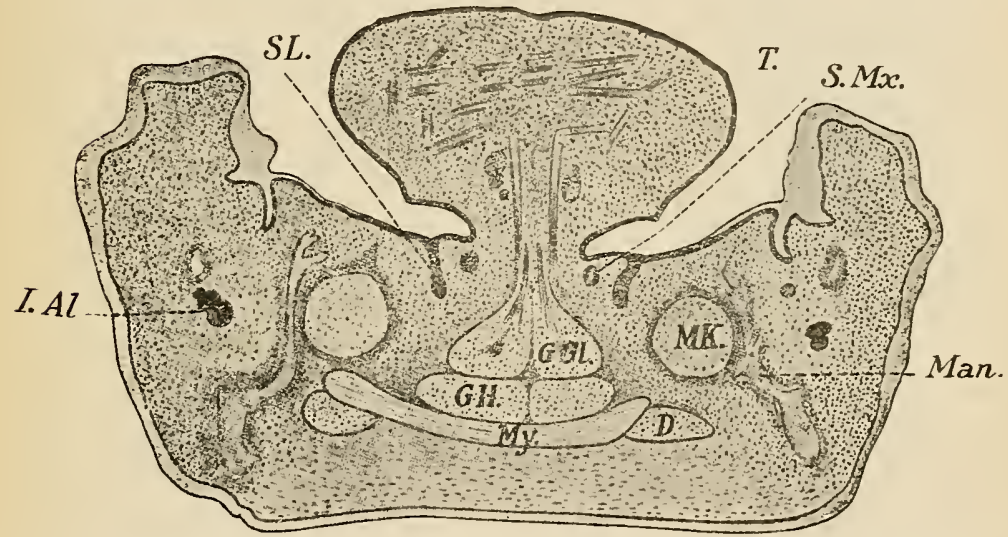

Fig. 177.-TRansverse Section of the Lower JaW and Tongue of an Embryo OF ABOUT $20 \mathrm{MM}$.

$D$, Digastric muscle; $G G l$., genioglossus, $G H$.; geniohyoid; $I . A l$, inferior alveolar nerve; $M a n$, mandible; $M K$, Meckel's cartilage; $M y$, mylohyoid; $S L$, sublingual gland; S.Mx, submaxillary duct; $T$, tongue.

they become lobed at their deeper ends, and the lobes later give rise to secondary outgrowths which branch repeatedly, the terminal branches becoming the alveoli of the glands. A lumen early appears in the duct portions of the structures, the alveoli remaining solid for a longer time, although they eventually also become hollow.

It is to be noted that each parotid and submaxillary consists of a single primary outgrowth, and is therefore a single structure and not a union of a number of originally separate parts. The sublingual glands of adult 
anatomy are usually described as opening upon the floor of the mouth by a number of separate ducts. This arises from the fact that the majority of the glands which form in the vicinity of the opening of Wharton's duct remain quite small, only one of them on each side giving rise to the sublingual gland proper. The small glands have been termed the alveolo-lingual glands, and each one of them is equivalent to a parotid or submaxillary gland. In other words, there are in reality not three pairs of salivary glands, but from fourteen to sixteen pairs, there being usually from eleven to thirteen alveolo-lingual glands on each side.

The Development of the Pharynx.-The pharynx represents the most anterior part of the archenteron, that portion in which the branchial arches develop, and in the embryo it is relatively much longer than in the adult, the diminution being brought about by the folding in of the posterior arches and the formation of the sinus præcervicalis already described (p. 97). Between the various branchial arches, grooves occur, representing the endodermal portions of the grooves which separate the arches. During development the first of these becomes converted into the tympanic cavity of the ear and the Eustachian tube (see Chapter XV); the second disappears in its upper part, the lower persisting as the fossa in which the tonsil is situated; while the lower parts of the remaining two are represented by the sinus piriformis of the larynx (His), and also leave traces of their existence in detached portions of their epithelium which form what are termed the branchial epithelzal bodies, and take part in the formation of the thyreoid and thymus glands.

In the floor of the pharynx behind the thickenings which produce the tongue there is to be found in early stages a pair of thickenings passing horizontally backward and uniting in front so that they resemble an inverted $\mathrm{U}$ (Fig. I78, $f$ ). These ridges, which form what is termed the furcula (His), are concerned in the formation of parts of the larynx (see p. 334). In the part of the roof of the pharynx which comes to lie between the openings of the Eustachian tubes, a collection of lymphatic tissue takes place beneath the mucous membrane, forming the pharyngeal tonsil, and immediately behind this there is formed in the median line an upwardly projecting pouch, the pharyngeal bursa, first certainly noticeable in embryos $6.5 \mathrm{~mm}$. in length. 
This bursa has very generally been regarded as the persistent remains of Rathke's pouch (p. 285), especially since it is much more pronounced in fetal than in adult life. It has been shown, however, that it is formed quite independently of and posterior to the true Rathke's pouch (Killian), though what its significance may be is still uncertain.

The tonsils are formed from the epithelium of the second branchial groove. At about the fourth month solid buds begin to grow from the epithelium into the subjacent mesenchyme, and depressions appear on the surface of this region. Later the buds become hollow by a cornification of their central cells, and open upon the floor of the depressions which represent the crypts of the tonsil. In the meantime lymphocytes, concerning whose origin there is a difference of opinion, collect in the subjacent mesenchyme and eventually aggregate to form lymphatic follicles in close relation with the buds. Whether the lymphocytes wander out from the blood into the mesenchyme or are derived directly from the epithelium or the mesenchyme cells is the question at issue.

The tonsil may grow to a size sufficient to fill up completely the groove in which it forms, but not infrequently a marked

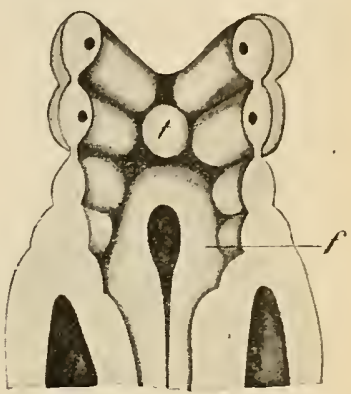

FIG. I78.-THE FLOOR OF THe Pharynx of an Embryo OF 2.I5 MM.

$f$. Furcula; $t$, tuberculum impar.-(His.) depression, the fossa supratonsillaris, exists above it and represents a portion of the original second branchial furrow.

The groove of Rosenmüller, which was at one time thought to be also a remnant of the second furrow, is a secondary depression which appears in embryos of $I I .5 \mathrm{~cm}$. behind the opening of the Eustachian tube, in about the region of the third branchial furrow.

The Development of the Branchial Epithelial Bodies.-These are structures which arise either as thickenings or as outpouchings of the epithelium lining the lower portions of the inner branchial furrows. Five pairs of these structures are developed and, in addition, there is a single unpaired median body. This last makes its appearance in embryos of about $3 \mathrm{~mm}$., and gives rise to the major por- 
tion of the thyreoid body. It is situated immediately behind the anterior portion of the tongue, at the apex of the groove between this and the posterior portion, and is first a slight pouch-like depression. As it deepens, its extremity becomes bilobed, and after the embryo has reached a length of $6 \mathrm{~mm}$. it becomes completely separated from the floor of the pharynx. The point of its original origin is, however, permanently marked by a circular depression, the foramen cacum (Fig. I75, fc). Later the bilobed body migrates down the neck and becomes a solid transversely elongated mass (Fig. I79, th), into the substance of which trabeculæ of connective tissue extend, dividing it into a network of anastomosing cords which

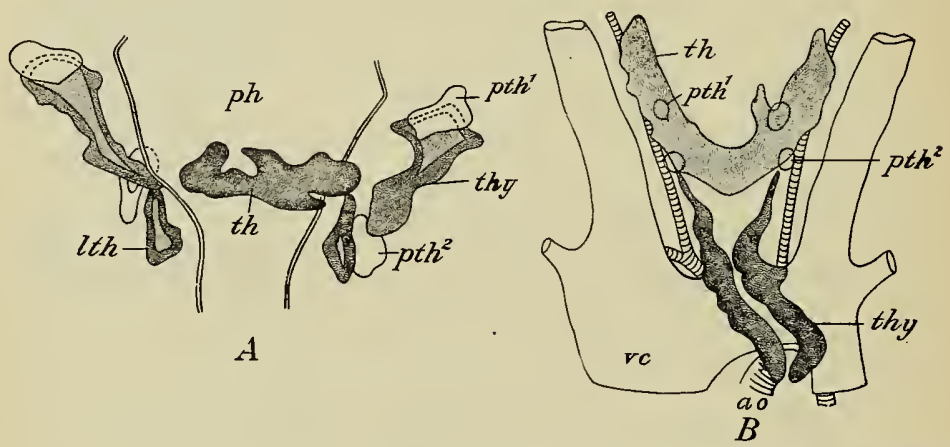

Fig. 179.-Reconstructions of the Branchial Epithelial Bodies of Embryos. OF (A) I4 MM. AND (B) $26 \mathrm{MM}$.

ao, Aorta; $l t h$, lateral thyreoid; $p h$, pharynx; $p t h^{1}$ and $p t h^{2}$, parathyreoids; $t h$, thyreoid; thy, thymus; vc, vena cava superior.-(Tourneux and Verdun.)

later divide transversely to form follicles. When the embryo has reached a length of $2.6 \mathrm{~cm}$., a cylindrical outgrowth arises from the anterior surface of the mass, usually a little to the left of the median line, and extends up the neck a varying distance, forming, when it persists until adult life, the so-called pyramid of the thyreoid body.

This account of the pyramid follows the statements made by recent workers on the question (Tourneux and Verdun); His has claimed that it is the remains of the stalk connecting the thyreoid with the floor of the pharynx, and which he terms the thyreo-glossal duct.

Two other pairs of bodies enter into intimate relations with the 
thyreoid, forming what have been termed the parathyreoid bodies (Fig. I $79, p t h^{1}$ and $p t h^{2}$ ). One of these pairs arises as a thickening of the dorsal portion of the fourth branchial groove and the other comes from the corresponding portion of the third groove. The members of the former pair, after separating from their points of origin, come to lie on the dorsal surface of the lateral portions of the thyreoid body (Fig. I8o, pthm IV) in close proximity to the lateral thyreoids, while those of the other pair, passing further backward, come to rest behind the lower border of the thyreoid (Fig. I8o, pthm III). The cells of these bodies do not become divided into cords by the ingrowth of connective tissue to the same extent as those of the thyreoids, nor do they become separated into follicles, so that the bodies are readily distinguishable by their structure from the thyreoid.

From the ventral portion of the third branchial groove a pair of evaginations develop, similar to those which produce

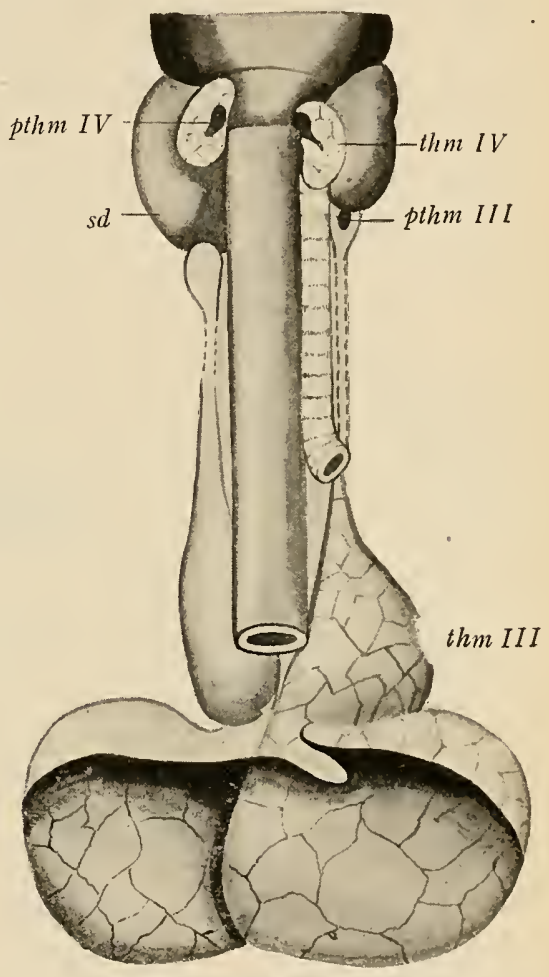

Fig. ISO.-ThYreoId, TyHmus AND Epithelial Bodies of a NEW-BORN CHILd.

pihm III and pthm IV, Parathyreoids; $s d$, thyreoid; thm III, thymus; thm IV, lateral thyreoid.-(Groschuff. the lateral thyreoids. These elongate greatly, and growing downward ventrally to the thyreoid and separating from their points of origin, come to lie below the thyreoids, forming the thymus gland (Fig. I79, thy). As development proceeds they pass further backward and come eventually to rest upon the anterior surface of the peri- 
cardium. The cavity which they at first contain is early obliterated and the glands assume a lobed appearance and become traversed by trabeculæ of connective tissue. Lymphocytes, derived, according to some recent observations, directly from the epithelium of the glands, make their appearance and gradually increase in number until the original epithelial cells are represented only by a number of peculiar spherical structures, consisting of cells arranged in concentric layers and known as Hassall's corpuscles.

The glands increase in size until about the fifteenth year, after

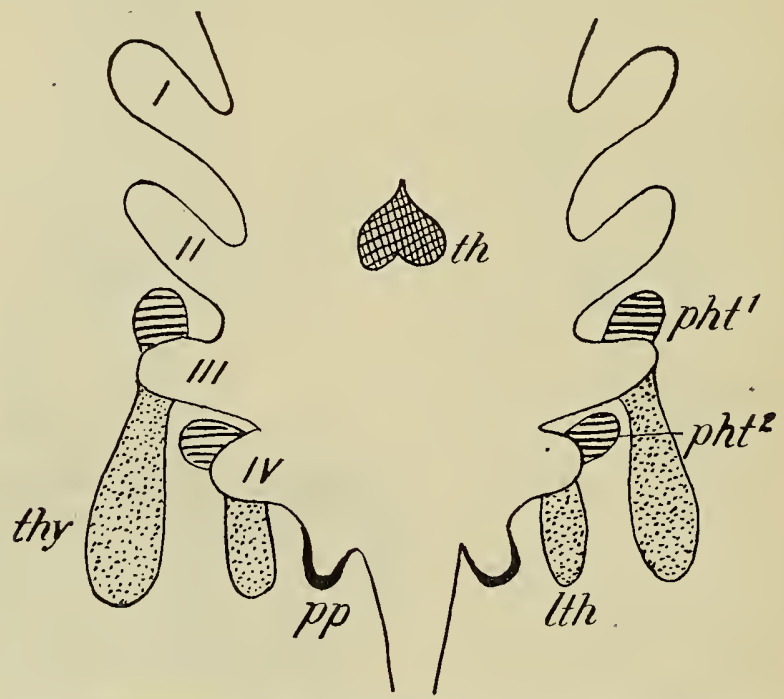

Fig. I8I.-DiagraM SHOWING the ORIgin of the Various Branchial Epithelial BODIES.

$l t h$, Lateral thyreoids; $p p$, ultimobranchial bodies; $p h t^{1}$ and $p h t^{2}$, parathyreoids; $t h$, median thyreoid; thy, thymus; I to $I V$, branchial grooves.- (Kohn.)

which they gradually undergo degeneration into a mass of fibrous and adipose tissue.

A pair of evaginations very similar to those that give rise to the thymus are also formed from the ventral portion of the fourth branchial groove (Figs. I79, $A$ and I8r, $l t h$ ). As a rule they completely disappear in later stages of development, but occasionally 
they undergo differentiation into small masses of thymus-like tissue, which remain associated with the parathyreoids from the same arch (Fig. I80, thm IV). They have been termed lateral thyreoids, but the term is a misnomer, since they take no essential part in the formation of the thyreoid body.

Finally, a pair of outgrowths arise from the floor of the pharynx just behind the fifth branchial arch, in the region where the fifth groove, if developed, would occur. These ultimo-branchial bodies, as they have been called, usually undergo degeneration at an early stage and disappear completely, though occasionally they persist as cystic structures embedded in the substance of the thyreoid.

The relation of these various structures to the branchial grooves is shown by the annexed diagram (Fig. I8I), and from it, it will be seen that the bodies derived from the third and fourth grooves are serially equivalent. Comparative embryology makes this fact still more evident, since, in the lower vertebrates, each branchial groove contributes to the formation of the thymus gland. The terminology used above for the various bodies is that generally applied to the mammalian organs, but it would be better, for the sake of comparison with other vertebrates, to adopt the nomenclature proposed by Groschuff, who terms each lateral thyreoid a thymus IV, while each thymus lobe is a thymus III. Similarly the parathyreoids are termed parathymus III and IV, the term thyreoid being limited to the median thyreoid.

The Musculature of the Pharynx.-The pharynx differs from other portions of the archenteron in the fact that its walls are furnished with voluntary muscles, the principal of which are the constrictors and the stylo-pharyngeus. This peculiarity arises from the relations of the pharynx to the branchial arches. It has been seen that in the higher mammalia the dorsal ends of the third, fourth, and fifth branchial cartilages disappear; the muscles originally associated with these structures persist, however, and give rise to the muscles of the pharynx, which consequently are innervated by the ninth and tenth nerves.

The Development of the Esophagus.-From the ventral side of the lower portion of the pharynx an evagination develops at an early stage which is destined to give rise to the organs of 
respiration; the development of this may, however, be conveniently postponed to a later chapter (Chapter XII).

The œesophagus is at first a very short portion of the archenteron (Fig. $182, A$ ), but as the heart and diaphragm recede into the thorax, it elongates (Fig. I82, B) until it eventually forms a considerable portion of the digestive tract. Its endodermal lining, like that of the rest of the digestive tract except the pharynx, is surrounded
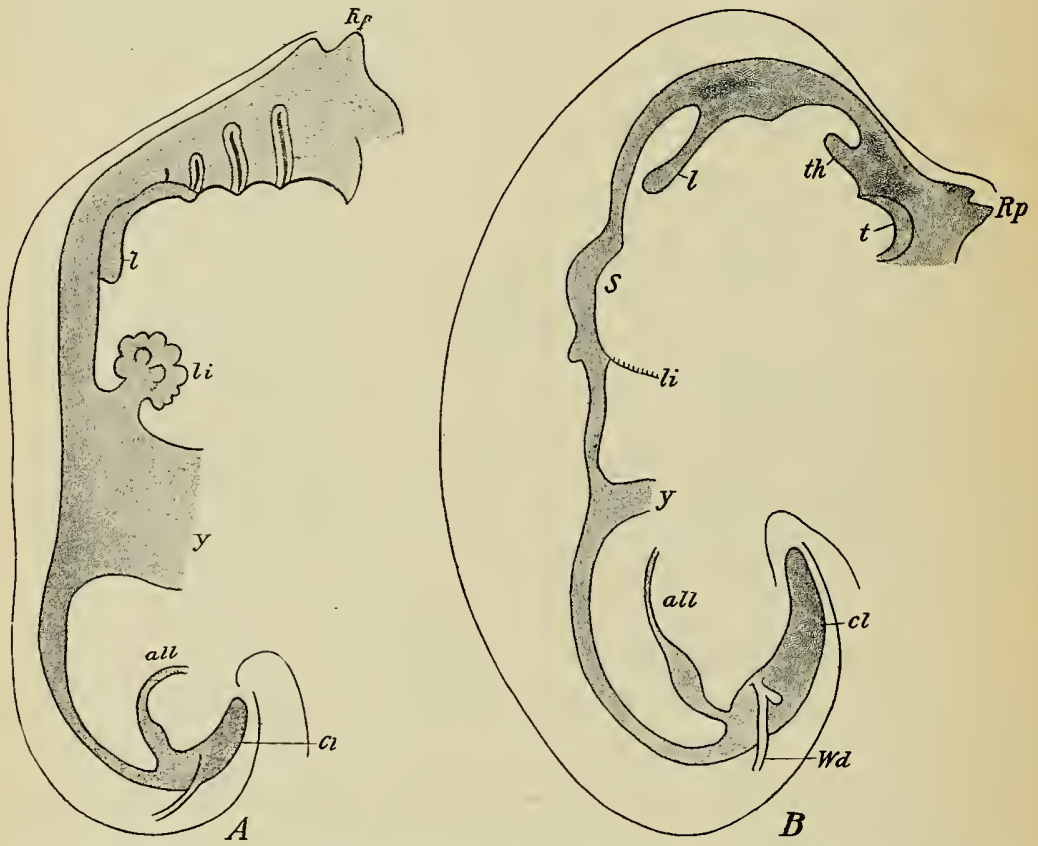

Fig. i82.-Reconstructions of the Digestive Tract of Embryos of $(A) 4.2 \mathrm{Mm}$. AND $(B) 5$ MM.

all, Allantois; $c l$, cloaca; $l$, lung; $l i$, liver; $R p$, Rathke's pouch; $S$, stomach; $t$, tongue; $t h$, thyreoid body; $W d$, Wolffian duct; $y$, yolk-stalk.-(His.)

by splanchnic mesoderm whose cells become converted into nonstriated muscular tissue, which, by the fourth month, has separated into an inner circular and an outer longitudinal layer.

The Development of the Stomach and Intestines.-By the time the embryo has reached a length of about $5 \mathrm{~mm}$. its constriction 
from the yolk-sac has proceeded so far that a portion of the digestive tract anterior to the yolk-sac can be recognized as the stomach and a portion posterior as the intestine. As first the stomach is a simple, spindle-shaped enlargement (Fig. I82) and the intestine a tube without any coils or bends, but since in later stages the intestine grows much more rapidly in length than the abdominal cavity, a coiling of the intestine becomes necessary.

The elongation of the stomach early produces changes in its position, its lower end bending over toward the right, while its upper end, owing to the development of the liver, is forced somewhat toward the left. At the same time the entire organ undergoes a rotation about its longitudinal axis through nearly ninety degrees, so that, as the result of the combination of these two changes, what was originally its ventral border becomes its lesser curvature and what was originally its left surface becomes its ventral surface.

Hence it is that the left vagus nerve passes over the ventral and the right over the dorsal surface of the stomach in the adult.

In the meantime the elongation of the œsophagus has carried the stomach further away from the lower end of the pharynx, and from being spindle-shaped it has become more pyriform, as in the adult. The fundus, it may be noted, is not due to a general enlargement of the organ but to a local outpouching of the upper dorsal portion of its wall.

The growth of the intestine results in its being thrown into a loop opposite the point where the yolk-stalk is still connected with it, the loop projecting ventrally into the portion of the cœlomic cavity which is contained within the umbilical cord, and being placed so that its upper limb lies to the right of the lower one. Upon the latter a slight pouch-like lateral outgrowth appears which is the beginning of the cacum and marks the line of union of the future small and large intestine. The small intestine, continuing to lengthen more rapidly than the large, assumes a sinuous course (Fig. I83), in which it is possible to recognize six primary coils which continue to be recognizable until advanced stages of development and even in the adult (Mall). The first of these is at first indistinguishable from the 
pyloric portion of the stomach and can be recognized as the duodenum only by the fact that it has connected with it the ducts of the liver and pancreas; as development proceeds, however, its caliber diminishes and it assumes the appearance of a portion of the intestine.

The remaining coils elongate rapidly and are thrown into numerous secondary coils, all of which are still contained within the

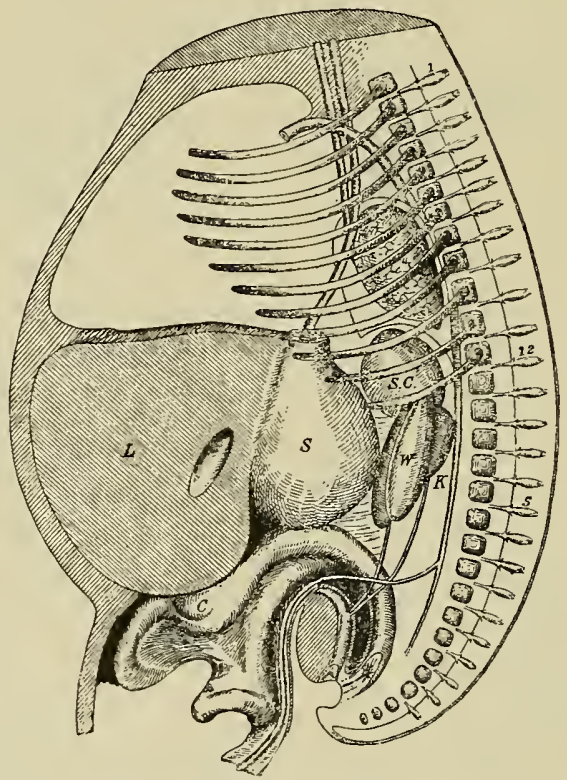

Fig. 183.-REConstruction of EMbryo of $20 \mathrm{MM}$.

$C$, Cæcum; K, kidney; $L$, liver; $S$, stomach; $S C$, suprarenal bodies; $W$, mesonephros.(Mall.)

cœlom of the umbilical cord (Fig. I84). When the embryo has reached a length of about $40 \mathrm{~mm}$. the coils rather suddenly return to the abdominal cavity, and now the cæcum is thrown over toward the right, so that it comes to lie immediately beneath the liver on the right side of the abdominal cavity, a position which it retains until about the fourth month after birth (Treves). The portion of the large intestine which formerly projected into the umbilical cœlom now 
lies transversely across the upper part of the abdomen, crossing in front of the duodenum and having the remaining portion of the small intestine below it. The elongation continuing, the secondary coils of the small intestine become more numerous and the lower portion of the large intestine is thrown into a loop which extends transversely across the lower part of the abdominal cavity and represents the sigmoid flexure of the colon. At the time of birth this portion of the large intestine is relatively much longer than in the adult, amounting to nearly half the entire length of the colon (Treves), but after the fourth month after birth a readjustment of the relative

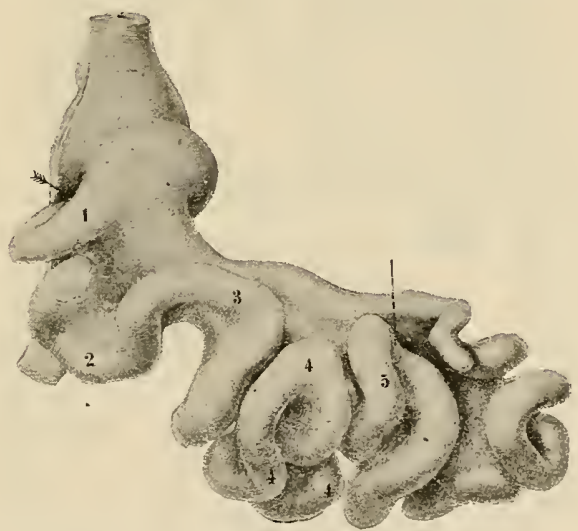

Fig. 184.-Reconstruction of the Intestine of an Embryo of ig mas. The Figures on the InTestine Indicate the Primary CoIls.-(Mall.)

lengths of the parts of the colon occurs, the sigmoid flexure becoming shorter and the rest of the colon proportionally longer, whereby the cæcum is pushed downward until it lies in the right iliac fossa, the ascending colon being thus established.

When this condition has been reached, the duodenum, after passing downward for a short distance so as to pass dorsally to the transverse colon, bends toward the left and the secondary coils derived from the second and third primary coils come to occupy the left upper portion of the abdominal cavity. Those from the fourth primary coil pass across the middle line and occupy the right 
upper part of the abdomen, those from the fifth cross back again to the left lumbar and iliac regions, and those of the sixth take possession of the false pelvis and the right iliac region (Fig. I85).

Slight variations from this arrangement are not infrequent, but it occurs with sufficient frequency to be regarded as the normal. A failure

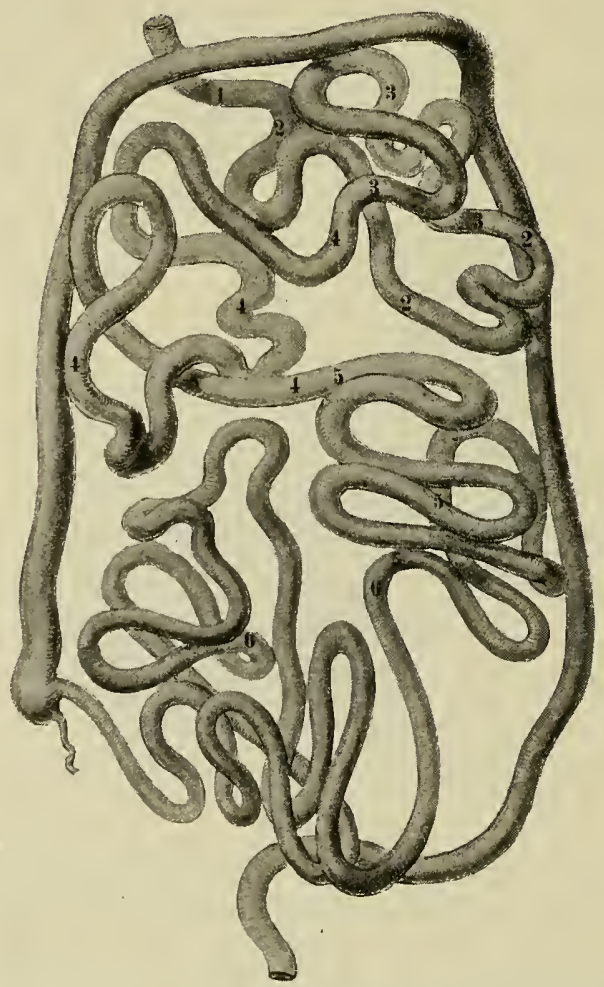

Fig. I85.-Representation of the Coilings of the Intestine in the Adult Condition. The Numbers indicate the Primary Coils.-(Mall.)

in the readjustment of the relative lengths of the different parts of the colon may also occasionally occur, in which case the cæcum will retain its embryonic position beneath the liver.

The yolk-stalk is continuous with the intestine at the extremity of the loop which extends out into the umbilical cnelom, and when the 
primary coils become apparent its point of attachment lies in the region of the sixth coil. As a rule, the caliber of the stalk does not increase proportionally with that of the intestine, and eventually its embryomic portion disappears completely. Occasionally, however, this portion of it does partake of the increase in size which occurs in the intestine, and it forms a blind pouch of varying length, known as Meckel's diverticulum (see p. II3).

The cacum has been seen to arise as a lateral outgrowth at a time when the intestine is first drawn out into the umbilicus. During subsequent development it continues to increase in size until it forms a conical pouch arising from the colon just where it is joined by the small intestine (Fig. I86). The enlargement of its terminal portion does not keep pace, however, with that of the portion nearest the intestine, but it becomes gradually more and more marked off from it by its lesser caliber and gives rise to the vermiform appendix. At birth the original conical form of the entire outgrowth is still quite evident, though it is more properly described as funnel-

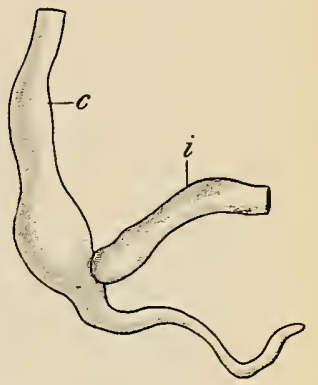

Fig. I86.-C EMBRYO OF IO.2 CM.

$c$, Colon; $i$, ileum. shaped, but later the proximal part, continuing to increase in diameter at the same rate as the colon, becomes sharply separated from the appendix, forming the cæcum of adult anatomy.

Up to the time when the embryo has reached a length of $\mathrm{I} 4 \mathrm{~mm}$., the inner surface of the intestine is quite smooth, but when a length of $\mathrm{I} 9 \mathrm{~mm}$. has been reached, the mucous membrane of the upper portion becomes thrown into longitudinal folds, and later these make their appearance throughout its entire length (Fig. I87). Later, in embryos of $60 \mathrm{~mm}$., these folds break up into numbers of conical processes, the villi, which increase in number with the development of the intestine, the new villi appearing in the intervals between those already present. Villi are formed as well in the large as in the small intestine, but in the former they decrease in size as development proceeds and practically disappear toward the end of fetal life. 
In the early stages the endodermal lining of the digestive tract assumes a considerable thickness, the lumen of the œsophagus and upper part of the small intestine being reduced to a very small caliber. In later stages a rapid increase in the size of the lumen occurs, apparently associated with the formation of cavities or vacuoles in the endodermal epithelium. These increase in size, the neighboring cells arrange themselves in an epithelial layer around their walls and they eventually break through into the general lumen. They are sometimes sufficiently large to give the appearance of diverticula of the gut, but later they flatten out, their cavities becoming portions of the general lumen.

In the case of the duodenum the thickening of the endodermal lining proceeds to such an extent that in embryos of from $12.5 \mathrm{~mm}$. to I $4.5 \mathrm{~mm}$. the lumen is completely obliterated immediately below the opening of the hepatic and pancreatic ducts. This condition is interesting in connection with the occasional occurrence in new-born children of an atresia of the duodenum. Under normal conditions, however, the lumen is restored by the process of vacuolization described above.

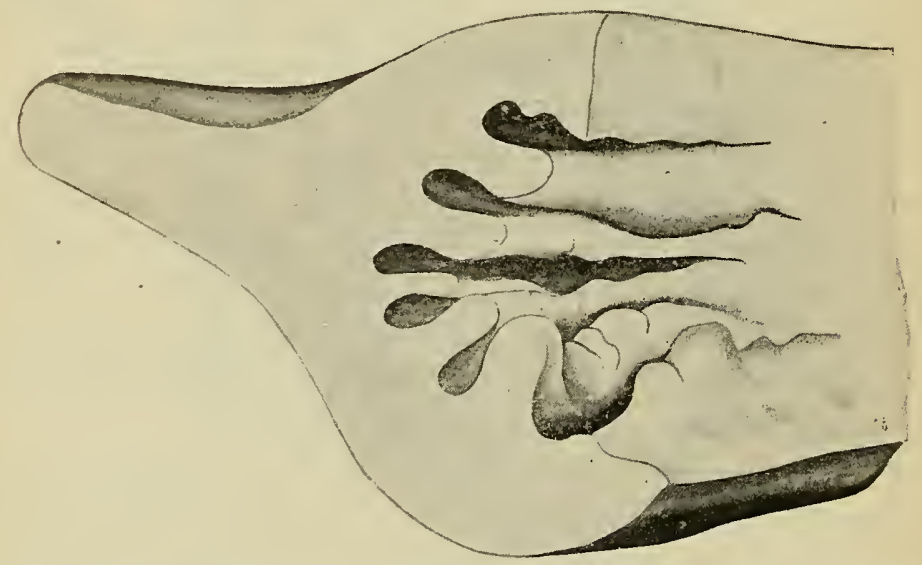

Fig. i87.-Reconstruction of a Portion of the Intestine of an Embryo of 28 MM. SHOWING THE LONGITUDINAL FoLDS FROM WHICH THE VILli ARE FORMED.(Berry.)

The Development of the Liver.-The liver makes its appearance in embryos of about $3 \mathrm{~mm}$. as a longitudinal groove upon the ventral surface of the archenteron just below the stomach and between it and the umbilicus. The endodermal cells lining the anterior portion of the groove early undergo a rapid proliferation, and form a solid mass which projects ventrally into the substance 
of a horizontal shelf, the septum transversum (see p. 3I8), attached to the ventral wall of the body. This solid mass (Fig. I88, L) forms the beginning of the liver proper, while the lower portion of the groove, which remains hollow, represents the future gall-bladder (Fig. I88, B). Constrictions appearing between the intestine and both the hepatic and cystic portions of the organ gradually separate these from the intestine, until they are united to it only by a stalk which represents the ductus choledochus (Fig. I88).

The further development of the liver, so far as its external

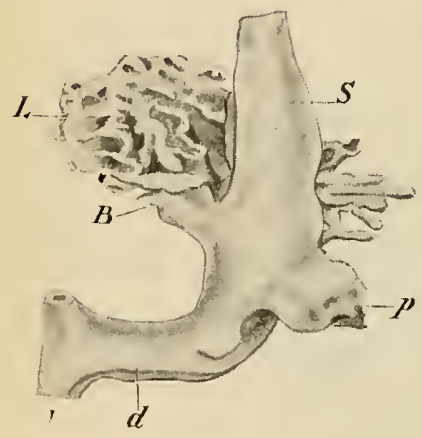

A

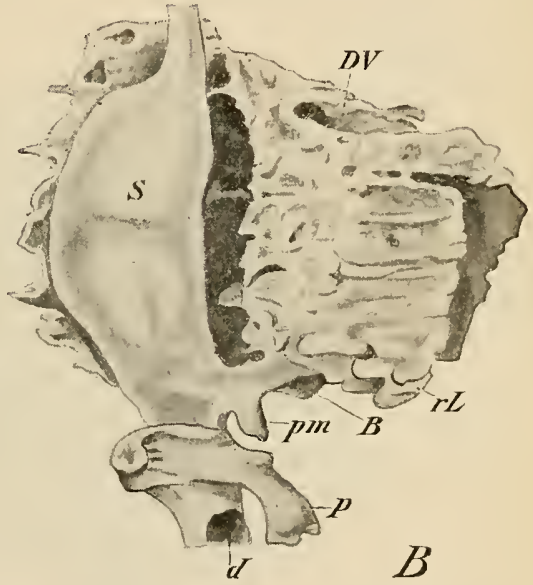

Fig. I88.-Reconstruction of the Liver OUtgrowtHS OF Rabitt Embryos of (A) 5 MM. AND $(B)$ OF $8 \mathrm{MM}$.

$B$, Gall-bladder; $d$, duodenum; $D V$, ductus venosus; $L$, liver; $p$, dorsal pancreas; $p m$, ventral pancreas; $r L$, right lobe of the liver; $S$, stomach.-(Hammar.)

form is concerned, consists in the rapid enlargement of the hepatic portion until it occupies the greater part of the upper half of the abdominal cavity, its ventral edge extending as far down as the umbilicus. In the rabbit its substance becomes divided into four lobes corresponding to the four veins, umbilical and vitelline, which traverse it, and the same condition occurs in the human embryo, although the lobes are not so clearly indicated upon the surface as in the rabbit. The two vitelline lobes are in close apposition and may 
almost be regarded as one, a median ventral lobe which embraces the ductus venosus (Fig. I88, B, DV), while the umbilical lobes are more lateral and dorsal and represent the right $(r L)$ and left lobes of the adult liver. The remaining definite lobes, the caudate (Spigelian) and quadrate, are of later formation, standing in relation to the vessels which cross the lower surface of the liver.

The ductus choledochus is at first wide and short, and near its proximal end gives rise to a small outgrowth on each side, one of which becomes the ventral pancreas (Fig. I88, B, pm). Later the duct elongates and becomes more slender, and the gall-bladder is

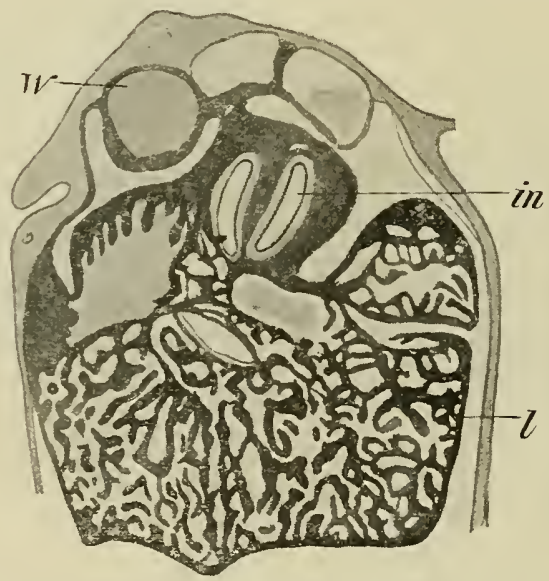

Fig. i89.-Transverse Section through the Liver of an Embryo of Four MoNTHS.

in, Intestine; $l$, liver; $W$, Wolffian body.-(Toldt and Zuckerkandl.)

constricted off from it, the connecting stalk becoming the cystic duct. The hepatic ducts are apparently developed from the liver substance and are relatively late in appearing.

Shortly after the hepatic portion has been differentiated its substance becomes permeated by numerous blood-vessels (sinusoids) and so divided into anastomosing trabeculæ (Fig. I89). These are at first irregular in size and shape, but later they become more slender and more regularly cylindrical, forming what have been termed the 
hepatic cylinders. In the center of each cylinder, where the cells which form it meet together, a fine canal appears, the beginning of a bile capillary, the cylinders thus becoming converted into tubes with fine lumina. This occurs at about the fourth week of development and at this time a cross-section of a cylinder shows it to be composed of about three or four hepatic cells (Fig. Igo, A), among which are to be seen groups of smaller cells $(e)$ which are erythrocytes, the liver having assumed by this time its hæmatopoietic function (see p. 225). This condition of affairs persists until birth, but

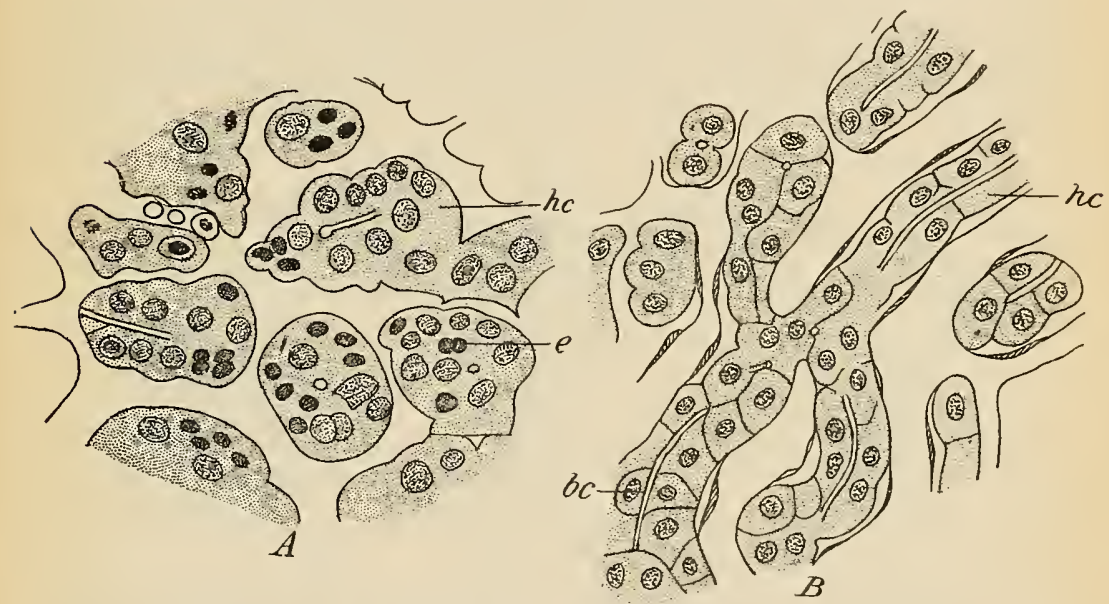

Fig. igo.-Transverse Sections of Portions of the Liver of $(A)$ a Fetus of Six Months AND $(B)$ a CHIld of Four Years.

$b c$, Bile capillary; $e$, erythrocyte; $h c$, hepatic cylinder.-(Toldt and Zuckerkandl.)

later the cylinders undergo an elongation, the cells of which they are composed slipping over one another apparently, so that the cylinders become thinner as well as longer and show for the most part only two cells in a transverse section (Fig. I9o, B); and in still later periods the two cells, instead of lying opposite one another, may alternate, so that the cylinders become even more slender.

The bile capillaries seem to make their appearance first in cylinders which lie in close relation to branches of the portal vein (Fig. IgI), 
and thence extend throughout the neighboring cylinders, anastomosing with capillaries developing in relation to neighboring portal branches. As the extension so proceeds the older capillaries continue to enlarge and later become transformed into bile-ducts (Fig. I9I, C), the cells of the cylinders in which these capillaries were situated becoming converted into the epithelial lining of the ducts.

The lobules, which form so characteristic a feature of the adult liver, are late in appearing, not being fully developed until some time after birth. They depend upon the relative arrangement of the branches of the portal and hepatic veins; these at first occupy distinct territories of the liver substance, being separated from one another by practically the entire thickness of the liver, although of
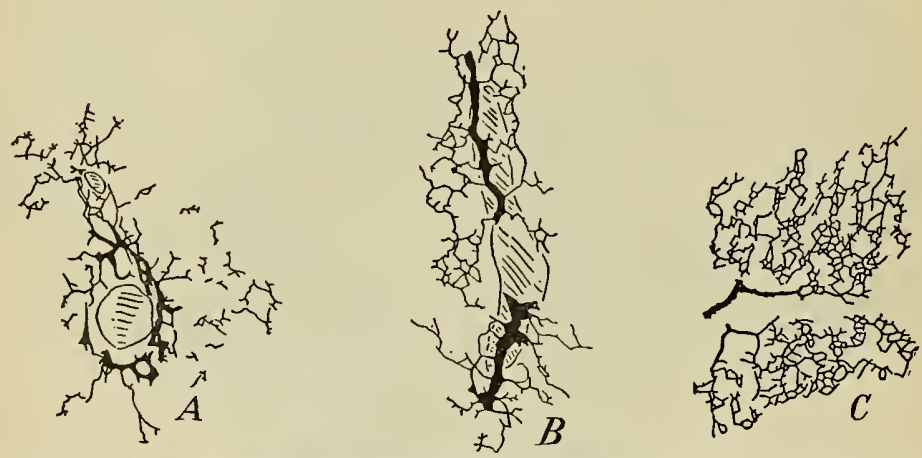

Fig. igi.-Injected Bile Capillaries of Pig Embryos of $(A) 8$ CM., $(B)$ i6 CM., AND (C) of Adult Pig.-(Hendrickson.)

course connected by the sinusoidal capillaries which lie between the hepatic cylinders. During development the two sets of branches extend more deeply into the liver substance, each invading the territory of the other, but they can readily be distinguished from one another by the fact that the portal branches are enclosed within a sheath of connective tissue (Glisson's capsule) which is lacking to the hepatic vessels. At about the time of birth the branches of the hepatic veins give off at intervals bunches of terminal vessels, around which branches of the portal vein arrange themselves, the liver tissue becoming divided up into a number of areas which may be termed 
hepatic islands, each of which is surrounded by a number of portal branches and contains numerous dichotomously branching hepatic terminals. Later the portal branches sink into the substance of the islands, which thus become lobed, and finally the sinking in extends so far that the original island becomes separated into a number of smaller areas or lobules, each containing, as a rule, a single hepatic terminal (the intralobular vein) and being surrounded by a number of portal terminals (interlobular veins), the two systems being united by the capillaries which separate the cylinders contained within the area. The lobules are at first very small, but later they increase in size by the extension of the hepatic cylinders.

Frequently in the human liver lobules are to be found containing two intralobular veins, a condition with results from an imperfect subdivision of a lobe of the original hepatic island.

The liver early assumes a relatively large size, its weight at one time being equal to that of the rest of the body, and though in later embryonic stages its relative size diminishes, yet at birth it is still a voluminous organ, occupying the greater portion of the upper half of the abdominal cavity and extending far over into the left hypochondrium. Just after birth there is, however, a cessation of growth, and the subsequent increase proceeds at a much slower rate than that of the rest of the body, so that its relative size bcomes still more diminished (see Chap. XVII). The cessation of growth affects principally the left lobe and is accompanied by an actual degeneration of portions of the liver tissue, the cells disappearing completely, while the ducts and blood-vessels originally present persist, the former constituting the vasa aberrantia of adult anatomy. These are usually especially noticeable at the left edge of the liver, between the folds of the left lateral ligament, but they may also be found along the line of the vena cava, around the gall-bladder, and in the region of the left longitudinal fissure.

The Development of the Pancreas.-The pancreas arises a little later than the liver, as two or three separate outgrowths, one from the dorsal surface of the duodenum (Fig. I92, $D P$ ) usually a little above the liver outgrowth, and one or two from the lower part 
of the common bile-duct. Of the latter outgrowths, that upon the left side $(V p s)$ may be wanting and, if formed, early disappears, while that of the right side $(V p d)$ continues its development to form what has been termed the ventral pancreas. Both this and the dorsal pancreas continue to elongate, the latter lying to the left of

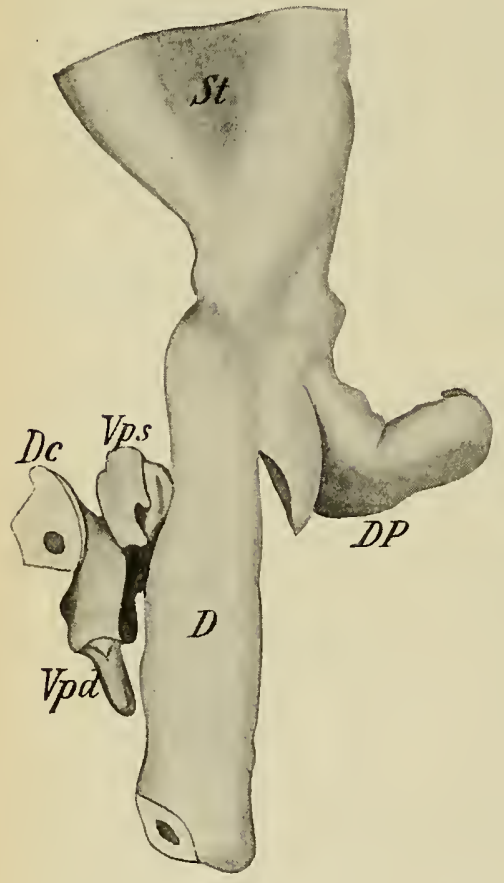

Fig. ig2.-Reconstruction OF THE Pancreatic OUTGROWTHS OF AN EMbryo OF $7.5 \mathrm{MM}$.

$D$, Duodenum; $D c$, ductus communis choledochus; $D P$, dorsal pancreas; $V p d$, and $V p s$, right and left ventral pancreas. - (Helly.) the portal vein, while the former, at first situated to the right of the vein, later grows across its ventral surface so as to come into contact with the dorsal gland, with which it fuses so intimately that no separation line can be distinguished. The body and tail of the adult pancreas represent the original dorsal outgrowth, while the right ventral pancreas becomes the head.

Both the dorsal and ventral outgrowths early become lobed, and the lobes becoming secondarily lobed and this lobation repeating itself several times, the compound tubular structure of the adult gland is acquired, the very numerous terminal lobules becoming the secreting acini, while the remaining portions become the ducts. Of the principal ducts, there are at first two; that of the dorsal pancreas, the duct of Santorini, opens into the duodenum on its dorsal surface, while that of the ventral outgrowth, the duct of Wirsung, opens into the ductus choledochus. When the fusion of the two portions of the gland occurs, an anastomosis of branches of the two ducts develops and the proximal portion of the duct of Santorini may 
degenerate, so that the secretion of the entire gland empties into the common bile-duct through the duct of Wirsung.

In the connective tissue which separates the lobules of the gland, groups of cells occur, which have no connection with the ducts of the gland, and form what are termed the areas of Langerhans. They arise by a differentiation of the cells which form the original pancreatic outgrowths, and have been distinguished in the dorsal pancreas of the guinea-pig while it is still a solid outgrowth. They gradually separate from the remaining cells of the outgrowth and come to lie in the mesenchyme of the gland in groups into which, finally, bloodvessels penetrate.

\section{LITERATURE.}

E. T. BELl: "The Development of the Thymus," Amer. Journ. of Anat., v, rgo6.

J. M. Berry: "On the Development of the Villi of the Human Intestine," Anat. Anzeiger, xVI, Igoo.

L. BoLK: "Die Entwicklungsgeschichte der menschlichen Lippen," Anat. Hefte. XLIV, x908.

L. Bolk: "Ueber die Gaumenentwicklung und die Bedeutung der oberen Zahnleiste beim Menschen," Zeit. für Morphol. und Anthropol., xIv, I9Ir.

J. BRACHET: "Recherches sur le développement du pancréas et du foie," Journ. de l'Anat. et de la Physiol., xxxir, r896.

O. C. Bradley: "A Contribution to the Morphology and Development of the Mammalian Liver," Journ. Anat. and Physiol., XLII, I908.

H. M. DE BURLET: "Die äusseren Formverhaltnisse der Leber beim menschlichen Embryo," Morphol. Jahrb., xLII, I9Io.

R. V. ChÁmberlin: "On the Mode of Disappearance of the Villi from the Colon of Mammals," Anat. Record. IIr, rgog.

J. H. CHIEvitz: "Beiträge zur Entwicklungsgeschichte der Speicheldrüsen," Archiv für Anat. und Physiol.,Anat. Abth., I885.

H. Fox: "The Pharyngeal Pouches and Their Derivatives in the Mammalia," Amer. Journ. Anat., vIIr, I908.

K. GROSCHUFF: "Ueber das Vorkommen eines Thymussegmentes der vierten Kiementasche beim Menschen," Anat. Anzeiger, xvII, I9oo.

O. Grosser: "Zur Kenntnis des ultimobranchialeı Körpers beim Menschen," Anat. Anzeiger, XxxvII, rgro.

L. GRÜNWALD: "Ein Beitrag zur Entstehung und Bedeutung der Gaumenmandeln," Anat. Anzeiger, xxxvir, I9io.

J. A. Hammar: "Einige Plattenmodelle zur Beleuchtung der früheren embryonal Leberentwicklung," Arch.f. Anat. und Phys., Anat. Abth., $\mathrm{x} 893$. 
J. A. Hammar: "Notiz über die Entwicklung der Zunge und der Mundspeicheldrüsen beim Menschen," Anat. Anzeiger, xIx, Igor.

J. A. Hammar: "Studien über die Entwicklung des Vorderdarms und einiger angrenzender Organe," Arch.f. mikrosk. Anat., LIX and LX, IgO2.

K. Helly: "Zur Entwickelungsgeschichte der Pancreasanlagen und Duodenalpapillen des Menschen," Archiv für mikrosk. Anat., LVI, Igoo.

K. Helly: "Studien über Langerhanssche Inseln," Arch. für mikrosk. Anat., LXVII, I907.

W. F. HENDrickson: "The Development of the Bile-capillaries as revealed by Golgi's Method," Johns Hopkins Hospital Bulletin, 1898.

W. HIs: "Anatomie menschlicher Embryonen," Leipzig, I882-1886.

F. Hochstetter: "Ueber die Bildung der primitiven Choanen beim Menschen," Anat. Anzeiger, viI, I892.

N. W. InGalLs: "A Contribution to the Embryology of the Liver and Vascular System in Man," Anat. Record, II, I908.

C. M. JACKSON: "On the Development and Topography of the Thoracic and Abdominal Viscera," Anat. Record, III, Igog.

F. P. JoHnson: "The Development of the Mucous Membrane of the Esophagus, Stomach and Small Intestine in the Human Embryo," Amer. Journ. Anat., x, I9I0.

E. Kallıus: "Beiträge zur Entwicklung der Zunge, 3te Th. Säugetiere. I. Sus scrofa," Anat. Hefte, XLI, I9Io.

F. KeIBEL: "Zur Entwickelungsgeschichte des menschlichen Urogenital-apparatus," Archiv für Anat. und Physiol., Anat. Abth., 1896.

G. Killian: "Ueber die Bursa und Tonsilla pharyngea," Morphol. Jahrbuch, xIv, I888.

A. KоHN: "Die Epithelkörperchen," Ergebnisse der Anat. und Entwicklungsgesch., Ix, I899.

H. KUSTER: "Zur Entwicklungsgeschichte der Langerhans'schen Inseln im Pancreas beim menschlichen Embryo," Arch. für mikrosk., Anat., LxIv, I904.

F. T. Lewis And F. W. Thyng: "The Regular Occurrence of Intestinal Diverticula in Embryos of the Pig, Rabbit and Man," Amer. Journ. Anat., VII, I go8.

F. P. MaLl: "Ueber die Entwickelung des menschlichen Darmes und seiner Lage beim Erwachsenen," Archiv für Anat. und Physiol., Anat. Abth., Supplement, I897.

F. P. MALL: "A Study of the Structural Unit of the Liver," Amer. Journ. of Anat., v, Ig06.

R. MAYER: "Ueber die Bildung des Recessus pharyngeus medius s. Bursa pharyngis in zusammenhang mit der Chorda bei menschlichen Embryonen," Anat. Anzeiger, XXXVII, I910.

J. F. MECKeL: "Bildungsgeschichte des Darmkanals der Säugethiere und namentlich des Menschen," Archiv für Anat. und Physiol., III, I8I7.

T. Mrronescu: "Ueber die Entwicklung der Langerhans' schen Inseln bei menschlichen Embryonen," Arch. für mikrosk. Anat., LXxvI, IgII.

W. J. OTIs: "Die Morphogenese und Histogenese des Analhöckers nebst Bemerkungen über die Entwicklung der Sphincter ani externus beim Menschen," Anat. Hefte, $\mathrm{xxx}, \mathrm{1906.}$ 
R. M. Pearce: "The Development of the Islands of Langerhans in the Human Embryo," A mer. Journ. of Anat., II, I902.

C. Róse: "Ueber die Entwicklung der Zähne des Menschen," Archiv für mikrosk. Anat., xxxviII, r89I.

G. SCHORR: "Zur Entwickelungsgeschichte des secundären Gaumens," Anat. Hefte, XXXVI, I908.

G. SCHORR: "Ueber Wolfsrachen von Standpunkt der Embryologie und pathologischen Anatomie," Arch. für patholog. Anat., cxcvir, I909.

A. SWAEn: "Recherches sur le dévelopement du foie, du tube digestif, de l'arrièrecavité du peritoine et du mésentère," Journ. de l'Anat. et de la Physiol., xxxII, I896, and XxxiII, 1897 .

J. TANDLER: "Zur Entwickelungsgeschichte des menschlichen Duodenum in frühen Embryonalstadien," Morphol. Jahrbuch, xxIx, Igoo.

P. Trompson: "A Note on the Development of the Septum Transversum and the Liver," Journ. Anat. and Phys., XLII, 1908.

F. W. Thyng: "Models of the Pancreas in Embryos of the Pig, Rabbit, Cat and Man," Amer, Journ. Anat., viI, Igo8.

C. Toldt and E. ZuckerkandL: "Ueber die Form und Texturveränderungen der menschlichen Leber während des Wachsthums," Sitzungsber. der kais. Akad. Wissensch. Wien., Math.-Naturwiss. Classe, LxxIr, 1875 .

F. Tourneux AND P. Verdun: "Sur les premiers développements de la Thyroide, du Thymus et des glandes parathyroidiennes chez l'homme," Journ. de l'Anat. et de la Physiol., xxxiIr, 1897 .

F. Treves: "Lectures on the Anatomy of the Intestinal Canal and Peritoneum in Man," British Medical Journal, I, 1885. 


\section{CHAPTER XI}

\section{THE DEVELOPMENT OF THE PERICARDIUM, THE PLEURO-PERITONEUM AND THE DIAPHRAGM.}

It has been seen (p. 229) that the heart makes its appearance at a stage when the greater portion of the ventral surface of the intestine is still open to the yolk-sac. 'The ventral mesoderm splits to form the somatic and splanchnic layers and the heart develops as a fold in the latter on each side of the median line, projecting into the cœlomic cavity enclosed by the two layers (Fig. $136, A$ ). As the constriction of the anterior part of the embryo proceeds the two heart folds are brought nearer together and later meet, so that the heart becomes a cylindrical structure lying in the median line of the body and is suspended in the cœlom by a ventral band, the ventral mesocardium, composed of two layers of splanchnic mesoderm which extend to it from the ventral wall of the body, and by a similar band, the dorsal mesocardium, which unites it with the splanchnic mesoderm surrounding the digestive tract. The ventral mesocardium soon disappears (Fig. ${ }_{3} 6 C$ ) and the dorsal one also vanishes somewhat later, so that the heart comes to lie freely in the cœlomic cavity, except for the connections which it makes with the body-walls by the vessels which enter and arise from it.

The colomic cavity of the embryo does not at first communicate with the extra-embryonic coelom, which is formed at a very early period (see p. 67), but later when the splitting of the embryonic mesoderm takes place the two cavities become continuous behind the heart, but not anteriorly, since the ventral wall of the body is formed in the heart region before the union can take place. It is possible, therefore, to recognize two portions in the embryonic cœlom, an anterior one, the parietal cavity (His), which is never connected laterally with the extra-embryonic cavity, and a posterior one, the trunk cavity, which is so connected. The heart is situated 
in the parietal cavity, a considerable portion of which is destined to become the pericardial cavity.

Since the parietal cavity lies immediately anterior to the still wide yolk-stalk, as may be seen from the position of the heart in the embryo shown in Fig. 53, it is bounded posteriorly by the yolkstalk. This boundary is complete, however, only in the median line, the cavity being continuous on either side of the yolkstalk with the trunk-cavity by passages which have been termed the recessus parietales (Fig. I93, $B p$ and Rca). Passing forward toward the heart in the splanchnic mesoderm which surrounds the yolkstalk are the large vitelline veins, one on either side, and these shortly become so large as to bring the splanchnic mesoderm in which they lie in contact with the somatic mesoderm which forms the lateral wall of each recess. Fusion of the two layers of mesoderm along the course of the veins now takes place, and each recess thus becomes divided into two parallel passages, which have been termed the dorsal (Fig. I94, rpd) and ventral $(r p v)$ parietal recesses. Later the two veins fuse in the upper portion of their course to form the be-

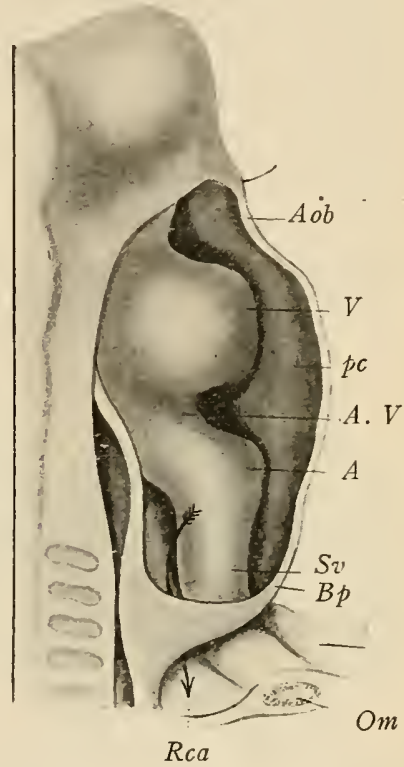

Fig. I93.-Reconstruction of a Rabbit EMbryo of Eight Days, With the Pericardal Cavity Laid Open.

$A$, Auricle; $A o b$, aortic bulb; $A . V$, a trio-ventricular communication; $B p$, ventral parietal recess; $O m$, vitelline vein; $P c$, pericardial cavity; Rca, dorsal parietal recess; $S v$, sinus venosus; $V$, ventricle.-(His.)

ginning of the sinus venosus, with the result that the ventral recesses become closed below and their continuity with the trunkcavity is interrupted, so that they form two blind pouches extending downward a short distance from the ventral portion of the floor of the parietal cavity. The dorsal recesses, however, retain their continuity with the trunk-cavity until a much later period. 
By the fusion of the vitelline veins mentioned above, there is formed a thick semilunar fold which projects horizontally into the cœlom from the ventral wall of the body and forms the floor of the ventral part of the parietal recess. This is known as the septum transversum, and besides containing the anterior portions of the vitelline veins, it also furnishes a passage by which the ductus Cuvieri, formed by the union of the jugular and cardinal veins, reach the heart. Its dorsal edge is continuous in the median line with the mesoderm surrounding the digestive tract just opposite the region where the liver outgrowth will form, but laterally this edge is free and forms the ventral walls of the dorsal parietal recess. An idea of the relations of the septum at this stage may be obtained
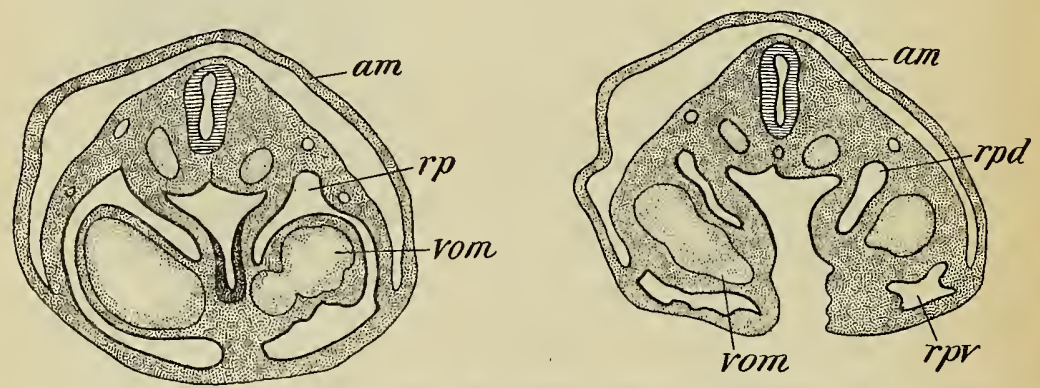

Fig. I94--Transverse Sections of a Rabbit Embryo SHowing the Division of the Parietal Recesses by the Vitelline Veins.

$a m$, Amnion; $r p$, parietal recess; $r p d$ and $r p v$, dorsal and ventral divisions of the parietal recess; vom, vitelline vein.-(Ravn.)

from Fig I95, which represents the anterior surface of the septum, together with the related parts, in a rabbit embryo of nine days.

The Separation of the Pericardial Cavity.-The septum transversum is at first almost horizontal, but later it becomes decidedly oblique in position, a change associated with the backward movement of the heart. As the closure of the ventral wall of the body extends posteriorly the ventral edge of the septum gradually slips downward upon it, while the dorsal edge is held in its former position by its attachment to the wall of the digestive tract and the ductus Cuvieri. The anterior surface of the septum thus comes to 
look ventrally as well as forward, and the parietal cavity, having taken up into itself the blind pouches which represented the ventral recesses, comes to lie to a large extent ventral to the posterior recesses. As may be seen from Fig. I95, the ductus Cuvieri, as they bend from the lateral walls of the body into the free edges of the septum, form a marked projection which diminishes considerably the opening of the dorsal recesses into the parietal cavity. In later stages

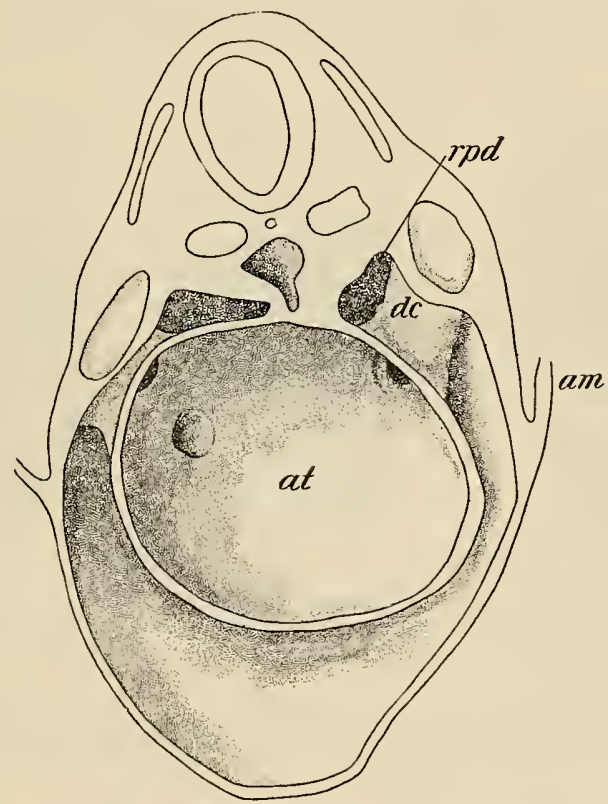

Fig. i95.-Reconstruction from a Rabbit Embryo of Nine Days Showing the Septum Transversum From Above.

$a m$, Amnion; at, atrium; $d c$, ductus Cuvieri; $r p d$, dorsal parietal recess.-(Ravn.)

this projection increases and from its dorsal edge a fold, which may be regarded as a continuation of the free edge of the septum, projects into the upper portions of the recesses and eventually fuses with the median portion of the septum attached to the wall of the gut. In this way the parietal cavity becomes a completely closed sac, and is henceforward known as the pericardial cavity, the original cœlom 
being now divided into two portions, (I) the pericardial, and (2) the pleuro-peritoneal cavities, the latter consisting of the abdominal cœlom together with the two dorsal parietal recesses which have been separated from the pericardial (parietal) cavity and are destined to be converted into the pleural cavities.

The Formation of the Diaphragm. - It is to be remembered that the attachment of the transverse septum to the ventral wall of the digestive tract is opposite the point where the liver outgrowth develops. When, therefore, the outgrowth appears, it pushes its
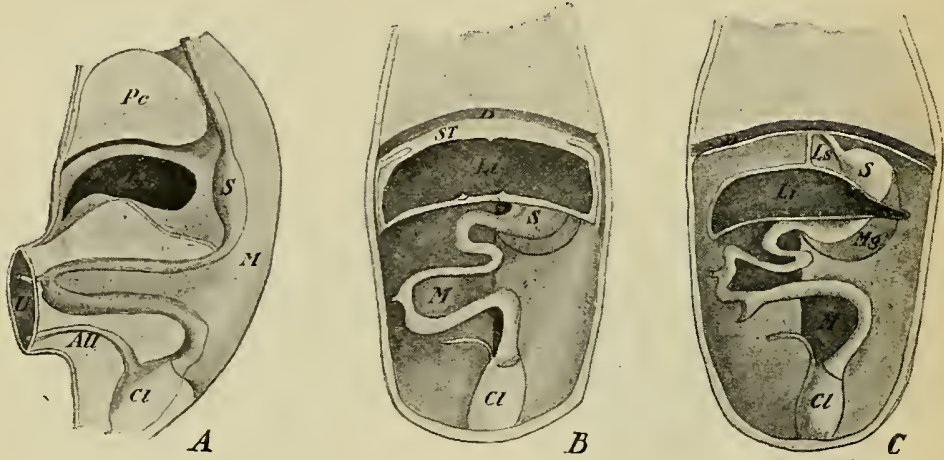

Fig. ig6,-Diagrams of $(A)$ a Sagittal Section of an Embryo showing the Liver Enclosed within the Septum Transversum; (B) a Frontal Section of the Same; $(C)$ a Frontal Section of a Later Stage when the Liver has Separated FROM THE DIAPHRAGM.

$A l l$, Allantois; $C l$, cloaca; $D$, diaphragm; $L i$, liver; $L s$, falciform ligament of the liver; $M$, mesentery; $M g$, mesogastrium; $P C$, pericardium; $S$, stomach; $S T$, septum transversum; $U$, umbilicus.

way into the substance of the septum, which thus acquires a very considerable thickness, especially toward its dorsal edge, and it furthermore becomes differentiated into two layers, an upper one, which forms the floor of the ventral portion of the pericardial cavity and encloses the Cuvierian ducts, and a lower one which contains the liver. The upper layer is comparatively thin, while the lower forms the greater part of the thickness of the septum, its posterior surface meeting the ventral wall of the abdomen at the level of the anterior margin of the umbilicus (Fig. I96, A). 
In later stages of development the layer containing the liver becomes separated from the upper layer by two grooves which, appearing at the sides and ventrally immediately over the liver (Fig. 196, B), gradually deepen toward the median line and dorsally. These grooves do not, however, quite reach the median line, a portion of the lower layer of the septum being left in this region as a fold, situated in the sagittal plane of the body and attached above to the posterior surface of the upper layer and below to the anterior surface of the liver, beyond which it is continued down the ventral wall of the abdomen to the umbilicus (Fig. 196, C,Ls). This is the falciform ligament of the liver of adult anatomy, and in the free edge of its prolongation down the ventral wall of the abdomen the umbilical vein passes to the under surface of the liver, while the free edge of that portion which lies between the liver and the digestive tract contains the vitelline (portal) vein, the common bile-duct, and the hepatic artery. The diagram given in Fig. 196 will, it is hoped, make clear the mode of formation and the relation of this fold, which, in its entirety, constitutes what is sometimes termed the ventral mesentery.

And not only do the grooves fail to unite in the median line, but they also fail to completely separate the liver from the upper layer of the septum dorsally, the portion of the lower layer which persists in this region forming the coronary ligament of the liver. The portion of the lower layer which forms the roof of the grooves becomes the layer of peritoneum covering the posterior surface of the upper layer (which represents the diaphragm), while the portion which remains connected with the liver constitutes its peritoneal investment.

In the meantime changes have been taking place in the upper layer of the septum. As the rotation of the heart occurs, so that its atrial portion comes to lie anterior to the ventricle, the Cuvierian ducts are drawn away from the septum and penetrate the posterior wall of the pericardium, the separation being assisted by the continued descent of the attachment of the edge of the septum to the ventral wall of the body. During the descent, when the upper 
layer of the septum has reached the level of the fourth cervical segment, portions of the myotomes of that segment become prolonged into it and the layer assumes the characteristics of the diaphragm, the supply of whose musculature from the fourth cervical nerves is thus explained.

The Pleura. - The diaphragm is as yet, however, incomplete dorsally, where the dorsal parietal recesses are still in continuity with the trunk-cavity. With the increase in thickness of the septum transversum, these recesses have acquired a considerable length antero-posteriorly, and into their upper portions the outgrowths from the lower part of the pharynx which form the lungs (see page 33I) begin to project. The recesses thus become transformed into the pleural cavities, and as the diaphragm continues to descend, slipping down the ventral wall of the body and drawing with it the pericardial cavity, the latter comes to lie entirely ventral to the pleural cavities. The free borders of the diaphragm, which now form the ventral boundaries of the openings by which the pleural and peritoneal cavities communicate, begin to approach the dorsal wall of the body, with which they finally unite and so complete the separation of the cavities. The pleural cavities continue to enlarge after their separation and, extending laterally, pass between the pericardium and the lateral walls of the body until they finally almost completely surround the pericardium. The intervals between the two pleuræ form what are termed the mediastina.

The downward movement of the septum transversum extends through a very considerable interval, which may be appreciated from the diagram shown in Fig. I97. From this it may be seen that in early embryos the septum is situated just in front of the first cervical segment and that it lies very obliquely, its free edge being decidedly posterior to its ventral attachment. When the downward displacement occurs, the ventral edge at first moves more rapidly than the dorsal, and soon comes to lie at a much lower level. The backward movement continues throughout the entire length of the cervical and thoracic regions, and when the level of the tenth thoracic segment is reached the separation of the pleural and peritoneal 
cavities is completed, and then the dorsal edge begins to descend more rapidly than the ventral, so that the diaphragm again becomes oblique in the same sense as in the beginning, a position which it retains in the adult.

The Development of the Peritoneum.-The peritoneal cavity is developed from the trunk-cavity of early stages and is at first in free communication on all sides of theyolk-stalk with the extra-embryonic cœlom. As the ventral wall of the body develops the two cavities become more and more separated, and with the formation of the umbilical cord the separation is complete. Along the middorsal line of the body the archenteron forms a projection into the cavity and later moves further out from the body-wall into the cavity, pushing in front of it the peritoneum, which thus comes to surround the intestine, forming its serous coat, and from it is continued back to the dorsal body-wall forming the mesentery.

It has already been seen that on the separation of the liver from the septum transversum, the tissue of the latter gives rise to the peritoneal covering of the liver and of the pos-

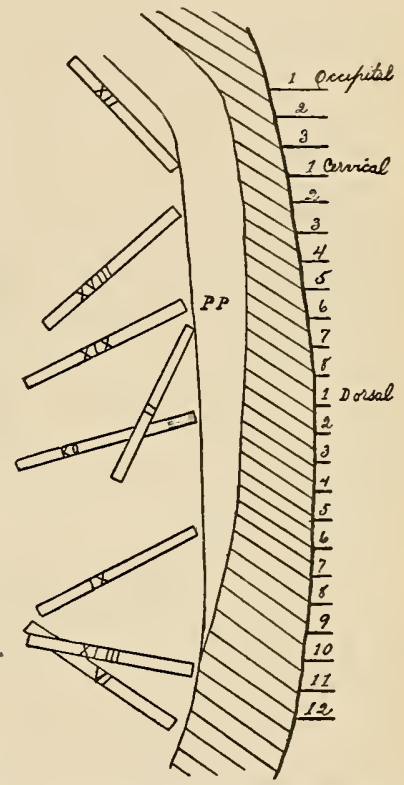

FIg. I97.-DIAGRAM SHOWING THE POSITION OF THE DIAPHRAGM in EMbryos of Different Ages. -(Mall.) terior surface of the diaphragm, and also to the ventral mesentery. When the separation is taking place, the rotation of the stomach already described (p. 30r) occurs, with the result that the portion of the ventral mesentery which stretches between the lesser curvature of the stomach and the liver shares in the rotation and comes to lie in a plane practically at right angles with that of the suspensory ligament, its surfaces looking dorsally and ventrally and its free edge being directed toward the right. This portion of the ventral mesentery forms 
what is termed the lesser omentum, and between it and the dorsal surface of the stomach as the ventral boundaries, and the dorsal wall of the abdominal cavity dorsally, there is a cavity, whose floor is formed by the dorsal mesentery of the stomach, the mesogastrium, the roof by the under surface of the left half of the liver, while to the right it communicates with the general peritoneal cavity dorsal to the free edge of the lesser omentum. This cavity is known as the bursa omentalis (lesser sac of the peritoneum), and the opening into it from the general cavity or greater sac is termed the epiploic foramen (foramen of Winslow). Later, the floor of the lesser sac is drawn downward to form a broad sheet of peritoneum lying ventral to the coils of the small intestine and consisting of four layers; this represents the great omentum of adult anatomy (Fig. 20I).

Although the form assumed by the bursa omentalis is associated with the rotation of the stomach, it seems probable that its real origin is independent of that process (Broman). The subserous tissue of the transverse septum is at first thick and includes not only the liver, but also the pancreas and the portion of the digestive tract which becomes the stomach and the upper part of the duodenum (Fig. 196, A). The shrinkage of this tissue by which these organs become separated from the septum cannot take place evenly on account of the relations which the organs bear to one another, so that on the right side certain peritoneal recesses are formed, one between the right lung and the stomach, a second between the liver and the stomach, and a third between the pancreas and the same structure. In man these three recesses communicate with one another to form the primary bursa omentalis, and open by a common epiploic foramen into the general peritoneal cavity. The rotation of the stomach, which takes place later, merely serves to modify the original bursa.

In the human embryo a small recess also forms upon the left side between the left lung and the stomach. Later it separates from the rest of the bursa omentalis and passes up along the side of the oesophagus, coming to lie on its right side between it and the diaphragm. It gives rise to a small serous sac that lies beneath the infracardial lobe of the right 
lung, when this is present, and hence has been termed the infracardial bursa.

Below the level of the upper part of the duodenum the ventral mensentery is wanting; only the dorsal mesentery occurs. So long as the intestine is a straight tube the length of the intestinal edge of this mesentery is practically equal to that of its dorsal attached edge. The intestine, however, increasing in length much more rapidly than the abdominal walls, the intestinal edge of the mesentery soon becomes very much longer than the attached edge, and when the intestine grows out into the umbilical colom the mesentery accompanies it (Fig. 198). As the coils of the intestine develop, the intestinal edge of the mesentery is thrown.into corresponding folds, and on the return of the intestine to the abdominal cavity the mesentery is thrown into a somewhat funnel-like form by the twisting of the intestine to form its primary loop (Fig. I99). All that portion of the mesentery which is attached to the part of the intestine which will later become the jejunum, ileum, ascending and transverse colon, is attached to the body-wall at the apex of the funnel, at a point which lies to the left of the duodenum.

Up to this stage or to about the middle

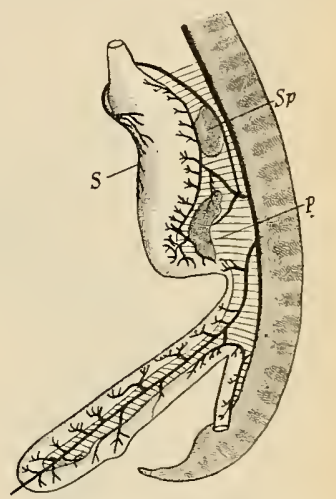

FIG. I 8 .-D IA G RA M SHOWING THE ARRANGEMIENT OF THE MESENTERY AND VISCERAL BRANCHES OF THE ABDOMINAL AORTA IN AN EMBRYO OF SIX WEEKS.

$p$, Pancreas ; $S$, stomach; $S p$, spleen.-(Toldt. $)$ of the fourth month the mesentery has retained its attachment to the median line of the dorsal wall of the abdomen throughout its entire length, but later fusions of certain portions occur, whereby the original condition is greatly modified. One of the earliest of these fusions takes place at the apex of the funnel, where the portion of the mesentery which passes to the tranverse colon and arches over the duodenum fuses with the ventral surface of the latter portion of the intestine and also with the peritoneum covering the dorsal wall of the abdomen both to the right and to the left of the duodenum. In this 
way the attachment of the transverse mesocolon takes the form of a transverse line instead of a point, and this portion of the mesentery divides the abdominal cavity into two portions, the upper (anterior) of which contains the liver and stomach, while the lower contains the remainder of the digestive tract with the exception of the duodenum. By passing across the ventral surface of the duodenum and fusing with it, the transverse mesocolon forces that portion of the intestine against the dorsal wall of the abdomen and fixes it in that position, and its mesentery thereupon degenerates, becoming
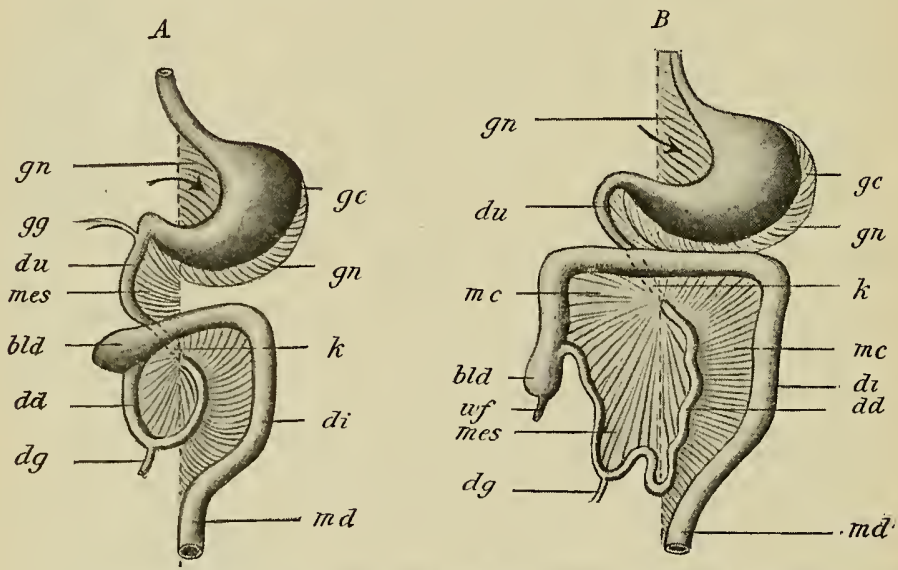

Fig. I99.-Diagrams Illustrating the Development of the Great Omentum aND THE Transverse MEsocolon.

$b l d$, Cæcum; $d d$, small intestine; $d g$, yolk-stalk; $d i$, colon; $d u$, duodenum; $g c$, greater curvature of stomach; $g g$, bile duct; $g n$, mesogastrium; $k$, point where the loops of the intestine cross; $m c$, mesocolon; $m d$, rectum; mes, mesentery; wf, vermiform appendix. -(Hertwig.)

subserous areolar tissue, the duodenum assuming the retroperitoneal position which characterizes it in the adult.

The descending colon, which on account of the width of its mesentery is at first freely movable, lies well over to the left side of the abdominal cavity, and in consequence the left layer of its mesentery lies in contact with the parietal layer of the peritoneum. A fusion of these two layers, beginning near the middle line and thence extending outward, takes place, the fused layers becoming converted into 
connective tissue, and this portion of the colon thus loses its mesentery and becomes fixed to the abdominal wall. The process by which the fixation is accomplished may be understood from the diagrams which constitute Fig. 200. When the ascending colon is formed, its mesentery undergoes a similar fusion, and it also becomes fixed to the abdominal wall.

The fusion of the mesentery of the ascending and descending colon remains incomplete in a considerable number of cases (one-fourth to onethird of all cases examined), and in these the colons are not perfectly fixed to the abdominal wall. It may also be pointed out that the cæcum and appendix, being primarily a lateral outpouching of the intestine, do
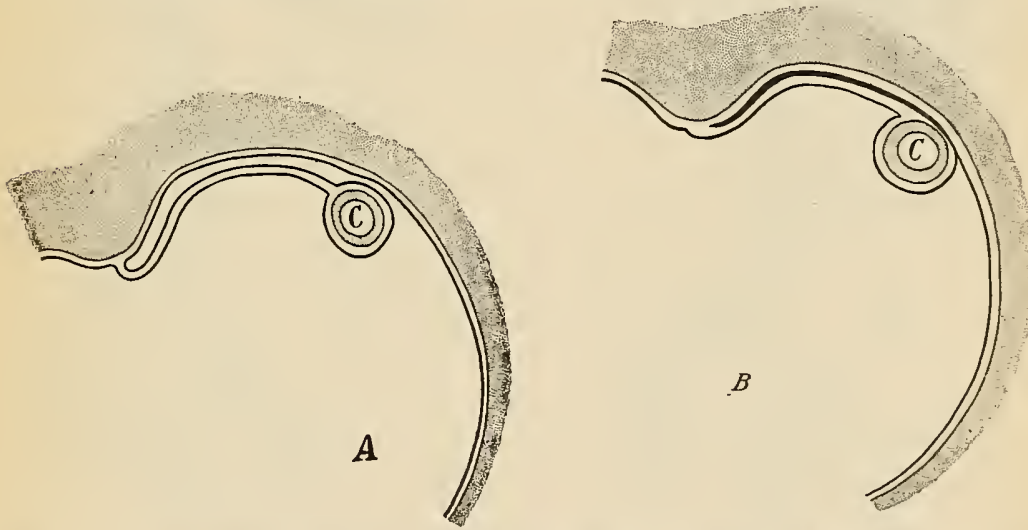

Fig. 200.--Diagrams Illustrating the Manner in Which the Fixation of the Descending Colon (C) takes Place.

not possess any true mesentery, but are completely enclosed by peritoneum. Usually a falciform fold of peritoneum may be found extending along one surface of the appendix to become continuous with the left layer of the mesentery of the ileum. This, however, is not a true mesentery, and is better spoken of as a mesenteriole.

One other fusion is still necessary before the adult condition of the mesentery is acquired. The great omentum consists of two folds of peritoneum which start from the greater curvature of the stomach and pass downward to be reflected up again to the dorsal wall of the abdomen, which they reach just anterior to (above) the line of attachment of the transverse mesocolon (Fig. 2or, A). At 
first the attachment of the omentum is vertical, since it represents the mesogastrium, but later, by fusion with the parietal peritoneum, it assumes a transverse direction, while at the same time the pancreas, which originally lay between the two folds of the mesogastrium, is carried dorsally and comes to have a retroperitoneal position in the line of attachment of the omentum. By this change the lower layer of the omentum is brought in contact with the upper layer of the
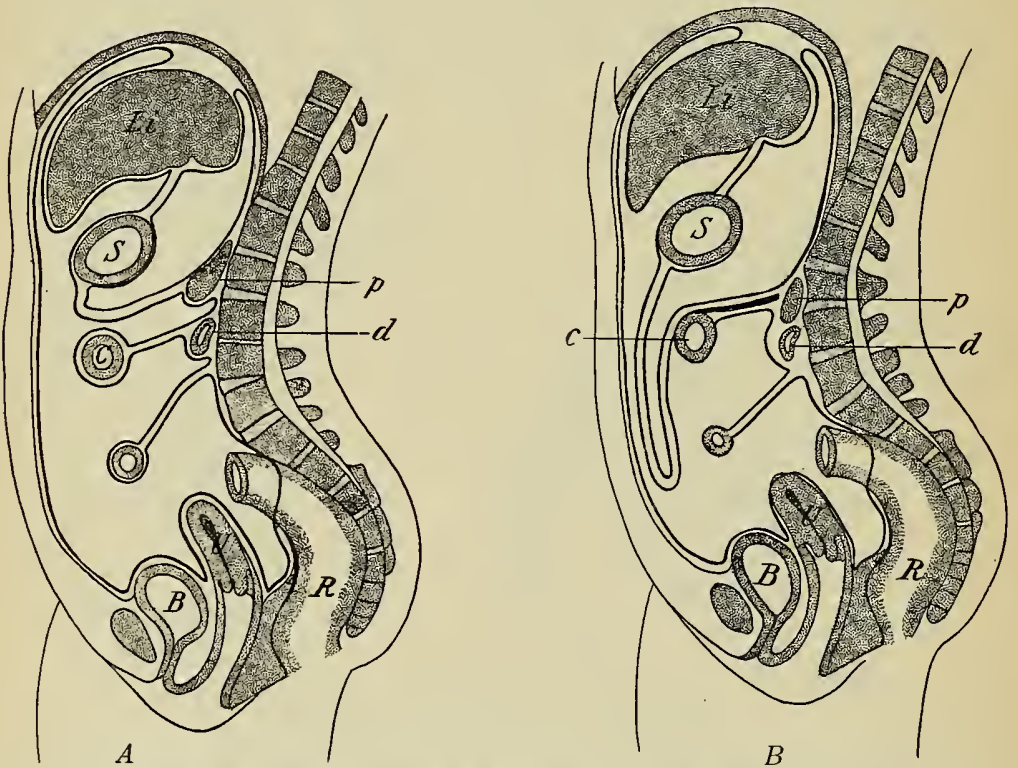

Fig. 201.-Diagrams showing the Development of the Great Omentum and its FUSION WITH THE TRANSVERSE MESOCOLON.

$B$, Bladder; $c$, transverse colon; $d$, duodenum; $L i$, liver; $p$, pancreas; $R$, rectum; $S$, stomach; $U$, uterus.-(After Allen Thomson.)

transverse mesocolon and a fusion and degeneration of the two results (Fig. 20I B), a condition which brings it about that the omentum seems to be attached to the transverse colon and that the pancreas seems to lie in the line of attachment of the transverse mesocolon. This mesentery, as is occurs in the adult, really consists partly of a portion of the original transverse mesocolon and partly of a layer of the great omentum. 
By these various changes the line of attachment of the mesentery to the dorsal wall of the body has become somewhat complicated and has departed to a very considerable extent from its original simple vertical arrangement. If all the viscera be removed from the body of an adult and the mesentery be cut close to the line of its attachment, the course of the latter will be seen to be as follows: Descending from the under surface of the diaphragm are the lines of attachment of the suspensory ligament, which on reaching the liver spread out to become the coronary and lateral ligaments of that organ. At about the mid-dorsal line these lines become continuous with those of the mesogastrium which curve downward toward the left and are continued into the transverse lines of the transverse mesocolon. Between these last, in a slight prolongation, there may be seen to the right the cut end of the first portion of the duodenum as it passes back to the dorsal wall of the abdomen, and at about the mid-dorsal line the cut ends of its last part become visible as it passes ventrally again to become the jejunum. From the transverse mesocolon three lines of attachment pass downward; the two lateral broad ones represent the lines of fixation of the ascending and descending colons, while the narrower median one, which curves to the right, represents the attachment of the mesentery of the small intestine other than the duodenum. Finally, from the lower end of the fixation line of the descending colon the mesentery of the sigmoid is continued downward.

The special developments of the peritoneum in connection with the genito-urinary apparatuus will be considered in Chapter XIII.

\section{LITERATURE.}

I. BROMAN: "Ueber die Entwicklung und Bedeutung der Mesenterien und der Körperhöhlen bei den Wirbeltieren," Ergebn. der Anat. u. Entw., xv, 1906.

A. BRACHET: "Die Entwickelung der grossen Körperhöhlen und ihre Trennung von Einander," Ergebnisse der Anat. und Entwickelungsgesch., viI, I898.

W. HIs: "Mittheilungen zur Embryologie der Säugethiere und des Menschen," Archiv fïr Anat. und Physiol., Anat. Abth., I88г.

F. P. MALL: "Development of the Human Colom," Journal of Morphol., XII, I897. F. P. MaLl: "On the Development of the Human Diaphragm," Johns Hopkins Hospital Bull., xIr, I9or. 
E. Ravn: "Ueber die Bildung der Scheidewand zwischen Brust- und Bauchhöhle in Säugethierembryonen," Archiv für Anat. und Physiol., Anat, Abth., I889.

A. SWAEn: "Recherches sur le développement du foie, du tube digestif, de l'arrièrecavité du peritoine et du mésentère," Journ. de l'Anat. et de la Physiol., xxxrr, I896; XxxIII, r897.

C. Toldt: "Bau und Wachstumsveränderungen der Gekröse des menschlichen Darmkanals," Denkschr. der kais. Akad. Wissensch. Wien, Math.-Naturwiss. Classe, XLI, 1879 .

C. Toldt: "Die Darmgekröse und Netze im gesetzmassigen und gesetzwidrigen Zustand," Denkschr. der kais. Akad. Wissensch. Wien. Math.-Naturwiss. Classe, LVI, I889.

F. Treves: "Lectures on the Anatomy of the Intestinal Canal and Peritoneum," British Medical Journal, I, I885. 


\section{CHAPTER XII.}

\section{THE DEVELOPMENT OF THE ORGANS OF RESPIRATION.}

The Development of the Lungs. - The first indication of the lungs and trachea is found in embryos of about $3.2 \mathrm{~mm}$. in the form of a groove on the ventral surface of the osophagus, at first extending almost the entire length of that portion of the digestive tract. As the œsophagus lengthens the lung groove remains connected with its upper portion (Fig. I82, A), and furrows which appear along the line of junction of the groove and the oesophagus gradually deepen and separate the two structures (Fig. I82, B). The separation takes place earliest at the lower end of the groove and thence extends upward, so that the groove is transformed into a cylindrical pouch lying ventral to the oesophagus and dorsal to the heart and opening with the œsophagus into the terminal portion of the pharynx.

Soon after the separation of the groove from the osophagus its lower end becomes enlarged and bilobed, and since this lower

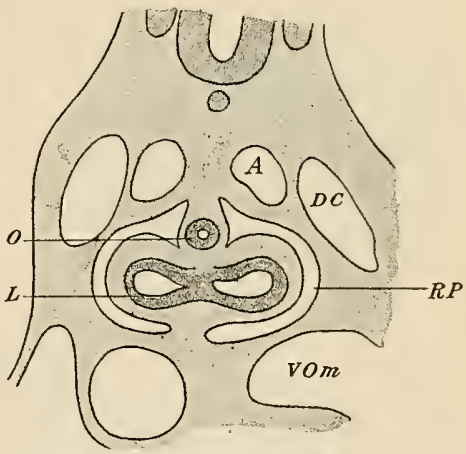

Fig. 202.-Portion OF a Section THROUGH AN EMBRYO OF THE FOURTH WEEK.

$A$, Aorta; $D C$, ductus̀ Cuvieri; $L$, lung; $O$, œsophagus; $R P$, parietal recess; VOm, vitelline vein.-(Toldt.) end lies, with the œsophagus, in the median attached portion of the dorsal edge of the septum transversum, the lobes, as they enlarge, project into the dorsal parietal recesses (Fig. 202), and so become enclosed within the peritoneal lining of the recesses which later become the pleural cavities.

The lobes, which represent the lungs, do not long remain simple, 
but bud-like processes arise from their cavities, three appearing in the right lobe and two in the left (Fig. 203, $A$ ), and as these increase in size and give rise to additional outgrowths, the structure of the lobes rapidly becomes complicated (Fig. 203, $B$ and $C$ ).

The lower primary process on each side may be regarded as a prolongation of the bronchus, while the remaining process or processes represent lateral outgrowths from it. Considerable difference of opinion has existed as to the nature of the further branching of the bronchi, some authors regarding it as a succession of dichotomies, one branch of each of these placing itself so as to be in the line of the

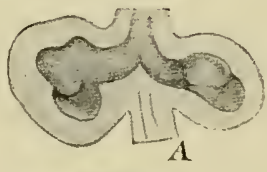

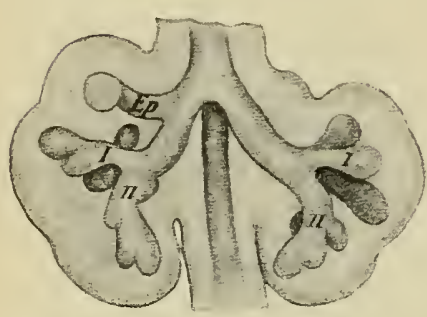

$B$

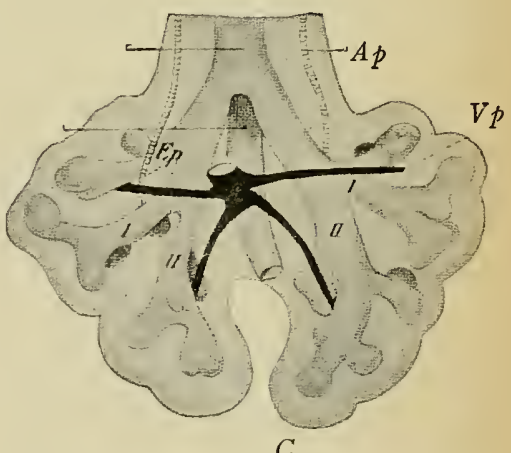

C

Fig. 203.-Reconstruction of the Lung OUtgrowths of Embryos of $(A)$ 4.3, (B) 8.5, AND (C) IO. 5 MM.

$A p$, Pulmonary artery; $E p$, eparterial bronchus; $V p$, pulmonary vein; $I$, second lateral bronchus; II, main bronchi.-(His.)

original main bronchus, while the other comes to resemble a lateral outgrowth, and other observers have held that the main bronchus has an uninterrupted growth, all other branches being lateral outgrowths from it, and the branching therefore a monopodial process. The recent thorough study by Flint of the development of the lung of the pig shows that, in that form at least, the branching is a monopodial one, and that from the main bronchus as it elongates four sets of secondary outgrowths develop, namely, a strong lateral, a dorsal, a ventral, and a weak and variable medial set. 
There is a general tendency for the individual branches of the various sets to be arranged in regular succession and for their development to be symmetrical in the two lungs. But on account of the necessity under which the lungs are placed of adapting themselves to the neighboring structures and at the same time affording a respiratory surface as large as possible, an amount of asymmetry supervenes. Thus, it has already been noted that in the earliest branching a single lateral bronchus is formed in the left lung and two in the right. The uppermost of these latter, the first lateral bronchus, is unrepresented in the left lung, and is peculiar in that it lies behind the right pulmonary artery (Fig. 203, C), or in the adult, after the recession of the heart, above it, whence it is termed the eparterial bronchus. Its absence on the left side is perhaps due to its suppression to permit the normal recession of the aortic arch (Flint).

So, too, the inclination of the heart causes a suppression of the second ventral bronchus in the left lung, but at the same time it affords opportunity for an excessive development of the corresponding bronchus of the right lung, which pushes its way between the heart and the diaphragm and is known as the infra-cardiac bronchus.

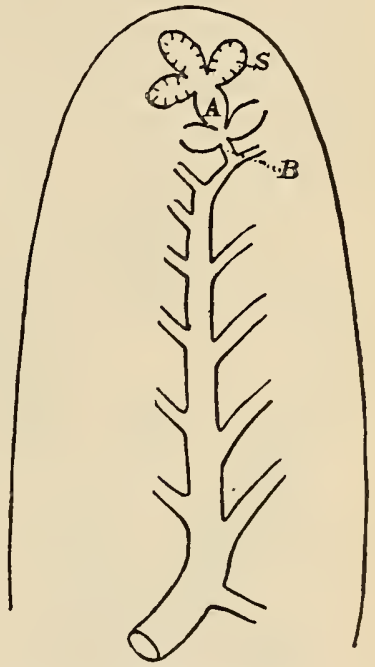

Fig. 204.-DIAGRAM OF THE Final Branches of the MaMMALIAN BRONCHI.

$A$, Atrium; $B$, bronchus; $S$, air-sac.-(Miller.)

As soon as the unpaired first lateral bronchus and the paired second lateral bronchi are formed mesenchyme begins to collect around each of them and also around the main bronchi, the lobes of the adult lung, three in the right lung and two in the left, being thus outlined. A development of mesenchyme also takes place around the excessively developed right second ventral bronchus, and sometimes produces a well-marked infra-cardiac lobe in the right lung. 
In later stages the various bronchi of each lobe give rise to additional branches and these again to others, and the mesenchyme of each lobe grows in between the various branches. At first the amount of mesenchyme separating the branches is comparatively great, but as the branches continue, the growth of the mesenchyme fails to keep pace with it, so that in later stages the terminal enlargements are separated from one another by only very thin partitions of mesenchyme, in which the pulmonary vessels form a dense network. The final branching of each ultimate bronchus or bronchiole results in the formation at its extremity of from three to five enlargements, the atria (Fig. 204, A), from which arise a number of air-sacs (S) whose walls are pouched out into slight diverticula, the air-cells or alveoli. Such a combination of atria, air-sacs, and air-cells

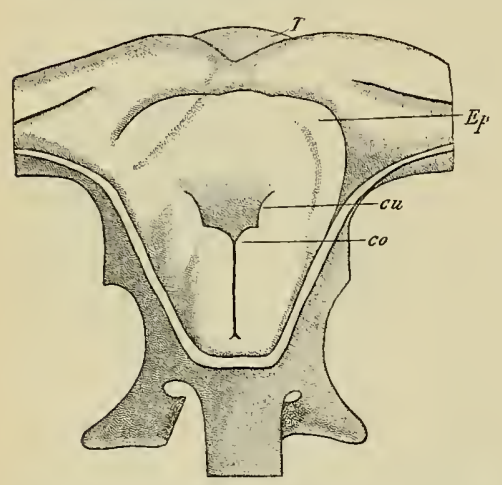

Fig. 205.-Reconstruction OF THE OPENING INTO THE LARYNX IN AN EMBRYo OF TWENTy-eight DAYS, SEEN FROM BEHIND AND ABOVE, THE DORSAL Wall of the Pharynx being Cut AWAY.

$c o$, Cornicular, and $c u$, cuneiform tubercle; $E p$, epiglottis; $T$, unpaired portion of the tongue.-(Kallius.) constitutes a lobule, and each lung is composed of a large number of such units.

The greater part of the original pulmonary groove becomes converted into the trachea, and in the mesenchyme surrounding it the incomplete cartilaginous rings develop at about the eighth or ninth week. The cells of the epithelial lining of the trachea and bronchi remain columnar or cubical in form and become ciliated at about the fourth month, but those of the epithelium of the airsacs become greatly flattened and constitute an exceedingly thin layer of pavement epithelium.

The Development of the Larynx.-The opening of the upper end of the pulmonary groove into the pharynx is situated at first just behind the fourth branchial furrow and is surrounded anteriorly and laterally by the $\cap$-shaped ridge already described (p. 294) as 
the furcula, this separating it from the posterior portion of the tongue (Fig. I78). The anterior portion of this ridge, which is apparently derived from the ventral portions of the third branchial arch, gradually increases in height and forms the epiglottis, while the lateral portions, which pass posteriorly into the margins of the pulmonary groove, form the aryepiglottic folds. When the pulmonary groove separates from the œsophagus, the opening of the trachea into the pharynx is somewhat slit-like and is bounded laterally by the aryepiglottic folds, whose margins present two elevations which may be termed the cornicular and cuneiform tubercles (Fig. 205, co and $c u$, and Fig. I 75). The opening is, however, for a time almost obliterated by a thickening of the epithelium covering the ridges,

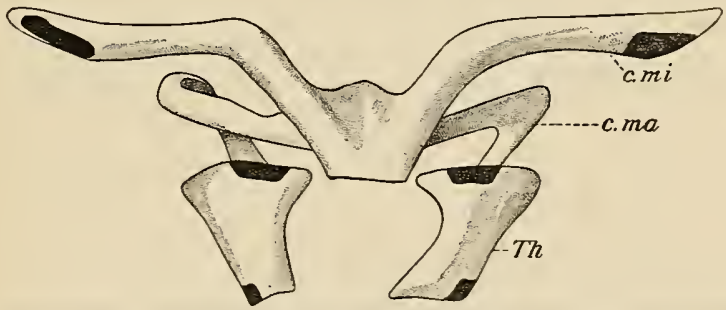

Fig. 206.-RECONSTRUCTION OF THE MESENCHYME CONDENSATIONS WHICH REPRESENT the Hyoid and Thyreoid Cartilages in an Embryo of Forty Days.

The darkly shaded areas represent centers of chondrification. c.ma, Greater cornu of hyoid; c.mi, lesser cornu; Th, thyreoid cartilage.-(Kallius.)

and it is not until the tenth or eleventh week of development that it is re-established. Later than this, at the middle of the fourth month, a linear depression makes its appearance on the mesial surface of each ary-epiglottic fold, forming the beginning of the ventricle, and although at first the depression lies horizontally, its lateral edge later bends anteriorly, so that its surfaces look outward and inward. The lips which bound the opening of the ventricle into the laryngeal cavity give rise to the ventricular and vocal folds.

The cartilages of the larynx can be distinguished during the seventh week as condensations of mesenchyme which are but indistinctly separated from one another. The thyreoid cartilage is represented at this stage by two lateral plates of mesenchyme, 
separated from one another both ventrally and dorsally, and each of these plates undergoes chondrification from two separate centers (Fig. 206). These, as they increase in size, unite together and send prolongations ventrally which meet in the mid-ventral line with the corresponding prolongations of the plates of the opposite side, so as to enclose an area of mesenchyme into which the chondrification only extends at a later period, and occasionally fails to so extend, producing what is termed a foramen thyreoideum.

The mesenchymal condensations which represent the cricoid and arytenoid cartilages are continuous, but each arytenoid has a distinct center of chondrification, while the cartilage of the cricoid appears as a single ring which is at first open dorsally and only later becomes complete. The epiglottis cartilage resembles the thyreoid in being formed by the fusion of two originally distinct cartilages, from each of which a portion separates to form the cuneiform cartilages (cartilages of Wrisberg) which produce the tubercles of the same name on the ary-epiglottic fold, while the corniculate cartilages (cartilages of Santorini) are formed by the separation of a small portion of cartilage from each arytenoid.

The formation of the thyreoid cartilage by the fusion of two pairs of lateral elements finds an explanation from the study of the comparative anatomy of the larynx. In the lowest group of the mammalia, the Monotremata, the four cartilages do not fuse together and are very evidently serially homologous with the cartilages which form the cornua of the hyoid. In other words, the thyreoid results from the fusion of the fourth and fifth branchial cartilages. The cricoid, in its development, presents such striking similarities to the cartilaginous rings of the trachea that it is probably to be regarded as the uppermost cartilage of that series, but the epiglottis seems to be a secondary chondrification in the glossolaryngeal fold (Schaffer). The arytenoids possibly represent an additional pair of branchial cartilages, such as occur in the lower vertebrates (Gegenbaur).

These last arches have undergone almost complete reduction in the mammalia, the cartilages being their only representatives, but, 
in addition to the cartilages, the fourth and fifth arches have also preserved a portion of their musculature, part of which becomes transformed into the muscles of the larynx. Since the nerve which corresponds to these arches is the vagus, the supply of the larynx is derived from that nerve, the superior laryngeal nerve probably corresponding to the fourth arch, while the inferior (recurrent) answers to the fifth.

The course of the recurrent nerve finds its explanation in the relation of the nerve to the fourth branchial artery. When the heart occupies its primary position ventral to the floor of the pharynx, the inferior laryngeal nerve passes transversely inward to the larynx beneath the fourth branchial artery. As the heart recedes the nerve is caught by the vessel and is carried back with it, the portion of the vagus between it and the superior laryngeal nerve elongating until the origins of the two laryngeal nerves are separated by the entire length of the neck. Hence it is that the right recurrent nerve bends upward behind the right subclavian artery, while the left curves beneath the arch of the aorta (see Fig. 149).

\section{LITERATURE.}

J. M. Flint: "The Development of the Lungs," Amer. Journ. Anat., VI, I9o6.

J. E. Frazer: "The Development of the Larynx," Journ. Anat. and Phys., xIIV, I9Io.

E. GópPert: "Ueber die Herkunft der Wrisbergschen Knorpels," Morphol. Jahrbuch, $\mathrm{XXI}, \mathrm{I} 894$.

W. His: "Zur Bildungsgeschichte des Lungen beim menschlichen Embryo," Archiv für Anat. und Physiol., Anat. Abth., I887.

E. Kallius: "Beiträge zur Entwickelungsgeschichte des Kehlkopfes," Anat. Hefte, IX, I897.

E. Kallius: "Die Entwickelung des menschlichen Kehlkopfes," Verhandl. der Anat. Gesellsch., XII, I8g8.

A. Lisser: "Studies on the Development of the Human Larynx," Amer. Journ. Anat., XII, I9II.

A. NARATH: "Der Bronchialbaum der Säugethiere und des Menschen," Bibliotheca Medica, Abth. A, Heft 3, I9or.

J. Schaffer: "Zur Histologie Histogenese und phylogenetischen Bedeutung der Epiglottis," Anat. Hefte, xxxII, I907.

A. Soulié AND E. BARDier: "Recherches sur le développement du larynx chez l'homme," Journ. de l'Anat. et de la Physiol., XLIII, I907. 


\section{CHAP'TER XIII.}

\section{THE DEVELOPMENT OF THE URINOGENITAL SYSTEM.}

The excretory and reproductive systems of organs are so closely related in their development that they must be considered together. They both owe their origin to the mesoderm which constitutes the intermediate cell-mass (p. 77), this, at an early period of development, becoming thickened so as to form a ridge projecting into the dorsal portion of the cœlom and forming what is known as the Wolffan ridge (Fig. 207, wr). The greater portion of the substance

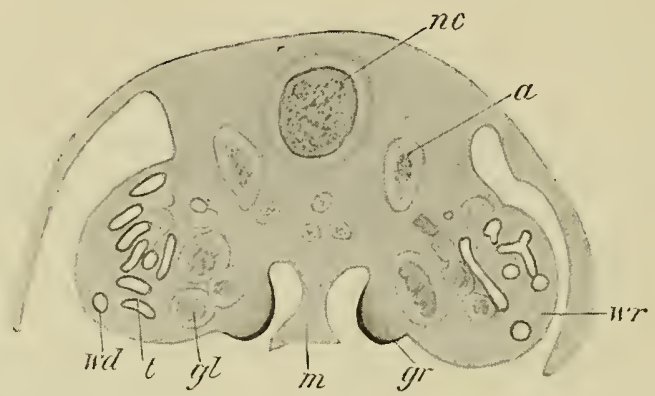

Fig. 207.-Transverse Section through the Abdominal Region of a Rabit EMBRYO OF I2 MM.

$a$, Aorta; $g l$., glomerulus; $g r$, genital ridge; $m$, mesentery; $n c$, notochord; $t$, tubule of mesonephros; wd, Wolffian duct; wr, Wolffian ridge.-(Mihalkovicz.)

of this ridge is concerned in the development of the primary and secondary excretory organs, but on its mesial surface a second ridge appears which is destined to give rise to the ovary or testis, and hence is termed the genital ridge $(g r)$.

The development of the excretory organs is remarkable in that three sets of organs appear in succession. The first of these, the pronephros, exists only in a rudimentary condition in the human 
embryo, although its duct, the pronephric or Wolffian duct, undergoes complete development and plays an important part in the development of the succeeding organs of excretion and also in that of the reproductive organs. The second set, the mesonephros or Wolffian body, reaches a considerable development during embryonic life, but later, on the development of the final set, the definite kidney or metanephros, undergoes degeneration, portions only persisting as rudimentary structures associated for the most part with the reproductive organs.

The Development of the Pronephros and the Pronephric Duct.-The first portions of the excretory system to make their appearance are the pronephric or Wolffian ducts, which develop as

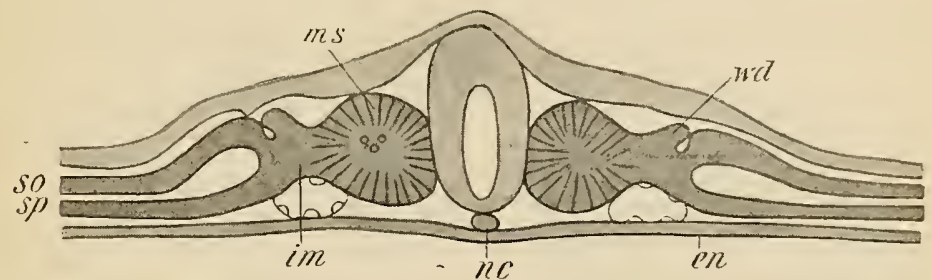

Fig. 1 208. -Transverse Section through Chick Embryo of about Thirty-six Hours.

en, Endoderm; $i m$, intermediate cell mass; $m s$, mesodermic somite; $n c$, notochord; $s o$, somatic, and $s p$, splanchnic mesoderm; wd, Wolffian duct.-(Waldeyer.)

outgrowths of the dorsal walls of the intermediate cell masses. At first the outgrowths are solid cords of cells (Fig. 208, wd), but later a lumen appears in the center of each and the canal so formed from each intermediate cell mass, bending backward at its free end, comes into contact and fuses with the canal from the next succeeding segment. Two longitudinal canals, the pronephric or Wolffian ducts, are thus formed, with which the cavities of the intermediate cell masses communicate. The formation of the ducts begins in the anterior segments before the segmentation of the posterior portions of the mesoderm has taken place, and the further backward extension of the ducts takes place independently of the formation of excretory tubules, apparently by a process of terminal growth. The free end 
of each duct comes into intimate relation with the ectoderm above it, so much so that its posterior portion has been held by some observers to be formed from that layer, but it seems more probable that the relation to the ectoderm is a secondary process and that the ducts are entirely of mesodermal origin. They reach the cloaca in embryos of a little over $4 \mathrm{~mm}$., and later they unite with that organ, so that their lumina open into its cavity.

The pronephric tubules make their appearance in embryos of about I.7 $\mathrm{mm}$., while as yet there are only nine or ten mesodermic somites, and they are formed from the intermediate cell masses of the seventh to the fourteenth segment, and perhaps from those situated

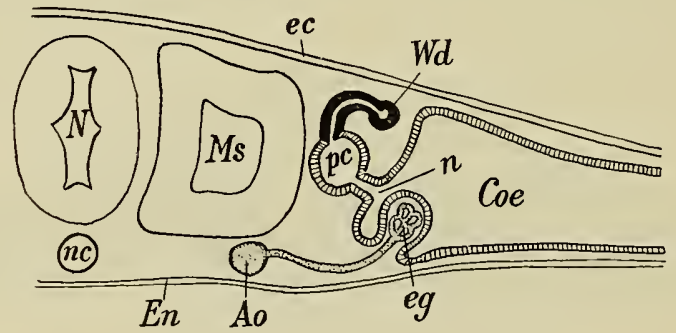

Fig. 209.-Diagram showing the Structure of a Fully Developed PRONEPHRIC TUBULE.

Ao, Aorta; Coe, cœlom; ec, Ectoderm; eg, external glomerulus; en, endoderm; $M s$, mesodermic somite; $N$, nervous system; $n$, nephrostome; $n c$, notochord; $p c$, pronephric chamber; $W d$, Wolffian duct.-(Modified from Felix.)

still more anteriorly. The entire series, however, is never in existence at any one time, for before the more posterior tubules are formed, those of the anterior segments have undergone degeneration. Each pronephric tubule, when fully formed, consists of a portion which unites it to the Wolffian duct, and opens at its other end into an enlargement, the pronephric chamber, (Fig. 209, pc), which, on its part opens into the cœlomic cavity by means of a nephrostome canal. In the neighborhood of the cœlomic opening, or nephrostome, an outgrowth of the cœlomic epithelium is formed, and a branch from the aorta penetrates into this to form a stalked external glomerulus lying free in the cœlomic cavity (Fig. 209, e.g.). Internal 
glomeruli, such as occur in connection with the mesonephric tubules do not occur in the pronephros of the human embryo, and this fact, together with the presence of external glomeruli and the participation of the tubules in the formation of the Wolffian duct, serve to distinguish the pronephros from the mesonephros.

The pronephric tubules, are, as has been stated, transitory structures and by the time the embryo has reached a length of about $5 \mathrm{~mm}$. they have all disappeared. Before their disappearance is complete, however, a second series of tubules has commenced to develop, forming what is termed the mesonephros or Wolffian body.

The Development of the Mesonephros.-The pronephric duct does not disappear with the degeneration of the pronephric tubules, but persists to serve as the duct for the mesonephros and to play an important part in the development of the metanephros also. In the Wolffian ridge there appear in embryos of between 3 and $4 \mathrm{~mm}$. a number of coiled tubules, which arise by some of the cells of the ridge aggregating to form solid cords, at first entirely unconnected with either the cœlomic epithelium or the Wolffian duct. Later the cords become connected with the cœlomic epithelium and acquire a

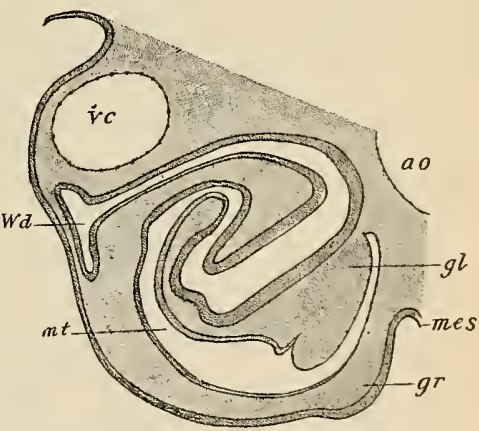

Frg. 2io.-Transverse Section of THE Wolffian Ridge of A CHICK EMBRYO OF THREE DAYS.

ao, Aorta; $g l$, glomerulus; gr, genital ridge; mes, mesentery; $m t$, mesonephric tubule; $v c$, cardinal vein; $W d$, Wolffian duct.-(Mihalkovicz.) lumen, and near the cœlomic end of the tubule, at a region corresponding to the chamber of a pronephric tubule, a condensation of the mesenchyme of the Wolffian ridge occurs to form a glomerulus into which a branch extends from the neighboring aorta. The tubules finally acquire connection with the Wolffian duct and at the same time lose their connections with the colomic epithelium, their nephrostomes being accordingly but transitory structures. The tubules rapidly increase in length and 
become coiled, and the glomeruli project into their cavities, pushing in front of them the wall of the tubule so that it has the appearance represented in Fig. 2ro.

In its anterior portion the Wolffian ridge is formed by distinct intermediate cell masses, but posterior to the tenth segment it becomes distinguishable from the rest of the mesoderm before this has become segmented, and, failing to undergo transverse division into segments, it forms a continuous column of cells, known as the nephrogenic cord. The anterior tubules of the mesonephros make their appearance in the intermediate cell masses belonging to the sixth cervical segment, its tubules thus overlapping those of the pronephros, and from this level they appear in all succeeding segments and in the nephrogenic cord as far back as the region of the third or fourth lumbar segment, where the cord is partially interrupted. This interruption marks the dividing line between the mesonephric and metanephric portions of the cord, the portions posterior to it being destined to give rise to the metanephros. But, as is the case with the pronephros, the entire series of mesonephric tubules is never in existence at any one time, a degeneration of the anterior ones supervening even before the posterior ones have differentiated, and the degeneration proceeds to such an extent that in an embryo of about $2 \mathrm{I} \mathrm{mm}$. all the tubules of the cervical and thoracic segments have disappeared, only those of the lumbar segments persisting.

This does not mean, however, that the number of persisting tubules corresponds with that of the segments in which they occur, for the tubules are not segmental in their arrangement, but are much more numerous than such an arrangement would allow. Two, three, or even as many as nine may correspond with the extent of a mesodermic somite and when the reduction is complete in an embryo of $2 \mathrm{I} \mathrm{mm}$., where only the tubules corresponding with four or five segments remain, they may number twenty-six in each mesonephros (Felix). This arrangement of the tubules together with the size which they assume when fully developed brings it about that the Wolffian ridges become somewhat voluminous structures in their mesonephric portions, projecting markedly into the cœlomic cavity 
(Fig. 2II). Each is attached to the dorsal wall of the body by a distinct mesentery and has in its lateral portion, embedded in its substance, the Wolffian duct, while on its mesial surface anteriorly is the but slightly developed genital ridge $(t)$. This condition is reached in the human embryo at about the sixth or seventh week of development, and after that period the mesonephros again begins to undergo rapid degeneration, so that at about the sixteenth week

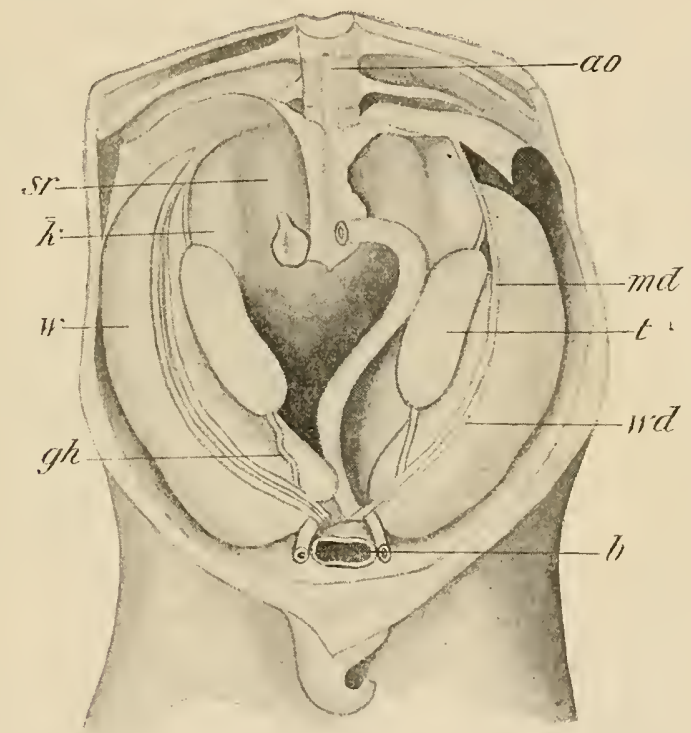

Fig. 2it.-Urinogenital Apparatus of a Male Pig Embryo of 6 cu. $a$, Aorta; $b$, bladder; $g h$, gubernaculum testis; $k$, kidney; $m d$, Müllerian duct; $s r$, suprarenal body; $t$, testis; $w$, Wolffian body; wd, Wolffian duct.-(Mihalkovicz.)

nothing remains of it except the duct and a few small rudiments whose history will be given later.

The Development of the Metanephros.-The first indication of the metanephros or permanent kidney is a tubular outgrowth from the dorsal surface of the Wolffian duct shortly before its entrance into the cloaca (Fig. I70). When first formed this outgrowth lies lateral to the posterior portion of the Wolffian ridge, 
which, as has already been noted (p. 342), is separated from the portion that gives rise to the mesonephros. This terminal portion of the ridge forms what is termed the metanephric blastema and in embryos of $7 \mathrm{~mm}$. it has come into relation with the outgrowth from the Wolffian duct and covers its free extremity as a cap. Since both the blastema and the outgrowth from the Wolffian duct take

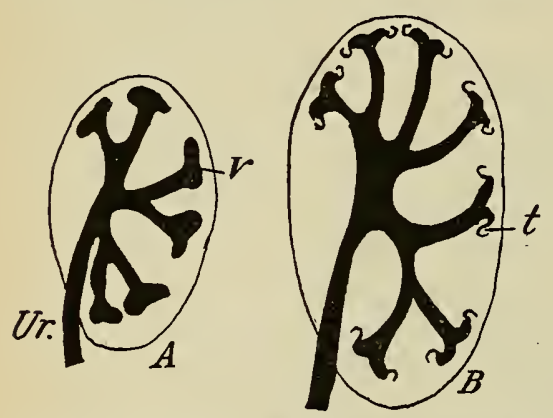

Fig. 212.-Diagrams of Eariy Stages in THE DEVELOPMENT OF THE METANEPHRIC Tubules.

$t$, Urinary tubule; $U r$, ureter; $v$, renal ampulla.-(Haycraft.)

part in the formation of the uriniferous tubules, these have a double origin.

The outgrowth from the Wolffian duct as it continues to elongate comes to lie dorsal to the mesonephros, carrying the cap of blastema with it, and it soon assumes a somewhat club-shaped form, its terminal enlargement or ampulla forming what may be termed the primary renal pelvis, while the remainder represents the ureter. The primary renal pelvis then gives rise to from three to six, usually four, tubular outgrowths, which may be termed primary collecting tubules, and with their formation the original cap of metanephric blastema undergoes a division into as many portions as there are tubules, so that each of the latter has its own cap of blastema. As soon as each tubule has reached a certain length it begins to enlarge at its free extremity to form an ampulla, just as did the primary renal pelvis, and from this ampulla there grow out from two to four secondary collecting tubules, a further corresponding division of the metanephric blastema taking place. In their turn these secondary tubules similarly enlarge at their extremities to form ampullæ (Fig. 212, A) from which tertiary collecting tubules are budded out, accompanied by a third fragmentation of the blastema and so the process goes on until about the fifth fetal month, the number of generations of collecting tubules formed being between 
eleven and thirteen, each tubule of the final generation having its cap of blastema.

In this way there is formed a complicated branching system of tubules all of which ultimately communicate with the primary renal pelvis, and all of which have, in the last analysis, had their origin from the Wolffian duct. They represent, however, only the collecting portions of the uriniferous tubules, their excreting por-
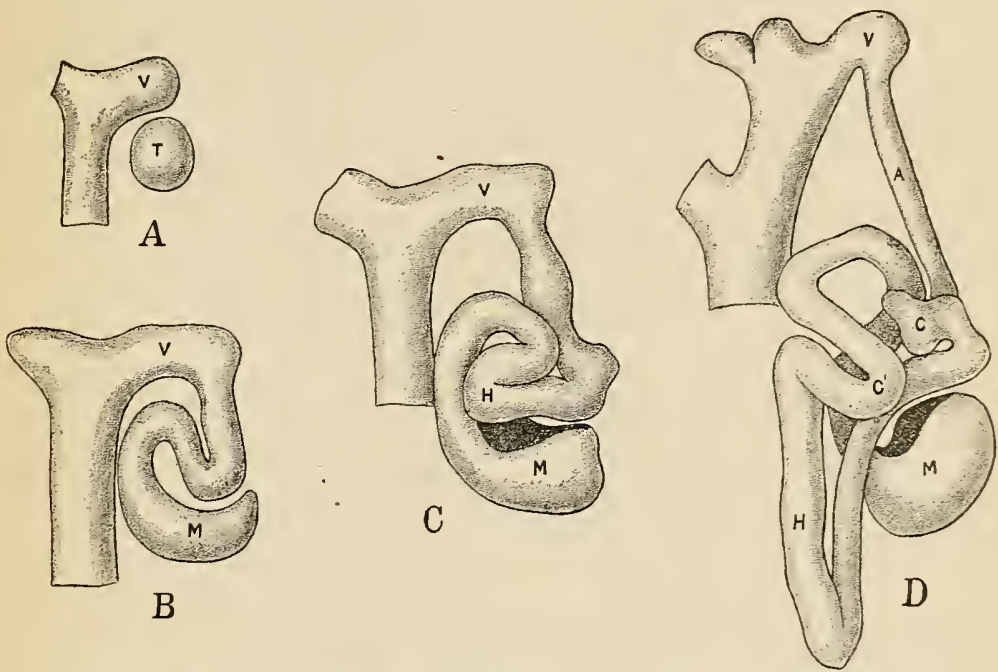

Fig. 213.-Four Stages in the Development of a Uriniferous Tubule of a Cat.

A, Arched collecting tubule, $\mathrm{C}$, distal convoluted tubule; $\mathrm{C}^{\prime}$, proximal convoluted tubule; $\mathrm{H}$, loop of Henle; $\mathrm{M}$, glomerulus; $\mathrm{T}$, renal vesicle; $\mathrm{V}$, ampulla (drawn from reconstructions prepared by G. C. Huber).

tions having yet to form, and these take their origin from the metanephric blastema.

When the terminal collecting tubules have been formed the blastemic cap in connection with each one condenses to form a renal vesicle (Fig. $2 \mathrm{I}_{3}, A, T$ ), which is at first solid, but later becomes hollow and proceeds to elongate to an S-shaped tubule, one end of which becomes continuous with the neighboring ampulla (Figs. $2 \mathrm{I}_{2}, \mathrm{~B}$, and $2 \mathrm{I}_{3}, \mathrm{~B}$ ), and in the space enclosed by what may be termed the lower loop of the $\mathrm{S}$ a collection of mesenchyme cells 
appears, into which branches penetrate at an early stage from the renal artery to form a glomerulus, the neighboring walls of the tubule becoming exceedingly thin and being transformed into a capsule of Bowman. The upper loop of the $\mathbf{S}$ now begins to elongate (Fig. $2 \mathrm{I}_{3}, \mathrm{C}$ ), growing toward the hilus of the kidney, parallel to the branch of the outgrowth from the Wolffian duct to which it is attached and between this and the glomerulus, and forms a loop of Henle. From the portion of the horizontal limb of the $\mathbf{S}$ which lies between the glomerulus and the descending limb of the loop of Henle the proximal convoluted tubule $\left(\mathrm{C}^{\prime}\right)$ arises, while the distal convoluted and the arched collecting tubules ( $\mathrm{C}$ and $\mathrm{A})$ are formed from the uppermost portion of the upper loop (Fig. 213, D). The entire length of each uriniferous tubule from Bowman's capsule to the arched collecting tubule inclusive is thus derived from a renal vesicle, that is to say, from the metanephric blastema.

Since the tubules of the kidney are formed by the union of two originally distinct structures it is conceivable that in the cases of certain tubules there may be a failure of the union. The blastemic portion of the tubules would, nevertheless, continue their development and become functional and, since there would be not means of escape for the secretion, the result would be a cystic kidney. Occasionally the two blastemata of opposite sides fuse across the middle line, the result being the formation of a single transverse or horse-shoe shaped kidney, or, what is much rarer, the blastema of one side may cross the middle line to fuse with that of the other, the result being an apparently single kidney with two ureters which open normally into the bladder.

The primary renal pelvis is the first formed ampulla and does not exactly represent the definitive pelvis. This is produced partly by the enlargement of the primary pelvis and partly by the enlargement of the collecting tubules of the first four generations, those of the third and fourth generations later being taken up or absorbed into those of the second generation, so that the tubules of the fifth generation appear to open directly into those of the second, which form the calices minores, while those of the first constitute the calices majores. In some kidneys the process of reduction of the earlier formed collecting tubules proceeds a step further, those of the first generation 
being taken up into the primary renal pelvis, the secondaries then forming a series of short calices arising from a single pelvic cavity.

At about the tenth week of development the surface of the human kidney becomes marked by shallow depressions into lobes, of which there are about eighteen, one corresponding to each of the groups of tubules which arise from the same renal vesicle. This lobation persists until after birth and then disappears completely, the surface of the kidney becoming smooth.

The Development of the Muillerian Duct and of the Genital Ridge.-At the time when the Wolffian body has almost reached its greatest development the Wolffian ridge is distinctly divided into three portions (Fig. 214), a median or mesonephric portion attached to the body wall, a lateral or tubal portion containing the Wolffian duct and attached to the mesonephric portion, and a genital portion, formed by the genital ridge and also attached to the mesonephric portion, but to its medial surface. In the tubal portion a second longitudinal duct, known as the Müllerian duct (Fig. 2I4, Md), makes its appearance. Near the anterior end of each Wolffian ridge there is formed on the free edge of the tubal portion an invagination of the peritoneal covering, and by the proliferation of the cells at its tip this invagination gradually extends backward in the substance of the tubal portion and reaches the cloaca in embryos of about $22 \mathrm{~mm}$. The primary peritoneal invagination becomes the abdominal ostium of the Müllerian duct, the backward prolongation forming the duct itself.

In Fig. $2 \mathrm{I}_{4}$ it will be seen that the tubal portion of the left Wolffian ridge is somewhat bent inward toward the median line and in the lower parts of their extent this becomes more pronounced in both tubal portions until finally their free edges come in contact and fuse in the median line, while at the same time their lower edges fuse with the floor of the cœlomic cavity. In this way a transverse partition is formed across what will eventually be the pelvis of the adult, this cavity being thus divided into two compartments, a posterior one containing the lower portion of the intestine and an anterior one containing the bladder. With the formation of this trans- 


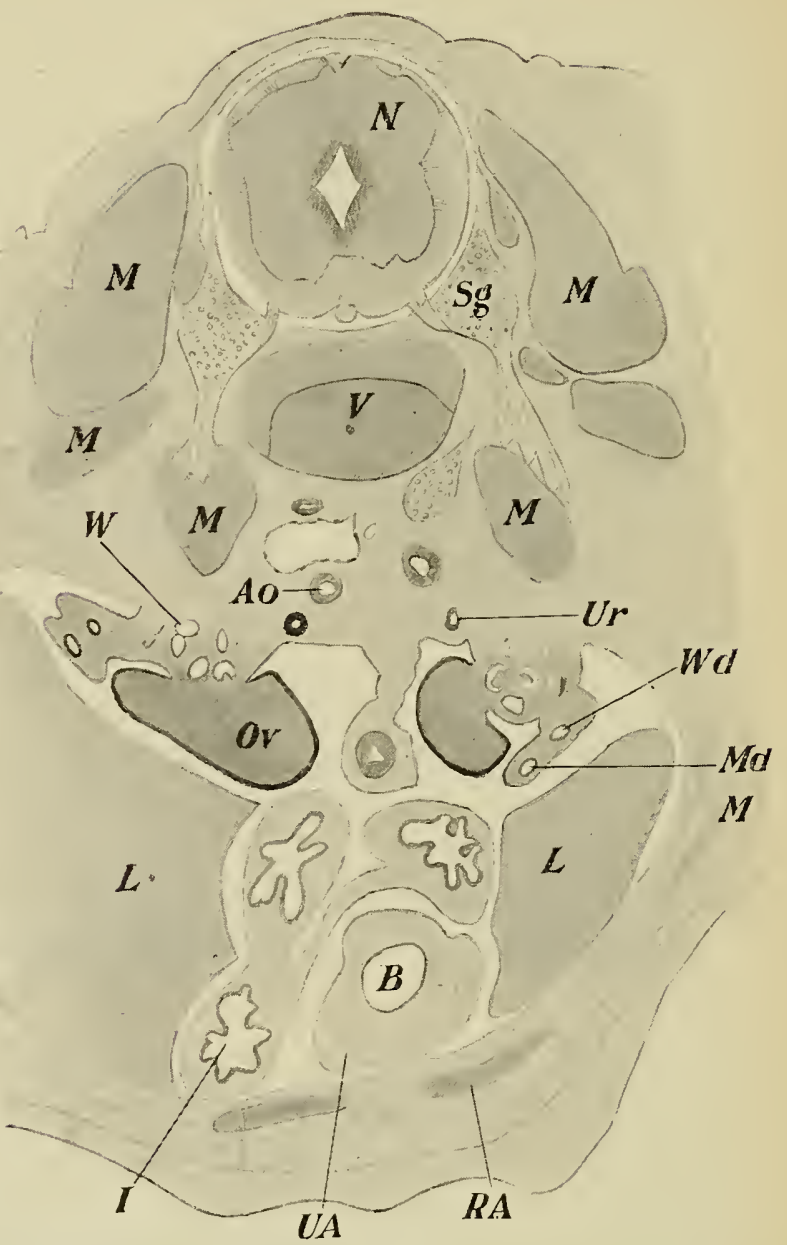

Fig. 2i4.-Transverse Section through the Abdominal Region of an Embryo OF 25 MM.

$A o$, Aorta; $B$, bladder; $I$, intestine; $L$, liver; $M$, muscle; $M d$, Müllerian duct; $N$, spinal cord; $O v$, ovary; $R A$, rectus abdominis; $S g$, spinal ganglion; $U A$, umbilical artery; $U r$, ureter; $V$, vertebra; $W$, Wolffian body; $W d$, Wolffian duct.-(Keibel.) 
verse fold, which is represented by the broad ligament in the female, the Müllerian ducts of opposite sides are brought into contact and finally fuse in the lower portions of their course to form an unpaired utero-vaginal canal.

Upon the lateral surface of the mesonephric portion of the Wolffian ridge a longitudinal elevation is formed at about this time. It is the inguinal fold and on the union of the transverse fold with the floor of the cœlomic cavity it comes into contact and fuses with the lower part of the anterior abdominal wall, just lateral to the lateral border of the rectus abdominis muscle. In the substance of the fold the mesenchyme condenses to form a ligament-like cord, the inguinal ligament, whose further history will be considered later on.

The genital ridge makes its apearance as a band-like thickening of the epithelium covering the mesial surface of the Wolffian ridge (Fig. 207, gr ). Later columns of cells grow down from the thickening into the substance of the Wolffian ridge, displacing the mesonephric tubules to a greater or less extent. These columns are composed of two kinds of cells: (I) smaller epithelial cells with a relatively small amount of cytoplasm and (2) large, spherical cells with more abundant and clear cytoplasm known as sex-cells. The growth of the cell-columns down into the substance of the Wolffian body does not take place, however, to an equal extent in all portions of the length of the genital ridge. Indeed, three regions may be recognized in the ridge; an anterior one in which a relatively small number of cell-columns, extending deeply into the stroma, is formed; a middle one in which numerous columns are formed; and a posterior one in which practically none are formed. The first region has been termed the rete region and its cell-columns the retecords, the second region the sex-gland region and its columns the sex-cords, and the posterior region is the mesenteric region and plays no part in the actual formation of the ovary or testis.

In the human embryo all the sex-cells seem to have their origin from the epithelium of the genital ridge, but in the lower vertebrates and also in mammals (Allen, Rubaschkin) they have been found to make their appearance in the endoderm of the digestive tract. Thence they wander 
into the mesentery and some of them eventually into the peritoneum covering the mesial surface of the Wolffian ridge, where they give rise to the sex-cells found in the epithelium of the genital ridge. This origin of the sex-cells has not yet been observed in the human embryo.

The various steps in the differentiation of the reproductive organs so far described occur in all embryos, no matter what their future sex may be. The later stages, however, differ according to sex, and consequently it will be necessary to follow the further development first of the testis and then of the ovary, the changes
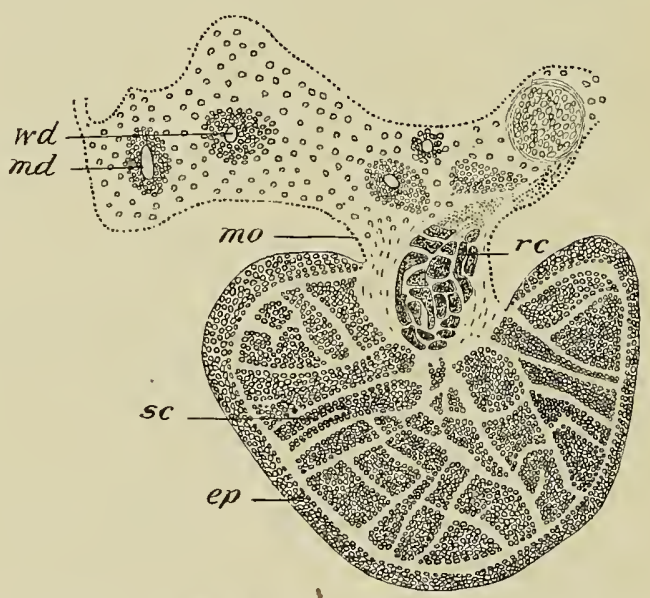

Fig. 2 I5.-Section through the Testis and the Broad Ligament of the Testis OF AN EMBRYO OF 5.5 MM.

$e p$, Epithelium; md, Müllerian duct; mo, mesorchium; rc, rete-cords; sc, sex-cords; wd, Wolffian duct.-(Mihalkovicz.)

that take place in the ducts and other accessory structures being reserved for a special section.

The Development of the Testis. - At about the fourth or fifth week there appears in the sex-gland region of the genital ridge a structure which serves to characterize the region as a testis. This is a layer of somewhat dense connective tissue which grows in between the epithelial and stroma layers of the sex-gland region and gradually extends around almost the entire sex-gland to form the tunica albuginea. By its development the sex-cords are separated from the 
epithelium, which later becomes much flattened and eventually almost disappears. Shortly after the appearance of the albuginea the sex-cords unite to from a complicated network and the rete-cords grow backward along the line of attachment of the testis to the mesonephric portion of the Wolffian ridge, coming to lie in the hilus

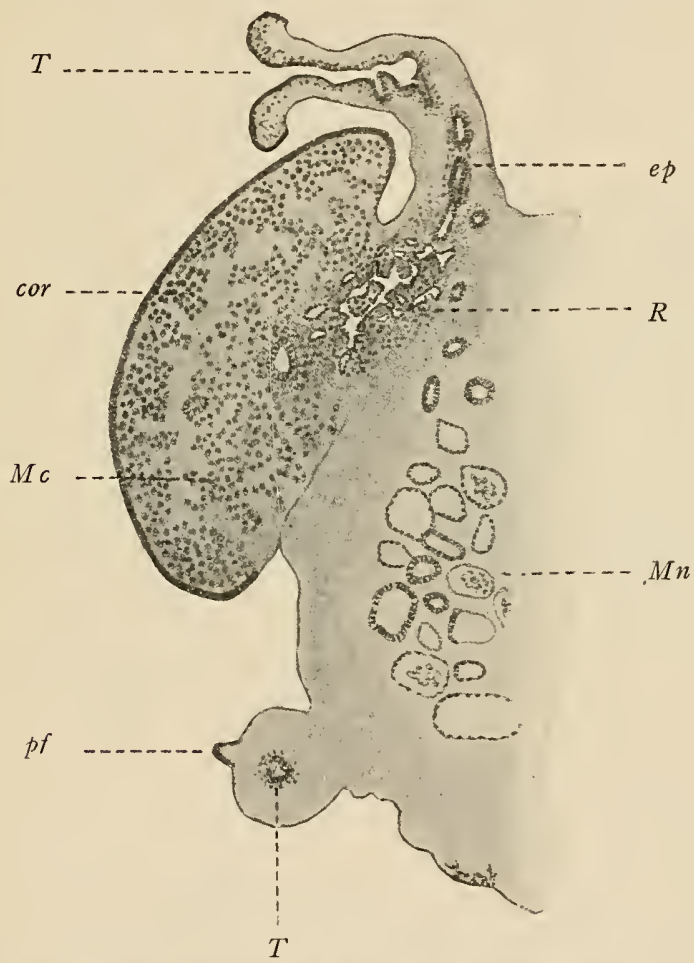

Fig. 2 i6.-Longitudinal Section of the Ovary of an Embryo Cat of 9.4 CM.

$c o r$, Cortical layer; $e p$, epoöphoron; $M c$, medullary cords; $M n$, mesonephros; $p f$, peritoneal fold containing Fallopian tube; $R$, rete; $T$, Fallopian tube.-(Coert, from Bühler.)

of the testis (Fig. 215). They then develop a lumen and send off branches which connect with the sex-cord reticulum and they also make connection with the glomerular portions of the tubules belonging to the anterior part of the mesonephros. Since like the sexcords, they have by this time separated from the epithelium that 
gave rise to them, they now extend between the sex-cord reticulum and the anterior mesonephric tubules. Certain portions of the sex-cords now begin to break down leaving other portions to form convoluted stems which eventually become the seminiferous tubules, while from the rete-cords are formed the tubuli recti and rete testis, by which the spermatozoa are transmitted to the mesonephric tubules and so to the Wolffian duct (see p. 355).

The development of the seminiferous tubules is not, however, completed until puberty. The stems derived from the sex-cords form cylindrical cords, between which lie stroma cells and interstitial cells derived from the stroma; but until puberty these cords remain solid, a lumen developing only at that period. The cords contain the same forms of cells as were described as occurring in the epithelium of the germinal ridge, and while in the early stages transitional forms seem to occur, in later periods the two varieties of cells are quite distinct, the sex-cells becoming spermatogonia (see p. 14) and being the mother cells of the spermatozoa, while the remaining epithelial cells perhaps become transformed into the connective-tissue walls of the tubules.

The Development of the Ovary. - In the case of the ovary, after the formation of the sex-cords, connective tissue grows in between these and the epithelium, forming a layer equivalent to the tunica albuginea of the testis. It is, however, a much looser tissue than its homologue in the male, and, indeed, does not completely isolate the sex-cords from the epithelium, although the majority of the cords are separated and sink into the deeper portions of the ovary where they form what have been termed the medullary cords. In the meantime the germinal epithelium has continued to bud off cords which unite to form a cortical layer of cells lying below the epithelium and separated from the medullary cords by the tunica albuginea (Fig. 2I6).

Later the cortical layer becomes broken up by the ingrowth of stroma tissue into spherical or cord-like masses, consisting of sexcells and epithelial cells (Fig. 217). The invasion of the stroma continuing, these spheres or cords (Pflüger's cords) become divided 
into smaller masses, the primary ovarian follicles, each of which consists as a rule of a single sex-cell surrounded by a number of epithelial cells, the whole being enclosed by a zone of condensed stroma tissue, which eventually becomes richly vascularized and forms a theca folliculi (Fig. Io). The epithelial cells in each follicle are at first comparatively few in number and closely surround the sex-cell (Fig. 217, f), which is destined to become an ovum, but in certain of the follicles they undergo an increase by mitosis, becoming extremely numerous, and later secrete a fluid, the liquor folliculi, which collects at one side of the follicle and eventually forms a considerable portion of its contents. The follicular cells are differentiated by its appearance in to the stratum granulosum, which surrounds the wall of the follicle, and the discus proligerus, in which the ovum is embedded (Fig. Io, $d p$ ), and the cells which immediately surround the ovum, becoming cylindrical in shape, give rise to the corona radiata (Fig. I I, cr).

A somewhat similar fate is

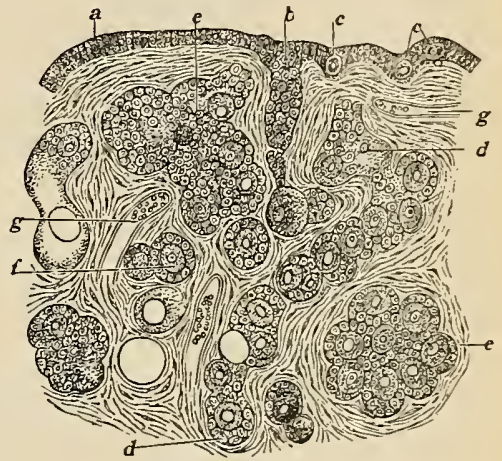

Fig. 217.- Section OF THE OVARy OF A NEW-BORN CHILD.

$a$, Ovarial epithelium; $b$, proximal part of a Pflüger's cord; $c$, sex-cell in epithelium; $d$ and $e$, spherical masses; $f$, primary follicle; $g$, blood-vessel.-( F r o $m$ Gegenbaur, after Waldeyer.) shared by the medullary cords, these also breaking up into a number of follicles, but sooner or later these follicles undergo degeneration so that shortly after birth practically no traces of the cords remain. It must be noted that degeneration of the follicles formed from the cortical layer also takes place even during fetal life and continues to occur throughout the entire periods of growth and functional activity, numerous atretic follicles being found in the ovary at all times. Indeed it would seem that degeneration is the fate of the great majority of the follicles and sex-cells of the ovary, but few ova coming to maturity during the life-time of any individual. 
Rete-cords developed from the rete portion of the germinal ridge occur in connection with the ovary as well as with the.testis and form a rete ovarii (Fig. $2 \mathrm{I} 6, R$ ). They do not, however, extend so deeply into the ovary, remaining in the neighborhood of the mesovarium, and they do not become tubular, but resemble closely the medullary cords with which they are serially homologous. They separate from the epithelium and make connections with the glomeruli of the anterior portion of the mesonephros, on the one hand, and on the other with medullary cords, and in later stages show a tendency to break up into primary follicles, which early degenerate and disappear like those of the medullary cords.

The Transformation of the Mesonephros and the Ducts.At one period of development there are present, as representatives of the urinogenital apparatus, the Wolffian body (mesonephros) and duct, the Müllerian duct, and the developing ovary or testis. Such a condition forms an indifferent stage from which the development proceeds in one of two directions according as the genital ridge becomes a testis or an ovary, the Wolffian body in part undergoing degeneration and in part persisting to form organs which for the most part are rudimentary, while in the female the Wolffian duct also degenerates except for certain rudiments and in the male the Müllerian duct behaves similarly.

In the Male.-It has been seen that the Wolffian body, through the rete cords, enters into very intimate relations with the testis, and it may be regarded as divided into two portions, an upper genital and a lower excretory. In the male the genital portion persists in its entirety, serving as the efferent ducts of the testis, which, beginning in the spaces of the rete testis, already shown to be connected with the capsules of Bowman, open into the upper part of the Wolffian duct and form the globus major of the epididymis. The excretory portion undergoes extensive degeneration, a portion of it persisting as a mass of coiled tubules ending blindly at both ends, situated near the head of the epididymis and known as the paradidymis or organ of Giraldès, while a single elongated tubule, arising from the portion of the Wolffian duct which forms the 
globus minor of the epididymis, represents another portion of it and is known as the vas aberrans.

The Wolffian duct is retained complete, the portion of it nearest the testis becoming greatly elongated and thrown into numerous coils, forming the body and globus minor of the epididymis, while the remainder of it is converted into the vas deferens and the ductus ejaculatorius. A lateral outpouching of the wall of the duct to form a longitudinal fold appears at about the third month and gives rise to the vesicula seminalis, the lateral position of the outgrowth explaining the adult position of the vesiculæ lateral to the vasa deferentia.

With the Müllerian ducts the case is very different, since they disappear completely throughout the greater part of their course, only their upper and lower ends persisting, the former giving rise to a small sac-like body, the sessile hydatid of Morgagni, attached to the upper end of each testis near the epididymis. It has been seen (p. 349) that the lower ends of the Müllerian ducts, in the male as well as the female, fuse to form the utero-vaginal canal, and the lower portion of this also persists to form what is termed the uterus masculinus, although it corresponds to the vagina of the female rather than to the uterus. It is a short cylindrical pouch of varying length, that opens into the urethra at the bottom of a depression known as the utriculus prostaticus (simus pocularis).

The transverse pelvic partition, produced by the union of the two tubal portions of the Wolffian body, is formed in the male embryo, but at an early stage its anterior surface fuses with the posterior surface of the bladder and consequently there is in the male no pelvic compartment equivalent to the vesico-uterine pouch of the female. The male recto-vesical pouch is, however, the homologue of the rectouterine pouch of the female.

The formation of the inguinal ligament on the surface of the mesonephros has been described on p. 349. On the degeneration of the mesonephros the layer of peritoneum that covered it persists to form a mesorchium extending from the body wall to the hilus of the testis and the inguinal ligament now comes to have its origin from 
the lower pole of that organ, whence it extends to the anterior abdominal wall. Owing to the rudimentary nature of the uterus masculinus and the slight development of its walls the inguinal ligament does not become involved with it, but remains independent and forms the gubernaculum testis of the adult, whose adult position is brought about by the descent of the testis into the scrotum (see p. 366).

In the Female.-In the female the transverse partition of the pelvis does not fuse $w^{\text {th }}$ the bladder but remains distinct as the broad ligament. Consey tently there is in the female both a vesicouterine and a recto-uterine pouch. Since the genital ridges form upon the mesial surfaces of the Wolffian ridges and the tubal portions are their lateral portions, when these latter unite to form the broad ligament the ovary will come to lie upon the posterior surface of that structure, projecting into the recto-vesical pouch. On the degeneration of the mesonephros the peritoneum that covered it becomes a part of the broad ligament, forming that part of it which contains the Fallopian tubes and hence is known as the mesosalpinx, while the lower part of the ligament, on account of its relation to the uterus, is termed the mesometrium.

The genital portion of the mesonephros, though never functional as ducts in the female, persists as a group of ten to fifteen tubules, situated between the two layers of the broad ligament and in close proximity to the ovary; these constitute what is known as the epoöphoron (parovarium or organ of Rosenmüller). The tubules terminate blindly at the ends nearest the ovary, but at the other extremity, where they are somewhat coiled, they open into a collecting duct which represents the upper end of the Wolffian duct. Near this rudimentary body is another, also composed of tubules, representing the remains of the excretory portion of the mesonephros and termed the paroophoron which, however, degenerates during the early years of extra-uterine life. So far as the mesonephros is concerned, therefore, the persisting rudiments in the female are comparable to those occurring in the male.

As regards the ducts, however, the case is different, for in the 
female it is the Müllerian ducts which persist, while the Wolffians undergo degeneration, a small portion of their upper ends persisting in connection with the epoöphora, while their lower ends persist as straight tubules lying at the sides of the vagina and forming what are known as the canals of Gartner. The Müllerian ducts, on the other hand, become converted into the Fallopian tubes (tube uterince), and in their lower portions into the uterus and vagina. From the margins of the openings by which the Müllerian ducts communicate with the cœlom projections develop at an early period and give rise to the fimbria, with the exception of the one connected with the ovary, the fimbria ovarica, which is the persisting upper portion of the original genital ridge. From the utero-vaginal canal the two structures which give it its name are formed, the entire canal being transformed into the mucous membrane of the uterus and vagina. Indeed, the lower ends of the Fallopian tubes are also taken up into the uterus, for the condensation of mesenchyme that takes place around the mucosa to form the muscular wall of the uterus is so voluminous that it includes not only the utero-vaginal canal but also the adjacent portions of the Müllerian ducts. The histological differentiation of the uterus from the vagina begins to manifest itself at about the third month, and during the fourth month the vaginal portion of the duct becomes flattened and the epithelium lining its lumen fuses so as to completely occlude it and, a little later, there appears at its lower opening a distinct semicircular fold. This is the hymen, a structure which seems to be represented in the male by the colliculus seminalis. The obliteration of the lumen of the vagina persists until about the sixth month, when the cavity is re-established by the breaking down of the central epithelial cells.

The extent of the mesenchymal condensation to form the muscularis uteri also produces a modification of the relations of the inguinal ligament in the female. For the ligament becomes for a short portion of its length included in the condensation and thus attached to the upper portion of the uterus. It is consequently divided into two portions, one extending from the lower pole of 
the ovary to the uterus and forming the ligamentum ovarii proprium and the other extending from the uterus to the anterior abdominal wall and forming what is known in the adult as the round ligament of the uterus.

The diagram, Fig. 2I8, illustrates the transformation from the indifferent condition which occurs in the two sexes, and that the

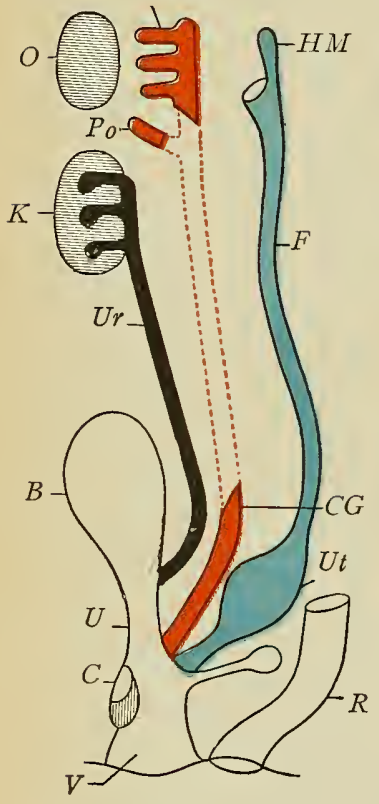

FEMALE

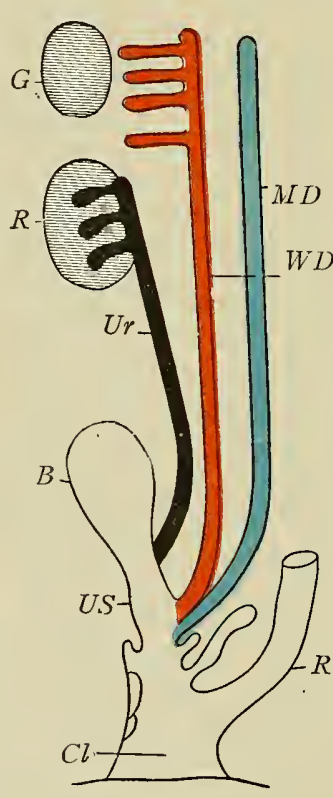

INDIFFERENT

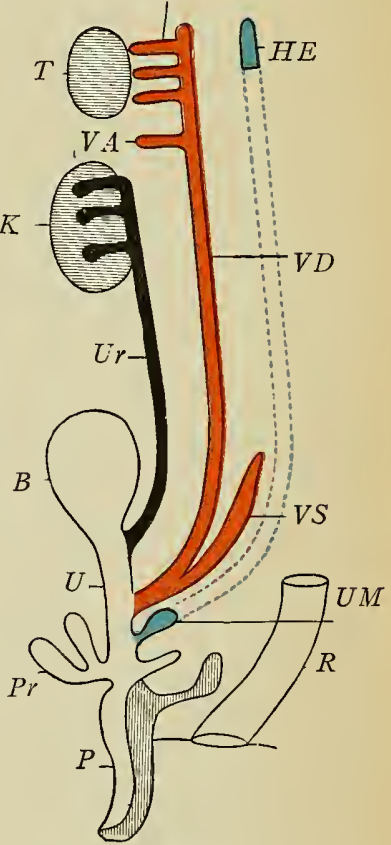

MALE

Fig. 2I8.-Diagrams Illustrating THE Transformation of the MÜllerian and WOLFFIAN DUCTS.

$B$, Bladder; $C$, clitoris; $C G$, canal of Gaertner; $C l$, cloaca; $E o$, epoöphoron; $E p$, epididymis; $F$, Fallopian tube; $G$, genital gland; $H E$, hydatid of epididymis; $H M$, hydatid of Morgagni; K, kidney; $M D$, Müllerian duct; $O$, ovary; $P$, penis; $P o$, paroöphron; $P r$, prostate gland; $R$, rectum; $T$, testis; $U$, urethra; $U M$, uterus masculinus; $U r$, ureter; $U S$, urogenital sinus; $U t$, uterus; $V$, vagina; $V a$, vas aberrans; $V D$, vas deferens; $V S$, vesicula seminalis; $W B$, Wolffian body; $W D$, Wolffian duct.-(Modified from Huxley.)

homologies of the various parts may be clearly understood they may also be stated in tabular form as on the next page. 


\begin{tabular}{|c|c|c|}
\hline Indifferent Stage. & Male. & Female. \\
\hline Genital ridge .... & $\begin{array}{l}\text { Testis. } \\
\text { Gubernaculum. . }\end{array}$ & $\begin{array}{l}\text { Fimbria ovarica. } \\
\text { Ovary. } \\
\text { Ovarian ligament. } \\
\text { Round ligament. }\end{array}$ \\
\hline Wolffian body.... & $\begin{array}{l}\text { Globus major of epididymis. } \\
\text { Paradidymis. } \\
\text { Vasa aberrantia. }\end{array}$ & $\begin{array}{l}\text { Epoöphoron. } \\
\text { Paroöphoron. }\end{array}$ \\
\hline Wolffian ducts... & $\begin{array}{l}\text { Body and globus minor of } \\
\text { epididymis. } \\
\text { Vasa deferentia. } \\
\text { Seminal vesicles.' } \\
\text { Ejaculatory ducts. }\end{array}$ & $\begin{array}{l}\text { Collecting tubules of epo- } \\
\text { öphoron. } \\
\text { Canal of Gartner. }\end{array}$ \\
\hline Mïllerian ducts... & $\begin{array}{l}\text { Sessile hyatid. } \\
\text { Uterus masculinus. }\end{array}$ & $\begin{array}{l}\text { Fallopian tubes. } \\
\text { Uterus. } \\
\text { Vagina. }\end{array}$ \\
\hline
\end{tabular}

In addition to the sessile hydatid, a stalked hydatid also occurs in connection with the testis, and a similar structure is attached to the fimbriated opening of each Fallopian tube. The significance of these structures is uncertain, though it has been suggested that they are persisting rudiments of the pronephros.

A failure of the development of the various parts just described to be completed in the normal manner leads to various abnormalities in connection with the reproductive organs. Thus there may occur a failure in the fusion of the lower portions of the Müllerian ducts, a bihorned or bipartite uterus resulting, or the two ducts may come into contact and their adjacent walls fail to disappear, the result being a median partition separating the vagina or both the vagina and uterus into two compartments. The excessive development of the fold which gives rise to the hymen may lead to a complete closure of the lower opening of the vagina, while, on the other hand, a failure of the Müllerian ducts to fuse may produce a biperforate hymen.

The Development of the Urinary Bladder and the Urogenital Sinus. - So far the relations of the lower ends of the urinogenital ducts have not been considered in detail, although it has been 
seen that in the early stages of development the Wolffian and Müllerian ducts open into the sides of the ventral portion of the cloaca; that the ureters communicate with the lower portions of the Wolffian ducts; that from the ventral anterior portion of the cloaca the allantoic duct extends outward into the belly-stalk; and, finally (p. 28I), that the cloaca becomes divided into a dorsal portion, which forms the lower part of the rectum, and a ventral portion, which is continuous with the allantois and receives the urinogenital ducts

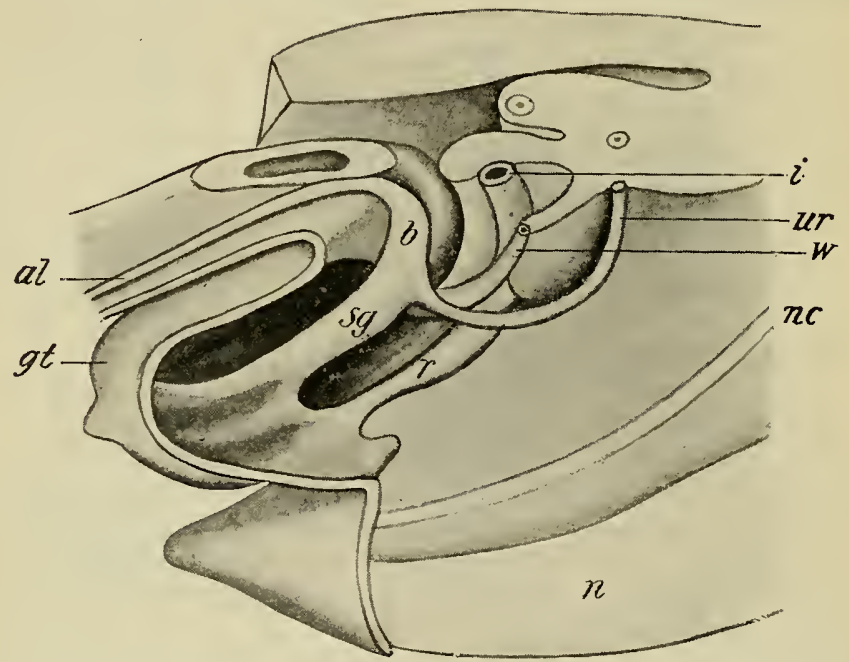

Fig. 219.-Reconstruction of the Cloacal Region of an Embryo of 14 Mm. $a l$, Allantois; $b$, bladder; $g t$, genital tubercle; $i$, intestine; $n$, spinal cord; $n c$, notochord ; $r$, rectum; sg, urogenital sinus; $u r$, ureter; $w$, Wolffian duct.-(Keibel.)

(Fig. 219). It is the history of this ventral portion of the cloaca which is now to be considered.

It may be regarded as consisting of two portions, an anterior and a posterior, the line of insertion of the urinogenital ducts marking the junction of the two. The anterior or upper portion is destined to give rise to the urinary bladder (Fig. 2 I9, $b$ ), while the lower one forms what is known for a time as the urogenital sinus $(\mathrm{sg})$. The bladder, when first differentiated, is a tubular structure, whose lumen is continuous with that of the allantois, but after the second 
month it enlarges to become more sac-like, while the intra-embryonic portion of the allantois degenerates to a solid cord extending from the apex of the bladder to the umbilicus and is known as the urachus. During the enlargement of the bladder the terminal portions of the urinogenital ducts are taken up into its walls, a process which continues until finally the ureters and Wolffian ducts open into it separately, the ureters opening to the sides of and a littleanterior to the ducts. This condition is reached in embryos of about $\mathrm{I} 4 \mathrm{~mm}$.

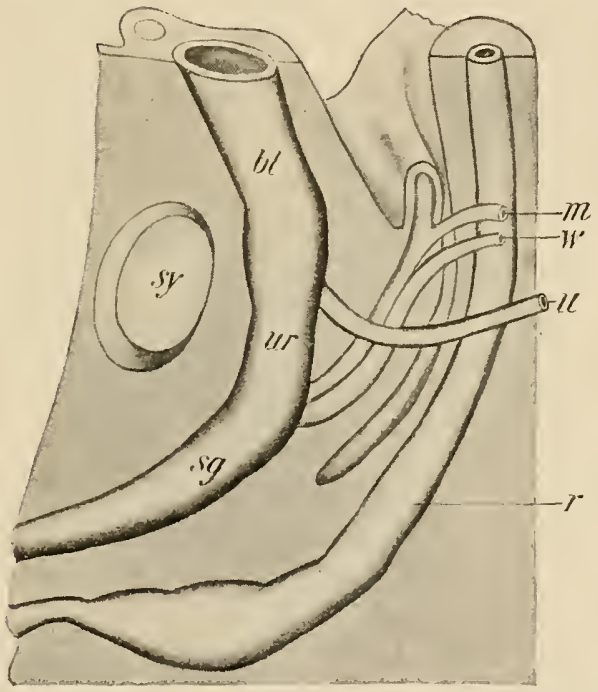

Fig. 220.-Reconstruction of the Cloacal Structures of an Embryo of 25 mim. $b l$, Bladder; $m$, Müllerian duct; $r$, rectum; $s g$, urogenital sinus; $s y$, symphysis pubis; $u$, ureter; ur, urethra; $w$, Wolffian duct.-(Adapted from Keibel.)

(Fig. 219), and in later stages the interval between the two pairs of ducts is increased (Fig. 220), resulting in the formation of a short canal connecting the lower end of the bladder which receives the ureters with the upper end of the urogenital sinus, into which the Wolffian and Müllerian ducts open. This connecting canal represents the urethra (Fig. 220, ur), or rather the entire urethra of the female and the proximal part of that of the male, since a considerable portion of the latter canal is still undeveloped (see p. 364). From 
this urethra there is developed, at about the third month, a series of solid longitudinal folds which project upon the outer surface and separate from the urethra from above downward. These represent the tubules of the prostate gland and are developed in both sexes, although they remain in a somewhat rudimentary condition in the female. The muscular tissue, so characteristic of the gland in the adult male, is developed from the surrounding mesenchyme at a later stage.

The bladder is, accordingly, essentially a derivative of the cloaca and its mucous membrane is therefore largely of endodermal origin. Portions of the Wolffian ducts which are of mesodermal origin are, however, taken up into the wall of the bladder and form a portion of it. The extent of the portion so formed is indicated by the position of the orifices of the ureters above and of the ejaculatory ducts below, and it corresponds therefore with what is termed the trigonum vesica together with the floor of the urethra as far as the openings of the ejaculatory ducts. Throughout this region the mucous membrane is of mesodermal origin.

The urogenital sinus is in the early stages also tubular in its upper part, though it expands considerably below, where it is closed by the cloacal membrane. This, by the separation of the cloaca into rectum and sinus, has become divided into two portions, the more ventral of which closes the sinus and the dorsal the rectum, the interval between them having become considerably thickened to form the perineal body. In embryos of about I $7 \mathrm{~mm}$. the urogenital portion of the membrane has broken through, and in later stages the tubular portion of the sinus is gradually taken up into the more expanded lower portion, until finally the entire sinus forms a shallow depression, termed the vestibule, into the upper part of which the urethra opens, while below are the openings of the Wolffian (ejaculatory) ducts in the male or the orifice of the vagina in the female. From the sides of the lower part of the sinus a pair of evaginations arise toward the end of the fourth month and give rise to the bulbo-vestibular glands (Bartholin's) of the female or the corresponding bulbo-urethral glands (Cowper's) in the male. 
The Development of the External Genitalia.-At about the fifth week, before the urogenital sinus has opened to the exterior, the mesenchyme on its ventral wall begins to thicken, producing a slight projection to the exterior. This eminence, which is known as the genital tubercle (Fig. $2 \mathrm{I} 9, g t$ ), rapidly increases in size, its extremity becomes somewhat bulbously enlarged (Fig. 22I, $g l$ ) and a groove, extending to the base of the terminal enlargement, appears upon its vestibular surface, the lips of the groove forming two wellmarked genital folds (Fig. 22 I, $g f$ ). At about the tenth week there appears on either side of the tubercle an enlargement termed the genital swelling (Fig. 22I, gs), which is due to a thickening of the mesenchyme of the lower part of the ventral abdominal wall in the

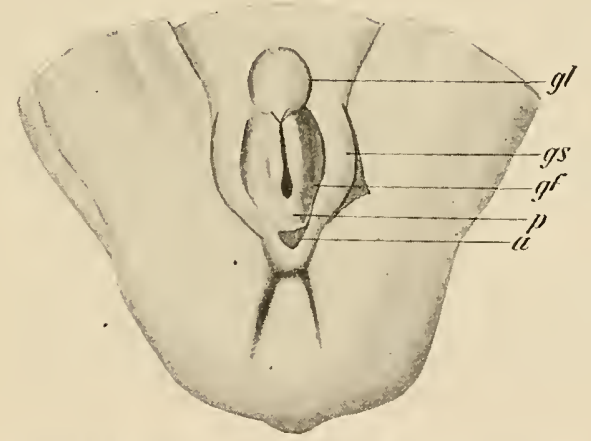

Fig. 22 I.-The External Genitalia of an Embryo of 25 MM. $a$, Anus; $g f$, genital fold; $g l$, glans; $g s$, genital swelling; $p$, perineal body.--(Keibel.)

region where the inguinal ligament is attached, and with the appearance of these structures the indifferent stage of the external genitals is completed.

In the female the growth of the genital tubercle proceeds rather slowly and it becomes transformed into the clitoris, the genital folds becoming prolonged to form the labia minora. The genital swellings increase in size, their mesenchyme becomes transformed into a mass of adipose and fibrous tissue and they become converted into the labia majora, the interval between them constituting the vulva. In the male the early stages of development are closely similar to 
those of the female; indeed, it has been well said that the external genitals of the adult female resemble those of the fetal male. In early stages the genital tubercle elongates to form the penis and the integument which covers the proximal part of it grows forward as a fold which encloses the bulbous enlargement or glans and forms the prepuce, whose epithelium fuses with that covering the glans and only separates from it later by a cornification of the cells along the plane of fusion. The genital folds meet together and fuse, converting the vestibule and the groove upon the vestibular surface of the penis into the terminal portion of the male urethra and bringing it about that the vasa deferentia and the uterus masculinus open upon the floor of that passage. The two genital swellings are at the same time brought closer together, so as to lie between the base of the penis and the perineal body and, eventually, they form the scrotum. The mesenchyme of which they were primarily composed differentiates into the same layers as are found in the wall of the abdomen and a peritoneal pouch is prolonged into them from the abdomen, so that they form sacs into which the testes descend toward the close of fetal life (p. 366).

The homologies of the portions of the reproductive apparatus derived from the cloaca and of the external genitalia in the two sexes may be perceived from the following table.

\begin{tabular}{l|l|l}
\hline & \multicolumn{1}{|c|}{ Male } & \multicolumn{1}{|c}{ Female } \\
\hline & $\begin{array}{l}\text { Urinary bladder. } \\
\text { Proximal portion of urethra. } \\
\text { Bulbo-urethral glands. } \\
\text { The rest of the urethra. } \\
\text { Penis. } \\
\text { Grogenital sinus.... } \\
\text { Genital tubercle.... } \\
\text { Genital folds....... }\end{array}$ & $\begin{array}{l}\text { Prinary bladder. } \\
\text { Urethra. } \\
\text { Bulbo-vestibular glands. } \\
\text { Vestibule. } \\
\text { Clitoris. }\end{array}$ \\
Sabia minora \\
Labia majora.
\end{tabular}

It is stated above that the layers which compose the walls of the scrotum are identical with those of the abdominal wall. This may be seen in detail from the following scheme: 
Abdominal Walls.

Integument.

Superficial fascia.

External oblique muscle.

Internal oblique muscle.

Transverse muscle.

Peritoneum.
SCROTUM.

Integument.

Dartos.

Intercolumnar fascia.

Cremasteric fascia.

Infundibuliform fascia.

Tunica vaginalis.

Numerous anomalies, depending upon an inhibition or excess of the development of the parts, may occur in connection with the external genitalia. Should, for instance, the lips of the groove on the vestibular surface of the penis fail to fuse, the penial portion of the urethra remains incomplete, constituting a condition known as hypospadias, a condition which offers a serious bar to the fulfilment of the sexual act. If the hypospadias is complete and there be at the same time an imperfect development of the penis, as frequently occurs in such cases, the male genitalia closely resemble those of the female and a condition is produced which is usually known as hermaphroditism. It is noteworthy that in such cases there is frequently a somewhat excessive development of the uterus masculinus, and a similar condition may be produced in the female by an excessive development of the clitoris. Such cases, however, which concern only the accessory organs of reproduction, are instances of what is more properly termed spurious hermaphroditism, true hermaphroditism being a term which should be reserved for possible cases in which the genital ridges give rise in the same individual to both ova and spermatozoa. Such cases are of exceeding rarity in the human species, although occasionally observed in the lower vertebrates, and the great majority of the examples of hermaphroditism hitherto observed are cases of the spurious variety.

The Descent of the Ovaries and Testes.-The positions finally occupied by the ovaries and testes are very different from those which they possess in the earlier stages of development, and this is especially true in the case of the testes. The change of position is partly due to the rate of growth of the inguinal ligaments being less than that of the abdominal walls, the reproductive organs being thereby drawn downward toward the inguinal regions where the ligaments are attached. The point of attachment is beneath the bottom of a slight pouch of peritoneum which projects a short distance into the substance of the genital swellings and is known as the canal of Nuck in the female, and in the male as the vaginal process.

In the female a second factor combines with that just mentioned. 
The relative shortening of the inguinal ligaments acting alone would draw the ovaries toward the inguinal regions, but since they are united to the uterus by the ovarian ligaments movement in that direction is prevented and the ovaries come to lie in the recto-uterine compartment of the pelvic cavity.

With the testes the case is more complicated, since in addition to the relative shortening of the inguinal ligaments there is an elongation of the vaginal processes into the substance of the genital swellings, and it must be remembered that the testes, like the ovaries, are primarily connected with the peritoneum. Three stages may be recognized in the descent of the testes. The first of these depends
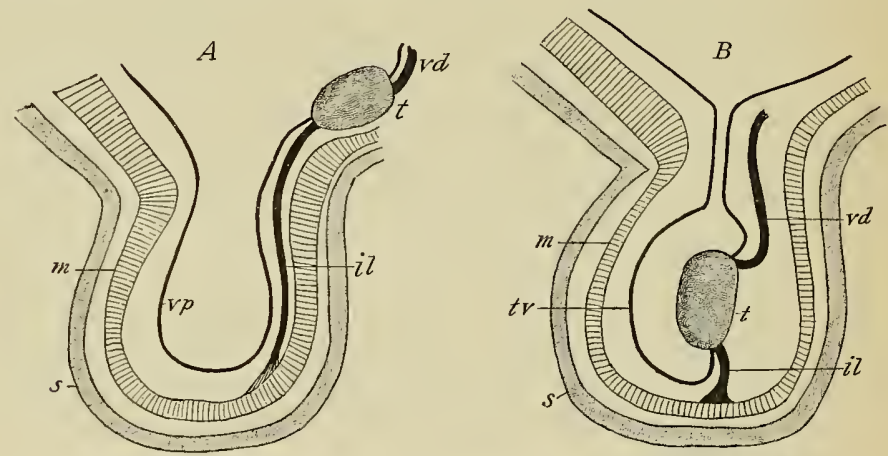

Fig. 222.-Diagrams Illustrating the Descent of the Testis.

$i l$, Inguinal ligament; $m$, muscular layer; $s$, skin and dartos of the scrotum; $t$, testis; $t v$, tunica vaginalis; $v d$, vas deferens; $v p$, vaginal process of peritoneum. - (After Hertwig.)

on the slow rate of elongation of the inguinal ligaments or gubernacula. It lasts until about the fifth month of development, when the testes lie in the inguinal region of the abdomen, but during this month the elongation of the gubernaculum becomes more rapid and brings about the second stage, during which there is a slight ascent of the testes, so that they come to lie a little higher in the abdomen. This stage is, however, of short duration, and is succeeded by the stage of the final descent, which is characterized by the elongation of the vaginal processes of the peritoneum into the substance of the scrotum (Fig. 222, A). Since the gubernaculum is attached to the 
abdominal wall beneath this process, and since its growth has again diminished, the testes gradually assume again their inguinal position, and are finally drawn down into the scrotum with the vaginal processes.

The condition which is thus acquired persists for some time after birth, the testicles being readily pushed upward into the abdominal cavity along the cavity by which they descended. Later, however, the size of the openings of the vaginal processes into the general peritoneal cavity becomes greatly reduced, so that each process becomes converted into an upper narrow neck and a lower sac-like cavity (Fig. 222, B), and, still later, the walls of the neck portion fuse and become converted into a solid cord, while the lower portion, wrapping itself around the testis, becomes the tunica vaginalis (tv). By these changes the testes become permanently located in the scrotum. During the descent of the testes the remains of each Wolffian body, the epididymis, and the upper part of each vas deferens together with the spermatic vessels and nerves, are drawn down into the scrotum, and the mesenterial fold in which they were originally contained also practically disappears, becoming converted into a sheath of connective tissue which encloses the vas deferens and the vessels and nerves, binding them together into what is termed the spermatic cord. The mesorchium, which united the testis to the peritoneum enclosing the Wolffian body, does not share in the degeneration of the latter, but persists as a fold extending between the epididymis and the testis and forming the sinus epididymis.

In the text-books of anatomy the spermatic cord is usually described as lying in an inguinal canal which traverses the abdominal walls obliquely immediately above Poupart's ligament. So long as the lumen of the neck portion of the vaginal process of peritoneum remains patent there is such a canal, placing the cavity of the tunica vaginalis in communication with the general peritoneal cavity, but the cord does not traverse this canal, but lies outside it in the retroperitoneal connective tissue. When, however, the neck of the vaginal process disappears, a canal no longer exists, although the connective tissue which surrounds the spermatic cord and unites it with the tissues of the abdominal walls is less dense than the neighboring tissues, so that the cord may readily be separated from these and thus appear to lie in a canal. 


\section{LITERATURE.}

B. M. Allen: "The Embryonic Development of the Ovary and Testes in Mammals," Amer. Journ. of Anat., III, I904.

J. L. Bremer: "Morphology of the Tubules of the Human Testis and Epididymis," Amer. Journ. Anat., XI, I9I.

E. J. Evatr: "A Contribution to the Development of the Prostate in Man," Journ. Anat. and Phys., XIIII, Igog.

E. J. Evatt: "A Contribution to the Development of the Prostate Gland in the Human Female," Journ. Anat. and Phys., XLV, IgI I.

W. FELIX: "Entwickelungsgeschichte des Exkretions-systems," Ergebn. der Anat. und Entwicklungsgesch., XIII, I903.

W. Felix: "Die Entwicklung der Harn- und Geschlechtsorgane," in KeIBeL-MaLL Human Embryology, II, I9I2.

A. FleischmanN: "Morphologische Studien über Kloake und Phallus der Amnioten, Morphol. Jarhbuch, xxx, XxxII und XxxvI, I902, 1904, I907.

O. FránKL: "Beiträge zur Lehre vom Descensus testiculorum," Sitzungsber. der kais. Akad. Wissensch. Wien, Math.-Naturwiss. Classe, crx, Igoo.

S. P. GAGE: "A Three Weeks Human Embryo, with especial reference to the Brain and the Nephric System," Amer. Journ. of Anat., IV, I905.

D. B. HART: "The Nature and Cause of the Physiological Descent of the Testes," Journ. Anat. and Phys., XLIV, I909.

D. B. HART: "The Physiological Descent of the Ovaries in the Human Fœtus," Journ. Anat. and Phys., xLrv, Igog.

E. HaucH: "Ueber die Anatomie und Entwicklung der Nieren," Anat. Hefte, XxII, I903.

G. C. Huber: "On the Development and Shape of the Uriniferous Tubules of Certain of the Higher Mammals," Amer. Journ. of Anat., IV, Suppl. I905.

J. JANOSIK: "Histologisch-embryologische Untersuchungen über das Urogenitalsystem," Sitzungsber. der kais. Akad.Wissensch. Wien, Math.-Naturwiss. Classe, xcI, I887

J. Janosık: "Ueber die Entwicklung der Nachniere bei den Amnioten," Arch. für Anat. u. Phys., Anat. Abth., I907.

J. Janosik: "Entwicklung des Nierenbeckens beim Menschen," Arch. für mikrosk. Anat., LxxviII, I9I.

F. KEIBEL: "Zur Entwickelungsgeschichte des menschlichen Urogenital-apparatus," Archiv für Anat. und Physiol., Anat. Abth., I896.

J. B. Macallum: "Notes on the Wolffian Body of Higher Mammals," Amer. Journ. o Anat., I, I902.

E. Martin: "Ueber die Anlage der Umiere beim Kaninchen," Archiv für Anat. und Physiol., Anat. Abth., I888.

H. Meyer: "Die Entwickelung der Urnieren beim Menschen," Archiv für mikrosk. Anat., Xxxvi, I89o.

R. MEYER: “Zur Kenntnis des Gartner'schen Ganges besonders in der Vagina und dem Hymen des Menschen," Arch. für mikrosk. Anat., IxxIII, Igog.

R. MEYER: "Zur Entwicklungsgeschichte und Anatomie des utriculus prostaticus beim Menschen," Arch. für mikrosk. Anat., LXxIv, I9०9 
G. voN MrHalkovicz: "Untersuchungen über die Entwickelung des Harn- und Geschlechtsapparates der Amnioten," Internat. Monatsschrift für Anat. und Physiol., II, I885.

W. NAGEL: "Ueber die Entwickelung des Urogenitalsystems des Menschen," Archiv für mikros. Anat., xxxrv, I889.

W. NAGEL: "Ueber die Entwickelung des Uterus und der Vagina beim Menschen," Archiv für mikrosk. Anat., xxxvII, I8gI.

W. NAGEL: "Ueber die Entwickelung der innere und äussere Genitalien biem menschlichen Weibes," Archiv fïr Gynäkol., xLv, I894.

K. Peter: "Untersuchungen über Bau und Entwicklung der Niere. I. Die Nierenkanälchen des Menschen und einiger Säugetiere, Jena, I909.

A. G. Pohlman: "The Development of the Cloaca in Human Embryos." A mer. Journ. of Anat., XII, IgI I.

W. Rubaschkin: "Ueber die Urgeschlechtszellen bei Säugetiere," Anat. Hefte, xxxix, I909.

K. E. SchreIner: "Ueber die Entwicklung der Amniotenniere," Zeit. für wissensch. Zool., LXXI, I902.

O. Stokrk: "Beitrag zur Kenntnis des Aufbaues der menschlichen Niere," Anat. Hefte, xxiII, I904.

J. TANDleR: "Ueber Vornieren-Rudimente beim menschliche Embryo," Anat. Hefte, XXVIII, I905.

F. J. TAussig: "The Development of the Hymen," Amer. Journ. Anat., viII, I9o8.

F. Tourneux: "Sur le développement et l'évolution du tubercule genital chez le fœtus humain dans les deux sexes," Journ. de l'Anat. et de la Physiol., xxv, I889.

S. Weber: "Zur Entwickelungsgeschichte des uropoetischen Apparates bei Säugern, mit besonderer Berücksichtigung der Urniere zur Zeit des Auftretens der bleibenden Niere," Morphol. Arbeiten, vII, I897. 


\section{CHAPTER XIV.}

\section{THE SUPRARENAL SYSTEM OF ORGANS.}

To the suprarenal system a number of bodies of peculiar structure, probably concerned with internal secretion, may be assigned. In the fishes they fall into two distinct groups, the one containing organs derived from the colomic epithelium and known as interrenal organs, and the other consisting of organs derived from the sympathetic nervous system and which, on account of the characteristic affinity they possess for chromium salts, have been termed the chromaffine organs. But in the amphibia and amniote vertebrates, while both the groups are represented by independent organs, yet they also become intimately associated to form the suprarenal bodies, so that, notwithstanding their distinctly different origins, it is convenient to consider them together.

The Development of the Suprarenal Bodies.-The suprarenal bodies make their appearance at an early stage, while the Wolffian bodies are still in a well-developed condition, and they are situated at first to the medial side of the upper ends of these structures (Fig. 2II, sr). Their final relation to the metanephros is a secondary event, and is merely a topographic relation, there being no developmental relation between the two structures.

In the human embryo they make their appearance at about the beginning of the fourth week of development as a number of proliferations of the cœlomic epithelium, which project into the subjacent mesenchyme, and are situated on either side of the median line between the root of the mesentery and the upper portion of the Wolffian body. The various proliferations soon separate from the epithelium and unite to form two masses situated in the mesenchyme, one on either side of the upper portion of the abdominal aorta. In certain forms, such as the rabbit, the primary proliferations arise 
from the bottom of depressions of the cœlomic epithelium (Fig. 223), but in the human embryo these depressions do not form.

Up to this stage the structure is a pure interrenal organ, but during the fifth week of development masses of cells, derived from the abdominal portion of the sympathetic nervous system, begin to penetrate into each of the interrenal masses (Fig. 224), and form strands traversing them. At about the ninth or tenth week fatty granules begin to appear in the interrenal cells and somewhat later, about the fourth month, the sympathetic constituents begin to show their chromaffine characteristics. The two tissues, however, remain intermingled for a considerable time, and it is not until a much later

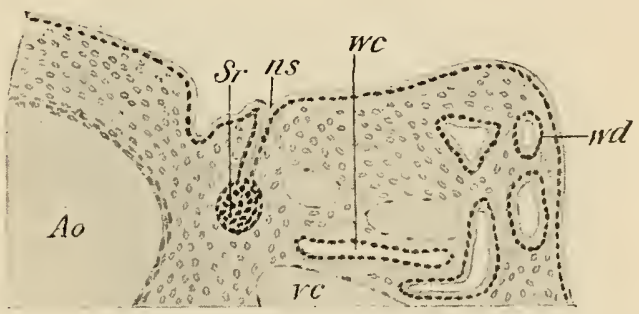

Fig. 223.-Section through a Portion of the Wolffian Ridge of a Rabbit EMBRYO OF 6.5 MM.

Ao, Aorta; $n s$, nephrostome; $S r$, suprarenal body; $v c$, cardinal vein; $w c$, tubule of Wolffian body; wd, Wolffian duct.-(Aichel.)

period that they become definitely separated, the sympathetic elements gradually concentrating in the center of the compound organ to become its medullary substance, while the interrenal tissue forms the cortical substance. Indeed, it is not until after birth that the separation of the two tissues and their histological differentiation is complete, occasional masses of interrenal tissue remaining imbedded in the medullary substance and an immigration of sympathetic cells continuing until at least the tenth year (Wiesel).

A great deal of difference of opinion has existed in the past concerning the origin of the suprarenal glands. By several authors they have been regarded as derivatives in whole or in part of the excretory apparatus, some tracing their origin to the mesonephros and others even to the pronephros. The fact that in some mammals the cortical (interrenal) cells are 
formed from the bottom of depressions of the cœlomic epithelium seemed to lend support to this view, but it is now pretty firmly established that the appearances thus presented do not warrant the interpretation placed upon them and that the interrenal tissue is derived from the colomic epithelium quite independently of the nephric tubules. That the chromaffine tissue is a derivative of the sympathetic nervous system has long been recognized.

During the development of the suprarenal glands portions of their tissue may be separated as the result of unequal growth and form what are commonly spoken of as accessory suprarenal glands, although, since they are usually composed solely of cortical sub-

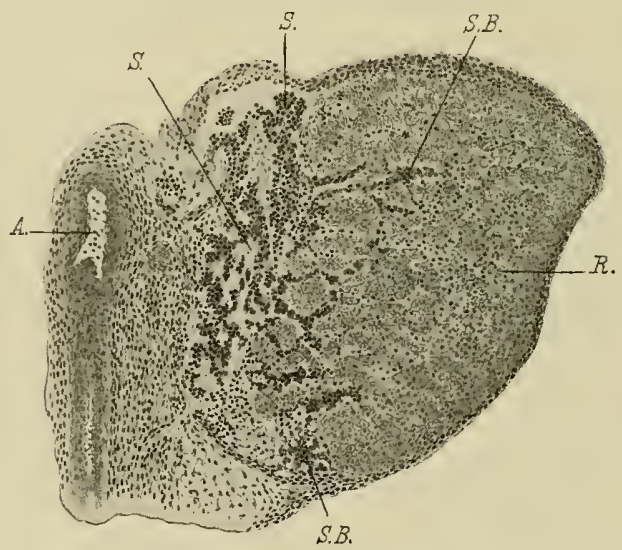

Fig. 224.-Section throdgh the Suprarenal Body of an Embryo of 77 mM. $A$, Aorta; $R$, interrenal portion; $S$, sympathetic nervous system; $S B$, sympathetic cells penetrating the interrenal portion.-(Wiesel.)

stance, the term accessory interrenal bodies would be more appropriate. They may be formed at different periods of development and occur in various situations, as for instance, in the vicinity of the kidneys or even actually imbedded in their substance, on the walls of neighboring blood-vessels, in the retroperitoneal tissue below the level of the kidneys, and in connection with the organs of reproduction, in the spermatic cord, epididymis or rete testis of the male and in the broad ligament of the female.

It seems probable that the bodies associated with the reproductive 
apparatus are separated from the main mass of interrenal tissue before the immigration of the sympathetic tissue and before the descent of the ovaries or testes, while those which occur at higher levels are of later origin, and in some cases may contain some medullary substance, being then true accessory suprarenals. Such bodies are, however, comparatively rare, the great majority of the accessory bodies being composed of interrenal tissuc alone.

Independent chromaffine organs also occur, among them the

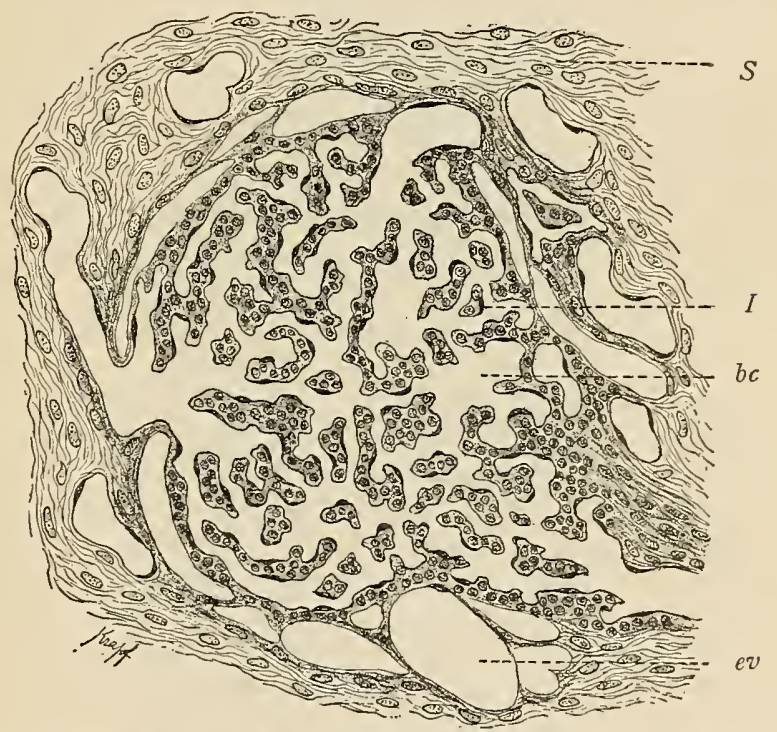

Fig. 225.-Section of a Cell Ball from the Intercarotid Ganglion of Man. $b c$, Blood capillaries; $e v$, efferent vein; $S$, connective-tissue septum; $I$, trabeculæ.(From Böhm and Davidoff, after Schaper.)

intercarotid ganglia and the organs of Zuckerkandl being especially deserving of note. It may also be pointed out, however, that the chromaffine cells have the same origin as the cells of the sympathetic ganglia and may sometimes fail to separate from the latter, so that the sympathetic ganglia and plexuses frequently contain chromaffine cells.

The Intercarotid Ganglia.-These structures, which are fre- 
quently though incorrectly termed carotid glands, are small bodies about $5 \mathrm{~mm}$. in length, which lie usually to the mesial side of the upper ends of the common carotid arteries. They possess a very rich arterial supply and stand in intimate relation with the branches of an intercarotid sympathetic plexus, and, furthermore, they are characterized by possessing as their specific constituents markedly chromaffine cells, among which are scattered stellate cells resembling the cells of the sympathetic ganglia.

They have been found to arise in pig embryos of $44 \mathrm{~mm}$. by the separation of cells from the ganglionic masses scattered throughout the carotid sympathetic plexuses. These cells, which become the chromaffine cells, arrange themselves in round masses termed cell balls, many of which unite to form each ganglion, and in man each cell ball becomes broken up into trabeculæ by the blood-vessels (Fig. 225) which penetrate its substance, and the individual balls are separated from one another by considerable quantities of connective tissue.

Some confusion has existed in the past as to the origin of this structure. The mesial wall of the proximal part of the internal carotid artery becomes considerably thickened during the early stages of development and the thickening is traversed by numerous blood lacunæ which communicate with the lumen of the vessel. This condition is perhaps a relic of the branchial capillaries which in the lower gill-breathing vertebrates represent the proximal portion of the internal carotid, and has nothing to do with the formation of the intercarotid ganglion, although it has been believed by some authors (Schaper) that the ganglion was derived from the thickening of the wall of the vessel. The fact that in some animals, such as the rat and the dog, the ganglion stands in relation with the external carotid and receives its blood-supply from that vessel is of importance in this connection.

The thickening of the internal carotid disappears in the higher vertebrates almost entirely, but in the Amphibia it persists throughout life, the lumen of the proximal part of the vessel being converted into a fine meshwork by the numerous trabeculæ which traverse it. This carotid labyrinth has been termed the carotid gland, a circumstance which has probably assisted in producing confusion as to the real significance of the intercarotid ganglion.

The Organs of Zuckerkandl.-In embryos of $14.5 \mathrm{~mm}$. there have been found, in front of the abdominal aorta, closely packed 
groups of cells which resemble in appearance the cells composing the ganglionated cord, two of these groups, which extend downward along the side of the aorta to below the point of origin of the inferior mesenteric artery, being especially distinct. These cell groups give rise to the ganglia of the prævertebral sympathetic plexuses and also

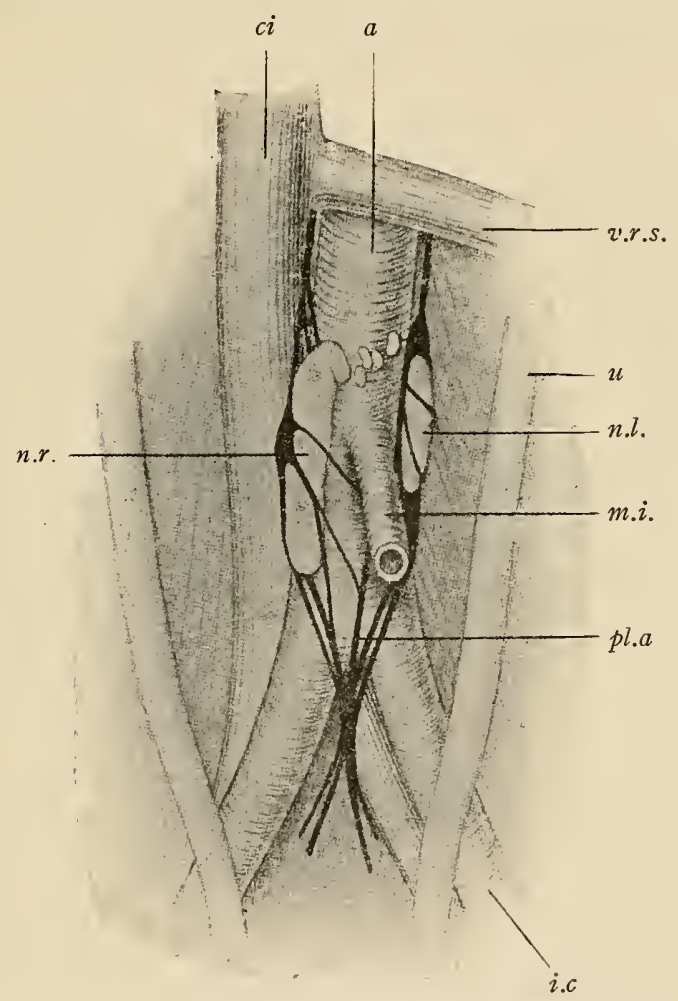

Fig. 226.-Organs of Zuckerkandl from a New-born Child.

$a$, Aorta; $c i$, inferior vena cava; i.c, common iliac artery; $m i$, inferior mesenteric artery; $n . l$ and $n . r$, left and right accessory organs; pl.a, aortic plexus; $u$, ureter; v.r.s, left renal vein.-(Zuckerkandl.)

to peculiar bodies which, from their discoverer, may be termed the organs of Zuckerkandl. Each body stands in intimate relation with the fibers of the sympathetic plexuses and has a rich blood-supply, resembling in these respects the intercarotid ganglia, and the resem- 
blance is further increased by the fact that the specific cells of the organ are markedly chromaffine.

At birth the bodies situated in the upper portion of the abdominal cavity have broken up into small masses, but the two lower ones, mentioned above, are still well defined (Fig. 226). Even these, however, seem to disappear later on and no traces of them have as yet been found in the adult.

\section{LITERATURE.}

A. KoHN: "Ueber den Bau und die Entwickelung der sog. Carotisdrüse," Archiv. für mikrosk. Anat., LVI, I900.

A. KоHN: "Das chromaffine Gewebe," Ergebn. der Anat. und Entwickelungsgesch., XII, IgO2.

H. PolL: "Die vergleichende Entwicklungsgeschichte der Nebennierensysteme der Wirbeltiere," Hertwig's Handb. der vergl. und exper. Entwicklungslehre der Wirbeltiere, III, I906.

A. Soulié: "Recherches sur le développement des capsules surrénales chez les Vertébrés," Journ. de l'Anat. et de la Physiol., xxxix, I903.

J. WIESEL: "Beiträge zur Anatomie und Entwickelung der menschlichen Nebenniere," Anat. Heft., XIX, I902.

E. ZuckerKandL: "Ueber Nebenorgane des Sympathicus im Retroperitonealraum des Menschen," Verhandl. Anat. Gesellsch., xv, I9or. 
CHAPTER XV.

\section{THE DEVELOPMENT OF THE NERVOUS SYSTEM.}

The Histogenesis of the Nervous System.-The entire central nervous system is derived from the cells lining the medullary groove, whose formation and conversion into the medullary canal has already been described (p. 72). When the groove is first formed, the cells lining it are somewhat more columnar in shape than those on either side of it, though like them they are arranged in a single layer; later they increase by mitotic division and arrange themselves in several layers, so that the ectoderm of the groove becomes very much thicker than that of the general surface of the body. At the same time the cell boundaries, which were originally quite distinct, gradually disappear, the tissue becoming a syncytium. While its tissue is in this condition the lips of the medullary groove unite, and the subsequent differentiation of the canal so formed differs somewhat in different regions, although a fundamental plan may be recognized. This plan is most readily perceived in the region which becomes the spinal cord, and may be described as seen in that region.

Throughout the earlier stages, the cells lining the inner wall of the medullary tube are found in active proliferation, some of the cells so produced arranging themselves with their long axes at right angles to the central canal (Fig. 227), while others, whose destiny is for the most part not yet determinable, and which therefore may be termed indifferent cells are scattered throughout the syncytium. At this stage a transverse section of the medullary tube shows it to be composed of two well-defined zones, an inner one immediately surrounding the central canal and composed of the indifferent cells and the bodies of the inner or ependymal cells, and an outer one consisting of branched prolongations of the syncytial cytoplasm. This 
outer layer is termed the marginal velum (Randschleier) (Fig. 227, $m)$. The indifferent cells now begin to wander outward to form a definite layer, termed the mantle layer, lying between the marginal velum and the bodies of the ependymal cells (Fig. 228), and when this layer has become well established the cells composing it begin to divide and to differentiate into (I) cells termed neuroblasts, destined to become nerve-cells, and (2) others which appear to be supportive in character and are termed neuroglia cells (Fig. 228, B).

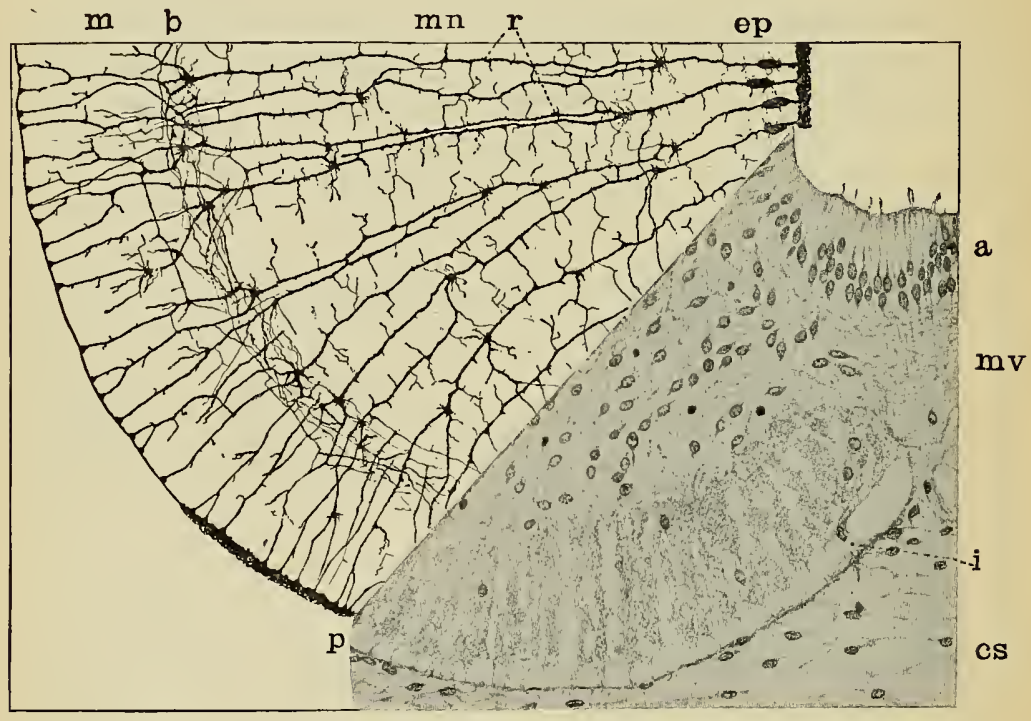

Fig. 227.-Transverse Section through the Spinal Cord of a Pig Embryo

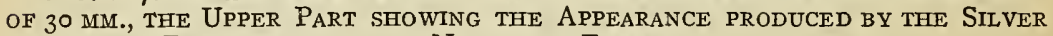
Method of Demonstrating the Neuroglia Fibers.

$a$, Ependyma of floor plate; $b$, boundary between mantle, layer and marginal zone; $c s$, mesenchymal connective-tissue syncytium; $e p$, ependymal cells; $i$, ingrowth of connective tissue; $m$, marginal velum; $m n$, mantle layer; $m v$, mantle layer of floor plate; $p$, pia mater; $r$, neuroglia fibers.-(Hardesty.)

The latter are for the most part small and are scattered among the neuroblasts, these, on the other hand, being larger and each early developing a single strong process which grows out into the marginal velum and is known as an axis-cylinder. At a later period the 
neuroblasts also give rise to other processes, termed dendrites, more slender and shorter than the axis-cylinders, branching repeatedly, and, as a rule, not extending beyond the limits of the mantle layer.

In connection with the neuroglia cells peculiar neuroglia fibrils develop very much in the same way as the fibers are formed in mesenchymal connective tissue. That is to say, they are formed from the peripheral portions of the cytoplasm of the neuroglial and ependymal cells. But since these cells are connected together to form a syncytium the fibrils are not confined to the territories of the indi-
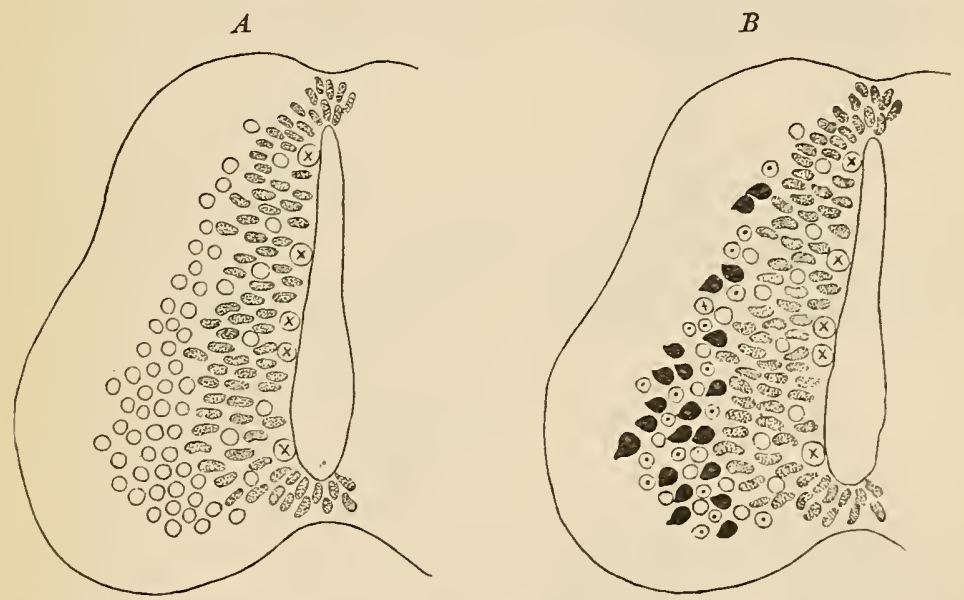

Fig. 228.-Diagrams Showing the Developaient of the Mantle Layer in the SPINAL CORD.

The circles, indifferent cells; circles with dots, neuroglia cells; shaded cells, germinal cells; circles with cross, germinal cells in mitosis; black cells, nerve-cells.-(Schaper.)

vidual cells, but may extend far beyond these, passing in the syncytium from the territory of one neuroglial cell to another, many of those, indeed, arising in connection with the ependymal cells extending throughout the entire thickness of the medullary wall (Fig. 227). The fibrils branch abundantly and form a supportive network extending through all portions of the central nervous system.

The axis-cylinder processes of the majority of the neuroblasts on reaching the marginal velum bend upward or downward and, after 
traversing a greater or less length of the cord, re-enter the mantle layer and terminate by dividing into numerous short branches which come into relation with the dendrites of adjacent neuroblasts. The processes of certain cells situated in the ventral region of the mantle zone pass, however, directly through the marginal velum out into the surrounding tissues and constitute the ventral nerveroots (Fig. 23I).

The dorsal nerve-roots have a very different origin. In embryos
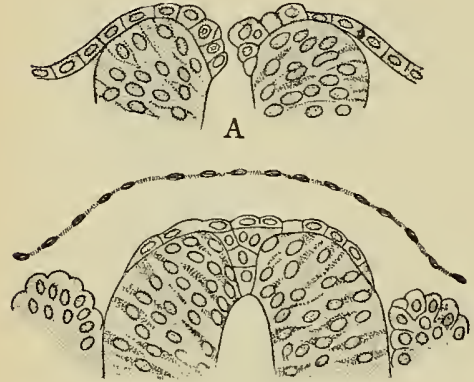

B

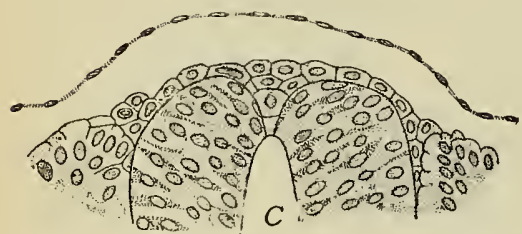

Fig. 229.-Three Sections through the Medullary Canal of an Embryo OF 2.5 MM.-(von Lenhossek.)

of about $2.5 \mathrm{~mm}$, in which the medullary canal is only partly closed (Fig. 53), the cells which lie along the line of transition between the lips of the groove and the general ectoderm form a distinct ridge readily recognized in sections and termed the neural crest (Fig. 229, A). When the lips of the groove fuse together the cells of the crest unite to form a wedge-shaped mass, completing the closure of the canal (Fig. 229, B), and later proliferate so as to extend outward over the surface of the canal (Fig. 229, C). Since this proliferation is most active in the regions of the crest which correspond to the mesodermic somites there is formed a series of cell masses, arranged segmentally and situated in the mesenchyme at the sides of the medullary canal (Fig. 2I4). These cell masses represent the dorsal root ganglia, and certain of their constituent cells, which may also be termed neuroblasts, early assume a fusiform shape and send out a process from each extremity. One of these processes, the axiscylinder, grows inward toward the medullary canal and penetrates its 
marginal velum, and, after a longer or shorter course in this zone, enters the mantle layer and comes into contact with the dendrites of some of the central neuroblasts. The other process extends peripherally and is to be regarded as an extremely elongated dendrite. The processes from the cells of each ganglion aggregate to form a nerve, that formed by the axis-cylinders being the posterior root of a spinal nerve, while that formed by the dendrites soon unites with the ventral nerve-root of the corresponding segment to form the main stem of a spinal nerve.

There is thus a very important difference in the mode of development of the two nerve-roots, the axis-cylinders of the ventral roots

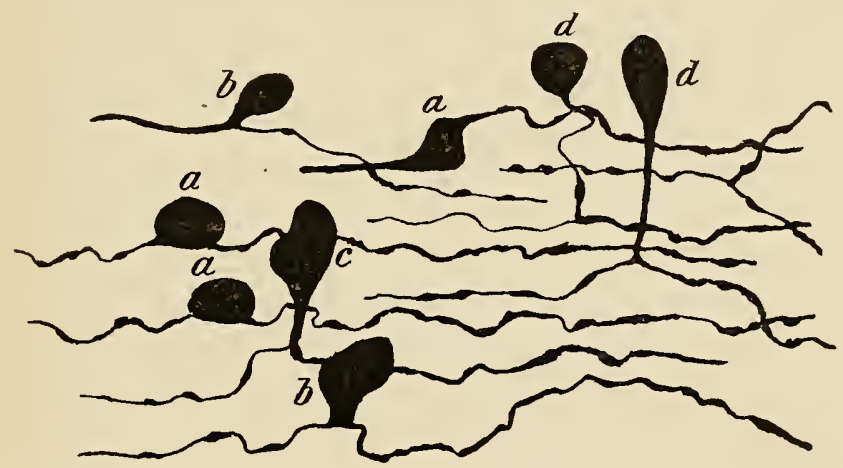

Fig. 230.-Cells from the Gasserian Ganglion of a Guinea-pig Embryo. $a$, Bipolar cell; $b$ and $c$, transitional stages to $d$, T-shaped cells.-(von Gehuchten.)

arising from cells situated in the wall of the medullary canal and growing outward (centrifugally), while those of the dorsal root spring from cells situated peripherally and grow inward (centripetally) toward the medullary canal. In the majority of the dorsal root ganglia the points of origin of the two processes of each bi-polar cell gradually approach one another (Fig. 230, b) and eventually come to rise from a common stem, a process of the cell-body, which thus assumes a characteristic $T$ form (Fig. 230, d).

From what has been said it will be seen that each axis-cylinder is an outgrowth from a single neuroblast and is part of its cell-body, as are also the dendrites. Another view has, however, been advanced to the 
effect that the nerve fibers first appear as chains of cells and that the axiscylinders, being differentiated from the cytoplasm of the chains, are really multicellular products. Many difficulties stand in the way of the acceptance of this view and recent observations, both histogenetic (Cajal) and experimental (Harrison), tend to confirm the unicellular origin of the axis-cylinders. The embryological evidence therefore goes to support the neurone theory, which regards the entire nervous system as composed of definite units, each of which corresponds to a single cell and is termed a neurone.

By the development of the axis-cylinders which occupy the meshes of the marginal velum, that zone increases in thickness and comes to consist principally of nerve-fibers, while the cell-bodies of the neurones of the cord are situated in the mantle zone. No such definite distinction of color in the two zones as exists in the adult is, however, noticeable until a late period of development, the medullary sheaths, which give to the nerve-fibers their white appearance not beginning to appear until the fifth month and continuing to form from that time onward until after birth. The origin of the myelin which composes the medullary sheaths is as yet uncertain, although the more recent observations tend to show that it is picked out from the blood and deposited around the axis-cylinders in some manner not yet understood. Its appearance is of importance as being associated with the beginning of the functional activity of the nerve-fibers.

In addition to the medullary sheaths the majority of the fibers of the peripheral nervous system are provided with primitive sheaths, which are lacking, however, to the fibers of the central system. They are formed by cells which wander out from the dorsal root-ganglia and are therefore of ectodermal origin. Frog larvæ deprived of their neural crests at an early stage of development produce ventral nerve-fibers altogether destitute of primitive sheaths (Harrison).

Various theories have been advanced to account for the formation of the medullary sheaths. It has been held that the myelin is formed at the expense of the outermost portions of the axis-cylinders themselves (von Kölliker), and on the other hand, it has been regarded as an excretion of the cells which compose the primitive sheaths surrounding the fibers 
(Ranvier), a theory which is, however, invalidated by the fact that myelin is formed around the fibers of the central nervous system which possess no primitive sheaths. As stated above, the more recent observations (Wlassak) indicate its exogenous origin.

It has been seen that the central canal is closed in the mid-dorsal line by a mass of cells derived from the neural crest. These cells do not take part in the formation of the mantle layer, but become completely converted into ependymal tissue, and the same is true of the cells situated in the mid-ventral line of the canal. In these two regions, known as the roof-plate and floor-plate respectively, the wall of the canal has a characteristic structure and does not share to any great extent in the increase of thickness which distinguishes the other regions (Fig. 23I). In the lateral walls of the canal there is also noticeable a differentiation into two regions, a dorsal one standing in relation to the ingrowing fibers from the dorsal root ganglia and known as the dorsal zone, and a ventral one, the ventral zone, similarly related to the ventral nerve-roots. In different regions of the medullary tube these zones, as well as the roof- and floor-plates, undergo different degrees of development, producing peculiarities which may now be considered.

The Development of the Spinal Cord.-Even before the lips of the medullary groove have met a marked enlargement of the anterior portion of the canal is noticeable, the region which will become the brain being thus distinguished from the more posterior portion which will be converted into the spinal cord. When the formation of the mesodermic somites is completed, the spinal cord terminates at the level of the last somite, and in this region still retains its connection with the ectoderm of the dorsal surface of the body; but in that portion of the cord which is posterior to the first coccygeal segment the histological differentiation does not proceed beyond the stage when the walls consist of several layers of similar cells, the formation of neuroblasts and nerve-roots ceasing with the segment named. After the fourth month the more differentiated portion elongates at a much slower rate than the surrounding tissues and so appears to recede up the spinal canal, until its 
termination is opposite the second lumber vertebra. The less differentiated portion, which retains its connection with the ectoderm until about the fifth month, is, on the other hand, drawn out into a slender filament whose cells degenerate during the sixth month, except in its uppermost part, so that it comes to be represented throughout the greater part of its extent by a thin cord composed of pia mater. This cord is the structure known in the adult as the filum terminale, and lies in the center of a leash of nerves occupying the lower part of the spinal canal and termed the cauda equina. The existence of the cauda is due to the recession of the cord which necessitates for the lower lumbar, sacral and coccygeal nerves, a descent through the spinal canal for a greater or less distance, before they can reach the intervertebral foramina through which they make their exit.

In the early stages of development the central canal of the cord is quite large and of an elongated oval form, but later it becomes somewhat rhomboidal in shape (Fig. 23I, A), the lateral angles marking the boundaries between the dorsal and ventral zones. As development proceeds the sides of the canal in the dorsal region gradually approach one another and eventually fuse, so that this portion of the canal becomes obliterated (Fig. 23I, B) and is indicated by the dorsal longitudinal fissure in the adult cord, the central canal of which corresponds to the ventral portion only of the embryonic cavity. While this process has been going on both the roofand the floor-plate have become depressed below the level of the general surface of the cord, and by a continuance of the depression of the floor-plate-a process really due to the enlargement and consequent bulging of the ventral zone-the anterior median fissure is produced, the difference between its shape and that of the dorsal fissure being due to the difference in its development.

The development of the mantle layer proceeds at first more rapidly in the ventral zone than in the dorsal, so that at an early stage (Fig. 23I, A) the anterior column of gray matter is much more pronounced, but on the development of the dorsal nerve-roots the formation of neuroblasts in the dorsal zone proceeds apace, resulting 
in the formation of a dorsal column. A small portion of the zone, situated between the point of entrance of the dorsal nerve-roots and the roof-plate, fails, however, to give rise to neuroblasts and is entirely converted into ependyma. This represents the future funiculus gracilis (fasciculus of Goll) (Fig. 23r, A, cG), and at the point of entrance of the dorsal roots into the cord a well-marked oval bundle of fibers is formed (Fig. 23I, A, ob) which, as develop-
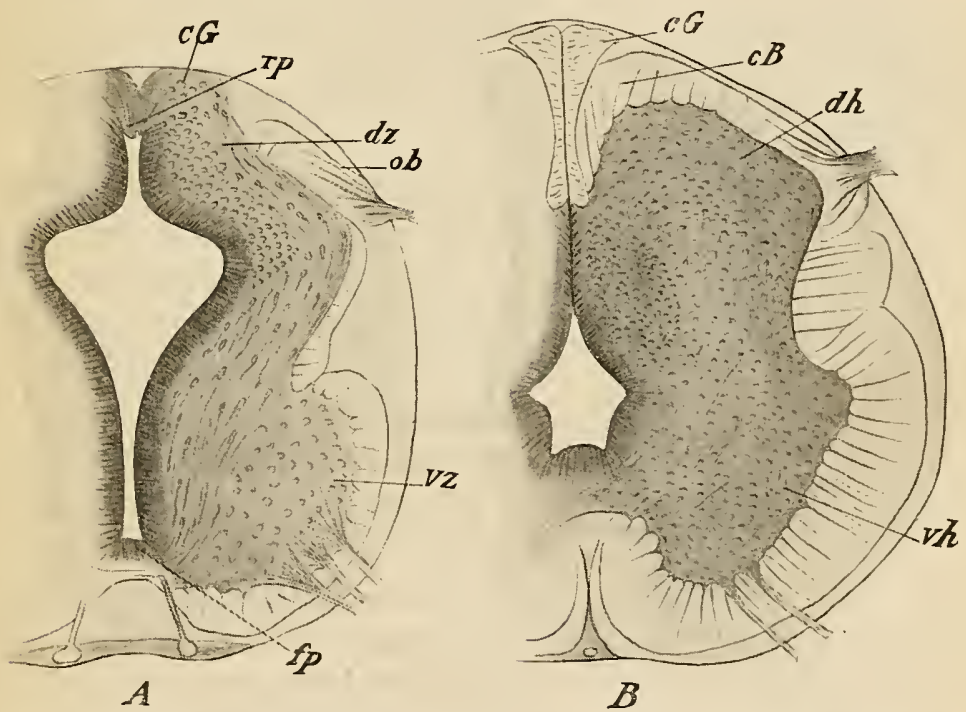

Fig. 23i.-Transverse Sections through the Spinal Cords of Embryos of (A) about Four and a Hale Weeks and $(B)$ about Three Months.

$c B$, Fasciculus of Burdach; $c G$, fasciculus of Goll; $d h$, dorsal column; $d z$, dorsal zone; $f p$, floor-plate; $o b$, oval bundle; $r p$, roof-plate; $v h$, ventral column; $v z$, ventral zone. -(His.)

ment proceeds, creeps dorsally over the surface of the dorsal horn until it meets the lateral surface of the fasciculus of Goll, and, its further progress toward the median line being thus impeded, it insinuates itself between that fasciculus and the posterior horn to form the funiculus cuneatus (fasciculus of Burdach) (Fig. 23 I, B, cB).

Little definite is as yet known concerning the development of the other fasciculi which are recognizable in the adult cord, but it seems 
certain that the lateral and anterior cerebro-spinal (pyramidal) fasciculi are composed of fibers which grow downward in the meshes of the marginal velum from neuroblasts situated in the cerebral cortex, while the cerebello-spinal (direct cerebellar) fasciculi and the fibers of the ground-bundles have their origin from cells of the mantle layer of the cord.

The myelination of the fibers of the spinal cord begins between the fifth and sixth months and appears first in the funiculi cuneati, and about

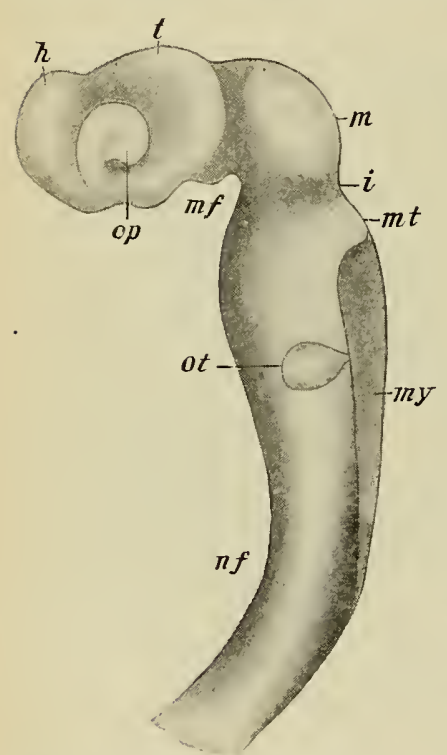

Fig. 232.-RECONSTRUCTION OF THE BRAIN OF AN EMBRYO OF 2.I 5 MM.

$h$, Hemisphere; $i$, isthmus; $m$, mesencephalon; $m f$, mid-brain flexure; $m t$, metencephalon; myl, myelencephalon; $n f$, nape flexure; ot, otic capsule; $o p$, optic evagination; $t$, diencephalon.-(His.)

a month later in the funiculi graciles. The myelination of the great motor paths, the lateral and anterior cerebro-spinal fasciculi, is the last to develop, appearing toward the end of the ninth month of fetal life.

\section{The Development of the Brain.} - The enlargement of the anterior portion of the medullary canal does not take place quite uniformly, but is less along two transverse lines than else where, so that the brain region early becomes divided into three primary vesicles which undergo further differentiation as follows. Upon each side of the anterior vesicle an evagination appears and becomes converted into a club-shaped structure attached to the ventral portion of the vesicle by a pedicle. These evaginations (Fig. $232, o p)$ are known as the optic evaginations, and being concerned in the formation of the eye will be considered in the succeeding chapter. After their formation the antero-lateral portions of the vesicle become bulged out into two protuberances $(h)$ which rapidly increase in size and give rise eventually to the two cerebral hemispheres, which form, together with the portion of the vesicle which lies between them, what is termed the telencephalon or forebrain, the remainder of the vesicle giving rise to what is known as 
the diencephalon or 'tween-brain (Fig. 232, $t$ ). The middle vesicle is bodily converted into the mesencephalon or mid-brain $(m)$, but the posterior vesicle differentiates so that three parts may be recognized: (I) a rather narrow portion which immediately succeeds the midbrain and is termed the isthmus $(i)$; (2) a portion whose roof and floor give rise to the cerebellum and pons respectively, and which is termed the metencephalon or hind-brain $(m t)$; and (3) a terminal portion which is known as the medulla oblongata, or, to retain a consistent nomenclature, the myelencephalon or after-brain (my). From each of these six divisions definite structures arise whose relations to the secondary divisions and to the primary vesicles may be understood from the following table and from the annexed figure (Fig. 233), which represents a median longitudinal section of the brain of a fetus of three months.

\begin{tabular}{|c|c|c|}
\hline \multirow{3}{*}{3 rd Vesicle } & Myelencephalon & Medulla oblongata (I). \\
\hline & Metencephalon & $\begin{array}{l}\text { Pons (II I). } \\
\text { Cerebellum (II 2). }\end{array}$ \\
\hline & Isthmus & $\begin{array}{l}\text { Brachia conjunctiva (III). } \\
\text { Cerebral peduncles (posterior } \\
\text { portion). }\end{array}$ \\
\hline \multirow[t]{2}{*}{ and Vesicle } & .. Mesencephalon & $\begin{array}{l}\text { Cerebral peduncles (anterior por- } \\
\text { tion) (IV I). } \\
\text { Corpora quadrigemina (IV 2). }\end{array}$ \\
\hline & Diencephalon & 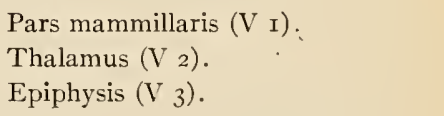 \\
\hline Ist Vesicle & Telencephalon & $\begin{array}{l}\text { Infundibulum (VI I). } \\
\text { Corpus striatum ( } \mathrm{VI}_{2} \text { ). } \\
\text { Olfactory bulb ( } \mathrm{VI}_{3} \text { ). } \\
\text { Hemispheres ( } \mathrm{VI}_{4} \text { ). }\end{array}$ \\
\hline
\end{tabular}

But while the walls of the primary vesicles undergo this complex differentiation, their cavities retain much more perfectly their original relations, only that of the first vesicle sharing to any great extent the modifications of the walls. 
The cavity of the third vesicle persists in the adult as the fourth ventricle, traversing all the subdivisions of the vesicle; that of the second, increasing but little in height and breadth, constitutes the aqueductus cerebri; while that of the first vesicle is continued into the cerebral hemispheres to form the lateral ventricles, the remainder of it constituting the third ventricle, which includes the cavity of the median portion of the telencephalon as well as the entire cavity of the diencephalon.

During the differentiation of the various divisions of the brain certain flexures appear in the roof and floor, and to a certain extent

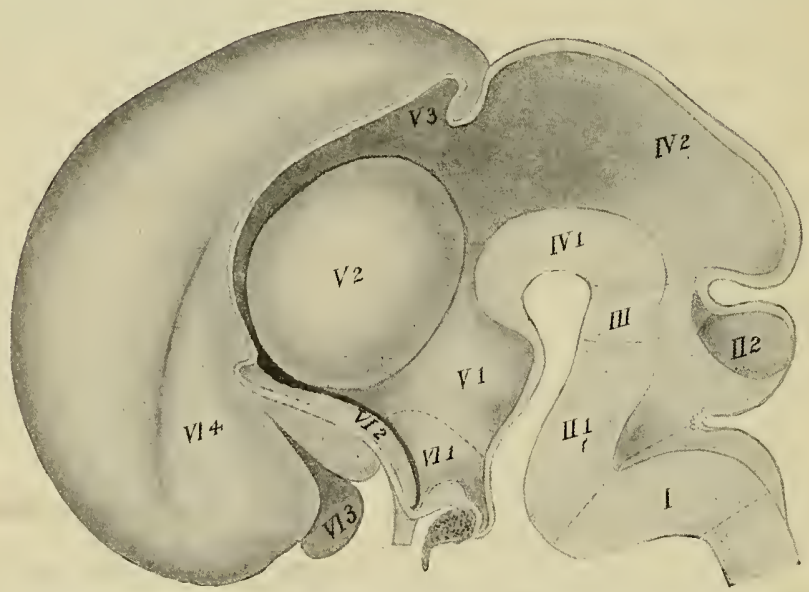

Fig. 233.-Median Longitudinal Section of the Brain of an Embryo of the THIRd MONTH.-(His.)

correspond with those already described as occurring in the embryo. The first of these flexures to appear occurs in the region of the midbrain, the first vesicle being bent ventrally until it comes to lie at practically a right angle with the axis of the mid-brain. This may be termed the mid-brain flexure (Fig. 232, $m f$ ) and corresponds with the head-bend of the embryo. The second flexure occurs in the region of the medulla oblongata and is known as the nape flexure (Fig. 232, nf); it corresponds with the similarly named bend of the embryo and is produced by a bending ventrally of the entire head, so 
that the axis of the mid-brain comes to lie almost at right angles with that of the medulla and that of the first vesicle parallel with it. Finally, a third flexure occurs in the region of the metencephalon and is entirely peculiar to the nervous system; it consists of a bending ventrally of the floor of the hind-brain, the roof of this portion of the brain not being affected by it, and it may consequently be known as the pons flexure (Fig. 233).

In the later development the pons flexure practically disappears, owing to the development in this region of the transverse fibers and nuclei of the pons, but the mid-brain and nape flexures persist, though greatly reduced in acuteness, the axis of the anterior portion of the adult brain being inclined to that of the medulla at an angle of about I34 degrees.

The Development of the Myelencephalon.-In its posterior portion the myelencephalon closely resembles the spinal cord and has a very similar development. More anteriorly, however, the roof-plate (Fig. 234, rp) widens to form an exceedingly thin membrane, the posterior velum; with the broadening of the roof-plate there is associated a broadening of the dorsal portion of the brain cavity, the dorsal and ventral zones bending outward, until, in the anterior portion of the after-brain, the margins of the dorsal zone have a lateral position, and are, indeed, bent ventrally to form a reflected lip (Fig. 234, l). The portion of the fourth ventricle contained in this division of the brain becomes thus converted into a broad shallow cavity, whose floor is formed by the ventral zones separated in the median line by a deep groove, the floor of which is the somewhat thickened floor-plate. About the fourth month there appears in the roof-plate a transverse groove into which the surrounding mesenchyme dips, and, as the groove deepens in later stages, the mesenchyme contained within it becomes converted into blood-vessels, forming the chorioid plexus of the fourth ventricle, a structure which. as may be seen from its development, does not lie within the cavity of the ventricle, but is separated from it by the portion of the roofplate which forms the floor of the groove.

In embryos of about $9 \mathrm{~mm}$. the differentiation of the dorsal 
and ventral zones into ependymal and mantle layers is clearly visible (Fig. 234), and in the ventral zone the marginal velum is also weil developed. Where the fibers from the sensory ganglion of the vagus nerve enter the dorsal zone an oval area (Fig. 234, $f s$ ) is to be seen which is evidently comparable to the oval bundle of the cord and consequently with the fasciculus of Burdach. It gives rise to the solitary fasciculus of adult anatomy, and in embryos of I I to I $3 \mathrm{~mm}$. it becomes covered in by the fusion of the reflected lip of the dorsal zone with the sides of the myelencephalon, this fusion, at the same time, drawing the margins of the roof-plate ventrally to form a

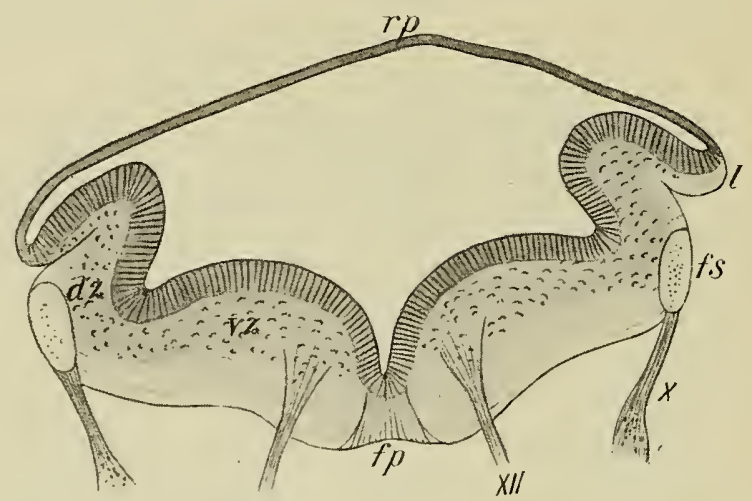

Fig. 234.-Transverse Section through the Medulla Oblongata of AN EMBRyo OF 9.I MM.

$d z$, Dorsal zone; $f p$, floor-plate; $f s$, fasciculus solitarius; $l$, lip; $r p$, roof-plate; $v z$, ventral zone; $X$ and $X I I$, tenth and twelf th nerves.-(His.)

secondary lip (Fig. 235). Soon after this a remarkable migration ventrally of neuroblasts of the dorsal zone begins. Increasing rapidly in number the migrating cclls pass on either side of the solitary fasciculus toward the territory of the ventral zone, and, passing ventrally to the ventral portion of the mantle layer, into which fibers have penetrated and which becomes the formatio reticularis (Fig. 235, fr), they differentiate to form the olivary body (ol).

The thickening of the floor-plate gives opportunity for fibers to pass across the median line from one side to the other, and this opportunity is taken advantage of at an early stage by the axis-cylin- 
ders of the neuroblasts of the ventral zone, and later, on the establishment of the olivary bodies, other fibers, descending from the cerebellum, decussate in this region to pass to the olivary body of the opposite side. In the lower part of the medulla fibers from the neuroblasts of the nuclei gracilis and cuneatus, which seem to be

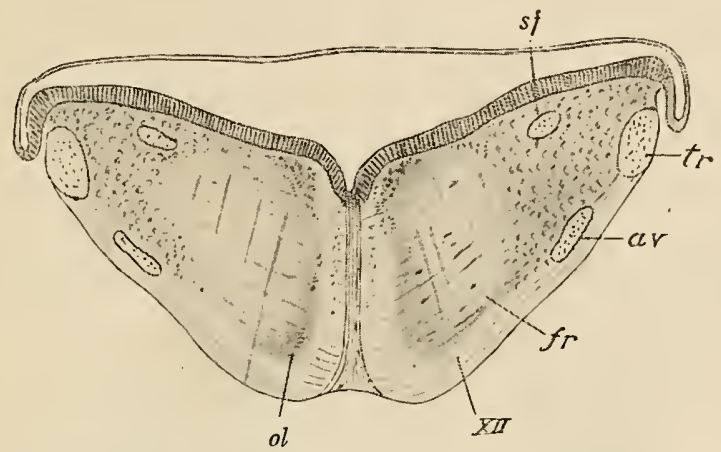

Fig. 235.-Transverse Section through the Medulla Oblongata of an Embryo OF ABOUT EIGHT WEEKS.

$a v$, Ascending root of the trigeminus; $f r$, reticular formation; $o l$, olivary body; $s f$, solitary fasciculus; $t r$, restiform body; XII, hypoglossal nerve.-(His.)

developments from the mantle layer of the dorsal zone, also decussate in the substance of the floor-plate; these fibers, known as the arcuate fibers, pass in part to the cerebellum, associating themselves with fibers ascending from the spinal cord and with the olivary fibers to form a round bundle situated in the dorsal portion of the marginal velum and known as the restiform body (Fig. 235, tr).

The principal differentiations of the zones of the myelencephalon may be stated in tabular form as follows:

Roof-plate ......... Posterior velum.

Dorsal zones........ $\left\{\begin{array}{l}\text { Nuclei of termination of sensory roots of cranial nerves. } \\ \text { Nuclei gracilis and cuneatus. } \\ \text { The olivary bodies. }\end{array}\right.$

Ventral zones....... $\left\{\begin{array}{l}\text { Nuclei of origin of the motor roots of cranial nerves. } \\ \text { The reticular formation. }\end{array}\right.$

Foor-plate ......... The median raphe. 
The Development of the Metencephalon and Isthmus.-Our knowledge of the development of the metencephalon, isthmus, and mesencephalon is by no means as complete as is that of the myelencephalon. The pons develops as a thickening of the portion of the brain floor which forms the anterior wall of the pons flexure, and its transverse fibers are well developed by the fourth month (Mihalkovicz), but all details regarding the origin of the pons nuclei are as yet wanting. If one may argue from what occurs in the myelencephalon, it seems probable that the reticular formation of the metencephalon is derived from the ventral zone, and that the median raphe represents the floor-plate. Furthermore, the relations of the pons nuclei to the reticular formation on the one hand, and its connection by means of
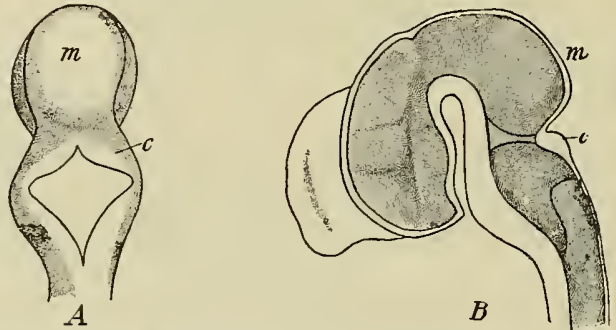

Fig. 236.- $A$, Dorsal View of the Brain of a Rabbit Embryo of i6 mM.; $B$, Median Longitudinal Section of a Calf Embryo of $3 \mathrm{~cm}$.

$c$, Cerebellum; $m$, mid-brain.-(Mihalkovicz.)

the transverse pons fibers with the cerebellum on the other, suggest the possibility that they may be the metencephalic representatives of the olivary bodies and are formed by a migration ventrally of neuroblasts from the dorsal zones, such a migration having been observed to occur (Essick).

The cerebellum is formed from the dorsal zones and roof-plate of the metencephalon and is a thickening of the tissue immediately anterior to the front edge of the posterior velum. This latter structure has in early stages a rhomboidal shape (Fig. 236, A) which causes the cerebellar thickening to appear at first as if composed of two lateral portions inclined obliquely toward one another. In reality, however, the thickening extends entirely across the roof of 
the brain (Fig. 236, B), the roof-plate probably being invaded by cells from the dorsal zones and so giving rise to the vermis, while the lobes are formed directly from the dorsal zones. During the second month a groove appears on the ventral surface of each lobe, marking out an area which becomes the flocculus, and later, during the third month, transverse furrows appear upon the vermis dividing it into five lobes, and later still extend out upon the lobes and increase in number to produce the lamellate structure characteristic of the cerebellum.

The histogenetic development of the cerebellum at first proceeds along the lines which have already been described as typical, but after the development of the mantle layer the cells lining the greater portion of the cavity of the ventricle cease to multiply, only those which are situated in the roofplate of the metencephalon and along the line of junction of the cerebellar thickening

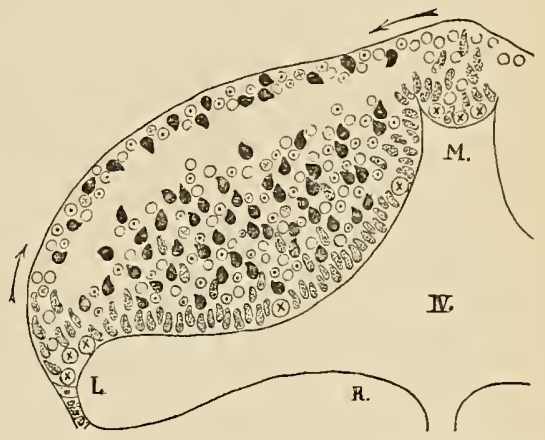

Fig. 237.-DIAgRAM REPRESENTING THE Differentiation of the Cerebeliar Cells.

The circles, indifferent cells; circles with dots, neuroglia cells; shaded cells, germinal cells; circles with cross, germinal cells in mitosis; black cells, nerve-cells. $L$, Lateral recess; $M$, median furrow, and $R$, floor of $I V$, fourth ventricle.-(Schaper.) with the roof-plate continuing to divide. The indifferent cells formed in these regions migrate outward from the median line and forward in the marginal velum to form a superficial layer, known as the epithelioid layer, and cover the entire surface of the cerebellum (Fig. 237). The cells of this layer, like those of the mantle, differentiate into neuroglia cells and neuroblasts, the latter for the most part migrating centrally at a later stage to mingle with the cells of the mantle layer and to become transformed into the gramular cells of the cerebellar cortex. The neuroglia cells remain at the surface, however, forming the principal constituent of the outer or, as it is now termed, the molecular layer of the cortex, and into this the dendrites of the Purkinje cells, 
probably derived from the mantle layer, project. The migration of the neuroblasts of the epithelial layer is probably completed before birth, at which time but few remain in the molecular layer to form the stellate cells of the adult. The origin of the dentate and other nuclei of the cerebellum is at present unknown, but it seems probable that they arise from cells of the mantle layer.

The nerve-fibers which form the medullary substance of the cerebellum do not make their appearance until about the sixth month, when they are to be found in the ependymal tissue on the inner surface of the layer of granular cells. Those which are not commissural or associative in function converge to the line of junction of the cerebellum with the pons, and there pass into the marginal velum of the pons, myelencephalon, or isthmus as the case may be.

The dorsal surface of the isthmus is at first barely distinguishable from the cerebellum, but as development proceeds its roof-plate undergoes changes similar to those occurring in the medulla oblongata and becomes converted into the anterior velum. In the dorsal portion of its marginal velum fibers passing to and from the cerebellum appear and form the brachia conjunctiva, while ventrally fibers, descending from the more anterior portions of the brain, form the cerebral peduncles. Nothing is at present known as to the history of the gray matter of this division of the brain, although it may be presumed that its ventral zones take part in the formation of the tegmentum, while from its dorsal zones the nuclei of the brachia conjunctiva are possibly derived.

The following table gives the origin of the principal structures of the metencephalon and isthmus:

Metencephalon.

Roof-plate ........ $\left\{\begin{array}{l}\text { Posterior velum. } \\ \text { Vermis of cerebellum. }\end{array}\right.$
Dorsal zones....... $\left\{\begin{array}{l}\text { Lobes of cerebellum. } \\ \text { Flocculi. } \\ \begin{array}{l}\text { Nuclei of termination of sen- } \\ \text { sory roots of cranial nerves. } \\ \text { Pons nuclei. }\end{array}\end{array}\right.$

Isthmus.

Anterior velum.

Brachia conjunctiva. 
Metencephalon.

ISTHMUS.

Ventral zones ....... $\left\{\begin{array}{l}\begin{array}{c}\text { Nuclei of origin of motor } \\ \text { roots of cranial nerves. } \\ \text { Reticular formation. }\end{array} \\ \text { Median raphe. }\end{array}\right.$

The Development of the Mesencephalon.-Our knowledge of the development of this portion of the brain is again very imperfect. During the stages when the flexures of the brain are well marked (Figs. 232 and 233) it forms a very prominent structure and possesses for a time a capacious cavity. Later, however, it increases in size less rapidly than adjacent parts and its walls thicken, the roofand floor-plates as well as the zones, and, as a result, the cavity becomes the relatively smaller canal-like cerebral aquæduct. In the marginal velum of its ventral zone fibers appear at about the third month, forming the anterior portion of the cerebral peduncles, and, at the same time, a median longitudinal furrow appears upon the dorsal surface, dividing it into two lateral elevations which, in the fifth month, are divided transversely by a second furrow and are thus converted from corpora bigemina (in which form they are found in the lower vertebrates) into corpora quadrigemina.

Nothing is known as to the differentiation of the gray matter of the dorsal and ventral zones of the mid-brain. From the relation of the parts in the adult it seems probable that in addition to the nuclei of origin of the oculomotor and trochlear nerves, the ventral zones give origin to the gray matter of the tegmentum, which is the forward continuation of the reticular formation. Similarly it may be supposed that the corpora quadrigemina are developments of the dorsal zones, as may also be the red muclei, whose relations to the brachia conjunctiva suggest a comparison with the olivary bodies and the nuclei of the pons.

A tentative scheme representing the origin of the mid-brain structures may be stated thus:

Roof-plate.......

Dorsal zones...... \{ $\begin{aligned} & \text { Corpora quadrigemina. } \\ & \text { Red nuclei. }\end{aligned}$

Ventral zones..... $\left\{\begin{array}{l}\text { Nuclei of origin of the third and fourth nerves. } \\ \text { Anterior part of tegmentum. } \\ \text { Anterior part of cerebral peduncles. }\end{array}\right.$

Floor-plate..... Median raphe. 
The Development of the Diencephalon.-A transverse section through the diencephalon of an embryo of about five weeks (Fig. $238)$ shows clearly the differentiation of this portion of the brain into the typical zones, the roof-plate $(r p)$ being represented by a thinwalled, somewhat folded area, the floor-plate $(f p)$ by the tissue forming the floor of a well-marked ventral groove, while each lateral wall is divided into a dorsal and ventral zone by a groove known as the sulcus Monroi $(\mathrm{Sm})$, which extends forward and ventrally

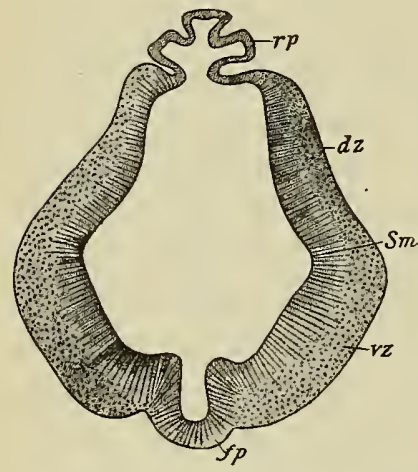

Fig. 238.-Transverse Section OF THE DIENCEPHALON OF AN EMBRYO OF FIVE WEEKS.

$d z$, Dorsal zone; $f p$, floor-plate; $r p$, roof-plate; $S m$, sulcus Monroi; $v z$, ventral zone.-(His.)

toward the point of origin of the optic evagination (Fig. 240). At the posterior end of the ridge-like elevation which represents the roof-plate is a rounded elevation (Fig. 239, p) which, in later stages, elongates until it almost reaches the dermis, forming a hollow evagination of the brain roof known as the pineal process. The distal extremity of this process enlarges to a sac-like structure which later becomes lobed, and, by an active proliferation of the cells lining the cavities of the various lobes, finally becomes a solid structure, the pineal body. The more proximal portion of the evagination, remaining hollow, forms the pineal stalk, and the entire structure, body and stalk, constitutes what is known as the epiphysis.

The significance of this organ in the Mammalia is doubtful. In the Reptilia and other lower forms the outgrowth is double, a secondary outgrowth arising from the base or from the anterior wall of the primary one. This anterior evagination elongates until it reaches the dorsal epidermis of the head, and, there expanding, develops into an unpaired eye, the epidermis which overlies it becoming converted into a transparent cornea. In the Mammalia this anterior process does not develop and the epiphysis in these forms is comparable only to the posterior process of the Reptilia.

In addition to the epiphysial evaginations, another evagination arises 
from the roof-plate of the first brain vesicle, further forward, in the region which becomes the median portion of the telencephalon. This paraphysis as it has been called, has been observed in the lower vertebrates and in the Marsupials (Selenka), but up to the present has not been found in other groups of the Mammalia. It seems to be comparable to a chorioid plexus which is evaginated from the brain surface instead of being invaginated as is usually the case. There is no evidence that a paraphysis is developed in the human brain.

The portion of the roof-plate which lies in front of the epiphysis represents the velum interpositum of the adult brain, and it forms at first a distinct ridge (Fig. 239, rp). At an early stage, however, it becomes reduced to a thin membrane upon the surface of which bloodvessels, developing in the surrounding mesenchyme, arrange themselves at about the third month in two longitudinal plexuses, which, with the subjacent portions of the velum, become invaginated into the cavity of the third ventricle to form its chorioid plexus.

The dorsal zones thicken in their more dorsal and anterior portions to form massive structures, the thalami (Figs. 233, V2, and

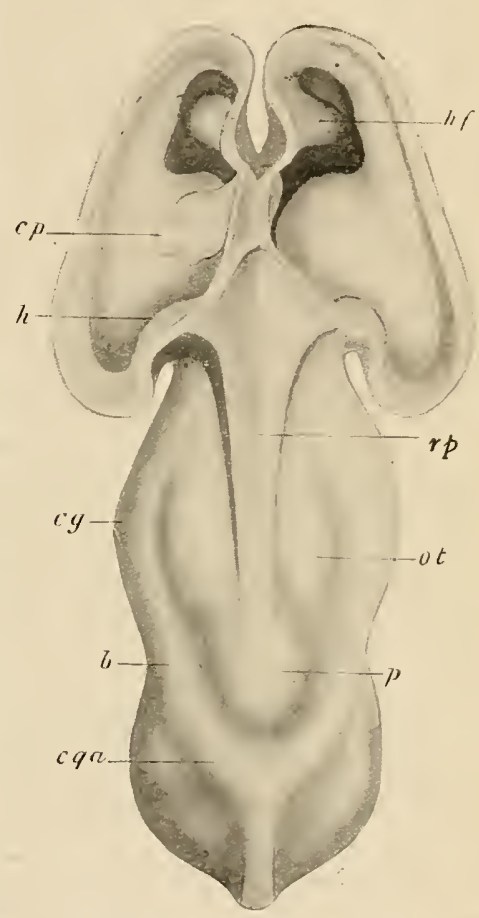

Fig. 239.-DORSAL VIEW OF THE Brain, the RoOF OF THE LATERAL VENTRICLES BEING REMOVED, OF AN EMBRYO OF I 3.6 MM.

$b$, Superior brachium; $c g$, lateral geniculate body; $c p$, chorioid plexus; $c q a$, anterior corpus quadrigeminum; $h$, hippocampus; $h f$, hippocampal fissure; ot, thalamus; $p$, pineal body; $r p$, roof-plate.-(His.) 239, ot), which, encroaching upon the cavity of the ventricle, transform it into a narrow slit-like space, so narrow, indeed, that at about the fifth month the inner surfaces of the two thalami come in contact in the median line, forming what is known as the intermediate mass. More ventrally 
and posteriorly another thickening of the dorsal zone occurs, giving rise on each side to the pulvinar of the thalamus and to a lateral geniculate body, and two ridges extending backward and dorsally from the latter structures to the thickenings in the roof of the midbrain which represent the anterior corpora quadrigemina, give a path along which the nerve-fibers which constitute the superior quadrigeminal brachia pass.

From the ventral zones what is known as the hypothalamic region develops, a mass of fibers and cells whose relations and development are not yet clearly understood, but which may be regarded as the forward continuation of the tegmentum and reticular formation. In the median line of the floor of the ventricle an unpaired thickening appears, representing the corpora mamillaria, which during the third month becomes divided by a median furrow into two rounded eminences; but whether these structures and the posterior portion of the tuber cinereum, which also develops from this region of the brain, are derivatives of the ventral zones or of the floor-plate is as yet uncertain.

Assuming that the mamillaria and the tuber cinereum are derived from the ventral zones, the origins of the structures formed from the walls of the diencephalon may be tabulated as follows:

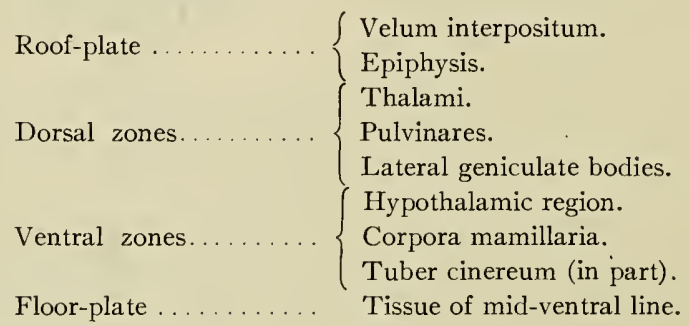

The Development of the Telencephalon.-For convenience of description the telencephalon may be regarded as consisting of a median portion, which contains the anterior part of the third ventricle, and two lateral outgrowths which constitute the cerebral hemispheres. The roof of the median portion undergoes the same transformation as does the greater portion of that of the diencephalon 
and is converted into the anterior part of the velum interpositum (Fig. 240, vi). Anteriorly this passes into the anterior wall of the third ventricle, the lamina terminalis $(l t)$, a structure which is to be regarded as formed by the union of the dorsal zones of opposite sides, since it lies entirely dorsal to the anterior end of the sulcus Monroi. From the ventral part of the dorsal zones the optic evaginations are formed, a depression, the optic recess (or), marking their point of origin.

The ventral zones are but feebly developed, and form the anterior part of the hypothalamic region, while at the antericr extremity of the floor-plate an evagination occurs, the infundibular recess ( $\mathrm{ir}$ ), which elongates to form a funnel-shaped structure known as the hypophysis. At its extremity the hypophysis comes in contact during the fifth week with the enlarged extremity of Rathke's pouch formed by an invagination of the roof of the oral sinus (see p. 285), and applies itself closely to the posterior surface of this (Fig. 233) to form with it the pituitary body. The anterior lobe at an early stage separates from the mucous membrane of the oral sinus, the stalk by which it was attached completely disappearing, and toward the end of the second month it begins to send out processes from its walls into the surrounding mesenchyme and so becomes converted into a mass of solid epithelial cords embedded in a mesenchyme rich in blood and lymphatic vessels. The cords later on divide transversely to a greater or less extent to form alveoli, the entire structure coming to resemble somewhat the parathyreoid bodies (see p. 297), and, like these, having the function of producing an internal secretion. The posterior lobe, derived from the brain, retains its connection with that structure, its stalk being the infundibulum, but its terminal portion does not undergo such extensive modifications as does the anterior lobe, although it is claimed that it gives rise to a glandular epithelium which may become arranged so as to form alveoli.

The cerebral hemispheres are formed from the lateral portions of the dorsal zones, each possessing also a prolongation of the roofplate. From the more ventral portion of each dorsal zone there is 
formed a thickening, the corpus striatum (Figs. 240, cs, and 233, VI 2), a structure which is for the telencephalon what the optic thalamus is for the diencephalon, while from the more dorsal portion there is formed the remaining or mantle (pallial) portions of the hemispheres (Figs. 240, $h$, and 233, VI 4). When first formed, the hemispheres are slight evaginations from the median portion of the telencephalon, the openings by which their cavities communicate with the third ventricle, the interventricular foramina, being relatively very large (Fig. 240), but, in later stages (Fig. 233), the hemispheres increase more markedly and eventually surpass all the other portions of the

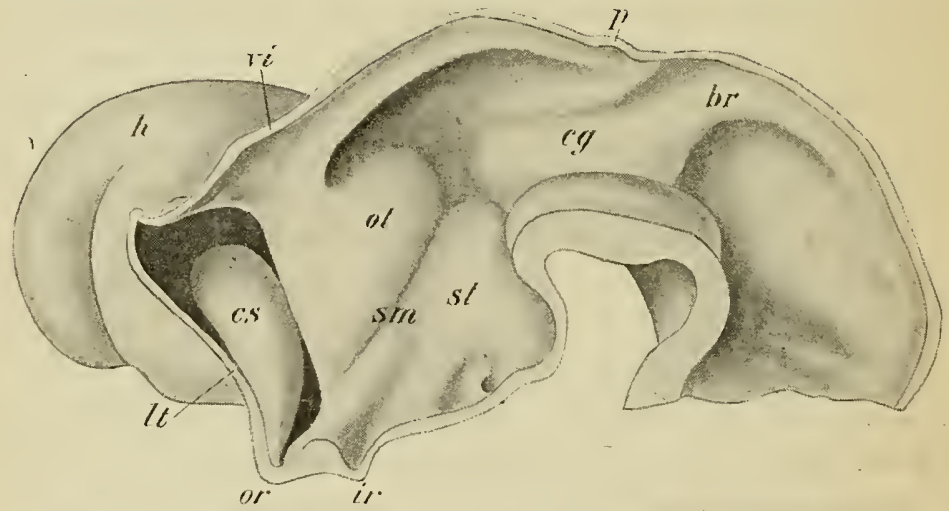

Fig. 240.-Median Longitudinal Section of the Brain of an Embryo of i6.3 Mm.

$b r$, Anterior brachium; $c g$, corpus geniculatum laterale; $c s$, corpus striatum; $h$, cerebral hemisphere; $i r$, infundibular recess; $l t$, lamina terminalis; or, optic recess; ot, thalamus; $p$, pineal process; $s m$, sulcus Monroi; $s t$, hypothalamic region; $v i$, velum interpositum.-(His.)

brain in magnitude, overlapping and completely concealing the roof and sides of the diencephalon and mesencephalon and also the anterior surface of the cerebellum. In this enlargement, however, the interventricular foramina share only to a slight extent, and consequently become relatively smaller (Fig. 233), forming in the adult merely slit-like openings lying between the lamina terminalis and the thalami and having for their roof the anterior portion of the velum interpositum.

The velum interpositum - that is to say, the roof-plate-where 
it forms the roof of the interventricular foramen, is prolonged out upon the dorsal surface of each hemisphere, and, becoming invaginated, forms upon it a groove. As the hemispheres, increasing in height, develop a mesial wall, the groove, which is the so-called chorioidal fissure, comes to lie along the ventral edge of this wall, and as the growth of the hemispheres continues it becomes more and more elongated, being carried at first backward (Fig. 24I), then ventrally, and finally forward to end at the tip of the temporal lobe. After the establishment of the grooves the mesenchyme in their vicinity dips into them, and, developing blood-vessels, becomes the chorioid plexuses of the lateral ventricles, and at first these plexuses grow much more rapidly than the ventricles, and so fill them almost completely. Later, however, the walls of the hemispheres gain the ascendancy in rapidity of growth and the plexuses become relatively much smaller. Since the portions of the roof-plate which form the chorioidal fissures are continuous with the velum interpositum in the roofs of the interventricular foramina, the chorioid plexuses of the lateral and third ventricles become continuous also at that point.

The mode of growth of the chorioid fissures seems to indicate the mode of growth of the hemispheres. At first the

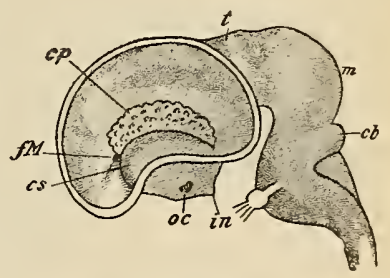

Fig. 24I,-MEdian LongiTUdinal SECTION OF THE BRAIN of an Embryo Calf of 5 CM.

$c b$, Cerebellum; $c p$, chorioid plexus; $c s$, corpus striatum; $f M$, interventricular foramen; in, hypophysis; $m$, mid-brain; oc, optic commissure; $t$, posterior part of the diencephalon.(Mihalkovicz.)

growth is more or less equal in all directions, but later it becomes more extensive posteriorly, there being more room for expansion in that direction, and when further extension backward becomes difficult the posterior extremities of the hemispheres bend ventrally toward the base of the cranium, and reaching this, turn forward to form the temporal lobes. As a result the cavities of the hemispheres, the lateral ventricles, in addition to being carried forward to form an anterior horn, are also carried backward and ventrally to form the lateral or,descending horn, and the corpus striatum likewise extends 
backward to the tip of each temporal lobe as a slender process known as the tail of the caudate nucleus. In addition to the anterior and lateral horns, the ventricles of the human brain also possess posterior horns extending backward into the occipital portions of the hemispheres, these portions, on account of the greater persistence of the mid-brain flexure (see p. 388), being enabled to develop to a greater extent than in the lower mammals.

The scheme of the origin of parts in the telencephalon may be stated as follows:

MEdian Part.

HEMISPHERES.

Roof-plate....... $\left\{\begin{array}{l}\text { Anterior part of velum inter- } \\ \text { positum. }\end{array}\right\}$ Floor of chorioidal fissure.
Dorsal zones...... $\left\{\begin{array}{l}\text { Lamina terminalis. } \\ \text { Optic evaginations. }\end{array}\right\}\left\{\begin{array}{l}\text { Pallium. } \\ \text { Corpus striatum. } \\ \text { Olfactory lobes (see p. 406) } \\ \text { Ventral zones...... part of hypothalamic } \\ \text { Anterior part of tuber cinereum. }\end{array}\right.$

The Convolutions of the Hemispheres. - The growth of the hemispheres to form the voluminous structures found in the adult depends mainly upon an increase of size of the pallium. The corpus striatum, although it takes part in the elongation of each hemisphere, nevertheless does not increase in other directions as rapidly and extensively as the pallium, and hence, even in very early stages, a depression appears upon the surface of the hemispheres where the corpus is situated (Fig. 242). This depression is the lateral cerebral fossa, and for a considerable period it is the only sign of inequality of growth on the outer surfaces of the hemispheres. Upon the mesial surfaces, however, at about the time that the choroid fissure appears, another linear depression is formed dorsal to the chorioid, and when fully formed extends from in front of the interventricular foramen to the tip of the temporal lobe (Fig. 244, $h$ ). It affects the entire thickness of the pallial wall and consequently produces an elevation upon the inner surface, a projection into the cavity of the ventricle which is known as the hippocampus, whence 
the fissure may be termed the hippocampal fissure. The portion of the pallium which intervenes between this fissure and the chorioidal forms what is known as the dentate gyrus.

Toward the end of the third or the beginning of the fourth month two prolongations arise from the fissure just where it turns to be continued into the temporal lobe, and these, extending posteriorly, give rise to the parieto-occipital and calcarine fissures. Like the hippocampal, these fissures produce elevations upon the inner surface of the pallium, that formed by the parieto-occipital early disappearing, while that produced by the calcarine persists to form the calcar (hippocampus minor) of adult anatomy.

The three fissures just described, together with the chorioidal and the lateral cerebral fossa, are all formed by the beginning of the fourth month and all the fissures affect the entire thickness of the wall of the hemisphere, and hence have been termed the primary or total fissures. Until the beginning of the fifth

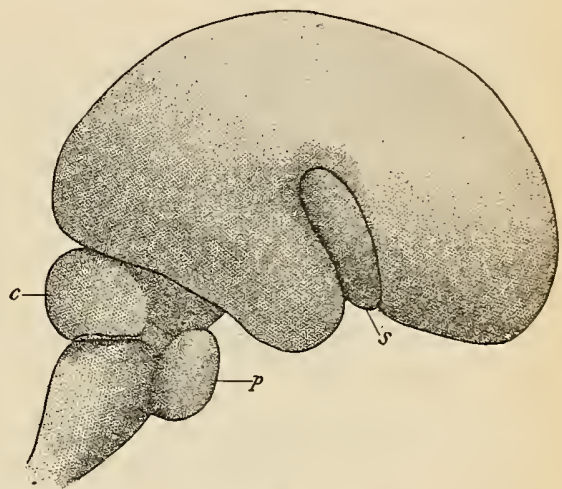

Fig. 242.-Brain of an Embryo of the FOURTh MONTH.

$c$, Cerebellum; $p$, pons; $s$, lateral cerebral fossa. month they are the only fissures present, but at that time secondary fissures, which, with one exception, are merely furrows of the surface of the pallium, make their appearance and continue to form until birth and possibly later. Before considering these, however, certain changes which occur in the neighborhood of the lateral cerebral fossa may be described.

The fossa is at first a triangular depression situated above the temporal lobe on the surface of the hemisphere. During the fourth month it deepens considerably, so that its upper and lower margins become more pronounced and form projecting folds, and, during the fifth month, these two folds approach one another and eventually 
cover in the floor of the fossa completely, the groove which marks the line of their contact forming the lateral cerebral fissure, while the floor of the fossa becomes known as the insula.

The first of the secondary fissures to appear is the sulcus cinguli, which is formed about the middle of the fifth month on the mesial surface of the hemispheres, lying parallel to the anterior portion of the hippocampal fissure and dividing the mesial surface into the gyri marginalis and fornicatus. A little later, at the beginning of the sixth month, several other fissures make their appearance upon

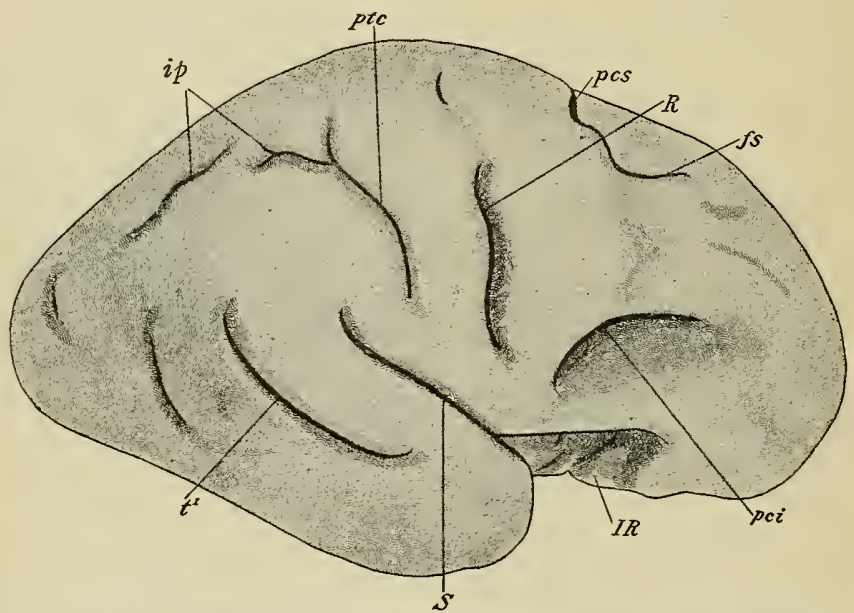

Fig. 243.-Cerebral Hemisphere of an Embryo of about the Seventh Month. $f s$, Superior frontal sulcus; $i p$, interparietal; $I R$, insula; $p c i$, inferior pre-central; $p c s$, superior pre-central; $p t c$, post-central; $R$, central; $S$, lateral; $\mathfrak{t}$, first temporal.(Cunningham)

the outer surface of the pallium, the chief of these being the central sulcus, the inter-parietal, the pre-and post-central, and the temporal sulci, the most ventral of these last running parallel with the lower portion of the hippocampal fissure and differing from the others in forming a ridge on the wall of the ventricle termed the collateral eminence, whence the fissure is known as the collateral. The position of most of these fissures may be seen from Fig. 243, and for a more 
complete description of them reference may be had to text-books of descriptive anatomy.

In later stages numerous tertiary fissures make their appearance and mask more or less extensively the secondaries, than which they are, as a rule, much more inconstant in position and shallower.

The Corpus Callosum and Fornix.-While these fissures have been forming, important structures have developed in connection with the lamina terminalis. Up to about the fourth month the lamina is thin and of nearly uniform thickness throughout, but at this time it begins to thicken near its dorsal edge and fibers appear in the thickening. These fibers belong to three sets. In the first place, certain of them arise in connection with the olfactory tracts (see p. 407) and from the region of the hippocampal gyrus, which is also associated with the olfactory sense, and, passing through tbe substance of the lamina terminalis, they extend across the median line to the corresponding regions of the opposite cerebral hemisphere. They are therefore commissural fibers and form what is termed the anterior commissure (Figs. 244, ca and 245,ac). Secondly, fibers, which have their origin from the cells of the hippocampus, develop along the chorioidal edge of that structure, forming what is termed the fimbria. They follow along the edge of the chorioidal fissure and, when this reaches the interventricular foramen, they enter as the pillars of the fornix (Figs. 244, cf; Fig. 245, $f$ ) the substance of the lamina terminalis and, passing ventrally in it, eventually reach the hypothalamic region, where they terminate in the corpora mammillaria.

Thirdly, as the mantle develops fibers radiate from all parts of it toward the dorsal portion of the lamina terminalis and traversing it are distributed to the corresponding portions of the mantle of the opposite side. There fibers are also commissural in character and form the corpus callosum (Figs. 244 and $245, c c$ ). With the development of these three sets of fibers and especially those forming the corpus callosum, the dorsal portion of the lamina terminalis becomes enlarged so as to form a triangular area extending between the two cerebral hemispheres (Fig. 245), the corpus callosum form- 
ing its dorsal portion and base, which is directed anteriorly, the pillars of the fornix its ventral portion, while the anterior commissure occupies its ventral anterior angle.

The portion of the triangle included between the callosum and the fornix remains thin and forms the septum pellucidum, and a split occurring in the center of this gives rise to the so-called fifth ventricle,

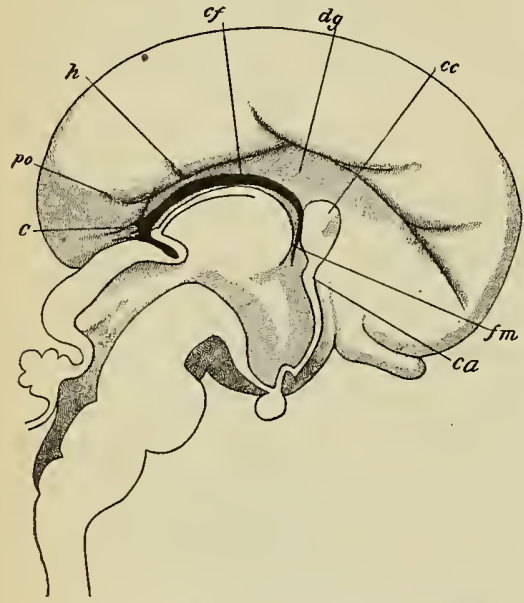

Fig. 244.-MEdian Longitudinal SeCTION OF THE BRAIN OF AN EMBRYO OF Four MoNTHS.

$c$, Calcarine fissure; $c a$, anterior commissure; $c c$, corpus callosum; $c f$. chorioidal fissure; $d g$, dentate gyrus; $f m$, interventricular foramen; $h$, hippocampal fissure; po, parieto-occipital fissure.-(Mihalkovicz.) which, from its mode of formation, is a completely closed cavity and is not lined with ependymal tissue of the same nature as that found in the other ventricles.

Owing to the very considerable size reached by the triangular area whose history has just been described, important changes are wrought in the adjoining portions of the mesial surface of the hemispheres. Before the development of the area the gyrus dentatus and the hippocampus extend forward into the anterior portion of the hemispheres (Fig. 244), but on account of their position they become encroached upon by the enlargement of the corpus callosum, with the result that the hippocampus becomes practically obliterated in that portion of its course which lies in the region occupied by the corpus callosum, its fissure in this region becoming known as the callosal fissure, while the corresponding portions of the dentate gyrus become reduced to narrow and insignificant bands of nerve tissue which rest upon the upper surface of the corpus callosum and are known as the lateral longitudinal stria.

The Olfactory Lobes.-At the time when the cerebral hemispheres 
begin to enlarge - that it to say, at about the fourth week-a slight furrow, which appears on the ventral surface of each anteriorly, marks off an area which, continuing to enlarge with the hemispheres, gradually becomes constricted off from them to form a distinct lobelike structure, the olfactory lobe (Fig. 233, VI 3). In most of the lower mammalia these lobes reach a very considerable size, and consequently have been regarded as constituting an additional division of the brain, known as the rhinencephalon, but in man they remain smaller, and although they are at first hollow, containing prolongations from the lateral ventricles, the cavities later on disappear and the lobes become solid. Each lobe becomes differentiated into two portions, its terminal portion becoming converted into the club-shaped struc-

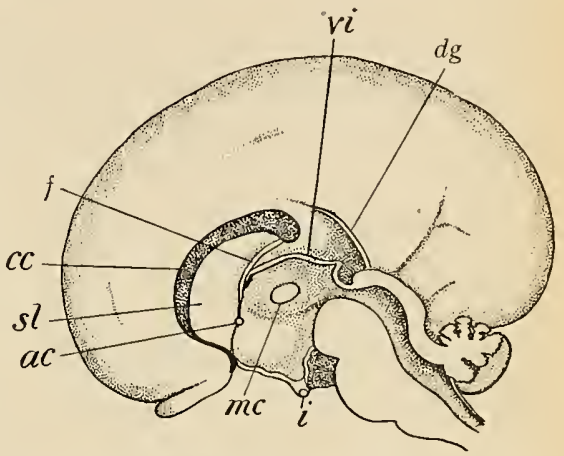

Fig. 245.-Median Longitudinal Section of the Brain of an EMbryo of the Fifth MONTH.

$a c$, Anterior commissure; $c c$, corpus callosum; $d g$, dentate gyrus; $f$, fornix; $i$, infundibulum; $m c$, intermediate mass; sl, septum pellucidum; $v i$, velum interpositum.-(Mihalkovicz.)

ture, the olfactory bulb and stalk, while its proximal portion gives rise to the olfactory tracts, the trigone, and the anterior perforated substance.

Histogenesis of the Cerebral Cortex.-A satisfactory study of the histogenesis of the cortex has not yet been made. In embryos of three months a marginal velum is present and probably gives rise to the stratum zonale of the adult brain; beneath this is a cellular layer, perhaps representing the mantle layer; beneath this, again, a layer of nerve-fibers is beginning to appear, representing the white substance of the pallium; and, finally, lining the ventricle is an ependymal layer. In embryos of the fifth month, toward the innermost part of the second layer, cells are beginning to differentiate into the large pyramidal cells, but almost nothing is known as to the 
origin of the other layers recognizable in the adult cortex, nor is it known whether any migration, similar to what occurs in the cerebellar cortex, takes place. The fibers of the white substance do not begin to acquire their myelin sheaths until toward the end of the ninth month, and the process is not completed until some time after birth (Flechsig), while the fibers of the cortex continue to undergo myelination until comparatively late in life (Kaes).

The Development of the Spinal Nerves.-It has already been seen that there is a fundamental difference in the mode of development of the two roots of which the typical spinal nerves are composed, the ventral root being formed by axis-cylinders which arise from neuroblasts situated within the substance of the spinal cord, while the dorsal roots arise from the cells of the neural crests, their axiscylinders growing into the substance of the cord while their dendrites become prolonged peripherally to form the sensory fibers of the nerves. Throughout the thoracic, lumbar and sacral regions of the cord the fibers which grow out from the anterior horn cells converge to form a single nerve-root in each segment, but in the cervical region fibers which arise from the more laterally situated neuroblasts make their exit from the cord independently of the more ventral neuroblasts and form the roots of the spinal accessory nerve (see p. 4I6). In the cervical region there are accordingly three sets of nerve-roots, the dorsal, lateral, and ventral sets.

In a typical spinal nerve, such as one of the thoracic series, the dorsal roots as they grow peripherally pass ventrally as well as outward, so that they quickly come into contact with the ventral roots with whose fibers they mingle, and the mixed nerve so formed soon after divides into two trunks, a dorsal one, which is distributed to the dorsal musculature and integument, and a larger ventral one. The ventral division as it continues its outward growth soon reaches the dorsal angle of the pleuro-peritoneal cavity, where it divides, one branch passing into the tissue of the body-wall while the other passes into the splanchnic mesoderm. The former branch, continuing its onward course in the body-wall, again divides, one branch becoming the lateral cutaneous nerve, while the other continues inward to 
terminate in the median ventral portion of the body as the anterior cutaneous nerve. The splanchnic branch forms a ramus communicans to the sympathetic system and will be considered more fully later on.

The conditions just described are those which obtain throughout the greater part of the thoracic region. Elsewhere the fibers of the ventral divisions of the nerves as they grow outward tend to separate from one another and to become associated with the fibers of adjacent nerves, giving rise to plexuses. In the regions where the limbs occur the formation of the plexuses is also associated with a shifting of the parts to which the nerves are supplied, a factor in plexus formation which is, however, much more evident from comparative anatomical than from embryological studies.

The Development of the Cranial Nerves.-During the last thirty years the cranial nerves have received a great deal of attention in connection with the idea that an accurate knowledge of their development would afford a clue to a most vexed problem of vertebrate morphology, the metamerism of the head. That the metamerism which was so pronounced in the trunk should extend into the head was a natural supposition, strengthened by the discovery of head-cavities in the lower vertebrates and by the indications of metamerism seen in the branchial arches, and the problem which presented itself was the correlation of the various structures belonging to each metamere and the determination of the modifications which they had undergone during the evolution of the head.

In the trunk region a nerve forms a conspicuous element of each metamere and is composed, according to what is known as Bell's law, of a ventral or efferent and a dorsal or afferent root. Until comparatively recently the study of the cranial nerves has been dominated by the idea that it was possible to extend the application of Bell's law to them and to recognize in the cranial region a number of nerve pairs serially homologous with the spinal nerves, some of them, however, having lost their afferent roots, while in others a dislocation, as it were, of the two roots had occurred.

The results obtained from investigation along this line have not, 
however, proved entirely satisfactory, and facts have been elucidated which seem to show that it is not possible to extend Bell's law, in its usual form at least, to the cranial nerves. It has been found that it is not sufficient to recognize simply afferent and efferent roots, but these must be analyzed into further components, and when this is done it is found that in the series of cranial nerves certain components occur which are not represented in the nerves of the spinal series.

Before proceeding to a description of these components it will be well to call attention to a matter already alluded to in a previous chapter (p. 84) in connection with the segmentation of the mesoderm of the head. It has been pointed out that while there exist "head-cavities" which are serially homologous with the mesodermal somites of the trunk, there has been imposed upon this primary cranial metamerism a secondary metamerism represented by the branchiomeres associated with the branchial arches, and, it may be added, this secondary metamerism has become the more prominent of the two, the primary one, as it developed, gradually slipping into the background until, in the higher vertebrates, it has become to a very considerable extent rudimentary. In accordance with this double metamerism it is necessary to recognize two sets of cranial muscles, one derived from the cranial myotomes and represented by the muscles of the eyeball, and one derived from the branchiomeric mesoderm, and it is necessary also to recognize for these two sets of muscles two sets of motor nerves, so that, with the dorsal or sensory nerve-roots, there are altogether three sets of nerve-roots in the cranial region instead of only two, as in the spinal region.

These three sets of roots are readily recognizable both in the embryonic and in the adult brain, especially if attention be directed to the cell groups or nuclei with which they are associated (Fig. 246). Thus there can be recognized: (I) a series of nuclei from which nerve-fibers arise, situated in the floor of the fourth ventricle and aquæduct close to the median line and termed the ventral motor miclei; (2) a second series of nuclei of origin, situated more laterally 
and in the substance of the formatio reticularis, and known as the lateral motor nuclei; and (3) a series of nuclei in which afferent nervefibers terminate, situated still more laterally in the floor of the ventricle and forming the dorsal or sensory nuclei. None of the twelve cranial nerves usually recognized in the text-books contains fibers associated with all three of these nuclei; the fibers from the lateral motor nuclei almost invariably unite with sensory fibers to form a

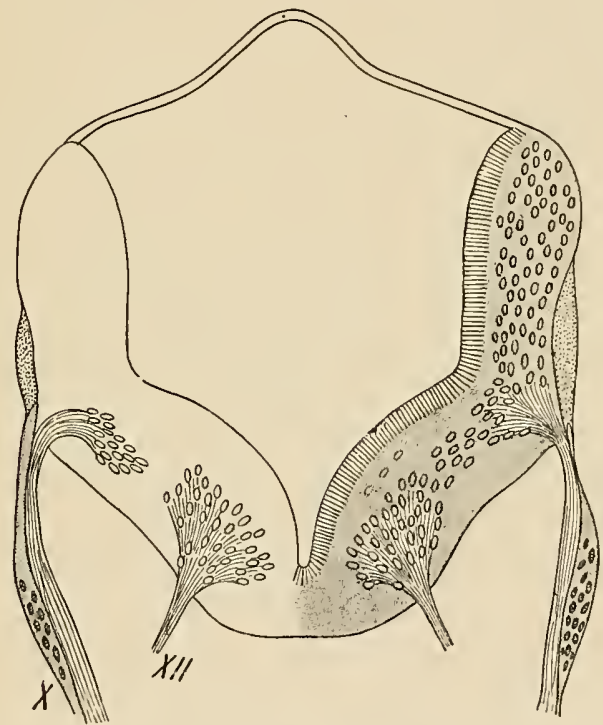

Fig. 246.-Transverse Section through the Medulla Oblongata of an Embryo of io mM., SHOWING the Nuclei of ORigin of the VAgus $(X)$ and HypogLOSSAL (XII) Nerves.-(His.)

mixed nerve, but those from all the ventral motor nuclei form independent roots, while the olfactory and auditory nerves alone, of all the sensory roots (omitting for the present the optic nerve), do not contain fibers from either of the series of motor nuclei. The relations of the various cranial nerves to the nuclei may be seen from the following table, in which the + sign indicates the presence and the - sign the absence of fibers from the nuclear series under which it stands: 


\begin{tabular}{|c|c|c|c|c|}
\hline Number & Name & Ventral Motor & Lateral Motor & Sensory \\
\hline I. & Olfactory. & - & - & + \\
\hline III. & Oculomotor. & + & - & - \\
\hline IV. & Trochlear. & + & - & - \\
\hline V. & Trigeminus. & - & + & + \\
\hline VI & Abducens. & + & - & - \\
\hline VII. & Facial. & - & + & + \\
\hline VIII. & Auditory. & - & - & + \\
\hline IX. & Glossopharyngeal. & - & + & + \\
\hline $\begin{array}{l}\text { X. } \\
\text { XI. }\end{array}$ & $\begin{array}{l}\text { Vagus. } \\
\text { Spinal Accessory. }\end{array}$ & - & + & + \\
\hline
\end{tabular}

Two nerves - namely, the second and twelfth-have been omitted from the above table. Of these, the second or optic nerve undoubtedly belongs to an entirely different category from the other peripheral nerves, and will be considered in the following chapter in connection with the sense-organ with which it is associated (see especially p. 460). The twelfth or hypoglossal nerve, on the other hand, really belongs to the spinal series and has only secondarily been taken up into the cranial region in the higher vertebrates. It has already been seen (p. I7o) that the bodies of four vertebræ are included in the basioccipital bone, and that three of the nerves corresponding to these vertebræ are represented in the adult by the hypoglossal and the fourth by the first cervical or suboccipital nerve. The dorsal roots of the hypoglossal nerves seem to have almost disappeared, although a ganglion has been observed in embryos of 7 and ro $\mathrm{mm}$. in the posterior part of the hypoglossal region (His), and probably represents the dorsal root of the most posterior portion of the hypoglossal nerve. This ganglion disappears, as a rule, in later stages, and it is interesting to note that the ganglion of the suboccipital nerve is also occasionally wanting in the adult condition. The hypoglossal roots are to be regarded, then, as equivalent to the ventral roots of the cervical spinal nerves, and the nuclei from which they arise lie in series with the cranial ventral motor roots, a 
fact which indicates the equivalency of these latter with the fibers which arise from the neuroblasts of the anterior horns of the spinal cord.

The equivalents of the lateral motor roots may more conveniently be considered later on, but it may be pointed out here that these are the fibers which are distributed to the muscles of the branchiomeres. In the case of the sensory nerves a further analysis is necessary before their equivalents in the spinal series can be determined. For this the studies which have been made in recent years of the components entering into the cranial nerves of the amphibia (Strong) and fishes (Herrick) must supply a basis, since as yet a direct analysis of the mammalian nerves has not been made. In the forms named it has been found that three different components enter into the formation of the dorsal roots of the cranial nerves: (I) fibers belonging to a general cutaneous or somatic sensory system, distributed to the skin without being connected with any special sense-organs; (2) fibers belonging to what is termed the communis or viscero-sensory system, distributed to the walls of the mouth and pharyngeal region and to special organs found in the skin of the same character as those occurring in the mouth; and (3) fibers belonging to a special set of cutaneous sense-organs largely developed in the fishes and known as the organs of the lateral line.

The fibers of the somatic sensory system converge to a group of cells, situated in the lateral part of the floor of the fourth ventricle and forming what is termed the trigeminal lobe, and also extend posteriorly in the substance of the medulla (Fig. 247), forming what has been termed the spinal root of the trigeminus and terminating in a column of cells which represents the forward continuation of the posterior horn of the cord. In the fishes and amphibia fibers belonging to this system are to be found in the fifth, seventh, and tenth nerves, but in the mammalia their distribution has apparently become more limited, being confined almost exclusively to the trigeminus, of whose sensory divisions they form a very considerable part. Since the cells around which the fibers of the spinal root of the trigeminus terminate are the forward continuations of the posterior 
horn of the cord, it seems probable that the fibers of this system are the cranial representatives of the posterior roots of the spinal nerves, which, it may be noted, are also somatic in their distribution.

The fibers of the viscero-sensory system are found in the lower forms principally in the ninth and tenth nerves (see Fig. 247), although groups of them are also incorporated in the seventh and fifth. They converge to a mass of cells, known as the lobus vagi, and like the first set are also continued down the medulla to form

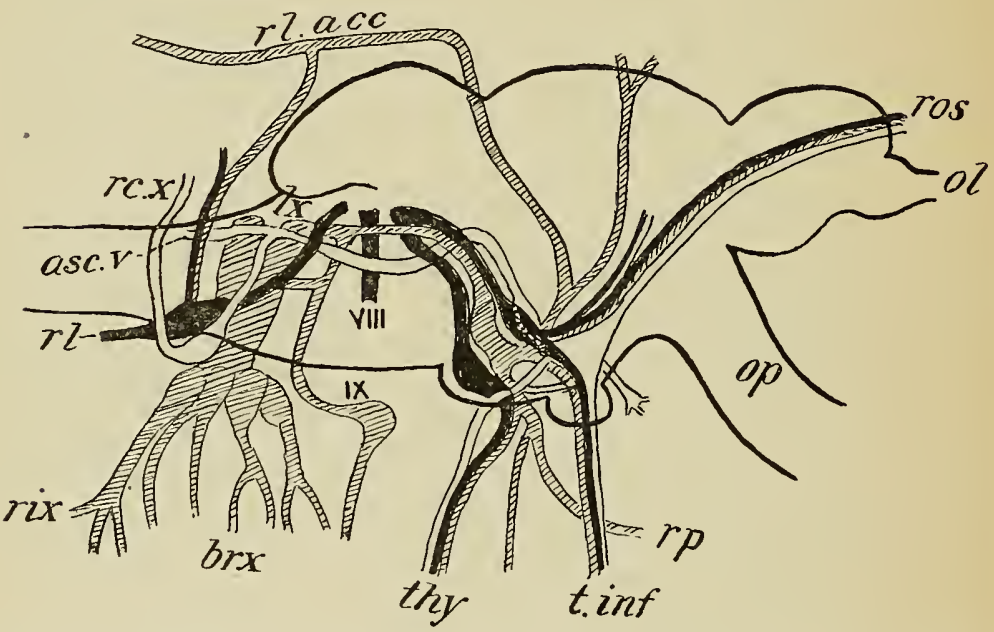

Fig. 247.-Diagrams showing the Sensory Components of the Cranial Nerves of A FISH (Menidia).

The somatic sensory system is unshaded, the viscero-sensory is cross-hatched, and the lateral line system is black. asc.v, Spinal root of trigeminus; brx, branchial branches of vagus; $l x$, lobus vagi; ol, olfactory bulb; op, optic nerve; $r c . x$, cutaneous branch of the vagus; $r i x$, intestinal branch of vagus; $r l$, lateral line nerve; $r l . a c c$, accessory lateral line nerve; $r o s$, superficial ophthalmic; $r p$, ramus palatinus of the facial; thy, hyomandibular branch of the facial; t.inf, infraorbital nerve.-(Herrick.)

a tract known as the fasciculus solitarius or fasciculus communis. In the mammalia the system is represented by the sensory fibers of the glosso-pharyngeo-vagus set of nerves, of which it represents practically the entire mass; by the sensory fibers of the facial arising from the geniculate ganglion and included in the chorda tympani and probably also the great superficial petrosal; and also, probably, by 
the lingual branch of the trigeminus. Furthermore, since the mucous membrane of the palate is supplied by branches from the trigeminus which pass by way of the spheno-palatine (Meckel's) ganglion, and the same region is supplied in lower forms by a palatine branch from the facial, it seems probable that the palatine nerves of the manmalia are also to be assigned to this system.* If this be the case, a very evident clue is afforded to the homologies of the system in the spinal nerves, for since the spheno-palatine ganglion is to be regarded as part of the sympathetic system, the sensory fibers which pass from the viscera to the spinal cord by way of the sympathetic system (p. 420) present relations practically identical with those of the palatine nerves.

Finally, with regard to the system of the lateral line, there seems but little doubt that it has no representation whatsoever in the spinal nerves. It is associated with a peculiar system of cutaneous senseorgans found only in aquatic or marine animals, and also with the auditory and possibly the olfactory organs, the former of which are certainly and the latter possibly primarily parts of the lateral line system of organs. The organs are principally confined to the head, although they also extend upon the trunk, where they are followed by a branch from the vagus nerve, the entire system being accordingly supplied by cranial nerves. In the fishes, in which the development of the organs is at a maximum, fibers belonging to the system are found in all the branchiomeric nerves and all converge to a portion of the medulla known as the tuberculum acusticum. In the Mammalia, with the disappearance of the lateral line organs there has been a disappearance of the associated nerves, and the only certain representative of the system which persists is the auditory nerre.

The table given on page 4I2 may now be expanded as follows, though it must be recognized that such an analysis of the mammalian nerves is merely a deduction from what has been observed in lower

* The fact that the palatine branches are associated with the trigeminus in the Mammalia and with the facial in the Amphibia is readily explained by the fact that in the latter the Gasserian and geniculate ganglia are not always separated, so that it is possible for fibers originating from the compound ganglion to pass into either nerve. 
forms, and may require some modifications when the components have been subjected to actual observation:

\begin{tabular}{|c|c|c|c|c|c|}
\hline Nerve & $\begin{array}{l}\text { Ventral } \\
\text { Motor }\end{array}$ & $\begin{array}{l}\text { Lateral } \\
\text { Motor }\end{array}$ & $\begin{array}{c}\text { Somatic } \\
\text { Sensory }\end{array}$ & $\begin{array}{l}\text { Visceral } \\
\text { Sensory }\end{array}$ & $\begin{array}{c}\text { Lateral } \\
\text { Line }\end{array}$ \\
\hline I. & - & - & - & - & + \\
\hline III. & + & - & - & - & - \\
\hline IV. & + & - & - & - & - \\
\hline $\mathrm{V}$ & - & + & + & + & - \\
\hline VI. & + & - & - & - & - \\
\hline vir. & - & + & - & + & - \\
\hline $\begin{array}{l}\text { VIII. } \\
\text { IX. }\end{array}$ & - & - & - & - & + \\
\hline $\left.\begin{array}{r}\text { X. } \\
\text { XI. }\end{array}\right\}$ & - & + & + & + & - \\
\hline XII. & + & - & - & - & - \\
\hline Spinal. & + & (?) & + & + & - \\
\hline
\end{tabular}

An additional word is necessary concerning the spinal accessory nerve, for it presents certain interesting relations which possibly furnish a clue to the spinal equivalents of the lateral motor roots. In the first place, the neuroblasts which give rise to those fibers of the nerve which come from the spinal cord are situated in the dorsal part of the ventral zones. As the nuclei of origin are traced anteriorly they will be found to change their position somewhat as the medulla is reached and eventually come to lie in the reticular formation, the most anterior of them being practically continuous with the motor nucleus of the vagus. Indeed, it seems that the spinal accessory nerve is properly to be regarded as an extension of the vagus downward into the cervical region (Fürbringer, Streeter), a process which reaches its greatest development in the mammalia and seems to-stand in relation to the development of those portions of the trapezius and sterno-mastoid muscles which are supplied by the spinal accessory nerve.

It is believed that the white rami communicantes which pass from the spinal cord to the thoracic and upper lumbar sympathetic 
ganglia arise from cells situated in the dorso-lateral portions of the ventral horns, and it is noteworthy that white rami are wanting in the region in which the spinal accessory ncrve occurs. Since this nerve represents a cranial lateral motor root the temptation is great to regard the cranial lateral motor roots as equivalent to the white rami of the cord, and this temptation is intensified when it is recalled that there are both embryological and topographical reasons for regarding the branchiomeric muscles, to which the cranial lateral motor nerves are supplied, as equivalent to the visceral muscles of the trunk. But in view of the fact that a sympathetic neurone is always interposed between a white ramus fiber and the visceral musculature (see Fig. 249), while the lateral motor fibers connect directly with the branchiomeric musculature, it seems advisable to await further studies before yielding to the temptation.

As regards the actual development of the cranial nerves, they follow the general law which obtains for the spinal nerves, the motor fibers being outgrowths from neuroblasts situated in the walls of the neural tube, while the sensory nerves are outgrowths from the cells of ganglia situated without the tube. In the lower vertebrates a series of thickenings, known as the suprabranchial placodes, are developed from the ectoderm along a line corresponding with the level of the auditory invagination, while on a line corresponding with the upper extremities of the branchial clefts another series occurs which has been termed that of the epibranchial placodes, and with both of these sets of placodes the cranial nerves are in connection. In the human embryo epibranchial placodes have been found in connection with the fifth, seventh, ninth and tenth nerves, to whose ganglia they contribute cells. The suprabranchial placodes, which in the lower vertebrates are associated with the lateral line nerves, are unrepresented in man, unless, as has been maintained, the sense-organs of the internal ear are their representatives.

From what has been said above it is clear that the usual arrangement of the cranial nerves in twelve pairs does not represent their true relationships with one another. The various pairs are serially homologous neither 
with one another nor with the typical spinal nerves, nor can they be regarded as representing twelve cranial segments. Indeed, it would seem that comparatively little information with regard to the number of myotomic segments which have fused together to form the head is to be derived from the cranial nerves, for while there are only four of these nerves which are associated with structures equivalent to the mesodermic somites of the trunk, a much greater number of head cavities or mesodermic somites has been observed in the cranial region of the embryos of the lower vertebrates, Dohrn, for instance, having found nineteen and Killian eighteen in the cranial region of Torpedo. Furthermore, it is not possible to say at present whether the branchiomeres and their associated nerves correspond with one or several of the cranial mesodermic somites, or whether, indeed, any correspondence whatever exists.

In early stages of development a series of constrictions have been observed in the cranial portion of the neural tube and have been regarded as indicating a primitive segmentation of that structure. The neuromeres, as the intervals between successive constrictions have been termed, seem to correspond with the cranial nerves as usually recognized and hence cannot be regarded as primitive segmental structures. They are more probably secondary and due to the arrangement of the neuroblasts corresponding to the various nerves.

\section{The Development of the Sympathetic Nervous System.-} From the embryological standpoint the distinction which has been generally recognized between the sympathetic and central nervous systems does not exist, the former having been found to be an outgrowth from the latter. This mode of origin has been observed with especial clearness in the embryos of some of the lower vertebrates, in which masses of cells have been seen to separate from the posterior root ganglia to form the ganglia of the ganglionated cord (Fig. 248). In the mammalia, including man, the relations of the two sets of ganglia to one another is by no means so apparent, since the sympathetic cells, instead of being separated from the posterior root ganglion en masse, migrate from it singly or in groups, and are therefore less readily distinguishable from the surrounding mesodermal tissues.

To understand the development of the sympathetic system it must be remembered that it consists typically of three sets of ganglia. One of these is constituted by the ganglia of the ganglionated cord (Fig. 249, GC), the second is represented by the ganglia of the 


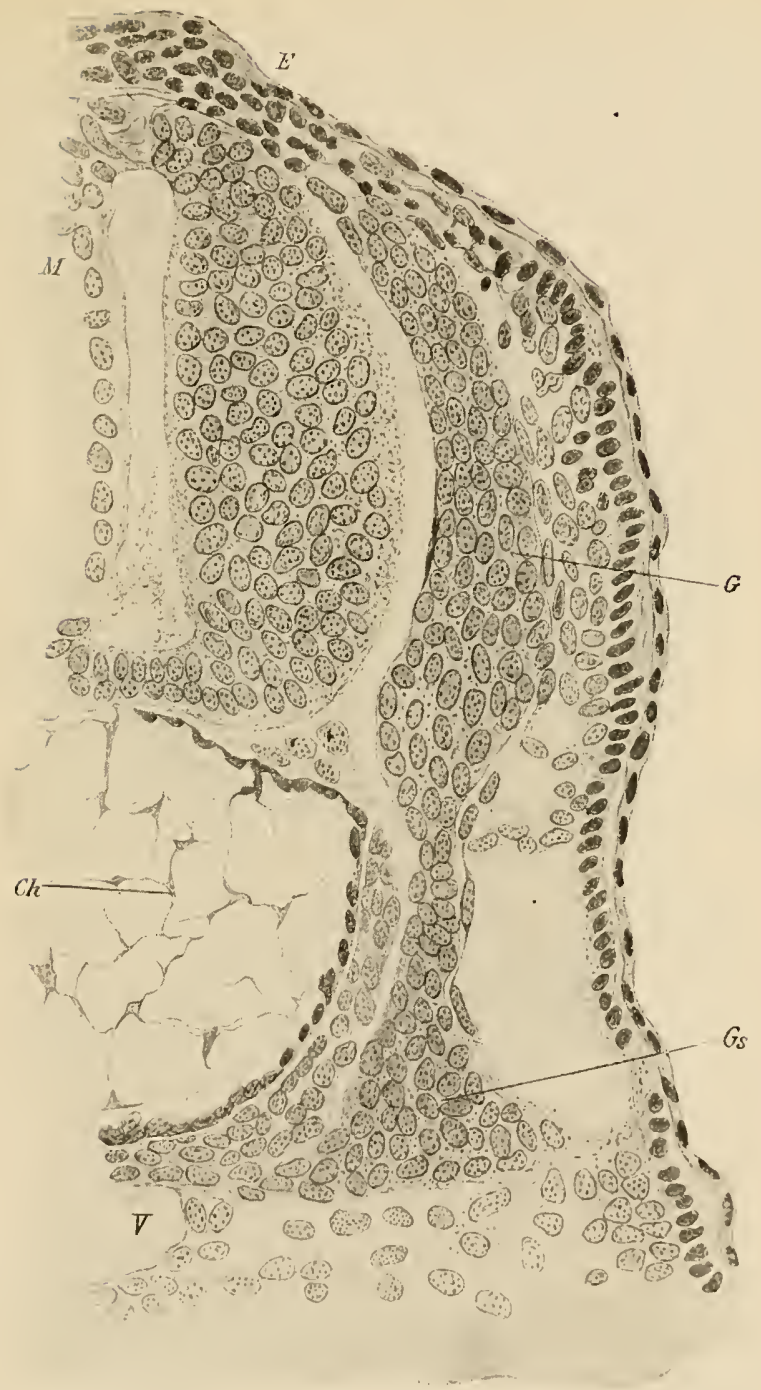

Fig. 248.-Transverse Section throvgh an Embryo Shark (Scyllium) of 15 mim., Showing the Origin of a Srapathetic Ganglion.

$C h$, Notochord; $E$, ectoderm; $G$, posterior root ganglion; $G s$, sympathetic ganglion; $M$, spinal cord.-(Onodi.) 
prævertebral plexuses $(P V G)$, such as the cardiac, solar, hypogastric, and pelvic, while the third or peripheral set $(P G)$ is formed by the cells which occur throughout the tissues of probably most of the visceral organs, either in small groups or scattered through plexuses such as the Auerbach and Meissner plexuses of the intestine. Each cell in these various ganglia stands in direct contact with the axiscylinder of a cell situated in the central nervous system, probably in the lateral horn of the spinal cord or the corresponding region of the brain, so that each cell forms the terminal link of a chain whose first link is a neurone belonging to the central system (Huber). Through-

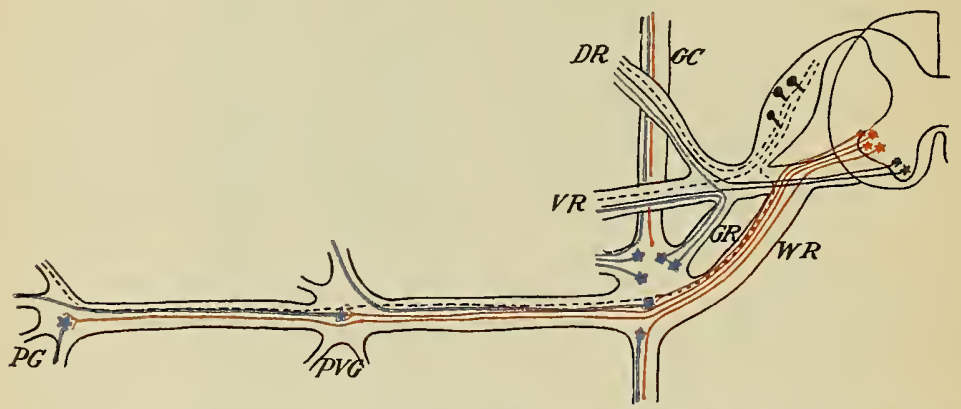

Fig. 249.-Diagram showing the Arrangement of the Neurones of the SympaTHETIC System.

The fibers from the posterior root ganglia are represented by the broken black lines; those from the anterior horn cells by the solid black; the white rami by red; and the sympathetic neurones by blue. $D R$, Dorsal ramus of spinal nerve; $G C$, ganglionated cord; $G R$, gray ramus communicans; $P G$, peripheral ganglion; $P V G$, prævertebral ganglion; $V R$, ventral ramus of spinal nerve; $W R$, white ramus communicans.(Adapted from Huber.)

out the thoracic and upper lumbar regions of the body the central system neurones form distinct cords known as the while rami communicantes (Fig. 249,WR), which pass from the spinal nerves to the adjacent ganglia of the ganglionated cord, some of them terminating around the cells of these ganglia, others passing on to the cells of the prevertebral ganglia, and others to those of the peripheral plexuses. In the cervical, lower lumbar and sacral regions white rami are wanting, the central neurones in the first-named region probably making their way to the sympathetic cells by way of the upper 
thoracic nerves, while in the lower regions they may pass down the ganglionated cord from higher regions or may join the prævertebral and peripheral ganglia directly without passing through the proximal ganglia. In addition to these white rami, what are known as gray rami also extend between the proximal ganglia and the spinal nerves; these are composed of fibers, arising from sympathetic cells,

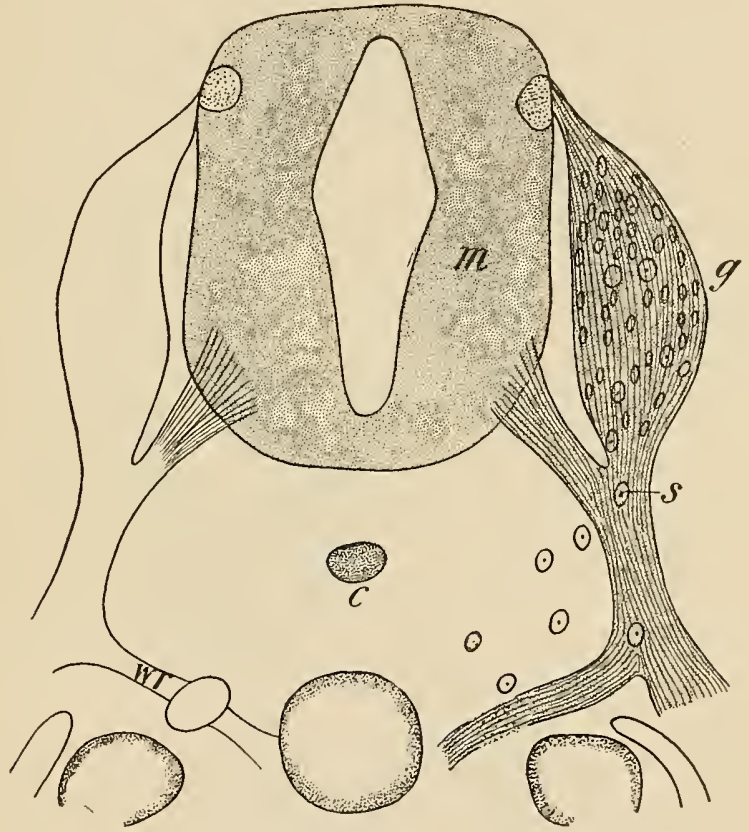

Fig. 250.-Transverse Section through the Spinal Cord of an Embryo of 7 Mim. $c$, Notochord; $g$, posterior root ganglion; $m$, spinal cord; $s$, sympathetic cell migrating from the posterior root ganglion; $w$, white ramus.-(His.)

which join the spinal nerves in order to pass with them to their ultimate distribution.

The brief description here given applies especially to the sympathetic system of the neck and trunk. Representatives of the system are also found in the head, in the form of a series of ganglia connected with the trigeminal and facial nerves and known as the ciliary, spheno-palatine, otic, and submaxillary ganglia; and, as will 
be seen later, there are probably some sympathetic cells which owe their origin to the root ganglia of the vagus and glossopharyngeal nerves. There is nothing, however, in the head region corresponding to the longitudinal bundles of fibers which unite the various proximal ganglia of the trunk to form the ganglionated cord.

The first distinct indications of the sympathetic system are to be seen in a human embryo of about $7 \mathrm{~mm}$. As the spinal nerves reach the level of the dorsal edge of the body-cavity, they branch, one of the branches continuing ventrally in the body-wall, while the other (Fig 250, wr) passes mesially toward the aorta, some of its fibers reaching that structure, while others bend so as to assume a longitudinal direction. These mesial branches represent the white rami communicantes, but as yet no ganglion cells can be seen in their course. The cells of the posterior root ganglia have already, for the most part, assumed their bipolar form, but among them there may still be found a number of cells in the neuroblast condition, and these (Fig. 250, s), wandering out from the ganglia, give rise to a column of cells standing in relation to the white rami. At first there is no indication of a segmental arrangement of the cells of the column (Fig. 25I), but at about the seventh week such an arrangement makes its appearance in the cervical region, and later, extends posteriorly, until the column assumes the form of the ganglionated cord.

This origin of the ganglionated cord from cells migrating out from the posterior root ganglia has been described by various authors, but recently the origin of the cells has been carried a step further back, to the mantle layer of the central nervous system (Kuntz). Indifferent cells and neuroblasts are said to wander out from the walls of the medullary canal by way of both the posterior and anterior nerve roots and it is claimed that these are the cells that give rise to the ganglionated cord in the manner just described.

Before, however, the segmentation of the ganglionated cord becomes marked, thickenings appear at certain regions of the cell column, and from these, bundles of fibers may be seen extending ventrally toward the viscera. The thickenings represent certain of 
the prevertebral ganglia, and later cells wander out from them and take a position in front of the aorta. In an embryo of $10.2 \mathrm{~mm}$. two ganglionic masses (Fig. 25 I, pc) occur in the vicinity of the origin

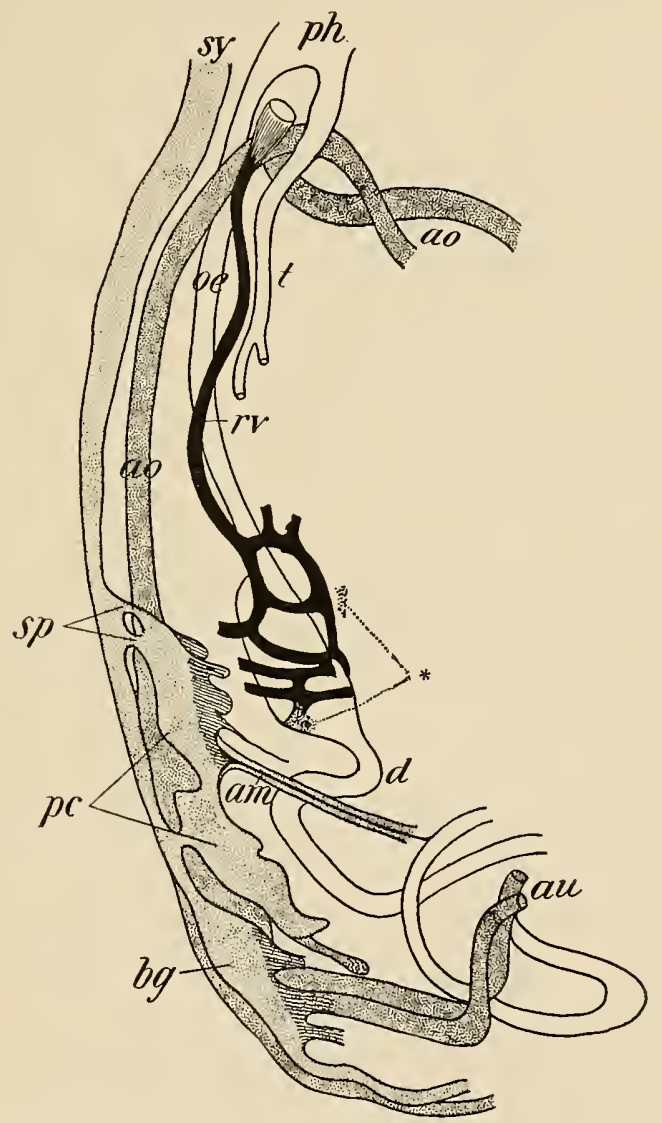

Fig. 25I.-Reconstruction of the Sympathetic System of An Embryo of 10.2 Mm.

$a m$, Vitelline artery; $a o$, aorta; $a$, umbilical artery; $b g$, ganglionic mass representing the pelvic plexus; $d$, intestine; oe, œesophagus; $p c$, ganglia of the coliac plexus; ph, pharynx; $r v$, right vagus nerve; $s p$, splanchnic nerves; $s y$, ganglionated cord; $t$, trachea; *, peripheral sympathetic ganglia in the walls of the stomach.-(His, Jr.)

of the vitelline artery $(a m)$, one lying above and the other below that vessel; these masses represent the ganglia of the cœliac 
plexus and have separated somewhat from the ganglionated cord, the fiber bundles which unite the upper mass with the cord representing the greater and lesser splanchnic nerves $(s p)$, while that connected with the lower mass represents the connection of the cord with the superior mesenteric ganglion. Lower down, in the neighborhood of the umbilical arteries, is another enlargement of the cord $(b g)$, which probably represents the inferior mesenteric and hypogastric ganglia which have not yet separated from the cell column.

With the peripheral ganglia the conditions are slightly different, in that they are formed very largely, if not exclusively, from cells that migrate from the walls of the hind-brain by way of the vagus nerves (Fig. 25r). In this way the ganglia of the myenteric, pulmonary and cardiac plexuses are formed, though in the case of the last named it is probable that contributions are also received from the ganglionated cord.

The elongated courses of the cardiac sympathetic and splanchnic nerves in the adult receive an explanation from the recession of the heart and diaphragm (see pp. 239 and 322), the latter process forcing downward the cœliac plexus, which originally occupied a position opposite the region of the ganglionated cord from which the splanchnic nerves drise.

As regards the cephalic sympathetic ganglia, the observations of Remak on the chick and Kölliker on the rabbit show that the ciliary, sphenopalatine, and otic ganglia arise by the separation of cells from the semilunar (Gasserian) ganglion, and from their adult relations it may be supposed that the cells of the submaxillary and sublingual ganglia have similarly arisen from the geniculate ganglion of the facial nerve. Evidence has also been obtained from human embryos that sympathetic cells are derived from the ganglia of the vagus and glossopharyngeal nerves, but, instead of forming distinct ganglia in the adult, these, in all probability, associate themselves with the first cervical ganglia of the ganglionated cord.

\section{LITERATURE.}

C. R. BARDEEN: "The Growth and Histogenesis of the Cerebrospinal Nerves in Mammals," Amer. Journ. Anat., Ir, I903. 
S. R. CajaL: “Nouvelles Observations sur l'evolution des neuroblasts avec quelques remarques sur l'hypothèse neurogénétique de Hensen-Held," Anat. Anzeiger, xxxil, I908.

A. F. Dixon: "On the Development of the Branches of the Fifth Cranial Nerve in Man," Scient. Trans. Roy. Dublin Soc., Ser. I, VI, I896.

C. R. Essick: "The Development of the Nuclei pontis and the Nucleus Arcuatus in Man," Amer. Journ. Anat., XIII, I9I2.

E. Giglio-Tos: "Sugli organi branchiali e laterali di senso nell' uomo nei primordi del suo sviluppo," Monit. Zool. Ital., xIII, Igo2.

E. Giclio-Tos: "Sull' origine embrionale del nervo trigemino nell' uomo," Anat. Anzeiger, XXI, I902.

E. Giglio-Tos: "Sui primordi dello sviluppo del nervo acustico-faciale nell' uomo," Anat. Anzeiger, xxI, 1902.

K. Goldstern: "Die erste Entwicklung der grossen Hirncommissuren und die 'Verwachsung' von Thalamus und Striatum" Archiv für Anat. und Physiol., Anat. Abth., I903.

G. Groenberg: "Die Ontogenese einer niederen Säugergehirns nach Untersuchungen an Erinaceus europaeus," Zoolog. Jahrb. Abth. f. Anat. und Ontogen., xv, rgor.

I. Hardesty: "On the Development and Nature of the Neuroglia," Amer. Journ Anat., III, 1904.

R. G. Harrison: "Further Experiments on the Development of Peripheral Nerves," Amer. Journ. of Anat., v, I9o6.

W. His: "Zur Geschichte des menschlichen Rückenmarkes und der Nervenwurzeln,' Abhandl. der königl. Sächsischen Gesellsch., Math.-Physik. Classe, xIII, I886.

W. His: "Zur Geschichte des Gehirns sowie der centralen und peripherischen Nervenbahnen beim menschlichen Embryo," Abhandl. der königl. Sächsischen Gesellsch., Math.-Physik. Classe, xiv, I888.

W. His: "Die Formentwickelung des menschlichen Vorderhirns vom Ende des ersten bis zum Beginn des dritten Monats," Abhandl. der königl. Sächsischen Gesellsch., Math.-Physik. Classe, xv. I889.

W. His: "Histogenese und Zusammenhang der Nervenelemente," Archiv für Anat. und Physiol., Anat. Abth., Supplement, 1890.

W. His: "Die Entwickelung des menschlichen Gehirns während der ersten Monate," Leipzig, I904.

W. His, JR.: "Die Entwickelung des Herznervensystem bei Wirbelthieren," Abhandl. der königl. Sächsischen Gesellsch., Math.-Physik. Classe, xviII, I893.

W. HIs, JR.: "Ueber die Entwickelung des Bauchsympathicus beim Hühnchen und Menschen," Archiv fiur Anat. und Physiol., Anat. Abth., Supplement, I897.

C. J. Herrick: "The Cranial and First Spinal Nerves of Menidia: A Contribution upon the Nerve Components of the Bony Fishes," Journ. of Comp. Neurol., Ix, IS99.

C. J. Herrick: "The Cranial Nerves and Cutaneous Sense-organs of the North American Siluroid Fishes," Journ. of Comp. Neurol., xI, I9or.

G. C. Huber: "Four Lectures on the Sympathetic Nervous System," Journ. of Comp. Neurol., viI, 1897 .

A. Kuntz: "A Contribution to the Histogenesis of the Sympathetic System," Anat. Record, III, Igog. 
A. Kuntz: "The rôle of the Vagi in the Development of the Sympathetic Nervous System," Anat. Anzeiger, xxxv, rgog.

A. Kuntz: "The Development of the Sympathetic Nervous System in Mammals," Journ. Compar. Neurol., xx, I910.

M. von Lenhossek: "Die Entwickelung der Ganglienanlagen bei dem menschlichen Embryo," Archiv für Anat. und Physiol., Anat. Abth., x891.

F. Marchand: "Ueber die Entwickelung des Balkens im menschlichen Gehirn," Archiv für mikrosk. Anat., xxxviI, I8gI.

V. von Minalkovicz: "Entwickelungsgeschichte des Gehirns," Leipzig, i877.

A. D. ONODi: "Ueber die Entwickelung des sympathischen Nervensystems," Archiv für mikrosk. Anat., xxviI, I886.

G. Retzius: "Das Menschenhirn," Stockholm, 1896.

A. SCHAPER: "Die frühesten Differenzirungsvorgänge im Central-nerven-system,' Archiv für Entwicklungsmechanik, v, $\mathrm{I} 897$.

G. L. Streeter: "The Development of the Cranial and Spinal Nerves in the Occipita Region of the Human Embryo," Amer. Journ. Anat., IV, 1904.

O. S. Strong: "The Cranial Nerves of Amphibia," Journal of Morphol., x, 1895 .

R. Wlassak: "Die Herkunft des Myelins," Archiv für Entwicklungsmechanik, vi 1898.

E. ZuCKerkandl: "Zur Entwicklung des Balkens," Arbeiten aus neurol. Inst. Wien. XVII, rgog. 


\section{CHAPTER XVI.}

\section{THE DEVELOPMENT OF THE ORGANS OF SPECIAL SENSE.}

Like the cells of the central nervous system, the sensory cells are all of ectodermal origin, and in lower animals, such as the earthworm, for instance, they retain their original position in the ectodermal epithelium throughout life. In the vertebrates, however, the majority of the sensory cells relinquish their superficial position and sink more or less deeply into the subjacent tissues, being represented by the posterior root ganglion cells and by the sensory cells of the special sense-organs, and it is only in the olfactory organ that the original condition is retained. Those cells which have withdrawn from the surface receive stimuli only through overlying cells, and in certain cases these transmitting cells are not specially differentiated, the terminal branches of the sensory dendrites e ding among ordinary epithelial cells or in such structures as the Pacinian bodies or the end-bulbs of Krause situated beneath undifferentiated epithelium. In other cases, however, certain specially modified superficial cells serve to transmit the stimuli to the peripheral sensory neurones, forming such structures as the hair-cells of the auditory epithelium or the gustatory cells of the taste-buds.

Thus three degrees of differentiation of the special sensory cells may be recognized and a classification of the sense-organs may be made upon this basis. One organ, however, the eye, cannot be brought into such a classification, since its sensory cells present certain developmental peculiarities which distinguish them from those of all other sense-organs. Embryologically the retina is a portion of the central nervous system and not a peripheral organ, and hence it will be convenient to arrange the other sense-organs 
according to the classification indicated and to discuss the history of the eye at the close of the chapter.

\section{The Development of the Olfactory Organ.-The general} development of the nasal fossa, the epithelium of which contains the olfactory sense cells, has already been described (pp. 99 and 283), as has also the development of the olfactory lobes of the brain (p. 406), and there remains for consideration here merely the formation of the olfactory nerve and the development of the rudimentary organ of Jacobson.

The Olfactory Nerve.-Very diverse results have been obtained by various observers of the development of the olfactory nerve, it having been held at different times that it was formed by the outgrowth of fibers from the olfactory lobes (Marshall), from fibers which arise partly from the olfactory lobes and partly from the olfactory epithelium (Beard), from the cells of an olfactory ganglion originally derived from the olfactory epithelium but later separating from it (His), and, finally, that it was composed of the prolongations of certain cells situated and, for the most part at least, remaining permanently in the olfactory epithelium (Disse). The most recent observations on the structure of the olfactory epithelium and nerve indicate a greater amount of probability in the last result than in the others, and the description which follows will be based upon the observations of His, modified in conformity with the results obtained by Disse from chick embryos.

In human embryos of the fourth week the cells lining the upper part of the olfactory pits show a distinction into ordinary epithelial and sensory cells, the latter, when fully formed, being elongated cells prolonged peripherally into a short but narrow process which reaches the surface of the epithelium and proximally gives rise to an axis-cylinder process which extends up toward and penetrates the tip of the olfactory lobe to come into contact with the dendrites of the first central neurones of the olfactory tract (Fig. 252). These cells constitute a neuro-epithelium and in later stages of development retain their epithelial position for the most part, a few of them, however, withdrawing into the subjacent mesenchyme and becoming 
bipolar, their peripheral prolongations ending frecly among the cells of the olfactory epithelium. These bipolar cells resemble closely in form and relations the cells of the embryonic posterior root ganglia, and thus form an interesting transition between these and the neuroepithelial cells.

The Organ of Jacobson.- - In embryos of three or four months a

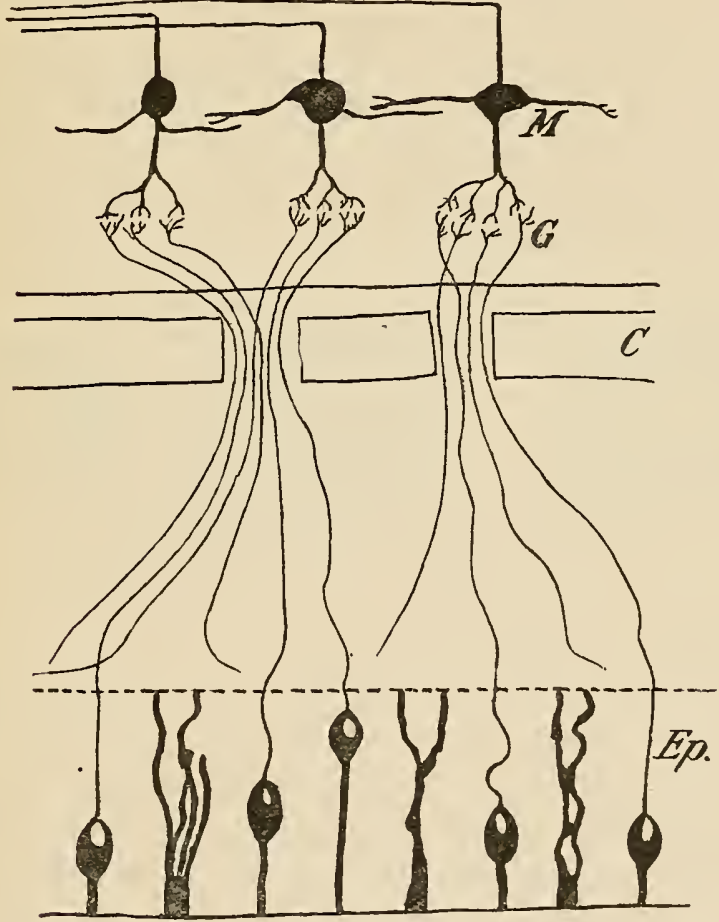

Fig. 252.-Diagram Illustrating the Relations of the Fibers of the Olfactory NERVE.

$E p$, Epithelium of the olfactory pit; $C$, cribiform plate of the ethmoid, $G$, glomerulus of the olfactory bulb; $M$, mitral cell.-(Van Gehuchten.).

small pouch-like invagination of the epithelium covering the lower anterior portion of the median septum of the nose can readily be seen. This becomes converted into a slender pouch, 3 to $5 \mathrm{~mm}$. long, ending blindly at its posterior extremity and opening at its other end 
into the nasal cavity. Its lining epithelium resembles that of the respiratory portion of the nasal cavity, and there is developed in the connective tissue beneath its floor a slender plate of cartilage, distinct from that forming the septum of the nose.

This organ, which may apparently undergo degeneration in the adult, and in some cases completely disappears, appears to be the representative of what is known as Jacobson's organ, a structure which reaches a much more extensive degree of development in many of the lower mammals, and in these contains in its epithelium sensory cells whose axis-cylinder processes pass with those of the olfactory sense cells to the olfactory bulbs. In man, however, it seems to be a rudimentary organ, and no satisfactory explanation of its function has as yet been advanced.

The olfactory neuro-epithelium, considered from a comparative standpoint, seems to have been derived from the system of lateral line organs so highly developed in the lower vertebrates (Kupffer). In higher forms the system, which is cutaneous in character, has disappeared except in two regions where it has become highly specialized. In one of these regions it has given rise to the olfactory sense cells and in the other to the similar cells of the auditory apparatus.

The Organs of Touch and Taste.-Little is yet known concerning the development of the various forms of tactile organs, which belong to the second class of sensory organs described above.

The Organs of Taste.- The remaining organs of special sense belong to the third class, and of these the organs of taste present in many respects the simplest condition. They are developed principally in connection with the vallate and foliate papillæ of the tongue, and of the former one of the earliest observed stages has been found in embryos of $9 \mathrm{~cm}$. in the form of two ridges of epidermis, lying toward the back part of the tongue and inclined to one another in such a manner as to form a $\mathrm{V}$ with the apex directed backward. From these ridges solid downgrowths of epidermis into the subjacent tissue occur, each downgrowth having the form of a hollow truncated cone with its basal edge continuous with the 
superficial epidermis (Fig. 253, A). In later stages lateral outgrowths develop from the deeper edges of the cone, and about the same time clefts appear in the substance of the original downgrowths (Fig. 253, B) and, uniting together, finally open to the surface, forming a trench surrounding a papilla (Fig. 253, C). The lateral outgrowths, which are at first solid, also undergo an axial degeneration and become converted into the glands of Ebner $(b)$, which open into the trench near its floor. The various papillæ which occur in the adult do not develop simultaneously, but their number increases with the age of the fetus, and there is, moreover, considerable variation in the time of their development.

The taste-buds are formed by a differentiation of the epithelium which covers the papillæ, and this differentiation appears to stand
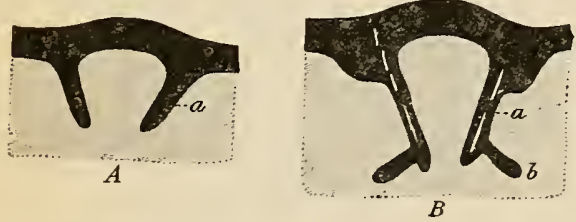

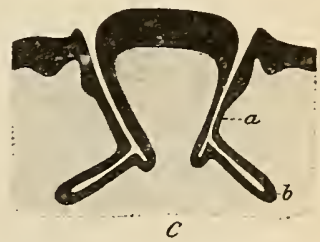

C

Fig. 253.-Diagrams Representing the Development of a Vallate Papilla. $a$, Valley surrounding the papilla; $b$, von Ebner's gland.-(Graberg.)

in intimate relation with the penetration of fibers of the glossopharyngeal nerve into the papillæ. The buds form at various places upon the papillæ, and at one period are especially abundant upon their free surfaces, but in the later weeks of intrauterine life these surface buds undergo degeneration and only those upon the sides of the trench persist, as a rule.

The foliate papillæ do not seem to be developed until some time after the circumvallate, being entirely wanting in embryos of four and a half and five months, although plainly recognizable at the seventh month.

The Development of the Ear.-It is customary to describe the mammalian ear as consisting of three parts, known as the inner, middle, and outer ears, and this division is, to a certain extent at 
least, confirmed by the embryonic development. The inner ear, which is the sensory portion proper, is an ectodermal structure, which secondarily becomes deeply seated in the mesodermal tissue of the head, while the middle and outer ears, which provide the apparatus necessary for the conduction of the sound-waves to the inner ear, are modified portions of the anterior branchial arches. It will be convenient, accordingly, in the description of the ear, to accept the usually recognized divisions and to consider first of all the development of the inner ear, or, as it is better termed, the otocyst.

The Development of the Otocyst.-In an embryo of $2.4 \mathrm{~mm}$. a pair of pits occur upon the surface of the body about opposite the middle portion of the hind-brain (Fig. 254, A). The ectoderm lining the pits is somewhat thicker than is the neighboring ectoderm
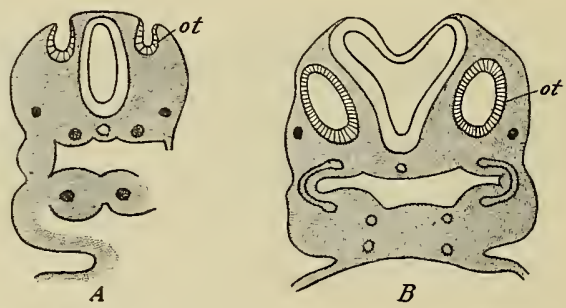

Fig. 254.-Transverse Section Passing through the Otocyst (ot) of Embryos of (A) 2.4 MM. AND (B) 4 MM. - (His.)

of the surface of the body, and, from analogy with what occurs in other vertebrates, it seems probable that the pits are formed by the invagination of localized thickenings of the ectoderm. The mouth of each pit gradually becomes smaller, until finally the invagination is converted into a closed sac (Fig. 254, B), which separates from the surface ectoderm and becomes enclosed within the subjacent mesoderm. This sac is the otocyst, and in the stage just described, found in embryos of $4 \mathrm{~mm}$., it has an oval or more or less spherical form. Soon, however, in embryos of $6.9 \mathrm{~mm}$., a prolongation arises from its dorsal portion and the sac assumes the form shown in Fig. 255, A; this prolongation, which is held by some authors to be the remains of the stalk which originally connected the otocyst sac 
with the surface ectoderm, represents the ductus endolymphaticus, and, increasing in length, it soon becomes a strong club-shaped process, projecting considerably beyond the remaining portions of the otocyst (Fig. 255, B). In embryos of about $10.2 \mathrm{~mm}$. the sac begins to show certain other irregularities of shape (Fig. 255, B, sc). Thus, about opposite the point of origin of the ductus endolymphaticus three folds make their appearance, representing the semi-
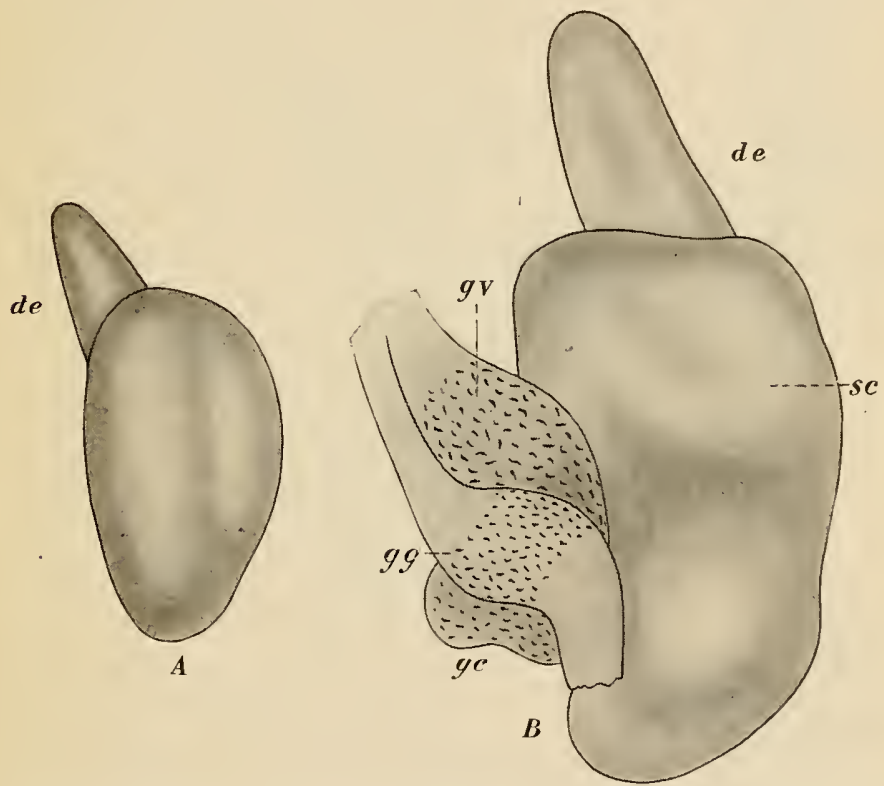

Fig. 255.-Reconstruction of the Otocysts of Embryo of (A) 6.9 MM. AND (B) I0.2 MM.

de, Endolymphatic duct; $g c$, ganglion cochleare; $g g$, ganglion geniculatum; $g v$, ganglion vestibulare; sc, lateral semicircular duct.-( $H$ is, $J r$.)

circular ducts, and as they increase in size the opposite walls of the central portion of each fold come together, fuse, and finally become absorbed, leaving the free edge of the fold as a crescentic canal, at one end of which an enlargement appears to form the ampulla. The transformation of the folds into canals takes place somewhat earlier in the cases of the two vertical than in that of the horizontal duct, as 
may be seen from Fig. 256 , which represents the condition occurring in an embryo of $13.5 \mathrm{~mm}$.

A short distance below the level at which the canals communicate with the remaining portion of the otocyst a constriction appears,

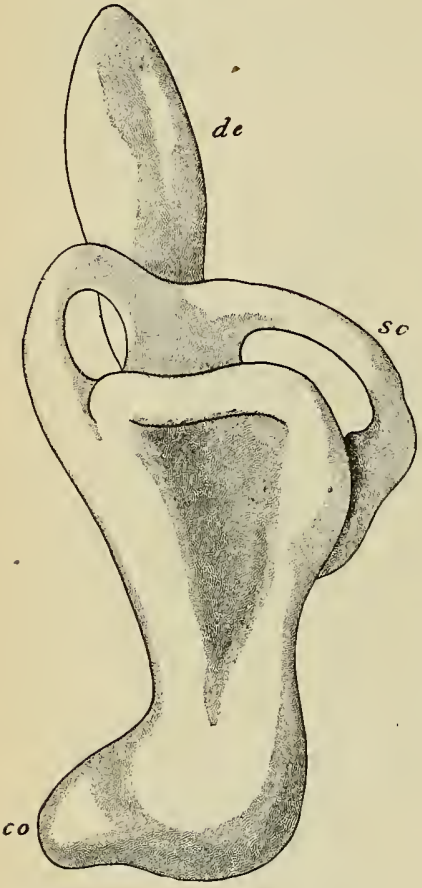

Fig. 256 .-RECONSTRUCTION OF THE OTOCYST OF AN EMBRYO OF I3.5 MM.

co, Cochlea; de, endolymphatic duct;.sc, semicircular duct.-(His, Jr.) indicating a separation of the otocyst into a more dorsal portion and a more ventral one. Later, the latter begins to be prolonged into a flattened canal which, as it elongates, becomes coiled upon itself and also becomes separated by a constriction from the remaining portion of the otocyst (Fig. 257). This canal is the ductus cochlearis (scala media of the cochlea), and the remaining portion of the otocyst subsequently becomes divided by a constriction into the utriculus, with which the semicircular ducts are connected, and the sacculus. The constriction which separates the cochlear duct from the sacculus becomes the ductus reuniens, while that between the utriculus and sacculus is converted into a narrow canal with which the ductus endolymphaticus connects, and hence it is that, in the adult, the connection between these two portions of, the otocyst seems to be formed by the ductus dividing proximally into two limbs, one of which is connected with the utricle and the other with the saccule.

When first observed in the human embryo the auditory ganglion is closely associated with the geniculate ganglion of the seventh nerve (Fig. 255, B), the two, usually spoken of as the acustico-facialis ganglion, forming a mass of cells lying in close contact with the 
anterior wall of the otocyst. The origin of the ganglionic mass has not yet been traced in the mammalia, but it has been observed that in cow embryos the geniculate ganglion is connected with the ectoderm at the dorsal end of the first branchial cleft (Froriep), and it may perhaps be regarded as one of the epibranchial placodes (see p. 4I7), and in the lower vertebrates a union of the ganglion with a suprabranchial placode has been observed (Kupffer), this union

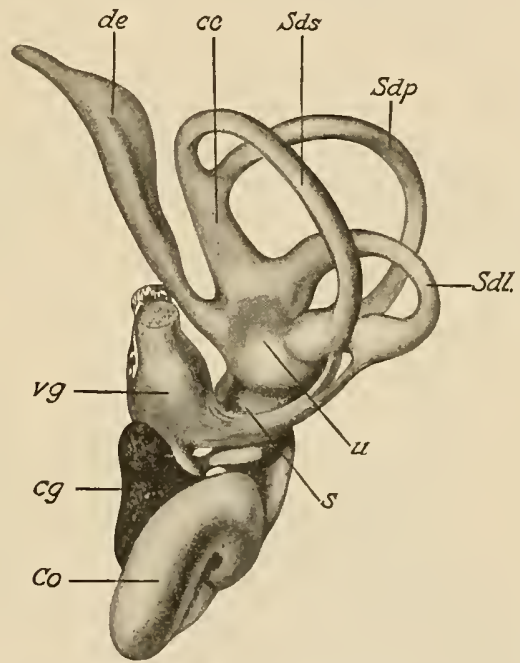

Fig. 257--Reconstruction OF THE OtOCyst OF AN EMbryo OF 20 MM., FRONT VIEW.

$c c$, Common limb of superior and posterior semicircular ducts; $c g$, cochlear ganglion; $c o$, cochlea; $d e$, endolymphatic duct; $s$, sacculus; $s d l, s d p$, and $s d s_{4}$ lateral, posterior and superior semicircular ducts; $u$, utriculus; $v g$, vestibular ganglion.-(Streeter.)

indicating the origin of the auditory ganglion from one or more of the ganglia of the lateral line system.

At an early stage in the human embryo the auditory ganglion shows indications of a division into two portions, a more dorsal one, which represents the future ganglion vestibulare, and a ventral one, the ganglion cochleare. The ganglion cells become bipolar, in which condition they remain throughout life, never reaching the $\mathrm{T}$-shaped condition found in most of the other peripheral cerebro-spinal ganglia. One of the prolongations of each cell is directed centrally to 
form a fiber of the auditory nerve, while the other penetrates the wall of the otocyst to enter into relations with certain specially modified cells which differentiate from its lining epithelium.

.In the earliest stages the ectodermal lining of the otocyst is formed of similar columnar cells, but later over the greater part of the surface the cells flatten down, only a few, aggregated together to

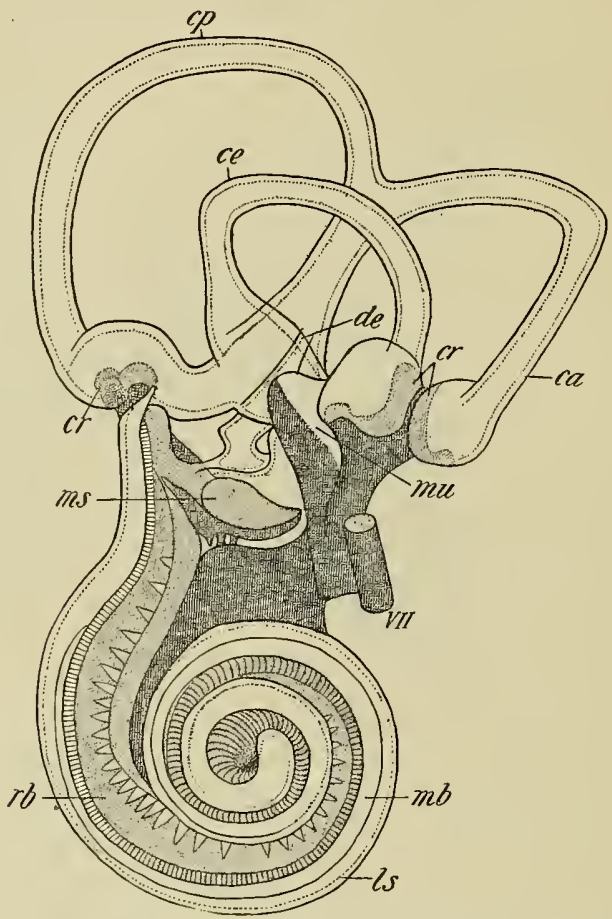

Fig. 258.-The Right Internal Ear of an Embryo of Six Months.

$c a, c e$, and $c p$, Superior, lateral, and posterior semicircular ducts; $c r$, crista acustica; $d e$, endolymphatic duct; $l s$, spiral ligament; $m b$, basilar membrane; $m s$ and $m u$, macula acustica sacculi and utriculi; $r b$, basilar branches of the cochlear nerve.-(Retzius.)

form patches, retaining the high columnar form and developing hairlike processes upon their free surfaces. These are the sensory cells of the ear. In the human ear there are in all six patches of these sensory cells, an elongated patch (crista ampullaris) in the ampulla of each semicircular canal (Fig. 258, cr), a round patch (macula acus- 
tica, $m u$ ) in the utriculus and another ( $m s$ ) in the sacculus, and, finally, an elongated patch which extends the entire length of the scala media of the cochlea and forms the sensory cells of the spiral organ of Corti. The cells of this last patch are connected with the fibers from the cochlear ganglion, while those of the vestibular ganglion pass to the cristæ and maculæ.

In connection with the spiral organ certain adjacent cells also retain their columnar form and undergo various modifications,

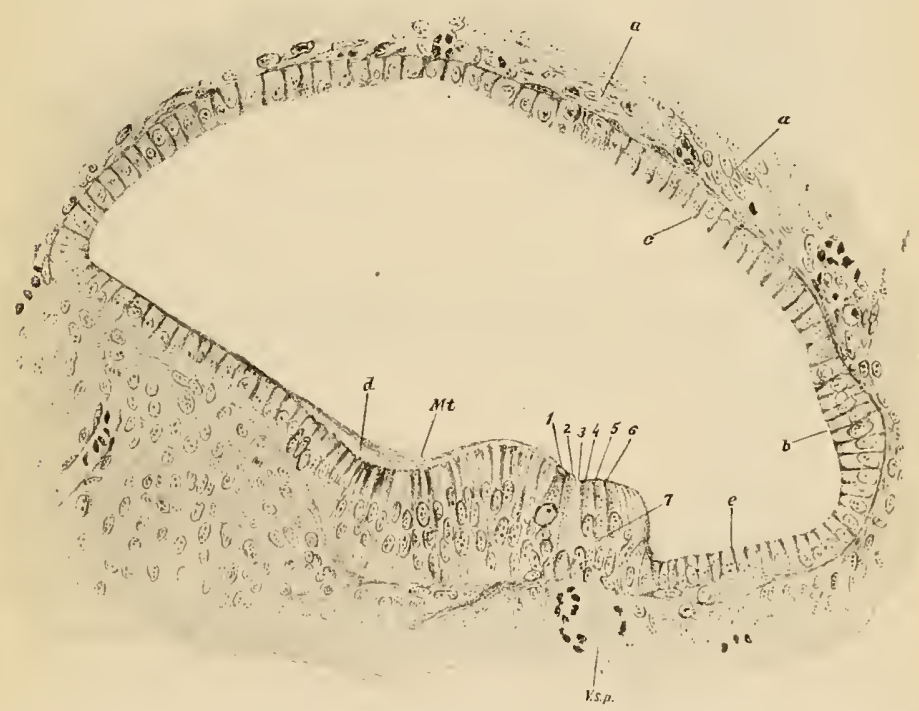

Fig. 259.-Section of the Cochlear Duct of a Rabbit Embryo of 55 mM. $a$, Mesenchyme; $b$ to $e$, epithelium of cochlear duct; M.t, membrana tectoria; V.s.p, vein; $x$ to 7 , spiral organ of Corti.-(Baginsky.)

giving rise to a rather complicated structure whose development has been traced in the rabbit. Along the whole length of the cochlear duct the cells resting upon that half of the basilar membrane which is nearest the axis of the cochlea, and may be termed the inner half, retain their columnar shape, forming two ridges projecting slightly into the cavity of the scala (Fig. 259). The cells of the inner ridge, much the larger of the two, give rise to the membrana tectoria, 
either as a cuticular secretion or by the artificial adhesion of long hair-like processes which project from their free surfaces (Ayers). The cells of the outer ridge are arranged in six longitudinal rows (Fig. 259, I-6); those of the innermost row (I) develop hairs upon their free surfaces and form the inner hair cells, those of the next two

- rows (2 and 3) gradually be-

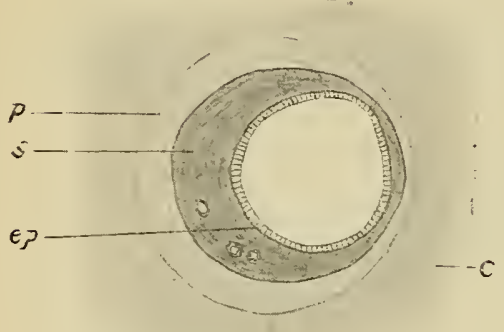
come transformed on their adjacent surfaces into chitinous substance and form the rods of Corti, while the three outer rows (4 to 6) develop into the outer hair cells. It is in connection with the hair cells that the peripheral prolongations of the cells of the cochlear ganglion ter-

Fig. 260.-TRANSVERSE Section tHROUGH A SEMICIRCULAR DUCT OF A RABbit EMbryo of TWENTy-Four Days.

$c$, Periotic cartilage; $e p$, fibrous membrane beneath the epithelium of the canal; $p$, perichondrium; $s$, spongy tissue.- (Von Kölliker.) minate, and since these hair cells are arranged in rows extending the entire length of the cochlear duct, the ganglion also is drawn out into a spiral following the coils of the cochlea, and hence is sometimes termed the spiral ganglion.

While the various changes described above have been taking place in the otocyst, the mesoderm surrounding it has also been undergoing development. At first this tissue is quite uniform in character, but later the cells immediately surrounding the otocyst condense to give rise to a fibrous layer (Fig. 260, ep), while more peripherally they become more loosely arranged and form a somewhat gelatinous layer $(s)$, and still more peripherally a second fibrous layer is differentiated and the remainder of the tissue assumes a character which indicates an approaching conversion into cartilage. The further history of these various layers is as follows: The inner fibrous layer gives rise to the connective-tissue wall which supports the ectodermal lining of the various portions of the otocyst; the gelatinous layer undergoes a degeneration to form a lymph-like 
fluid known as the perilymph, the space occupied by the fluid being the perilymphatic space; the outer fibrous layer becomes perichondrium and later periosteum; and the procartilage undergoes chondrification and later ossifies to form the petrous portion of the temporal bone.

The gelatinous layer completely surrounds most of the otocyst structures, which thus come to lie free in the perilymphatic space, but in the cochlear region the conditions are somewhat different. In this region the gelatinous layer is interrupted along two lines,

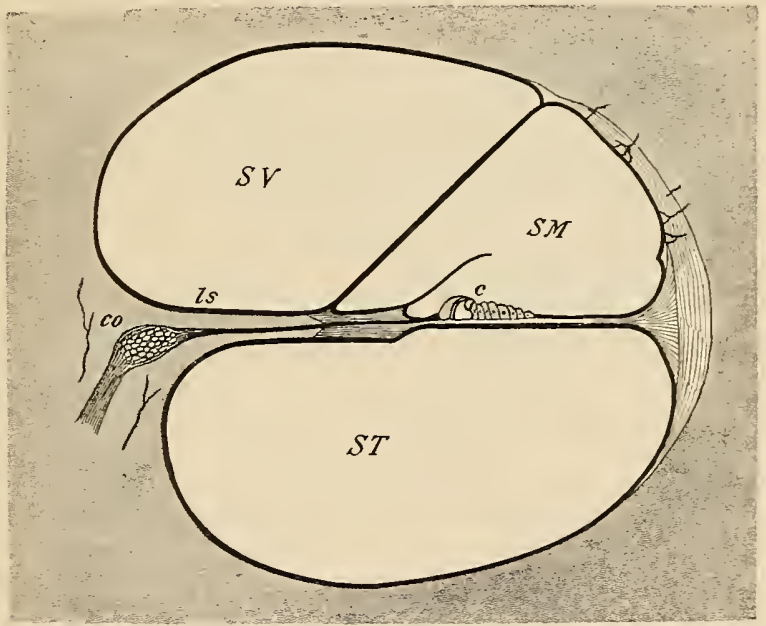

Fig. 26r.-Diagrammatic Transverse Section throvgh a Coll of the Cochlea SHOWING THE ReLation OF tHe SCALE.

$c$, Organ of Corti; $c o$, ganglion cochleare; $l s$, lamina spiralis; $S M$, cochlear duct; $S T$, scala tympani; $S V$, scala vestibuli.-(From Gerlach.)

an outer broad one where the connective-tissue wall of the cochlear duct is directly continuous with the perichondrium layer, and an inner narrow one, along which a similar fusion takes place with the perichondrium of a shelf-like process of the cartilage, which later ossifies to form the lamina spiralis. Consequently throughout the cochlear region the perilymphatic space is divided into two compartments which communicate at the apex of the cochlea, while below one, known as the scala vestibuli, communicates with the space 
surrounding the saccule and utricle, and the other, the scala tympani, abuts upon a membrane which separates it from the cavity of the middle ear and represents a portion of the outer wall of the petrous bone where chondrification and ossification have failed to occur. This membrane closes what appears in the dried skull to be an opening in the inner wall of the middle ear, known as the fenestra cochlece (rotunda); another similar opening, also closed by membrane in the fresh skull, occurs in the bony wall opposite the utricular portion of the otocyst and is known as the fenestra vestibuli (ovalis).

The Development of the Middle Ear.-The middle ear develops from the upper part of the pharyngeal groove which represents the endodermal portion of the first branchial cleft. This becomes prolonged dorsally and at its dorsal end enlarges to form the tympanic cavity, while the narrower portion intervening between this and the pharyngeal cavity represents the tuba auditiva (Eustachian tube).

To correctly understand the development of the tympanic cavity it is necessary to recall the structures which form its boundaries. Anteriorly to the upper end of the first branchial pouch there is the upper end of the first arch, and behind it the corresponding part of the second arch, the two fusing together dorsal to the tympanic cavity and forming its roof. Internally the cavity is bounded by the outer wall of the cartilaginous investment of the otocyst, while externally it is separated from the upper part of the ectodermal groove of the first branchial cleft by the thin membrane which forms the floor of the groove.

It has been seen in an earlier chapter that the axial mesoderm of each branchial arch gives rise to skeletal structures and muscles. The axial cartilage of the ventral portion of the first arch is what is known as Meckel's cartilage, but in that portion of the arch which forms the roof and anterior wall of the tympanic cavity, the cartilage becomes constricted to form two masses which later ossify to form the malleus and incus (Fig. 262, $m$ and $i$ ), while the muscular tissue of this dorsal portion of the arch gives rise to the tensortympani. Similarly, in the case of the second arch there is to be found, dorsal to 
the extremity of the cartilage which forms the styloid process of the adult, a narrow plate of cartilage which forms an investment for the facial nerve (Fig. 262,VII), and dorsal to this a ring of cartilage $(s t)$ which surrounds a small stapedial artery and represents the stapes.

It has been found that in the rabbit the mass of cells from which the stapes is formed is at its first appearance quite independent of the second branchial arch (Fuchs), and it has been held to be a

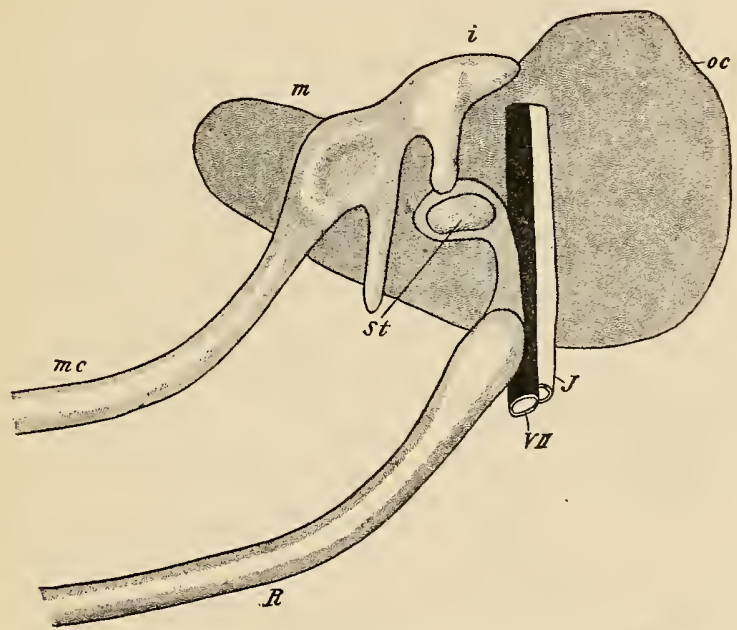

Fig. 262.-Semi-diagrammatic View of the Auditory Ossicles of an Embryo of SIX WEEKS.

$i$, Incus; $j$, jugular vein; $m$, malleus; $m c$, Meckel's cartilage; $o c$, capsule of otocyst; $R$, cartilage of the second branchial arch; st, stapes; VII, facial nerve.-(Siebenmann.)

derivative of the mesenchyme from which the periotic capsule is formed. In later stages, however, it becomes connected with the cartilage of the second branchial arch, as shown in Fig. 262, and it is a question whether this connection, which is transitory, does not really indicate the phylogenetic origin of the ossicle from the second arch cartilage, its appearance as an independent structure being a secondary ontogenetic phenomenon. However that may be, the stapedial artery disappears in later stages and the stapedius 
muscle, derived from the musculature of the second branchial arch and therefore supplied by the facial nerve, becomes attached to the ossicle.

The three ossicles at first lie embedded in the mesenchyme forming the roof of the primitive tympanic cavity, as does also the
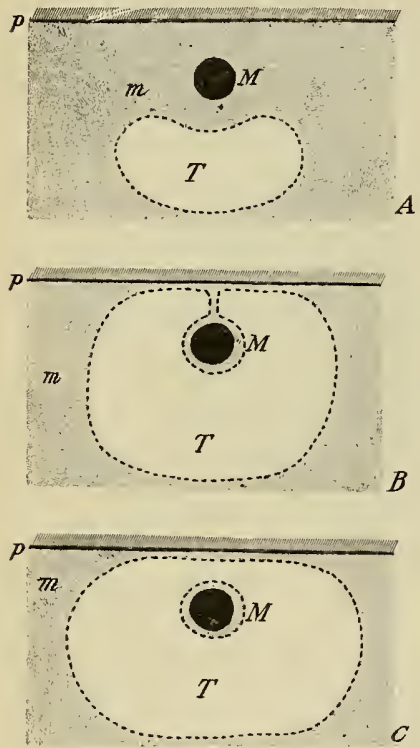

Fig. 263--Diagrams ILLUSTRATING THE MODE OF EXTENSION OF THE TYMPANIC CAVITY ARound the AUditory OSSicLes.

$M$, Malleus; $m$, spongy mesenchyme; $p$, surface of the periotic capsule; $T$, tympanic cavity. The broken line represents the epithelial lining of the tympanic cavity. chorda tympani, a branch of the seventh nerve, as it passes into the substance of the first arch on the way to its destination. The mesenchyme in which these various structures are embedded is rather voluminous (Fig. 264), and after the end of the seventh month becomes converted into a peculiar spongy tissue, which, toward the end of fetal life, gradually degenerates, the tympanic cavity at the same time expanding and wrapping itself around the ossicles and the muscles attached to them (Fig. 263). The bones and their muscles, consequently, while appearing in the adult to traverse the tympanic cavity, are really completely enclosed within a layer of epithelium continuous with that lining the wall of the cavity, while the handle of the malleus and the chorda tympani lie between the epithelium of the outer wall of the cavity and the fibrous mesoderm which forms the tympanic membrane.

The extension of the tympanic cavity does not, however, cease with its replacement of the degenerated spongy mesenchyme, but toward the end of fetal life it begins to invade the substance of the temporal bone by a process similar to that which produces the ethmoidal cells and the other osseous sinuses in connection with the 
nasal cavities (see p. I75). This process continues for some years after birth and results in the formation in the mastoid portion of the bone of the so-called mastoid cells, which communicate with the tympanic cavity and have an epithelial lining continuous with that of the cavity.

The lower portion of the diverticulum from the first pharyngeal groove which gives rise to the tympanic cavity becomes converted into the Eustachian tube. During development the lumen of the tube disappears for a time, probably owing to a proliferation of its lining epithelium, but it is re-established before birth.

In the account of the development of the ear-bones given above it is held that the malleus and incus are derivatives of the first branchial (mandibular) arch and the stapes probably of the second. This view represents the general consensus of recent workers on the difficult question of the origin of these bones, but it should be mentioned that nearly all possible modes of origin have been at one time or other suggested. The malleus has very generally been accepted as coming from the first arch, and the same is true of the incus, although some earlier authors have assigned it to the second arch. But with regard to the stapes the opinions have been very varied. It has been held to be derived from the first arch, from the second arch, from neither one nor the other, but from the cartilaginous investment of the otocyst, or, finally, it has been held to have a compound origin, its arch being a product of the second arch while its basal plate was a part of the otocyst investment.

\section{The Development of the Tympanic Membrane and of the Outer} Ear.-Just as the tympanic cavity is formed from the endodermal groove of the first branchial cleft, so the outer ear owes its origin to the ectodermal groove of the same cleft and to the neighboring arches. The dorsal and most ventral portions of the groove flatten out and disappear, but the median portion deepens to form, at about the end of the second month, a funnel-shaped cavity which corresponds to the outer portion of the external auditory meatus. From the inner end of this a solid ingrowth of ectoderm takes place, and this, enlarging at its inner end to form a disk-like mass, comes into relation with the gelatinous mesoderm which surrounds the malleus and chorda tympani. At about the seventh month a split occurs in the disk-like mass (Fig. 264), separating it into an outer and an inner 
layer, the latter of which becomes the outer epithelium of the tympanic membrane. Later, the split extends outward in the substance of the ectodermal ingrowth and eventually unites with the funnel-shaped cavity to complete the external meatus.

The tympanic membrane is formed in considerable part from

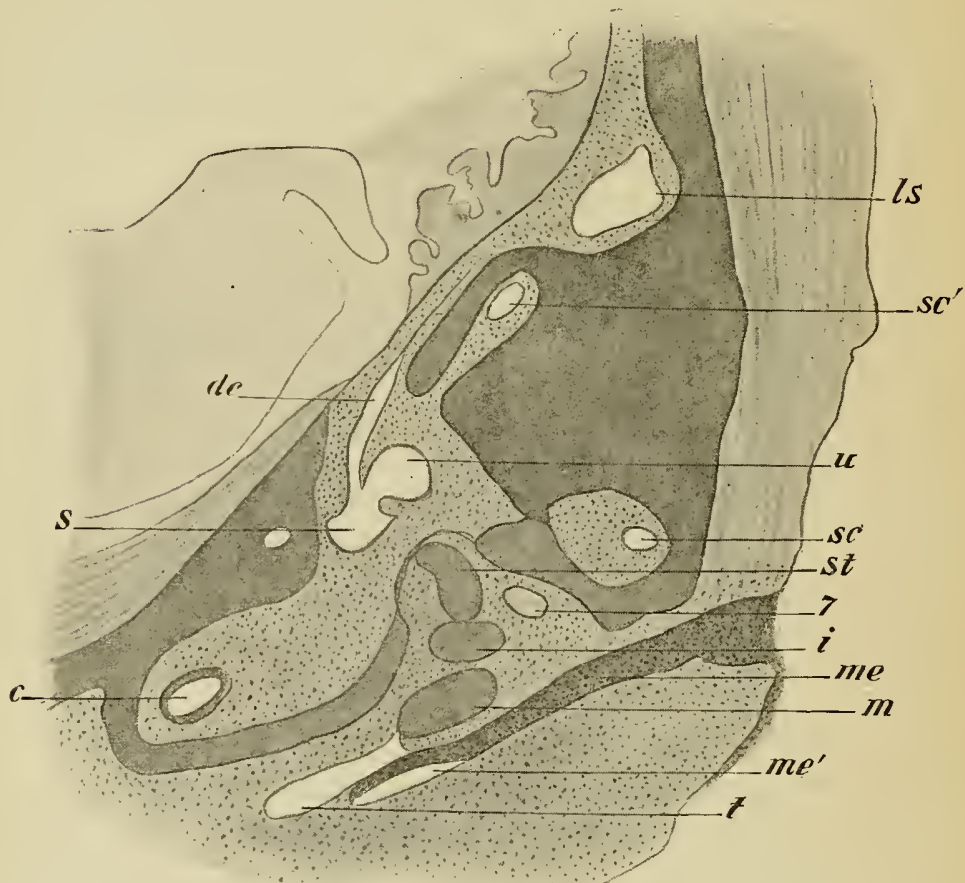

Fig. 264.-Horizontal Section Passing through the Dorsal Wall of the External Auditory Meatus in an Embryo of 4.5 CM.

$c$, Cochlea; $d e$, endolymphatic duct; $i$, incus; $l s$, transverse sinus; $m$, malleus; me, meatus auditorius externus; $m e^{\prime}$, cavity of the meatus; $s$, sacculus; $s c$, lateral semicircular canal; $s c^{\prime}$, posterior semicircular canal; st, stapes; $t$, tympanic cavity; $u$, utriculus; 7 , facial nerve.-(Siebenmann.)

the substance of the first branchial arch, the area in which it occurs not being primarily part of the wall of the tympanic cavity, but being brought into it secondarily by the expansion of the cavity. The membrane itself is mesodermal in origin and is lined on its outer 
surface by an ectodermal and on the inner by an endodermal epithelium.

The auricle (pinna) owes its origin to the portions of the first and second arches which bound the entrance of the external meatus. Upon the posterior edge of the first arch there appear about the end of the fourth week two transverse furrows which mark off three tubercles (Fig. 258, A, I-3) and on the anterior edge of the second
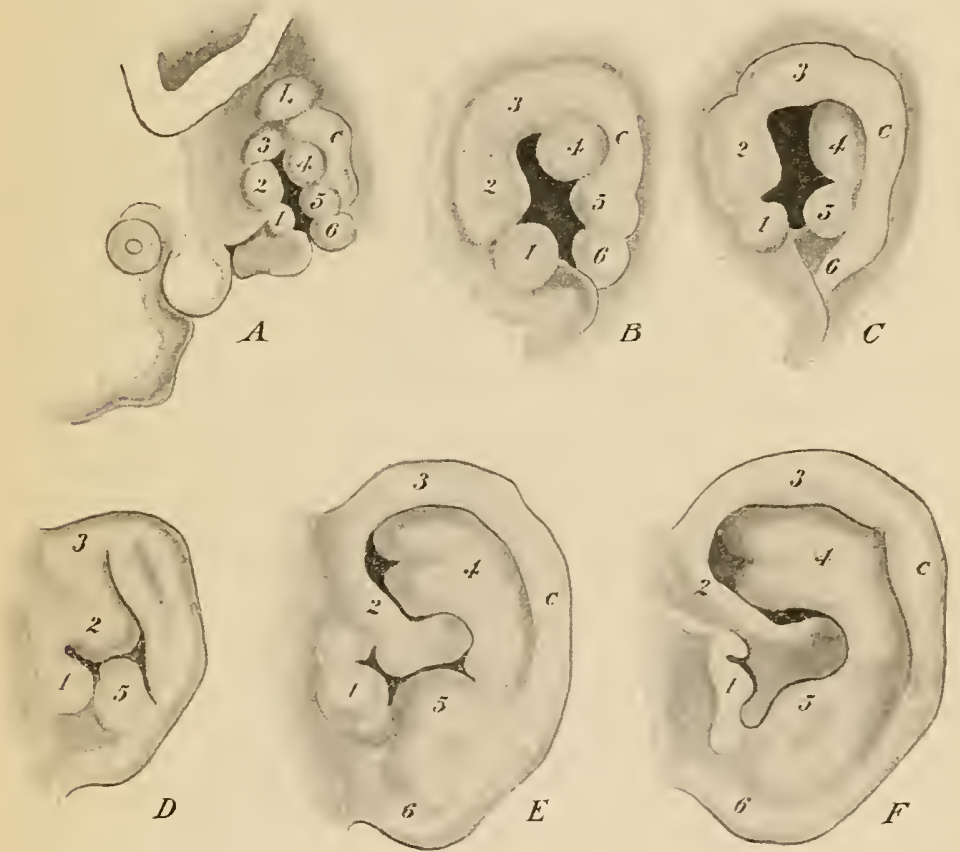

Fig. 265.-Stages in the Development of the Auricle.

$A$, Embryo of II mm.; $B$, of $13.6 \mathrm{~mm}$.; $\mathrm{C}$, of $\mathrm{I}_{5} \mathrm{~mm}$.; $D$, at the beginning of the third month; $E$, fetus of $8.5 \mathrm{~cm}$.; $F$, fetus at term.-(His.)

arch a corresponding number of tubercles (4-6) is formed, while, in addition, a longitudinal furrow, running down the middle of the arch, marks off a ridge (c) lying posterior to the tubercles. From these six tubercles and the ridge are developed the various parts of the auricle, as may be seen from Fig. 265 which represents the 
transformation as described by His. According to this, the most ventral tubercle of the first arch (I) gives rise to the tragus, and the middle one (5) of the second arch furnishes the antitragus. The middle and dorsal tubercles of the first arch (2 and 3$)$ unite with the ridge $(c)$ to produce the helix, while from the dorsal tubercle of the second arch (4) is produced the anthelix and from the ventral one (6) the lobule. More recent observations, however, seem to indicate that the lobule is an accessory structure unrelated to the tubercles and that the sixth tubercle gives rise to the antitragus, while the fifth is either included in the anthelix or else disappears. It is noteworthy that up to about the third month of development the upper and posterior portion of the helix is bent forward so as to conceal the anthelix (Fig. $265, D$ ); it is at just about a corresponding stage that the pointed form of the ear seen in the lower mammals makes its appearance, and it is evident that, were it not for the forward bending, the human ear would also be assuming at this stage a more or less pointed form. Indeed, there is usually to be found upon the incurved edge of the helix, some distance below the upper border of the auricle, a more or less distinct tubercle, known as Darwin's tubercle, which seems to represent the point of the typical mammalian ear, and is, accordingly, the morphological apex of the pinna.

There seems to be little room for doubt that the otocyst belongs primarily to the system of lateral line sense-organs, but a discussion of this interesting question would necessitate a consideration of details concerning the development of the lower vertebrates which would be foreign to the general plan of this book. It may be recalled, however, that the analysis of the components of the cranial nerves described on page $4 \mathrm{I} 5$ refers the auditory nerve to the lateral line system.

The Development of the Eye.-The first indications of the development of the eye are to be found in a pair of hollow outgrowths from the side of the first primary brain vesicle, at a level which corresponds to the junction of the dorsal and ventral zones. Each evagination is directed at first upward and backward, and, enlarging at its extremity, it soon shows a differentiation into a 
terminal bulb and a stalk connecting the bulb with the brain (Fig. 232). At an early stage the bulb comes into apposition with the ectoderm of the side of the head, and this, over the area of con-

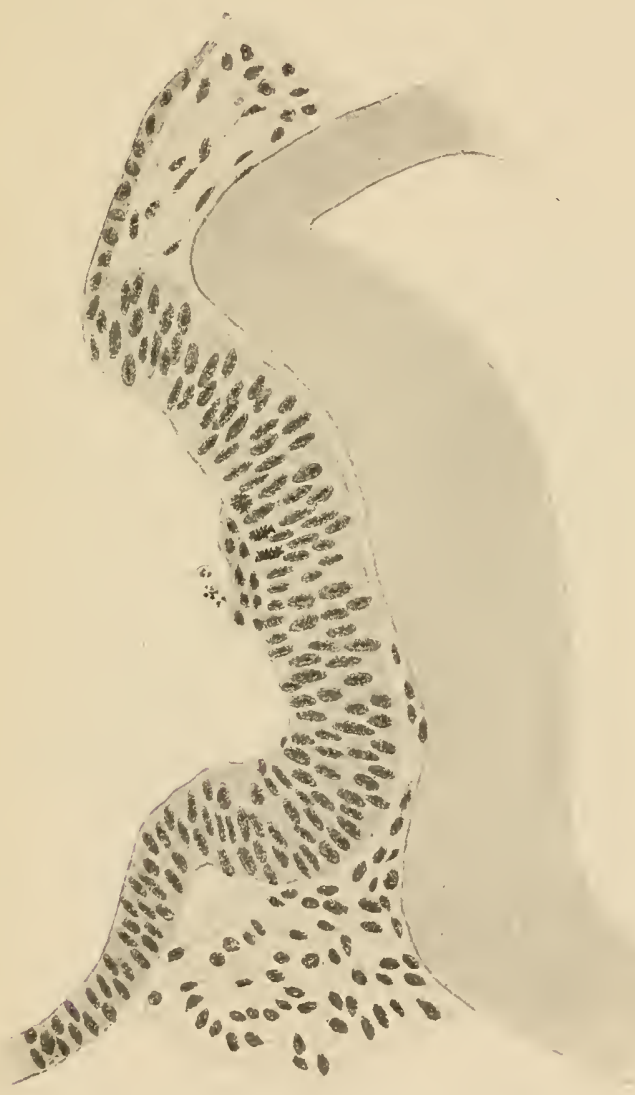

Fig. 266.-Early Stages in the Development of the Lens in a Rabbit Embrio.

The nucleated layer to the left is the ectoderm and the thicker lens epithelium, beneath which is the outer wall of the optic evagination; above and below between the two is mesenchyme.-(Rabl.)

tact, becomes thickened and then depressed to form the beginning of the future lens (Fig. 266).

As the result of the depression of the lens ectoderm, the outer wall 
of the optic bulb becomes pushed inward toward the inner wall, and this invagination continuing until the two walls come into contact, the bulb is transformed into a double-walled cup, the optic cup, in the mouth of which lies the lens (Fig. 268). The cup is not perfect, however, since the invagination affects not only the optic bulb, but also extends medially on the posterior surface of the stalk, forming upon this a longitudinal groove and producing a defect of the ventral wall of the cup, known as the chorioidal fissure (Fig. 267). The groove and fissure become occupied by mesodermal tissue, and in this, at about the fifth week, a blood-vessel develops which traverses

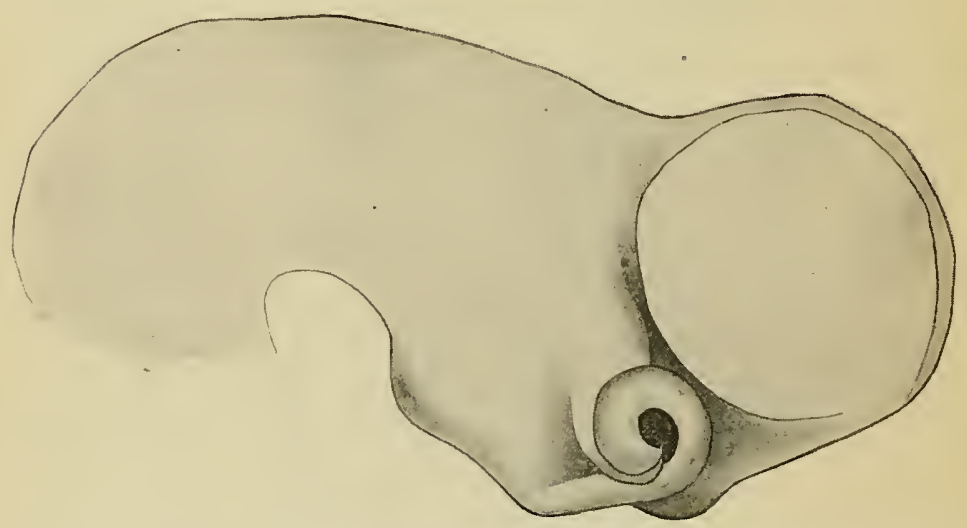

Fig. 267.-Reconstruction of the Brain of an Embryo of Four Weeks, SHowing THE CHORIOID FISSURE.-(His.)

the cavity of the cup to reach the lens and is known as the arteria hyaloidea.

In the meantime further changes have been taking place in the lens. The ectodermal depression which represents it gradually deepens to form a cup, the lips of which approximate and finally meet, so that the cup is converted into a vesicle which finally separates completely from the ectoderm (Fig. 268), much in the same way as the otocyst does. As the lens vesicle is constricted off, the surrounding mesodermal tissue grows in to form a layer between it and the overlying ectoderm, and a split appearing in the layer 
divides it into an outer thicker portion, which represents the cornea, and an inner thinner portion, which covers the outer surface of the lens and becomes highly vascular. The cavity between these two portions represents the anterior chamber of the eye. The cavity of the optic cup has also become filled by a peculiar tissue which represents the vitreous humor, while the mesodermal tissue surrounding

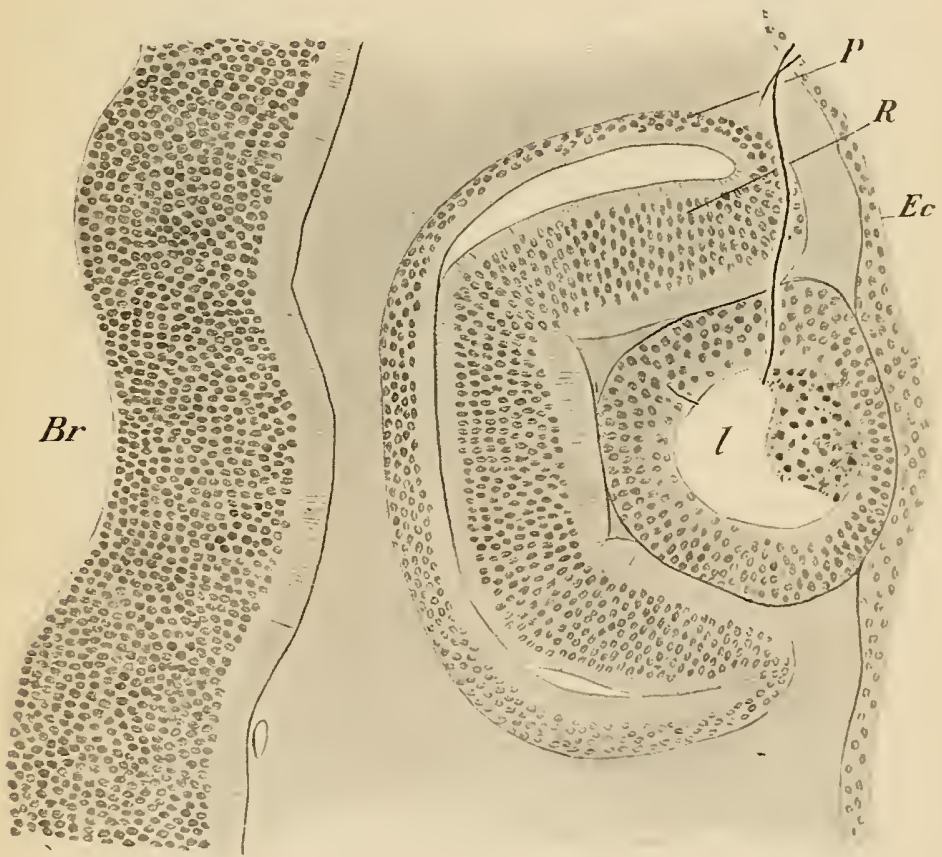

Fig. 268.-Horizontal Section through the Eye of an Embryo Pig of 7 mas. $B r$, Diencephalon; $E c$, ectoderm; $l$, lens; $P$, pigment, and $R$, retinal layers of the retina.

the cup condenses to form a strong investment for it, which is externally continuous with the cornea, and at about the sixth week shows a differentiation into an inner vascular layer, the chorioid coat, and an outer denser one, which becomes the sclerotic coat.

The various processes resulting in the formation of the eye, 
which have thus been rapidly sketched, may now be considered in greater detail.

The Development of the Lens.-When the lens vesicle is complete, it forms a more or less spherical sac lying beneath the superficial ectoderm and containing in its cavity a few cells, either scattered or in groups (Fig. 268). These cells, which have wandered into the cavity of the vesicle from its walls, take no part in the further development of the lens, but early undergo complete degeneration, and the first change which is concerned with the actual formation of the lens is an increase in the height of the cells forming its inner wall and a thinning out of its outer wall (Fig. 269, A). These changes continuing, the outer half of the vesicle becomes converted into a single layer of somewhat flat cells which persist in the adult condition to form the anterior epithelium of the lens, while the cells of the posterior wall form a marked projection into the cavity of the vesicle and eventually completely obliterate it, coming into contact with the inner surface of the anterior epithelium (Fig. 269, B).

These posterior elongated cells form, then, the principal mass of the lens, and constitute what are known as the lens fibers. At first those situated at the center of the posterior wall are the longest, the more peripheral ones gradually diminishing in length until at the equator of the lens they become continuous with and pass into the anterior epithelium. As the lens increases in size, however, the most centrally situated cells fail to elongate as rapidly as the more peripheral ones and are pushed in toward the center of the lens, the more peripheral fibers meeting below them along a line passing across the inner surface of the lens. The disparity of growth continuing, a similar sutural line appears on the outer surface beneath the anterior epithelium, and the fibers become arranged in concentric layers around a central core composed of the shorter fibers. In the human eye the line of suture of the peripheral fibers becomes bent so as to consist of two limbs which meet at an angle, and from the angle a new sutural line develops during embryonic life, so that the suture assumes the form of a three-rayed star. In later life the 

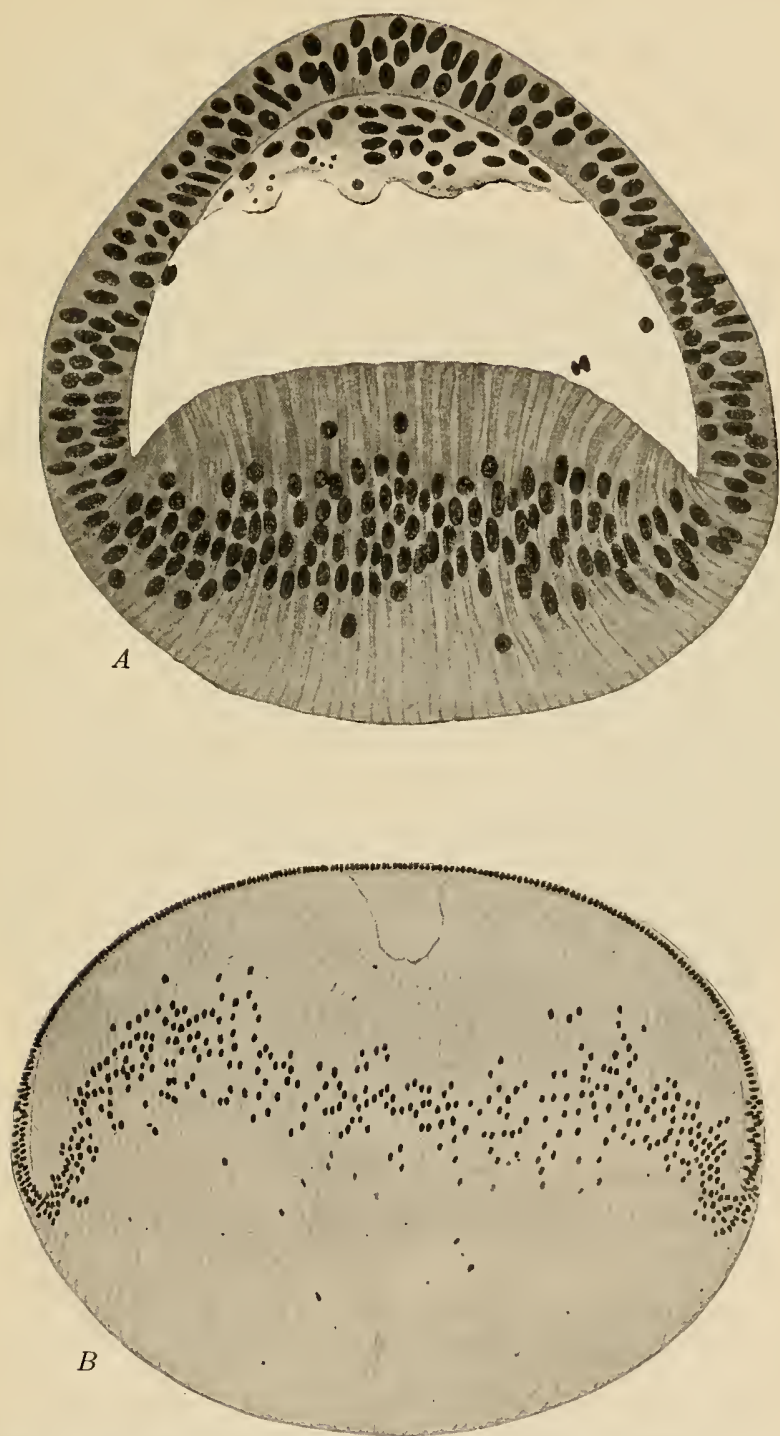

Fig. 269.-Sections throdgh the Lens $(A)$ of Human Embryo of Thirty to Thirty-one Days and $(B)$ of Pig EMrbryo of $36 \mathrm{~mm}$.-(Rabl.) 
stars become more complicated, being either six-rayed or more usually nine-rayed in the adult condition 'Fig. 270).

As early as the second month of development the lens vesicle becomes completely invested by the mesodermal tissue in which blood-vessels are developed in considerable numbers, whence the

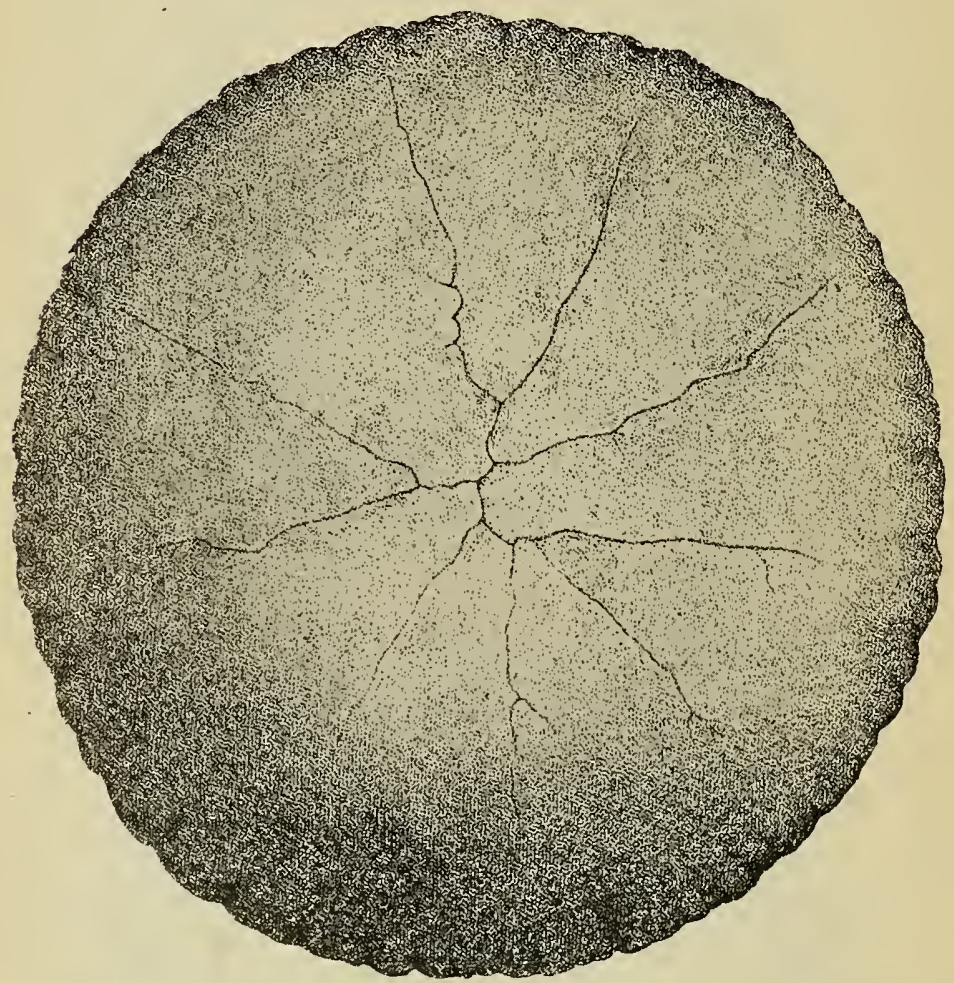

Fig. 270.-Posterior (InNer) Surface of the Lens from an Adult Showing the SUTURAL LiNES.-(Rabl.)

investment is termed the tunica vasculosa lentis (Fig. $278, t v$ ). The arteries of the tunic are in connection principally with the hyaloid artery of the vitreous humor (Fig. 276), and consist of numerous fine branches which envelop the lens and terminate in loops almost at the center of its outer surface. This tunic undergoes degenera- 
tion after the seventh month of development, by which time the lens has completed its period of most active growth, and, as a rule, completely disappears before birth. Occasionally, however, it may persist to a greater or less extent, the persistence of the portion covering the outer surface of the lens, known as the membrana pupillaris, causing the malformation known as congenital atresia of the pupil.

In addition to the vascular tunic, the lens is surrounded by a non-cellular membrane termed the capsule. The origin of this structure is still in doubt, some observers maintaining that it is a product of the investing mesoderm, while others hold it to be a product of the lens epithelium.

It is interesting from the standpoint of developmental mechanics to note that W. H. Lewis and Spemann have shown that in the Amphibia contact of the optic vesicle with the ectoderm is necessary for the formation of the lens, and, furthermore, if the vesicle be transplanted to other regions of the body of a larva, a lens will be developed from the ectoderm with which it is then in contact, even in the abdominal region,

The Development of the Optic Cup.-When the invagination of the outer wall of the optic bulb is completed, the margins of the resulting cup are opposite the sides of the lens vesicle (Fig. 268), but with the enlargement of the lens and cup the margins of the latter gradually come to lie in front of - that is to say, upon the outer surface of-the lens, forming the boundary of the opening known as the pupil. The lens, consequently, is brought to lie within the mouth of the optic cup, and that portion of the latter which covers the lens takes part in the formation of the iris and the adjacent ciliary body, while its posterior portion gives rise to the retina.

The chorioidal fissure normally disappears during the sixth or seventh week of development by a fusion of its lips, and not until this is accomplished does the term cup truly describe the form assumed by the optic bulb after the invagination of its outer wall. In certain cases the lips of the fissure fail to unite perfectly, producing the defect of the eye known as coloboma; this may vary in its extent, sometimes affecting both the iris and the retina and forming what 
is termed coloboma iridis, and at others being confined to the retinal portion of the cup, in which case it is termed coloboma chorioidæ.

Up to a certain stage the differentiation of the two layers which form the optic cup proceeds along similar lines, in both the ciliary and retinal regions. The layer which represents the original internal portion of the bulb does not thicken as the cup increases in size, and becomes also the seat of a deposition of dark pigment, whence it may be termed the pigment layer of the cup; while the other layerthat formed by the invagination of the outer portion of the bulb, and which may be termed the retinal layer-remains much thicker (Fig. 268) and in its proximal portions even increases in thickness. Later, however, the development of the ciliary and retinal portions of the retinal layers differs, and it will be convenient to consider first the history of the ciliary portion.

The Development of the Iris and Ciliary Body.-The first change noticeable in the ciliary portion of the retinal layer is its thinning out, a process which continues until the layer consists, like the pigment layer, of but a single layer of cells (Fig. 27I), the transition of which to the thicker retinal portion of the layer is somewhat abrupt and corresponds to what is termed the ora serrata in adult anatomy. In embryos of $10.2 \mathrm{~cm}$. the retinal layer throughout its entire extent is readily distinguishable from the pigment layer by the absence in it of all pigmentation, but in older forms this distinction gradually diminishes in the iris region, the retinal layer there acquiring pigment and forming the wvea.

When the anterior chamber of the eye is formed by the splitting of the mesoderm which has grown in between the superficial ectoderm and the outer surface of the lens, the peripheral portions of its posterior (inner) wall are in relation with the ciliary portion of the optic cup and give rise to the stroma of the ciliary body and of the iris (Fig. 27I), this latter being continuous with the tunica vasculosa lentis so long as that structure persists (Fig. 278). In embryos of about $\mathrm{I} 4.5 \mathrm{~cm}$. the ciliary portion of the cup becomes thrown into radiating folds (Fig. 27I), as if by a too rapid growth, and into the 
folds lamellæ of mesoderm project from the stroma. These folds occur not only throughout the region of the ciliary body, but also extend into the iris region, where, however, they are but temporary structures, disappearing entirely by the end of the fifth month. The folds in the region of the corpus ciliare persist and produce the ciliary processes of the adult eye.

Embedded in the substance of the iris stroma in the adult are non-striped muscle-fibers, which constitute the sphincter and dila-

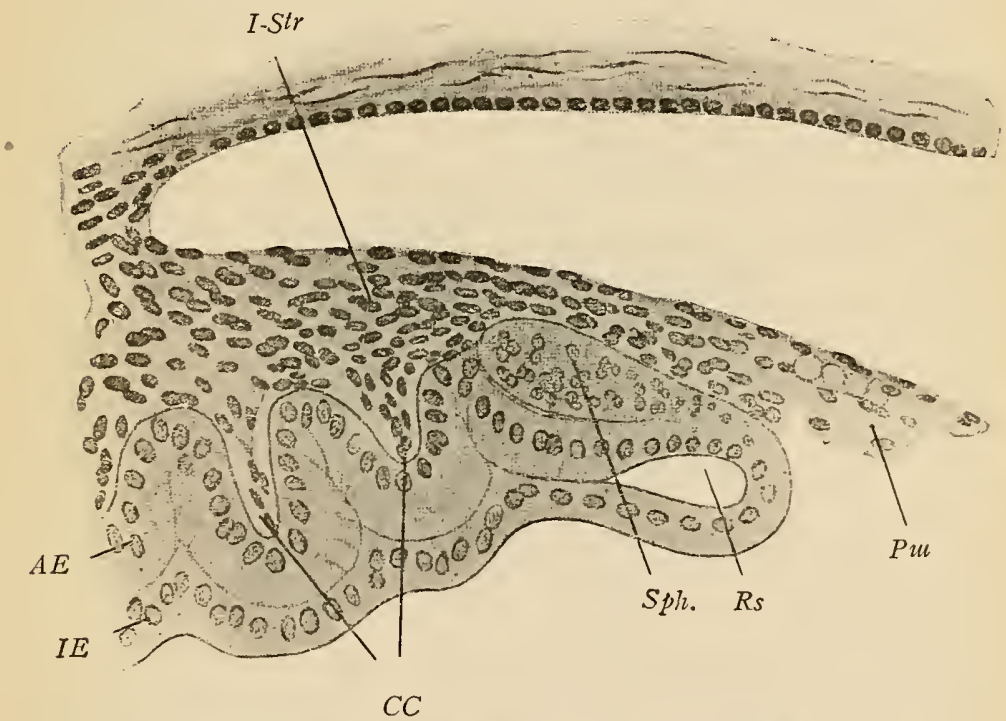

Fig. 27I.-Radial Section through the Iris of an Embryo of ig CM. $A E$, Pigment layer; $C C$, ciliary folds; $I E$, retinal layer; $I$.Str, iris stroma; $P m$, pupillary membrane; $R s$, marginal sinus; $S p h$, sphincter iridis.-(Szili.)

tator iridis. It has long been supposed that these fibers were differentiated from the stroma of the iris, but recent observations have shown that they arise from the cells of the pigment layer of the optic cup, the sphincter appearing near the pupillary border (Fig. $27 \mathrm{I}$, $S p h)$ while the dilatator is more peripheral.

The Development of the Retina.-Throughout the retinal region of the cup the pigment layer, undergoing the same changes as in 
the ciliary region, forms the pigment layer of the retina (Fig. 272, $p$ ). The retinal layer increases in thickness and early becomes differentiated into two strata (Fig. 268), a thicker one lying next the pigment layer and containing numerous nuclei, and a thinner one containing no nuclei. The thinner layer, from its position and structure, suggests an homology with the marginal velum of the central nervous system, and probably becomes converted into the nerve-fiber layer
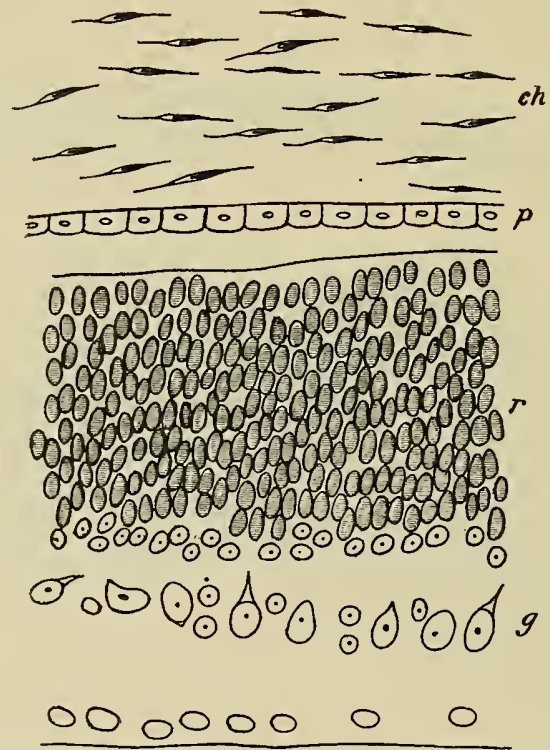

Fig. 272.-Portion of a Transverse Section of the Retina of a New-Born RABBIT.

ch, Chorioid coat; $g$, ganglion-cell layer; $r$, outer layer of nuclei; $p$, pigment layer.-(Falchi.)

of the adult retina, the axis-cylinder processes of the ganglion cells passing into it on their way to the optic nerve. The thicker layer similarly suggests a comparison with the mantle layer of the cord and brain, and in embryos of $38 \mathrm{~mm}$. it becomes differentiated into two secondary layers (Fig. 272), that nearest the pigment layer $(r)$ consisting of smaller and more deeply staining nuclei, probably representing the rod and cone and bipolar cells of the adult retina, 
while the inner layer, that nearest the marginal velum, has larger nuclei and is presumably composed of the ganglion cells.

Little is as yet known concerning the further differentiation of the nervous elements of the human retina, but the history of some of them has been traced in the cat, in which, as in other mammals, the histogenetic processes take place at a relatively later period than in man. Of the histogenesis of the inner layer the information is

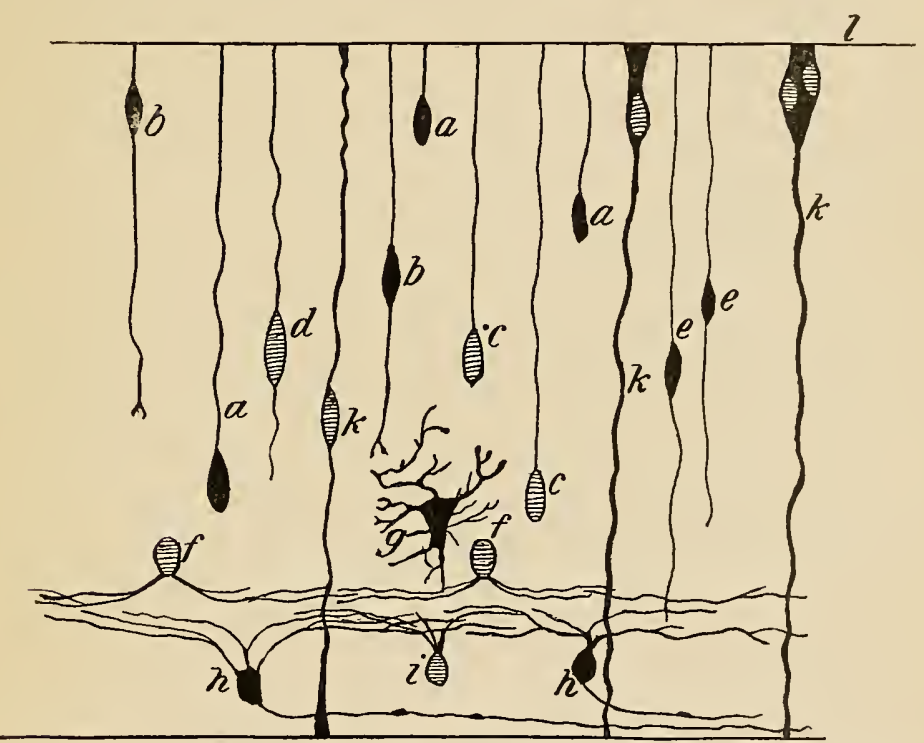

Fig. 273.-Diagram Showing the Development of the Retinal Et.ements.

$a$, Cone cell in the unipolar, and $b$, in the bipolar stage; $c$, rod cells in the unipolar, and $d$, in the bipolar stage; $e$, bipolar cells; $f$ and $i$, amacrine cells; $g$, horizontal cells; $h$, ganglion cells; $k$, Müller's fiber; $l$, external limiting membrane--(Kallius, after Cajal.)

rather scant, but it may be stated that the ganglion cells are the earliest of all the elements of the retina to become recognizable. The rod and cone cells, when first distinguishable, are unipolar cells (Fig. 273, $a$ and $c$ ), their single processes extending outward from the cell-bodies to the external limiting membrane which bounds the outer surface of the retinal layer. Even at an early stage the cone cells $(a)$ are distinguishable from the rod cells $(c)$ by their more 
decided reaction to silver salts, and at first both kinds of cells are scattered throughout the thickness of the layer from which they arise. Later, a fine process grows out from the inner end of each cell, which thus assumes a bipolar form (Fig. 273, $b$ and $d$ ), and, later still, the cells gradually migrate toward the external limiting membrane, beneath which they form a definite layer in the adult. In the meantime there appears opposite the outer end of each cell a rounded eminence projecting from the outer surface of the external limiting membrane into the pigment layer. The eminences over the cone cells are larger than those over the rod cells, and later, as both increase in length, they become recognizable by their shape as the rods and cones.

The bipolar cells are not easily distinguishable in the early stages of their differentiation from the other cells with which thy are mingled, but it is believed that they are represented by cells which are bipolar when the rod and cone cells are still in a unipolar condition (Fig. 273,e). If this identification be correct, then it is noteworthy that at first their outer processes extend as far as the external limiting membrane and must later shorten or fail to elongate until their outer ends lie in what is termed the outer granular layer of the retina, where they stand in relation to the inner ends of the rod and cone cell processes. Of the development of the amacrine $(f, i)$ and horizontal cells $(g)$ of the retina little is known. From their position in new-born kittens it seems probable that the former are derived from cells of the same layer as the ganglion cells, while the horizontal cells may belong to the outer layer.

In addition to the various nerve-elements mentioned above, the retina also contains neuroglial elements known as Müller's fibers (Fig. 273,k), which traverse the entire thickness of the retina. The development of these cells has not yet been thoroughly traced, but they resemble closely the ependymal cells observable in early stages of the spinal cord.

The Development of the Optic Nerve.-The observations on the development of the retina have shown very clearly that the great majority of the fibers of the optic nerve are axis-cylinders of the ganglion cells of the retina and grow from these cells along the optic 
stalk toward the brain. Their embryonic history has been traced most thoroughly in rat embryos (Robinson), and what follows is based upon what has been observed in that animal.

The optic stalk, being an outgrowth from the brain, is at first a hollow structure, its cavity communicating with that of the third ventricle at one end and with that of the optic bulb at the other. When the chorioid fissure is developed, it extends, as has already been described, for some distance along the posterior surface of the stalk and has lying in it a portion of the hyaloid artery. Later, when the lips of the fissure fuse, the artery becomes enclosed within the stalk to form the arteria centralis retince of the adult (Fig. 276). By the formation of the fissure the original cavity of the distal portion of the stalk becomes obliterated, and at the same time the ventral and posterior walls of the stalk are brought into continuity with the retinal layer of the op-

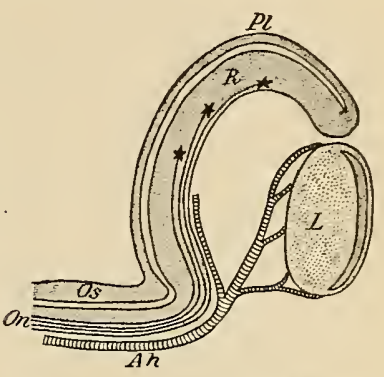

Fi g. 274.-DLAgrammatic Longitudinal SEction OF the OPTIC CUP AND STALK PASSING THROUGH THE CHORIOID FISSURE.

$A h$, Hyaloid artery; $L$, lens; $O n$, fibers of the optic nerve; $O s$, optic stalk; $P l$, pigment layer, and $R$, retinal layer of the retina. tic cup, and so opportunity is given for the passage of the axis-cylinders of the ganglion cells along those walls (Fig. 274). At an early stage a section of the proximal portion of the optic stalk (Fig. 275, A) shows the central cavity surrounded by a number of nuclei representing the mantle layer, and surrounding these a non-nucleated layer, resembling the marginal velum and continuous distally with the similar layer of the retina. When the ganglion cells of the latter begin to send out their axis-cylinder processes, these pass into the retinal marginal velum and converge in this layer toward the bottom of the chorioidal fissure, so reaching the ventral wall of the optic stalk, in the velum of which they may be distinguished in rat embryos of $4 \mathrm{~mm}$., and still more clearly in those of $9 \mathrm{~mm}$. (Fig. 275, A). Later, as the fibers become more numerous, they gradually invade the lateral and finally the dorsal 
walls of the stalk, and, at the same time the mantle cells of the stalk become more scattered and assume the form of connective-tissue (neuroglia) cells, while the original cavity of the stalk is gradually obliterated (Fig. 275, B). Finally, the stalk becomes a solid mass of nerve-fibers, among which the altered mantle cells are scattered.

From what has been stated above it will be seen that the sensory cells of the eye belong to a somewhat different category from those of the other sense-organs. Embryologically they are a specialized portion of the mantle layer of the medullary canal, whereas in the other organs they are peripheral structures either representing or being associated with representatives of posterior root ganglion cells. Viewed from this standpoint, and taking into consideration the fact that the sensory portion of the retina is formed from the invaginated part of the optic bulb, some light
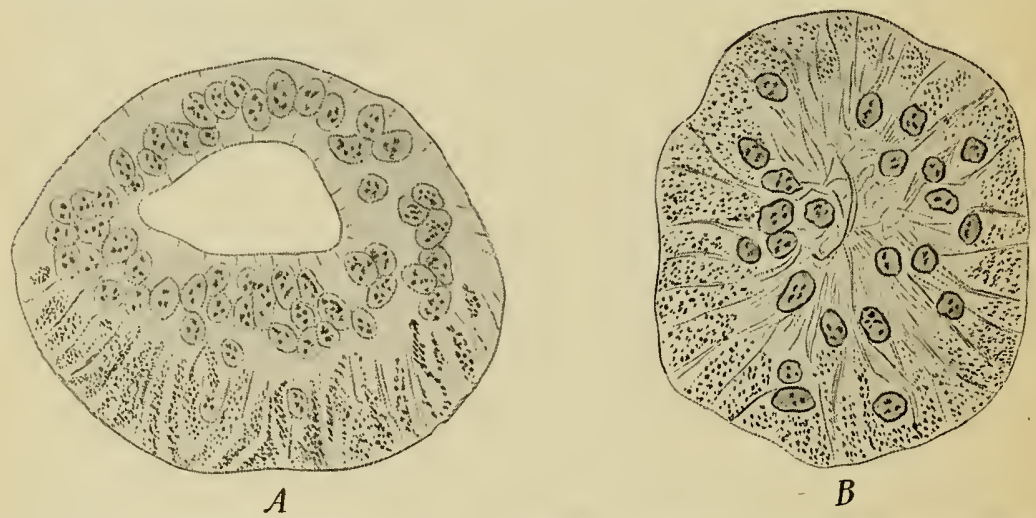

Fig. 275.-Transverse Sections through the Proximal Part of the Optic Stalk of Rat Embryos of $(A) 9$ MM. AND $(B)$ Ix MM.-(Robinson.)

is thrown upon the inverted arrangement of the retinal elements, the rods and cones being directed away from the source of light. The normal relations of the mantle layer and marginal velum are retained in the retina, and the latter serving as a conducting layer for the axis-cylinders of the mantle layer (ganglion) cells, the layer of nerve-fibers becomes interposed between the source of light and the sensory cells. Furthermore, it may be pointed out that if the differentiation of the retina be imagined to take place before the closure of the medullary canal-a condition which is indicated in some of the lower vertebrates-there would be then no inversion of the elements, this peculiarity being due to the conversion of the medullary plate into a tube, and more especially to the fact that the retina develops from the outer wall of the optic cup. In 
certain reptiles in which an eye is developed in connection with the epiphysial outgrowths of the diencephalon, the retinal portion of this pineal eye is formed from the inner layer of the bulb, and in this case there is no inversion of the elements.

A justification of the exclusion of the optic nerve from the category which includes the other cranial nerves has now been presented. For if the retina be regarded as a portion of the central nervous system, it is clear that the nerve is not a nerve at all in the strict sense of that word, but is a tract, confined throughout its entire extent within the central nervous system and comparable to such groups of fibers as the direct cerebellar or fillet tracts of that system.

The Development of the Vitreous Humor.-It has already been pointed out (p. 448) that a blood-vessel, the hyaloid artery, accompanied by some mesodermal tissue makes its way into the cavity

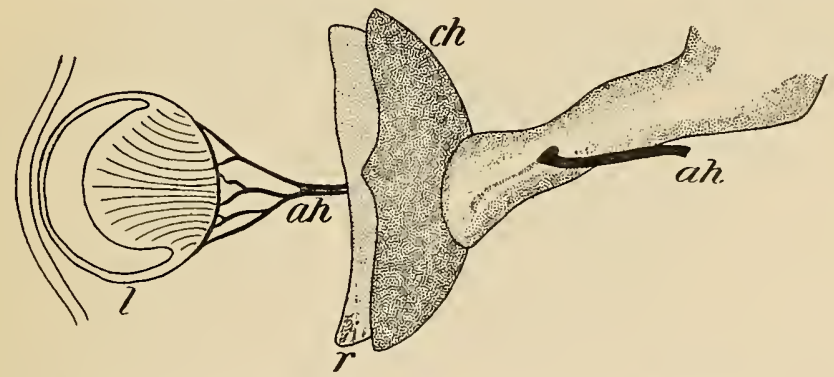

Fig. 276.-Reconstruction of a Portion of the Eye of an Embryo of i 3.8 mm. $a h$, Hyaloid artery; $c h$, chorioid coat; $l$, lens; $r$, retina.-(His.)

of the optic cup through the chorioid fissure. On the closure of the fissure the artery becomes enclosed within the optic stalk and appears to penetrate the retina, upon the surface of which its branches ramify. In the embryo the artery does not, however, terminate in these branches as it does in the adult, but is continued on through the cavity of the optic cup (Fig. 276) to reach the lens, around which it sends branches to form the tunica vasculosa lentis.

According to some authors, the formation of the vitreous humor is closely associated with the development of this artery, the humor being merely a transudate from it, while others have maintained that it is a derivative of the mesoderm which accompanies the ressel, and is therefore to be regarded as a peculiar gelatinous form of 
connective tissue. More recently, however, renewed observations by several authors have resulted in the deposition of the mesoderm from the chief rôle in the formation of the vitreous and the substitution in it of the retina. At an early stage of development delicate protoplasmic processes may be seen projecting from the surface of the retinal layer into the cavity of the optic cup, these processes probably arising from those cells which will later form the Müller's

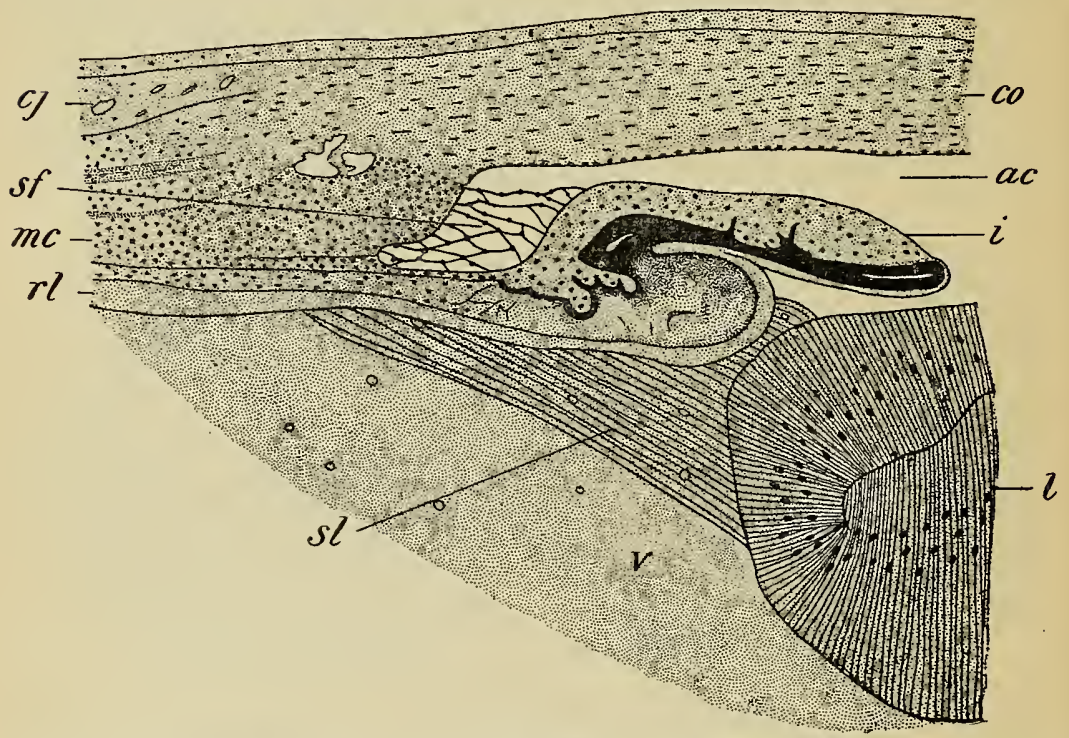

Fig. 277.-Transverse Section through the Ciliary Region of a Chick Embryo of Sixteen Days.

$a c$, Anterior chamber of the eye; $c j$, conjunctiva; $c o$, cornea; $i$, iris; $l$, lens; $m c$, ciliary muscle; $r l$, retinal layer of optic cup; $s f$, spaces of Fontana; $s l$, suspensory ligament of the lens; $v$, vitreous humor.-(Angelucci.)

(neuroglia) fibers of the retina. As development proceeds they increase in length, forming a dense and very fine fibrillar reticulum traversing the space between the lens and the retina and constituting the primary vitreous humor. The formation of the fibers is especially active in the ciliary portion of the retina and it is probable that it is from some of the fibers developing in this region that the suspensory ligament of the lens (zomula Zinnii) (Fig. 277, sl) is formed 
spaces which occur between the fibers of the ligament enlarging to produce a cavity traversed by scattered fibers and known as the canal of Petit.

A participation of similar protoplasmic prolongations from the cells of the lens in the formation of the vitreous humor has been maintained (von Lenhossek) and as strenuously denied. But it is generally admitted that at the time when the hyaloid artery penetrates the vitreous to form the tunica vasculosa lentis it carries with it certain mesodermal elements, whose fate is at present uncertain. It has been held that they take part in the formation of the definitive vitreous, which, according to this view, is of mixed origin, being partly ectodermal and partly mesodermal (Van Pée), and, on the contrary, it has been maintained that they eventually undergo complete degeneration, the vitreous being of purely ectodermal origin (von Kölliker).

The degeneration of the mesodermal elements which the latter view supposes is associated with the degeneration of the hyaloid artery. This begins in human embryos in the third month and is completed during the ninth month, the only trace after birth of the existence of the vessel being a more fluid consistency of the axis of the vitreous humor, this more fluid portion representing the space originally occupied by the artery and forming what is termed the hyaloid canal (canal of Cloquet).

The Development of the Outer Coat of the Eye, of the Cornea, and of the Anterior Chamber.-Soon after the formation of the optic bulb a condensation of the mesoderm cells around it occurs, forming a capsule. Over the medial portions of the optic cup the further differentiation of this capsule is comparatively simple, resulting in the formation of two layers, an inner vascular and an outer denser and fibrous, the former becoming the chorioid coat of the adult eye and the latter the sclera.

More laterally, however, the processes are more complicated. After the lens has separated from the surface ectoderm a thin layer of mesoderm grows in between the two structures and later gives place to a layer of homogeneous substance in which a few cells, 
more numerous laterally than at the center, are embedded. Still later cells from the adjacent mesenchyme grow into the layer, which increases considerably in thickness, and blood-vessels also grow into that portion of it which is in contact with the outer surface of the lens. At this stage the interval between the surface ectoderm and the lens is occupied by a solid mass of mesodermal tissue (Fig. 278 , $c o$ and $t v)$, but as development proceeds, small spaces (ac) filled

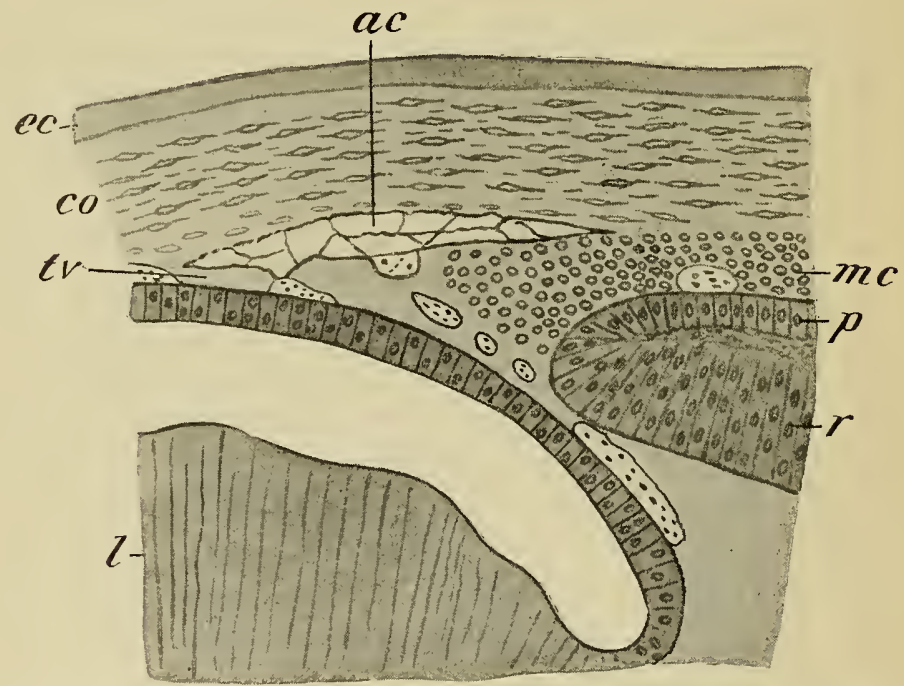

Fig. 278.-Transverse Section through the Ciliary Region of a Pig Embryo of 23 MM.

$a c$, Anterior chamber of the eye; $c o$, cornea; $e c$, ectoderm; $l$, lens; $m c$, ciliary muscle; $p$, pigment layer of the optic cup; $r$, retinal layer; $t v$, tunica vasculosa lentis. - (Angelucci.)

with fluid begin to appear toward the inner portion of the mass, and these, increasing in number and size, eventually fuse together to form a single cavity which divides the mass into an inner and an outer portion. The cavity is the anterior chamber of the eye, and it has served to separate the cornea (co) from the tunica vasculosa lentis $(t v)$, and, extending laterally in all directions, it also separates from the cornea the mesenchyme which rests upon the marginal portion of the optic cup and constitutes the stroma of the iris. Cells arrange themselves on the corneal surface of the cavity to form a 
continuous endothelial layer, and the mesenchyme which forms the peripheral boundary of the cavity assumes a fibrous character and forms the ligamentum pectinatum iridis, among the fibers of which cavities, known as the spaces of Fontana (Fig. 277, sf), appear. Beyond the margins of the cavity the corneal tissue is directly continuous with the sclerotic, beneath the margin of which is a distinctly thickened portion of mesenchyme resting upon the ciliary processes and forming the stroma of the ciliary body, as well as giving rise to the muscle tissue which constitutes the ciliary muscle (Figs. 277 and $278, m c)$.

The ectoderm which covers the outer surface of the eye does not proceed beyond the stage when it consists of several layers of cells, and never develops a stratum corneum. In the corneal region it rests directly upon the corneal tissue, which is thickened slightly upon its outer surface to form the anterior elastic lamina; more peripherally, however, a quantity of loose mesodermal tissue lies between the ectoderm and the outer surface of the sclerotic, and, together with the ectoderm, forms the conjunctiva (Fig. 277, cj).

The Development of the Accessory Apparatus of the Eye.-The eyelids make their appearance at an early stage as two folds of skin, one a short distance above and the other below the cornea. The center of the folds is at first occupied by indifferent mesodermal tissue, which later becomes modified to form the connective tissue of the lids and the tarsal cartilage, the muscle tissue probably secondarily growing into the lids as a result of the spreading of the platysma over the face, the orbicularis oculi apparently being a derivative of that sheet of muscle tissue.

At about the beginning of the third month the lids have become sufficiently large to meet one another, whereupon the thickened epithelium which has formed upon their edges unites and the lids fuse together, in which condition they remain until shortly before birth. During the stage of fusion the eyelashes (Fig. 279, $h$ ) develop at the edges of the lids, having the same developmental history as ordinary hairs, and from the fused epithelium of each lid there grow upward or downward, as the case may be, into the mesodermic 
tissue, solid rods of ectoderm, certain of which early give off numerous short lateral processes and become recognizable as the tarsal (Meibomian) glands $(m)$, while others retain the simple cylindrical form and represent the glands of Moll. When the eyelids separate, these solid ingrowths become hollow by a breaking down of their

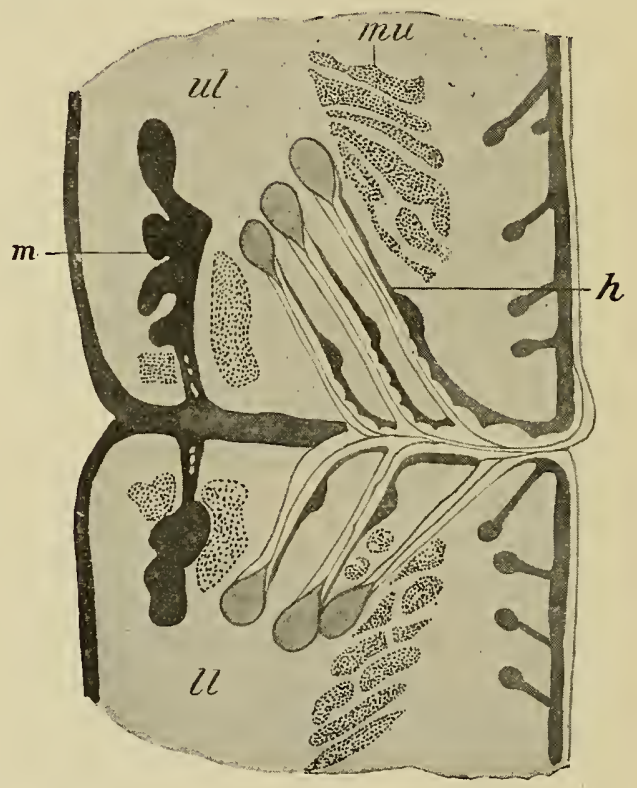
Fig. 279.-Section through the Margins of the Fused Eyelids in an Embryo] $]$
OF Six Months.

$h$, Eyelash; $l l$, lower lid; $m$, tarsal gland; $m u$, muscle bundle; $u l$, upper lid.-(Schweigger Seidl.)

central cells, just as in the sebaceous and sudoriparous glands of the skin, the tarsal glands being really modifications of the former glands, while the glands of Moll are probably to be regarded as specialized sudoriparous glands.

A third fold of skin, in addition to the two which produce the eyelids, is also developed in connection with the eye, forming the plica semilunaris. This is a rudimentary third eyelid, representing the nictitating membrane which is fairly well developed in many of the lower mammals and especially well in birds. 
The lachrymal gland is developed at about the third month as a number of branching outgrowths of the ectoderm into the adjacent mesoderm along the outer part of the line where the epithelium of the conjunctiva becomes continuous with that covering the inner surface of the upper eyelid. As in the other epidermal glands, the outgrowths and their branches are at first solid, later becoming hollow by the degeneration of their axial cells.

The naso-lachrymal duct is developed in connection with the groove which, at an early stage in the development (Fig. 62), extends
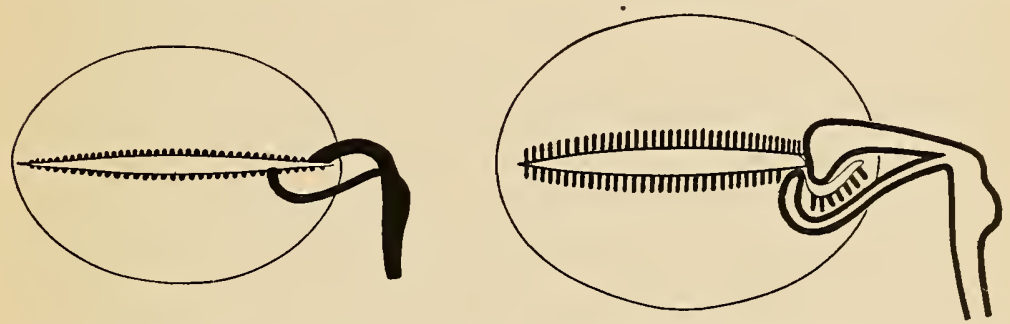

Fig. 280.-Diagram SHowing THE INSERTIONS OF THE LACHRyMaL Ducts INEMBRYOS OF 40 MM. AND I70 MM.. THE CARUNCULA LACRIMALIS BEING FORMED IN THE LATTER.

The eyelids are really fused at these stages but have been represented as separate - for the sake of clearness.-(Ask.)

from the inner corner of the eye to the olfactory pit and is bounded posteriorly by the maxillary process of the first visceral arch. The epithelium lying in the floor of this groove thickens toward the begining of the sixth week to form a solid cord, which sinks into the subjacent mesoderm. From its upper end two outgrowths arise which become connected with the ectoderm of the edges of the upper and lower lids, respectively, and represent the lachrymal ducts, and, finally, the solid cord and its outgrowths acquire a lumen and a connection with the mucous membrane of the inferior meatus of the nasal cavity.

The inferior duct connects with the border of the eyelid some distance lateral to the inner angle of the eye, and between its opening and the angle a number of tarsal glands develop. The superior duct, on the other hand, opens at first close to the inner angle and 
later moves laterally until its opening is opposite that of the inferior duct. During this change the portion of the lower lid between the opening of the inferior duct and the angle is drawn somewhat upward, and, with its glands, forms a small reddish nodule, resting upon the plica semilunaris and known as the caruncula lacrimalis (Fig. 280).

\section{LITERATURE.}

G. Alexander: "Ueber Entwicklung und Bau des Pars inferior Labyrinthi der höheren Säugethiere," Denkschr. kais. wissench. Acad. Wien, Math.-Naturw. Classe, Lxx, Igor.

A. ANGeluccr: "Ueber Entwickelung und Bau des vorderen Uvealtractus der Vertebraten," Archiv für mikrosk. Anat., XIx, I88I.

F. Ask: "Ueber die Entwickelung der Caruncula lacrimalis beim Menschen, nebst Bemerkungen über die Entwickelung der Tränenröhrshen und der Meibom'schen Drüsen," Anatom. Anzeiger, xxx, I907.

F. Ask: "Ueber die Entwicklung der Lidränder, der Tränenkarunkel und der Nickhaut beim Menschen, nebst Bemerkungen zur Entwicklung der Tränenabführungswege," Anat. Hefte, xxxvr, r9o8.

B. Baginsky: "Zur Entwickelung der Gehörschnecke," Archiv fïr mikrosk. Anat., XXVIII, I886.

I. BRoman: "Die Entwickelungsgeschichte der Gehörknöchelchen beim Menschen," Anat. Hefte, xI, I 898 .

S. RAMON y CAJAL: "Nouvelles contributions a l'étude histologique de la rétine," Journ. de l'Anat. et de la Physiol., xxxir, I896.

G. Cirincione: "Ueber den gegenwärtigen Stand der Frage hinsichtlich der Genese des Glaskörpers," Arch. für Augenheilk., L, I904.

A. Contino: "Ueber Bau and Entwicklung des Lidrandes beim Menschen," Arch. fïr Ophthalmol., LXVI, Igo8.

A. Contino: "Ueber die Entwicklung der Karunkel und der plica semilunaris beim Menschen," Arch. für Ophthalmol, Lxxi, I909.

J. Disse: "Die erste Entwickelung der Riechnerven," Anat. Hefte, Ix, I897.

B. Fleischer: "Die Entwickelung der Tränenröhrchen bei den Säugetiere," Archiv fïr Ophthalmol., LXII, I9o6.

H. FuCHs: "Bemerkungen über die Herkunft und Entwickelung der Gehörknöchelchen bei Kaninchen-Embryonen (nebst Bemerkungen über die Entwickelung des Knorpelskeletes der beiden ersten Visceralbogen)," Archiv. für Anat und Phys., Anat. Abth., Supplement, I905.

J. Graberg: "Beiträge zur Genese des Geschmacksorgans der Menschen," Morphol. Arbeiten, VII, I 898 .

J. A. Hammar: "Zur allgemeinen Morphologie der Schlundspalten des Menschen. Zur Entwickelungsgeschichte des Mittelohrraumes, des ausseren Gehörganges und des Paukenfelles beim Menschen," Anat. Anzeiger, xx, Igor. 
J. A. Hammar: "Studien über die Entwicklung des Vorderdarms und einigèr angrenzender Organe," Arch. für mikrosk. Anat., LIX, I9O2.

C. HeErfordt: "Studien über den Musc, dilatator pupillæ sammt Angabe von gemeinschaftlicher Kennzeichen einiger Falle epithelialer Musculatur," Anat. Hefte, xiv.

J. Hegetschweiler: "Die embryologische Entwickelung des Steigbugels," Archiv für Anat. und Physiol., Anat. Abth., r898.

F. Hochstetter: "Ueber die Bildung der primitiven Choanen beim Menschen," I'erhandl. Anat. Gesellsch., VI, I892.

W. HIs, JR.: "Die Entwickelungsgeschichte des Acustico-Facialisgebietes beim Menschen," Archiv für Anat. und Physiol., Anat. Abth., Supplement, I897.

A. von Kolliker: "Die Entwicklung und Bedeutung des Glaskörpers," Zeitschr. für wissensch. Zoolog., LXXVI, I904.

P. LANG: "Zur Entwicklung des Tränenausführsapparates beim Menschen," Anat. Anzeiger," xxxvir, I9II.

G. LeвoucQ: "Contribution à l'étude de l'histogénèse de la rétine chez les mammifères," Arch. Anat., Microsc., x, Igog.

V. von Minalkovicz: "Nasenhohle und Jacobsonsches Organ. Eine morphologische Studie." Anat. Hefte. XI, I898.

J. L. Paulet: "Contribution à l'étude de l'organe de Jacobson chez l'embryon humain," Bibliogr. Anat., xVII, I907.

P. VAN PÉE: "Recherches sur l'origine du corps vitré," Archives de Biol., XIX, I902.

C. RABL: "Ueber den Bau und Entwickelung der Linse," Zeitschrift für wissensch. Zoologie, LxIII and LXV, I898; LXVIII, I899.

A. Robinson: "On the Formation and Structure of the Optic Nerve and Its Relation to the Optic Stalk," Journal of Anat. and Physiol., xxx, I896.

G. Speciale-Cirincione: "Ueber die Entwicklung der Tränendrüse beim Menschen," Arch. fiir Ophthalmol., Lxix, I908.

J. P. Schaeffer: "The Genesis and Development of the Nasolacrimal Passages in Man," Amer. Journ. Anat., xIII, IgI2.

G. L. Streeter: "On the Development of the Membranous Labyrinth and the Acoustic and Facial Nerves in the Human Embryo," Amer. Journ. of Anat., VI, 1907 .

N. VAN DER STRICHT: "L'histogénèse des parties constituantes du neuroépithélium acoustique, des taches et des crêtes acoustiques et de l'organe de Corti," Arch. de Biol., xxill, Igo8.

A. SzILI: "Zur Anatomie und Entwickelungsgeschichte der hinteren Irisschichten, mit besonderer Berücksichtigung des Musculus sphincter iridis des Menschen," Anat. Anzeiger, xx, I9or.

A. SzILI: "Ueber das Entstehen eines fibrilläres Stützgewebes im Embryo und dessen Verhältnis zur Glaskörperfrage," Anat. Hefte, xxxv, Igo\&.

F. Tuchervan: "On the Development of the Taste Organs in Man," Journal of Anat. and Physiol., xxiv, s\$89.

R. VERSARI: "Ueber die Entwicklung der Blutgefässe des menschlichen Auges," Anat. Anzeiger, xxxv, 1909. 


\section{CHAPTER XVII.}

\section{POST-NATAL DEVELOPMENT.}

In the preceding pages attention has been directed principally to the changes which take place in the various organs during the period before birth, for, with a few exceptions, notably that of the liver, the general form and histological peculiarities of the various organs are acquired before that epoch. Development does not, however, cease with birth, and a few statements regarding the changes which take place in the interval between birth and maturity will not be out of place in a work of this kind.

The conditions which obtain during embryonic life are so different from those to which the body must later adapt itself, that arrangements, such as those connected with the placental circulation, which are of fundamental importance during the life in utero, become of little or no use, while the relative importance of others is greatly diminished, and these changes react more or less profoundly on all parts of the body. Hence, although the post-natal development consists chiefly in the growth of the structures formed during earlier stages, yet the growth is not equally rapid in all parts, and indeed in some organs there may even be a relative decrease in size. That this is true can be seen from the annexed figure (Fig. 28I), which represents the body of a child and that of an adult man drawn as of the same height. The greater relative size of the head and upper part of the body in the child is very marked, and the central point of the height of the child is situated at about the level of the umbilicus, while in the man it is at the symphysis pubis.

That there is a distinct change in the geometric form of the body during growth is also well shown by the following consideration. (Thoma). Taking the average height of a new-born male as 500 $\mathrm{mm}$., and that of a man of thirty years of age as $1686 \mathrm{~mm}$., the 
height of the body will have increased from birth to adolescence I686 $500=3.37$ times. The child will reigh. $3 . I$ kilos and the man 66. I kilos, and if the specific gravity of the body with the included gases be taken in the one case as 0.90 and in the other $a s 0.93$, then the volume of the child's body will be 3.44 liters and that of the man's $i$. $.0 S$ liters, and the increase in rolume will be $\frac{i 1.08}{3 \cdot 4}=20.66$.

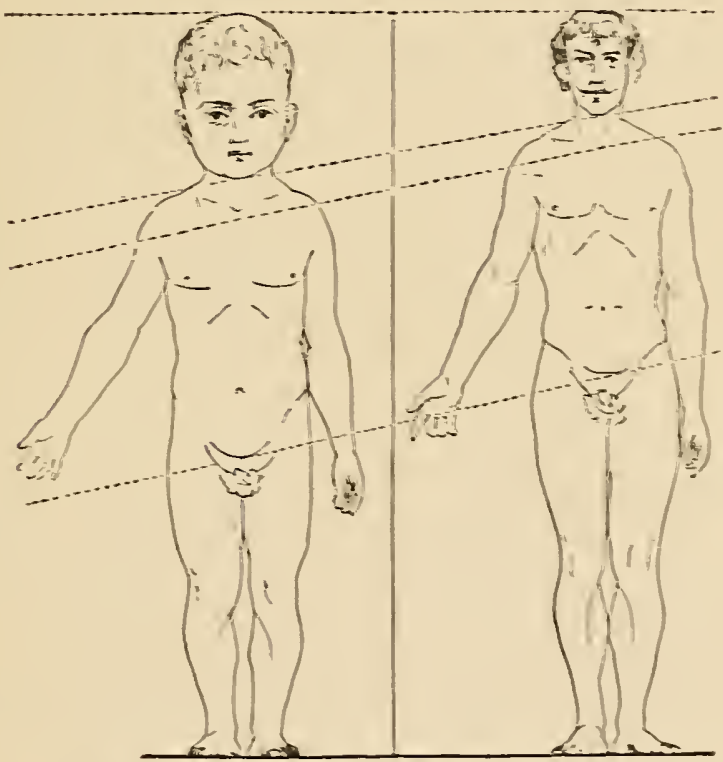

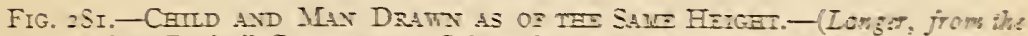

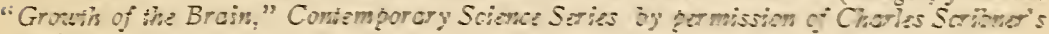
Sons.)

If the increase in rolume had taken place without any alteration in the geometric form of the body, it should be equal to the cube of the increase in height: this, however, is $3.37^{3}=3 \mathrm{~S} .27$, a number wellnigh twice as large as the actual increase.

But in-addition to these changes, which are largely dependent 
upon differences in the supply of nutrition, there are others associated with alterations in the general metabolism of the body. Up to adult life the constructive metabolism or anabolism is in excess of the destructive metabolism or katabolism, but the amount of the excess is much greater during the earlier periods of development and gradually diminishes as the adult condition is approached. That this is true during intrauterine life is shown by the following figures, compiled by Donaldson:

\begin{tabular}{c|c||c|c} 
Age in Weeks & Weight in Grams & Age in Weeks & Weight in Grams \\
\hline \multirow{2}{*}{ (ovum) } & 0.0006 & 24 & 635 \\
4 & - & 28 & 1,220 \\
8 & 4 & 32 & 1,700 \\
12 & 20 & 36 & 2,240 \\
16 & 120 & 40 (birth) & 3,250 \\
20 & 285 & & \\
\hline
\end{tabular}

From this table it may be seen that the embryo of eight weeks is six thousand six hundred and sixty-seven times as heavy as the ovum from which it started, and if the increase of growth for each of the succeeding periods of four weeks be represented as percentages, it will be seen that the rate of increase undergoes a rapid diminution after the sixteenth week, and from that on diminishes gradually but less rapidly, the figures being as follows:

\begin{tabular}{c|c||c|c}
\hline Periods of Weeks & Percentage Increase & Periods of Weeks & Percentage Increase \\
\hline $8-12$ & 400 & $24-28$ & 92 \\
I $2-\mathrm{I} 6$ & 500 & $28-32$ & 39 \\
I6-20 & I37 & $32-36$ & 32 \\
$20-24$ & I23 & $36-40$ & 45 \\
\hline
\end{tabular}


That the same is true in a general way of the growth after birth may be seen from the following table, representing the average weight of the body in English males at different years from birth up to twenty-three (Roberts), and also the percentage rate of increase.

\begin{tabular}{|c|c|c|c|}
\hline Y'ear & Number of Cases & $\begin{array}{l}\text { Weight in } \\
\text { Kilograms }\end{array}$ & $\begin{array}{l}\text { Percentage } \\
\text { Increase }\end{array}$ \\
\hline o & $45^{I}$ & $3 \cdot 2$ & \\
\hline I & - & (10.8) & $\left(23^{8}\right)$ \\
\hline 2 & 2 & I $4 \cdot 7^{*}$ & $(36) *$ \\
\hline 3 & $4 \mathrm{I}$ & I $5 \cdot 4$ & $4.8 *$ \\
\hline 4 & 102 & 16.9 & $9 \cdot 7$ \\
\hline 5 & I93 & I8.I & $7 \cdot I$ \\
\hline 6 & 224 & $20 . I$ & I I \\
\hline 7 & 246 & 22.6 & 12.4 \\
\hline 8 & 820 & $24 \cdot 9$ & 10.2 \\
\hline 9 & $I, 425$ & $27 \cdot 4$ & IO \\
\hline IO & $I, 464$ & 30.6 & I I $\cdot 5$ \\
\hline I I & I, 599 & 32.6 & $6 \cdot 5$ \\
\hline I2 & $I, 786$ & $34 \cdot 9$ & 7 \\
\hline I3 & 2,443 & $37 \cdot 6$ & $7 \cdot 7$ \\
\hline I4 & $2,95^{2}$ & $4 I \cdot 7$ & 10.9 \\
\hline I 5 & $3, \mathrm{I}$ IS & 46.6 & II $\cdot 7$ \\
\hline I6 & 2,235 & $53 \cdot 9$ & I5.7 \\
\hline I7 & 2,496 & $59 \cdot 3$ & IO \\
\hline IS & $2, \mathrm{I} 5 \mathrm{O}$ & 62.2 & $4 \cdot 9$ \\
\hline I9 & $\mathrm{I}, 43^{8}$ & $63 \cdot 4$ & I.9 \\
\hline 20 & $85 I$ & $64 \cdot 9$ & $2 \cdot 5$ \\
\hline $2 \mathrm{I}$ & 738 & $65 \cdot 7$ & I. 2 \\
\hline 22 & 542 & 67.0 & I.9 \\
\hline 23 & $55^{\mathrm{I}}$ & 67.0 & $\circ$ \\
\hline
\end{tabular}

Certain interesting peculiarities in post-natal growth become apparent from an examination of this table. For while there is a

* From a comparison with other similar tables there is little doubt but that the weight given above for the second year is too high to be accepted as a good average. 
general diminution in the rate of growth, yet there are marked irregularities, the most noticeable being (I) a rather marked diminution during the eleventh and twelfth years, followed by (2) a rapid

I

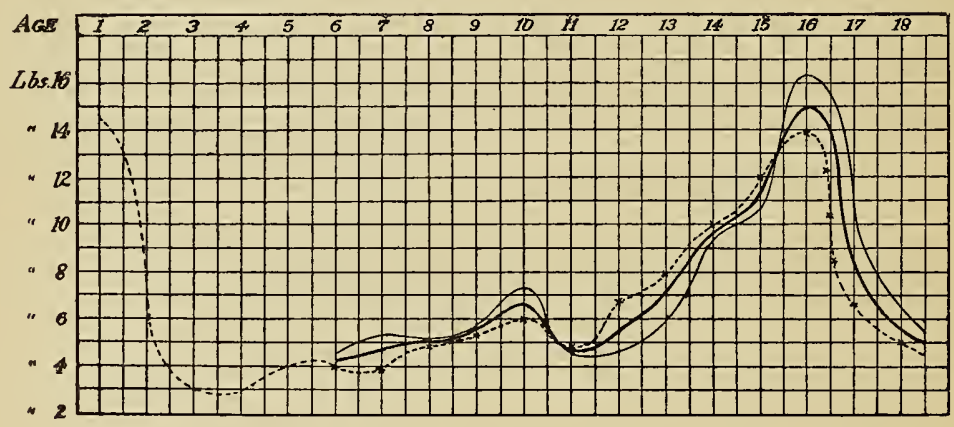

II

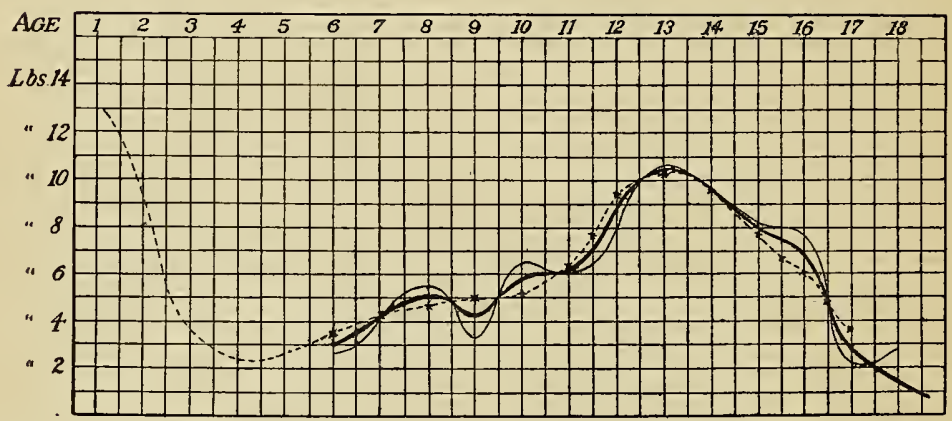

Fig. 282.-Curves Showing the Anndal Increase in Weight IN (I) Boys and (II) GIRLS.

The faint line represents the curve from British statistics, the dotted line that from American (Bowditch), and the heavy line the average of the two. Before the sixth year the data are unreliable.-(Stephenson.)

acceleration which reaches its maximum at about the sixteenth year and then very rapidly diminishes. These irregularities may be more

Consequently the percentage increase for the second year is too high and that for the third year too low.

It may be mentioned that the weights in the original table are expressed in pounds avoirdupois and have been here converted into kilograms, and further the figures representing the percentage increase have been added. 
clearly seen from the charts on page 474, which represent the curves obtained by plotting the annual increase of weight in boys (Chart I) and girls (Chart II). The diminution and acceleration of growth referred to above are clearly observable and it is interesting to note that they occur at earlier periods in girls than in boys, the diminution occurring in girls at the eighth and ninth years and the acceleration reaching its maximum at the thirteenth year.

Considering, now, merely the general diminution in the rate of growth which occurs from birth to adult life, it becomes interesting to note to what extent the organs which are more immediately associated with the metabolic activities of the body undergo a relative reduction in weight. The most important of these organs is undoubtedly the liver, but with it there must also be considered the thyreoid and thymus glands, and probably the suprarenal bodies. In all these organs there is a marked diminution in size as compared with the weight of the body, as will be seen from the following table (H. Vierordt), which also includes data regarding other organs in

ABSOLUTE WEIGHT IN GRAMS.

NEW-BORN AND ADULT.

\begin{tabular}{|c|c|c|c|c|c|c|c|c|}
\hline Liver & $\begin{array}{l}\text { Thy- } \\
\text { reoid }\end{array}$ & $\begin{array}{l}\text { Thy- } \\
\text { mus }\end{array}$ & $\begin{array}{c}\text { Suprarenal } \\
\text { Bodies }\end{array}$ & Spleen & Heart & Kidney & Brain & $\begin{array}{l}\text { Spinal } \\
\text { Cord }\end{array}$ \\
\hline $\mathrm{r}_{4} \mathrm{I} \cdot 7$ & 4.85 & 8.15 & 7.05 & I0. 6 & 23.6 & $23 \cdot 3$ & 381.0 & $5 \cdot 5$ \\
\hline $\mathrm{I}, 8 \mathrm{r} 9.0$ & 33.8 & 26.9 & $7 \cdot 4$ & I63.0 & 300.6 & 305.9 & $x, 430.9$ & 39.15 \\
\hline
\end{tabular}

PERCENTAGE WEIGHT OF ENTIRE BODY

NEW-BORN AND AdULT.

\begin{tabular}{l|c|c|c|c|c|c|c|c}
\hline Liver & $\begin{array}{c}\text { Thy- } \\
\text { reoid }\end{array}$ & $\begin{array}{c}\text { Thy- } \\
\text { mus }\end{array}$ & $\begin{array}{c}\text { Suprarenal } \\
\text { Bodies }\end{array}$ & Spleen & Heart & Kidney & Brain & $\begin{array}{c}\text { Spinal } \\
\text { Cord }\end{array}$ \\
\hline & & & & & & & & \\
4.57 & 0.16 & 0.26 & 0.23 & 0.34 & 0.76 & 0.75 & 12.29 & 0.18 \\
2.57 & 0.05 & 0.04 & 0.01 & 0.25 & 0.46 & 0.46 & 2.16 & 0.06 \\
\hline
\end{tabular}


which a marked relative diminution, not in all cases readily explainable, occurs.

Recent observations by Hammar render necessary some modification of the figures given for the thymus in the above table. He finds the average weight of the gland at birth to be 13.26 grms., and that the weight increases up to puberty, averaging $37.5^{2}$ grms. between the ages of II and I5. After that period it gradually diminishes, falling to 16.27 grms. between 36 and 45, and to 6.0 grms. between 66 and 75 . Expressed in percentage of the body weight this gives a value in the new-born of 0.42 and in an individual of 50 years of 0.02 , a difference much more striking than that shown in Vierordt's table.

It must be mentioned, however, that the gland is subject to much individual variation, being largely influenced by nutritive conditions.

The remaining organs, not included in the tables given above, when compared with the weight of the body, either show an increase or remain practically the same.

ABSOLUTE WEIGHT IN GRAMS.

NEW-BORN AND ADULT.

\begin{tabular}{c|r|r|r|r|r}
\hline $\begin{array}{c}\text { Skin and Sub- } \\
\text { cutaneous Tissues }\end{array}$ & Skeleton & Musculature & $\begin{array}{c}\text { Stomach and } \\
\text { Intestines }\end{array}$ & Pancreas & Lungs \\
\hline $\begin{array}{c}6 \text { II } .75 \\
\text { II }, 765.0\end{array}$ & $\begin{array}{r}425.5 \\
\text { II, } 575.0\end{array}$ & $28,732.0$ & 1,364 & 97.6 & 994.9 \\
\hline
\end{tabular}

PERCENTAGE OF BODY-WEIGHT.

NEW-BORN AND ADULT.

\begin{tabular}{c|c|c|c|c|c}
\hline $\begin{array}{c}\text { Skin and Sub- } \\
\text { cutaneous Tissues }\end{array}$ & Skeleton & Musculature & $\begin{array}{c}\text { Stomach and } \\
\text { Intestines }\end{array}$ & Pancreas & Lungs \\
\hline & & & & & \\
19.73 & 13.7 & 25.05 & $2 . I$ & $0.1 \mathrm{I}$ & I.75 \\
17.77 & 17.48 & 43.40 & 2.06 & 0.15 & I.50 \\
\hline
\end{tabular}

From this table it will be seen that the greatest increment of weight is that furnished by the muscles, the percentage weight of which is one and three-fourths times as great in the adult as in the 
child. The difference does not, however, depend upon the differentiation of additional muscles; there are just as many muscles in the new-born child as in the adult, and the increase is due merely to an enlargement of organs already present. The percentage weight of the digestive tract, pancreas, and lungs remains practically the same, while in the case of the skeleton there is an appreciable increase, and in that of the skin and subcutaneous tissue a slight

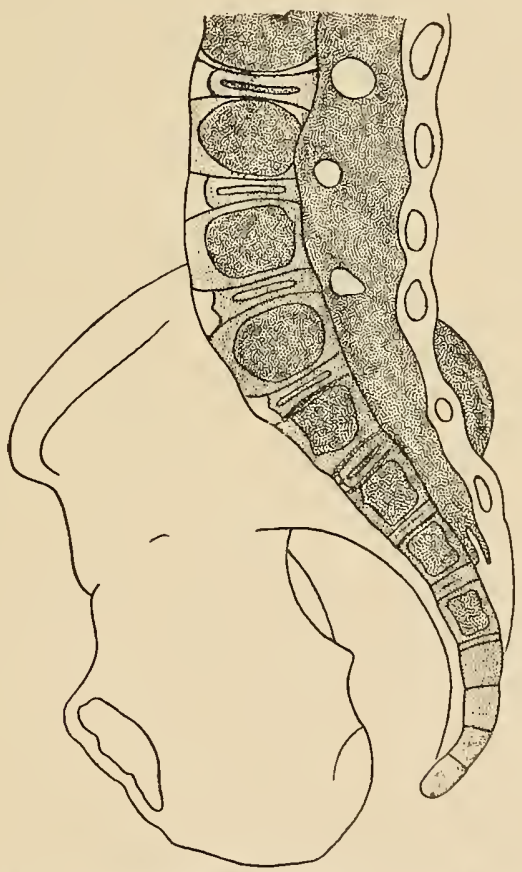

Fig. 283.-Longitudinal Section through the Sacrum of a New-born Female CHILD.-(Fehling.)

diminution. The latter is readily understood when it is remembered that the area of the skin, granting that the geometric form of the body remains the same, would increase as the square of the length, while the mass of the body would increase as the cube, and hence in comparing weights the skin might be expected to show a diminution even greater than that shown in the table. 
The increase in the weight of the skeleton is due to a certain extent to growth, but chiefly to a completion of the ossification of the cartilage largely present at birth. A comparison of the weights of this system of organs does not, therefore, give evidence of the many changes of form which may be perceived in it during the period under consideration, and attention may be drawn to some of the more important of these changes.

In the spinal column one of the most noticeable peculiarities observable in the new-born child is the absence of the curves so characteristic of the adult. These curves are due partly to the weight of the body, transmitted through the spinal column to the hipjoint in the erect position, and partly to the action of the muscles, and it is not until the erect position is habitually assumed and the musculature gains in development that the curvatures become pronounced. Even the curve of the sacrum, so marked in the adult, is but slight in the new-born child, as may be seen from Fig. 283, in which the ventral surfaces of the first and second sacral vertebræ look more ventrally than posteriorly, so that there is no distinct promontory.

But, in addition to the appearance of the curvatures, other changes also occur after birth, the entire column becoming much more slender and the proportions of the lumbar and sacral vertebræ becoming quite different, as may be seen from the following table (Aeby):

LENGTHS OF THE VERTEBRAL REGIONS EXPRESSED AS PERCENTAGES OF THE ENTIRE COLUMN.

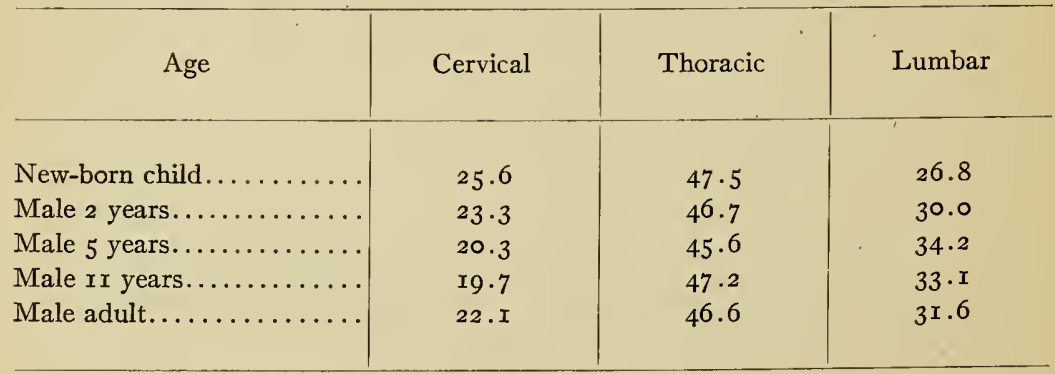


The cervical region diminishes in length, while the lumbar gains, the thoracic remaining approximately the same. It may be noticed, furthermore, that the difference between the two variable regions is greater during youth than in the adult, a condition possibly associated with the general more rapid development of the lower portion of the body made necessary by its imperfect development during fetal life. The difference is due to changes in the vertebræ, the intervertebral disks retaining approximately the same relative thickness throughout the period under consideration.

The form of the thorax also alters, for whereas in the adult it is barrel-shaped, narrower at both top and bottom than in the middle, in the new-born child it is rather conical, the base of the cone being below. The difference depends upon slight differences in the form and articulations of the ribs, these being more horizontal in the child and the opening of the thorax directed more directly upward than in the adult.

As regards the skull, the processes of growth are very complicated. Cranium and brain react on one another, and hence, in harmony with the relatively enormous size of the brain at birth, the cranial cavity has a relatively greater volume in the child than in the adult. The fact that the entire roof and a considerable part of the sides of the skull are formed of membrane bones which, at birth, are not in sutural contact with one another throughout, gives opportunity for considerable modifications, and, furthermore, the base of the skull at the early stage still contains a considerable amount of unossified cartilage. Without entering into minute details, it may be stated that the principal general changes which the skull undergoes in its post-natal development are (I) a relative elongation of its anterior portion and (2) an increase in the relative height of the maxillæ.

If a line be drawn between the central points of the occipital condyles, it will divide the base of the skull into two portions, which in the child's skull are equal in length. The portion of the skull in front of a similar line in the adult skull is very much greater than that which lies behind, the proportion between the two parts being 
$5: 3$, against $3: 3$ in the child (Froriep). There has, therefore, been a decidedly more rapid growth of the anterior portion of the skull, a growth which is asssociated with a corresponding increase in the dorso-ventral dimensions of the maxillæ. These bones, indeed, play a very important part in determining the proportions of the skull at different periods. They are so intimately associated with the cranial portions of the skull that their increase necessitates a
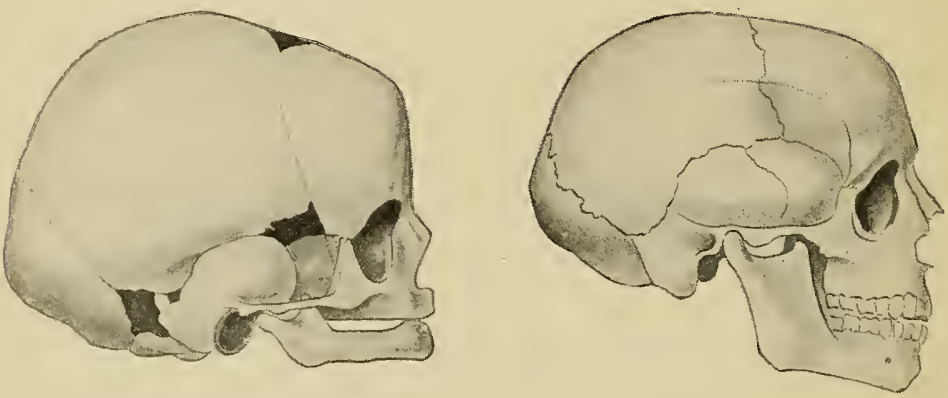

Fig. 284.-Skull of a New-born Child and of an Adult Man, Drawn as of Approximately the Same Size.-(Henke.)

corresponding increase in the anterior part of the cranium, and their increase in this direction stands in relation to the development of the teeth, the eight teeth which are developed in each maxilla (including the premaxilla) in the adult requiring a longer bone than do the five teeth of the primary dentition, these again requiring a greater length when completely developed than they do in their immature condition in the new-born child.

But far more striking than the difference just described is that in the relative height of the cranial and facial regions (Fig. 284). It has been estimated that the volumes of the two portions have a ratio of $8: I$ in the new-born child, $4: I$ at five years of age, and $2: \mathrm{I}$ in the adult skull (Froriep), and these differences are due principally to changes in the vertical dimensions of the maxillæ. As with the increase in length, the increase now under consideration is, to a 
ertain extent at least, associated with the development of the teeth, hese structures calling into existence the alveolar processes which re practically wanting in the child at birth. But a more important actor is the development of the maxillary sinuses, the practically olid bodies of the maxillæ becoming transformed into hollow shells. Chese cavities, together with the sinuses of the sphenoid and frontal ones, which are also post-natal developments, seem to stand in elation to the increase in length of the anterior portion of the skull, erving to diminish the weight of the portion of the skull in front if the occipital condyles and so relieving the muscles of the neck of a onsiderable strain to which they would otherwise be subjected.

These changes in the proportions of the skull have, of course, nuch to do with the changes in the general proportions of the face. 3ut the changes which take place in the mandible are also imporant in this connection, and are similar to those of the maxillæ in eing associated with the development of the teeth. In the neworn child the horizontal ramus is proportionately shorter than in he adult, while the vertical ramus is very short and joins the orizontal one at an obtuse angle. The development of the teeth $f$ the primary dentition, and later of the three molars, necessitates n elongation of the horizontal ramus equivalent to that occurring a the maxillæ, and, at the same time, the separation of the alveolar orders of the two bones requires an elongation of the vertical ramus f the condyle is to preserve its contact with the mandibular fossa, nd this, again, demands a diminution of the angle at which the ami join if the teeth of the two jaws are to be in proper apposition.

In the bones of the appendicular skeleton secondary epiphysial enters play an important part in the ossification, and in few are hese centers developed prior to birth, while the union of the epiphyes to the main portions of the bones takes place only toward maurity. The dates at which the various primary and secondary enters appear, and the time at which they unite, may be seen from he following table: 
UPPER EXTREMITY.

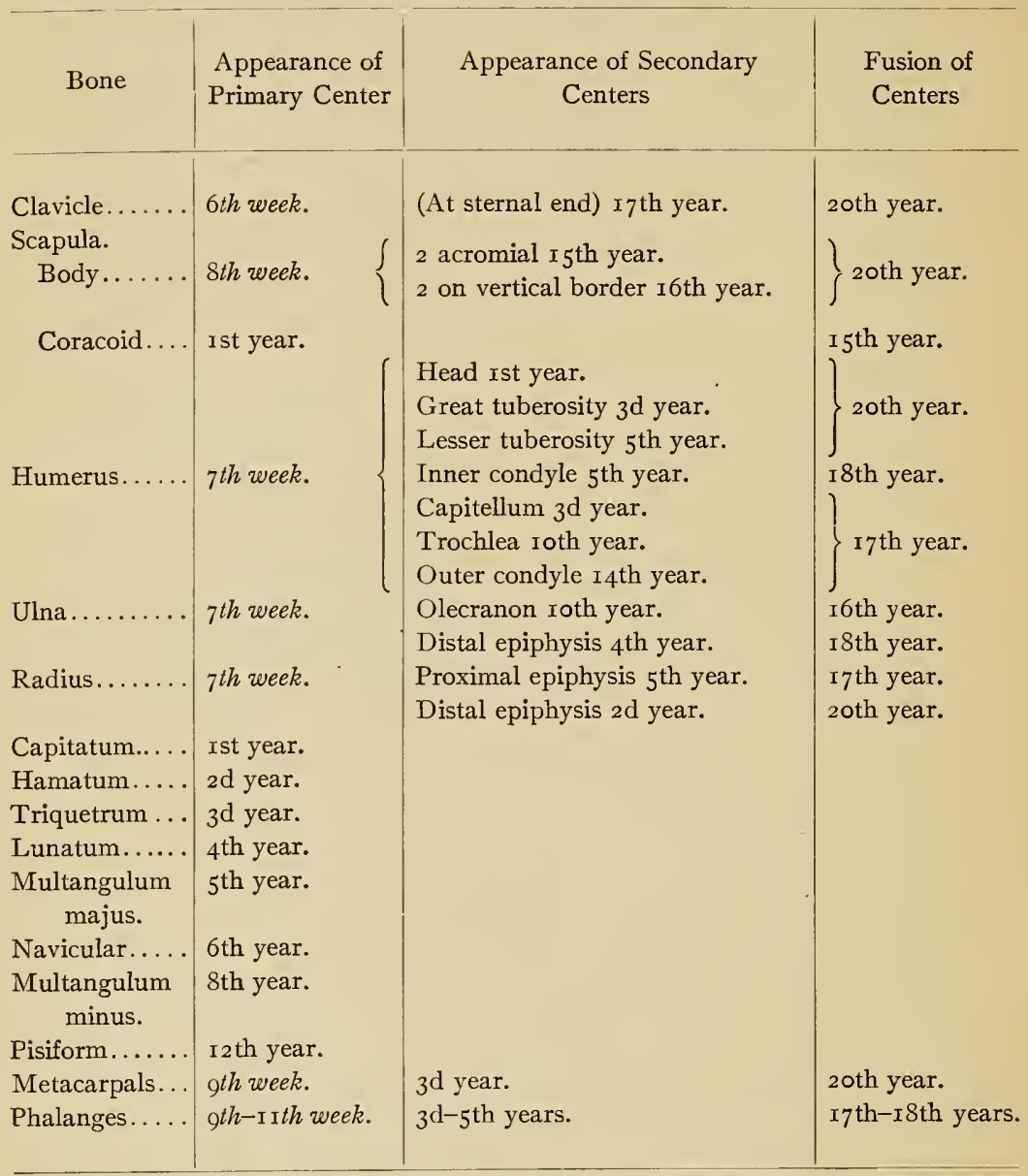

The dates in italics are before birth. 
LOWER EXTREMITY.

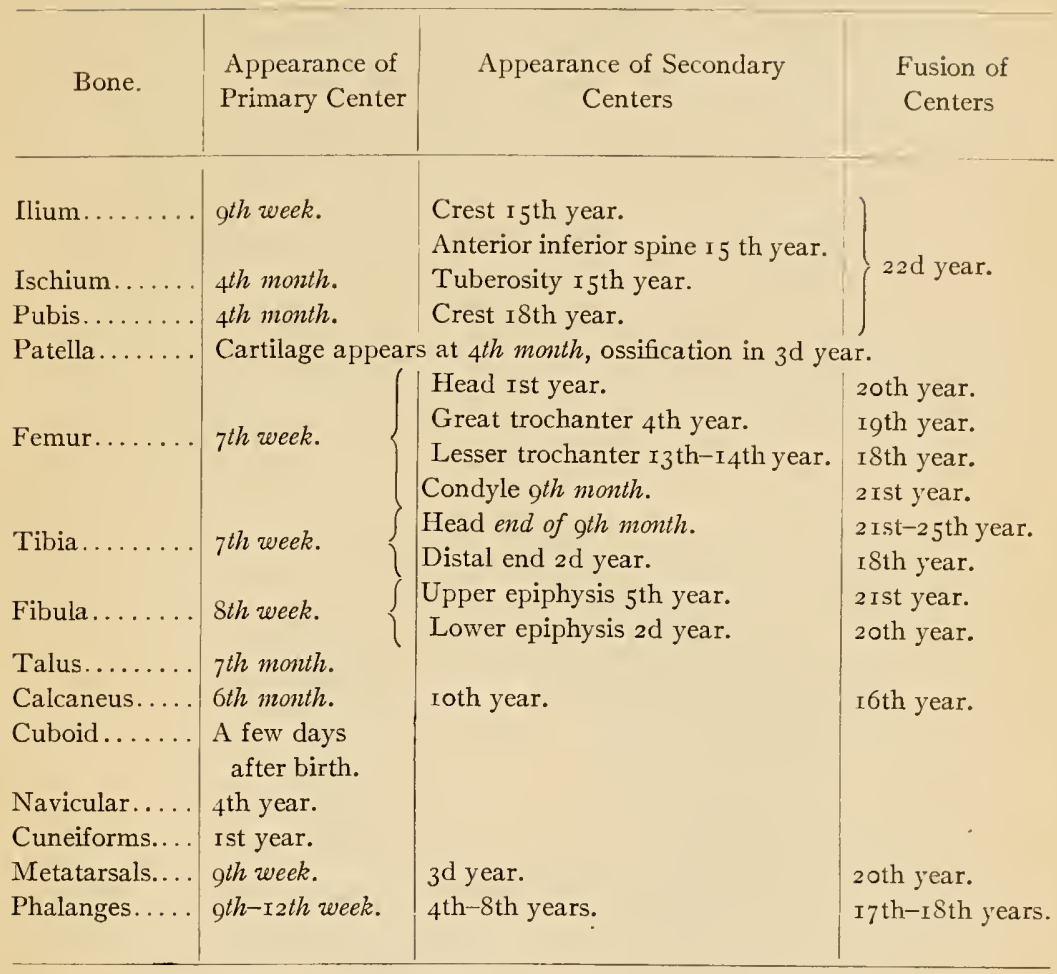

The dates in italics are before birth.

So far as the actual changes in the form of the appendicular bones are concerned, these are most marked in the case of the lower limb. The ossa innominata alter somewhat in their proportions after birth, a fact which may conveniently be demonstrated by considering the changes which occur in the proportions of the pelvic diameters, although it must be remembered that these diameters are greatly influenced by the development of the sacral curve. Taking the conjugate diameter of the pelvic brim as a unit for comparison, the antero-posterior (dorso-ventral) and transverse diameters of the child and adult have the proportions shown in the table on the opposite page (Fehling). 
It will be seen from this that the general form of the pelvis in the new-born child is that of a cone, gradually diminishing in diameter from the brim to the outlet, a condition very different from what obtains in the adult. Furthermore, it is interesting to note

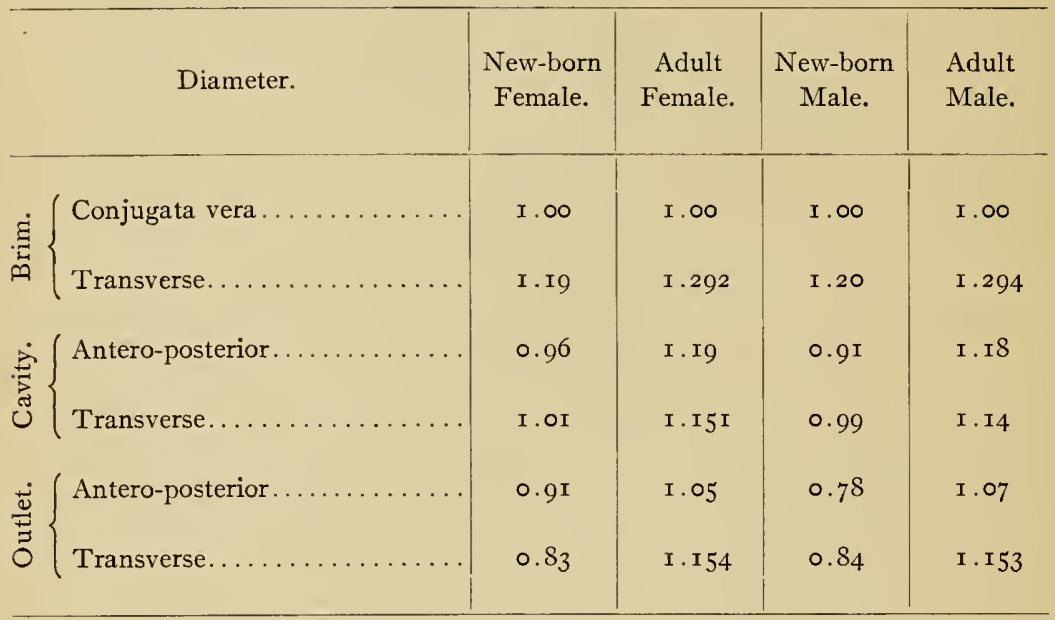

that sexual differences in the form of the pelvis are clearly distinguishable at birth; indeed, according to Fehling's observations, they become noticeable during the fourth month of intrauterine development.

The upper epiphysis of the femur is entirely unossified at birth and consists of a cartilaginous mass, much broader than the rather slender shaft and possessing a deep notch upon its upper surface (Fig. 285). This notch marks off the great trochanter from the head of the bone, and at this stage of development there is no neck, the head being practically sessile. As development proceeds the inner upper portion of the shaft grows more rapidly than the outer portion, carrying the head away from the great trochanter and forming the neck of the bone. The acetabulum is shallower at birth than in the adult and cannot contain more than half the head of the femur; consequently the articular portion of the head is much less extensive than in the adult. 
It is a well-known fact that the new-born child habitually holds the feet with the soles directed toward one another, a position only reached in the adult with some difficulty, and associated with this supination or inversion there is a pronounced extension of the foot (i.e., flexion upon the leg as usually understood; see p. I02), it being difficult to flex the child's foot beyond a line at right angles with the axis of the leg. These conditions are due apparently to the extensor and tibialis muscles being relatively shorter and the opposing muscles relatively longer than in the adult, and with the elongation or shortening, as the case may be, of the muscles on the assumption
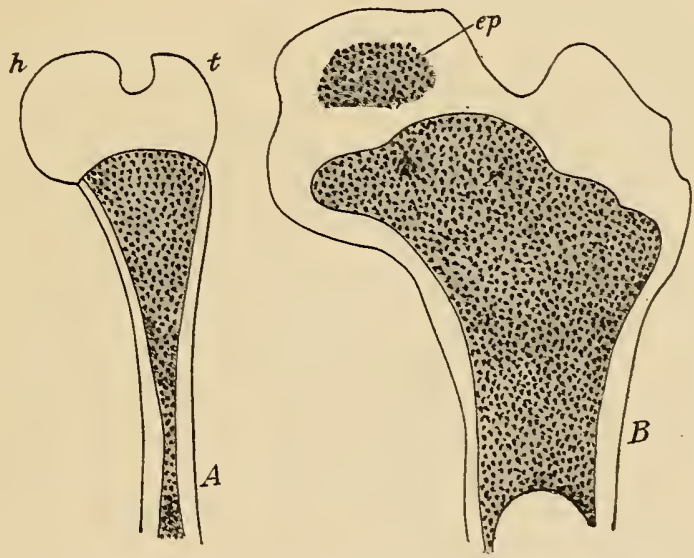

Fig. $2 S_{5}$.-Longitudinal Sections of the Head of the Femur of (A) NEw-BORN Child and (B) a Later Stage of Developient.

$e p$, Epiphysial center for the head; $h$, head; $t$, trochanter.-(Henke.)

of the erect position, the bones in the neighborhood of the anklejoint come into new relations to one another, the result being a modification of the form of the articular surfaces, especially of the talus (astragalus). In the child the articular cartilage of the trochlear surface of this bone is continued onward to a considerable extent upon the neck of the bone, which comes into contact with the tibia in the extreme extension possible in the child. In the adult, however, such extreme extension being impossible, the cartilage upon the neck gradually disappears. The supination in the child brings the talus 
in close contact with the inner surface of the calcaneus and with the sustentaculum tali; with the alteration of position a growth of these portions of the calcaneus occurs, the sustentaculum becoming higher and broader, and so becoming an obstacle in the way of supination in the adult. At the same time a greater extent of the outer surface of the talus comes into contact with the lateral malleolus, with the result that the articular surface is considerably increased on that portion of the bone. Marked changes in the form of the talo-navicular articulation also occur, but their consideration would lead somewhat further than seems desirable.

\section{LITERATURE.}

C. AEвy: "Die Altersverschiedenheiten der menschlichen Wirbelsäule." Archiv für Anat. und Physiol., Anat. Abth., 1879 .

W. CAMERER: "Utersuchungen über Massenwachsthum und Längenwachsthum der Kinder," Jahrbuch für Kinderheilkunde, xxxvI, I893.

H. H. Donaldson: "The Growth of the Brain," London, r895.

H. FeHLing: "Die Form des Beckens beim Fötus und Neugeborenen und ihre Beziehung zu der beim Erwachsenen," Archiv für Gynäkol., x, I876.

H. Friedenthal: "Das Wachsthum des Körpergewichtes des Menschen und anderer Säugethiere in verschiedenen Lebensaltern," Zeit. allgem. Physiol., Ix, I909.

J. A. Hammar: "Ueber Gewicht, Involution und Persistenz der Thymus im Postfötalleben des Menschen," Archiv für Anat. und Phys., Anat. Abth., Supplement, Igo6.

W. HENKE: "Anatomie des Kindersalters," Handbuch der Kinderkrankheiten (Gerhardt), Tubingen, I88I.

C. Hennig: "Das kindliche Becken," Archiv für Anat. und Physiol., Anat. Abth., r88o.

C. HƯTER: "Anatomische Studien an den Extremitätengelenken Neugeborener und Erwachsener," Archiv für patholog. Anat. und Physiol., xxv, 1862.

W. Stephenson: "On the Relation of Weight to Height and the Rate of Growth in Man," The Lancet, II, I888.

R. Thома: "Untersuchungen über die Grösse und das Gewicht der anatomischen Bestandtheile des menschlichen Körpers," Leipzig, I882.

H. VIERORDT: "Anatomische, Physiologische und Physikalische Daten und Tabellen," Jena, I893.

H. WeLCKER: "Untersuchungen über Wachsthum und Bau des menschlichen Schadels," Leipzig, r862. 


\section{INDEX}

\section{A}

After-birth, 137

After-brain, $3^{87}$

Agger nasi, 176

Allantois, $x_{3}, 361$

Alveolo-lingual glands, 294 groove, 290

Amitotic division, 7

Amnion, ro8, 109

Amniotic cavity, 54

Amphiarthrosis, I 88

Amphiaster, 4

Angioblast, 22 I

Annulus of Vieussens, 233

Anterior commissure, 405

Anthelix, 446

Antitragus, 446

Anus, 282

Aortic arches, 243

bulb, 23 I

septum, 236

Archenteron, 48, 280

Archoplasm sphere, 4

Arcuate fibers, $39 \mathrm{r}$

Areas of Langerhans, 3 I3

Arrectores pilorum, I47

Arteries, 240

anterior tibial, 253

aorta, 244

branchial, 242

carotid, 243

centralis retinæ, 459

coliac, 246

common iliac, 245

epigastric, $25^{\circ}$

external iliac, 247,253 maxillary, 243

femoral, 254

hyaloid, 448

hypogastric, 247,268

inferior mesenteric, 246

innominate, 244

intercostal, 245

internal mammary, $25^{\circ}$

maxillary, 242

spermatic, 246
Arteries, interosseous, $25 \mathrm{I}$

$$
\begin{aligned}
& \text { lingual, } 243 \\
& \text { lumbar, 245 } \\
& \text { median, 25 I } \\
& \text { middle sacral, } 245 \\
& \text { peroneal, 254 } \\
& \text { popliteal 253 } \\
& \text { posterior tibial, } 255 \\
& \text { pulmonary, 243 } \\
& \text { radial, 253 } \\
& \text { renal, } 246 \\
& \text { saphenous, 253 } \\
& \text { sciatic, 253 } \\
& \text { subclavian, 245 } \\
& \text { superficial radial, } 25 \text { I } \\
& \text { superior intercostal, } 248 \\
& \quad \text { mesenteric, 246 } \\
& \quad \text { vesical, 247 } \\
& \text { temporal, 242 } \\
& \text { ulnar, 25I } \\
& \text { umbilical, I } 6,24 \text { I, } 247 \\
& \text { vertebral, 248 } \\
& \text { vitelline, I I9, 223 }
\end{aligned}
$$

Articular capsule, I88

Ary-epiglottic folds, 335

Arytenoid cartilages, 336

Aster, 4

Atresia of duodenum, 306 of pupil, 453

Atrial septum, 233

A trio-ventricular valves, 238

Auerbach, plexus of, 420

Auricle, 445

Axis cylinder, 378

B

Bartholin, glands of, 362

Belly-stalk, 68, I 44

Bile capillaries, 309

Bladder, 359

Blastoderm, 42

Blastopore, 48, 54, 57

Blastula, 39

Blood, 224

islands, 222 
Blood platelets, 229 vessels, 22 I

Body cavity, 48

Bone, development of, I 54 growth of, $\mathrm{r}_{57}$

Bone-marrow, ${ }_{5} 6$

Bones:

atlas, 162,165

axis, $\mathrm{I}_{5}$

carpal, I84, I87, 482

clavicle, 183,482

coccyx, 166

conchæ, 176

epistropheus, I62, I 65

ethmoid, I74

femur, I86, 483,484

fibula, I86, 483

frontal, 178

humerus, I 84,482

hyoid, 182

ilium, 186,483

incus, 179,440

innominate, 185,483

interparietal, $\mathrm{I}_{72}$

ischium, 186,483

lachrymal, $\mathrm{I} 78$

malleus, $I 79,44^{\circ}$

mandible, 180

maxilla, $\mathbf{I} 79$

metacarpal, 185,482

metatarsal, 188,482

nasal, $\mathrm{r} 78$

occipital, I70, I 72

palatine, I79

parietal, 178

patella, I86, 483

periotic, 169, I 76

phalanges, I $85, I 88,482,483$

premaxilla, $\mathbf{1} 79$

pubis, I86, 483

radius, 184,482

ribs, $162, I 65$

sacrum, 165

scapula, 183,482

sphenoid, I73

stapes, $44 \mathrm{I}$

sternum, I 66

suprasternal, $\mathrm{x} 66$

tarsal, I87, 483

temporal, I 76

tibia, I86, 483

turbinated, $\mathbf{1} 75$

ulna, I84, 482

vertebræ, I60, I6 4,478

vomer, I 75

zygomatic, I 78

Brachia conjunctiva, 394
Brain, 386, 475

Branchial arches, 90, 97

clefts, 90

epithelial bodies, 294, 295

fistula, $9^{\mathrm{I}}$

Branchiomeres, 8r

Bronchi, 333

Bucconasal membrane, 283

Bulbo-urethral glands, 362

Bulbo-vestibular glands, 362

Burdach, fasciculus of, $3^{8} 5$

Bursa omentalis, 324

C

Cæcum, 30r, 305

Calcar, 403

Canal of Cloquet, 463

of Gartner, 357

of Nuck, 365

of Petit, 463

Canalized fibrin, 128

Capillaries, 224

Cartilages of Santorini, 336 of Wrisberg, 336

Caruncula lacrimalis, 468

Cauda equina, $3^{84}$

Caul, I I 2

Cell, 1,3 division, 4 theory, I

Centrosome, 4

Cerebellum, 392

Cerebral aqueduct, 395 convolutions, 402 cortex, 407

hemispheres, $39^{8}$ peduncles, 394

Cheek groove, $29 \mathrm{I}$

Chin ridge, 100

Chondrocranium, I69, I72

Chorda canal, 57 dorsalis, 75 endoderm, 75

Chorioid coat, 449,463 plexus, $389,397,401$

Chorioidal fissure of brain, $40 \mathrm{OI}$ of eye, 448,453

Chorion, 67,118 frondosum, I24

læve, I24

Chorionic villi, I23

Chromaffine organs, 370

Chromatin, 3

Chromosomes, 4 accessory, I5 reduction of, $\mathrm{x} 4,30$ 
Ciliary body, 4.54 ganglion, 424 muscle, 465

Cisterna chyli, 270

Cleft palate, 284 sternum, 168

Clitoris, $36_{3}$

Cloaca, 280, 360

Cloacal membrane, 287

Cloquet, canal of, 463

Coccygeal ganglion, 275

Colom, 48, 78

Collateral eminence, 404

Colliculus seminalis, 357

Coloboma, 453

Colon, 303

Conjunctiva, 465

Connective tissues, 153

Cornea, 449, 464

Corniculate cartilages, $33^{6}$

Corona radiata, 2I, 353

Coronary sinus, 232

Corpora mamillaria, 398 quadrigemina, 395

Corpus albicans, 24 callosum, 405

luteum, 23 striatum, 400

Corti, spiral organ of, 437

Cowper, glands of, 362

Cranial nerves, 409 sinuses, 255

Cricoid cartilage, 336

Cuneiform cartilages, 336

Cutis plate, 80

Cytoplasm, 3

Cyto-trophoblast, I22

\section{D}

Darwin's tubercle, 446

Decidua basalis, I 32 capsularis, I 2 I, I3I reflexa, I2 I

serotina, $\mathrm{I}_{32}$

vera, I30

Decidual cells, I3I, I37

Dendrites, 379

Dental groove, 285 papilla, 285 shelf, 285

Dentate gyrus, 403

Dermatome, 80

Descent of ovary, 365 of testis, 366

Diaphragm, 320
Diarthrosis, 188

Diencephalon, 387,396

Discus proligerus, I 9,353

Double monsters, 46

Duct of Santorini, $3^{12}$ of Wrisberg, 3 I 2

Ductus arteriosus, 244, 268 Botalli, 244 choledochus, 307,308 cochlearis, 434

Cuvieri, 257

ejacula torius, 355

endolymphaticus, 433

reuniens, 434

venosus, 260

Duodenum, 302, 303, 306

$\mathrm{E}$

Ear, 43I

Ebner, glands of, $43 \mathrm{I}$

Ectoderm, 48

Embryo, age of, to2 external form, 86 growth of, 472

Embryonic disc, 54

Embryotroph, I23

Enamel organ, 285

Enchylema, 3

Endocardium, 229

Endoderm, 43

Enveloping layer, 42

Ependymal cells, 377

Epiblast, 48

Epibranchial placodes, 4I 7

Epidermis, I4I

Epididymis, 354

Epiglottis, 335

Epiphyses, I 56

Epiphysis cerebri, 396

Epiploic foramen, 324

Episternal cartilages, I 66

Epitrichium, I4I

Eponychium, I45

Epoöphoron, 356

Erythrocytes, 225

Erythroplastids, 226

Eustachian tube, 294, 440 valve, 234

Extrauterine pregnancy, 22

Eye, 446

Eyelids, 465

F

Fallopian tubes, 357

Fasciculus communis, 4I4 
Fasciculus of Burdach, 385 of Goll, 385 solitarius, 4 I 4

Fenestra cochleæ, 440 ovalis, 440 rotunda, 440 vestibuli, $44^{\circ}$

Fertilization of ovum, 3 1

Fetal circulation, 266

Fibrinoid, 128

Fifth ventricle, 406

Filum terminale, $3^{84}$

Fimbria, 405 ovarica, 357

Foliate papillæ, 43 I

Fontana, spaces of, $46_{5}$

Foramen cæcum, 296 of Winslow, 324 ovale, 233,240

Fore-brain, 386

Formatio reticularis, $39^{\circ}$

Fornix, 405

Frontal sinuses, $x_{7} 6$

Funiculus cuneatus, 385 gracilis, 385

Furcula, 294

G

Gartner, canals of, 357

Gall bladder, 307, 308

Ganglionated cord, 422

Gastral mesoderm, 50, 62

Gastrula, 48

Geniculate bodies, 398

Genital folds, 363 ridge, 338,349

swelling, 363

tubercle, 363

Germ cells, 7

layers, 47,60 plasm, 8

Giraldes, organ of, 354

Glands of Bartholin, 362 bulbo-urethral, 362

bulbo-vestibular, $3^{62}$

of Cowper, $3^{62}$

of Ebner, 43I

Meibomian, 466

of Moll, 466

salivary, 292

tarsal, 466

Goll, fasciculus of, 385

Graafian follicle, $x_{9}$

Great omentum, 324

Groove of Rosenmüller, 295
Gubernaculum testis, $35^{6}$

Gynæcomastia, $x_{5}$ I

\section{$\mathrm{H}$}

Hæmatopoietic organs, 225

Hæmolymph nodes, 273

Hairs, $x_{4} 6$

Hare lip, 100, I79

Hassall's corpuscles, 298

Haversian canals, ${ }^{2} 5^{8}$

Head cavities, 79 process, 56,69

Heart, 229, 475

Helix, 446

Hensen's node, 56

Hermaphroditism, 365

Hind-brain, 387

Hippocampus, 402

Hyaloid canal, 463

Hydatid of Morgagni, 355 stalked, 359

Hydramnios, $x \geq 2$

Hymen, 357

Hyperthelia, $\mathbf{x}_{5} \mathrm{x}$

Hypertrichosis, I48

Hy poblast, 48

Hypochordal bar, I6I

Hypophysis, 399

Hypospadias, 365

Hypothalamic region, 398

I

Implantation of ovum, II9

Infracardial bursa, 345

Infundibulum, 399

Inguinal canal, 367

Inner cell mass, 44

Insula, 404

Interarticular cartilages, I89

Intercarotid ganglion, 373

Intermediate cell mass, 77

Interrenal organs, $37^{\circ}$

Interventricular foramen, 400

Intervertebral fibro-cartilage, $\mathrm{I}_{6} 2$

Intestine, 3 or, 476

Iris, 454

Isthmus cerebri, $387,39^{2}$

Jacobson, organ of, 429

Joints, I88

Jugular lymph sac, 286 
K

Karyokinesis, 7

Karyoplasm, 3

Kidney (see Metanephros), 343, 475

L

Labia majora, $36_{3}$ minora, 303

Lachrymal gland, 467

Lamina terminalis, 399

Langerhans, areas of, 3 I 3

Langhans cells, I26

Lanugo, I47

Larynx, 334

Lateral thyreoids, 299

Lens, 447,450

Lesser omentum, 324

Leukocytes, 227

Ligaments:

broad, of uterus, 349,356

coraco-humeral, 2 I 6

coronary, of liver, 32 I

falciform, of liver, $32 \mathrm{I}$

fibular lateral, of knee, 200

flavan, I62

inguinal, 349, 355, 357

interspinous, 162

of the ovary, $35^{8}$

pectinatum iridis, $46_{3}$

round, of liver, 268

round, of uterus, $35^{8}$

sacro-tuberous, $2 \mathrm{co}$

spheno-mandibular, I8o

Limbs, 90, I00 suspensory of lens, 462

Lip-ridge, I o०

Lips, 284

Liver, 306,475

Lungs, 33 I, 476

Luschka's ganglion, 275

Lymphatics, 268

Lymph nodes, 272 sacs, 268,270

Lymphocytes, 227, 273

M

Mammary gland, I 48

Mandibular process, 92

Mastoid cells, 443

Maturation of ovum, $2 \mathrm{~S}$

Maxillary antrum, I 76 process, 92

Meckel's cartilage, I 7 I, I 79 diverticulum, I I 3,305
Mediastina, 322

Medulla oblongata, 387

Medullary canal, 73,88

folds, $70,7^{2}$

groove, 70

sheath, 382

Megacaryocytes, 228

Meibomian glands, 466

Meissner, plexus of, 420

Membrana pupillaris, 453 reuniens, $8 \mathrm{I}$ tectoria, 437

Membrane bone, I 54

Menstruation, 26

Mesamœboids, 222

Mesencephalon, 387, 395

Mesenchyme, 6I

Mesenteriole, 327

Mesentery, 323

Mesocardium, 3 I6

Mesocolon, 326

Mesoderm, 48 somatic, 78

splanchnic, 78

ventral, 77

Mesodermic somites, 72, 76

Mesogastrium, 324

Mesonephros, 34I

Mesorchium, 367

Mesothelium, 6I

Metamere, 83

Metanephros, 343

Metencephalon, $387,39^{2}$

Mid-brain, 387

Middle ear, $44^{\circ}$

Milk ridge, I 48

Mitosis, 7

Moll, glands of, 466

Montgomery's glands, I 50

Morgagni, hydatid of, 355

Morula, 43

Mouth cavity, 283

Müllerian duct, 347

Muscle plates, 8o

Muscles:

arrectores pilorum, I47

biceps femoris, 216

branchiomeric, 206

chondroglossus, 208

ciliary, 465

coccygeus, 204

constrictor of pharynx, 208, 299

cranial, 205

curvator coccygis, 204

depressors of hyoid, 202

digastric, 206

dilatator iridis, 455 
Muscles, dorsal, 200

eye, 205

facial, 206

gastrocnemius, 2 I 5,2 I9

geniohyoid, 202

genioglossus, 202

glosso-palatinus, 208

hyoglossus, 202

hyposkeletal, 202

intercostal, 202

laryngeal, 208

latissimus dorsi, $\mathbf{1 9 8}$

levator ani, 204

limb, 2 Io

longus capitis, 202 colli, 202

lumbrical, 2 I 8

masseter, 206

mylohyoid, 206

obliqui abdominis, 202

occipito-frontalis, $\mathrm{x} 98,206$

omohyoid, I98

pectorals, 2 I 6

perineal, 204

peroneus longus, 2 I 6

platysma, 206

pronator quadratus, 2 I6

psoas, 202

pterygoids, 206

pyramidalis, 202

rectus abdominis, I99, 202

sacro-spinalis, I99, 204

scaleni, 202

serrati posteriores, 199

serratus anterior, I99

skeletal, I97

soleus, 2I 5,2 I 9

sphincter ani, 204

cloacæ, 205

iridis, 455

stapedius, 206, 44I

sternohyoid, r 98

sternomastoid, I98, 202, 208

styloglossus, 202

stylohyoid, 206

stylopharyngeus, 208, 299

temporal, 206

tensor tympani, 206, 440

veli palati, 206

transversus abdominis, 202 thoracis, 202

trapezius, I98, 202, 208

Muscle tissue, r93

Myelencephalon, 387,389

Myelin, 382

Myelocytes, 227

Myoblasts, I 95
Myocardium, 229

Myotome, 80, I 98

\section{$\mathrm{N}$}

Nails, I44

Nape bend, 90

Nasal pit, 99 process, 99

Naso-lachrymal duct, 467

Nephrogenic cord, 342

Nephrostome, 340

Nephrotome, 80

Nerve components, 4Io, 4I 3

Nerves: roots, 380

auditory, 4I 5

cranial, 4 og

hypoglossal, 4I2

olfactory, 428

optic, $45^{8}$

recurrent, 337

spinal, 408 accessory, 4I6

splanchnic, 424

Nerve tissue, 377

Neural crest, 380

Neurenteric canal, 58, 69, 73

Neuroblasts, 378

Neuroglia cells, $37^{8}, 379$

Neuromeres, 4I8

Neurone theory, $3^{82}$

Nitabuch's stria, I35

Non-sexual reproduction, 8

Normoblasts, 226

Notochord, 74

Nuck, canal of, $3^{6} 5$

Nucleoli, 4

Nucleus, 3

Esophagus, 299

Estrus, 27

Odontoblasts, 287

Olfactory lobes, 406

organ, 428

Olivary body, 390

Omentum, 324

Ö̈cyte, 29

Optic cup, 448, 453

recess, 399

Oral fossa, 88, 99, 280

Organ of Giraldes, 354

of Jacobson, 429

of Rosenmüller, $35^{6}$ 
Organs, 2

of taste, 430

of Zuckerkandl, 374

Osteoblasts, I 54

Osteoclasts, 158

Otocyst, 432

Otic ganglion, 424

Ovary, $35^{2}$ descent of, $3^{6} 5$

Ovulation, 2 I, 26

Ovum, I9 fertilization of, 3 I implantation of, I I 9 maturation of, 28 segmentation of, 38

\section{P}

Palate, 283

Pancreas, 3Ir, 476

Paradidymis, 354

Paraphysis, 397

Parathymus, 299

Parathyreoid bodies, 297

Paroöphoron, $35^{6}$

Parotid gland, 292

Parovarium, $35^{6}$

Parthenogenesis, 8

Penis, 364

Pericardial cavity, 3 I 7, 3 I 8

Perineal body, 362

Perionyx, I 45

Periosteum, I 55

Periotic capsule, 169,176

Peritoneum, 323

Petit, canal of, 463

Pflüger's cords, $35^{2}$

Pharyngeal bursa, 294 membrane, 280 tonsil, 294

Pharynx, 294

Pharyngo-palatine arches, 283

Pineal body, 396

Pinna, 445

Pituitary body, 399

Placenta, r33, I37 accessory, 126 embryotrophic, I 23 hæmatrophic, 123 prævia, 133

Placentar infarcts, I 35

Plasmodi-trophoblast, I 22

Plasmodium, I22

Pleuræ, 322

Pleuro-peritoneal cavity, 78,320

Plica semilunaris, 466
Polar globules, 30

Polycaryocytes, 228

Polymastia, I 5 I

Polyspermy, 34

Pons, $39^{2}$ flexure, 389

Post-anal gut, $28 \mathrm{r}$

Post-natal development, 470

Posterior lymph sac, 270

Precaudal recess, $28 \mathrm{I}$

Precoracoid, 189

Prepuce, 364

Primitive groove, 56, 69 streak, 50, 69

Processus globularis, 99

Pronephric duct, 339

Pronephros, 339

Pronuclei, 3 I

Procstrum, 27

Prostate gland, 362

Prostomial mesoderm, 50, 58

Protoplasm, 2

Protovertebræ, 77

\section{$\mathrm{R}$}

Rathke's pouch, 285, 399

Rauber's covering layer, 44

Rectum, 281

Red nucleus, 395

Reduction of chromosomes, I4, 30

Restiform body, 39I

Rete cords, 349 ovarii, 354 testis, $35^{2}$

Retina, 455

Retroperitoneal lymph sac, 270

Rhinencephalon, 407

Rosenmüller, groove of, 295 organ of, $35^{6}$

\section{S}

Sacculus, 434

Sacral bend, 90

Salivary glands, 291

Santorini, cartilages of, 336 duct of, 312

Sarcode, I

Scala tympani, 440 vestibuli, 439

Sclerotic coat, 449,463

Sclerotome, 80

Scrotum, 364 
Sebaceous glands, I 47

Segmentation of ovum, 38

Semicircular ducts, 433

Semilunar valves, 239

Seminiferous tubules, $35^{2}$

Septum pellucidum, 406

primum, 233

secundum, 233

spurium, 232

transversum, $3 \mathrm{I} 8,320,323$

Sertoli cell, I4

Sex cells, 349

cords, 349

Sexual reproduction, 8

Sinusoid, 223

Sinus, coronary, 232

pocularis, 355

præcervicalis, 97

terminalis, 222

venosus, 230

Situs inversus viscerum, 46

Skin, I4 I, 476

Skull, I68, 479

Socia parotidis, 291

Solitary fasciculus, 390

Somatic cells, 7

Spaces of Fontana, 465

Spermatic cord, 367

Spermatid, I4

Spermatocyte, I4

Spermatogenesis, I3

Spermatogonia, I4

Spermatozoön, II

Sphenoidal cells, I 76

Spheno-palatine ganglion, 424

Spinal cord, 383,475 nerves, 408

Spiral organ of Corti, 437

Spleen, 274, 475

Stomach, $30 \mathrm{r}$

Sublingual ganglion, 424 gland, 293

Submaxillary ganglion, 424 gland, 292

Substance islands, 222

Sudoriparous glands, 148

Sulcus Monroi, 396

Superfetation, 36

Suprabranchial placodes, $4 \mathrm{r} 7$

Suprarenal bodies, 370,475

accessory, 372

Supratonsillar.fossa, 295

Suture, I88

Sympathetic nervous system, 4 I 8

Synchondrosis, I88

Syncytium, I22

Systems, 2

\section{$\mathrm{T}$}

Tail filament, 94

Tarsal glands, 466

Taste, organs of, 430

Teeth, 285

Tegmentum, 394

Telencephalon, 386,398

Testis, $35^{\circ}$ descent of, 366

Thalami, 397

Thebesian valve, 234

Thoracic duct, $27 \mathrm{I}$

Thymus gland, 297,476

Thyreoid cartilage, 335 gland, 296, 475

Thyreo-glossal duct, 296

Tissues, 2

Tongue, 289

Tonsils, 295

Touch, organs of, $43^{\circ}$

Trachea, 334

Tragus, 446

Trophoblast, 55

Tuba auditiva, 440

Tubæ uterinæ, 357

Tuber cinereum, $39^{8}$

Tuberculum impar, 289

Tunica vaginalis testis, 367 vasculosa lentis, $45^{2}$

Tween-brain, 387

Twin-development, 46

Tympanic cavity, $44^{2}$ membrane, 443

\section{U}

Ultimo-branchial bodies, 299

Umbilical cord, 92, I 6

Umbilicus, 86

Urachus, II5, 36I

Ureter, 344

Urethra, 36I

Urogenital sinus, 360

Uterovaginal canal, 349

Uterus, 357,359 masculinus, 355

Utriculus, 434 prostaticus, 355

Vagina, 357

Vaginal process, 365

Vallate papillæ, $43^{\circ}$ 
Vas deferens, 355

Veins:

anterior cardinal, 255 tibial, $26_{5}$

ascending lumbar, 264

azygos, 264

basilic, 265

cephalic, 265

emissary, 259

external jugular, 258

hemiazygos, 264

hepatic, 262

inferior vena cava, 263

innominate, $25^{8}$

internal jugular, 255

jugulo-cephalic, 265

limb, 265

long saphenous, 265

portal, $26 \mathrm{r}$

posterior cardinal, 255

primary fibular, 265 ulnar, 265

pulmonary, 265

renal, 263

subcardinal, 262

superior vena cava, $25^{8}$

supracardinal, 263

suprarenal, 263

umbilical, I 6,260

vitelline, 223, 259

Velum, anterior, 394

interpositum, 397

marginal, 378
Velum, posterior, 389

Ventricular septum, 236

Vermiform appendix, 305

Vernix caseosa, II2, I47

Vertex bend, 86

Vesicula seminalis, 355

Vieussens, annulus of, 233

Villi, chorionic, I23 intestinal, 305

Vitreous humor, 449, 46I

Vulva, 363

\section{W}

Wharton's jelly, II 8

Winslow, foramen of, 324

Wirsung, duct of, 3 I 2

Witch milk, I5I

Wolffian body, 34I, 354 duct, 339,354 ridge, 338

Wrisberg, cartilage of, 336

Y

Yolk sac, 86, II 2

stalk, 86, 90, II2

Z

Zona pellucida, $2 \mathrm{I}$

Zuckerkandl, organ of, 374 



\section{BOOKS FOR STUDENTS OF BIOLOGY.}

KINGSLEY. Comparative Anatomy of Vertebrates. A text-book arranged upon an embryological basis and prepared especially to meet the needs of the under-graduate student. By J. S. Kingsley, Professor of Biology in Tufts College. Octavo; 346 Illustrations drawn or redrawn expressly for this book. ix +40 I pages.

Cloth, \$2.25.

DAVISON. Mammalian Anatomy. With Special Reference to the Anatomy of the Cat. By Alvin Davison, A. M., PH. D., Professor of Biology, Lafayette College, Easton, Pennsylvania. Second Edition, Revised. I I Illustrations.

Cloth, \$1.50.

FOLSOM. Entomology with Special Reference to Its Biological and Economical Aspects. By Justus Watson Folsom, SC. D. (Harvard), Assistant Professor of Entomology at the University of Illinois. 5 Plates ( $\mathrm{I}$ in colors) and 300 other Illustrations. $8 \mathrm{vo} ; 485$ pages.

Cloth, \$2.00.

GALLOWAY. Zoology. A Text-book for Secondary Schools, Normal Schools and Colleges. By T. W. Galloway, PH. D., Professor of Biology, James Milliken University, Decatur, Illinois. Second Edition, Revised. 240 Illustrations. 8vo; 460 pages. Cloth, \$2.00. Elementary Zoology. A Text-book for Secondary Educational Institutions. I60 Illustrations. $\mathrm{xx}+4 \mathrm{I} 8$ pages. Cloth, \$I.25.

GREEN. Vegetable Physiology, An Introduction to. By J. REyNoLDS Green, sc. D., F. R. S., Fellow of Downing College, Cambridge. Third Edition, Revised. I82 Illustrations. Octavo; 482 pages.

Cloth, $\$ 3.00$.

JOHNSTON. Nervous System of Vertebrates. By JOHN BLACK Johnston, PH. D., Professor of Comparative Neurology, University of Minnesota. With 180 Illustrations. Octavo; 390 pages.

Cloth, $\$ 3.00$.

SCHEFFER. Zoology. Loose Leaf System of Laboratory Notes. Second Edition. Revised and Enlarged. By Theo. H. Scheffer, A. M., formerly Assistant Professor of Zoology, Kansas State Agricultural College. Square 8 vo.

Adjustable Cloth Covers, $\$ .75$.

BRUBAKER. Text-book of Physiology. Illustrated. Fourth Edition. A Text-book of Physiology, specially adapted for the use of Students. Including a Section on Physiologic Apparatus. By A. P. Brubaker, M. D., Professor of Physiology and Medical Jurisprudence at Jefferson Medical College. With an appendix giving a brief account of some essential forms of apparatus suited to those who have not large laboratory opportunities. Fourth Edition. Thoroughly Revised and in Parts Rewritten. I Colored Plate and 377 other Illustrations. Octavo; xii +735 pages. Cloth, $\$ 3.00$.

P. BLAKISTON'S SON \& CO., PHILADELPHIA. 


\section{BOOKS FOR STUDENTS OF BIOLOGY.}

MARSHALL. Microbiology. A Text-book of Microörganisms, General and Applied. By various writers. Edited by CHARLes E. MARSHALL, Professor of Microbiology and Director of Graduate School, Massachusetts Agricultural College. Discusses Morphology, Culture and Physiology of Microörganisms, including Nutrition and Metabolism, Physical Influences; B acteriology of Dairy, Soil, Water Supplies, Sewage Disposal, Air, Special Manufactures, Diseases of Man, Animals and Plants. I Colored Plate. I28 Other Illustrations. I2mo, xxi 724 pages.

Flexible Cloth, $\$ 2.50$.

MINOT. Embryology. A Laboratory Text-book of Embryology. By Charles S. Minot, S. D., LL. D., Professor of Comparative Anatomy, Harvard University Medical School. Second Edition, Revised. With 262 Illustrations. xii +402 Pages.

Cloth, $\$ 3 \cdot 50$.

VINAL. A Guide for Laboratory and Field Studies in Botany. By William. Gould Vinal, A. M. (Harvard), Salem Normal School, Salem, Massachusetts. Second Edition, Revised. Square Octavo.

Paper Covers, $\$ .60$.

STEVENS. Plant Anatomy from the Standpoint of the Development and Functions of the Tissues. By WM. C. Stevens, M. S., Professor of Botany in the University of Kansas. Second Edition, Enlarged. I 52 Illustrations. 8vo; 394 pages.

Cloth, \$2.00.

STOHR. Text-book of Histology. Arranged upon an Embryological Basis. By Dr. Frederic T. Lewis, Assistant Professor of Embryology at the Harvard Medical School. From the Twelfth German Edition by Dr. PhIllip StoHr, Professor of Anatomy at the University of Wurzburg. Sixth American Edition, Revised. 450 Illustrations, 45 in Colors. 8vo; 443 pages.

Cloth, $\$ 3.00$.

CRARY. Field Zoology, Insects and Their Near Relatives and Birds. By L. E. Crary, Assistant Professor of Biology and Geology, Kansas State Normal College, Emporia. I I 7 Illustrations. $\quad$ I2mo. 376 pages. Cloth, \$1.25.

McMURRICH. The Development of the Human Body. A Manual of Human Embryology. By J. PlayfaIr McMurRICH, A. M., PH. D., Professor of Anatomy, University of Toronto; A merican Editor of Morris' "Text-book of Anatomy." Fourth Edition, Revised. 285 Illustrations. Octavo; $\mathrm{x}+495$ pages.

Cloth, $\$ 2.50$.

PATTEN. The Evolution of the Vertebrates and Their Kin. By William Patten, PH. D., Professor of Zoology, and Head of the Department of Biology, Dartmouth College, Hanover, N. H. With 307 Figures engraved especially for this book, largely from original sources. Octavo. Cloth, $\$ 4.50$.

\section{P. BLAKISTON'S SON \& CO., PHILADELPHIA.}




COLUMBIA UNIVERSITY LIBRARIES ( $h \mathrm{sl}$, stx) QM $601 . M 361914$ C.1

The development of the human body

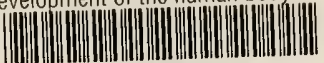

2002238152 
